UNITED STATES DEPARTMENT OF THE INTERIOR

Ray Lyman Wilbur, Secretary

GEOLOGICAL SURVEY

George Otis Smith, Director

Professional Paper 160

\title{
GEOLOGIC HISTORY OF THE YOSEMITE VALLEY
}

BY

\author{
FRANÇOIS E. MATTHES
}

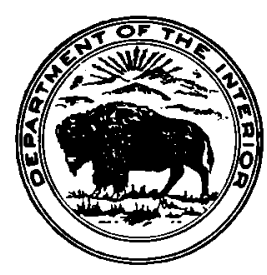

UNITED STATES

GOVERNMENT PRINTING OFFICE

WASHINGTON : 1930

For salo by the Superintendent of Documents, Washington, D. C.

Price \$1.10 



\section{CONTENTS}

Technical abstract.-

Introduction

Acknowledgments

Geographic sketch of the Yosemite region and the Sierra Nevada

Location and character of the Yosemite Valley

Other yosemites.-

The Sierra Nevada.

General character and dimensions

Relations to adjoining lowlands.

Climatic conditions and life zones

The Yosemite region

General configuration.

Hanging valleys

Stairlike steps in canyon floors

The High Sierra

General character

Merced Basin.

Tenaya Basin...

Tuolumne Basin.

The Yosemite Valley in detail.

Peculiar modeling of valley

Cliffs and rock monuments

Waterfalls

Comparison with waterfalls in other parts of the world.

Summary -

Early history of the Yosemite Valley

Antiquity of the Sierra Nevada and the Yosemite Valley

The Sierra block.

General character and outlines

Internal structure.

The rise of the Sierra Nevada

Sources of information

History of uplifts

Rearrangement of drainage system and origin of the Merced River

The cutting of the Merced Canyon

Stream-cut origin of the canyon.

Evidences of three stages of cutting

The story of the cutting

Explanation of hanging valleys.

Previous hypotheses....

Hanging side valleys of the lower Merced Canyon

Correlation with hanging valleys of the Yosemite region

Significance of higher hanging valleys

Preservation of the Yosemite upland on massive granite.

The half-yosemite at Wawona...

A third set of hanging valleys...

Preglacial profile of the Yosemite Valley

Interpretation of older profiles.

Evolution of the Yosemite Valley in preglacial time...

Landscape of broad-valley stage....

Landscape of mountain-valley stage

Landscape of canyon stage.

Glacial history of the Yosemite Valley

Glaciation of the Sierra Nevada.

Nature of ice mantle...-

Distribution of ice on Sierra-Cascade chain

Origin and growth' of ancient Sierra glaciers.

Extent reached by ancient Sierra glaciers. 
Glacial history of the Yosemite Valley-Continued.

Evidences of glacial action in the Yosemite region.

Kinds of evidence studied

Moraines in the Yosemite Valley

Moraines in the Little Yosemite Valley .

Moraines in the Tenaya Basin

Evidences of an earlier ice invasion

On the sides of the Little Yosemite Valley

In the vicinity of Glacier Point

Features at Glacier Point often mistaken for evidences of glaciation

On the south side of the Yosemite Valley ............

On the north side of the Yosemite Valley

In the lower Yosemite region.

Difference in age between older and younger moraines

Testimony of younger glaciated rock surfaces

Testimony of older glaciated rock surfaces

Indications of a still earlier ice invasion

Ancient glaciers of the Yosemite region.

Explanation of map of ancient glaciers

Glaciers of the Wisconsin stage

Yosemite Glacier

Merced Glacier

Tenaya Glacier.

Snow Creek Glacier

Hoffmann Glacier.

Glaciers of the Illilouette Basin

Glaciers of Bridalveil Basin .

Lowest level of glacier generation

Glaciers of earlier stages

Great extent and thickness.

Upper limit of glaciation in the High Sierra.

Merced Glacier

Illilouette Ice Field . .

Bridalveil Ice Field -

Tenaya Glacier

Hoffmann Glacier.

Cascade Glacier

Yosemite Glacier

Transformation of the Yosemite Valley by the ice

Kernel of the Yosemite problem...

Deepening effected by the Yosemite Glacier

Widening effected by the Yosemite Glacier.

Muir's explanation.

How do glaciers excavate?

Selective quarrying

The key to the secret of the Yosemite's origin

Configuration of the Yosemite Valley explained.

Origin of glacial stairways

Application to the Yosemite Valley

Development of the Little Yosemite Valley

Development of Tenaya Canyon

Summary of changes produced by the glaciers.

Postglacial history of the Yosemite region
Filling of the glacial lakes.

Filling of Lake Yosemite.

Filling of lake in the Little Yosemite Valley . .

Significance of Lost Lake

Survival of Emerald Pool.

Filling of lakes in Tenaya Canyon.

Production of rock waste in the Yosemite Valley

Unequal distribution of rock waste.

Modes of production.

Torrent fans and torrent channels.

Evolution of cliff sculpture.

Relation of form to structure

Influence of zones of fracturing

Forms carved in massive rock

Summary and conclusions.

Page

54

54

56

58

61

61

61

63

63

64

65

66

68

68

70

73

75

75

76

76

77

77

79

79

79

79

80

80

80

81

81

82

82

82

83

83

83

84

84

85

85

88

89

90

91

91

94

97

98

101

102

103

103

103

104

104

104

105

105

105

106

108 
Appendix. The granitic rocks of the Yosemite region, by F. C. Calkins. Introduction.....

General character of the rocks

Description of the rocks

El Capitan granite

Taft granite

Bridalveil granite

Leaning Tower quartz monzonite...

Pohono granodiorite

Hornblende gabbro and hornblendic diorite

Granitic rocks of lower Yosemite region

Sentinel granodiorite

Half Dome quartz monzonite

Cathedral Peak granite.

Johnson granite porphyry

Mount Clark granite

Porphyritic rocks of Clark Range.

Bibliography

Aplite and pegmatite

\section{ILLUSTRATIONS}

Puate 1. Relief map of California..... Page

2. Topographic map of Yosemite National Park

3. Yosemite Valley from Wawona Road

4. $A$, Little Yosemite Valley; $B$, Tehipite Valley

5. $A$, Kings River Canyon; $B$, Hetch Hetchy Valley; $C$, East front of Sierra Nevada.

6. $A$, Characteristic storm-bent tree at timber line; $B$, Giant sequoias in Mariposa grove

7. Topographic map of Yosemite Valley

8. $A$, Tenaya Canyon from Glacier Point; $B$, View across Yosemite Valley from Ribbon Fall

9. A, View northward over Yosemite upland from Horse Ridge; $B$, Hanging valley of Yosemite Creek and Yosemite

10. The giant stairway from Glacier Point

11. $A$, The High Sierra from El Capitan; $B$, Little Yosemite and Clark Range from Half Dome..............

12. $A$, Cathedral Peak; $B$, Merced Lake

13. $A$, Tuolumne Meadows; $B$, Head of upper Merced Basin .

14. Mount Lyell and Lyell Glacier .

15. Bird's eye view of Yosemite Valley and the High Sierra

16. $A$, Lower end of Yosemite Valley and head of Merced Gorge; B, Head of Yosemite Valley from Columbia Rock

17. El Capitan from the east.

18. Cathedral Rocks and Cathedral Spires

19. $A$, Sentinel Rock; $B$, The Three Brothers

20. $A$, North Dome from Merced River near Happy Isles; $B$, Silhouette profile of cliff at Glacier Point

21. $A$, Sentinel Dome; $B$, The Royal Arches and the Washington Column surmounted by North Dome.

22. Yosemite Falls from the Merced River.

23. $A$, Bridalveil Fall; $B$, The Cascades; $C$, Lower Yosemite Fall

24. Vernal Fall

25. Nevada Fall and Liberty Cap. $A$, View down lower Merced Canyon from El Capitan; $B$, Upturned beds of slate and schist in lower Merced
26. Canyon; $C$, Contorted layers of chert exposed in bed of Merced River

27. $A$, Longitudinal profile of Yosemite Valley; $B$, Longitudinal profile of Merced Canyon and Yosemite Valley

28. A, Empty cirque on Kuna Crest; $B$, Dana Glacier

29. Map of glacial and postglacial deposits

30. $A$, Crest of morainal embankment on the side of Moraine Dome; $B$, One of the lateral moraines on north side of Little Yosemite' Valley . . .

31. $A$, View across Little Yosemite Valley from a point near Helen Lake; $B$, The great morainal embankment from top of Moraine Dome.

32. A, Sandy flat in Illilouette Valley and Starr King group; $B$, Lateral moraines of Merced Glacier on south side of Little Yosemite Valley

33. $A$, Weather pit at Glacier Point; $B$, Typical perched boulder of an earlier glaciation; $C$, Weather pits in slab on North Dame.

$34 .: A$, Old moraine near Wawona Road; $B$, Typical pothole of subglacial origin at lower end of Tuolumne Meadows.

35. $A$, Glacial grooves on border of lake in Cathedral Pass; $B$, Glacier polish on floor of massive granite.......

36. Glaciated floor and side of upper Merced Canyon. 
Plate 37. A, Wall of aplite on Moraine Dome; $B$, Large erratic boulder on Moraine Dome

38. $A$, Glacial boulder perched on 5-foot pedestal; $B$, Erratic boulder at base of Sentinel Dome

39. Map of ancient glaciers of Yosemite region . .

40. $A$, Echo Peaks and the Cockscomb; $B$, The great façade of Clouds Rest from Mount Watkins.

41. $A$, Crest of Sierra Nevada and head of Tuolumne Basin; $B$, Well-jointed granite in the High Sierra..........

42. $A$, Moraine composed of angular blocks; $B$, Joint blocks loosened by frost . . . . . . . . . . . .

43. A, Turtleback Dome and Merced Gorge below Yosemite Valley; B, Glaciated rock mass under Glacier Point

44. $A$, Rear view of Liberty Cap and Mount Broderick; $B$, Front view of Liberty Cap and Mount Broderick .......

45. $A$, Cascade Cliffs, in Little Yosemite Valley; $B$, Sugar Loaf and Bunnell Point from Moraine Dome.........

46. A, Upper part of Tenaya Canyon from upper Quarter Dome; $B$, The rock façade of Clouds Rest from upper Quarter Dome.

47. $A$, Mirror Lake; $B$, Agassiz Column_

48. $A$, Arched exfoliation shell; $B$, Brink of precipice cf ufper Yosemite Fall; $C$, Exfoliating granite on lower Quarter Dome.

49. Northeast side of Half Dome

51. $A$, Back of Half Dome; $B$, Front of Half Dome

52. $A$, Half Dome quartz monzonite; $B$, Cathedral Peak granite, polished by the ancient glaciers

Figure 1. Generalized diagram of part of tilted Sierra block

2. Idealized cross section of Sierra block

3. Block diagram illustrating parallel mountain ranges carved from strongly folded strata

4. Cross sections illustrating successive stages in the cutting of Merced Canyon...

5. Longitudinal profile of Saxon Gulch.

6. Longitudinal profile of hanging valley of Feliciana Creek

7. Longitudinal profiles of hanging valley of Fireplace Creek and of ravine on opposite side cf Yosemite Valley -

8. Longitudinal profile of hanging valley of Indian Creek

9. Longitudinal profile of hanging valley of Yosemite Creek

10. Longitudinal profile of hanging valley of Bridalveil Creek

11. Longitudinal profile of hanging valley of Chilnualna Creek

12. Longitudinal profiles of hanging gulch of Bridalveil Creek and of hanging upland valley of Ribbon Creek

13. Bird's-eye view of Yosemite Valley in broad-valley stage

14. Bird's-eye view of Yosemite Valley in mountain-valley stage

15. Bird's-eye view of Yosemite Valley in canyon stage

16. Bird's-eye view of Yosemite Valley immediately after the ice age

17. Idealized sketch of a glacier leaving successive moraine loops as it melts back

18. Section across moraine dam at El Capitan Bridge

19. Sketch showing in section lateral moraines on north side of Little Yosemite Valley

20. Section across lateral moraines on south side of Little Yosemite Valley

21. Section across parts of Moraine Dome

22. Longitudinal profiles of Yosemite and Merced Glaciers in the El Portal and Wisconsin stages of glaciation..-.

23. Section across Tenaya Canyon and Little Yosemite showing highest levels reached by Tenaya and Merced Glaciers .

24. Cross profile from Eagle Peak to Sentinel Rock

25. Cross profile from North Dome to Glacier Point

26. Cross profile below Bridalveil Meadow

27. Cross profile from El Capitan to the Cathedral Rocks

28. Cross profile at head of Merced Gorge

29. Cross profile at mouth of Little Yosemite Valley

30. Cross profile at middle of Little Yosemite Valley

31. Diagram illustrating the quarrying of joint blocks by a glacier cross cliffs

33. Longitudinal section of a typical roche moutonnee

34. Longitudinal section of a canyon illustrating the development of a glacial stairway by selective quarrying--.-

35. Longitudinal section of Yosemite Valley

36. Section across Little Yosemite Valley

37. Section across Merced Gorge above Little Yosemite Valley

38. Diagram showing how by progressive exfoliation the angularities of a rock mass are replaced by smooth curves.. 


\title{
GEOLOGIC HISTORY OF THE YOSEMITE VALLEY
}

\author{
By Frangois E. Matthes
}

\section{TECHNICAL ABSTRACT}

The problem of the origin of the Yosemite Valley inherently demands a solution in quantitative terms. Its essence is, To what extent is the valley a product of glacial action, to what extent a product of stream erosion? The principal result of the investigations upon which this report is based is the determination within narrow limits of the preglacial depth of the Yosemite Valley and of other facts concerning its preglacial development which permit fairly definite estimates of the proportionate shares of work performed by stream and by glacier. The investigations comprise a detailed survey of the glacial and geomorphologic features of the Yosemite region and an equally intensive study of its rock formations, supplemented by reconnaissance work of both kinds in adjoining parts of the Sierra Nevada. The petrologic studies were made by Frank C. Calkins; the glacial and geomorphologic survey by François E. Matthes.

Detailed mapping of the morainal system of the ancient Yosemite Glacier has served not only to determine the farthest limits reached by that glacier but to throw new light on the significance of the hanging valleys of the Yosemite region. It is reasonably certain that the glacier never extended more than about a mile beyond the site of El Portal. The hanging side valleys of the Merced Canyon below El Portal, therefore, hang not because of any glacial deepening suffered by that canyon. The explanation is offered that they hang because their streamlets have been unable to trench as rapidly as the Merced River since the rejuvenation of the Merced by the last uptilting of the Sierra Nevada. The streamlets were handicapped not only by their comparatively small volume but also by the fact that their courses trend northwestward and southeastward, substantially at right angles to the direction of the tilting, and therefore have remained essentially unsteepened, whereas the Merced's course trends southwestward, directly down the slope of the Sierra block, and therefore has been appreciably steepened.

Projection of the longitudinal profiles of these hanging valleys forward to the axis of the Merced Canyon shows that they are closely accordant in height. Their profiles indicate a series of points on a former profile of the Merced with respect to which the side streams had graded their courses prior to the last uplift. This old profile can be extended upward into the glaciated part of the Merced Canyon above El Portal and even into the profoundly glaciated Yosemite Valley, accordant points being furnished by a number of hanging side valleys (due allowance being made for glacial erosion suffered by those valleys). However, not all the hanging valleys of the Yosemite region are accordant with this set. Several of them, including the upland valley of Yosemite Creek, constitute a separate set indicating another old profile of the Merced at a level 600 to 1,000 feet higher than the first. Others, including the hanging gulch of lower Bridalveil Creek, point to an old profile of the Merced about 1,200 feet lower than the first. There are thus three distinct sets of hanging valleys produced in three cycles of stream erosion. The valleys of the upper set, like those of the middle set, were left hanging as a result of rapid trenching by the Merced induced by an uplift of the range, there having been two such uplifts. Only the valleys of the lower set hang because of glacial deepening and widening of the Yosemite Valley, the cycle in which they were cut having been interrupted by the advent of the Pleistocene glaciers.
They consequently indicate the preglacial depth of the Yosemite Valley. That depth, measured from the brow of El Capitan, was about 2,400 feet; measured from the rim at Glacier Point it was about 2,000 feet.

During that remote cycle of which the hanging valleys of the upper set and the undulating Yosemite upland are representative the Yosemite Valley itself was broad and shallow, past mature in form. That early stage in its development, accordingly, is called the broad-valley stage. The deeper hanging valleys of the middle set were graded with respect to a deeper Yosemite of submature form which must have had the aspect of a mountain valley. That stage in its development is therefore called the mountain-valley stage. The short, steep hanging valleys of the lower set and certain topographic features associated with them show that during the third cycle of erosion the Yosemite was a roughly V-shaped canyon with a narrow inner gorge. This stage of the Yosemite, which immediately preceded the glacial epoch, is therefore called the canyon stage.

Correlation of the Yosemite upland with the upland of the Table Mountain district, between the canyons of the Tuolumne and Stanislaus Rivers, shows that it is in all probability a feature of late Miocene age; for fossil remains of plants and animals found in the lava-entombed stream channels on the upland near Table Mountain appear to be of late Miocene age, according to determinations made by Dr. Ralph W. Chaney and Dr. Chester Stock. Uplift of the Sierra Nevada at the end of the Miocene epoch initiated the next cycle, during which the mountainvalley stage was evolved. That cycle lasted presumably through most if not all of the Pliocene epoch. The canyon stage was produced in all probability wholly during the Quaternary period.

The excellent preservation of the hanging valleys of the upper set, in spite of their great age, is explained by the exceedingly resistant nature of the massive granite that underlies them. The valleys of the middle set were carved in prevailingly jointed rocks that were less resistant to stream erosion, and the gulches of the lower set were carved in closely fractured rocks in which the streams eroded with relative ease. The important part played by massive granite in the preservation of the upland valleys and the upland itself is most convincingly demonstrated near Wawona, in the valley of the South Fork of the Merced, whici may be termed a half-yosemite. The north side of this valley, which is carved from prevailingly massive granite, has sheer cliffs, that reach up to a lofty upland, the analog of the Yosemite upland; and from the hanging valley of Chilnualna Creek, on this upland, leaps a waterfall similar to the falls that leap from the hanging side valleys of the Yosemite. The south side, which is carved from prevailingly jointed rocks, has sloping forms, and the side streams there descend to the level of the master stream without making any falls.

In addition to the three sets of hanging valleys and the three old profiles of the Merced to which they point, there are at hand enough other topographic data to permit an approximate reconstruction of the configuration of the Yosemite Valley at each stage. Three bird's-eye views are shown, all drawn from the same point of view, in which the development of the significant features of the Yosemite Valley can be traced from stage to stage. A fourth bird's-eye view affords a direct comparison of the canyon stage, immediately preceding glaciation, with the U-trough stage at the end of the glacial epoch. 
The gradients of the two higher profiles of the Merced, further, furnish data from which the amplitude of each of the two great uplifts of the Sierra Nevada can be calculated roughly. The uplift at the end of the Miocene epoch added about 3,000 feet to the height of the range; the uplift at the end of the Pliocene epoch added fully 6,000 feet more. Mount Lyell, which now stands about 13,090 feet above the sea, therefore stood at about 7,000 feet during the Pliocene epoch and about 4,000 feet during the Miocene epoch.

Of the earlier geomorphologic history of the Yosemite region a glimpse is afforded in the explanation of the origin of the southwesterly course of the Merced River and the arrangement of the lesser tributaries at right angles to it. The Merced established its course conformably to the southwesterly slant of the Sierra region, presumably early in the Tertiary period, when there still existed remnants of a system of northwestward-trending mountain ridges of Appalachian type, which had been formed at the end of the Jurassic period by the folding of sedimentary and volcanic strata of Paleozoic and Mesozoic age. As it grew headward the Merced probably captured the drainage from the longitudinal valley troughs between these ridges. Below El Portal, on the lower slope of the Sierra Nevada, where the folded strata still remain in a broad belt, the lesser tributaries of the Merced are for the most part adjusted to the northwesterly strike of the beds. In the Yosemite region and the adjoining parts of the High Sierra, from which the folded strata are now stripped away, so that the granitic rocks are broadly exposed, the northwesterly and southeasterly trends of many of the streams are largely an inheritance by superposition from the drainage system of the now vanished older mountain system. It seems entirely probable that the northwesterly trend of the Clark Range, the Cathedral Range, and certain stretches of the main crest of the Sierra Nevada is likewise inherited from that ancient mountain system.

The mapping of the morainal system of the Yosemite Glacier has, further, led to the recognition of three stages of glaciation. During the last or Wisconsin stage, which is recorded by well-preserved, sharp-crested moraines, the Yosemite Glacier advanced only as far as the Bridalveil Meadow. During the preceding El Portal stage, which is recorded by relatively obscure, partly demolished moraines, the glacier reached as far as a point about a mile below El Portal, in the lower Merced Canyon. Remnants of a valley train of outwash material can be traced for a distance of 30 miles farther down the canyon. Of the still more remote Glacier Point stage evidence is found only in erratic boulders that lie scattered at levels about 200 feet above the highest lateral moraines of the El Portal stage, notably near the west base of Sentinel Dome, $\mathbf{7 0 0}$ feet above Glacier Point, and on the broad divide east of Mount Starr King.

On both sides of the Little Yosemite the younger lateral moraines culminate in two parallel crests of about equal height, yet separated by a broad depression. The interval of time between the deposition of the outer and inner crests appears to have been much shorter than an interglacial stage, hence it is concluded that the Wisconsin stage was characterized by two glacial maxima. On the other hand, the interval of time between the Wisconsin stage and the $\mathrm{El}$ Portal stage must have been very long, for whereas the massive granite on the sides of the Little Yosemite retains over large areas the polish imparted to it by the Wisconsin ice, it has lost all the polish that was imparted to it by the El Portal ice and in addition has disintegrated and been stripped by rain wash to a depth of several feet. The most reliable measures of the stripping are furnished by three dikes of slow-weathering aplite that project like little walls from the summit of Moraine Dome. Since the ice of the El Portal stage passed over the dome these dikes have come to stand out, by reason of the stripping of the surrounding granite, with heights of 7,8 , and 12 feet. It is estimated, accordingly, that a period at. least ten times and perhaps twenty times as long as the postglacial interval has elapsed since the El Portal stage. That stage is therefore perhaps to be correlated with either the Illinoian or the Kansan stage of the continental glaciation.

That the El Portal stage was in turn separated from the Glacier Point stage by a long interval of time is inferred from the fact that whereas the oldest lateral moraines of the El Portal stage still persist as continuous bodies, even on steep. slopes, nothing is now left of the moraines of the Glacier Point. stage save a few boulders of exceptionally durable quartzite and siliceous granite, even on nearly level surfaces where the conditions are particularly favorable for the preservation of moraines. The Glacier Point stage is therefore held to be comparable in age with the Kansan or possibly with the Nebraskan stage of the continental glaciation.

The discussion of the glacial history of the Yosemite region is supplemented by a map of the valley on a scale of $1: 24,000$ on which all the moraines and the more significant erratic boulders are shown in detail, also by a map on a scale of $1: 125,000$ on which are delineated the entire Yosemite Glacier from its sources on Mount Lyell and in the Tuolumne Basin down to its terminus near El Portal and all the lesser ice bodies. that lay within the area tributary to the Yosemite Valley. A brief description is given of each glacier as it appeared in the earlier and in the later ice stages. It is shown that Half Dome at no time was overtopped by the ice; also that the Yosemite Glacier at no time received a tributary ice stream from the Illilouette Valley, as has been commonly assumed. Instead, a lobe of the Merced Glacier pushed up into the Illilouette Valley. Imprisoned between that lobe and the Illilouette Glacier lay a temporary lake, whose extent is indicated by deposits of sand and gravel.

The depth of glacial excavation in the Yosemite Valley is revealed in a longitudinal section affording a direct comparison of the preglacial and postglacial bottom profiles. It increases gradually from 500 feet at the lower end of the valley to a maximum of 1,500 feet opposite Glacier Point; thence it decreases abruptly to a minimum of 250 feet at the mouth of the Little Yosemite. The glacial widening is shown in a series of cross sections in each of which the preglacial form is superimposed upon the postglacial form. It exceeds the glacial deepening at all points and ranges from a maximum of 1,800 feet on each side in the upper half of the valley to a minimum of 500 feet on each side at the head of the lower Merced Gorge. These marked variations are explained by the selective action of the glacier in rocks of widely varying structure. Where the rocks were thoroughly jointed the glacier excavated effectively by quarrying; where the rocks were too massive to be quarried the glacier only ground and polished. The capacious $U$ form of the Yosemite Valley is therefore a product of wholesale quarrying in an area of well-jointed rocks. The gorges above and below the valley, on the other hand, have remained narrow because glacial abrasion has been able to effect but slight changes in their prevailingly massive rocks.

Highly significant in this connection is the fact that the Yosemite Valley lies in an area where a plexus of local intrusions composed mostly of granodiorite, diorite, and gabbro, all welljointed rocks, breaks the continuity of the vast bodies of siliceous granite, generally massive in habit, that make up the central part of the batholith of the Sierra Navada. This plexus did not of itself give rise to the formation of the Yosemite, but it happened to lie in the path of the Merced River, which was superimposed upon it.

The stepwise mode of ascent of the floors of the Yosemite, the Little Yosemite, the upper Merced Canyon, and Tenaya Canyon is a characteristic result of glacial action. However, the edges and risers of the steps are composed invariably of 
massive rock not susceptible of being quarried. They were therefore not migrant features that receded rapidly headward during the process of glaciation, in the manner implied by certain hypotheses that have been advanced in explanation of the development of glacial stairways. They were essentially fixed features definitely related to the structure of the rock. The canyon steps, accordingly, are conceived to have been produced by selective glacial quarrying. Each tread is essentially a basin quarried out in jointed rock; each edge is essentially a residual obstruction of unquarriable rock, smoothed on the upstream side by abrasion, steepened on the downstream side by the removal of jointed rock. Glacial excavation proceeds with greatest vigor at the head of each tread, because there the ice exerts the greatest force in consequence of its plunge from the step above and accumulates to greatest thickness.

This explains how the steeply rising preglacial floor of the Yosemite Valley was replaced by a nearly level, basined rock floor, and why the depth of excavation is three times as great at the head of the valley as at its lower end. The ice descended into the head of the valley not merely by way of the giant stairway from whose steps the Vernal and Nevada Falls now leap, but during the culminating phases of glaciation it also plunged from the lofty platform at the southwest base of $\mathrm{Half}$ Dome in the form of a mighty glacial cataract. The deep, walled-in heads of the Little Yosemite and Tenaya Canyon similarly were excavated mainly by great cataracts of ice.

Structure control also has determined the level of each step. The high level of the Little Yosemite was determined by the height of the body of massive granite that forms the upper step of the giant stairway. The absence of a step at the mouth of Tenaya Canyon, on the other hand, is explained by the fact that glacial excavation there was facilitated by the presence of a belt of fractured rock.

The detailed sculpture of the walls of the Yosemite Valley is likewise a function of the structure of its rocks, the actions of the weathering processes having been sharply controlled by local variations in the jointing. Vertical master joints have determined the profile and orientation of most of the great cliff faces, including the sheer precipices over which the waterfalls leap. Northeasterly and northwesterly master joints account for much of the faceted sculpture. Easterly master joints have controlled the trend of the great precipice of the upper Yosemite Fall and of the famous cliff at Glacier Point. Oblique joint planes dominate the sculpture of the Three Brothers and of many lesser spurs. Prevailingly sparse jointing in the more siliceous rocks explains the predominance of massive rock forms. Narrow zones of intense fracturing, on the other hand, have given rise to deep recesses, even in places where no drainage descends or formerly descended from the uplands. All the notches, gulches, and alcoves in the vicinity of the waterfalls at the mouths of hanging valleys and on the steps of the giant stairway are carved along fracture zones. Only a few have been produced in the manner explained by Branner, by torrents that flowed along the margins of the glaciers.

The domes of the Yosemite region have been evolved from giant monoliths by long-continued exfoliation due to expansion of the granite, presumably in consequence of relief from load by denudation. The irregularities of their curvature still betray to some extent the trend of the master fractures that originally bounded the monoliths. Half Dome is exceptional in that its sheer northwest side has been exposed only recently by glacial plucking and therefore still retains the plane form which it has inherited from a sheeted structure with northeasterly trend. Exfoliation here and in certain other localities is producing essentially plane sheets. On cliffs ground concave by the glaciers, notably on the step above the Vernal Fall, it produces concave shells.

Examination of the débris piles at the bases of the cliffs dispels the belief of some of the earlier observers that 90 per cent of the material was precipitated by a single great postglacial earthquake. There is evidence that in addition to many small rock falls there have occurred several great rock avalanches, and that the intervals between those avalanches were of sufficient length to permit forests to grow up repeatedly on the talus slopes. Earthquake action appears to be indicated most definitely by far-flung hummocky masses of débris that contrast with the sloping taluses and that must have been precipitated from the cliff fronts in their entirety.

The greatest postglacial change in the appearance of the Yosemite region was brought about by the filling of the glaciallake basins with stream-borne sediment. The level sandy floors of the Yosemite and the Little Yosemite and the successive treads of Tenaya Canyon all replace glacial lakes. The floor of the Yosemite Valley does not, however, indicate the exact level at which the water of ancient Lake Yosemite stood. It is a flood plain of the Merced River cut about 15 feet below the old lake level, which is indicated by terraces. Mirror Lake is not a remnant of a glacial lake but was impounded by great rock avalanches that fell from the cliffs at the mouth of Tenaya Canyon, presumably as the result of an earthquake, some time after the glacial epoch.

An attempt is made in this volume to set forth these facts and interpretations in language intelligible to the general reader as well as to the scientist. The Yosemite Valley is treated not by itself but in its setting, as an erosional feature of the Sierra Nevada that came into being and was evolved by successive stages in consequence of certain epochal events in the orogenic history and in the glaciation of the range.

In the appendix the nature and significance of the remarkable complex of igneous intrusions into which the Yosemite Valley is hewn are outlined by Frank C. Calkins. A geologic map of the Yosemite region, the upper Merced Basin, and the upper Tuolumne Basin shows the complex in its relations to the vast intrusive masses that occupy the surrounding parts of the Sierra Nevada. The rocks described range from nearly white alaskite to nearly black hornblende gabbro, yet a strong family resemblance is visible in all. Two distinct series of intrusions are recognized-the biotite granite series of the Yosemite Valley and the Tuolumne intrusive series-and in addition there are several kinds of rock not definitely assignable to either of these series.

\section{INTRODUCTION}

"The incomparable valley" the Yosemite has been called by those who admire and love it-and rightly so, for where can be found another valley of such distinctive beauty, such impressive grandeur, such captivating charm? Yet hardly less appropriate, from another point of view, would be the title "valley of mystery," for surely no other valley has aroused more curiosity among scientists or laymen or given rise to more speculation and discussion as to the secret of its origin. So extraordinary is the appearance of the Yosemite Valley, with its sheer, monumental cliffs and massive, rounded domes, its lofty, swaying waterfalls and verdant, parklike floor, that it seems in a class by itself, created in some special, unusual way, apart from all other valleys and canyons. No person of intelligence, it is safe to say, ever beheld the Yosemite Valley who did not instantly wonder by what strange process it was formed and through what fortuitous circumstances it became endowed with such surpassing beauty and loveliness. 
Not unnaturally the layman's inclination has ever been to appeal to a dramatic, violent cause, to a cataclysm of some kind; for those not versed in the earth sciences find it difficult to believe that so unusual a chasm could have been fashioned by slow everyday processes. Of varied and imaginative conjectures as to the Yosemite's mode of origin, consequently, there has been no lack. Speculation began on the very day, in 1851, when the valley was first entered by white men. Seated around their camp fire on the bank of the Merced, in view of the stupendous cliffs of $\mathrm{El}$ Capitan, the rough pioneers composing the historic Mariposa Battalion hazarded the first crude guesses.

Even among scientists there have been more than one to whom the remarkable configuration of the Yosemite Valley has seemed inexplicable save as the result of some paroxysm of nature. It happened, indeed, that the first geologist of note who was in a position to speak authoritatively on the subject, Prof. Josiah D. Whitney, believed in a catastrophic cause, and his belief naturally did much to confirm the prevailing trend of thought. Whitney, as State geologist of California, in 1863 instituted the first scientific exploration of the Sierra Nevada, the great mountain range in which the Yosemite is situated, and as a result of his observations was led to conclude that the valley had been roughly hewn into its present proportions by a dislocation of the earth's crust involving the engulfment of a great block, or group of blocks. ${ }^{1}$ In his own homely but expressive phrase, he conceived the bottom of the valley to have dropped out, owing to some convulsive movements within the earth, associated, presumably, with the upheaval of the Sierra Nevada. This hypothesis, having been set forth by Whitney not only in his official report but also in his popular Yosemite guidebook, ${ }^{2}$ which was issued with the approval of the State legislature, became widely accepted as authoritative; and, being simple, plausible, and sensational, it did not fail to make a strong appeal to the popular imagination.

The underlying idea of Whitney's hypothesis was, it should be added in all fairness, not so absurd as some of his opponents have intimated, for there are many well-authenticated instances of valleys that have been created by the subsidence of blocks of the earth's crust. Several such depressions are associated with the Sierra Nevada-notably Owens Valley and the basin occupied by Lake Tahoe. However, Whitney's hypothesis rested on no tangible evidence, and nothing has been found thus far to substantiate it.

Another scientist who believed in a catastrophic origin of the Yosemite was Clarence King, who in the early sixties was one of Whitney's younger assistants on the survey of the Sierra Nevada and who later became chief of the United States Geological Survey

1 Whitney, J. D., Geological survey of California; Geology, vol. 1, pp. 421-422, 1865. Thitney, J. D., The Yosemite guidebook, pp. 84-87, 1870. of the Fortieth Parallel and, finally, Director of the United States Geological Survey. King ${ }^{3}$ conceived the Yosemite to be essentially a "yawning crack" due to the rupturing, or "splitting asunder," of the earth. He was the first to discover the unmistakable evidence of the passage of a glacier through the valley, but though he saw that that glacier had been at least 1,000 feet thick, he ascribed to it only slight influence in the modeling of the valley, for, like the other members of Whitney's staff, he believed glaciers to have inherently small excavating power.

Not long after the pioneer explorations of Whitney and King, however, it became manifest to scientists that the Yosemite Valley, far from being the product of a violent paroxysm of nature, had been evolved little by little, in the course of long periods of time, through the slow "eroding," literally "gnawing" action of streams and glaciers, seconded by the destructive work of rain, frost, and other atmospheric agents.

Prof. William P. Blake, of the University of Arizona, in 1866, was the first to express the belief that the Yosemite like most other valleys and canyons on this earth, is a feature wrought by erosional processes. He regarded it primarily as a stream-worn canyon in whose final shaping a glacier had played a part, but, like other geologists of that time, he was inclined to attribute the remodeling of the chasm to torrents flowing under the glacier rather than to the glacier itself. ${ }^{4}$ Unfortunately he presented this tentative interpretation, as well as the remarkably accurate analysis which he made on a later visit, ${ }^{5}$ to scientific audiences alone, and thus the general public has remained unacquainted with them.

It was John Muir, ${ }^{6}$ the keen student and ardent lover of nature, who first saw clearly that the glaciers themselves had done most of the excavating. Although not a geologist by profession, he was quick to perceive the manifold evidences of powerful glacial action in and about the Yosemite. Fascinated by the story which he read in them, he devoted most of his spare time during his sojourn in the valley in 1869 and the years following to tracing the pathways of the ancient glaciers, and thus the conviction grew upon him that the Yosemite and indeed all the great canyons of the Sierra Nevada are primarily channels gouged out by ice streams. Later, through his charming writings, he disseminated his ideas of glaciation far and wide, thereby uprooting in the minds of many people the primitive belief in a catastrophic origin of the valley.

\footnotetext{
${ }^{3}$ King, Clarence, Mountaineering in the Sierra Nevada, 4th ed., pp. 7, 134, Boston, 1874

4 Blake, W. P., Sur l'action des anciens glaciers dans la Sierra Nevada de Californie, et sur l'origine de la valjée de Yo-semite: Compt. Rend., vol. 65, pp. 179-181, 1867.

B Blake, W. P., Glacial erosion and the origin of the Yosemite Valley: Am. Inst. Min. Eng. Trans., vol. 29, pp. 823-835, 1900.

- For a partial list of Muir's writings on the Yosemite Valley, seo bibliography, pp. 130-131. A complete bibliography of Muir's writings was published in Sierra Club Bull., vol. 10, pp. 41-54, 1916.
} 
Prof. Joseph Le Conte, ${ }^{7}$ of the University of California, upon visiting the Yosemite in 1871, was deeply impressed by Muir's interpretations. He also recognized the valley to be an ancient glacier channel, but he differed from Muir in that he attributed a considerable share of the excavation to stream action prior to the coming of the glacier.

Of the controversy that arose between Muir and Whitney little need here be said. Whitney tenaciously clung to his "dropped-block hypothesis" and even denied outright that the Yosemite had ever been invaded by the ice, ${ }^{8}$ al though he had previously published the indubitable evidence, reported by Clarence King, of the former presence of a glacier in the valley. ${ }^{9}$ Muir, on his part, went too far in his claims for glacial erosion. Dominated by the belief that the Sierra Nevada had been mantled with ice "from summit to base" and to a depth sufficient to bury practically all its features, ${ }^{10}$ he maintained that the Yosemite and, indeed, all the great canyons of the range, thousands of feet in depth, had been gouged out entirely by the glaciers. These canyons, he asserted, owe not only their general forms but their very "trends and geographical positions" to glacial action." The average depth to which the Sierra had been stripped of rock by the ice he estimated at considerably over a mile. ${ }^{12}$

To many persons, naturally, these statements seemed extravagant. Geologists, especially, were slow to accept them, because of the evident lack of substantiating proof. It is to be borne in mind, also, that at the time when Muir first set forth his views of wholesale glaciation the ice age was still a new and rather vague concept. Little was known of the magnitude which the glaciers and ice sheets have attained in different parts of the earth, nor of the extent to which they have changed the configuration of the lands. The ability of glaciers to excavate deep canyons in hard rock was still regarded as a matter to be demonstrated.

How widely the best informed men of Muir's time differed in their estimates of the excavational work that has been accomplished by the ice in the Yosemite Valley is illustrated by the fact that Prof. Israel C. Russell, ${ }^{13}$ of the University of Michigan, in 1889, after having studied the extensive débris ridges, or moraines, which the glaciers descending from the east flank of the Sierra Nevada have built at the mouths of their canyons, declared that in his opinion the absence of similar bulky moraines at the foot of the Yosemite Valley argued strongly against the supposition that

\footnotetext{
' Le Conte, Joseph, A journal of ramblings through the Bigh Sierra of California by the University excursion party, San Francisco, Calif., 1875 (republished as Ramblings through the High Sierra: Sierra Club Bull., vol. 3, pp. 1-107, 1900).

8 Whitney, J. D., The Yosemite guidebook, pp. 83-84, 1870.

- Whitney J. D., Geological survey of California; Geology, vol. 1, p. 422, 1865.

10 Muir, Jobn, Studies in the Sierra-IV, Glacial denudation: Sierra Club Bull,

vol. 10, p. 316, 1918 (reprinted from Overland Monthly, vol. 13, pp. 174-184, 1874).

"I Idem, p. 308.

${ }^{12}$ Idem, p. 318.

13 Russell, I. C. Quaternary history of Mono Valley, Calif.: U. S. Geol. Survey Eighth Ann. Rept., pt. 1, p. 350, 1889.
}

that valley had been excavated mainly by glaciers. Though himself a noted student of glaciers, Russell therefore reverted to Whitney's hypothesis for an explanation.

Again, Henry W. Turner, of the United States Geological Survey, upon extending his investigations in the Sierra Nevada southward to the Yosemite Valley in 1899 , found it so similar in many respects to certain stream-worn canyons observed by him that he felt convinced that its features could be explained as products largely of stream erosion and weathering processes, facilitated by the jointed structure of the granite. The glaciers, in his opinion, had done little more than clear the valley of loose débris. ${ }^{14}$ Turner made the first attempt to determine the farthest limits reached by the Yosemite Glacier and tentatively located these limits in the vicinity of El Portal, only 9 miles below the valley. The relatively modest dimensions of the ice stream thus indicated, together with the small amount of débris it had left behind in the form of moraines, strengthened his conviction that it had had but slight erosive power. On the other hand, he rightly insisted that the upheaval of the Sierra Nevada in preglacial time must have greatly accelerated the flow of the Merced River and caused that stream to intrench itself deeply.

Turner's interpretation of the Yosemite as primarily a stream-cut canyon was, of course, challenged at once by the apostles of glacial erosion, notably by Henry Gannett, then chief geographer of the United States Geological Survey. Gannett, as a result of his studies on Lake Chelan, in the Cascade Range, had come to regard "hanging" side valleys as characteristic accessory features of deeply glaciated canyons, and contended that the height of such valleys affords a rough measure of the depth of glacial excavation in the main canyon. The Yosemite, he pointed out, has hanging side valleys of great height (the upland valleys from whose mouths the waterfalls pour into the chasm), and he therefore pronounced it to be "quite an ordinary and necessary product of glacial erosion." 15

Prof. John C. Branner, of Leland Stanford Junior University, on the other hand, stood by Turner, and on the strength of his cursory observations concluded that in the Yosemite Valley "the wearing done by the ice was trivial as compared with the wearing done by the glacial streams." 16

Several other scientists have since advanced tentative hypotheses in explanation of the Yosemite's origin, each based, however, on only a brief examination. All of them, significantly, assign a large share of the excavational work to glacial action, but they differ

"Turner, II. W., The Pleistocene geology of the south-central Sierra Nevada, with especial reference to the origin of Yosemite Valley: California Acad. Sci. Proc., 3d ser., vol. 1, pp. 319-320, 1900.

15 Gannett, Henry, Origin of Yosemite Valley: Nat. Geog. Mag., vol. 12, pp. $86-87,1901$.

16 Branner, J. C., A topographic feature of the banging valleys of the Yosemite: Jour. Geology, vol. 11, p. 551, 1903. 
considerably in their estimates of that share. E. C. Andrews, of the Department of Mines, New South Wales, interpreted the Yosemite as being essentially a gorge created by the powerful erosive action of a plunging ice cascade, or ice fall, in the Yosemite Glacier, that receded gradually headward, just as the Niagara Gorge has been created by the erosive action of the slowly receding Niagara Falls. The cross cliff over which the Yosemite Glacier plunged he estimated to have been "at least 2,000 feet in height." 17

Prof. Douglas W. Johnson, of Columbia University, following Gannett's idea out to its logical conclusion, undertook to deduce the depth of glacial excavation in the Yosemite chasm from the heights and gradients of its hanging side valleys. Reconciling as well as he could the discordant results which he obtained by this method, he arrived at a measure of " 2,200 to 2,500 feet at least." 18

Prof. Andrew C. Lawson, of the University of California, believed the Yosemite to have been elaborated by glaciation from "a profound erosional gorge." ${ }^{10}$ From the insight into the preglacial history of canyon cutting in the Sierra Nevada previously gained through his studies in the Kern River Basin, it was manifest to him that the Yosemite, like the other great canyons of the Sierra, must have had great depth prior to the arrival of the glaciers. He believed it to have been further deepened and also widened by glacial action, but the work done by the ice, in his estimation, was "probably not great," as the morainal débris deposited below the Yosemite is of scant volume.

The wide discordance in these different estimates of the amount of excavational work accomplished by the glaciers and the preglacial streams, respectively, was due chiefly to the lack of reliable information as to the extent and magnitude of the ancient Yosemite Glacier and its tributaries, to the haziness of ideas that prevailed regarding the preglacial history of the Yosemite region, and to fundamental differences in conception as to the eroding capacity of glaciers and the precise manner in which glaciers do their erosional work. It will be readily understood, therefore, why in 1913 the United States Geological Survey at once responded to the popular demand, voiced by the Sierra Club, for further and more definite information regarding the geologic history of the Yosemite Valley and instituted a systematic and intensive investigation covering the entire Yosemite region and the neighboring parts of the High Sierra. There was additional warrant for such an investigation in the fact that since the end of the nineteenth century there had come to maturity a

\footnotetext{
17 Andrews, E. C., An excursion to the Yosemite, California, or studies in the formation of alpine cirques, "steps," and valley "treads": Roy. Soc. New South Wales Jour. and Proc., vol. 44, p. 312, 1900.

18 Johnson, D. W., Hanging valleys of the Yosemite: Am. Geog. Soc. Bull., vol. 43, p. 831, 1911.

10 Lawson, A. C., Geology of Yosemite National Park, in Handbook of Yosemite National Park, compiled by Ansel E. Hall, p. 120, 1921.
}

new branch of geologic science-geomorphology, or physiography, as it is also termed-which deals specifically with the origin and development of the surface features of the earth and within whose scope a problem such as that of the Yosemite Valley largely belongs. Furthermore, a new detailed topographic map of the valley that afforded an excellent base for the proposed studies had recently been completed.

The privilege of carrying out the new investigations fell to Frank C. Calkins and the author of this paper. Mr. Calkins's task was to study the characteristics, significance, and relationships of the different kinds of rock that occur in the Yosemite region, and the writer was charged with deciphering its glacial history and studying the evolution of its sculptural features. For several years the two investigators carried on their work conjointly throughout the Yosemite region and the adjoining areas in the High Sierra. Then each made supplementary reconnaissances, Mr. Calkins carrying a geologic section across the range from the mouth of the Merced Canyon up through the Yosemite region and the writer extending his glacial and geomorphologic studies northward to the regions drained by the Tuolumne and Stanislaus Rivers and southward over the drainage basins of the San Joaquin, Kings, and Kaweah Rivers.

As a result there is now at hand a considerable body of new and definitely correlated data, upon which, with more confidence than has been possible heretofore, the story of the origin and evolution of the Yosemite Valley may be built. In the first place, the farthest limits reached by the ancient Yosemite Glacier and all its tributaries and neighboring ice streams have now been traced out and definitely mapped. Much has been learned also of the sequence of advances and retreats of the ancient glaciers, and some perspective has been gained upon the spans of time involved in those fluctuations. Thus it is now established beyond reasonable doubt that the Yosemite region-indeed, the entire Sierra Nevada-was glaciated at least three times during the ice age, having gone through alternating glacial and interglacial stages, like the central parts of the continent. Further, three important chapters of the Yosemite's preglacial history now stand revealed, and the successive stages in the valley's development recorded in those chapters are definitely linked with successive epochs in the growth of the Sierra Nevada. The geologic age of the earliest of those epochs, moreover, has been tentatively determined from fossil remains found in other parts of the range. Again, the depth to which the Yosemite was excavated at each stage in its history has been ascertained within narrow limits, and so the crucial question as to how much of the work was done by the streams and how much by the glaciers can now be answered fairly definitely. Last of all, the reason for the distinctive form of the Yosemite Valley and for its exceptional wealth of sculptural features has been found in 
the selective manner in which the glaciers and the other agents of erosion have acted upon the irregularly and unusually structured granitic rocks.

In the pages that follow the purpose has been to set forth the story of the Yosemite Valley in language simple enough to be understood by one having no geologic training, yet in sufficient fullness to leave no doubt in the critical reader's mind as to the foundation of observed facts or as to the processes of reasoning whereby the conclusions are reached. Each geologic concept is briefly explained, and ponderous scientific terms are avoided as far as practicable. Discussions of technical points regarding which there has been diversity of opinion are purposely made brief, in order not to weary the reader nor to rekindle a spirit of controversy.

For the guidance of those who may desire to acquaint themselves with the older hypotheses and compare their merits more fully than has here been attempted, a bibliography of all the scientific literature bearing on the geologic history of the Yosemite region is added at the end of the volume.

\section{ACKNOWLEDGMENTS}

The writer takes pleasure in expressing his appreciation to his colleague, Frank C. Calkins, for his whole-hearted collaboration in the field and for his numerous contributions to this paper. All statements relating to the petrographic character, areal distribution, and genetic relationships of the rocks are based on Mr. Calkins's findings. To Dr. Ralph W. Chaney, of the Carnegie Institution of Washington, the writer is indebted for the identification of significant plant remains from the Table Mountain district. To the officials of the National Park Service, in particular to Mr. W. B. Lewis, who was superintendent of the Yosemite National Park from 1916 to 1927, he desires to convey his gratitude for many courtesies and for effective cooperation in expediting the prosecution of the field work.

\section{GEOGRAPHIC SKETCH OF THE YOSEMITE REGION AND THE SIERRA NEVADA}

\section{LOCATION AND CHARACTER OF THE YOSEMITE VALLEY}

The Yosemite (yo-sem'i-ty) Valley ${ }^{20}$ is situated about 150 miles due east of San Francisco, on the west flank of the Sierra Nevada, the great mountain range that extends lengthwise through eastern California. (See pl. 1.) It is the principal scenic feature of the Yosemite National Park, which embraces a tract 1,124 square miles in extent-almost as large as Rhode Island. (See pl. 2.) Compared with the entire park, however, the Yosemite Valley is small, measuring

20 Yosemite comes from "üzümati" or "ühümati," which in the language of the Southern Miwoks meant "grizzly bear." It is said to have been originally the name of the tribe of Indians who inhabited the valley, or at least of that part of the tribe which dwelt on the north side of the river. The name was given to the valley, at the suggestion of Dr. Lafayette Houghton Bunnell, by the Mariposa Battalion, the first party of white men to enter the valley, in 1851 . but 7 miles in length and 2 miles in breadth. It is, in fact, only a widened portion of the prevailingly narrow canyon of the Merced (mare-sed') River, which traverses the south half of the reservation from east to west. Nor is it the only chasm of note within the park. A dozen miles to the north, and parallel to it, is the Grand Canyon of the Tuolumne (tu-ol'um-ne) River, a prodigious gash which exceeds the Yosemite Valley in length and in depth, though scarcely in scenic grandeur, and which opens into the Hetch Hetchy Valley, a lesser yosemite that now holds an artificial lake, impounded by a dam at its lower end.

Broadly viewed, the canyons of the Tuolumne and Merced Rivers are two long furrows in the west flank of the Sierra Nevada-two of a great series of such furrows, all of notable depth and nearly all arranged roughly parallel to one another and at right angles to the crest line of the range. The Yosemite, therefore, is but one chasm in a land of many chasms. It is, however, by far the most strikingly modeled of all.

From most other parts of the Merced Canyon, and indeed from most other canyons in the Sierra Nevada, the Yosemite is distinguished by its great width relative to its depth, by its exceptionally sheer walls, and by its level, almost gradeless floor. As is manifest from the views on Plates 3 and $16, B$, the Yosemite is broadly $U$-shaped in cross section. Even in the portal between El Capitan and the Cathedral Rocks, which is the narrowest part of the valley, the floor is many times broader than the channel of the river. By contrast the canyon immediately above and immediately below the valley is little more than a. narrow, V-shaped gorge. In the valley, moreover, the river has so gentle a gradient that it meanders about in leisurely fashion, but in the gorges above and below it makes a direct, tumultuous descent. The absence of prominent spurs, finally, gives the valley an open, roomy aspect; it permits a vista to be. had from one end almost through to the other, in spite of the fact that its course is sinuous. Muir aptly likened the Yosemite to "an immense hall or temple lighted from above."

In depth the valley does not greatly exceed the deepest of the other parts of the Merced Canyon; it. measures between 3,000 and 4,000 feet. But in the valley the effect of depth is enhanced, in spite of the breadth of floor, by the exceeding boldness of the cliffs, by the continuity of the bordering plateaulike uplands, and by the seeming deliberacy with which the great. waterfalls descend from the lofty rims.

Because of its walled-in character, its sequestered position more than halfway up the flank of the Sierra Nevada, and the ruggedness of the surrounding country, the Yosemite was originally very difficult of access. The Merced Canyon in its primeval wildness afforded no convenient avenue of approach. It had to be conquered by engineering skill and the use of 
dynamite. Before either railroad or highway had been constructed there was only a precarious trail for pack animals. All the earlier routes of travel to the Yosemite led over the mountainous uplands, so that one was obliged laboriously to ascend to altitudes of 5,000 and 6,000 feet and then to descend 1,000 to 2,000 feet to reach the floor of the valley.

At first the journey to the Yosemite could be made only on horseback. It consumed several days and was so arduous that only those inured to this mode of travel might undertake the trip with any real enjoyment. A vivid portrayal of those old-time conditions was given by Prof. Joseph Le Conte ${ }^{21}$ in his delightful narrative of his first excursion to the High Sierra in 1870.

In the fifties and sixties of the last century wagon roads were extended up from the foothills to mining camps west and south of the Yosemite, but it was not until 1874 that roads were opened to the valley itself (the Coulterville and Big Oak Flat Roads). The picturesque 4-horse stage then made its appearance, and although the roads were steep, rough, and notoriously dusty, tourist travel increased rapidly. The completion of the Yosemite Valley Railroad in 1907 naturally afforded a much easier route of approach. The first motor stage entered the valley in 1913, and by 1916 travel by motor car was rendered possible also in an eastward direction by the improvement of the old wagon trajl known as the Tioga Road, and thus a scenic route was opened to the crest of the Sierra and thence by another road to Mono Lake.

The construction of the State highway up the Merced Canyon, to connect with the Government road at El Portal, may be regarded as the crowning achievement in man's conquest of the mountain wilderness that guards the Yosemite. This highway affords the motorist a modern, well-graded route available in winter as well as in summer and is now the main artery of Yosemite-bound traffic.

The sequestered position of the valley accounts also for the lateness of its discovery by white men. To the Spanish settlers in California the chasm remained wholly unknown. The great mountain range which from afar they named Sierra Nevada ${ }^{22}$ was a forbidden land of mystery and lurking enemies. Even the early American miners who dug for gold in the foothills

\footnotetext{
${ }^{21}$ Le Conte, Joseph, A journal of ramblings through the High Sierra of California by the University excursion party, San Francisco, 1875 (republished as Ramblings tbrough the High Sierra: Sierra Club Bull., vol. 3, pp. 1-107, 1900).

${ }_{22}$ The Spanish word "sierra" means literally "saw" and is by the Spaniards commonly applied to serrate mountain ranges; "sierra nevada" therefore means "snowy mountain range." The great California range now known as the Sierra Nevada was first sighted, described, and placed on a map by the Franciscan missionaries Francisco Garces and Pedro Font, who accompanied the Anza expedition that marched overland from Sonora, Mexico, in 1775-76, for the purpose of founding San Francisco. "Looking to the northeast [from a point just south of Suisun Bay]," wrote Font in his diary on April 2, 1776, "we saw an immense treeless plain into which the water spreads widely, forming several low islets; at the opposite end of this extensive plain, about 40 leagues off, we saw a great snow-covered mountain range [una gran sierra nevada], which seemed to me to run from south-southeast to north-northwest." (The Anza expedition of 1775-76, Diary of Pedro Font, edited by Frederick J. Teggart: Acad. Pacific Coast History Pub., vol. 3, No. 1, pp. 84-85, 1913.)
}

remained unaware of the existence of the Yosemite Valley for two years, although they were only 30 or $\mathbf{4 0}$ miles from it. It is probably true that the valley was first viewed from a distance in 1833 by Joseph Reddeford Walker, who in that year first crossed the Sierra Nevada by the Mono Pass and, guided by Indians, made his way westward over the upland north of the valley. But the effective discovery of the Yosemite, through which it became known to the world, was not made until March, 1851, when the Mariposa Battalion of volunteers under Maj. James D. Savage, in pursuit of Chief Ten-ei-ya (Tenaya) and his marauding band of Yosemite Indians, unexpectedly came upon the natural stronghold of the tribe ${ }^{23}$ after a hard march over the snow-covered mountains.

\section{OTHER YOSEMITES}

Extraordinary though its character may be, the Yosemite Valley is not unique. There are in the Sierra Nevada several other valleys of essentially the same type. In the upper Merced Canyon, about 2 miles above the Yosemite and at a level 2,000 feet higher, is the Little Yosemite (pl. 4, A), which is described elsewhere in this paper. The Hetch Hetchy Valley, at the lower end of the Grand Canyon of the Tuolumne (pl. 5, B), though only half as long and half as wide, bears a striking resemblance to the Yosemite, having not only the same proportions of depth to width but the same style of cliff sculpture. Muir, who loved to dwell in the Hetch Hetchy, sometimes referred to it as the "Tuolumne Yosemite."

In the canyon of the Middle Fork of the Kings River, about 80 miles southeast of the Yosemite, is the famed Tehipite (te-hip'i-ty) Valley, which though only $1 \frac{1}{2}$ miles long and three-quarters of a mile wide, rivals the Yosemite in scenic grandeur. (See pl. 4,B.) The Tehipite Dome is, in fact, as strikingly modeled as any of the major rock forms in the Yosemite region. About 10 miles southeast of the Tehipite is the great yosemite of the South Fork of the Kings River, popularly known as the Kings River Canyon. (See pl. 5, A.) It is 9 miles long-2 miles longer than the Yosemite-but is proportionately narrower. Nor are its walls so high, so sheer, so impressively modeled as those of the Yosemite Valley. The Kings River Canyon, however, is surrounded by titanic peaks that rise $5,000,6,000$, and even 8,000 feet above its floor.

The occurrence of such valleys in different parts of the Sierra Nevada is highly significant and must be taken into account in any discussion of the Yosemite's mode of origin.

\section{THE SIERRA NEVADA}

\section{GENERAL CHARACTER AND DIMENSIONS}

The Sierra Nevada is a single unbroken mountain range, yet it is comparable in magnitude to an entire mountain system. As is manifest from the relief map

${ }^{23}$ Bunnell, L. H., Discovery of the Yosemite, and the Indian War of 1851, 4th ed., Los Angeles, 1911. 
(pl. 1), it occupies slightly less area than all the Coast Ranges of California together. Incredible though it may seem, the Sierra Nevada is nearly as extensive as the French, Swiss, and Italian Alps combined. It is a mammoth range, the greatest in the United States, exclusive of Alaska. It measures 430 miles in length and from 40 to 80 miles in breadth.

In height also the Sierra Nevada outrivals all the other mountain ranges in the United States. Not only is Mount Whitney (14,496 feet) the highest summit in this country, but the range as a whole stands higher above its immediate base than any other. The Rocky Mountains, many of whose summits rise above 14,000 feet, stand only 9,000 feet above the Great Plains, which attain altitudes of about 5,000 feet at the foothills; but the Sierra Nevada stands not less than 11,000 feet above Owens Valley, at its east base, and 14,000 feet above the Great Valley of California, at its west base.

In general form the Sierra Nevada may be likened to a gigantic ocean wave rolling landward from the west. It rises from the hollow of the Great Valley in a long, gentle slope, culminates in a resplendent row of snowy summits, and with its precipitous front seems to threaten the deserts to the east. At its north end, where it joins the less imposing Cascade Range, the wave form is indistinct, but southward it gains in height and sharpness, the climax being reached near Mount Whitney. Still farther south the range declines and, curving toward the west, merges with the Coast Ranges near the Tehachapi (te-hatch'a-py) Pass. So strongly asymmetric is the Sierra Nevada that its crest line is for the most part within a few miles of its east base but 30 to 70 miles from its west base.

The peaks on the main crest gain in altitude from about 7,000 feet at the north end to 9,000 feet in the neighborhood of Lake Tahoe (tah'ho), 12,000 and 13,000 feet in the Yosemite National Park, and more than 14,000 feet in the Mount Whitney region. Beyond this they decline progressively to altitudes of $12,000,9,000$, and 6,000 feet.

The east front of the Sierra Nevada is among the greatest mountain escarpments in the world. (See pl. 5, C.) The northernmost part is the least impressive, being only a few thousand feet high and split into minor ridges that branch off in northerly directions from the northwestward-trending body of the range. But toward the south the front gains in height and continuity. East of the Yosemite region it has a height of fully 6,000 feet above the basin of Mono Lake; opposite Bishop, at the head of Owens Valley, it measures 10,000 feet; and in the neighborhood of Mount Whitney nearly 11,000 feet, or about 2 miles.

The Sierra Nevada, because of its continuity, height, and ruggedness, presents a formidable obstacle to eastwest travel. The few available gaps or notches in its crest are neither deep nor easily accessible. The Donner Pass, through which the Southern Pacific Railroad is laid and which was formerly the main gateway for the California-bound wagon trains, has an altitude of about 7,000 feet. The Tioga Pass, familiar to motorists as the picturesque notch on the route from the Yosemite to Mono Lake, has an altitude of 9,941 feet. It is rarely free of snow before July. Thence southward to the Walker Pass there is a stretch of 180 miles without a single pass available for vehicular trafficonly steep and laborious pack trails which climb to altitudes over 11,000 feet, and even over 12,000 feet.

The streams that drain the Sierra Nevada are arranged largely at right angles to its axis, and as the divide between the westward and eastward flowing streams coincides essentially with the crest line, the drainage plan as a whole is as strongly asymmetric as the form of the range itself. The gentle west slope is traversed by a series of long rivers; the steep east front by small, short streams. Both the west slope and the east front are profoundly and intricately sculptured. Each master stream lies in a canyon several thousand feet deep. The Tuolumne and Kern Rivers, notably, have canyons between 4,000 and 5,000 feet in depth; the Kings River and its main branches have canyons between 6,000 and 8,000 feet in depth.

As the main canyons lie mostly at right angles to the crest line, one would expect the major corrugations of the range to have a similar trend; but this is not true everywhere. In many parts of the range the more prominent ridges trend northwestward, roughly parallel to the main crest. Subsidiary crests of this kind, 2,000 to 4,000 feet high, occur above the Yosemite region and throughout the south half of the range. To them is largely due the extreme ruggedness of its upper portion-that alpine region which has become known as the High Sierra.

\section{RELATIONS TO ADJOINING LOWLANDS}

- There could scarcely be a more complete antithesis between contiguous features of the earth's surface than there is between the Sierra Nevada and the lowlands that adjoin it on each side - the Great Valley of California and the Great Basin of Nevada and Utah. As compared with the lofty range the Great Valley of California is an almost featureless plain. More than one-third of its total area-nearly 3,000 square milesis less than 100 feet above the level of the sea. Upon this plain, which is on the whole arid, owing to the prolonged heat and drought of its summers, issue the numerous snow-fed rivers that descend from the west flank of the range. It is the life-giving waters of these rivers that have made possible the development of the great farming and fruit-growing industries for which the valley is famous. 
The Great Basin, which begins at the east foot of the Sierra Nevada, is a lowland of a wholly different type-a vast province of sagebrush plains interspersed with sharp-crested mountain ranges. Though low as a whole compared with the Sierra and the other highlands that inclose it, its plains lie mostly at altitudes between 3,000 and 6,000 feet, and its ranges attain 10,000 to 13,000 feet. The outstanding features of the Great Basin, however, are the saline lakes and salt-incrusted desert basins in which nearly all its streams terminate, the water evaporating into the thirsty air and leaving its salt content behind. Great Salt Lake, in Utah, is the largest and best known of these briny desert lakes, but there are many lesser ones. Several lie close to the Sierra Nevada and receive the waters from its east front. Among them are Mono Lake, which is directly east of the Yosemite region, and Owens Lake, which is southeast of Mount Whitney.

\section{CLIMATIC CONDITIONS AND LIFE ZONES}

To one who stands on the crest of the Sierra Nevada and views, on the one hand, the well-watered and largely forest-clad body of the range, and, on the other hand, the vast desert wastes that stretch to the east of it, the contrast between the conditions prevailing in these two regions is impressive. Why, he may ask, is this mountain country so well favored by nature and the lowland to the east so neglected and desolate? The reason is that the Sierra Nevada, like every other mountain range of great height and extent, is itself a "climate maker." In large measure it is the author of its own weather conditions and controls those of the regions that are situated to the leeward of it. Lying parallel to the Pacific coast, it forms a barrier over which the vapor-laden winds that blow in from the ocean must rise. As they are forced up to high levels, they are chilled and discharge their condensed water vapor. Most of this falls in the winter, in the form of snow, the summers being remarkably dry.

The exceeding abundance of the winter snows in the Sierra Nevada is not generally known. Actually they exceed those in any other part of the United States, save the Olympic Mountains and the northern Cascade Range. According to the records of the United States Weather Bureau the annual snowfall at stations on the Southern Pacific Railroad, at altitudes between 6,000 and 7,000 feet, aggregates 30 to 40 feet in depth. In some winters it reaches a total of 60 feet. As much as 20 feet of snow has been reported in a single month, and often there is 10 or 12 feet of snow on the ground at one time. This heavy precipitation on the Sierra Nevada explains the general barrenness of the Great Basin. The air currents are fairly wrung dry as they pass over the range.

Even the Sierra Nevada itself is not equally favored with moisture in all its parts. The bulk of the snow and rain falls on its west slope between the 4,000-foot and 9,000-foot levels. The foothills and lower slope partake in large measure of the semiarid conditions that prevail in the Great Valley; and the higher peaks and crests also are relatively dry, the air currents having discharged most of their vapor content before reaching those heights. The High Sierra, it is true, retains its white garb much longer in spring and summer than the middle slope, but that is due primarily to the lingering cold, which retards the melting. As for the east front of the range, naturally it also is arid as compared with the west slope.

The unequal distribution of the snow and rain on the Sierra Nevada, together with the wide range in temperature from the torrid foothills to the wintry crest, give rise to several distinct climatic belts or zones, each of which has its characteristic forms of vegetation and animal life. These zones are broadest and most distinct on the west flank of the range.

The semiarid foothill belt, hot and dry in the summer but rainy in the winter, corresponds to what biologists term the upper Sonoran life zone. Its vegetation consists characteristically of thin grass, bushy chaparral, and scattered groups of live oaks and digger pines. Between altitudes of 3,000 and 4,000 feet it merges with the great forest belt or transition life zone, which has a more genial climate in thesummer and receives considerable snow in the winter. In the midst. of its stately forests of yellow pine, sugar pine, incense cedar, Douglas fir, and white fir stand scattered groves. of giant sequoias, or big trees. (See pl. 6, B.) The Yosemite National Park contains three of these groves-the Maiposa, near its southern boundary, and the Merced and Tuolumne, near its western boundary.

The Yosemite Valley itself, being at an altitude of 4,000 feet, is situated in the forest belt, but owing to the fact that the cliffs on its north side are daily heated by the sun, whereas the cliffs on its south side remain mostly shaded and cool, it is in a sense the meeting place of many different species, including chaparral from the foothill belt and trees from the surrounding uplands.

At altitudes ranging from 6,000 to 7,000 feet begins. the Canadian life zone, which is characterized mainly by stands of lodgepole pine, Jeffrey pine, and red fir. It is sought in summer for its exceptionally delightful climate but shunned in winter because of its frigidity. Toward the 9,000-foot level the silver pine and mountain hemlock make their appearance, and the Hudsonian life zone sets in. This is the picturesque timber-line belt, in which only the hardiest species of trees can thrive. At its extreme upper limit, between 10,000 and 11,000 feet, the white-bark pine occurs in curiously storm-twisted, recumbent, or wholly prostrate forms. (See pl. 6, A.)

Above the timber line, in the alpine life zone, the mountain sides and peaks rise essentially bare of vegetation. Here, from altitudes of 11,000 feet upward, the precipitation, even in summer, consists largely of snow 


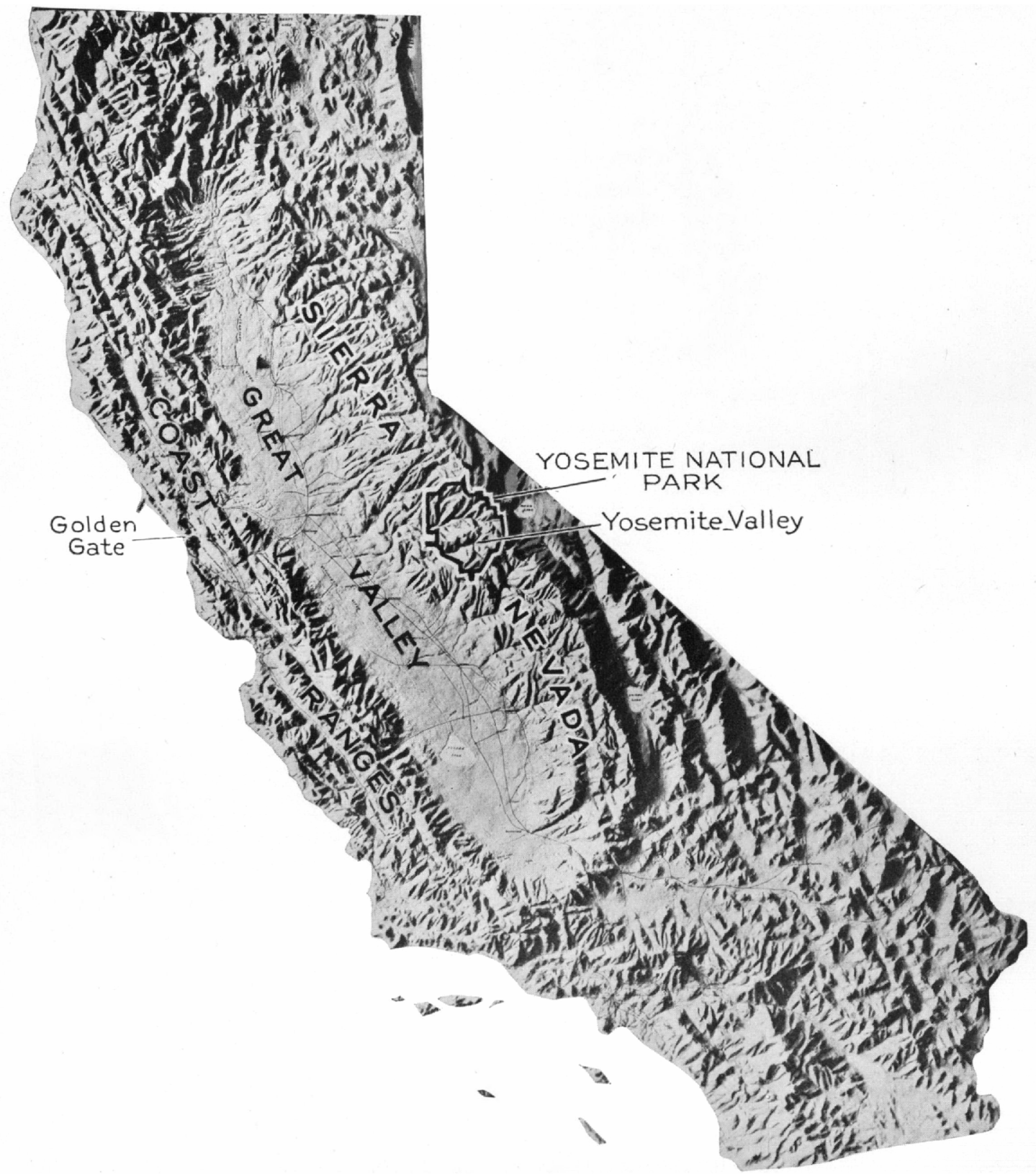

HELIEF MAP OF CALIFURNIA 



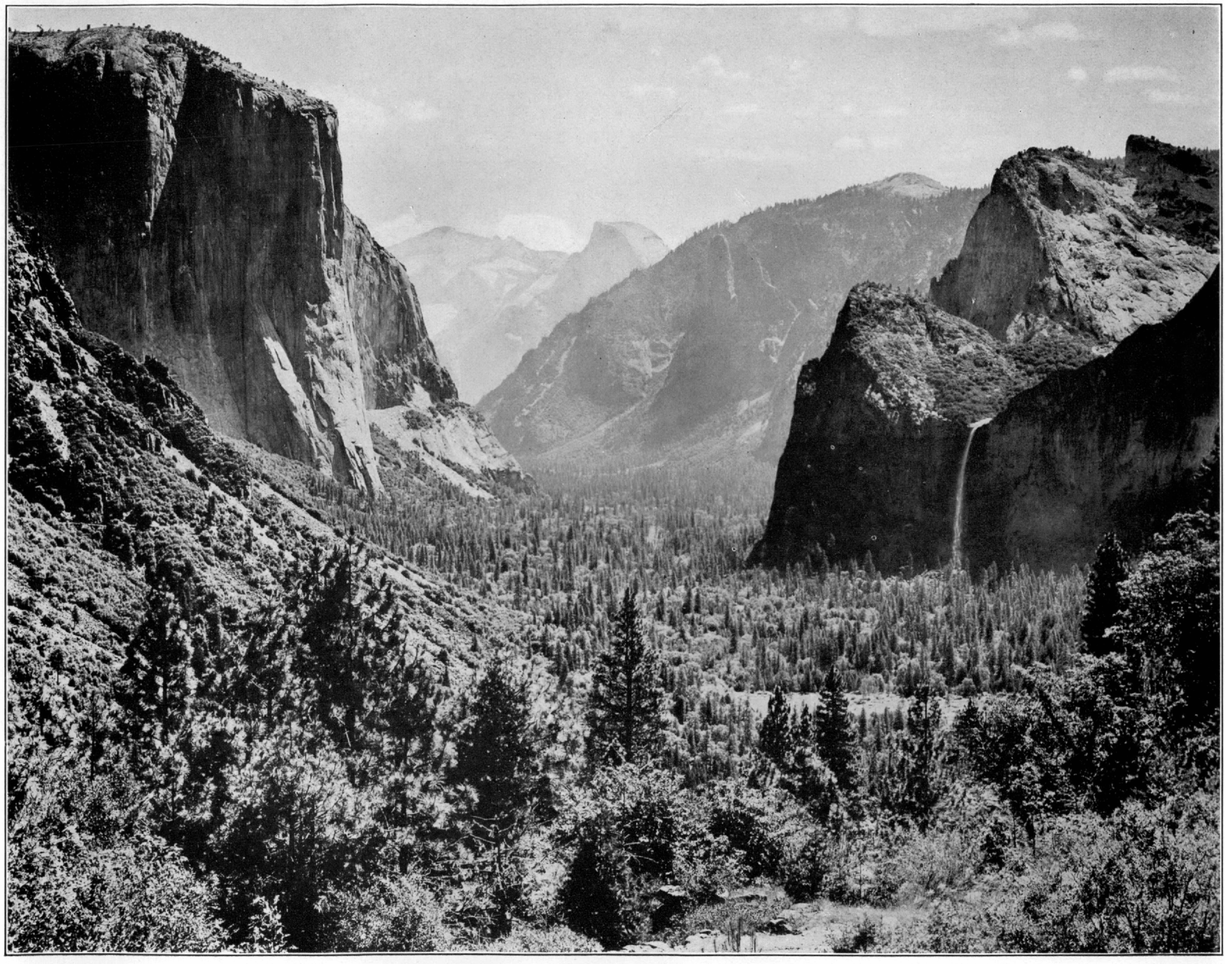
YOSEMITE VALLEY FROM WAWONA ROAD

At the left is the great cliff of El Capitan, at the right the Cathedral Rocks and the Bridalveil Fall. Through the portal between the opposing rock masses is seen the upper or main chamber of the Yosemite 


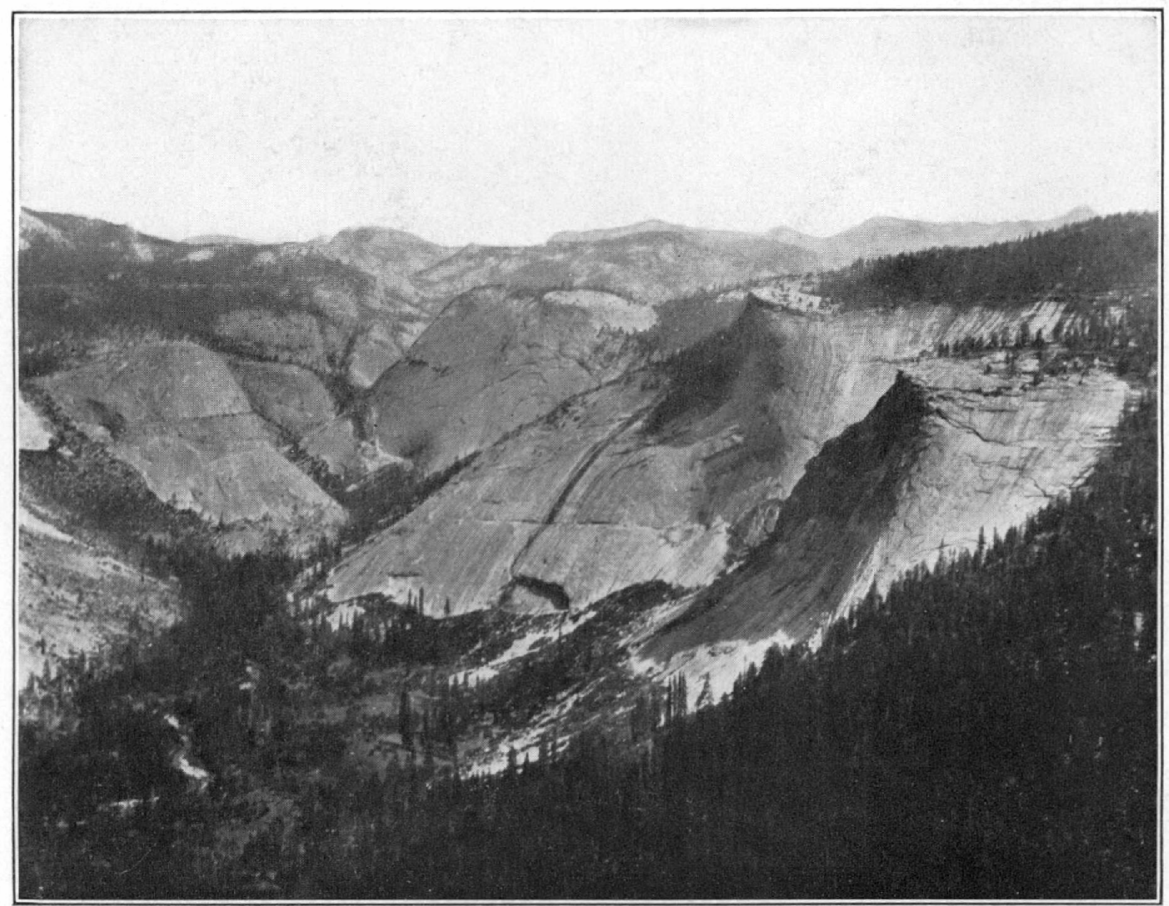

A. LITTLE YOSEMITE VALLEY

Through this broad antechamber the Mereel River appronches the main valley. At the right are the Cascade Clifls, sireaked by innumerible temporiry ciscades. Al the left. is Sugar Loif.

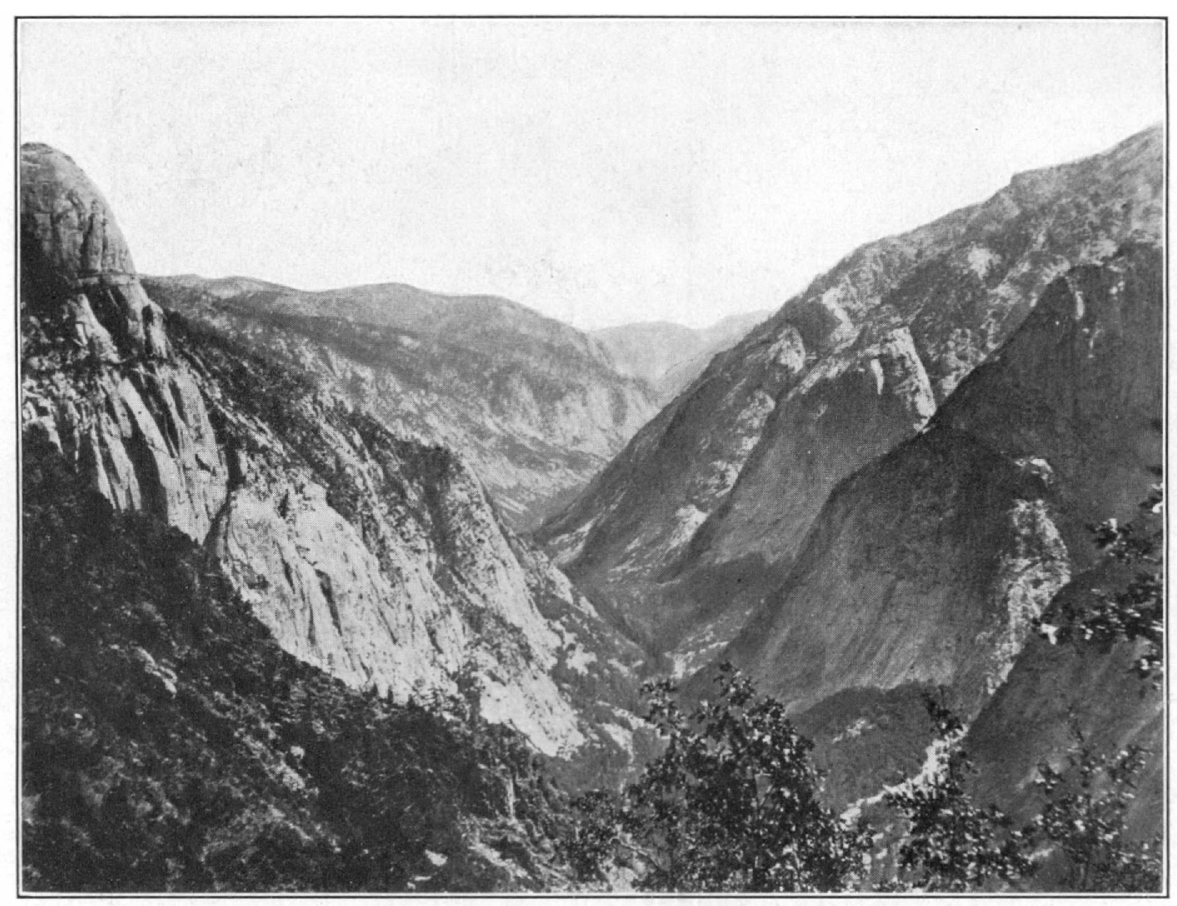

B. TEHIPITE VALLEY, THE YOSLMITE ON THE MIDDLE FORK OF 'THE KINGS RIVEH The shortest of all the yosemites in the Sierrit Nevada, yot onc of the most impressive. At the left is Tehipite Dowe. Pholograph by J. B. Lippincoll. 


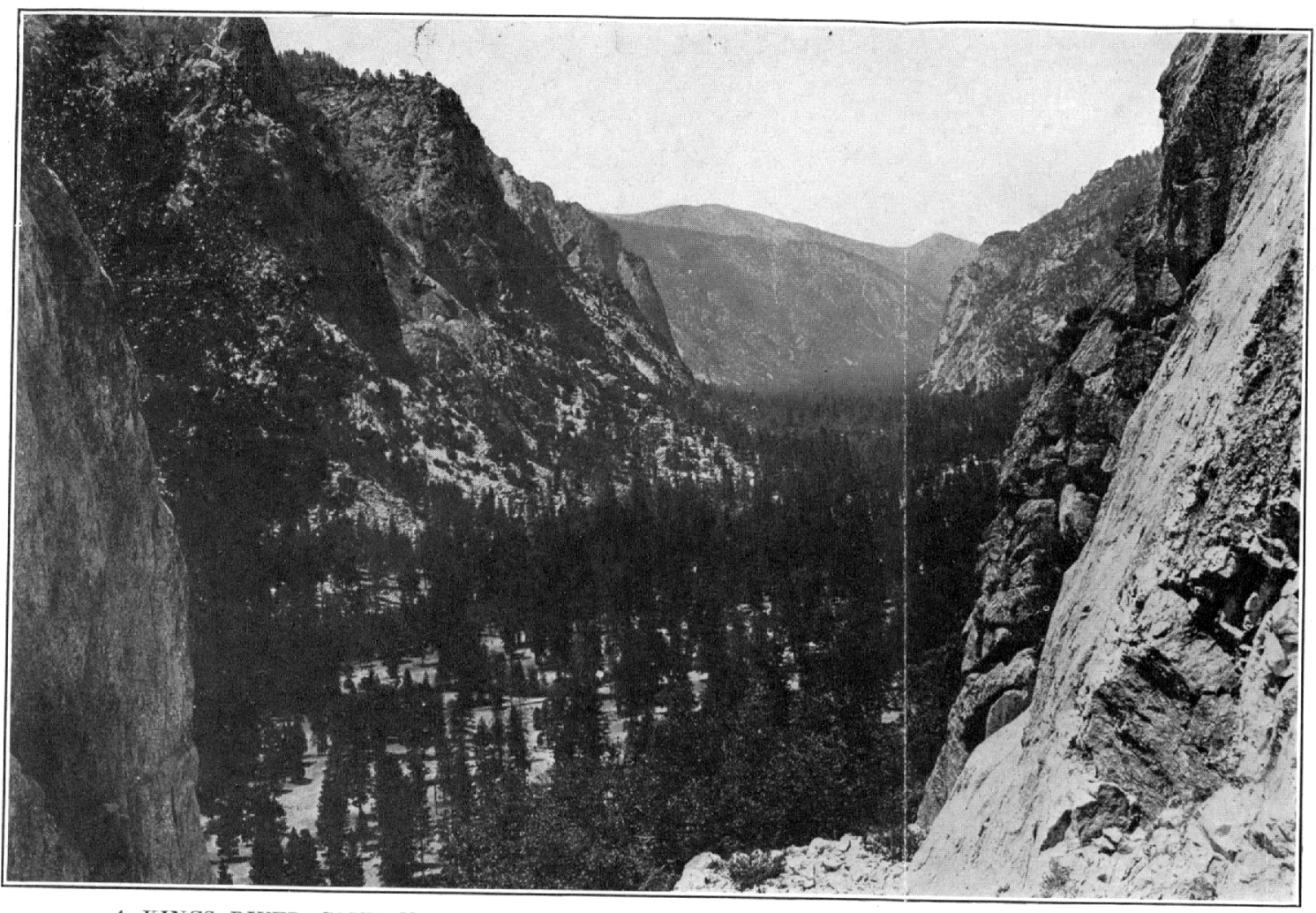

A. KINGS RIVER CANYON, THE YOSEMITE ON THE SOUTH FORK OF THE KINGS BIVFR

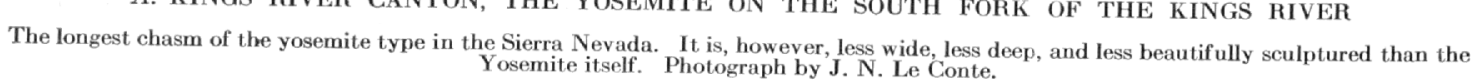

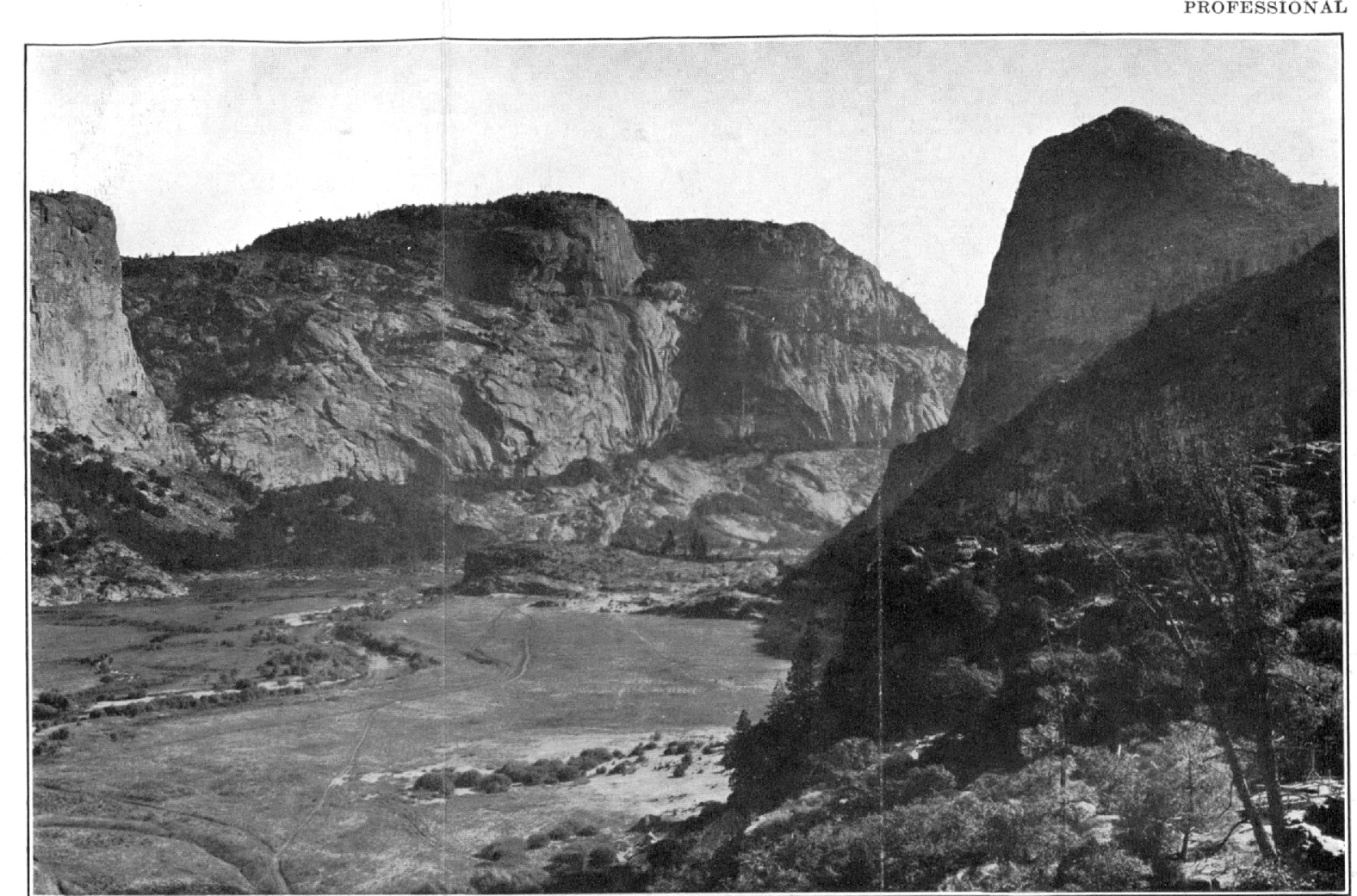

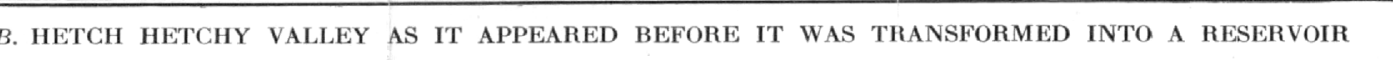

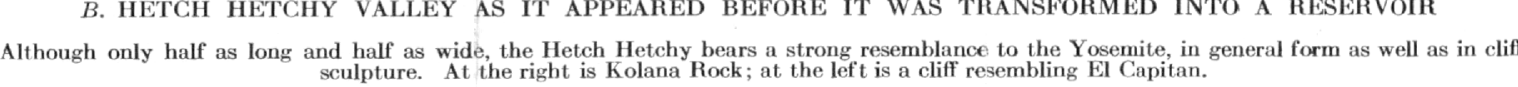

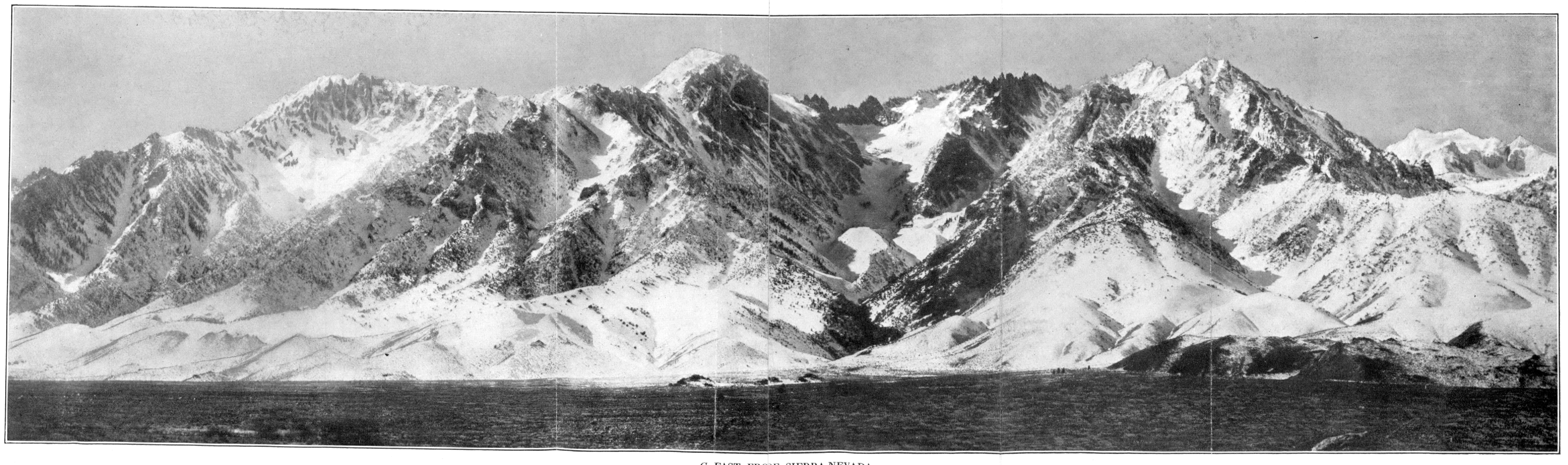





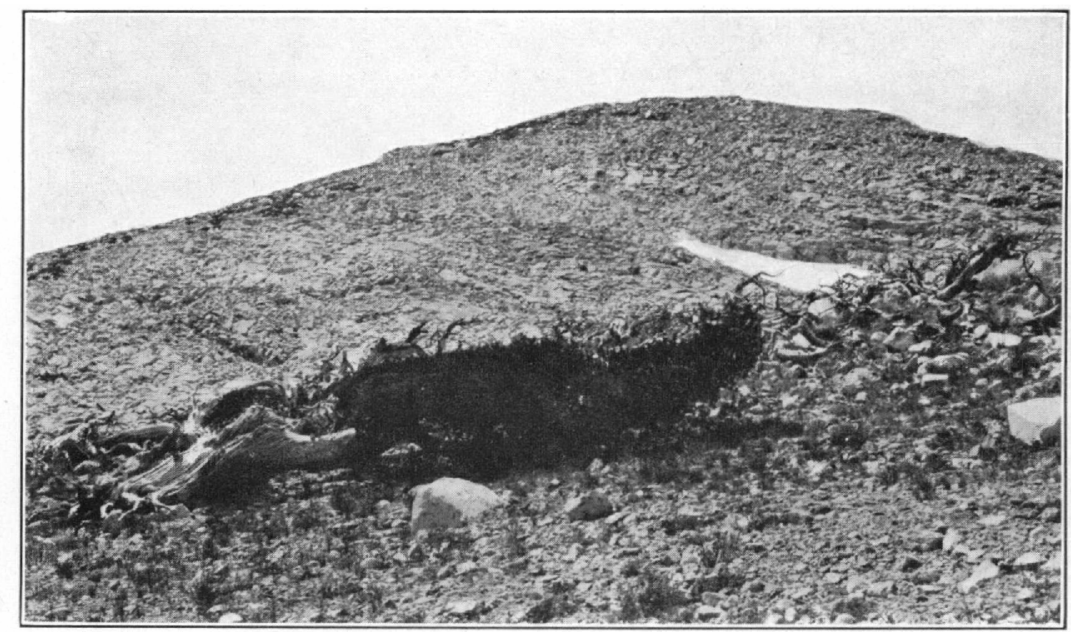

A. CHARACTERISTIC STOMM-BHET THE: AT TIMBLR IINE

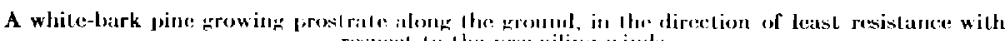
respect to the previtiling winds.

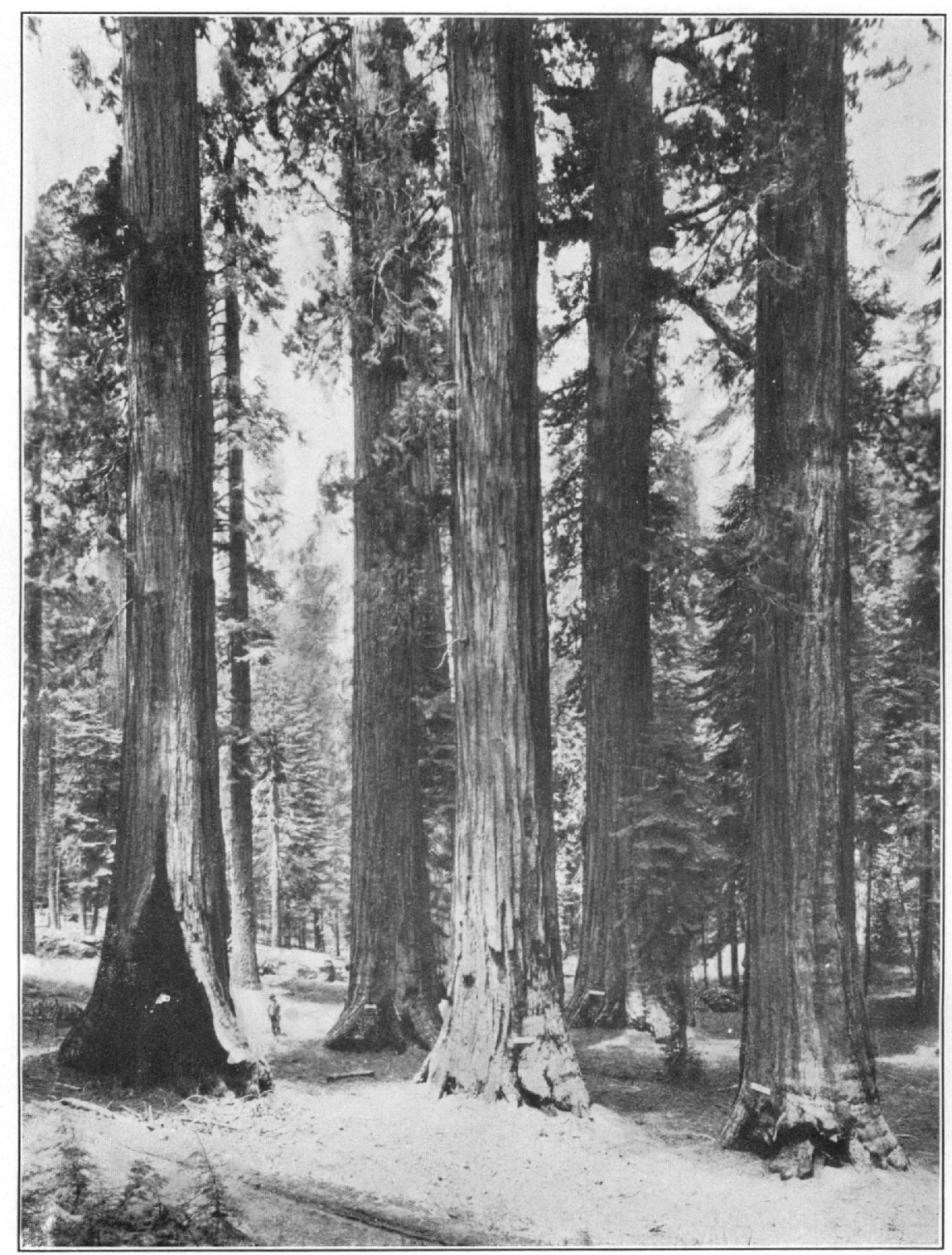

B. GIANT SEQUOIAS IN MAIIPOSA GROVE

The smuoins stand in groves surrounded by pines, firs, and cedars, about balfway up on thr westorn flank of the Sierra Nevada. I'holograph by $\mathbf{J}$. T. Boysen. 



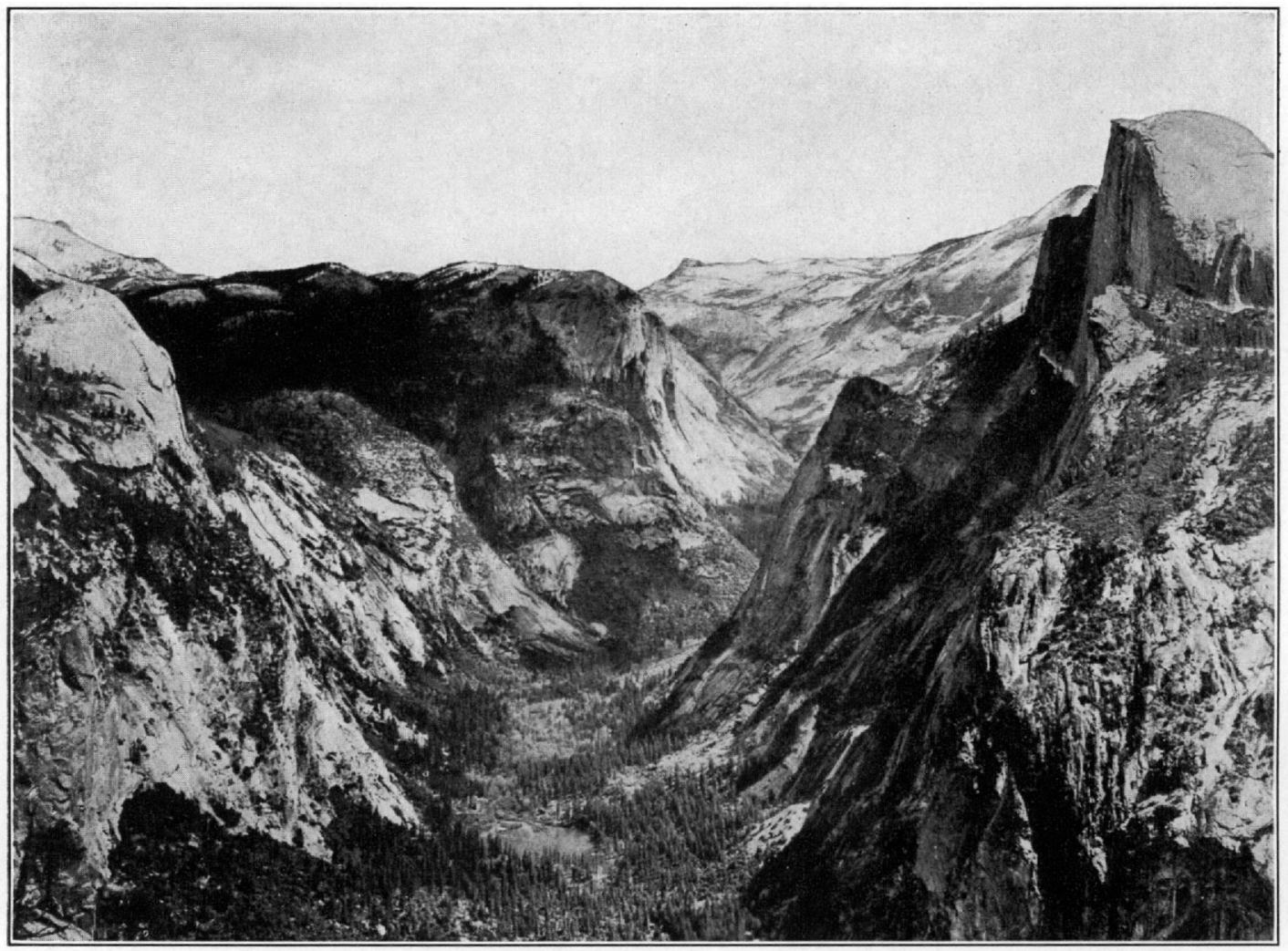

A. TENAYA CANYUN FIOM GIACIER POINT

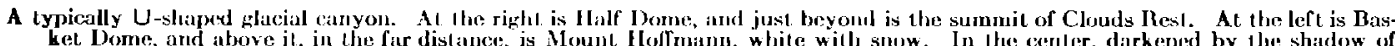
a cloud, is Mount Walkins, and below, at the mouth of the canyon, is Mirror liake. Pholograph by A. C. Pillsbury.

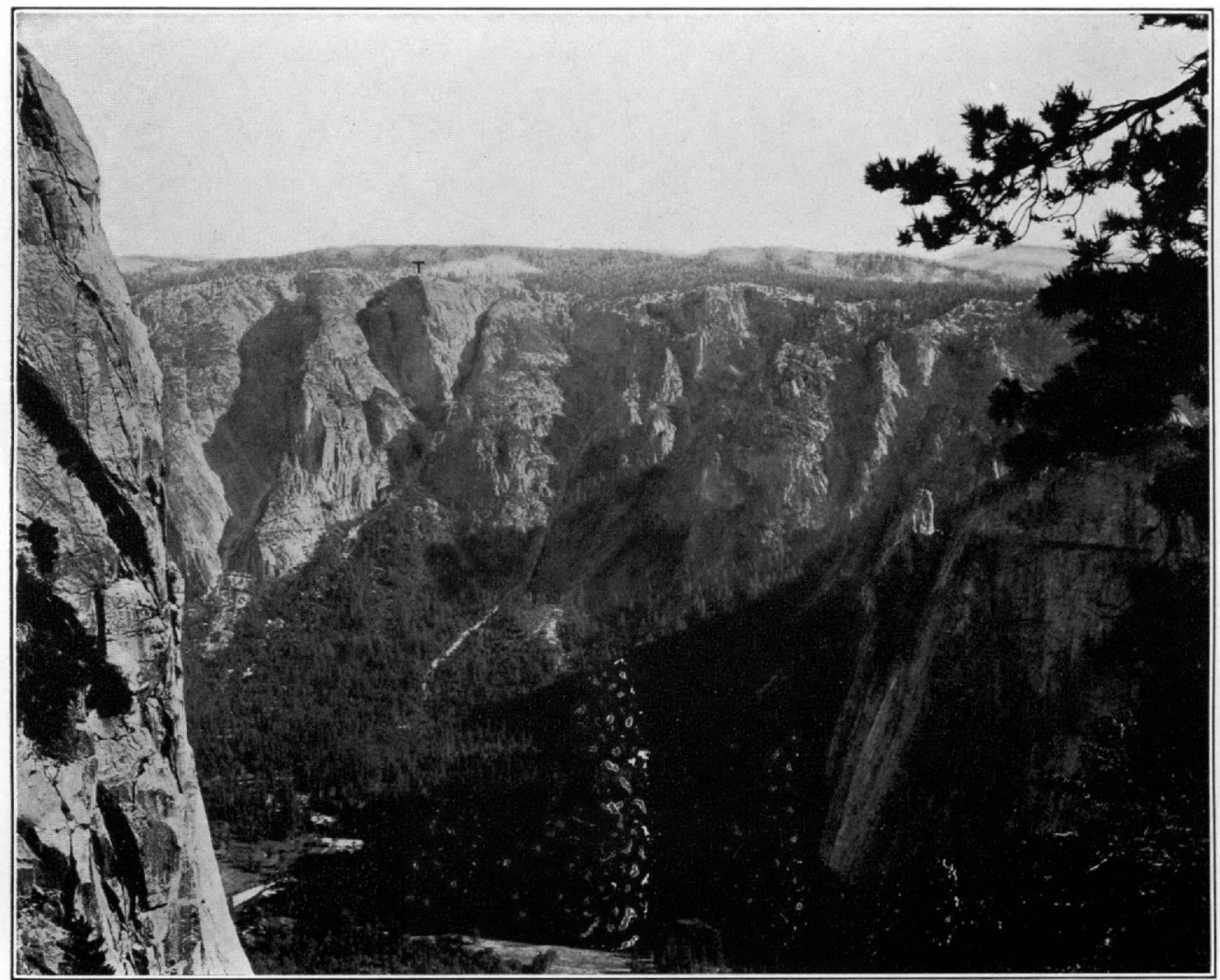

B. VIEH ACROSS YOSEMITE I ALLEY FHOM HIBBON FALL

The depth of the chasm and the abruptness with which il trenches the gently undulating upland are strikingly brought out in this riew. Taft Point is indicaled by leller T'. At the lower riphl is the base of the Canthedral Hocks. I'holograph by F. C. Calkins. 


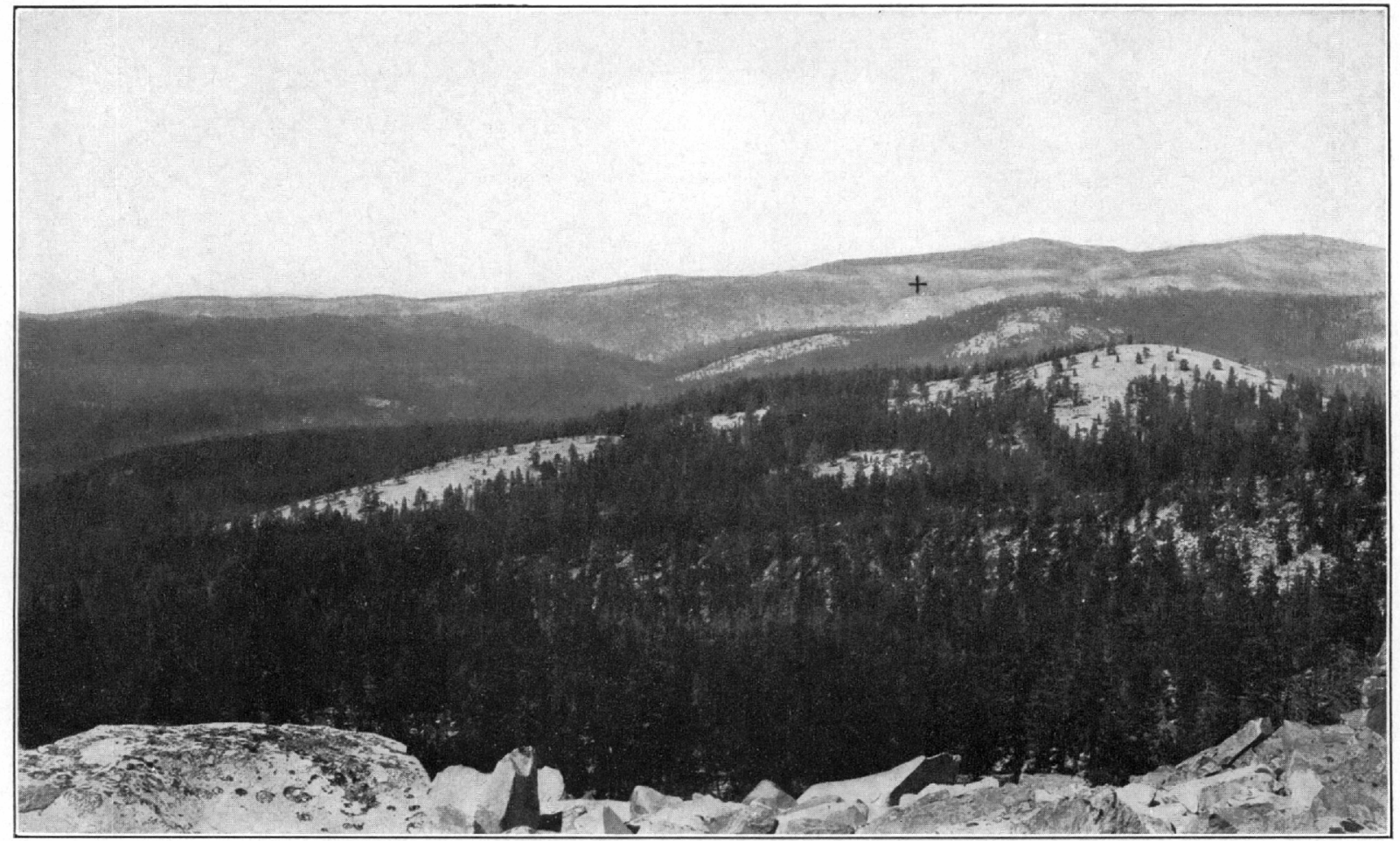

A. VIEW NORTHWAHI OVER YISEUITE IPLAND FROM IIORSE RIDGE

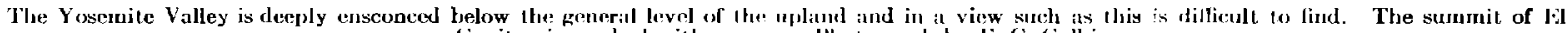
Cupilan is mirkid with a truss. I'lotorraph by li. C. Cialkins.

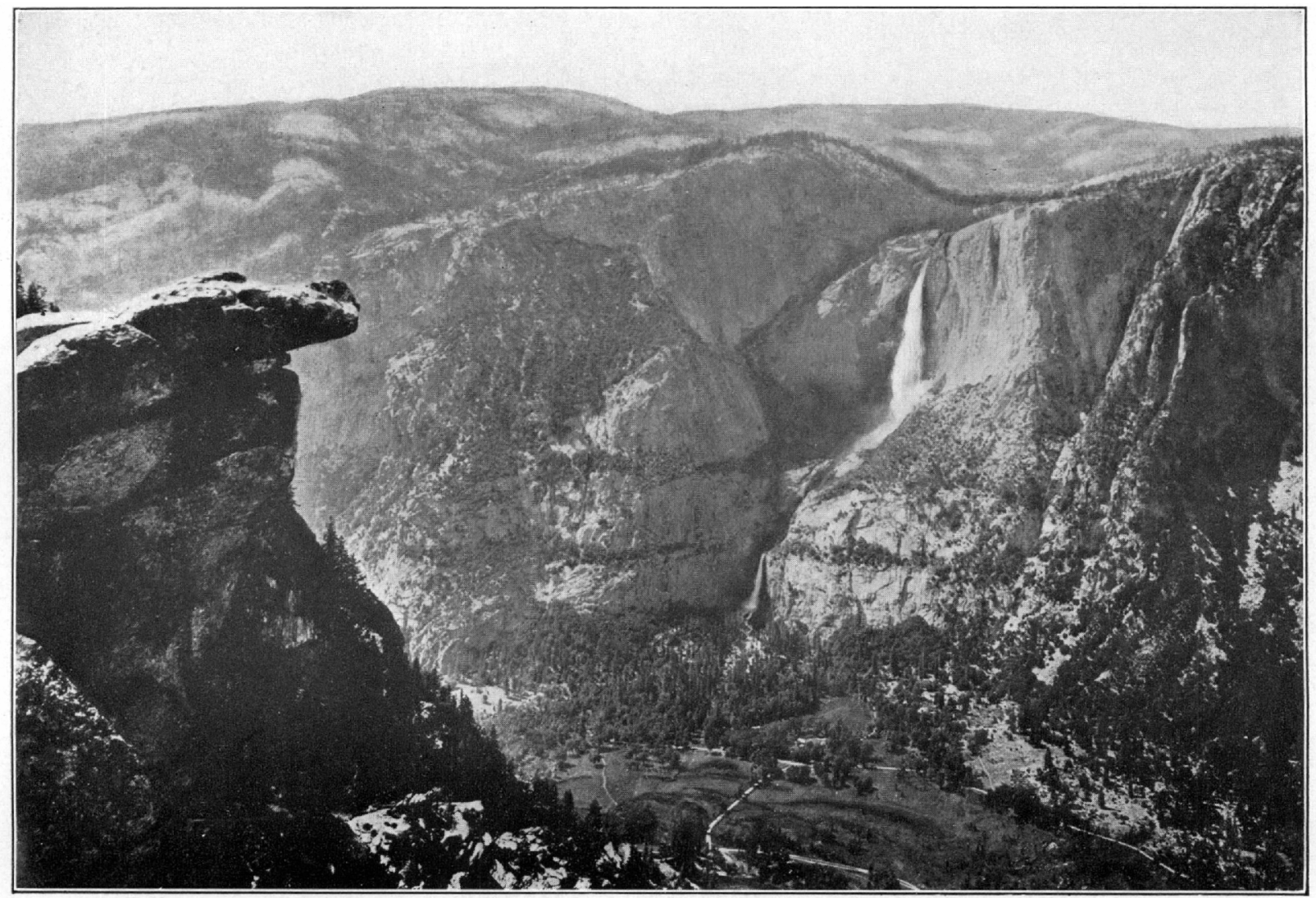

B. HANGING VALLFY OF YOSFMITE CREIK AND YOSF.MITE FALIS, FROM GLACIER POINT

The most striking example of a hanging valley with a waturfall lesping from its mouth to be found in the Yosemite region. At Ihe left is the overhanging rock of Glaciar Poirt. Photorraph by $A$. (.. Pillsbury. 


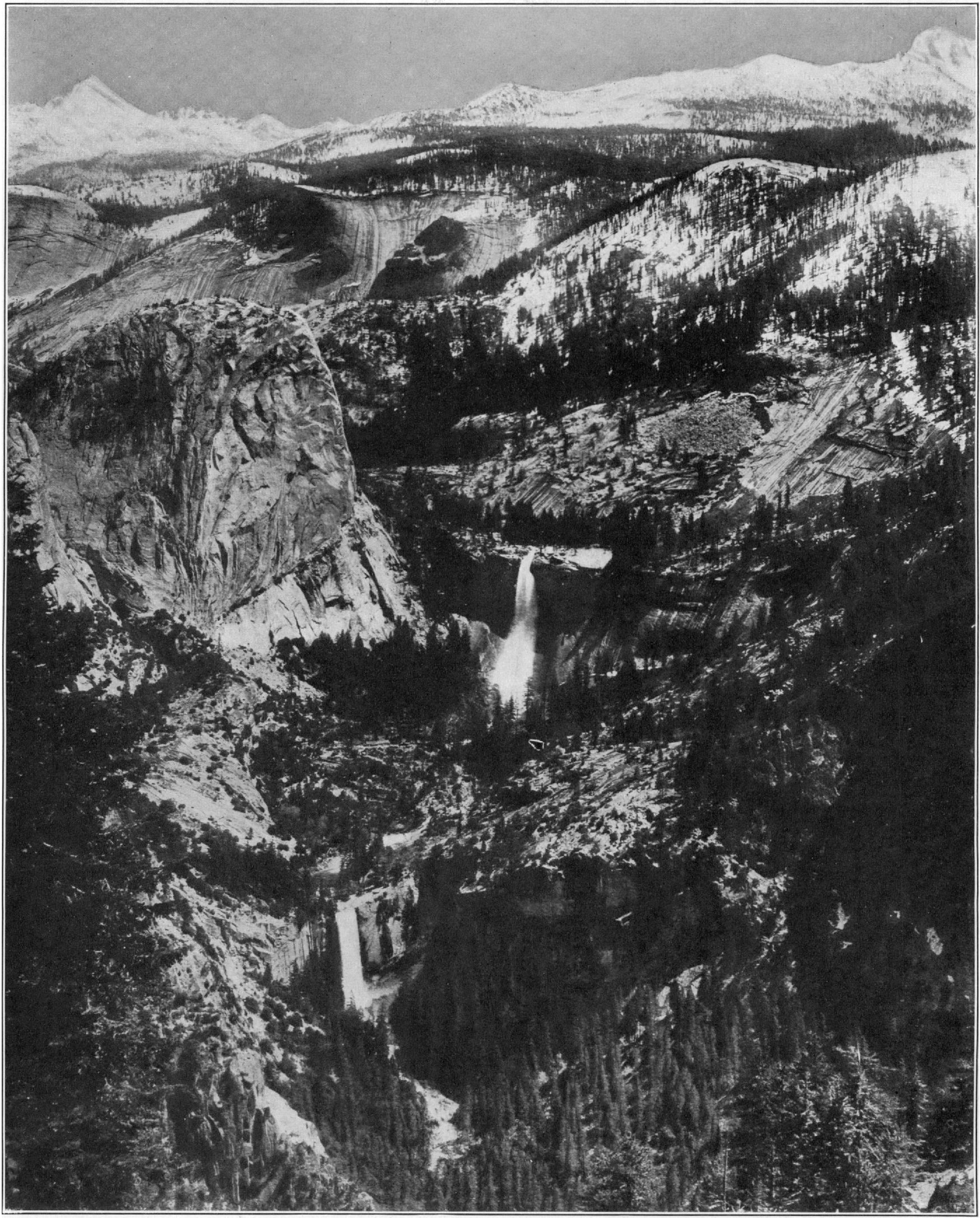

THE GIANT STAIRWAY, FROM GLACIER POINT

In the center is the Nevada Fall, which leaps from the upper step, flanked on the left by Liberty Cap. Below is the Vernal Fall, which leaps from the lower step. On the far side of the Little Yosemite, which is behind Liberty Cap, are the water-streaked Cascade Cliffs, and beyond are the peaks of the High Sierra mantled with snow. At the left is Mount Florence; at the right is Mount Clark. Photograph by A. C. Pillsbury. 


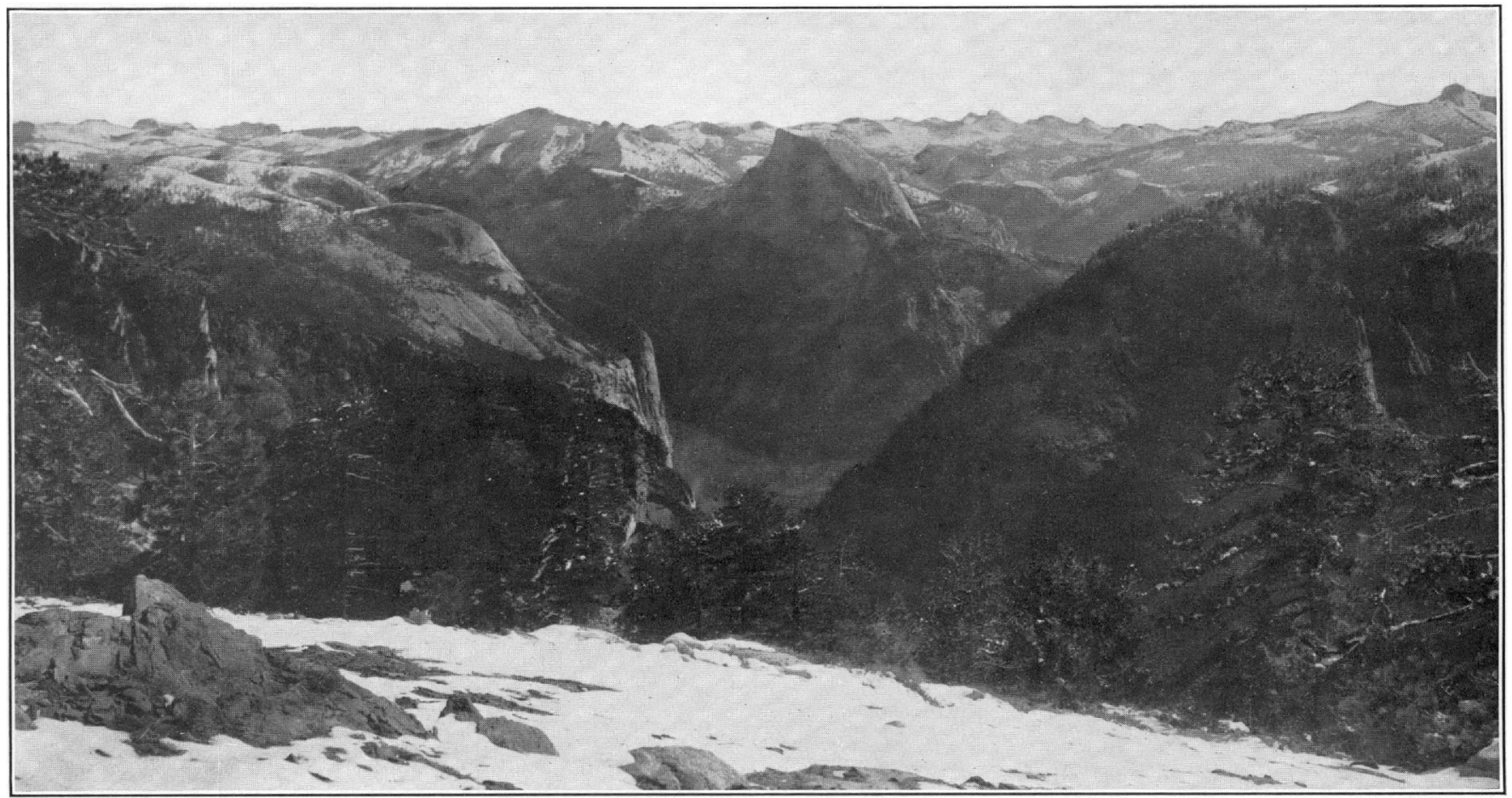

\section{A. THE HIGII SIERRA, FROM EI, CAPITAN}

IHall Dome and the heal of the Yosemite Valley appear in the center of the view. Freshly fallen snow whitens the distant peaks and gives them a wintry aspect representative in some measure of the conditions lhal provailed during the ice age, when lares glaciers extended from the High Sierra down to the Yosemite

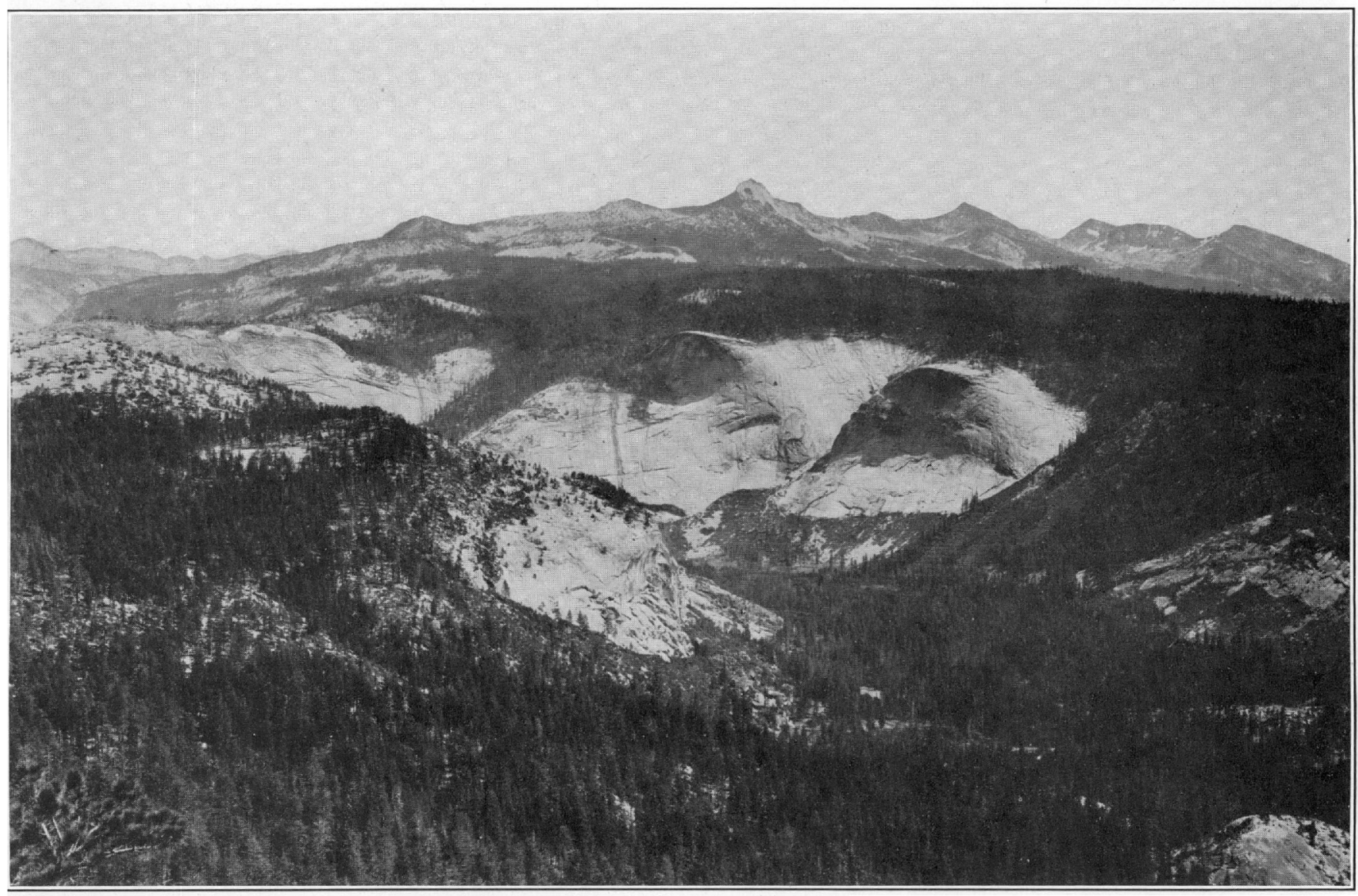

R. LITILE YOSEMITE AND CLARK RANGE, FROM HALF DOME

The Clark Rinnge stands alove the treneral level of the Yosente upland, of which a long slretch. covered with lorests, is visible beyond the Little Yosemite

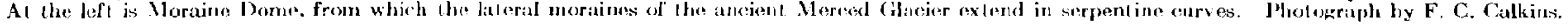


or hail, and the temperature in the shade seldom rises much above the freezing point. Snowdrifts abound until far into midsummer, and perennial bodies of old, hard snow and even a few small glaciers linger in the shaded, steep-walled recesses among the higher peaks. (See pls. 14 and 28, B.)

\section{THE YOSEMITE REGION}

\section{GENERAL CONFIGURATION}

That part of the Sierra Nevada of which the Yosemite Valley is the central feature is commonly referred to as the Yosemite region. By some the term is applied to the entire Yosemite National Park, but for the purposes of this paper it may to advantage be restricted to that part of the drainage basin of the Merced River which extends from El Portal (por-tal'), the lower entrance to the Yosemite National Park, up to the heads of the Little Yosemite Valley and Tenaya Canyon, the two main branches of the Yosemite chasm, and laterally out to the limiting divides on the bordering uplands. (See pl. 2.) The Yosemite region, as thus defined, embraces an area 20 miles long, measured in the direction of the master stream, and 20 miles broad. Beyond its upper border lies the High Sierra; beyond its lower border, what, for lack of a more precise term, may be called the lower Sierra slope.

A short distance above El Portal the winding, V-shaped Merced Canyon contracts abruptly to a sheer-walled gorge that has few turns, the Merced Gorge. This pronounced change in the character of the canyon is accompanied by a general change in the modeling of the landscape on each side, the choppy, intricate ridge and gulch topography of the lower Sierra slope giving way to massive, billowy features. The reason is that the Yosemite region is carved in prevailingly massive, resistant granitic rocks, whereas the lower Sierra slope is made up largely of upturned slates and other thin-bedded sedimentary rocks.

Proceeding up the Merced Gorge for a distance of 8 miles, the traveler emerges suddenly into the spacious Yosemite Valley. (See pl. 7.) On both sides its great cliffs reach up to undulating forested uplands that extend, unbroken by side canyons, to the head of the valley. (See pl. 8, B.) There, however, they are gashed by three converging branch chasms-the Little Yosemite (pl. 4, $A$ ), which is 2,000 feet deep; the Illilouette Valley, on the south side, which is between 1,500 and 2,000 feet deep; and Tenaya Canyon (pl. 8, $A$ ), on the north side, which is nearly 4,000 feet deep. The floor of the Yosemite itself has an altitude of about 4,000 feet above sea level; the uplands rise from 7,000 feet at their lower margin to 8,000 feet at the valley head.

Between the three branch chasms the uplands continue, covered with dense forests of lodgepole pine and fir, but they are surmounted by isolated domes, peaks, and crests of bare granite. South of the Little
Yosemite the upland is particularly well defined. (See pl. 11, B.) It there rises gradually to an altitude of about 9,000 feet, terminating at the base of the Clark Range, the first great bulwark of the High Sierra. The upland on the north side of the Yosemite Valley extends all the way to the Grand Canyon of the Tuolumne River, which is 10 miles distant; that on the south side extends for a similar distance to the canyon of the South Fork of the Merced River. At the brinks of those canyons the uplands break off just as sharply as they do at the brinks of the Yosemite chasm. They are, therefore, in the nature of elevated tablelands that stand essentially undissected in the broad spaces between the main canyons.

The two upland tracts, moreover, accord closely in general height. In a broad view, especially from a point so far back from the brink of the Yosemite that that chasm is not visible, their billowy surfaces seem continuous (pl. 9, A) and appear to be parts of one and the same westward-slanting high-level surface. This high-level surface has no local name, but as it is a topographic feature of prime importance, which has its analogs in other parts of the Sierra Nevada, it will here be designated, in so far as it lies within the limits of the Yosemite region, the Yosemite upland.

One characteristic of the Yosemite upland merits especial attention: Not one of its numerous vales and valleys that drain into the Yosemite slopes down to the bottom of that chasm; on the contrary, they continue with gentle gradients out to its lofty brinks and there terminate abruptly-some of them as abruptly as if cut off with a cyclopean knife. From the mouths of these "hanging valleys" leap most of the waterfalls and cascades for which the Yosemite region is renowned. (See pl. 9, B.)

Looking down into the Yosemite from the lip of one of these hanging valleys (pl. $8, B$ ), at a height of 2,500 or 3,000 feet, one readily gains the impression that the chasm is an abnormal abyss that lies sunk deep below the general level of the land. Indeed, the abrupt termination of the upland valleys at its brinks, together with the prevailing sheerness of its walls, strongly suggests that the Yosemite was produced by a rupturing of the earth's crust or by the caving in of a portion of it.

\section{HANGING VALLEYS}

A typical example of a hanging valley is that of Yosemite Creek (pl. 9, B), the largest upland valley on the north side. Extending with moderate gradient to the brink, it is there cut off sharply at a height of 2,565 feet above the floor of the main chasm. From its lip pour the Yosemite Falls, the most famous of the waterfalls of the Yosemite region. The valley is about 10 miles long and traverses the entire breadth of the northern upland; one of its branches, in fact, heads close to the brink of the Grand Canyon of the Tuolumne. Much shorter is the hanging vale of Ribbon 
Creek, west of Yosemite Creek. (See pl. 7.) This vale is cut off at a height of 3,050 feet, and from its lip descends the Ribbon Fall, the highest of the Yosemite's waterfalls. On the south side, a little farther west, is the upland vale of Meadow Brook, which hangs at a height of 2,585 feet; and several miles to the east is the somewhat longer valley of Sentinel Creek, which is the highest of all, opening 3,340 feet above the Yosemite floor.

The hanging valley of Bridalveil Creek, which drains the major part of the southern upland, does not terminate abruptly at the brink but opens into a steep V-shaped gulch that projects, flanked by rocky spurs, a mile and a half into the Yosemite Valley. (See pl. 3.) Down through this gulch, as through an immense smooth chute, the stream glides with amazing speed, finally leaping over the 600-foot precipice at the bottom in the Bridalveil Fall. Even the upland valley is not typical throughout-broad and gently sloping in its middle course, it contracts, about 2 miles from the brink, to a rock-walled gorge having a somewhat steeper gradient. Bridalveil Creek, accordingly, may be said to traverse first a normal upland valley, next a somewhat steeper gorge, and then a precipitous chute, before it makes its final leap.

The hanging valleys of Indian Creek and its East Fork, which are east of Yosemite Creek, differ from any of the valleys above described in that their mouths are deeply gashed by V-shaped gulches. Through these gulches the streamlets cascade without making any waterfalls of note, joining each other midway in their descent. The gulch of the main stream is fully a mile long and is known as Indian Canyon because, being unobstructed by cliffs, it served the Yosemite Indians, before the white man built his trails, as a route of egress from the valley.

Illilouette Valley (ill-i-lou-ette' ) is cut to much greater depth below the general level of the Yosemite upland than most of the preceding valleys, yet it also is a true hanging valley, for it terminates abruptly at a height of 1,850 feet above the Yosemite floor. Its relatively great depth-nearly 2,000 feet-can hardly be accounted for by the volume of Illilouette Creek. That stream, it is true, is the largest of the Merced's tributaries in the Yosemite region and drains the most extensive territory of them all; but the depth of the valley nevertheless seems out of proportion to the size of the stream. The same impression is created by the hanging valleys of Tamarack and Grouse Creeks, in the lower part of the Yosemite region, which likewise are intermediate in height between the true upland valleys and the main chasm, yet which contain relatively small streams.

If the Illilouette Valley thus seems anomalously deep, Tenaya Canyon seems vastly more so, for it is cut down within 100 feet of the level of the Yosemite Valley and is next to that valley the greatest chasm in the Yosemite region, yet it is traversed by a streamlet comparable in volume to Yosemite Creek. (See pl. $8, A$.) Moreover, its floor lies fully 2,000 feet below that of the Little Yosemite, which is the pathway of the Merced River. However, the Little Yosemite itself seems anomalous because of its lack of depth, considering that it forms part of the canyon of the master stream. It is cut off abruptly at a height of 2,000 feet above the main Yosemite and has the aspect of a hanging valley. From its mouth the Merced descends by successive leaps, forming the Nevada and Vernal Falls and a chain of turbulent cascades. (See pl. 10.) It will be readily understood, then, why Tenaya Canyon rather than the Little Yosemite has been by some observers regarded as the real upward continuation of the Yosemite Valley. The paradoxical relations between these two chasms constitute one of the most puzzling features of the Yosemite region.

Both Tenaya Canyon and the Little Yosemite have hanging side valleys of the true upland type. The largest, on the north side of Tenaya Canyon, is the valley of Snow Creek, which heads on the south slope of Mount Hoffmann. It terminates at a height of 2,500 feet above the canyon floor. On the south side of the Little Yosemite is the broadly open upland vale in which lie the Starr King Meadows. The streamlet that issues from those meadows makes a precipitous descent of 1,700 feet.

\section{STAIRLIKE STEPS IN CANYON FLOORS}

The successive falls which the Merced River makes in its descent from the Little Yosemite leap from the steps of what may be characterized as a giant stairway hewn in granite. From Glacier Point, the farfamed scenic viewpoint on the south side of the Yosemite Valley, this natural stairway may be beheld in its entirety, and an excellent conception may be gained of the clean-cut forms of its steps and of the nature of the canyon in which it is cut. (See pl. 10.) The uppermost step, from which the Nevada Fall drops, is 600 feet high; the next lower step, which gives rise to the relatively insignificant Diamond Cascade, is about 50 feet high; the lowermost step, from which the Vernal Fall drops, is more than 300 feet high. The total descent is 1,200 feet in a distance of slightly more than half a mile.

Viewed from the tourist trail that leads directly up over the giant stairway to the Little Yosemite, the steps are seen to have well-defined edges, sheer fronts, or risers, and approximately level treads. (See pls. 24 and 25.) The lowermost step is the most perfectly modeled; its edge is neatly squared, and its front is essentially vertical and straight. The tread, however, is hollowed out, like a wooden stair tread that has suffered many years of wear. In the shallow basin lies picturesque Emerald Pool. All the steps, moreover, are much broader than the stream bed. They are can- 
yon steps, not channel steps. The river, in fact, occupies but a small part of their width. In the distant view from Glacier Point it has the appearance of a mere trickle finding its way down a rugged pathway that is much too broad for its small volume. There is, nevertheless, a marked narrowing of the canyon at the edge of each step, followed by a widening on the tread below. At the Vernal Fall the constriction is produced mainly by a low spur on the south side of the canyon-the spur over which the horse trail leads in laborious zigzags. At the Nevada Fall the constriction is due to two great bosses of granite, Liberty Cap and Mount Broderick (pls. 10 and 44, $B$ ), which project from the north side. Immediately behind these obstructing masses the walls again flare out abruptly to the full width of the Little Yosemite.

Stairlike steps of this type accompanied by portallike constrictions are present also in Tenaya Canyon. There is a long series of them, extending over a distance of 7 miles and making a total rise of 4,000 feet; but, with one exception, these steps are not so perfectly modeled nor are the portals so accentuated as those of the giant stairway below the Little Yosemite. Tenaya Canyon opens scarcely a hundred feet above the Yosemite Valley and is almost level-floored for a distance of a mile and a half. Then it rises steeply about 500 feet, but so narrow and gorgelike is its bottom here that the effect of a step is almost lost. Yet above the rise is a relatively level, broad-floored stretch nearly a mile in length that is truly suggestive of a tread.

The second step is much better defined than the first, its front rising abruptly in the form of a cross cliff about 700 feet in height. Tenaya Creek, nevertheless, does not leap over this cliff but issues from a narrow gorge which it has cut into the step. The south half of the step, which is the better preserved of the two, still has a smooth, tabular top and a definite, sharp edge. The tread was originally $1 \frac{1}{2}$ miles long, but only its upper half remains untrenched.

The third and fourth steps are low and have short treads, but the fifth step, which is at the head of Tenaya Canyon, is remarkable both for its height and its long tread. It is one of the best-developed canyon steps in the Yosemite region. The front or riser is a sheer cliff 600 feet in height that connects without break with the canyon walls on each side. Down its marvelously smooth face the waters of Tenaya Creek glide rather than drop in the form of a continuous ribbon cascade. Above this great cliff begins a relatively shallow upper canyon carved throughout in bare granite. Its floor extends with gentle gradient for the distance of about a mile, then by a flight of minor rock steps it rises to the level of what may be termed the Tenaya Basin, whose central feature is Tenaya Lake.
THE HIGH SIERRA

\section{GENERAL CHARACTER}

A glance, next, at the High Sierra, which lies immediately above the Yosemite region. It contains the sources of the Merced River, and from it in glacial time advanced the powerful ice streams that converged upon the Yosemite chasm. It therefore is and always has been the place of origin of the agencies that have played the leading parts in fashioning the chasm. (See pl. 11, A.)

In several respects the High Sierra differs markedly from the Yosemite region. Its sky line is formed not by the timbered swells of a rolling upland but by sharp-profiled mountain crests that rise, mostly bare, high above the timber line. The Yosemite upland, it is true, continues up into the High Sierra, but only in the form of shoulders along the sides of the main canyons. It is an inconspicuous feature beneath the majestic peaks.

The canyons in the High Sierra are less deeply cut than those in the Yosemite region. They range from less than 1,000 feet to a maximum of 2,000 feet in depth below the flanking shoulders; measured with reference to the higher peaks, however, they range from 3,000 to more than 4,000 feet in depth. Hanging valleys abound at the sides of the main canyons, but they differ from the hanging valleys of the Yosemite region in that they ascend steeply by successive stairlike steps, and they head in amphitheaters sculptured among the peaks. Lakelets of emerald and sapphire hues lie on the steps, contrasting vividly with the light buff tones of the surrounding granite. Snow banks and snow fields fleck the mountain sides; a few small glaciers gleam in the deeper hollows.

Besides being more rugged and having greater variety of scenery, the High Sierra is distinguished from the Yosemite region also by its vast expanses of bare rock. Not only are the peaks bare because of their great elevation, but the floors and sides of the canyons and hanging valleys are mostly bare, partly because the soil was scraped from them by the ancient glaciers, partly because the granite over large areas is sparsely fractured and affords but scant roothold for vegetation. The High Sierra as a whole, therefore, presents a singularly clean-swept appearance that would border on the desolate, were it not for groves of trees, bright-green meadows, picturesque lakelets, and dazzling snow fields.

The mountain crests that traverse the High Sierra above the Yosemite region divide it into two drainage basins, those of the Merced and Tuolumne Rivers. (See pl. 2.) These crests have northwesterly trends, parallel to that of the main Sierra crest. As a consequence the master streams in the two basins flow 
northwestward, approximately at right angles to the directions which they pursue farther down the slope of the range.

The first mountain crest above the Yosemite region is the boldly sculptured Clark Range, which terminates in Mount Clark (11,506 feet), on the south side of the Merced. (See pl. 11, B.) It separates the Illilouette Basin and the upland south of the Little Yosemite from the Merced Basin. About 8 miles farther northeast, between the Merced Basin and the Tuolumne Basin, stands the still bolder Cathedral Range, which extends from Mount Lyell $(13,090$ feet $)$, the highest summit in the central part of the Sierra Nevada, northwestward to Cathedral Peak $(10,933$ feet). (See pl. 12, A.) The northeast wall of the Tuolumne Basin is formed by the main crest of the Sierra Nevada, which is surmounted by Mount Dana (13,050 feet) and a long row of other peaks between 12,000 and 13,000 feet in altitude that overlook Mono Lake and the deserts at the east base of the range.

\section{MERCED BASIN}

The central feature of the Merced Basin is the upper Merced Canyon, a trench about 2,000 feet in depth and half a mile to a mile in width. Though narrower and less deep, some parts of this canyon resemble the Yosemite Valley in their style of modeling-indeed, the canyon may be said to contain a succession of minor yosemites separated from one another by more or less accentuated constrictions. Those stretches which contain Merced Lake (pl. 12, B) and Washburn Lake have especially pronounced Yosemite characteristics: they are broadly $U$-shaped, steep-sided troughs with smooth, parallel walls devoid of spurs.

The Merced Canyon rises headward by successive steps, like the canyons in the Yosemite region. Most of the steps, it is true, are low and ill defined, and as a consequence the river makes no leaping falls but only cascades, yet the essentially stairwise mode of ascent of the canyon is manifest from a longitudinal profile such as that in Figure 22. Like the Yosemite Valley the upper Merced Canyon has fairly definite brinks. Its walls rise sheer to the edges of shoulders that slope in general at moderate angles up to the bases of the surrounding mountain crests. These shoulders, which are the equivalent of the Yosemite upland, extend, interrupted by spurs and hanging valleys, to the very head of the Merced Basin.

The hanging valleys on the side of the Clark Range are the best developed. (See pl. 13, B.) Most of them terminate at heights of 500 to 700 feet above the floor of the main canyon, but one, Clark Canyon, terminates at a height of 2,500 feet. At the upper end of the basin several typical hanging valleys converge toward the cliff-encircled canyon head, their waters pouring down from all sides in falls and cascades. The stairwise-ascending rock floors of these hanging valleys are largely bare and in many places gleam with glacier polish. They are, indeed, the pathways of ancient glaciers and were shaped by those glaciers rather than by the present streams. The same is true of the broad rock floor of the main canyon, which for long stretches, especially below Merced Lake, is wholly bare and bigbly polished.

The side valleys that head on the Cathedral Range are longer and deeper than those on the Clark Range and flanked by mountainous spurs. In spite of their ruggedness, however, some of these high-level valleys contain attractive stretches of meadowland. Two of them, the valleys of the Maclure Fork and Echo Creek, are so deeply cut at their mouths that they have lost the aspect of true hanging valleys. Nearly all head in amphitheaters deeply sculptured in the body of the range, but two head in broad gaps or passes that afford easy routes of communication across to the Tuolumne Basin. The valley of the Cathedral Fork of Echo Creek heads at the Cathedral Pass, and the valley of the twin streams Emeric Creek and Fletcher Creek heads at the Tuolumne Pass.

\section{TENAYA BASIN}

Forming part of the region tributary to the Merced River, yet a unit distinct from what has been called the Merced Basin, is the Tenaya Basin, which lies above Tenaya Canyon and contains the headwaters of Tenaya Creek. It is much smaller than the Merced Basin, being only 5 miles long and 4 miles broad, and it does not head at the main crest of the Sierra Nevada, yet it is an area of peculiar interest because it was formerly the thoroughfare for large masses of glacier ice that were diverted into it from the adjoining Tuolumne Basin and went to fill Tenaya Canyon.

The Tenaya Basin lies wholly above 8,000 feet of altitude-4,000 feet higher than the Yosemite Valley. Tenaya Lake, which lies in its center, has an altitude of 8,141 feet. On the east the basin is walled in by the sheer cliffs of Sunrise Mountain and Tenaya Peak; on the west it is flanked by the less abrupt cliffs of Mount Hoffmann and Tuolumne Peak. At its head the basin is separated from the Tuolumne Basin by a relatively low, inconspicuous divide.

The basin as a whole is a land of bare, glistening granite. Only at the head of Tenaya Lake and for some distance below it are there stretches of verdant meadowland. All the low wavelike swells and ridges as well as the intermediate troughs in its floor are essentially devoid of soil and are made of smooth, sparsely fractured rock on which the trees grow far apart or are wanting altogether. What is more, the rock floor as well as the surrounding cliffs retain in many places the high polish that was imparted to them 
by the grinding glaciers. It was this fact that led the Indians to call Tenaya Creek Py-we-ack ("the stream of the glistening rocks"). ${ }^{24}$

\section{TUOLUMNE BASIN}

What is commonly termed the Tuolumne Basin is only a small part of the vast area of mountain country drained by the Tuolumne River; it is, strictly, the basin of the main branch of the river whose headwaters are on Mount Lyell and Mount Dana. Its natural lower limit is at Tuolumne Peak and the head of the Tuolumne Canyon. Its central feature is the Tuolumne Meadows (pl. 13, A), the largest of the many subalpine gardens of the High Sierra, justly famed as one of the most attractive parts of the Yosemite National Park.

The basin, as thus defined, measures roughly 15 miles in length and 10 miles in greatest breadth and has an area comparable to that of the Merced Basin. It is, however, much less rugged, the broad meadows that stretch for many miles along the river and its two principal forks taking the place of a central rockfloored canyon. Because it is less deeply trenched, the Tuolumne Basin also is considerably higher than the Merced Basin. Its central meadows have an altitude of over 8,500 feet; they lie 1,500 feet above Merced Lake and 4,500 feet above the Yosemite Valley. Moreover, as the meadows extend with gentle slopes all the way to the Tioga Pass and Mono Pass on the crest of the Sierra Nevada, the Tuolumne Basin affords a particularly easy route of travel across the range. The Indians quickly perceived this fact and laid their trail from Mono Lake to the Yosemite region-the historic Mono Trail-through the length of the basin. The Tioga Road, which was built in 1882-83 to a mining camp near the main crest of the range, naturally was laid also through the Tuolumne Basin, and since this road has been acquired by the Government and improved for automobile traffic the Tuolumne Meadows have become the great thoroughfare for tourist travel between the Yosemite and Mono Lake.

Although the Tuolumne Basin differs so markedly in configuration from the Merced Basin, the two basins nevertheless have several features in common. The broad central valley of the Tuolumne, like the upper Merced Canyon, is flanked by elevated benches that are continuations of the Yosemite upland; and most of the valleys on these benches are of the hanging type, opening at heights of 500 to 1,200 feet above the grassy floor. Nor do the spurs between these hanging valleys project beyond the edges of the benches; they belong wholly to the upper story of the landscape, the broad valleys of the lower story being distinctly of the smooth-sided trough type.

2t Bunnell, L. H., Discovery of the Yosemite and the Indian war of 1851, 4th ed., p. $207,1911$.
The benches are best developed on the south side of the basin, where they attain a breadth of several miles. Especially is this true north and northeast of Tuolumne Pass, where they form a fairly continuous, undulating platform. This high-level surface rises gradually eastward, from 9,200 feet at the base of Cathedral Peak to 10,500 feet at the base of Mount Lyell, at the same time changing in aspect from a densely wooded to a desolate and barren country. (See pl. 41, A.)

Of peculiar interest to the sightseer as well as to the geologist are the small glaciers and ice fields that cling to the higher peaks about the Tuolumne Basin, for they are representative, on a diminutive scale, of the extensive ice masses that filled the basin during the glacial epoch. These small ice bodies lie in wellshaded amphitheaters or on slopes with northerly exposure. The Dana Glacier (pl. 28, B) is ensconced in a deep amphitheater north of the summit of Mount Dana. A somewhat broader ice mass clings to the slope north of Parker Pass. Largest and most prominent in the landscape are the glaciers on Mount Lyell and Mount Maclure. Each measures about half a mile in length, and the Lyell Glacier (pl. 14) is fully twice as broad. Situated close together, these dazzling ice bodies combine to give this group of peaks a truly alpine aspect, not excelled in beauty by any other part of the High Sierra.

The scientists of the Geological Survey of California, who first explored the range in the early sixties of the last century, paid little attention to these ice bodies and referred to them merely as snow fields. Nevertheless they are true glaciers, as was first pointed out by Muir. They are composed of old, granular snow ice and, though small, move slowly forward in the manner characteristic of large glaciers and are rent here and there by typical crevasses.

\section{THE YOSEMITE VALLEY IN DETAIL}

In the preliminary sketch on page 7 the Yosemite was described as a broadly $U$-shaped chasm having sheer, spurless walls and an almost level floor. In detail, however, the valley is far from having the geometric simplicity of form that might be suggested by this characterization. Its sides are not strictly parallel throughout, nor do they consist of monotonous blank walls. They are diversified by a host of boldly sculptured features and in addition are adorned by waterfalls. The Yosemite, indeed, owes its unique place among the valleys of the world to its wealth of monumental rock masses and the splendor and variety of its falling waters, as much as to its general"form.

\section{PECULIAR MODELING OF VALLEY}

The bird's-eye view on Plate 15, which shows the Yosemite Valley as it would look from an airplane, reveals the fact that its sides, though remarkably sheer in places, are at no point strictly vertical throughout 
their height. Almost everywhere the declivities are broken by slopes or ledges, and as a consequence the bases of the walls project considerably beyond the tops. The topographic map (pl. 7) shows by actual measurement that the horizontal distance from top to base of the walls averages more than half a mile. Even at those points where the cliffs are most sheer the horizontal distance is considerably greater than a mere "stone's throw." The cliffs below Glacier Point, which are noted for their abruptness, rise 3,200 feet in a distance of a quarter of a mile. El Capitan (pl. 3), the boldest of all the rock masses that flank the valley, rises 3,000 feet in a distance of 600 feet. Because of this lack of real verticality of its sides the Yosemite is less than half as wide at the bottom as it is at the top; from brink to brink it measures 2 miles across, but its floor, measured from cliff base to cliff base, is less than a mile wide. In places the talus slopes reduce it to less than half a mile.

The Yosemite Valley is divided by a marked constriction about a third of the way from its lower end, between El Capitan and the great promontory of which the Cathedral Rocks are the main summits. (See pls. 3 and 15.) This is the imposing portal that never fails to impress the incoming traveler with the stupendous scale on which the Yosemite is built. El Capitan really juts out but little from the north wall, but the Cathedral Rocks project fully a mile from the south wall. The Yosemite Valley, accordingly, consists of two broad chambers connected by a portal. The lower and smaller chamber is the less impressive of the two, being inclosed only in part by precipitous cliffs, in part by long and rather monotonous slopes of rock waste. These slopes nevertheless have a redeeming quality that deserves to be acknowledged; they have enabled man to build roads from the uplands down to the valley floor-the Big Oak Flat Road on the north side, the Wawona Road on the south side. In no other part of the Yosemite would it have been possible to construct roads making a descent of 2,000 or 3,000 feet without tunneling through the cliffs.

The lower end of the valley is in the main spoonshaped. It is closed off by a slope of solid rock about 800 feet in height which is cut only by the narrow, steep-walled gorge through which the Merced River leaves the valley. (See pl. 16, A.) This rock slope leads up to high rock benches that extend along both sides of the Merced Gorge for several miles.

The upper or main chamber of the Yosemite Valley is $51 / 2$ miles long and has a sinuous course. Its sides are on the whole remarkably equidistant and, although carved in a multitude of spectacular features, have the appearance of being planed off parallel to each other. The salients on one side, indeed, correspond roughly to the embayments on the other side - a fact which doubtless strengthened Clarence King's conviction that the chasm is a rent in the earth whose sides had been torn apart. There is nevertheless considerable variation in width from point to point. Immediately above the portal at El Capitan, which is about half a mile wide, the width from cliff base to cliff base increases to a maximum of more than 1 mile. Farther up it contracts to 3,500 feet, then to 3,000 feet, and finally it widens again to a full mile at the upper end of the valley.

Most strangely modeled is the valley head. (See pl. 16, B.) It is squared off, at right angles to the sides, by a high, straight rock wall a mile in length. At the north end of this wall is the broad U-shaped mouth of Tenaya Canyon; at the south end opens the narrow, tortuous gorge through which the Merced River descends from the Little Yosemite. Except for these two openings the head of the valley is bordered by continuous, massive cliffs. These cliffs, moreover, rise sheer almost directly from the valley floor, their bases being masked only by small piles of débris. As a result the valley head has a peculiar boxed-in appearance which, it must be admitted, is more suggestive of the subsidence of a block of the earth's crust, in the manner postulated by Whitney, than of the erosive action of either streams or glaciers.

\section{CLIFFS AND ROCK MONUMENTS}

The Yosemite Valley owes its scenic character not merely to its great depth and unusual form, but in large measure to the distinctive sculpture of its walls. The rock forms are astonishingly varied in designsome massive, colossal, and simple in outline, others frail and intricately chiseled; some conspicuous for their boldness, others carved in bas-relief-and many of them have arresting individuality. They are of such singularly clean-cut, monumental character that they impress themselves upon the memory of the beholder at once and forever. Some have become famed the world over.

El Capitan (see pls. 3 and 17) stands preeminent. among the massive, bulky forms. Its majestic cliff rises from the valley with so simple a sweep of line that its height is peculiarly difficult to evaluate at a. glance. The estimates of the first white men to camp. at the foot of El Capitan now seem ludicrous. As is related by Bunnell ${ }^{25}$ in his account of the discovery of the Yosemite Valley by the Mariposa Battalion, "one official estimated El Capitan at 400 feet; Captain Boling at 800 feet. *** My estimate was a sheer perpendicularity of at least 1,500 feet." Trigonometric measurements made in connection with the survey for the topographic map of the valley (pl. 7) have determined the height of the cliff, from its toe to the brow at the top, to be fully 3,000 feet. The dome-shaped crown above the brow rises 500 feet higher.

25 Bunnell, L. H., Discovery of the Yosemite and the Indian War of 1851 , th ed, p. 94, 1911. 
Opposite El Capitan is the ponderous group of the Cathedral Rocks (pls. 3 and 18), which project more than a mile out into the valley. The three summits, carved from a single asymmetric ridge, loom one above another in an ascending series. They stand 1,650 , 2,590 , and 2,680 feet, respectively, above the valley floor. On the west side they slope evenly to the V-shaped gulch through which the waters of Bridalveil Creek race down to the precipice of the Bridalveil Fall. Parallel to them, on the opposite side of the gulch, is a lesser ridge whose main summit is known as the Leaning Tower (see pl. 15), because it actually leans out over the 1,200-foot precipice beneath it.

In the embayment east of the Cathedral Rocks, offering a striking contrast to those massive piles, stand the two slender, tapering shafts of the Cathedral Spires, the frailest of all the rock forms in the valley. They rise to heights of 2,160 and 1,950 feet, above its floor. Farther east are a multitude of finely chiseled, hackly forms, followed by a series of strongly asymmetric spurs, with smooth slopes on the west side and vertical or overhanging cliffs on the east side. The spur under Taft Point is a notable example, but the asymmetric type of sculpture reaches its finest development on the opposite side of the valley, in the group of the Three Brothers (pl. 19, $B$ ), whose gabled forms rise one above another, all pitching at the same angle.

Still farther up in the valley vertical and horizontal lines of sculpture predominate. Sentinel Rock (pl. 19, A) stands forth from the south wall like an obelisk with sheer front and sharp, splintered top. The great cliff over which the Upper Yosemite Fall leaps is nearly vertical, and so is the rock wall to the west of it, which dominates the zigzag trail to the top of the fall. Below, on both sides of the recess in which the Lower Yosemite Fall descends, are two horizontal rock terraces with sheer fronts. Most impressive of all for height and verticality is the famous cliff at Glacier Point. It is a straight wall, a quarter of a mile long and 1,000 feet high, that terminates the promontory as abruptly as if it had been cut with a cychopean knife. That it is really vertical, and not merely inclined at a high angle, as are the majority of the cliffs that are popularly termed sheer or vertical, is evident from the silhouette profile in Plate $20, B$. It is this absolute verticality of the rock face that permits the "fire fall," which customarily is produced every night during the tourist season by pushing the glowing embers of a bonfire from the edge of the platform above, to descend through space untrammeled, deploying gradually like a waterfall of the Yosemite type.

At the extreme top of the precipice. which is 3,200 feet above the valley, there projects a large, rough slab-the famous "overhanging rock of Glacier Point." (See pl. 9, B.) A short distance to the west of it is a second, smaller overhanging rock, known as Photographer's Rock, because it affords a convenient base from which the venturesome ones on the main overhang may be photographed. It is the Photographer's Rock which appears in the silhouette profile shown on Plate 20, $B$.

The most remarkable rock forms cluster about the head of the Yosemite Valley. Directly opposite Glacier Point are the Royal Arches (see pl. 21, B), a series of immense natural arches carved in basrelief, one within another, in a slanting rock face 1,500 feet in height. Flanking them, as a corner post at the mouth of Tenaya Canyon stands the Washington Column, a colossal upright pillar 1,700 feet in height; and surmounting them is the North Dome (see pls. 16, $B$, and $20, A$ ), a smoothly rounded, helmetshaped mass of bare granite that rises to a height of 3,530 feet above the valley. A short distance to the northeast is Basket Dome, a less symmetrical dome of the same general type.

Dome-shaped features of bare granite abound in the upper Yosemite region. Most readily accessible to the sightseer is Sentinel Dome (pl. 21, $A$ ), which stands on the upland, to the southwest of Glacier Point. Highest of all, and least accessible, is Mount Starr King (pl. 32, $A$ ), the beautifully symmetrical, egg-shaped dome east of the Illilouette Valley. It is surrounded by several less conspicuous domes that seem almost insignificant in comparison with it, though each of them is larger, actually, than Sentinel Dome. To the general category of domes belong also Mount Broderick and Liberty Cap (pl. 44), the two bosses of granite that obstruct the mouth of the Little Yosemite; the Cascade Cliffs (pl. 45, $A$ ), Bunnell Point (pl. 45, B), Moraine Dome (pl. 31, $A$ ), and Sugar Loaf (pl. 45, $B$ ), near the head of that valley; and the rounded back of Mount Watkins (pl. 47, A), which is really a second El Capitan that rises sheer 3,000 feet above Tenaya Canyon.

Most imposing and most strangely shaped is the Half Dome (pls. 20, $B$, and 50), which stands at the head of the Yosemite Valley, on the divide between Tenaya Canyon and the Little Yosemite. Rounded on the south side and cut off sheer on the north side, it has indeed the appearance of a great dome which has been split in two and whose other half has been destroyed. Measured from southwest to northeast, parallel to its sheer front, it is nearly a mile long; measured at right angles to the front it is a quarter of a mile broad; from the base of the cliff to the extreme summit it is 2,200 feet high. The base of the cliff, however, is itself 2,570 feet above the level of Mirror Lake, hence the total height of the dome above Tenaya Canyon is 4,770 feet.

Only one eminence in the Yosemite region outtops Half Dome - namely, the lofty ridge that culminates in Clouds Rest. (See pl. 40,B.) It faces Tenaya Canyon 
with a cliff front 2 miles long and almost a mile highone of the greatest continuous fronts of bare granite in the Sierra Nevada. The rock face is not, however, as sheer as that of El Capitan but slants at a considerable angle and is diversified by billowy salients and smoothly concave hollows.

Every one of the rock forms enumerated is of a highly distinctive character, wholly different from the rank and file of rock features in canyons and mountain valleys. Even in the other yosemites of the Sierra Nevada, which are carved in granitic rocks of the same general type, such exceptional forms occur as a rule only isolated or in small groups. The Hetch Hetchy has its Kolana, the Tehipite its towering dome, the Kings River Canyon its Grand Sentinel and Sphinx, but none can match the Yosemite's wealth of sculpture.

\section{WATERFALLS}

Directly associated with the cliffs are the waterfalls of the Ycsemite region, and, like the cliffs, they are of many different types. Outstanding among them are those waterfalls that make free, untrammeled leaps of great height. Most waterfalls elsewhere are broken in their descent by projecting ledges. Such falls are properly termed cascades; but the leaping falls of the Yosemite region are "falls" in the truest sense. They represent a relatively rare type, for clean-cut rock walls of great height are rare in the paths of streams.

Because of the small volume of the mountain streams that form them, the waterfalls of the Yosemite region are generally slender, resembling shimmering veils or ribbons fluttering from the cliffs. Even the falls of the Merced, though heavier, are not of the broad cataract type, for in the Yosemite region, which is a scant 20 miles from the crest of the Sierra Nevada, the Merced is still no larger than what is ordinarily termed a creek.

Among the most perfect examples of a free-leaping waterfall is the Bridalveil (pls. 23, $A$, and 3 ), which descends over a vertical precipice 620 feet in height. Unlike most of the Yosemite's great waterfalls, however, the Bridalveil hangs low in the landscape. It pours from the lip of a $\mathrm{V}$-shaped gulch only 850 feet above the valley floor. In the spring and early summer, when the snow on the upland is melting fast, the Bridalveil Fall swells to the proportions of a massive aerial torrent that strikes the rocks and pool at its base with tremendous impact and sends great clouds of spray, suffused by the afternoon sun with prismatic colors, far out through the surrounding grove of trees. Most sightseers, however, know the Bridalveil only as it presents itself in midsummer, in that filmy, veil-like form which suggests its name. The prismatic colors persist, but only in a simple rainbow arc. In the autumn, when the volume is still smaller, it happens not infrequently that for a brief moment the water, wholly divided into spray, is blown up and back into the gulch whence it came by a strong puff of the daily up-valley breeze. At night, on the other hand, the fall is almost invariably accompanied by a downward rush of chilled air from the gulch above that violently sways the shrubs and trees about its base. It was probably because of this phenomenon that the Indians named the fall $\mathrm{Po}^{\prime}$ ho-no, the "fall of the puffing winds." 26

Almost directly opposite the Bridalveil the slender Ribbon Fall drops 1,612 feet from the brink of the upland. It is the highest of all the waterfalls in the valley but does not make a clear leap throughout, being constrained in a narrow sheer-walled recess. Ribbon Creek, which drains an area of only a few square miles, often dries up in the autumn, but in the early summer it attains sufficient volume to give its fall great splendor. Clouds of spray then shoot out with vigor from the base of the recess and swirl from the opening at the top like steam from a geyser hole.

Another fall of the slender ribbon type is the Silver Strand, really the cascade of Meadow Brook, which is situated in an angular recess between Old Inspiration Point and Stanford Point, near the lower end of the valley. It has a height of 1,170 feet but seldom has volume enough to leap clear of the inclined cliff face. By midsummer it usually dries up altogether. Its foot is about 2,000 feet above the bottom of the valley.

Of peculiar interest because its form is so clearly determined by the structure of the cliffs is the long chain of falls of Sentinel Creek, in the recess west of Sentinel Rock. The upper falls, which have an aggregate height of 1,500 feet, drop from successive rock steps 50 to 200 feet in height. Below them the main Sentinel Fall makes a clear leap over a sheer wall 500 feet in height.

Surpassing all the other falls in height and in splendor are the Yosemite Falls. (See pls. 22 and $9, B$.) Though produced by a mere tributary of the Merced River, it seems fitting that they should bear the name of the valley, for they are easily its most spectacular scenic feature. Even more than El Capitan and Half Dome they have given the Yosemite its wide renown.

The Yosemite Falls are composed of a great upper fall, a lesser lower fall, and an intermediate chain of cascades. These have a combined height of 2,565 feet, or almost half a mile, and reach all the way from the upland to the bottom of the valley. The upper fall, which descends directly from the lip of the hanging valley down the front of a sheer, straight cliff, has a height of 1,430 feet. It is, so far as can be ascertained at the time of writing, the highest freeleaping waterfall in existence. It does not, however,

${ }^{26}$ Hutchings, J. M., In the heart of the Sierras, pp. 405-406, 1886. 


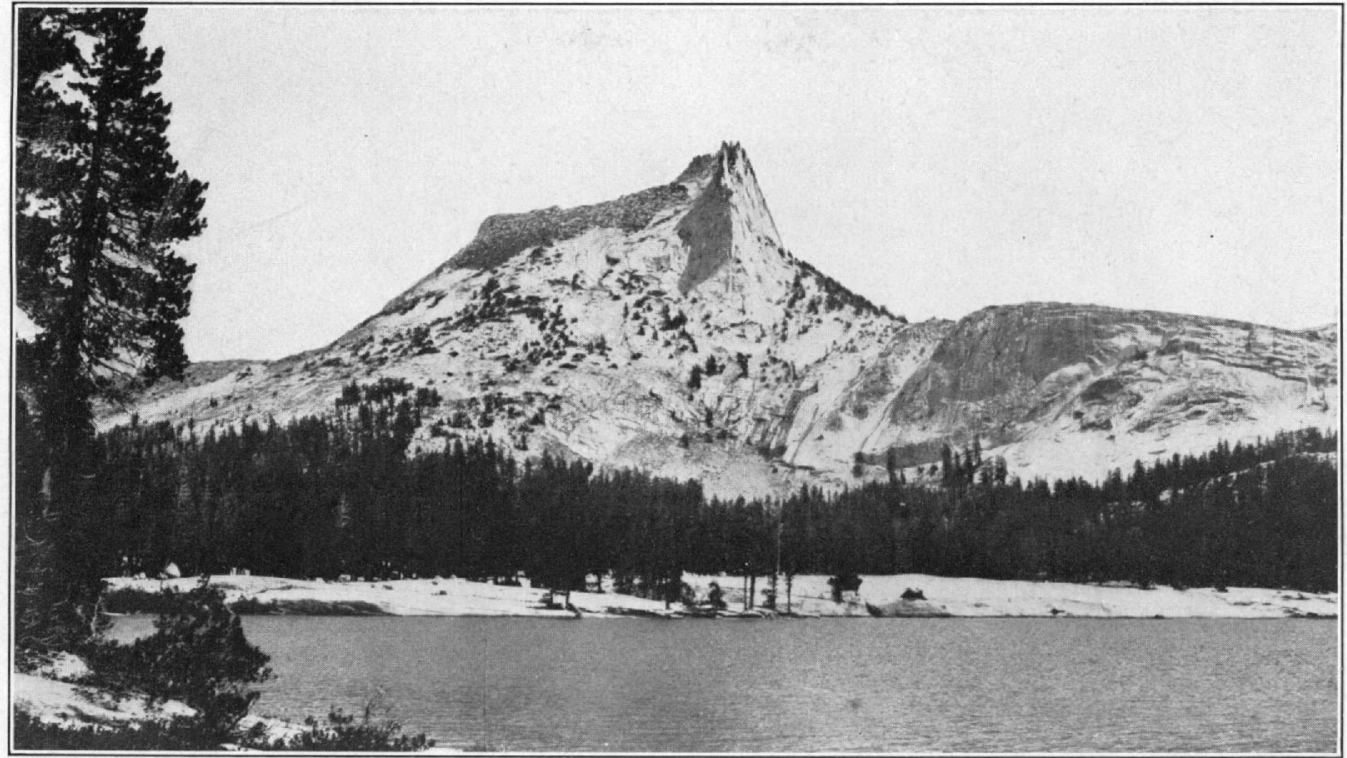

1. CATHEDRAL PEAk

The remarkable natural editice that stands at the northwest end of the Cathedral Range. In the foreground is Cathedral ake, which occupies a basin excavated in the granite by the ancient glaciers.

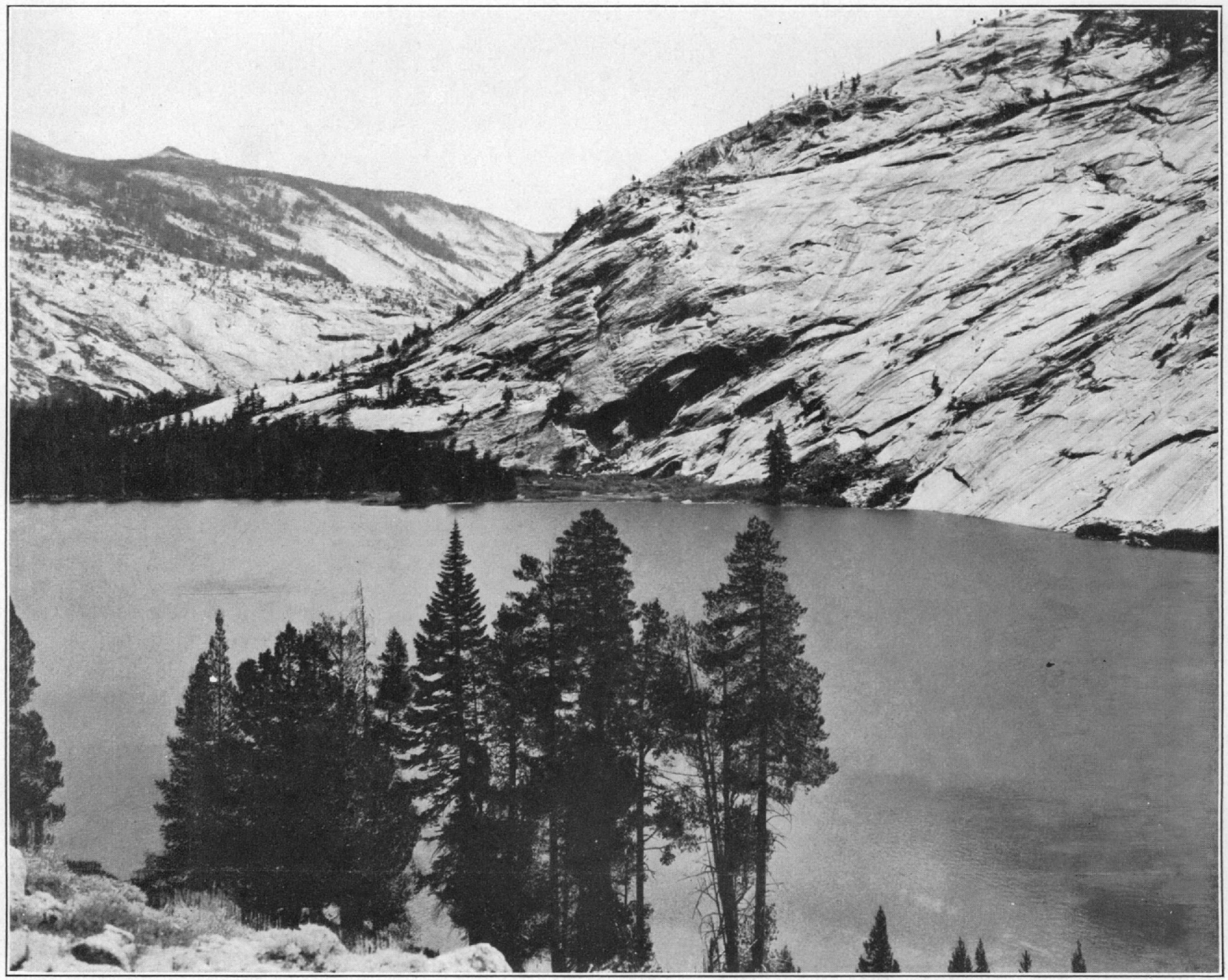

B. MERCED LAKF

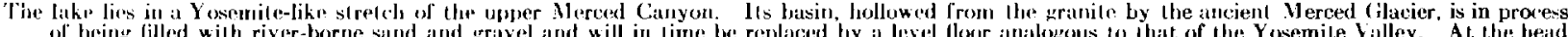

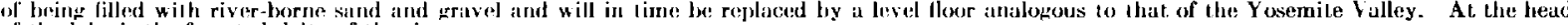
of the lake is the coresled dedlal of the river. 


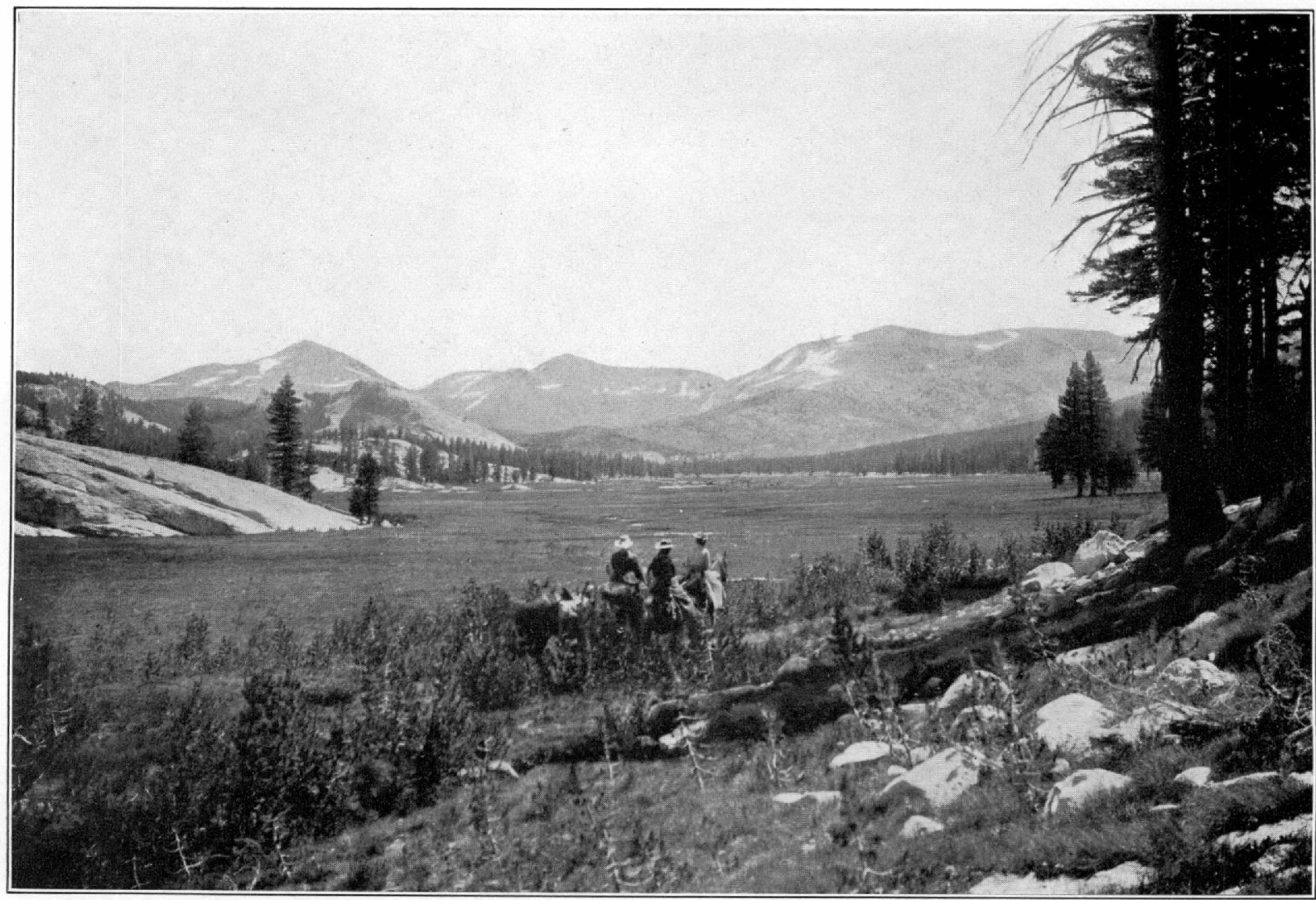

A. TUOLUMNE MEADOHS

These large meadows are the central feature of the upper Tiolumne Basin. In the backsround are, from left to right: Mount Dani, Mount

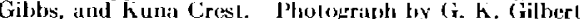

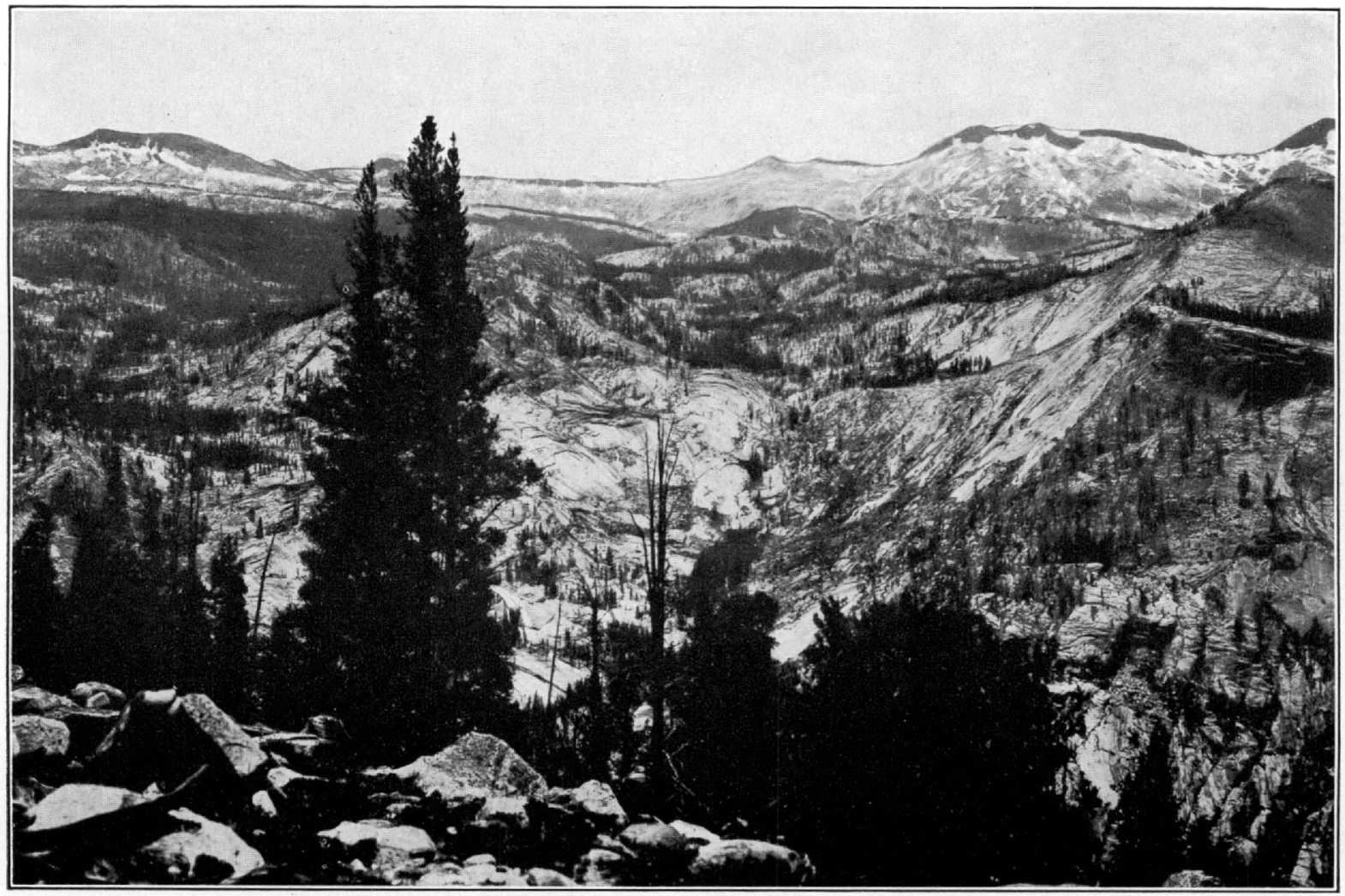

B. HEAD OF UPPER MERCED BASIN, FROM SHOULIEL NOHTH OF WASHBUHN LAKE

Below is the upper Merced Canyon, and heyond are some of the flanking rock henches and hanging valleys carved frorn prevailingly massive granite. Al the right are the peaks of the Clirk Hauge, ind to the liff of thern is the sharp) crest which convects with Monnt Lyell. 


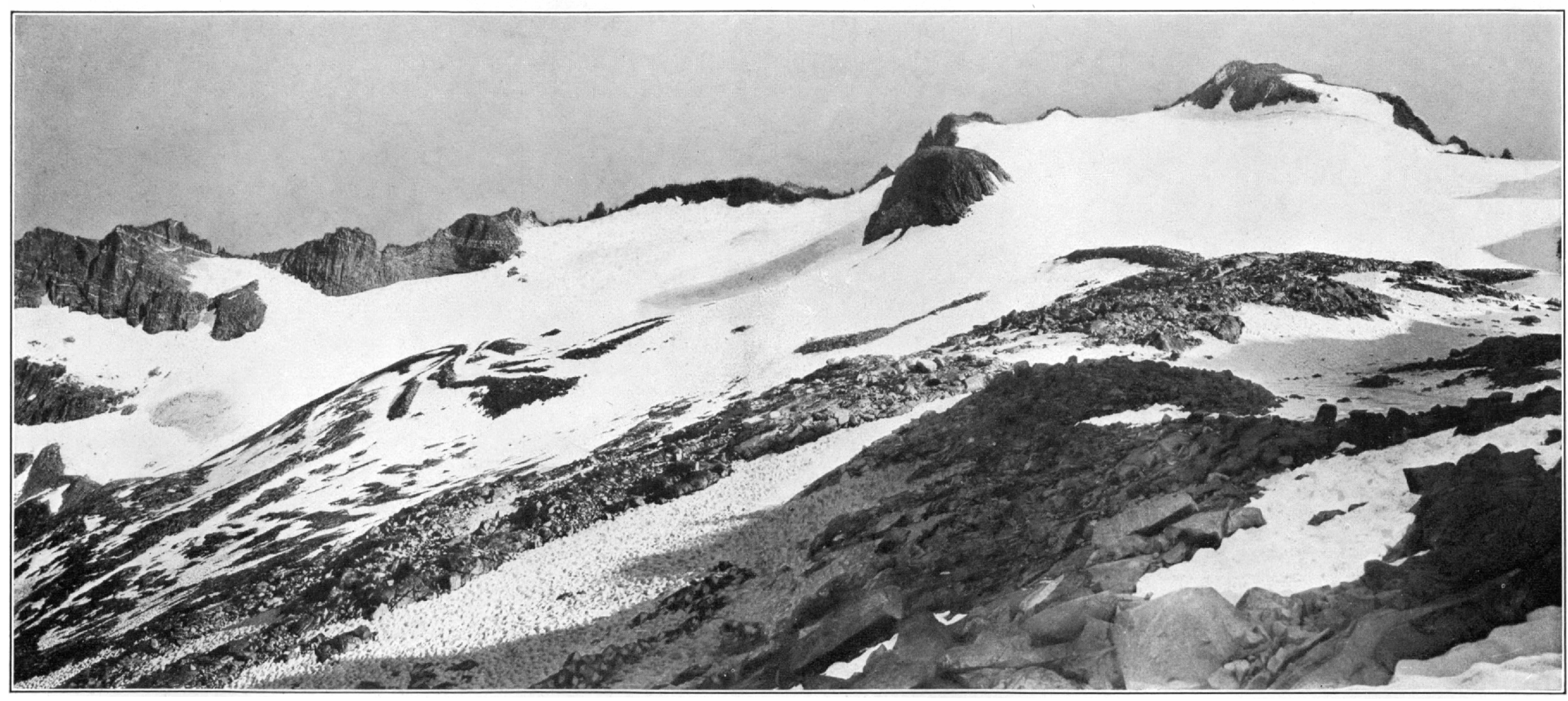

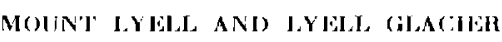

Moum Lyell stands ut the hend of the Mereed and Tholumne Rivers and is the culminating peak in the central part of the Sierra Nevada. The Lyell Gilacier is the largest ice body in the Yosemile National P'ark. 


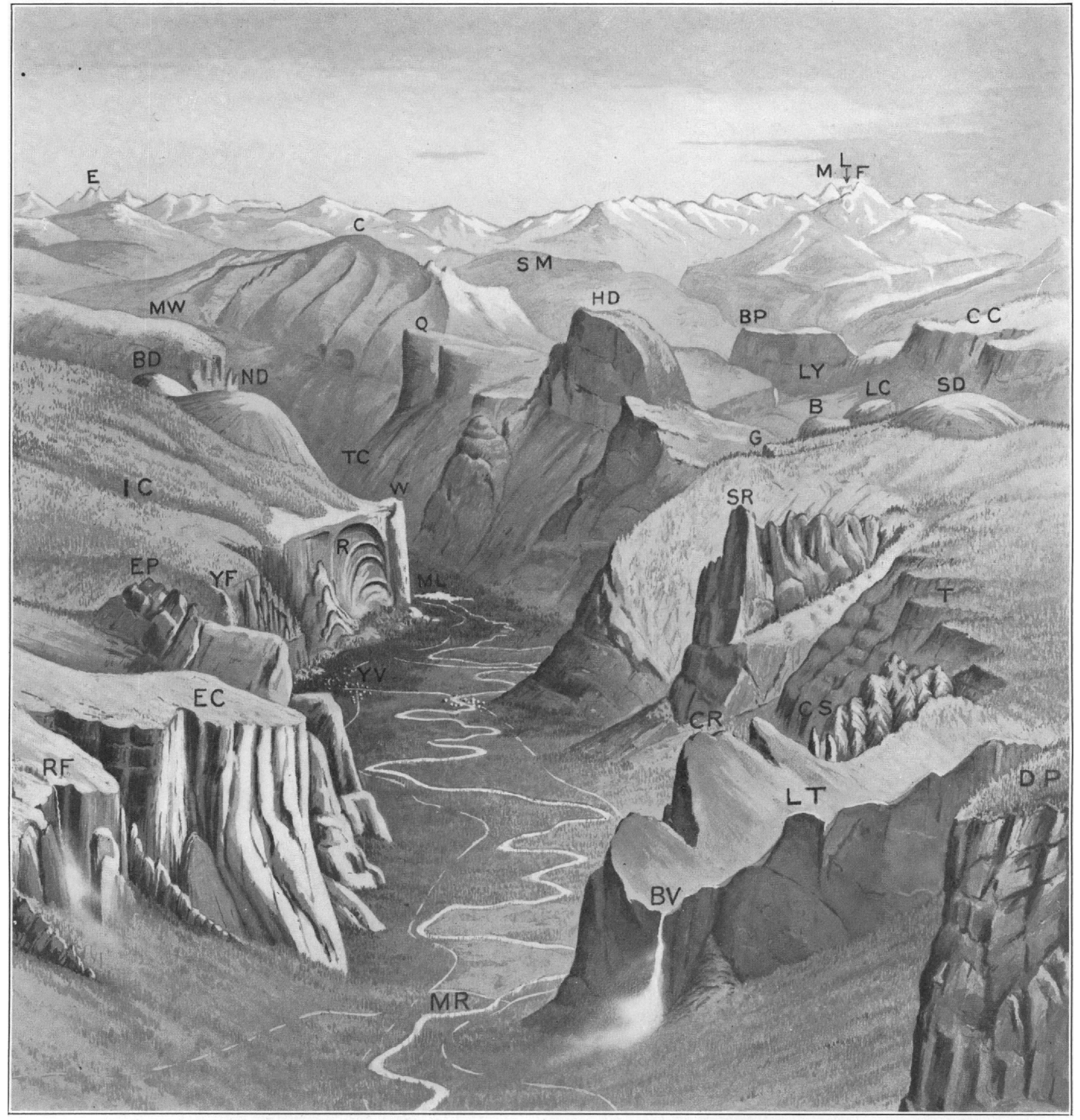

BIRD'S-EYE VIEW OF YOSEMITE VALLEY AND THE HIGH SIERRA

\section{Drawn by C. A. Weckerly}

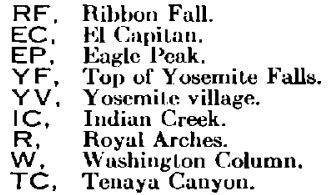

RF, Rilbbon Fal

YV. Yosemile village.

TC, Tenaya Canyun.
ML, Mirror Lake.
ND, Norih Dome.
MW. Masket Dome.
E. Fcho Penks.
$\stackrel{\mathrm{M}}{\mathrm{M}}$, Sunrise Mountain.
Q. Quarler Domes.
HD, Ilalf Dome.

GR Giacier P'oint-

T. Taft Point.

CS. Cat hedral Spires.

CR. Cathedral Rocks.

BV; Bridalveil Fall.

LT' Lraning Tower.

DP'. Dewey Point. 


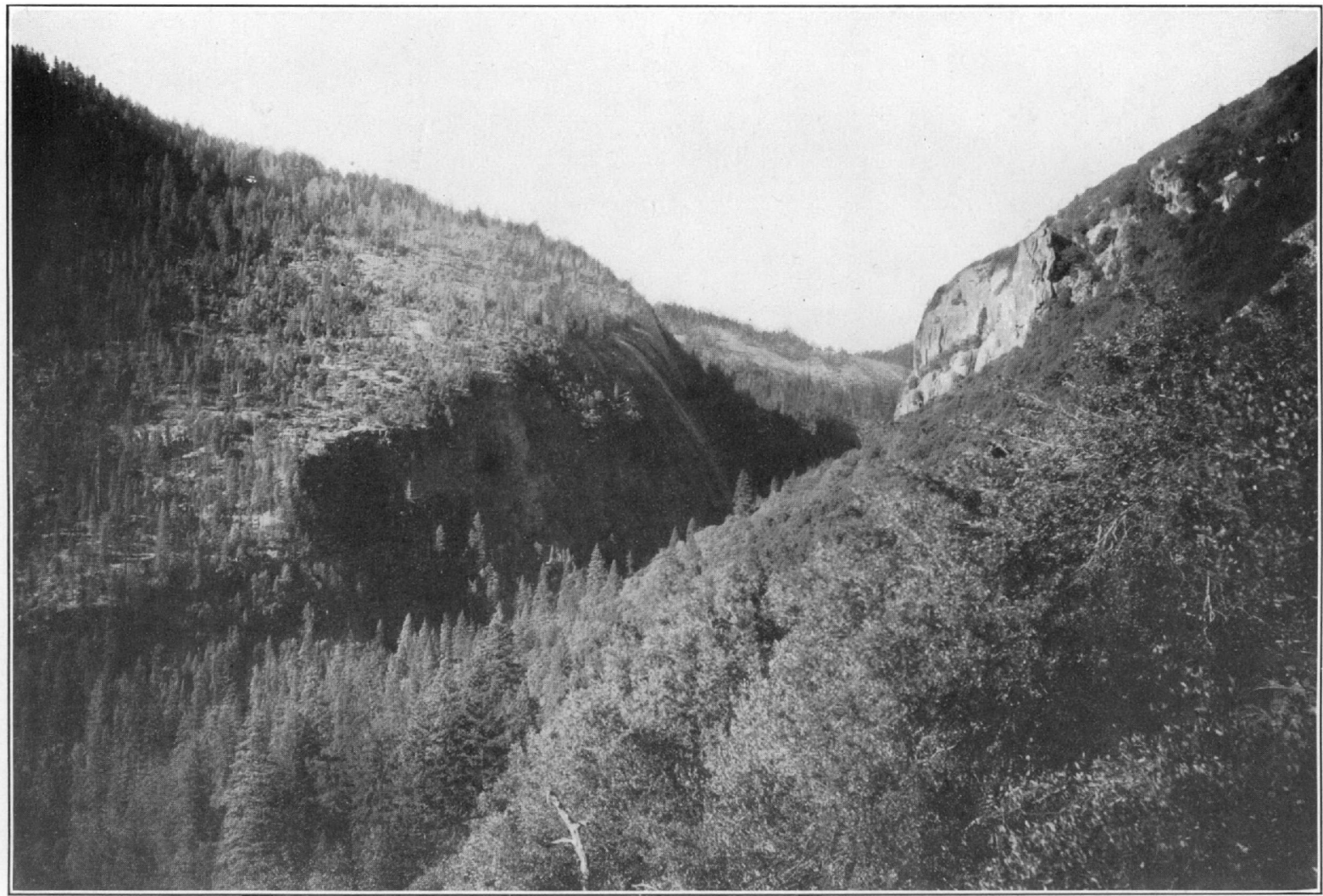

A. LOWER IEND OF YOSEMITE VAILLY AND HEAD OF MEHCED GORGE

This view from the Big Oak Flat Hoad shows the sloping barrier of massive granile that incloses the spmon-shaped end of the valley

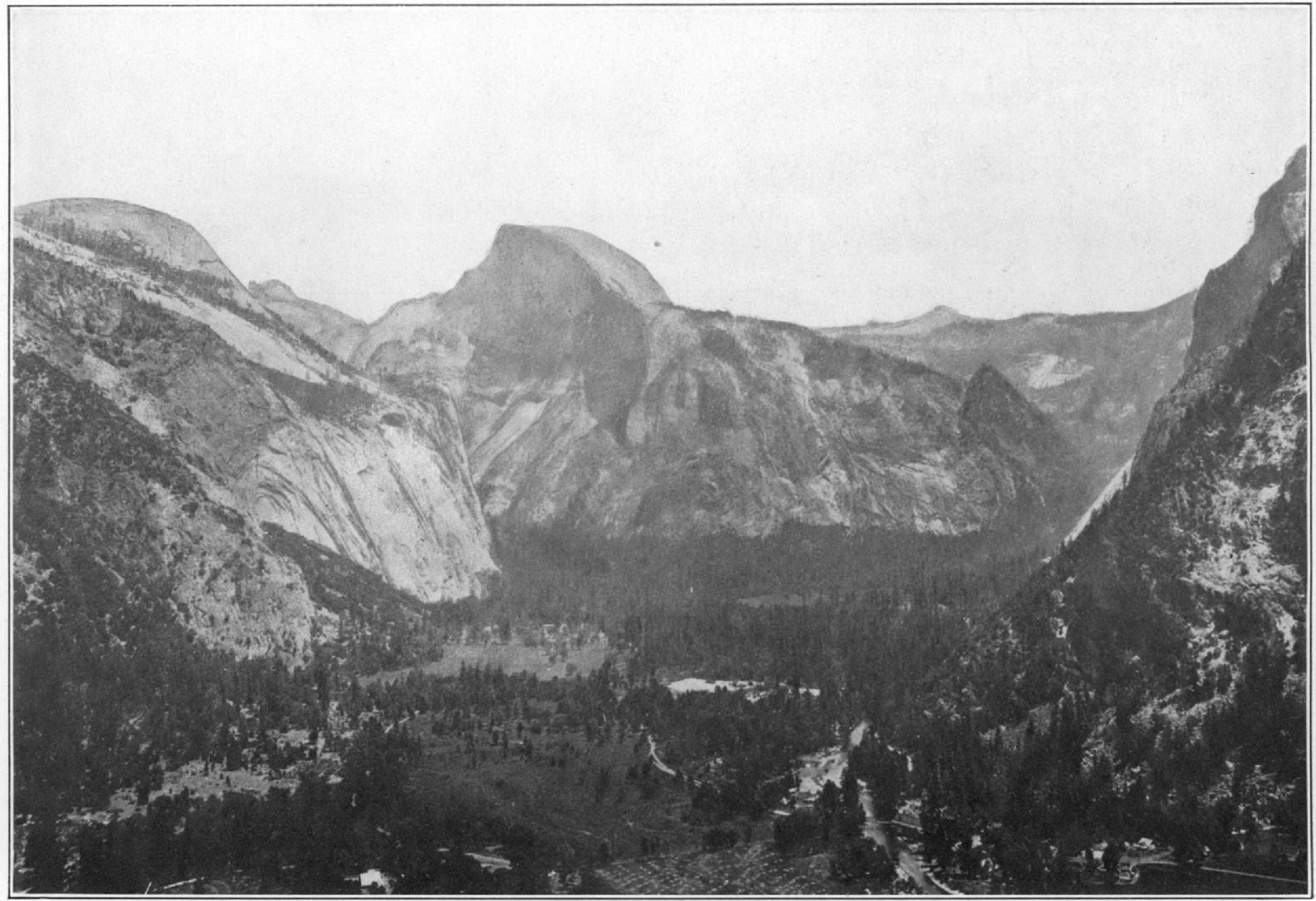

B. HEAD OF YOSEMITE VALLEY, FROM COLUMBIA ROCK

In the center is the great head wall, surmounted hy Half Dome. At the right is the promontory of Glacier Point. which conceals the upper canyon of the Merced. At the left are North Dome, the Hoyal Arches, the Washington Column, and the mouth of Tenaya Canyon. Phute graph by J. T. Boyseu. 


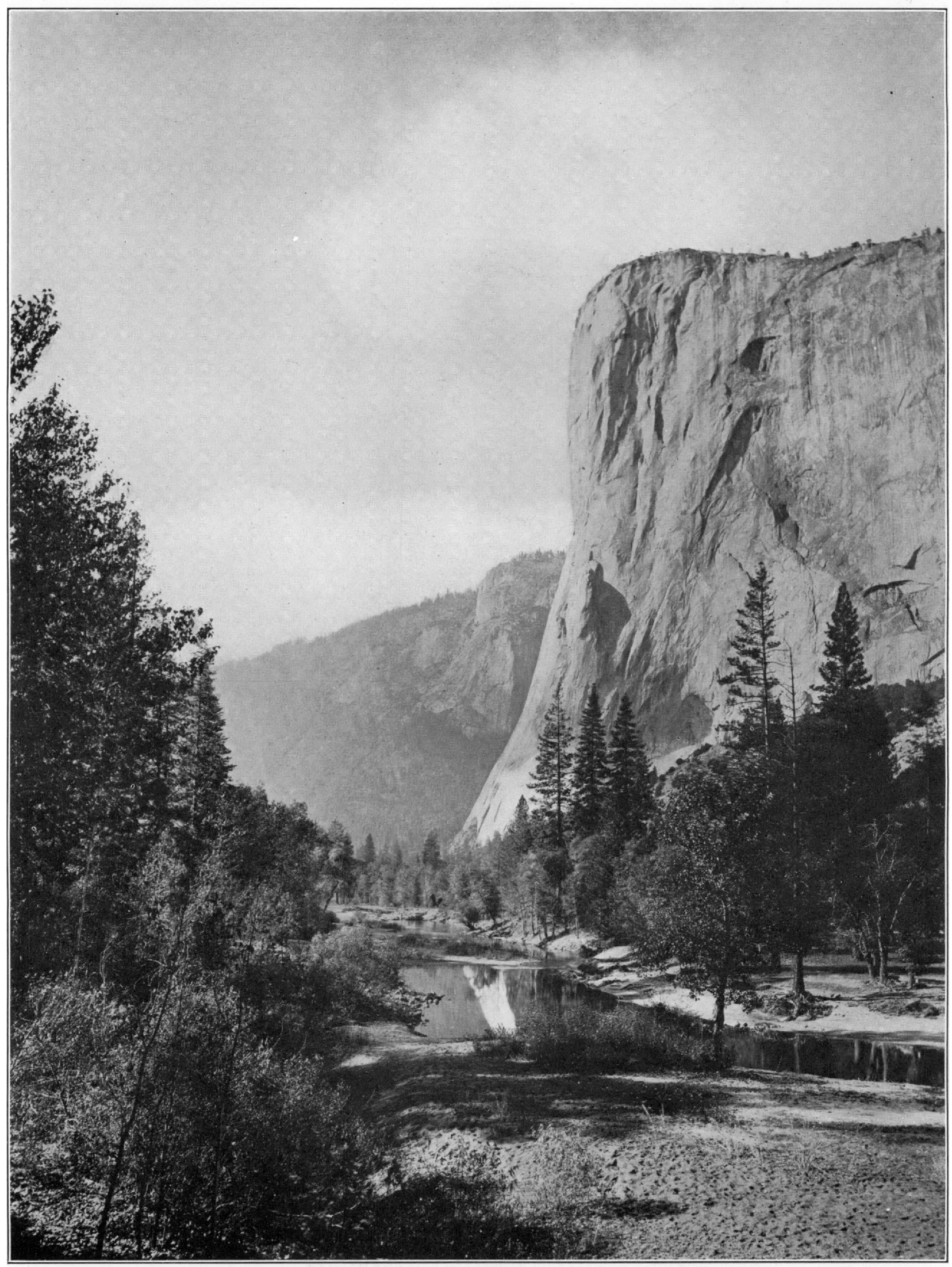

\section{eL CapITAN, FHOM THE EAS'}

The 3,000-fool cliff is the highest in the rosemite Valley and one of the highest in the world. The salient is composed throuxhout of unf ractureal, mits-

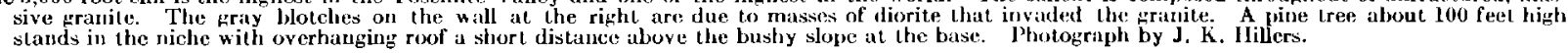




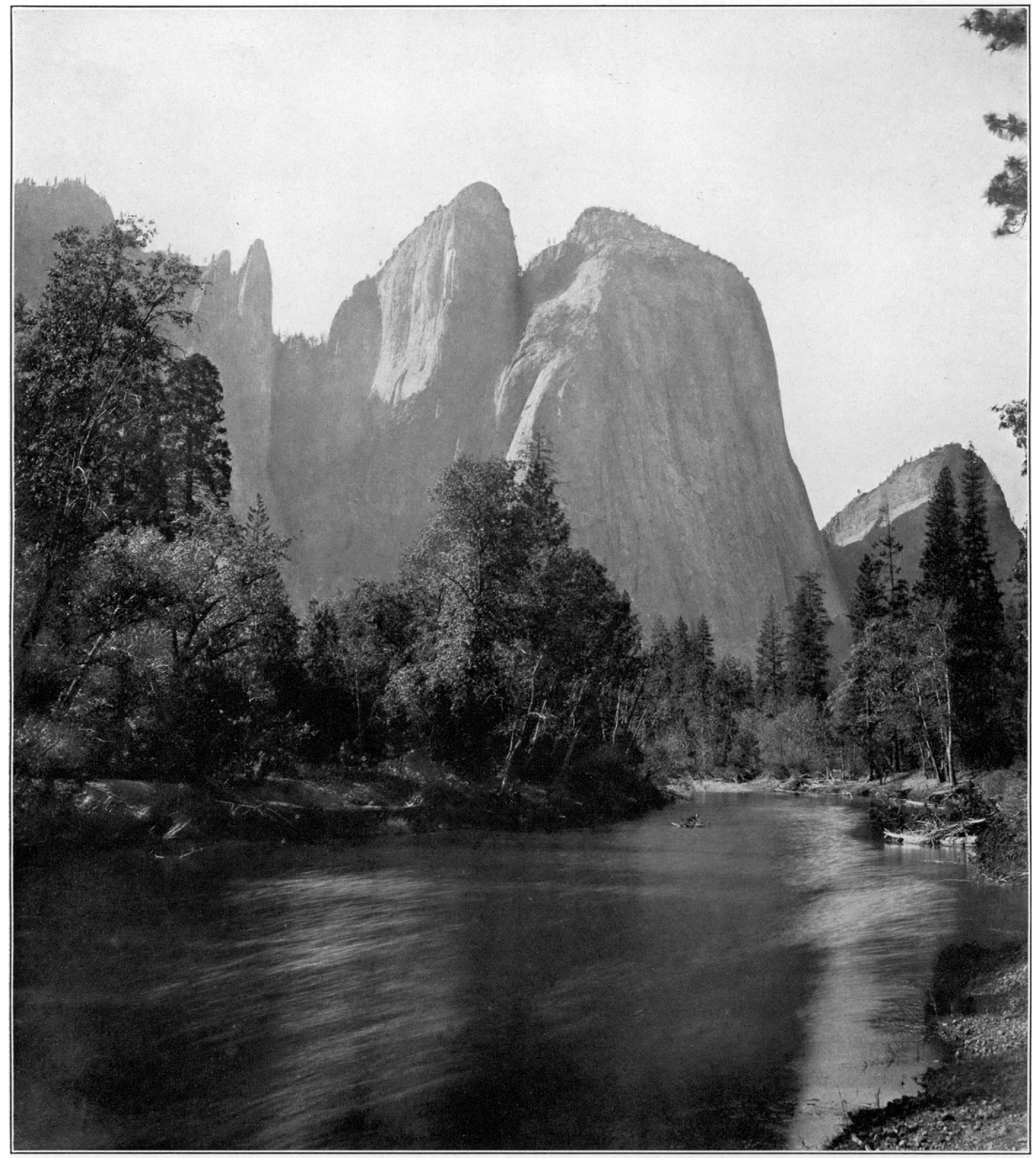

CATHEDRAL ROCKS AND CATHEDRAL SPIRES

The Calledral Hocks are among the most massive rock forns in the valley; the Cathedral Spirus arre imong the frailest. On the summits of the Cathedral Hocks lie glacial boulders which show that the ancient Yosemite Glacier once completely overwhelwed these rock masses. Pholograph by J. K. Hillers. 


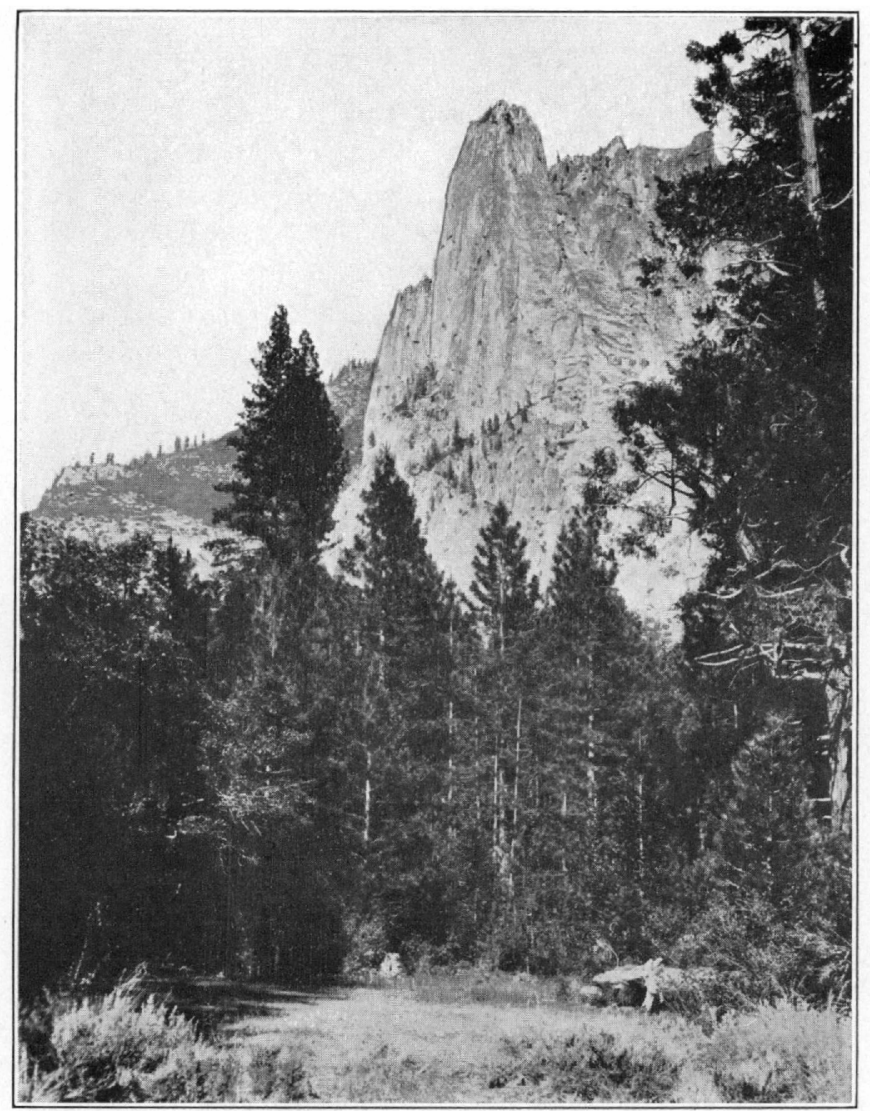

A. SENTINEI. ROCK

The smooth, sheer front of this tall shuft is delermined by nearly vertical joint rractures. Photograph by F. C. Calkins.

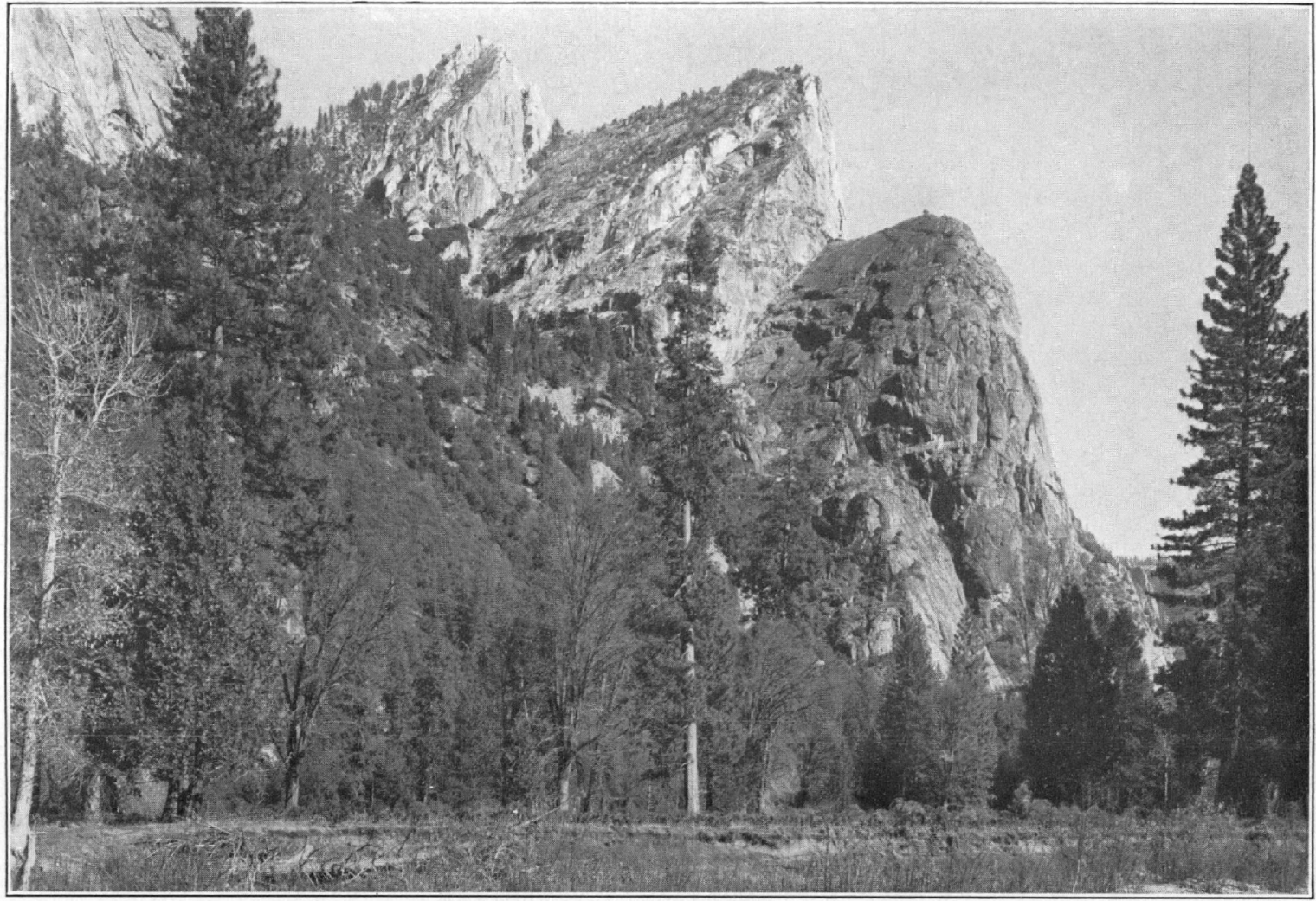

B. THE THHEE BROTHERS

This group is remarkable for its strongly asymmetric forms, which are due to the splitting of the rock along obligue master juints. Photograph by F. C. Culkins. 
clear the entire height of 1,430 feet. The water first cascades tumultuously about 70 feet through a narrow chute worn in the rock face; then, bounding out, it describes a parabolic curve through space, clearing even the bulging lower part of the cliff, which projects more than 100 feet beyond the top. Perhaps a truer conception of the height of the fall will be gained from the statement that it is about nine times as high as the Niagara Falls. The Eiffel Tower in Paris measures 987 feet, or only little over two-thirds the height of the upper Yosemite Fall. Because of the resistance offered by the air, the water in the fall deploys gradually, as it descends, into a broad curtain of lacelike spray. The more concentrated parts, however, shoot down in pointed arrowy masses, resembling comets. The tremendous force with which these water comets strike the slight projections in the cliff front and the rock basin at the foot of the fall is evident from the deafening reports. Involuntarily one looks for falling boulders in the water curtain, but in vain. Incredible it seems that a transparent fabric of mere spray, which at times is flung to one side, or is even lifted bodily by eddying breezes, should impinge so heavily. Muir ${ }^{27}$ once undertook to pass between fall and cliff on the narrow ledge that extends part way across the cliff front about 450 feet above the base - the Fern Ledge, he called itbut he was well-nigh crushed when a mass of spray swayed against the cliff, and he barely succeeded in groping out alive.

At the foot of the Yosemite Fall the waters, scattered over several acres, again collect in sheets and rivulets that converge toward a half-bowl of polished granite; and thence the stream, remade, dashes away through a narrow, winding gorge. After a boisterous descent of 815 feet it reaches the edge of a recess in the lowermost tier of cliffs and leaps down to the floor of the valley, producing the lower Yosemite Fall. (See pl. 23, C.) This fall, which is 320 feet high, also makes a clear leap at times of high water.

Another leaping fall is the Illilouette, 370 feet in height, which descends from the mouth of the hanging valley of Illilouette Creek. Ensconced in a deep gorge, it is visible from only a few directions and is relatively little known, yet it is in point of volume the largest fall made by any of the Merced's tributaries. In early summer it presents a peculiarly fascinating spectacle, as viewed from the Glacier Point Trail, because the water disappears thundering into a dark abyss of seemingly measureless depth.

The list of falling waters in the Yosemite Valley would scarcely be complete without mention of two minor falls that have each a distinctive character. The first is the Staircase Falls, situated back of Camp Curry, which tumbles, as the name implies, from successive stairlike rock steps. The total height is 1,300 feet.

${ }^{27}$ Muir, Jobn, The Yosemite, pp. ‘ $0-42,1912$.
The other is the Royal Arch Cascade, which glides rather than drops down the steeply inclined, smooth cliff face west of the Royal Arches. (See pl. 21, B.) It is a continuous ribbon of rushing, forming water 1,250 feet in height, the only representative in the valley of a special type of cascade associated with smooth walls of massive granite, of which there are many in the upper Yosemite region and the adjoining parts of the High Sierra.

The Merced Gorge below the Yosemite Valley also abounds in waterfalls. There is one at the mouth of each hanging side valley. Largest are the Cascades (pl. 23, B) at the elbow bend of the gorge, which are formed by the joint waters of Cascade Creek and Tamarack Creek. Unlike most of the major falls of the Yosemite region they are cascades in the real sense, irregularly broken in their descent. They have a total height of about 500 feet.

No part of the Yosemite region is richer in spectacular falling waters than the short stretch of the Merced Canyon that links the Little Yosemite with the main valley. The river there makes a descent of 2,000 feet in a distance of $1 \frac{1}{2}$ miles. Throughout the lower half of the canyon the river tumbles in forming cascades and rapids, but in the upper half it drops from the steps of the giant stairway, producing the Vernal and Nevada Falls. The Vernal Fall (pl. 24) has the form of a broad water curtain 317 feet high that falls from a straight, vertical cliff. It is distinguished from all other falls in the Yosemite region by the partly translucent, soft green hue of undivided water that shines through the foam at its surface. Iridescent clouds of mist rise from the pool and the rocks at the foot of the cliff and eddy about in the canyon, keeping the vegetation fresh and green. It was the suggestion of spring in the scene that inspired Doctor Bunnell ${ }^{28}$ to name this fall the Vernal. Scarcely less appropriate, however, was the Indian name Yan'o-pah ("cloud of water").

Between the Vernal and Nevada Falls the Merced makes several minor falls and cascades. Only one of these can be described here-the Silver Apron, which ends at the Emerald Pool. In the Silver Apron the water rushes with amazing speed down a gentle incline of smooth granite and spreads, unrestrained, into a broad, thin, sparkling sheet. One small obstruction occurs in the midst of the rock floor, and there the swift waters, leaping up suddenly, form an arched fountain of spray 3 to 5 feet high-a "water wheel," as it is locally termed. Sheet cascades of the Silver Apron type are not uncommon in the High Sierra. They are associated with the smooth floors of massive granite that are characteristic features of its glaciated canyons. The water wheel in the Silver Apron is but a diminutive example of the much larger

${ }^{29}$ Bunnell, L. H., Discovery of the Yosemite and the Indian war of 1851 , 4th ed., p. $209,1911$. 
fountains of this kind for which the Tuolumne River has become especially famous.

The Nevada Fall (pl. 25) is nearly twice as high as the Vernal-to be precise, it measures 594 feet-but it is far less regular in form. At the top the water issues in wild turmoil from a narrow, constraining channel and fairly flings itself out in a confused mass of downward-shooting rockets of spray. These, as they strike the sloping lower part of the cliff, are flattened out and reunited into a broad, resplendent apron. The dazzling whiteness of the fall suggested the name Nevada, which in Spanish means "snowy." By the Indians it was called Yo-wiye ("twisted fall").

The Little Yosemite receives no tributary streams of notable volume and consequently is graced by no large waterfalls; but it does possess numerous ribbon cascades similar to the Royal Arch Cascade. Most of these flow only a short time in the early summer, being fed by the snow on the forested uplands. They resemble parallel ribbons of silver filigree. Those on the Cascade Cliffs (pl. 45, $A$ ) are fully 1,500 feet in height. As they dry up they leave dark bands or stripes on the cliffs resembling somewhat the stains that disfigure the fronts of city buildings. Their inky hue is produced by minute purplish-black lichens that maintain life on the sun-heated cliffs in spite of the prolonged desiccation which they must endure every year. Longest and most spectacular are the ribbon cascades that glide down the stupendous cliff face of Clouds Rest, on the south side of Tenaya Canyon. They are fed by patches of snow that linger in the shaded recesses until midsummer. They make descents of 2,000 and even 3,000 feet.

On the north side of Tenaya Canyon, a mile above Mirror Lake, are the falls and cascades by which Snow Creek drops from its hanging valley. They have a total height of about 2,000 feet, but, being deeply ensconced in a gorge of their own cutting, they can not be viewed in their entirety from any one point and are little known to the public. Another waterfall that deserves to be better known is the Tenaya Cascade, which is situated at the head of Tenaya Canyon. It glides down a steeply inclined, marvelously smooth cliff of undivided granite and has a height of about 600 feet. It is strictly a ribbon cascade, but it is the most voluminous and most impressive of its kind; indeed, it is to be counted among the major waterfalls of the Yosemite region.

COMPARISON WITH WATERFALLS IN OTHER FARTS OF THE WORLD

Whether the Yosemite Valley possesses really the highest waterfall in the world is a question of wide interest, and a brief summary of waterfalls of notable height in other regions will thus be appropriate. The time has not yet come, however, when there can be absolute certainty as to which is the highest waterfall in existence; for even to-day the more remote mountain regions of the earth are not completely explored. The following list includes all the high falls of which definite information is at hand at the time of writing. Mile-wide cataracts produced by rivers of large volume, such as the Niagara, Victoria, or Iguazu, are omitted as being in a separate class. Only free-leaping falls are listed, cascades not being considered suitable for comparison.

Among the waterfalls in the United States is, first, the Tueeulala Fall, in the Hetch Hetchy Valley. It is, when at its best, comparable to the upper Yosemite Fall, but it has a total height estimated at about 1,000 feet and makes a clear leap of only 600 feet. The Multnomah Falls, in the gorge of the Columbia River, in Oregon, makes an essentially unbroken descent of about 700 feet. The Snoqualmie Fall, in the State of Washington, is comparable to the Vernal Fall but about 49 feet lower. The lower Yellowstone Fall measures 308 feet in height, or 9 feet less than the Vernal.

The deep fiords of the Alaskan coast are rich in falling waters, but most of these have the form of cascades. Muir ${ }^{29}$ believed that he saw in a bay of the Endicott Arm of Stephens Pass, which he referred to as Yosemite Bay, leaping falls of greater height than those of the Yosemite Valley. The topographic maps of the locality, however, give no hint of the presence of cliffs "five or six thousand feet high," and it seems probable, therefore, that Muir overestimated the height of the waterfalls, as well as of the cliffs.

Of the numerous waterfalls in British Columbia the Takakkaw Falls, in the Yoho Valley, are the best known. They make a total descent of 1,346 feet, including a partly free leap of about 900 feet. In the upper Yoho Valley are also the Twin Falls, said to be about 600 feet high. Less well known is the great leaping fall in the upper Bella Coola Valley, which, so far as can be ascertained, is 800 . possibly 1,000 feet high.

The numerous waterfalls in the Hawaiian Islands consist mostly of broken cascades. However, the Akaka Falls, above Honomu, on the island of Hawaii, make a free leap of about 400 feet; and the Hiilawe Falls, visible from Waipio Bay, leap fully 500 feet.

The Basaseachic Fall, in the Sierra Tarahumara, of Chihuahua, Mexico, makes a clear leap variously estimated at 827 to 986 feet. In the brief spring season this fall rivals the upper Yosemite in scenic splendor.

The Tequendama Fall, on the Bogotá River, Colombia, bears a resemblance to the Nevada Fall. It exceeds that fall in volume but measures about 150 feet less in height. 
The Kaieteur Fall, on the Potaro River, British Guiana, is a water curtain of the Vernal type about 740 feet in height. It is one of the highest falls produced by a river of considerable volume.

The most widely known fall of the slender Yosemite type in Europe is the Staubbach, in the valley of Lauterbrunnen, Switzerland. It is about 600 feet high and is comparable to the Bridalveil in volume.

Among the numerous waterfalls that adorn the steep-walled fiords of Norway are the celebrated Vöring Fos, which makes an almost unbroken descent of 850 feet; the Valur Fos, a more irregularly shaped fall 1,150 feet high; and the Vettis Fos, which makes an almost clear leap of 853 feet.

The falls of Gavarnie, situated in an alpine amphitheater of rare beauty on the French side of the Pyrenees, are noted as the highest waterfalls in Europe. They have a height of 1,385 feet -55 feet less than the upper Yosemite Fall-but, owing to the irregular sculpture of the cliffs, they consist, even at times of high water, mostly of broken, interlacing cascades.

The Kalambo River, which forms the boundary between northern Rhodesia and Tanganyika Territory, makes two falls, the upper of which is, so far as can be ascertained, not less than 1,200 feet in height. The volume is probably greater than that of the Merced River.

The Sharavati River, in southern India, descends from the Deccan Plateau by the Gersoppa Falls, which are estimated to be about 830 feet high. Only one of the four falls in the group, the Raja, makes an essentially clear leap.

The Wooloomumbi Fall, on a branch of the Macleay River, in New South Wales, Australia, is about 900 feet high. It not only leaps clear but shoots far out from the cliff, owing to its momentum.

Into the waters of Milford Sound, New Zealand, plunge the Stirling and Bowen Falls. The Stirling makes a fairly regular leap of 504 feet; the Bowen descends in the form of a parted curtain 550 feet in height. Both have a volume comparable to that of the Illilouette. Highest of the New Zealand falls, and among the highest in the world, are the Sutherland Falls, which drop into the canyon of the Arthur River from a typical hanging valley. They consist of a chain of three falls having a combined height of 1,904 feet. Their individual measurements are, beginning with the uppermost, 815,751 , and 338 feet. Only the lowermost makes a clear leap.

From this review it will be seen that the upper Yosemite Fall leads all the other leaping falls thus far known in height. The fact gains in significance when it is considered that the upper Yosemite is but one of a chain of falls having a total height of 2,565 feet. Few regions, besides the Yosemite, possess sheer declivities of that magnitude.

\section{SUMMARY}

To sum up this description, the outstanding features of the Yosemite Valley may be listed thus:

1. The spacious $U$ form of the valley, which stands in contrast to the prevailingly narrow $V$ shape of the Merced Canyon above and below the valley; its generally constant width, except for one constriction; and its level floor, which is disproportionately broad for the size of the Merced River.

2. The stepwise mode of ascent of the main branch canyons, which is most accentuated in the giant stairway leading up to the Little Yosemite, less strikingly so in Tenaya Canyon; and the association of a portallike constriction with each rise and a chamberlike widening with each tread-a recurrence, in other words of more or less typical yosemites at different levels, the Yosemite itself being the largest and lowest of them all.

3. The great height at which the hanging valleys on the flanking uplands terminate at the brinks; and the consequent production of numerous waterfalls; also, the notable lack of uniformity in the height of the hanging valleys, some opening thousands of feet higher than others.

4. The great depth of Tenaya Canyon, which, thougn the pathway of a small tributary stream, opens essentially at the level of the main chasm; and the relative shallowness of the Little Yosemite, which, though the pathway of the master stream, lies at a level 2,000 feet above the main chasm.

5. The prevailingly massive, simple style of sculpture of the walls; the astonishing diversity of rock forms; and the presence of sheer, straight walls, and rounded domes.

No explanation of the Yosemite's mode of origin would be complete that did not satisfactorily account for all the features enumerated and for the presence of other Yosemite-like valleys in different parts of the Sierra Nevada. The explanation that here follows is in the form, primarily, of a historical account, beginning with the earliest events connected with the origin of the Yosemite as a valley in the Sierra region and tracing its evolution step by step up to the present time. The distinctive shape of the valley and the remarkable sculpture of its walls will thus be seen to be the outcome of a long train of events, a number of processes having acted at different times, under widely differing conditions, upon an assemblage of variously structured rocks. 


\section{EARLY HISTORY OF THE YOSEMITE VALLEY}

\section{ANTIQUITY OF J'HE SIERRA NEVADA AND THE YOSEMITE} VAILEY

The story of the evolution of the Yosemite Valley is so intimately interwoven with the history of the rise of the Sierra Nevada that it can scarcely be told without reference to that larger history. Indeed, every stage in the development of the valley corresponds to a definite epoch in the growth of the range and assumes its real significance only when considered in the light of that relationship. It is but logical, therefore, to begin with a brief sketch of the history of the Sierra Nevada.

At once arises the question of the length of time involved. How far back does this history take us? Mountains are by many people supposed to stand forever, permanent and unchanging. "As old as the eternal hills" is a familiar phrase. Yet to those who study the earth nothing is more evident than that mountains have limited, measurable spans of life. They come into being by upheaval and, through the erosive action of streams, glaciers, and atmospheric agencies, are worn down by degrees, sometimes to mere hills or even to plains. The Sierra Nevada is decidedly a new range in the geologic sense, a still youthful feature of the continent. Its youth is manifest from the fact that it has not yet lost significantly in height by erosion. Though deeply furrowed by canyons, it still ranks with the highest ranges in this country and bears summits that retain in part the subdued outlines which they had acquired prior to their elevation. The Sierra Nevada has stood with its present.height and form about a million years-an astounding stretch of time compared with the few thousand years of recorded human history, yet very brief compared with the total length of geologic history, which runs into billions of years. Viewed in its proper historic perspective the Sierra Nevada is but the latest of several successive mountain ranges, or mountain systems, that have in turn occupied the same place. Each of these ancestral mountain systems must have been in existence a very long time, for each was reduced to ridges and hills of only moderate height, in part to an undulating lowland. The time required for their demolition was doubtless between $50,000,000$ and $100,000,000$ years for each system.

The major facts as to the character, structure, and history of at least two of these ancestral mountain systems are indicated by certain rock formations that are the roots, so to speak, of those earlier mountains, incorporated in the present range. And the approximate time of creation of each of these earlier mountain systems is indicated by the fossil remains that are preserved in their rocks, each geologic epoch being known by its characteristic life forms.

In the table of geologic time divisions on page 23 the outstanding events in the geologic history of the
Sierra region are set forth in chronologic order, each referred to its proper era, period, and epoch as definitely as the knowledge at hand permits. The figures for the duration of the successive time divisions are taken from the table which the late Professor Barrell ${ }^{30}$ compiled from calculations of the age of uranium minerals from different parts of the world. The age of these minerals. is computed from the ratio of lead to uranium present in them, the rate at which uranium breaks down and is reduced to lead by atomic disintegration being accurately known. The figures given are really the means of the maxima and minima of Professor Barrell's table, these means agreeing closely with the results obtained from the more refined calculations made by Holmes and Lawson. ${ }^{31}$ These measures of geologic time are much greater than those that have been current among scientists in the past, but they doubtless afford much closer approximations to the truth than the shorter measures, for they are of an order of magnitude that is consistent with many geologic facts, notably with the extremely slow rate at which mountains are worn down.

It will be seen from the table that the first of the two ancestral mountain systems of which the roots are still recognizable came into being in the Permian epoch, near the end of the Paleozoic era, more than 200,000,000 years ago. It was formed by the uplifting and folding of a great series of layers of slate, shale, and sandstone-originally mud, silt, and sand derived from a land mass lying mostly to the west of the present border of the continent and laid down in an arm of the Pacific Ocean. Folded in with these sediments, which aggregated thousands of feet in thickness, were beds of lime (calcium carbonate) deposited presumably in shallow water at times when the land was low and the streams brought down but little sand or mud.

In the long stretches of time that ensued the wrinkles in the earth's crust thus produced were in large part worn away, and finally the region again sank below the level of the sea and became a place of deposition. For millions of years new layers of mud, silt, and sand, together with beds of volcanic material, accumulated upon the submerged remnants of the first mountain system, and then, at the end of the Jurassic period, about $130,000,000$ years ago, there came another upheaval, the new strata were folded and crumpled and were invaded by molten granite from below, and there arose a second system of mountain ranges that occupied most of eastern California and large areas in adjoining States. Throughout the Cretaceous period, which followed upon the Jurassic, this second mountain system was being gradually worn down, until by the beginning of the Tertiary period only ridges of moderate height were left.

${ }^{30}$ Barrell, Joscph, Rhythms and the measurements of geologic time: Geol. Soc. America Bull., vol. 28, pp. 884-885, 1917.

31 Holmes, Arthur, and Lawson, R. W., Factors involved in the calculation of the ages of radioactive minerals: Am. Jour. Sci., 5th ser., vol. 13, p. 342, 1927. 
Sequence of mountain-building events in Sierra region

[Read from bottom up]

\begin{tabular}{|c|c|c|c|c|}
\hline Era & Period & Epoch & Nature of events & Duration in years \\
\hline \multirow{6}{*}{. } & \multirow[b]{2}{*}{ Quaternary. } & Recent. & Postglacial time. Return to normal climatic conditions. & 20,000 \\
\hline & & Pleistocene. & $\begin{array}{l}\text { The great ice age. The higher parts of the range are repeatedly } \\
\text { mantled by glaciers. } \\
\text { Renewed vigorous tilting, accompanied by strong faulting movements }\end{array}$ & $1,000,000$ \\
\hline & \multirow{4}{*}{ Tertiary. } & Pliocene. & $\begin{array}{l}\text { as a lofty block range with steep eastern front. } \\
\text { Period of relative stability. Occasional minor crustal movements } \\
\text { and volcanic outbreaks. } \\
\text { The region is tilted to the west and assumes mountainous height at its }\end{array}$ & $7,000,000$ \\
\hline & & Miocene. & $\begin{array}{l}\text { Volcanic eruptions begin anew, and the northern half of the region is } \\
\text { covered by successive flows of andesitic lava and mud.. } \\
\text { Prolonged interval marked by minor warpings of the earth's crust, up }\end{array}$ & $12,000,000$ \\
\hline & & Oligocene. & $\begin{array}{l}\text { rhyolitic materials are mostly worn away. } \\
\text { The region, together with the country to the east of it, is slowly up- } \\
\text { warped to moderate heights. Volcanoes burst forth in the northern }\end{array}$ & $16,000,000$ \\
\hline & & Eocene. & $\begin{array}{l}\text { ash. } \\
\text { The mountain ranges are worn down gradually and the region as a }\end{array}$ & $23,000,000$ \\
\hline \multirow{3}{*}{ 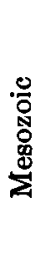 } & Cretaceous. & & $\begin{array}{l}\text { and the granite is uncovered over large areas. } \\
\text { The new sediments, together with remnants of the old, are folded and }\end{array}$ & $75,000,000$ \\
\hline & Jurassic. & & $\begin{array}{l}\text { Molten granite invades the folds from below. } \\
\text { More sediments are laid down as the sea bottom progressively sinks. }\end{array}$ & $40,000,000$ \\
\hline & Triassic. & & $\begin{array}{l}\text { The mountains are slowly worn down to hills. The land finally } \\
\text { sinks below the sea and new sediments are deposited. }\end{array}$ & $40,000,000$ \\
\hline \multirow{6}{*}{. } & \multirow{2}{*}{ Carboniferous. } & Permian. & $\begin{array}{l}\text { The sediments are uplifted and folded into the form of mountain } \\
\text { ranges. }\end{array}$ & \multirow{8}{*}{$415,000,000$} \\
\hline & & $\begin{array}{l}\text { Pennsylvanian. } \\
\text { Mississippian. }\end{array}$ & \multirow{5}{*}{$\begin{array}{l}\text { Sediments, mainly outwash from the continent, accumulate to thick- } \\
\text { nesses of thousands of feet on the floor of the Pacific Orean. }\end{array}$} & \\
\hline & Devonian. & & & \\
\hline & Silurian. & & & \\
\hline & Ordovician. & & & \\
\hline & Cambrian. & & & \\
\hline \multirow{2}{*}{ 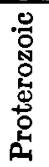 } & Algonkian. & & \multirow{2}{*}{ Nothing definite known. } & \\
\hline & Archean. & & & \\
\hline
\end{tabular}

The present Sierra Nevada was not formed until a long time thereafter. It assumed its present height and form about the dawn of the Quaternary period; but throughout most of the Tertiary period, especially in the later half, the region was the scene of repeated disturbances and minor mountain-building movements that finally led up to the culminating uplift. It is with these preliminary happenings in the Tertiary period, which may be traced back with some confidence fully 20,000,000 years, that the history of the Sierra Nevada properly begins, for it was in consequence of those happenings that many features which are now part and parcel of the physiognomy of the range were developed-among others the Yosemite upland, the parallel crests of the High Sierra, and the course of the Merced River, including that part in which the Yosemite Valley was finally elaborated.

It will be helpful to the reader pursuing this story to have at the outset some insight into the structure and general make-up of the Sierra Nevada, and accordingly these will first be explained. 
THE SIERRA BLOCK

\section{GENERAL CHARACTER AND OUTLINES}

Most mountain ranges are carved from great wrinkles or wavelike folds in the outer crust of the earth, produced by the buckling of originally flatlying strata. Both of the ancient mountain systems that formerly occupied the site of the Sierra Nevada were of that folded type, but the present range consists essentially of a single massive block of the earth's crust that has been dislocated and tilted toward the southwest, apparently without suffering any appreciable bending or warping. (See fig. 1.) The Sierra Nevada is therefore properly termed a "block range."

Even to the first geologists who explored the Sierra Nevada and the adjoining regions the real nature of its structure was apparent from its very shape and outlines. The long linear crest suggested the raised
This great dislocation at the eastern base of the Sierra Nevada is not to be regarded as an isolated phenomenon. Most of the mountain ranges that traverse the Great Basin, that semiarid province that extends from the Sierra Nevada eastward to the Wasatch Range, in Utah, are bounded by somewhat similar dislocations. Instead of buckling and wrinkling, this province apparently was broken into huge blocks, some of which now stand high in the form of mountains, the others having sunk, relatively, so as to form intermediate desert basins. The Sierra Nevada, accordingly, is but one - the westernmostof a vast assemblage of more or less closely related block ranges. It is, however, far and away the longest and highest of them all; it is one of the greatest block ranges in the world.

It might be inferred from the perhaps too simple diagram in Figure 1 that a single clean-cut master

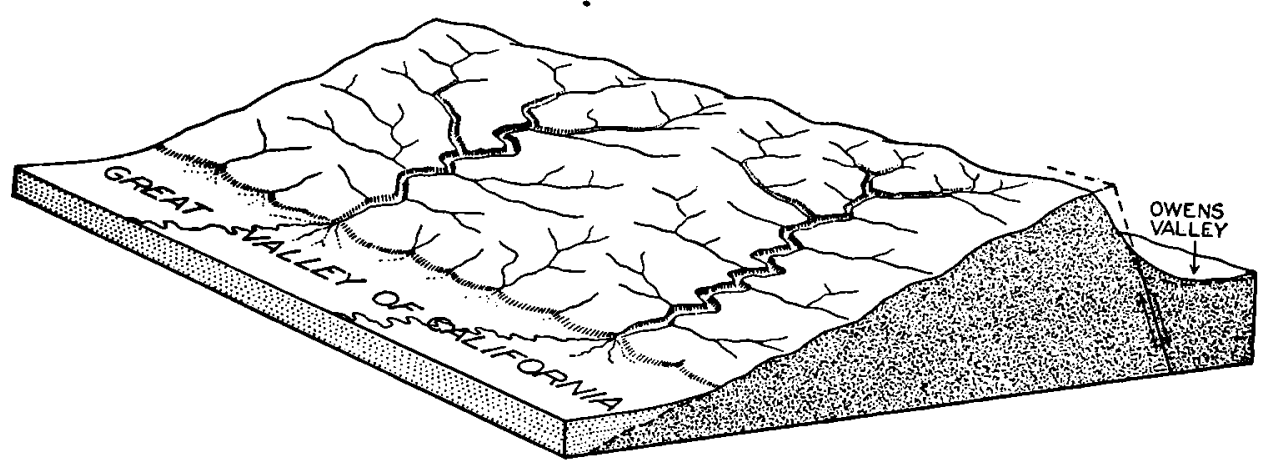

Figdre 1.-Generalized diagram of part of tilted Sierra block. The great fault fractures that separate the Sierra block from the Owens Valley block, on the east, are shown by a single line, and the relative directions in which the two blocks have sheared past each other are indicated by arrows. The height and slant of the Sierra block are much exaggerated. The streams are shown in their characteristic arrangement, the main rivers flowing down the western slope but many of their tributaries in directions approximately at right angles to them. No speciflc streams are represented. In front is a strip of the Great Valley of California, whose thick layers of sand and silt, derived from the elevated part of the Sierra block, bury the sunken part. At the back is a strip of Owens Valley, veneered with a thinner layer of sediment

eastern edge of the block; the abrupt eastern escarpment, the side of the block exposed to view by the uptilting; and the gentle western slope, down which the main rivers flow, the slanting upper surface. The essential correctness of this early interpretation has been abundantly confirmed by later observers, who have collected considerable evidence, direct and indirect, showing that great master fractures extend along the eastern base of the range and around its curving southern part, and that on these master fractures the earth's crust has been dislocated, the Sierra block rising, and the block adjoining it on the east sinking, relative to each other, in the manner indicated by the arrows in Figure 1.

The shearing of two earth blocks one past the other in this manner is termed "faulting," and the fractures at the eastern base of the range are therefore properly speaking "faults." The magnitude of the displacement-the "throw"-may be inferred from the great height of the eastern escarpment: it reaches a maximum of not less than 8,000 feet in the vicinity of Owens Lake. (See pl. 5, C.) fracture extends continuously all along the eastern margin of the Sierra block, but that is far from being true. Along the great escarpment that faces Owens Valley, in the southern half, there may be actually a single fault, or a set of closely spaced parallel faults, but farther north the successive offsets in the front of the range indicate the existence of discontinuous northward-trending fractures that replace one another at intervals, thereby splintering the northwestwardtrending margin of the block on a large scale. From the neighborhood of Lake Tahoe, which itself lies in a trough produced by the subsidence of a great splinter, long lines of faulting diverge in northerly directions, each marked by an escarpment of its own. Northward the eastern margin of the Sierra block becomes progressively more irregular, the displacements being distributed over a belt that broadens gradually to a maximum of 50 miles. Some of the escarpments measure but a few hundred feet in height, and the highest do not exceed 2,000 feet.

The causes of the uptilting of the Sierra block and of the down faulting of the valley blocks adjoining. 
it on the east-indeed, the causes of the comprehensive upwarpings and complex faulting movements that have affected the whole of the Great Basinare not yet fully understood. It seems probable, however, that they were primarily deep seated and only secondarily attributable to processes active at the surface of the earth, such as the erosion of valleys in some places and the deposition of the eroded materials in other places. The gradual lightening of mountain areas by the removal of rock waste and the concomitant loading of plains and ocean basins with the rock waste have doubtless acted at times as contributory causes, but such transfer of materials, constituting relatively a mere film of slight density at the surface of the globe, could scarcely have sufficed to initiate the upbulging and fracturing into blocks of a province comprising several hundred thousand square miles. In any event, a block such as that of which the Sierra Nevada is composed must have a tremendous depth, and the main fractures that bound it must reach far down into the earth, to depths where
The outstanding fact regarding this granitic batholith is that it is now exposed at the surface of the block over large areas, despite its deep-seated origin. One treads on granitic rocks of one kind or another almost everywhere in the Yosemite region and the adjoining parts of the High Sierra. Most of the prominent peaks, domes, and cliffs-indeed, nearly all the noteworthy sculptural features of these regions-are carved from such rocks. Yet it is clear from their crystalline structure that these igneous materials did not flow out upon the surface but cooled very slowly, under the pressure of a confining crust or roof of other rocks. The explanation is, of course, that they have become uncovered-that they now appear at the surface because the roof under which they crystallized has been in large part removed. The slate, quartzite, and limestone mentioned are, in fact, the materials of which the ancient roof was made, as is manifest from the position of the remnants of those formations on the granite, and from the fact that the fissures and cracks in them are deeply penetrated by the granite, which

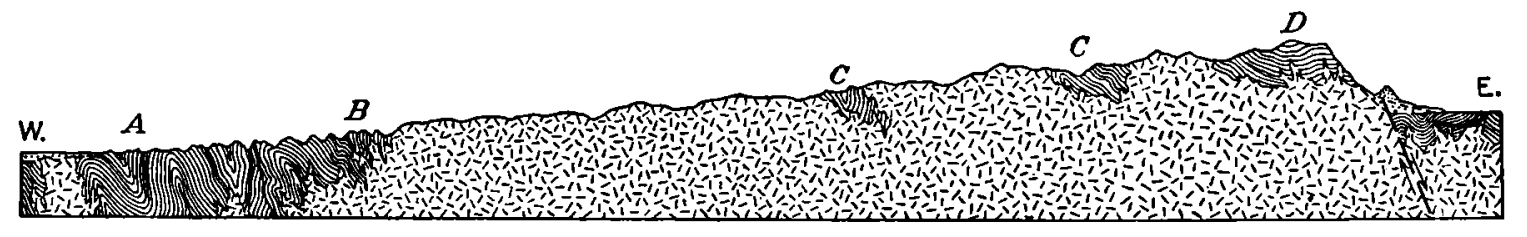

Figure 2.-Idealized cross section of Sierra block, showing the composition of its interior. The folded beds in the foothill belt ( $A-B$ ), at different points on the western slope of the range $(C-C)$, and on its crest $(D)$ are the remnants of a formerly continuous roof of mostly sedimentary rocks, under which the granitic materials welled up in a molten state. They are the roots, so to speak, of the mountain systems that occupied the place of the present range in times long past

the materials have relatively great density and require correspondingly powerful forces to displace them.

\section{INTERNAL STRUCTURE}

Of what manner of rock materials is this huge earth block constituting the Sierra Nevada built up? As will be apparent from the cross section in Figure 2, the block is composed largely of granitic rocks. Only on the lower part of its western slope and in some places on its crest are there considerable bodies of other rocks, such as slate, quartzite, limestone, and lava.

The granitic rocks all are of igneous origin; they are materials that have welled up from the depths of the earth in a molten state and have crystallized as they cooled. In the Sierra block there are present many different types, each formed by a separate uprising of molten material and each having a distinctive chemical and mineral composition. Thus there are different granites, monzonites, granodiorites, diorites, and gabbros (see appendix), but in this preliminary sketch those distinctions need not be considered, and it will be convenient, though not wholly accurate, to refer to all the granitic rocks collectively as granite. Together they form a great complex mass-what is termed a "batholith" (a mass that stopped in its rise at a considerable depth below the surface). was formerly fluid. The old roof rocks were originally thousands of feet thick, but in the course of ages, through the continued attacks of atmospheric agents and especially of surface streams, they have been gradually worn away.

It is in the remnants of this ancient rock roof that are to be recognized what have been termed the "roots" of the earlier mountain systems. For that reason they are here of more than passing interest. The largest mass extends along the western foothills and the lower slope of the range, as far up as El Portal, attaining there a breadth of 30 miles. Across this belt the Merced River has cut its canyon, thereby revealing to the traveler following the Yosemite Railroad or the State highway a section of its structure several thousand feet in depth. The mass is seen to be composed almost wholly of upturned beds of slate, quartzite, and marble, inclined $80^{\circ}$ or more toward the east (pl. 26, B) and trending generally northwestward, roughly parallel to the crest line of the range. The slate, quartzite, and marble are really shale, sandstone, and limestone, or, to go back to their ultimate origin, mud, sand, and lime, that have been indurated and metamorphosed by pressure and heat, as the beds were folded and squeezed together and baked by the neighboring masses of molten granite. Intercalated with them are ancient lavas-surface flows of earlier geologic times-that 
have been metamorphosed out of all semblance to their former selves. Cutting northwestward through the belt of metamorphic rocks, finally, is a group of gold-bearing quartz veins-the famous Mother Lode, which was the lure of fortune hunters in the "days of ' 49. ."

That these upturned beds of the lower Sierra slope represent the remnants of a series of closely compressed folds, or wrinkles, there can be not the slightest doubt, although the precise number of folds is difficult to determine, as the beds stand nearly parallel to one another and show little curvature over considerable distances; also because the slates, which predominate, are much alike in appearance, and beds of striking individuality, by the repetition of which one might identify opposite sides of a fold, are scarce.

Strongly bent, folded, even closely crumpled strata are not, however, wholly lacking in the Merced Canyon. A short distance above the mouth of Ned Gulch, for instance, the river cuts across a series of thin beds of chert (originally siliceous sea-bottom ooze) and shale, alternating with each other, that are compressed into astonishingly intricate, labyrinthine wrinkles. On the scoured and polished rocks in the river bed these wrinkles form prominent figures. (See pl. 26, C.)

In the granitic areas above the lower Sierra slope small bodies and individual slabs of metamorphic rock occur isolated here and there. A few are to be seen in the Yosemite region. For instance, on the slope east of Sentinel Dome, at an altitude of about 7,650 feet, a large slab of dark-gray schist (metamorphic shale) lies embedded in the granodiorite. The trail that leads from Glacier Point to the dome passes directly over it. Again, at the side of the Glacier Point Short Trail, a few hundred feet below Union Point, there are several slabs of light-gray schist and quartzite, and a quarter of a mile east of the main branch of Indian Creek, at an altitude of 7,900 feet, there is a knob composed entirely of rusty quartzite. On the north spur of Mount Clark is a body of dark mica schist and yellowish quartzite. The quartzite is of peculiar interest in that it is exceptionally resistant to decay, so that boulders of it, transported by ancient glaciers, still remain here and there as surviving witnesses of early glaciation, the other ice-borne débris that was associated with them having long since disintegrated and disappeared. A boulder of this quartzite lies on the summit of Liberty Cap.

Larger masses of metamorphic rocks, including white marble, occur near May Lake, at the southeastern base of Mount Hoffmann, and also in the rugged headwater basin of Yosemite Creek on the north side of that peak. The great depth below the neighboring granitic peaks at which these remnants of sedimentary rock occur is truly astonishing, but it is to be borne in mind that the ancient roof over the granite was strongly corrugated, having deep downfolds as well as high upfolds. Be- sides, its under surface must have been ragged in places, for doubtless many masses of rock, large and small, were torn loose from it and engulfed in the rising flood of molten granitic "magma," and others were left partly detached, or dangling, so to speak. Bodies of the latter kind have been aptly termed "roof pendants." The enormous size of some of them is strikingly attested by extensive and deep-lying masses of metamorphic rocks in different parts of the Sierra Nevada.

A spectacular and convincing example of a roof pendant that hung down to a great depth in the granitic magma is visible in the craggy spur that projects from the steep west side of Tuolumne Peak. This spur is composed of dark-hued sedimentary rocks, the contorted and broken strata of which dip steeply, immediately contiguous to the granitic mass of the peak itself. They reach down as far as they are in view, a full 2,000 feet, and doubtless continue some distance farther down.

An attempt has been made in Figure 2 to represent the roof pendants and other irregularities of the under side of the roof that once extended over the granitic rocks. Possibly their raggedness will seem exaggerated, yet the observed facts fully justify the representation.

Next to the broad belt on the lower slope of the Sierra Nevada, already described, the masses of metamorphic rocks situated near the crest of the range are the most extensive. They make up the bulk of Mount Dana, Mount Gibbs, and Parker Peak, as well as of that jumble of mountains north of Tioga Pass, whose central summit is Mount Warren. These mountains, in consequence of their composition, are variously tinted in subdued yellows, browns, reds, and purples and by contrast with the pale-gray peaks of granite near by appear somber, as if overcast by perpetual shadows. The metamorphic rocks in this crest region, however, differ appreciably in character as well as in structure from those in the lower belt. There is but little slate among them, schist, quartzite, and volcanic rocks being predominant; and the folding is less deep and less complex. These facts are readily observed on and about Mount Dana, which is capped by gently flexed beds of volcanic origin.

The age of the metamorphic rocks of the Sierra Nevada is not easily determined, owing to the dearth of fossil remains in them. However, a few fossils have been found in different parts of the range, notably in the limestone and sandstone of the lower belt, and from these it has been established that the strata composing that belt, though much alike in general aspect, fall into two distinct series, one of which is vastly older than the other. The older, known as the Calaveras formation, is of Paleozoic (Carboniferous) age; the younger, known as the Mariposa formation, is of Mesozoic (Jurassic) age. The older rocks make up approximately the eastern half of the belt, extending 
U. S. GROLOGICAL SURYH

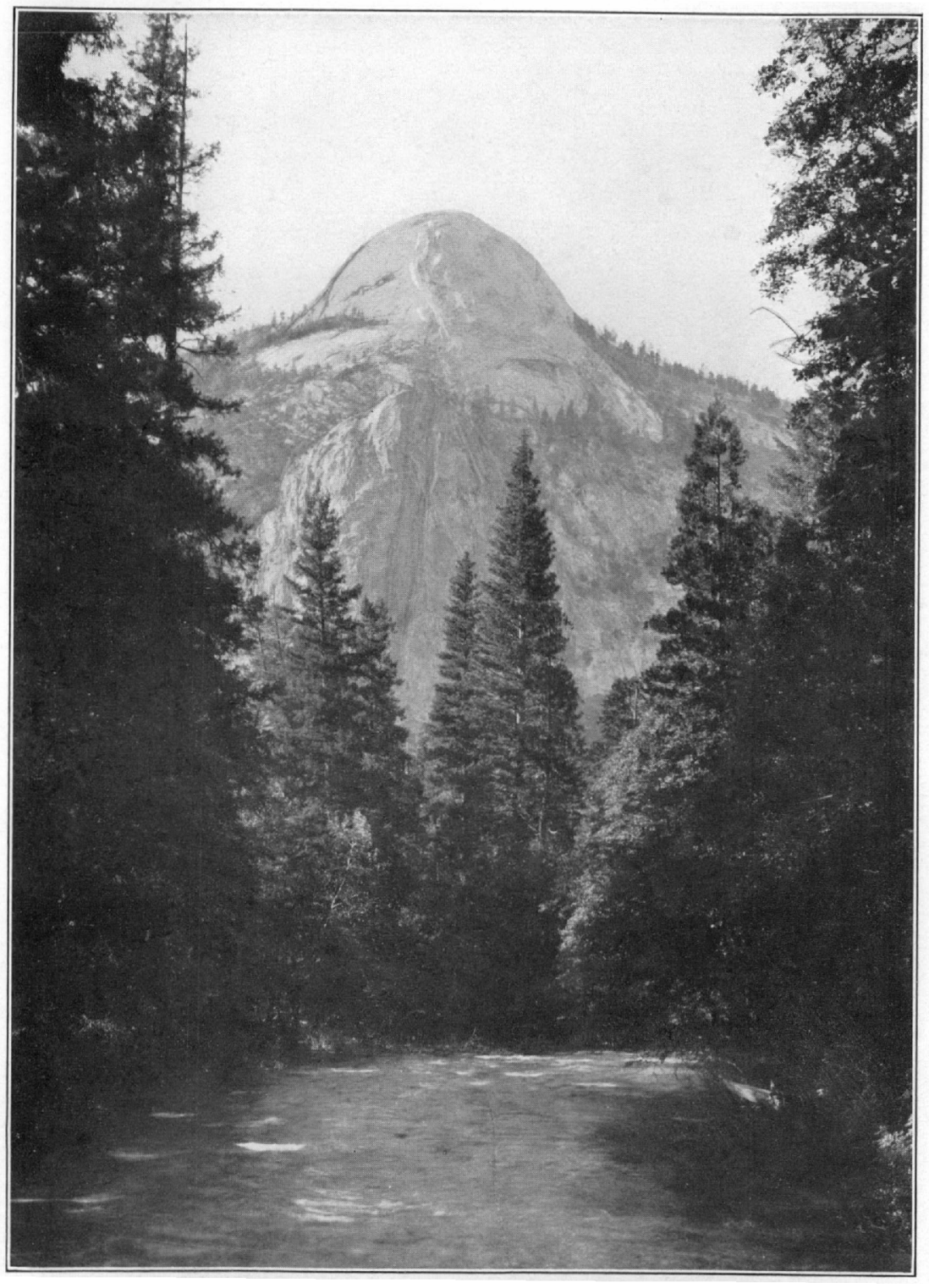

A. NORTII DOML, FROM MERCIED RIYLH NEAH HAP'Y ISLES

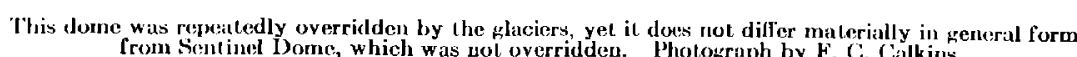

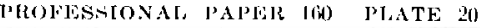

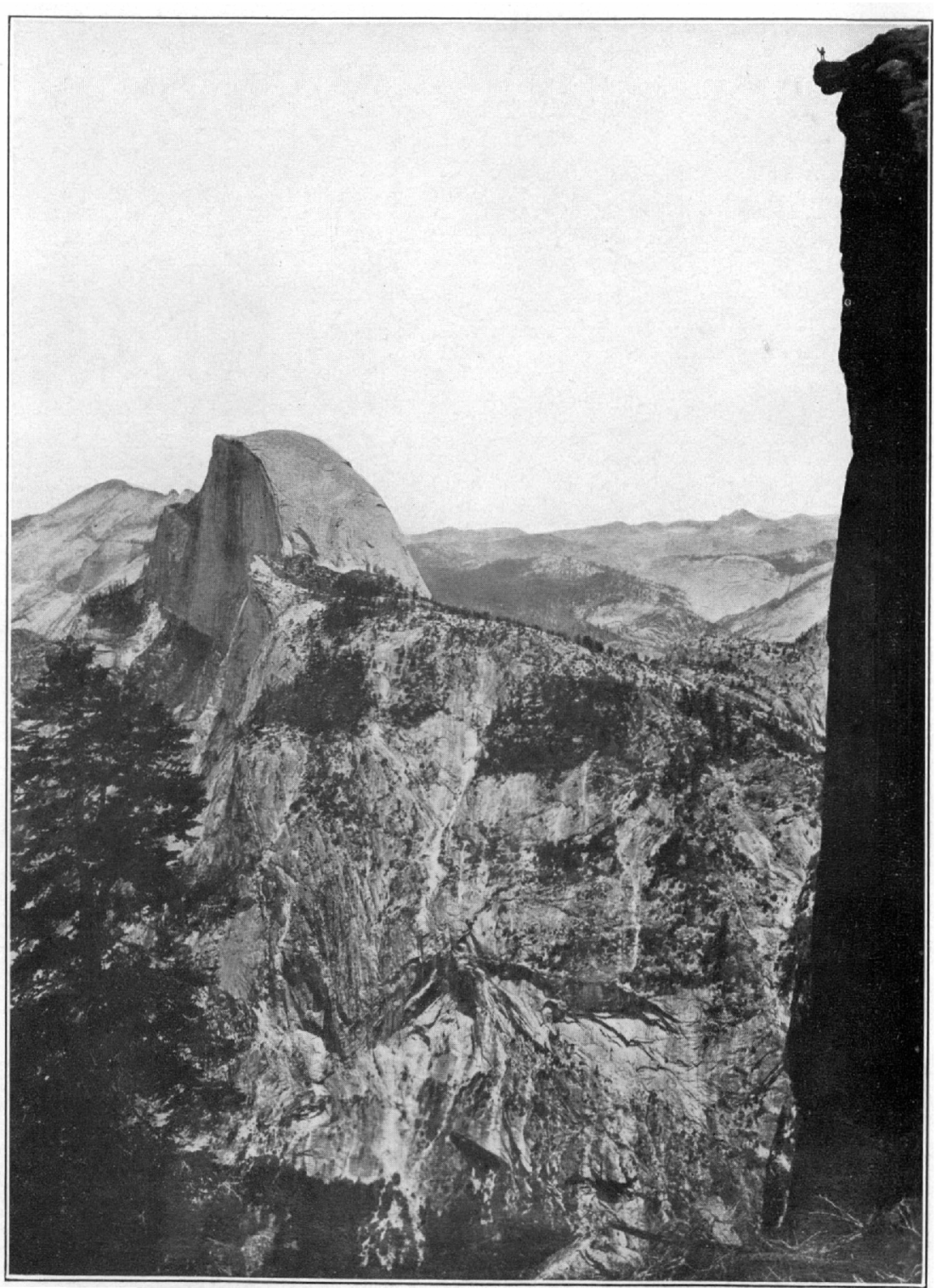

B. SILHOUETTE IPROFLLE OF CLIFF AT GLACIEK POIN'T

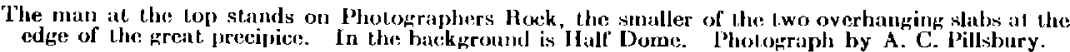




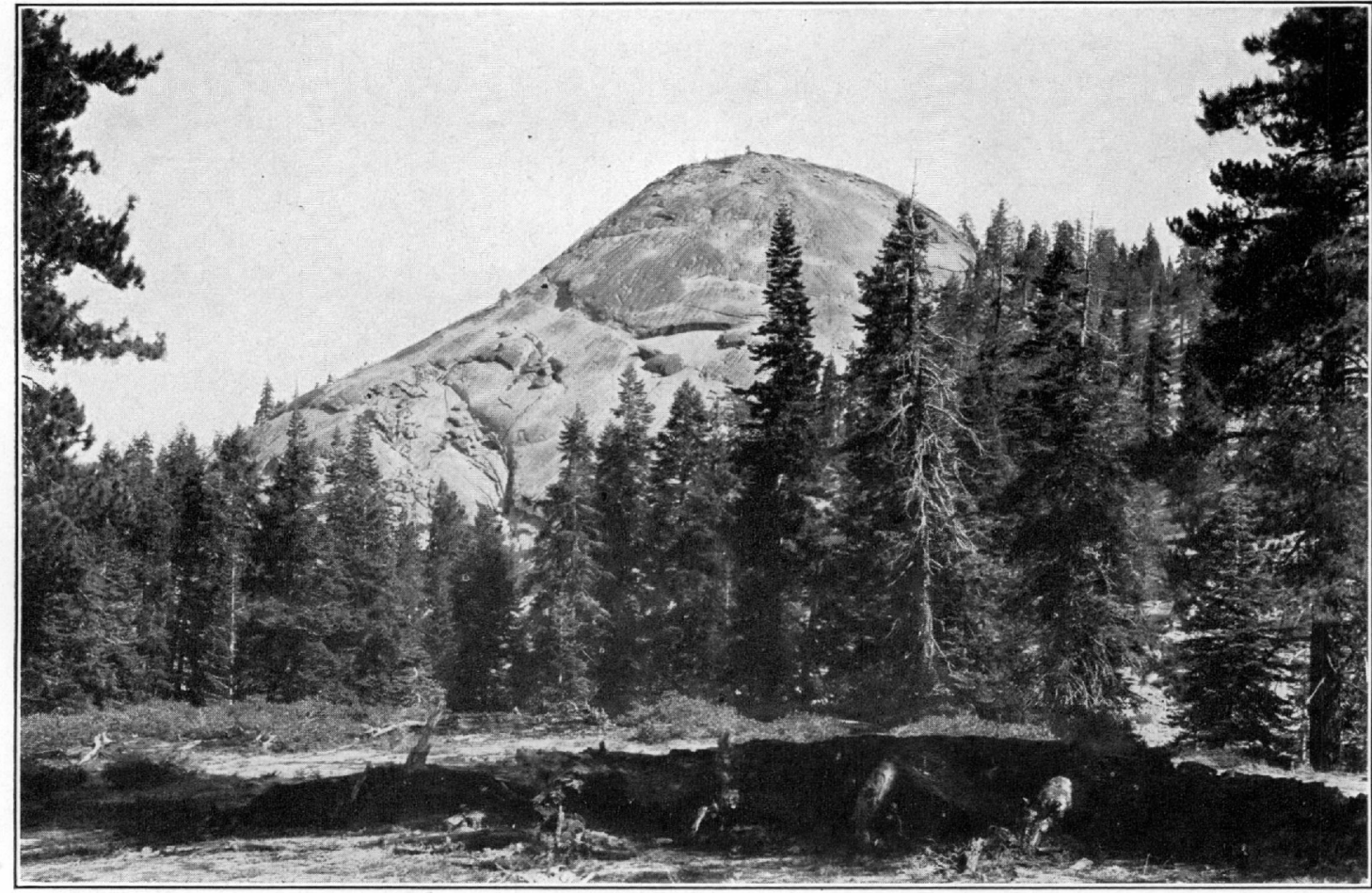

1. SENTINEL DOML: A typical dome of massive granite that owes its rounded form whelly to expoliation the casting off of succesive shells. It has not

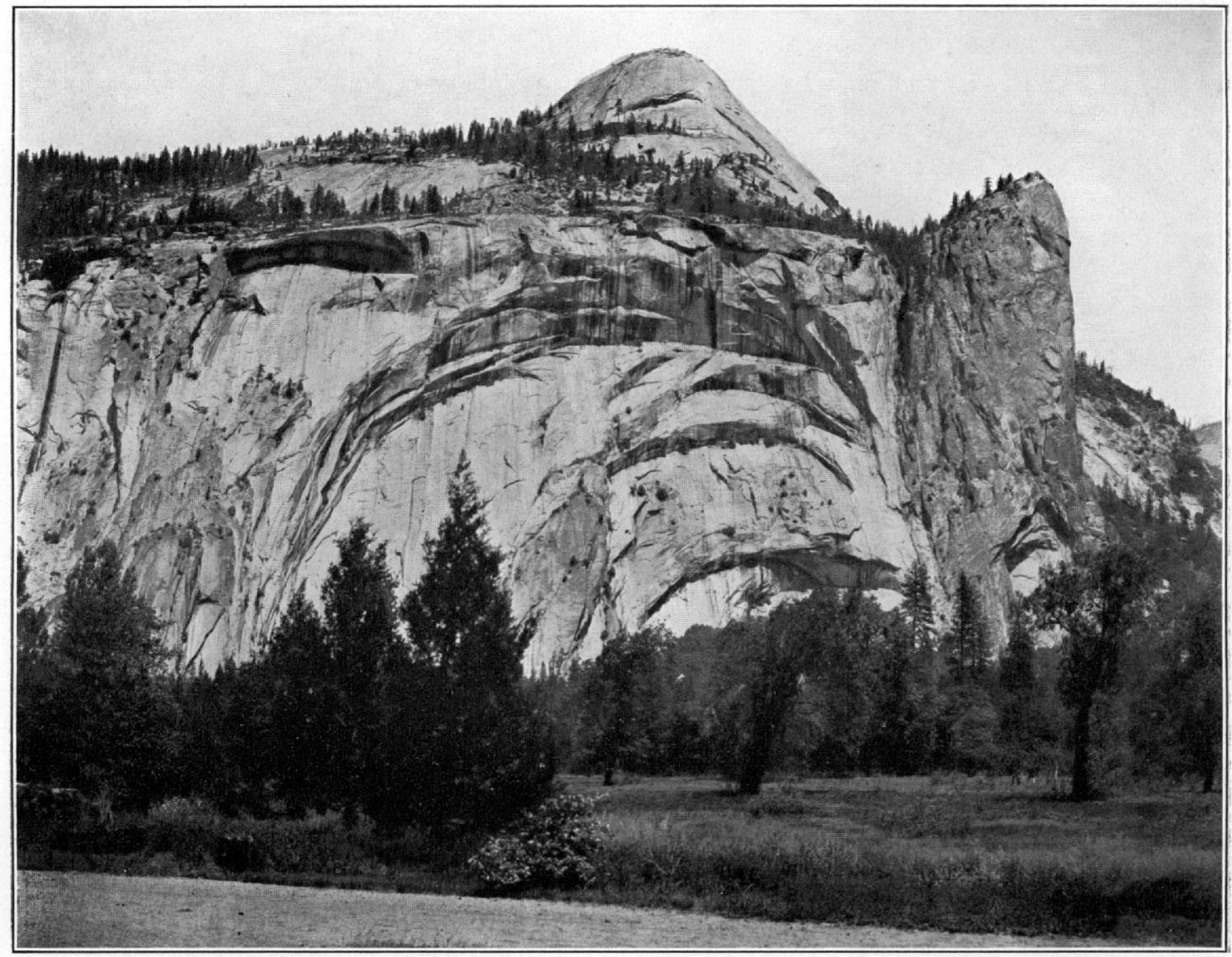

B. THE ROYAL ARCHES AND THE WASHINGTON COLUMN SURMOUNTED BY NORTH DOME

The Hoyal Arches are sculptured in a stanting clit face 1,500 feet high. Yorth Dome rises 2,000 feet higher. The dark streak on the cliff at the left indicates the path of the little Hoyal Arch Cascade. 


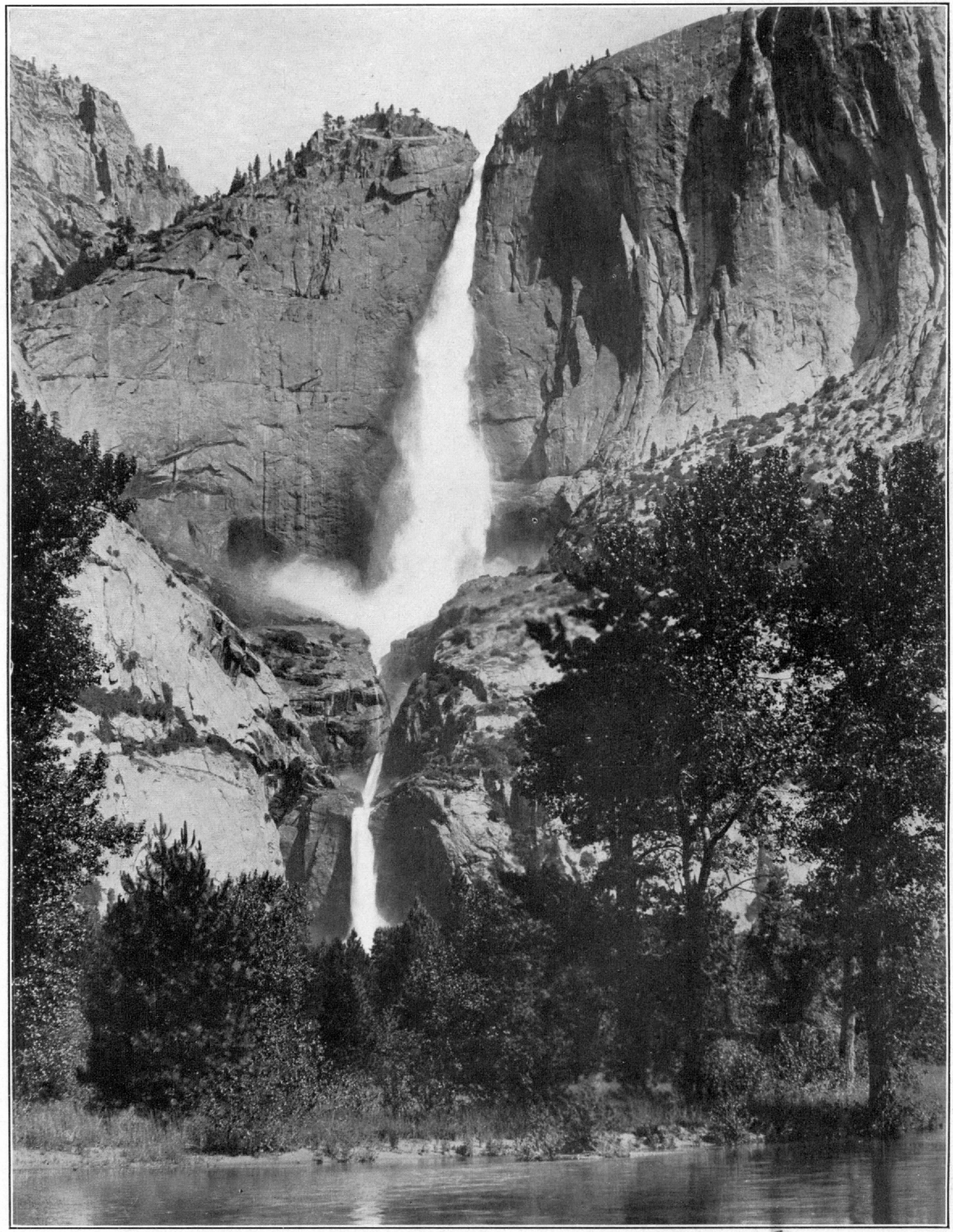

THE YOSEMITE FALLS, FHOM THE MEHCED RIVER

The upper fall, $1,430 \mathrm{feet}$ in height, is probably the highest leaping waterfall in the world. The lower full, 320 feet iu heighl, is twice as hiph as the Niagara Falls. The total height of the two falls and the intermediate cascade is 2,565 feet. To the right of the upper fall, partly detached from the cliff, is the pinnacle kuown as the Lost Arrow, about 1,500 feet in height. Pholograph by A. C. Pillsbury, 
U. S. GEOLORI'AL, SUIRVEY

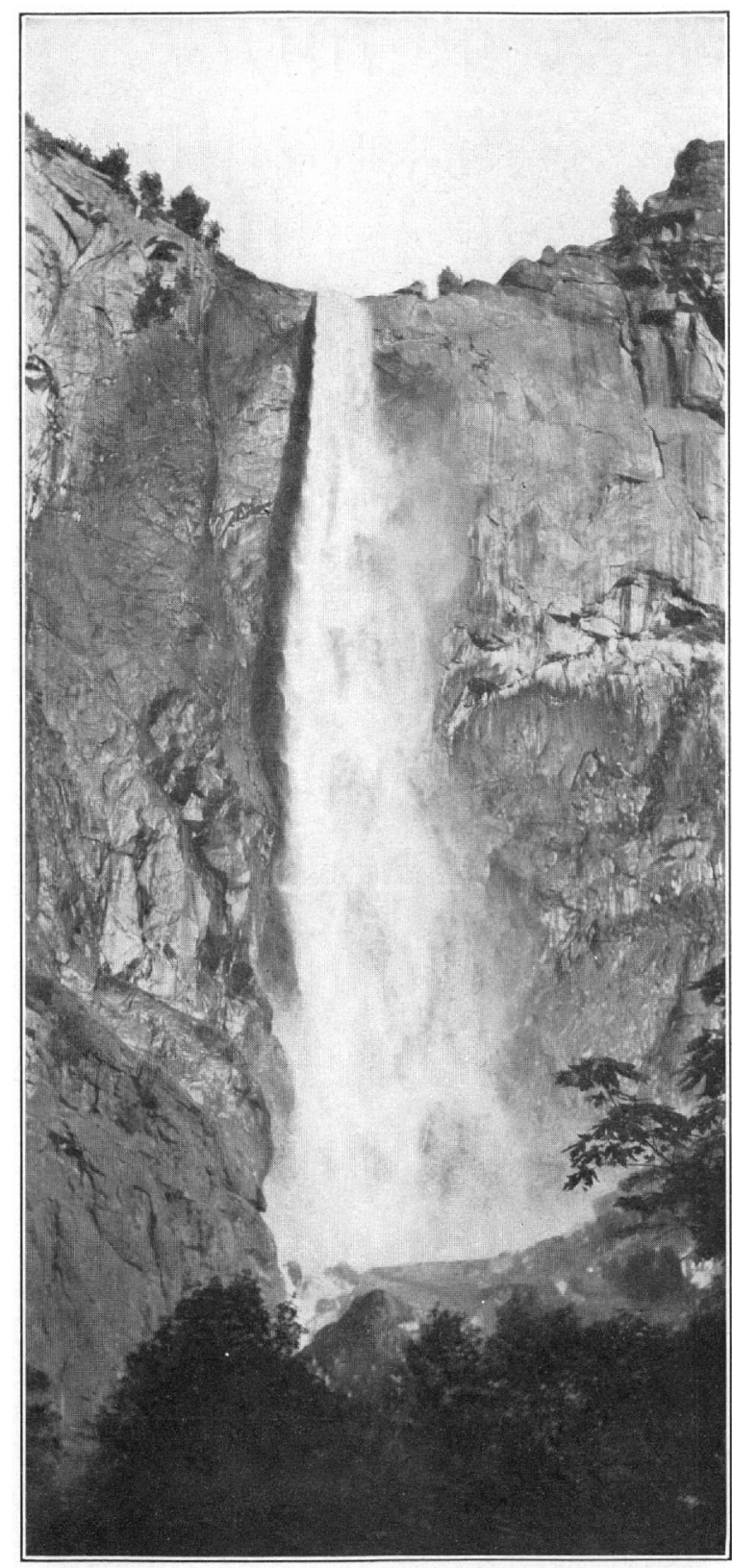

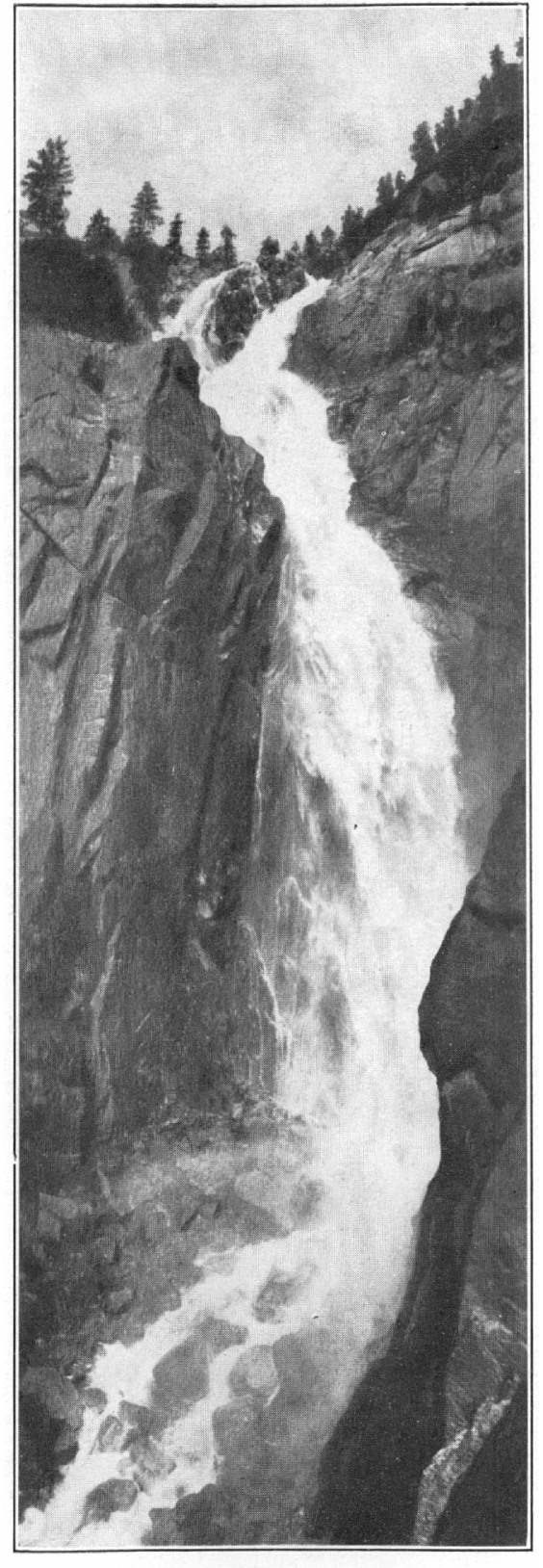

$B$
PROFESSIONAL PAPER 160 PLATE 23

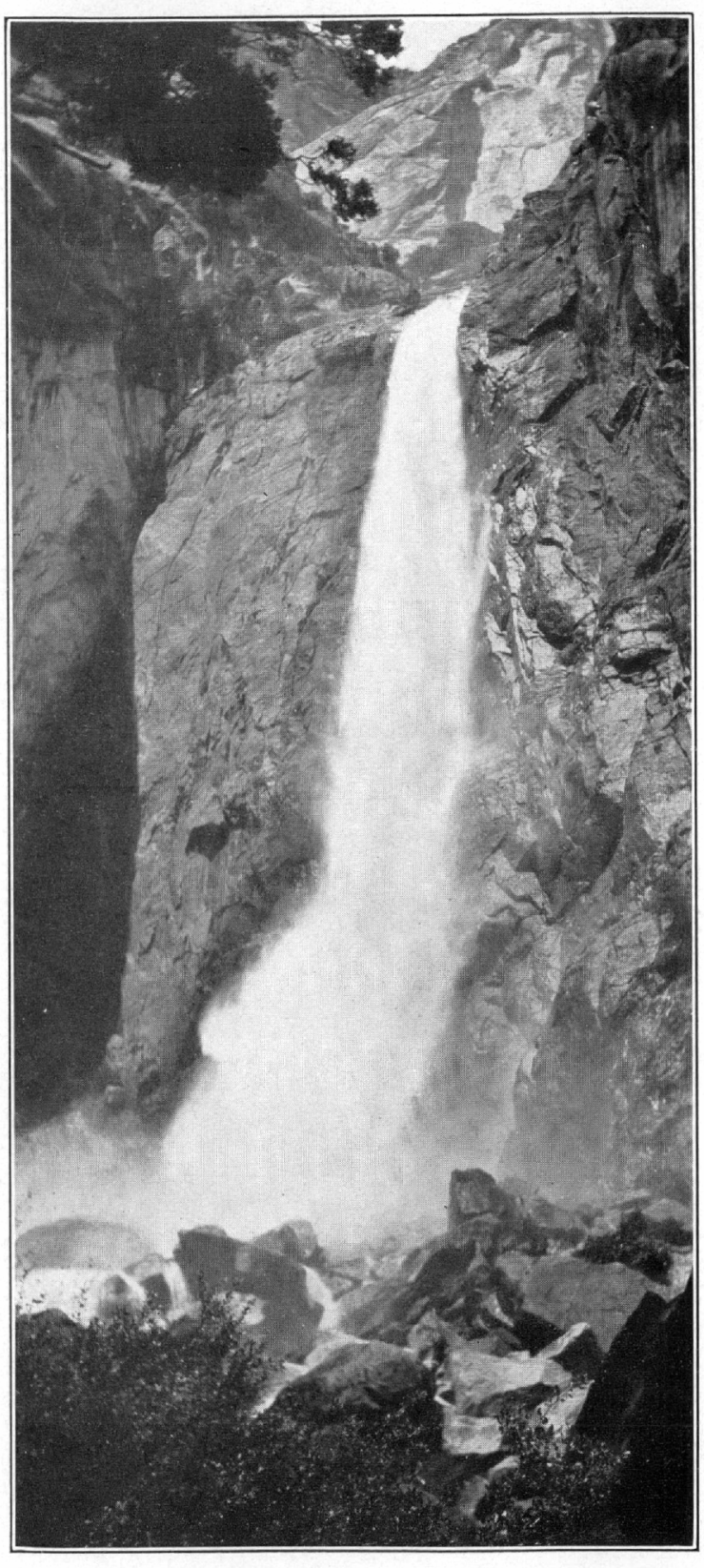

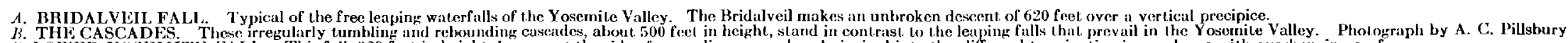

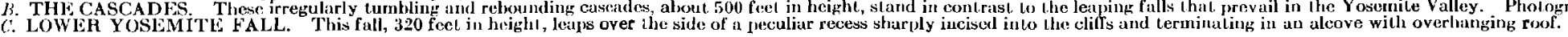




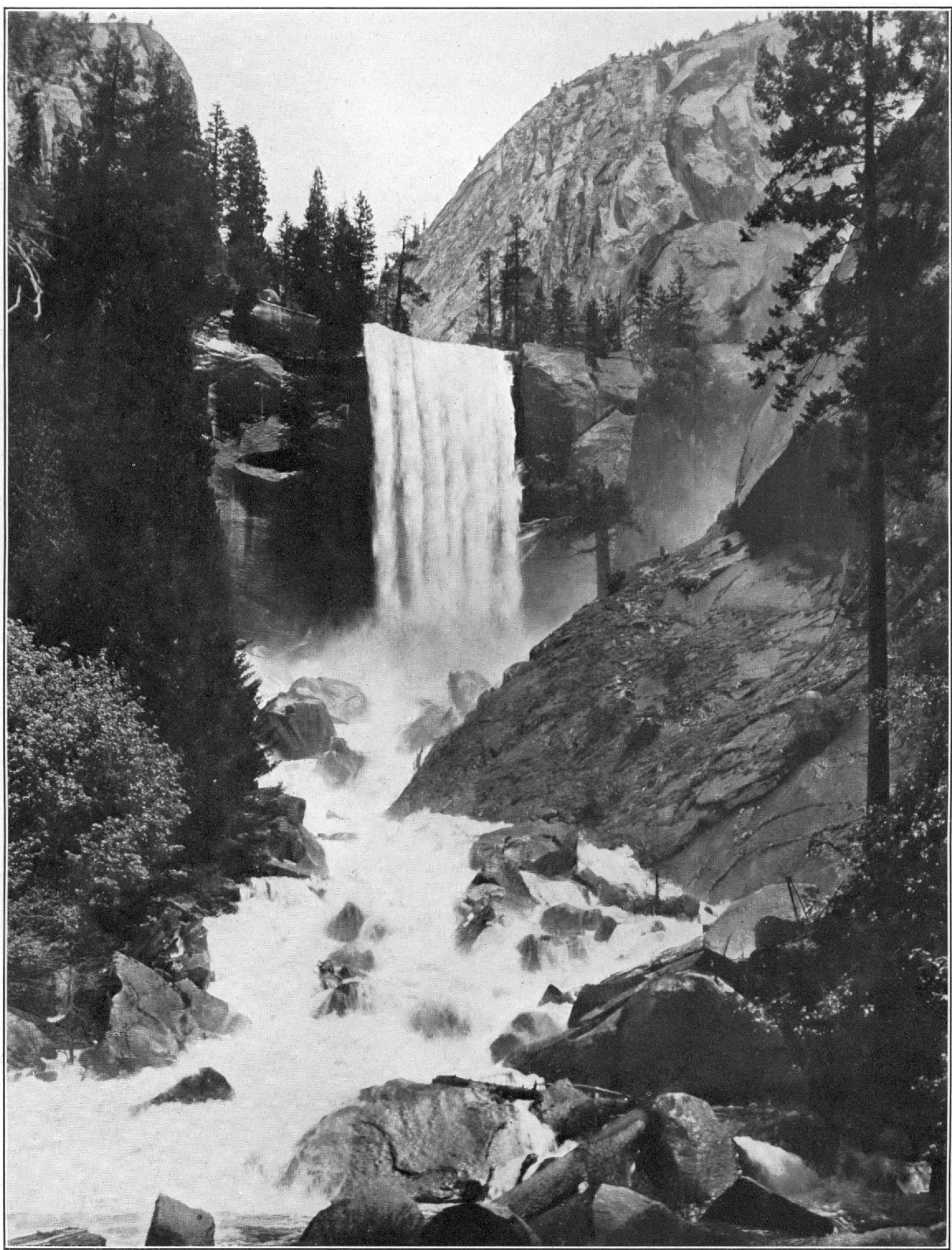

VERNAL FALL

The: Merced River descends by the Vernal Fall $317 \mathrm{feet}$ in height, from the lowermost step of the giant stairway. The slep is vert inal and is composed of unlractured, mussive granite throughout. Pholorraph by A. C. p'ilsbury. 


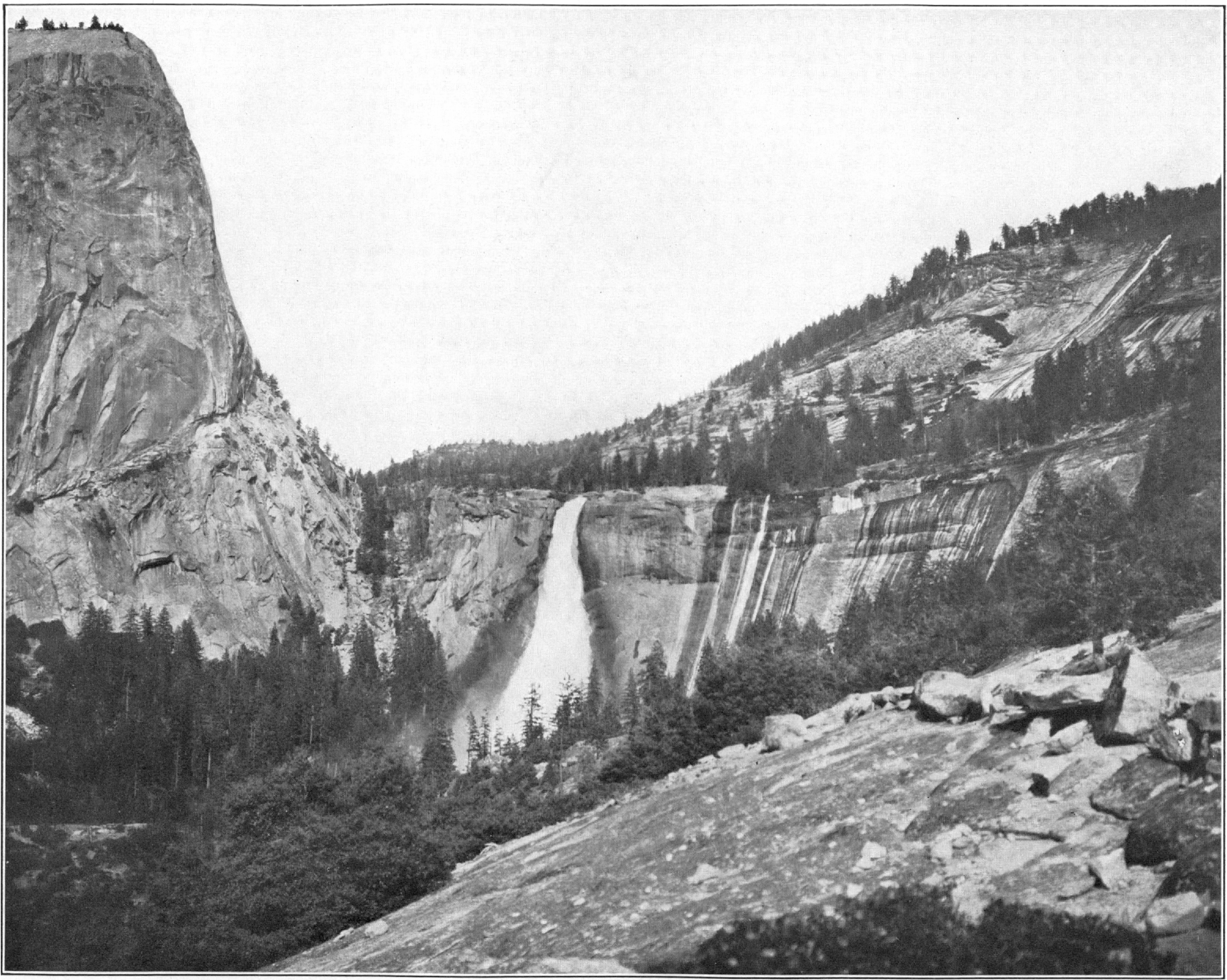

NEVADA FALL AND LIBERTY CAP

The Merced here descends from the uppermost step of the giant stairway by a fall 594 feet in height. Only the upper part of the fall leaps clear, the lower part gliding in the form of

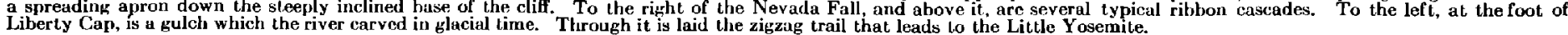


along the Merced Canyon from El Portal down to Bagby. The younger rocks make up most of the western half, extending from Bagby down to the foothills.

In the strongly deformed structure of these two distinct series of strata there is thus clear evidence of the former existence of two successive mountain systems. The general character of those ancient mountain systems, moreover, is indicated by the forms, mode of arrangement, and trend of the folds. Especially full are the data available concerning the younger (Cretaceous) system. Indeed, the similarity of its folded structure to that of the present Appalachian mountain system in the eastern United States enables the geologist to reconstruct its features with considerable confidence. Doubtless it was composed, like the Appalachian system, of long, roughly parallel ridges, separated by equally long, roughly parallel valley troughs. The trend was in general northwestward, but it varied locally. were broadly arched up to considerable height, so that the axis of the mountain system, and presumably its culminating heights and central divide, for a long time were situated in that region. Thus even its drainage system can be outlined in a general way. Although the streams flowed for the most part northwestward or southeastward, in the valley troughs between the parallel ridges, some of them doubtless drained westward, through gaps in the ridges, into the sea and others drained eastward, into adjoining lower lands.

These details of a mountain system that has long since vanished may possibly seem a needless digression, but they will help the reader to understand the significance of many topographic features of the present range; for, in spite of the profound stripping which the Sierra region has suffered since Jurassic time-a depth of stripping estimated at not less than 5,000 feet-the present range still possesses features that were inherited from the ancient mountains just described, as will become apparent in the following pages.

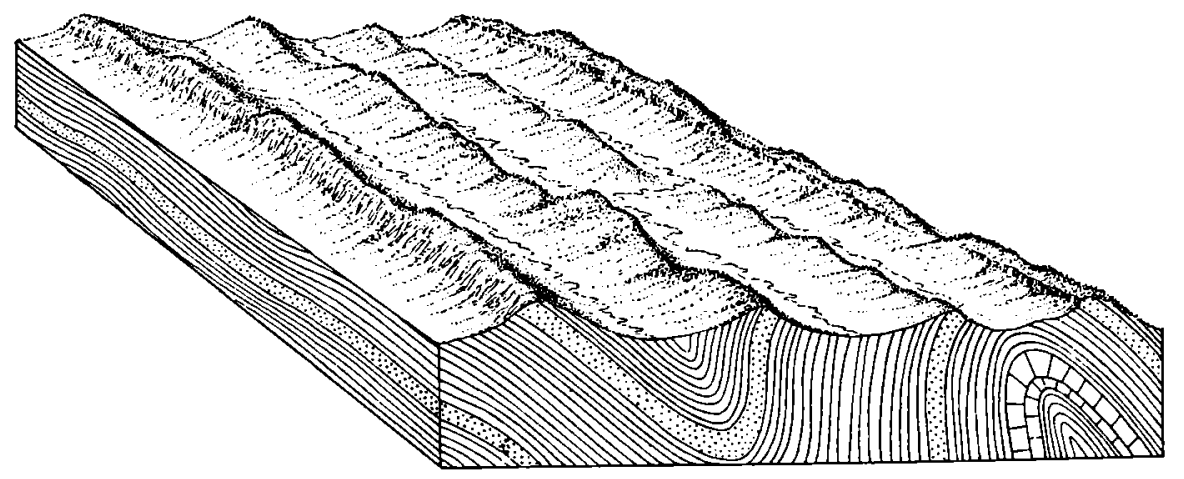

FIGURE 3.-Block diagram illustrating parallel mountain ranges carved from strongly folded strata. The ancient mountain ranges that occupied the place of the Sierra Nevada during the Cretaceous period were of this general type

As in the Appalachian Mountains, so probably also in the Sierra of Cretaceous time, the individual ridges were made up not of the rounded tops of entire upfolds but mostly of the stumps of resistant upturned strata, and the longitudinal valleys were etched out, so to speak, in the intermediate weaker strata, in the manner shown diagrammatically in Figure 3. The tops of the upfolds, being from the start fractured by tensile stresses and therefore particularly vulnerable to erosion, doubtless were worn away at an early stage during the slow, progressive upheaval.

From the steep inclination of the strata and the tightly compressed character of the folds in the belt traversed by the lower Merced Canyon, furthermore, it is to be inferred that the ridges in that part of the Cretaceous system were prevailingly linear, sharp crested and closely spaced, whereas in the region of gentle flexures near the summit of the present range doubtless the ancient mountains were relatively full bodied, round topped, and spaced far apart.

The almost complete removal of the metamorphic rocks from the middle part of the Sierra slope, finally, would seem to show that there the deformed strata

\section{THE RISE OF THE SIERRA NEVADA}

The history of the successive uplifts that gave the Sierra block its present height and tilted attitude is as yet imperfectly known. Only the major events stand out clearly. The reason will be apparent when the nature of the evidence is learned; it is mostly indirect or circumstantial, and some of it must be sought in places where the layman would hardly look for indications of earth movements that happened in remote ages. For these reasons it will be appropriate, before beginning the story of the rise of the Sierra Nevada, to give some idea of the sources from which it is pieced together.

\section{SOURCES OF INFORMATION}

First there is the testimony of the successive beds of rock waste that lie spread out at the western base of the range. They consist mainly of gravel, sand, and clay brought down by the Sierra rivers and deposited in the shallow sea which throughout most of Tertiary time occupied the basin of the Great Valley of California. The varying degrees of coarseness or fineness of these materials afford an index of the veloc-

$$
82564^{\circ}-30-3
$$


ity and transporting power of the rivers and therefore also of the degree of steepness of the river beds at different times. The layers of coarse gravel obviously record epochs of uplift, when the rivers dashed swiftly down steepened courses; the layers of finer gravel and sand record epochs of prevailing stability of the land, during which the streams flowed with gradually slackening speed, as they cut their beds down to lower and lower gradients; and the layers of silt and clay record epochs when the rivers had resumed tranquil, sluggish habits of flow on faint slopes, as a result either of long-continued down cutting or of gradual subsidence of the land. Moreover, the manner in which these different layers overlap one another and the rock body of the range and the occurrence of remnants of layers high above the present foothills tell clearly of former oscillations of the Sierra region with respect to sea level. The geologic epochs when these different oscillations took place are indicated by the fossil shells and other remains contained in the deposits.

Similar testimony is afforded by the layers of rock waste that have accumulated in the basins east of the Sierra Nevada and in the Mohave Desert, to the south.

Much has been learned also from the "fossil river beds" that occur in the north half of the rangeriver beds that were entombed by flows of lava and that were partly brought to light again later when newly formed rivers, accelerated by fresh uplifts, trenched deep canyons. Some of these ancient river beds are now situated on or near the divides between the canyons, a thousand or even several thousand feet above the present streams. From their sand and gravel considerable gold has been extracted, but, what to the geologist is more significant, petrified bones of animals, fragments of wood, and even delicately preserved imprints of leaves have occasionally been dug out. From these fossils some conception may be formed of the age of the stream beds.

Of particular interest are the fossil remains that have been found at and near Table Mountain (the Table Mountain of Tuolumne County), which stands about 40 miles northwest of the Yosemite Valley and which has become famous through the writings of Bret Harte. This long, flat-topped ridge, or really chain of ridges, consists of the remnants of a flow of dark basaltic lava that followed the course of an ancient valley all the way from the summit of the Sierra Nevada to the foothills. It represents the last notable volcanic flow that occurred in the north-central part of the range. Its prominence in the landscape to-day is due to the fact that in the long time that has elapsed since the lava was poured out the hills that flanked the path of the flow have been eroded away over distances of many miles, whereas the basalt, owing to its exceptional resistance to chemical decomposition as well as to mechanical disruption, has remained standing but little reduced in height. The fossil remains, which consist of casts of leaves and a tooth of an extinct species of horse, date back, according to determinations by Dr. Ralph W. Chaney and Dr. Chester Stock, to the later part of the Miocene epoch and thus tend to show that the upland on which Table Mountain stands is the remnant of a landscape of late Miocene time. The Yosemite upland, which is the correlative of the upland near Table Mountain, is therefore presumably also a remnant of the late Miocene landscape.

Other data concerning the successive uplifts have been derived from a critical study of the canyons in the south half of the Sierra Nevada, which were obstructed only by minor volcanic outpourings and therefore reveal clearly the effects of successive renewals of stream activity. The first studies of this kind were made in the Kern River region by Prof. Andrew C. Lawson ${ }^{32}$ in 1903; but the more recent investigations in those parts of the range which are drained by the Tuolumne, Merced, and San Joaquin Rivers have furnished most of the data for the sequence of Sierra uplifts here recorded. Other kinds of evidence might be mentioned, but to present them all would lead too far afield.

\section{HISTORY OF UPLIFTS}

The precise date in geologic history when the Sierra. block first became outlined by fault fractures is as yet uncertain. Some geologists have placed it tentatively as far back as the end of the Cretaceous period, but it seems more likely, in the light of recent studies of the eastern front of the range, as well as of the fault scarps of several ranges in the Great Basin, that the faulting began later, presumably in the second half of the Tertiary period. If that interpretation is accepted, the earlier uplifts in the Sierra region are to be conceived as having been mostly in the nature: of gradual upwarpings not attended by any breaking of the earth's crust.

The first upwarping that is definitely indicated in the sedimentary record at the western base of the Sierra Nevada took place early in the Eocene epoch - that is, nearly $60,000,000$ years ago. ${ }^{33}$ It increased the height. of the land only moderately, not enough to make it truly mountainous. Indeed, throughout the first half of the Tertiary period the Sierra region apparently remained a land of moderate altitude, little or no higher than the country adjoining it on the east. It was, however, by no means a lowland or plain throughout, for it was traversed by a number of parallel northwestward-trending ridges-slowly vanishing remnants of the Cretaceous mountain system

${ }_{32}$ Lawson, A. C., The geomorphogeny of the upper Kern Basin: California Univ. Dept. Geology Bull., vol. 3, pp. 291-376, 1904.

${ }_{33}$ This figure and those following are necessarily rough approximations, but they are introduced in order to afford the reader some perspective of the time distances in this history. All are taken from Barrell's scale of geologic time. 
already described. Westward the region sloped down to the sea, but the coast line did not remain fixed in position; it advanced at times many miles to the west of the present foot of the range, and at other times receded to the east of it, as a result of alternating heaving and sinking movements. Dense growths of rain-loving vegetation of types similar to those which now prevail in the southern Atlantic and Gulf Stateslaurel, maple, poplar, elm, beech, and magnoliaflourished in the mild, humid climate.

Toward the end of the Eocene epoch-about $40,000,000$ years ago-there commenced a period of intermittent volcanic outbreaks. A row of volcanoes at the eastern border of the Sierra region sent forth streams of white and pink rhyolitic lava and mud that flowed down the valleys, burying the river channels. The volcanic materials were gullied and in part washed away by the streams, but fresh eruptions undid this work. For a long period volcanism and stream erosion continued to act in alternation. Meanwhile, by intermittent, probably gradual uplifts the Sierra region was broadly raised and tilted to the southwest. At the same time the country lying to the east of it was warped and flexed; low ranges came into existence, and between them were formed wide basins in which the waters collected in shallow lakes.

The disturbances died out at last and were followed by a long interval of relative quiet, during which most of the rhyolite and much other rock waste was stripped from the Sierra region and deposited in the sea on its western border and in the basins to the east of it. Then, presumably in the second half of the Miocene epoch-roughly, about $12,000,000$ years ago-volcanic activity and earth movements began anew on a vast scale. This time the eruptions yielded mostly andesitic lava of brown, reddish, and grayish colors. Down the valleys these materials flowed, sheet upon sheet, obliterating the stream beds and compelling the waters to seek new paths. In the north half of the range the outpourings were especially frequent and voluminous; they piled up to thicknesses of a thousand feet or more, overwhelming all the features of the country save the higher peaks and crests. In the southern parts of the range the volcanic flows were less extensive and less thick; they filled only the bottoms of certain valleys and caused no notable displacements in the drainage system. Only the drainage basin of the Merced, in the central part of the range, remained free from volcanic outpourings.

The crustal movements of this epoch increased the height of the Sierra region by severa] thousand feet and gave it the aspect of a mountain range, or rather a belt of mountains, that dominated all the country roundabout. Mount Lyell probably attained an altitude of about 7,000 feet. Strong faulting took place along some parts of the eastern border, and the great depression in which Lake Tahoe is situated was formed by subsidence: the lava which dams the lake itself was not poured out, apparently, until after the depression was formed. The ranges and valleys of the Great Basin region also were accentuated, in part by warping, in part by faulting.

Next followed another lengthy interval of repose, or relative repose, that lasted through the entire Pliocene epoch. Only feeble eruptions took place from time to time, and meanwhile the waters in the lavacovered parts of the range reorganized themselves into new rivers and cut new canyons, some of which attained depths of more than 1,000 feet. Vegetation reestablished itself on the disintegrating volcanic materials, but this time in the form of forests adapted to a cooler and less equable climate. Sequoias, ancestors of the big trees of the present time, flourished throughout the region.

And then, at the beginning of the Quaternary period-about $1,000,000$ years ago-commenced those great upheavals and tilting movements that gave the Sierra Nevada its present great altitude. The summit peaks were raised to almost double their previous height, Mount Lyell being lifted to more than 13,000 feet above sea level. At the same time fracturing and faulting took place on an enormous scale. Owens Valley and the other desert regions adjoining the range on the east and south dropped back or else. suffered but slight uplifts as compared with the mountain block, and so the Sierra Nevada came to stand out. in its present imposing form, with gentle westward slope, sharply defined crest, and abrupt eastwardfacing escarpment. Strangely, the volcanic accompaniments of this great upheaval and inbreaking of the earth's crust were not extensive. Though molten. material forced its way up repeatedly through fractures in or near the zone of faulting and also through cracks in the Sierra block, the resulting volcanic cones and lava flows were insigificant compared with those of Tertiary time.

After the grand climax of mountain-building movements that ushered in the Quaternary period, the earth stresses abated in intensity. Upheaval and downfaulting took place less frequently, and as a. result the Sierra Nevada has suffered no marked further changes in height or in general form. Minor movements, however, have continued to occur at intervals into historically recent times.

The magnitude of the more recent movements on the fault fractures is indicated by small escarpments that cut across the débris slopes at the east base of the range. Most of these scarps are only 10 to 50 feet in height. Near Genoa, Nev., for instance, is a fault. scarp varying from 10 to 44 feet in height that extends. for several miles along the east base of the Carson Range, that offshoot from the main Sierra block which 
forms the east wall of the Tahoe Basin. ${ }^{34}$ The dislocation there probably involved a sinking of Carson Valley, for that valley is lowest next to the base of the range and abuts almost directly upon it. Another escarpment of recent orgin cuts across the glacial moraines that project from the base of the range at the mouth of Lundy Canyon, near the west border of Mono Lake. The vertical displacement is at least 50 feet, and its recency is attested by the fact that Mill Creek, which issues from Lundy Canyon, still cascades abruptly at the place where the fault crosses its bed, the stream not yet having had time to smooth out the step completely. Here too, apparently, the valley block was depressed relative to the mountain block and tilted toward it, for Mono Lake laps the immediate base of the range, and its ancient shore lines, which date back to the glacial epoch, decline gently toward the southwest.

At least one notable dislocation has taken place at the east base of the Sierra Nevada within historic time. It gave rise to the famous Owens Valley earthquake of March 26, 1872, which destroyed the village of Lone Pine and caused the death of many of its inhabitants. The fault scarps produced by this earth movement are still conspicuous and are easily traced for distances of several miles, although they cut for the most part only through unconsolidated débris at the foot of the range. They vary from 8 to 25 feet in height. A line of lesser scarps, facing westward, was produced in the floor of the valley, roughly parallel to the main scarps and about half a mile distant from them. The intermediate strip of valley floor was slightly depressed and locally warped, so that a number of shallow ponds came into existence. The tremors produced by this earth movement were so strong that even in the Yosemite Valley, more than a hundred miles away, great avalanches of rock fragments fell from the cliffs and one noted pinnacle was demolished, as has been graphically told by John Muir, who was an eyewitness of the scene. ${ }^{35}$

Since this great earthquake no further strong tremors have been felt in the Sierra Nevada nor in the lowlands immediately to the east of it. Evidently earth movements are now infrequent in these areascertainly infrequent compared with those in the mobile coastal belt-and it may be concluded, therefore, that the Sierra block and its neighbors are in fairiy stable adjustment.

REARRANGEMENT OF DRAINAGE SYSTEM AND ORIGIN OF THE MERCED RIVER

A direct consequence of the upwarping and tilting of the Sierra region in early Tertiary time was the rearrangement of its drainage system. Before the

\footnotetext{
34 Lawson, A. C., The recent fault scarps at Genoa, Nev.: Seismol. Soc. America Bull., vol. 2, pp. 193-200, 1912.

3s Muir, John, The Yosemite, pp. 76-86, 1912.
}

uplifts began, the master streams, with few exceptions, flowed in northwesterly or southeasterly directions, the trend of the valleys being determined in general by the parallel ridges of the ancestral mountains of Cretaceous time. But when the land acquired a definite slant to the southwest, this old drainage system was replaced by a new system whose master streams flowed prevailingly in southwesterly directions. The change doubtless took place very gradually and must have required considerable time, for it was effected mainly by the progressive headward growth of certain streams that already flowed in southwesterly directions and by their capture of other streams that were less favored by the tilting. The mountain ridges by that time, it may be presumed, were worn down and breached in places and thus afforded gaps through which transverse drainage could be established. Even so, they interfered not a little with the development of the southwesterly rivers, as is evident from the strongly winding courses of those streams.

The later tilting movements steepened the inclination of the land but did not appreciably alter its direction, and thus the system of southwestward-flowing master streams was perpetuated. It does not follow, however, that all the great rivers which now flow down the western slope of the Sierra Nevada are identical with the rivers which came into existence at that early epoch, for lava flows have repeatedly filled and buried the valleys, and the new streams that were formed along the margins or on the irregular surface of the volcanic materials established their courses regardless of the positions of their predecessors.

Such changes in drainage were most prevalent in the northern half of the Sierra region. Even the Tuolumne River was affected by them. Remnants of old gravel beds of that river, situated at different levels, partly capped by lava, clearly show that its course has been obliterated at least twice. The Merced, on the other hand, appears not to have been obstructed or displaced by lava flows at any time in its history. A careful survey of its drainage basin reveals no traces of volcanism, save two diminutive craters south and southeast of Merced Pass, in the upper basin of the South Fork. In this almost complete exemption from volcanic outpourings the Merced drainage basin is unique in the Sierra Nevada, and naturally, because of the absence of such complicating circumstances, it has had a relatively simple erosional history. In any event there is little doubt that, save for local shiftings here and there, the Merced has followed approximately the same general course throughout its existence.

The history of some of its tributaries has probably been less simple. Most of these streams flowed originally in northwesterly or southeasterly directions, between the parallel ridges of the Cretaceous mountain system. As long as these ridges, composed of resistant 
rocks, were prominent and continuous, doubtless the streams remained fixed in position; but when the ridges were finally worn low and in places cut through, a number of these streams were probably captured by the headward-growing Merced and annexed to its expanding drainage system. Here and there the direction of flow may have been reversed, a northwestwardflowing stream being supplanted by a southeastwardflowing stream, or vice versa, but the axes of the valleys, being controlled by the trend of the strata, remained unchanged.

On the lower Sierra slope, which is carved wholly from upturned strata, the original northwesterly or southeasterly trends of the valleys have, indeed, persisted down to the present time. There the resistant strata still form the ridges, the intermediate belts of weak strata are followed by the streams, and consequently almost all of the Merced's tributaries flow northwestward or southeastward, regardless of the general southwestward slope of the range. There, also, the Merced deviates most widely from a direct southwesterly course and swings in great loops to the northwest and the southeast.

In the Yosemite region, where the folded sedimentary rocks are now wholly stripped away and the granite is exposed, the drainage pattern is naturally more varied, and tributary streams join the Merced at different angles. But even there a number of streams have northwesterly or southeasterly courses that are probably an inheritance from the now vanished mountain system of the Cretaceous period. Among these streams are Ribbon Creek, Yosemite Creek, Indian Creek, Illilouette Creek, Sentinel Creek, Bridalveil Creek, and Meadow Brook. Their peculiar arrangement at right angles to the course of the Merced has had a far-reaching influence on the ultimate modeling of the Yosemite region, as will become clear further on.

In the High Sierra, above the Yosemite region, the northwestward trend of the mountain crests-the Clark Range, the Cathedral Range, Kuna Crest, and the main divide - is also probably inherited from the Cretaceous mountain system, although these crests are composed largely of granitic rocks and are covered with sedimentary rocks only in places. The northwesterly courses of the Merced and Tuolumne Rivers there betray the same guiding influence. The upper valleys of those streams are therefore probably of great antiquity.

\section{THE CUTTING OF THE MERCED CANYON}

STREAM-CUT ORIGIN OF THE CANYON

Whatever doubt there may have been once as to the stream-cut origin of the Merced Canyon and the other great canyons that furrow the western slope of the Sierra Nevada, surely there is none to-day. That these canyons have been cut primarily by the streams that flow through them was recognized as far back as
1863 by Whitney and King and has since been verified by every geologist who has had occasion to study the range. The belief that still lingers in some quarters that they have been excavated wholly, or largely, by the glaciers of the ice age is untenable in face of the facts that are now known. To be sure, the middle and upper portions of the canyons bear unmistakable signs of remodeling by the glaciers, but it is entirely clear that they were already cut by the streams to depths of 1,500 to 2,000 feet before they were invaded by the ice. Besides, it is certain that the lower courses of all the Sierra canyons have remained wholly untouched by the ice and are products of stream cutting solely. The Merced Canyon, for instance, appears never to have been glaciated beyond a point just below El Portal, which lies about 50 miles from the foothills. The Tuolumne Canyon, similarly, appears to have remained unglaciated for a distance of 30 miles up from the foothills and the San Joaquin Canyon for a distance of 45 miles.

A little reflection will show that canyon cutting by the rivers must have been an inevitable consequence of the uplifts of the Sierra region and the final tilting of the Sierra block. Whenever through any cause the slope of a stream is appreciably steepened, its flow will be greatly accelerated and the wear on its bed correspondingly intensified. Precisely this happened whenever the slopes of the Merced and the other Sierra rivers were steepened by an uplift of the range. With each renewed tilting these streams were accelerated, and they vigorously attacked their beds, intrenching themselves in narrow, steep-sided gorges that eventually became the profound canyons, thousands of feet in depth, in which they flow at the present time.

\section{EVIDENCES OF THREE STAGES OF CUTTING}

In the unglaciated lower portions of the Sierra canyons there are many features that still indicate plainly the successive stages in the cutting, and from these indications it is possible with a fair degree of certainty to build up the general history of the development of the canyons. In the broad view of the lower Merced Canyon that may be had from the summit of El Capit an there appear, beginning at the sky line, long, fairly even-topped ridges that advance from right and left and that decline gently toward one another so as to outline the broadly flaring profile of a very ancient and rather shallow valley. (See pl. 26, $A$.) There is now but little left of that valley, for the ridges mentioned are mere "skeleton ridges" separated by broad spaces, and the level floor of the valley itself is entirely cut away.

Next below this ancient valley appear the much better preserved features of a somewhat narrower and steeper-sided valley, evidently, of less remote origin. This valley was fully 1,500 feet deep, yet it also had a broad and fairly level floor, as is shown by the numer- 
ous flats and gently undulating surfaces that still re- $\mid$ like a mere slotlike winding trench, an obscure feature main. The Big Meadow flat, which is a few miles in the landscape.

northeast of El Portal and is traversed by the Coulter- What is commonly and loosely termed the Merced
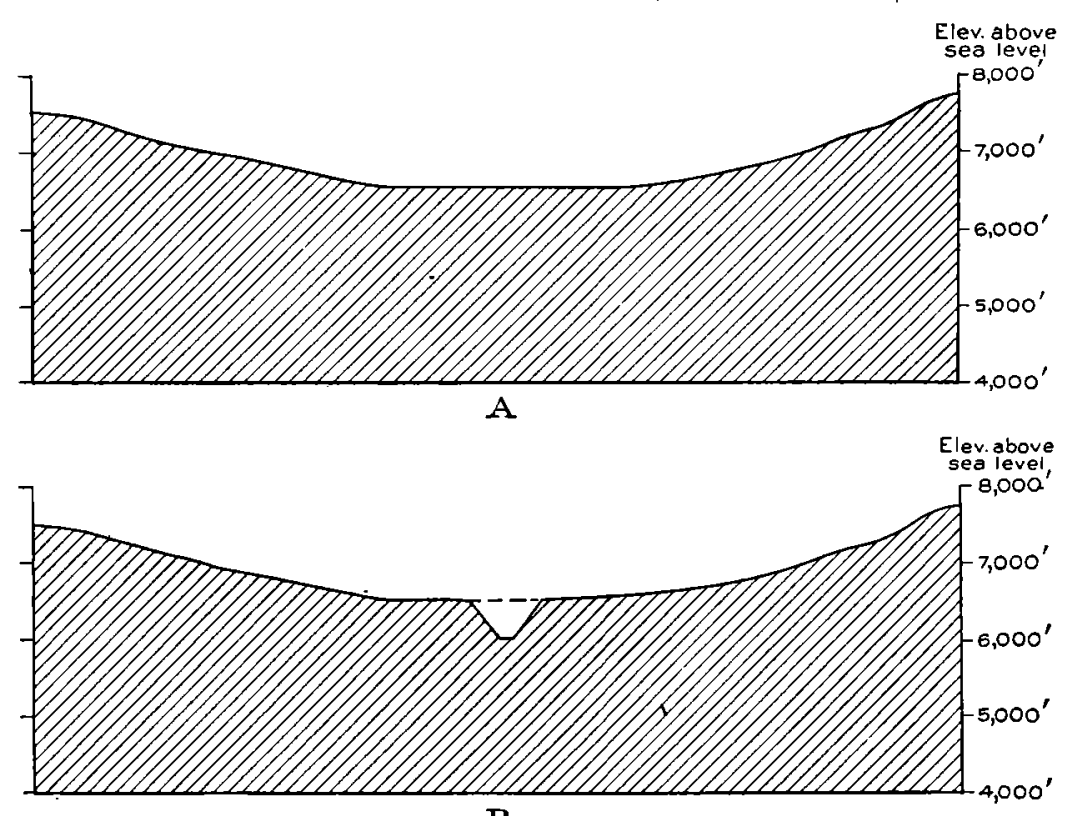

$\mathbf{B}$
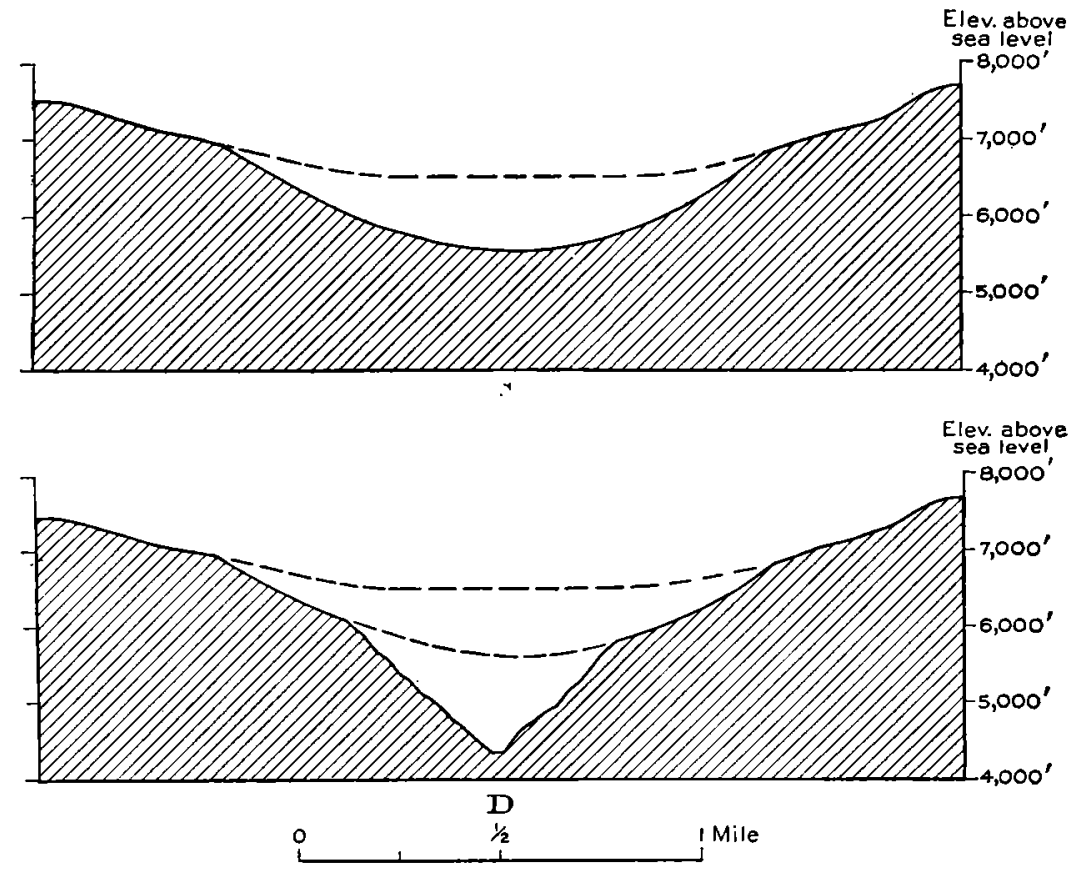

Figure 4.-Cross sections illustrating the successive stages in the cutting of the Merced Canyon. They are drawn to scale and show the general proportions of that part of the canyon which ultimately became the Yosemite Valley. A, The first or broad-valley stage, which dates back presumably to late Miocene time, when the Sierra region was still relatively low; B, the inner gorge cut by the Merced after the first strong tilting of the Sierra block; C, the second or mountain-valley stage, which dates back presumably to the end of the Pliocene epoch; $D$, the third or canyon stage, produced early in the Quaternary period by the rapid incision of the present inner gorge in consequence of the last great Sierra uplift

ville road, is the principal remnant of this old valley floor in the Yosemite region.

Sharply incised in the floor of this old valley is the narrow V-shaped inner gorge through which the Merced now flows. This gorge is 1,500 to 2,000 feet deep, but is so narrow that in the distant perspective it seems
Canyon, then, consists really of a steepwalled inner gorge cut into the floor of a spacious older valley, which in turn lies within a very broad valley of still greater antiquity. The lower canyons of the Tuolumne and San Joaquin Rivers have similar 3-story profiles; indeed, sculptural elements expressive of three stages of valley and canyon cutting may be discerned more or less clearly in the unglaciated lower course of every great Sierra canyon whose development has not been interfered with by volcanic flows. By the experienced eye they may be recognized even in the glaciated upper courses of some of the canyons, for the remodeling action of the ice has not everywhere been so thoroughgoing as to wipe out of existence these preglacial features.

The story of the cutting of the Merced Canyon, as built up from these and other data, may then be briefly told as follows:

\section{THE STORY OF THE CUTTING}

When the Merced first established its course conformably to the southwestward slant of the Sierra region, it fashioned for itself a valley of moderate depth that sloped seaward with gentle gradient. For a long period the general character of this valley remained but little changed, though doubtless the river deepened the valley whenever the land rose and again built up its floor with sediments whenever the land returned to lower levels. Meanwhile the flanking hills were being worn lower at a very slow rate. On the whole but little is known of this long early chapter, which lasted, probably, through the first half of the Tertiary period, but it is clear that the outstanding characteristics of the valley of the Merced at that time were great breadth and shallowness. Throughout its lower course, probably, the river meandered sluggishly over a broad, level flood plain, and even in its middle course, in which the Yosemite was later developed, it swung leisurely from side to side. The valley was flanked by rolling hills and a few ridges of 'greater height, but the headwater region was relatively rugged and had mountains 1,000 to 3,000 feet high. This first stage in the cutting of the Merced Canyon, accordingly, may be termed the broad-valley stage. (See fig. 4, A.) 
The great uplifts that supervened toward the end of the Miocene epoch naturally steepened considerably the Merced's gradient and quickened its flow. Forthwith the stream abandoned its meandering habit and began vigorously to deepen its valley. Indeed, so rapidly did it erode its bed that in a relatively short period it cut a narrow, steep-sided inner gorge. (See fig. 4, B.)

Throughout most of the Pliocene epoch the river continued to cut downward, though at an everslackening rate, for as the gorge grew deeper the gradient became flatter and the waters lost their swiftness and eroding power. Meanwhile the sides of the gorge were being worn back to slopes of moderate inclination, and thus at length the inner gorge developed into a V-shaped inner valley of considerable depth and breadth. (See fig. 4, C.)

In the mostly thin-bedded and relatively unresistant sedimentary rocks of the lower slope of the Sierra Nevada the inner valley grew to be very broad-in places so broad as to obscure the older valley in which it was cut. But in the prevailingly massive and exceedingly resistant granitic rocks of the Yosemite region the inner valley remained relatively narrow and steep-sided. It maintained the aspect of a rugged mountain valley, and accordingly this second stage in the cutting of the Merced Canyon, produced in the Pliocene epoch, may be termed the mountain-valley stage. (See fig. 4, C.)

Such was the state of things when, at the beginning of the Quaternary period, came those stupendous dislocations and tilting movements that resulted in the elevation of the Sierra Nevada to its present height. The sources of the Merced on Mount Lyell were then raised not less than 6,000 feet above their previous altitude, the general slope of the river was greatly steepened, and its waters were accelerated to torrential speed. With more vigor than before they deepened their bed, scouring it with sand and gravel, pounding it with boulders, and plucking out slabs and blocks wherever the fractured state of the rock permitted, and so they again produced a steep-walled inner gorge. (See fig. 4, D.)

Throughout the Quaternary period, down to the present day, the Merced has continued to deepen this new gorge. So rapidly has the cutting proceeded that in the vicinity of El Portal the gorge now attains a depth of about 2,000 feet, or about twice the depth of the Pliocene mountain valley, yet the time involved has been probably less than a million years, or only oneseventh of the duration of the Pliocene epoch. That the cutting is still in progress is shown by the fact that even in its lower course, where it traverses the relatively unresistant sedimentary rocks, the river still flows in a rock channel and makes cascades and rapids over the more obdurate ledges.
It is the combined depth of the Quaternary gorge and of the Pliocene and Miocene valleys above it that gives the great trench worn by the Merced its present canyonlike character. It seems appropriate, accordingly, to refer to this last stage in the cutting of the Merced Canyon as the canyon stage.

\section{EXPLANATION OF HANGING VALLEYS}

\section{PREVIOUS HYFOTHESES}

Several widely different hypotheses have been advanced in explanation of the hanging valleys of the Yosemite region. Professor Whitney ${ }^{36}$ supposed them to have been left hanging by the sinking of the floor of the main chasm, a great block of the earth's crust underlying the floor and bounded by fault fractures having dropped to a depth of several thousand feet owing to disturbances in the interior of the earth. Clarence King ${ }^{37}$ assumed that the two sides of the Yosemite chasm were torn asunder by some catastrophic earth movement, the bottom of the abyss thus formed having been filled later with débris up to the level of its present floor. Among those who believed the chasm to have been hewn to its present depth mainly by the glaciers of the ice age, Henry Gannett ${ }^{38}$ and Douglas W. Johnson ${ }^{39}$ regarded the hanging valleys as a characteristic and necessary product of glacial action; the powerful main glacier, in their opinion, having been able to excavate its bed to much greater depth than the relatively feeble branch glaciers had been able to excavate theirs. Prof. Andrew C. Lawson, ${ }^{40}$ the latest scientist to offer an explanation, has suggested that some of the hanging valleys might not have come into existence until after the ice age, when the waters began to channel the glacially smoothed surface of the uplands. These hanging valleys, according to his view, are shallow because they are of recent origin, the streams not yet having had time to cut them to any great depth.

Whitney's dropped-block hypothesis seemed to have support in the fact that there are in and adjoining the Sierra Nevada several well-authenticated examples of deep basins produced by the subsidence of crustal blocks. The best known is the basin that holds Lake Tahoe. However, careful search has failed to disclose any proof that the Yosemite is an abyss produced by subsidence: the great fault fractures which the mechanics of such a dislocation demand have not been discovered. It is true that such fractures would not be traceable along the bases of the walls on both sides,

${ }^{36}$ Whitney, J. D., Geology of the Sierra Nevada: Geological Survey of California, Geology, vol. 1, pp. 421-422, 1865; The Yosemite guidebook, pp. 84-87, 1870.

${ }^{87}$ King, Clarence, Mountaineering in the Sierra Nevada, 4th ed., pp. 7, 134, 1874

3a Gannett, Henry, The origin of the Yosemite Valley: Nat. Geog. Mag., vol. 12, pp. 86-87, 1901.

30 Johnson, D. W., The origin of the Yosemite Valley: Appalachia, vol. 12, pp. 138-146, 1910; Hanging valleys of the Yosemite: Am. Geog. Soc. Bull., vol. 43, pp. 1-25, 1911.

10 Lawson, A. C., Geology, in Handbook of Yosemite National Park, compiled by Ansel F. Hall, pp. 117-120, 1921. 
on account of the great thicknesses of gravel and rock waste that hide the rock floor of the chasm; but if they did exist they would necessarily extend some distance beyond the confines of the chasm and cut through its walls. However, the walls reveal no such fractures, although they are bare and afford the best possible chances for the detection of structural features of that sort.

The argument of the glacialists was undeniably a strong one, for hanging side valleys are notably characteristic features of profoundly ice-worn canyons in many parts of the world. Nor can it be doubted that a trunk glacier several thousand feet thick has inherently much greater excavating power than a glacier only a few hundred feet thick. Prolonged glaciation is therefore almost certain to result in deepening the main canyon below the levels of its tributary valleys, so that those valleys will be left hanging.

The history of the Yosemite, however, is much more complicated than the glacialists suspected, nor does their theory account for all the facts that are now known. It does not satisfactorily account for the val the Merced itself, with its superior volume, has been able to deepen its channel but a few feet, in rock very similar to that which prevails on the uplands. All the facts ascertained by the recent investigations, indeed, go to prove that the upland valleys of the Yosemite region, instead of being among its youngest features, are among its most ancient and date far back into the Tertiary period.

\section{HANGING SIDE VALLEYS OF LOWER MERCED CANYON}

The key to the mystery is to be found in the lower Merced Canyon, more especially in the part below El Portal. This part of the canyon also has several hanging side valleys, although it has never been glaciated. Good examples are Saxon Gulch and the valleys of Feliciana Creek and its branches. (See pl. 2.) To be sure, these are not hanging valleys of the clean-cut type prevalent in the Yosemite region. They do not end abruptly at the brink of the canyon, nor do their waters pour from their lips in spectacular falls. Instead, their lips are cut by narrow gulches through which the waters cascade steeply down to

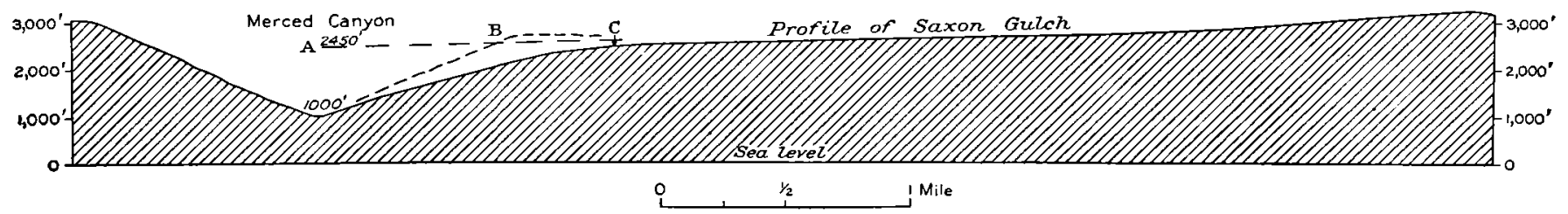

Figure 5.-Longitudinal profile of Saxon Gulch, a hanging side valley of the unglaciated Merced Canyon below El Portal. The curve of the profile, when extended forward to the axis of the canyon, indicates at $A$ the approximate level at which the Merced flowed before it intrenched itself - that is, prior to the last great uplift. B marks the original mouth of the hanging valley. C marks the point to which the hanging valley has been trenched by a new gulch. This profile and those in Figures 6-12 and Plate 27 are drawn strictly to scale-that is, without vertical exaggeration

great disparities in height between the different hanging valleys of the Yosemite region, nor does it explain the presence of hanging valleys on the sides of the lower Merced Canyon, which, it now appears, has never been glaciated.

Professor Lawson's surmise that some of the hanging valleys of the Yosemite region may be products of postglacial stream erosion, carved in the glacially smoothed surface of the uplands, is, in the first place, based on a misapprehension as to the magnitude of the glaciers that have lain on the uplands and as to the amount of erosional work they have performed, and, in the second place, it fails to consider the brevity of postglacial time and the exceptionally resistant nature of the rocks of which the uplands are made. It is now definitely known that the uplands have been covered with ice only in part and nowhere to any great depth, so that their original features could not possibly have been smoothed away by glaciation. And it is manifest that the little upland streams could not have carved, in the few thousand years that have elapsed since the departure of the glaciers, valleys from several hundred to a thousand feet in depth, especially when it is considered that in the same inter- the river. Nevertheless, these valleys are properly classed as hanging valleys, for their gently sloping floors lie at considerable heights above the bottom of the Merced Canyon, as will be evident from a glance at Figures 5 and 6 . Comparison with Figures 7, 8,9 , and 10, furthermore, will show that, except for the gulches at their mouths, these valleys do not differ materially from the best-developed hanging upland valleys of the Yosemite region, and they are quite comparable to notched hanging valleys such as those of the two forks of Indian Creek.

That the Merced Canyon below El Portal has remained in all probability unglaciated was pointed out in 1911 by Prof. Douglas W. Johnson, ${ }^{11}$ who based his conclusions mainly on the general shape and character of the inner gorge. That gorge is $\mathrm{V}$-shaped in cross section, no wider at the bottom than the channel of the river, and it winds in strongly serpentine curves, sharp spurs projecting into it from both sides. It has thus all the marks of a stream-cut gorge and none of the marks of a typical glacier channel, which is generally U-shaped in cross section, broad-bottomed,

"Johnson, D. W., Hanging valleys of the Yosemite: Am. Geog. Soc. Bull., vol. 43, pp. 1-25, 1911. 
and fairly smooth-sided. However, there is now more direct proof at hand. The systematic search for glacial deposits which was a part of the recent investigations (see pp. 67-68) has shown that the moraines of the Yosemite Glacier end in the vicinity of El Portal, and hence it is reasonably certain that the glacier never extended much beyond that point.

There being, then, no possibility that the side valleys of the lower Merced Canyon were left hanging as a result of glacial action, the question is, To what other process can they owe their hanging character? The most obvious explanation that suggests itself is that when the Merced cut its inner gorge, upon acceleration by the tilting of the Sierra block, its feeble side streams were unable to keep up with it. They were handicapped not only by reason of their lesser volume but also by reason of their northwesterly courses, arranged at right angles to the direction of the Sierra slope. The side streams thus remained unsteepened and their flow unaccelerated.

Indirect proof of the soundness of this explanation is to be found in the fact that those side streams which did not labor under these handicaps have no rock beds have largely determined the positions and trend of most of the valleys and ridges of the present landscape; the valleys follow the belts of weaker rocks, the ridges are composed of the more resistant rocks. Valleys such as those of Feliciana Creek and Saxon Gulch, therefore, are hanging not because of the resistant nature but in spite of the unresistant nature of their floors.

It may seem surprising, in view of this curious fact, that these valleys should be hanging at all. It is to be remembered, however, that only a relatively brief time has elapsed since the last Sierra uplift took place and the Merced began to cut its inner gorge. The time has been too short to permit feeble streamlets unaccelerated by tilting to do much cutting. The headway they have made may be gaged by the length of the gulches they have cut at the mouths of their hanging valleys. The streamlet in Saxon Gulch, which is among the smallest, has cut its gulch back a distance of only half a mile; Feliciana Creek, which is somewhat larger, has cut back a distance of $1 \frac{1}{2}$ miles; and Bear Creek, which is larger still, has destroyed the greater part of its hanging valley.

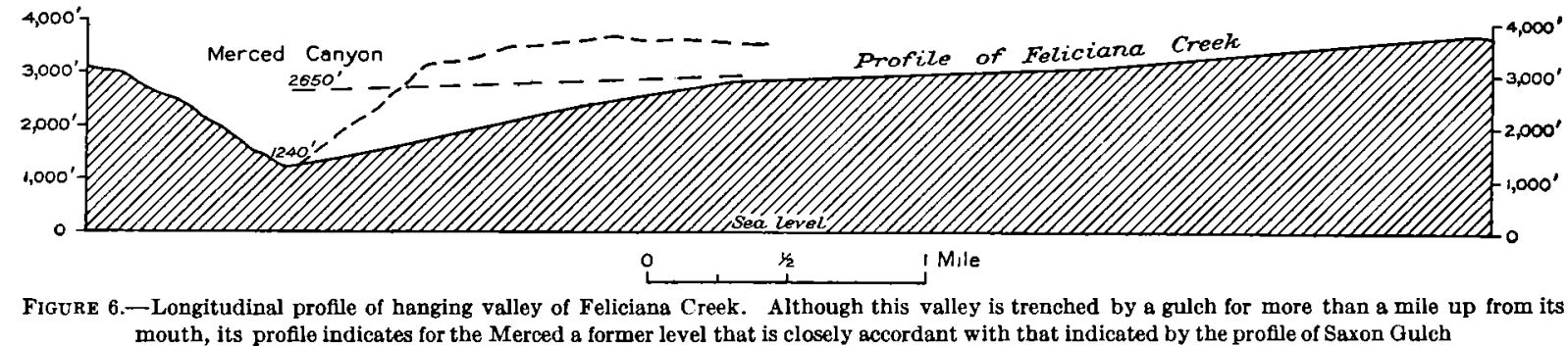

hanging valleys. For instance, the stream in Ned Gulch, which is of small volume but has a southwesterly course, substantially in the direction of the tilting, descends steeply all the way from its head to the bottom of the canyon, and the South Fork of the Merced, which runs northwestward for many miles but which, next to the Merced, is the largest stream of the region, has cut just as deeply as the master stream. Probably neither of these side streams was able at first to cut as fast as the master stream, but evidently they were able to catch up with it later, when the cutting power of the Merced had declined owing to the reduction of its slope in its lower course.

It might be suggested, perhaps, that the hanging valleys are held up by bodies of extremely resistant rock that have retarded the cutting action of their streams. But the reverse is actually true. These valleys are underlain by relatively unresistant rocks. As is explained on page 25 (see also fig. 2), the Merced Canyon from El Portal to the foothills traverses a broad belt of upturned, nearly vertical strata of sedimentary rocks-the worn-down remnants of the great rock folds that formed the northwestward-trending mountain ridges of Cretaceous time. The differences in resistance to stream wear of these upturned
The Merced Canyon, it should be added, is not the only canyon in the Sierra Nevada that has hanging side valleys in its unglaciated lower course. The canyons of the Stanislaus and San Joaquin Rivers notably have hanging side valleys down to points within a few miles of the foothills. Almost every one of these hanging side valleys has a northwesterly or southeasterly course. Those of the lower Stanislaus, being underlain by unresistant sedimentary rocks, are in process of being trenched by headward-growing gulches. (See topographic map of Copperopolis quadrangle.) Those of the lower San Joaquin, on the other hand, being carved in prevailingly massive granite, are as a rule well preserved. Their lips are but slightly notehed, and their waters still leap down abruptly in spectacular cascades and falls. (See topographic map of Kaiser quadrangle.)

\section{CORRELATION WITH HANGING VALLEYS OF THE YOSEMITE REGION}

In Figure 5, if the curve of the longitudinal profile of a hanging valley such as Saxon Gulch is prolonged forward to the axis of the Merced Canyon, the destroyed lower part of the valley may be "restored" with a fair degree of accuracy, and the level at which its streamlet 
formerly joined the master stream may be determined. The method assumes, of course, that there was originally no break in the profile, but this assumption is entirely justified, in view of the mature form of the valley and the smoothly concave curve of its profile, as far as it remains preserved. These two characteristics, which all the hanging valleys here concerned have in common, show that they were developed in a protracted epoch of undisturbed stream erosion-a "cycle of erosion," as it is termed-during which the side streams evolved smoothly graded courses down to the level of the master stream.

Applying this method of restoration to each of the hanging side valleys of the lower Merced Canyon yields a series of points indicative of the former level of the river. These points when plotted on the longitudinal profile of the Merced Canyon, as in Plate 27, $B$, are remarkably accordant. They lie on a smooth, flat curve that extends nearly parallel to the present profile of the river, though at a height of 1,400 to 1,500 feet above it. Doubtless this line represents the profile of the Merced at the stage which immediately trial shows that many of them do give accordant points.

The first hanging valley above El Portal is that of Crane Creek. It forms part of the Big Meadow flat, which evidently is closely related to the broad older valley floor into which the inner gorge is cut. The flat, it is true, was invaded by a lobe of the Yosemite Glacier that spilled over the low divide between the gorge and the flat, but that circumstance does not introduce any serious complication, for the lobe spread out with only moderate thickness and had therefore but slight excavating power. Besides, the flat is underlain by fairly resistant granite; hence it was presumably but very slightly deepened by the ice. The profile of the hanging valley, unfortunately, is rather short, owing to the rapid gulch cutting done by Crane Creek in its lower course, which is on the unresistant rocks that mark the zone of contact between thegranite and the sedimentary rocks near El Portal. Nevertheless, the profile, when carefully plotted, indicates a point on the mountainvalley profile of the Merced that accords well with the points already obtained. (See pl. $27, B$.)

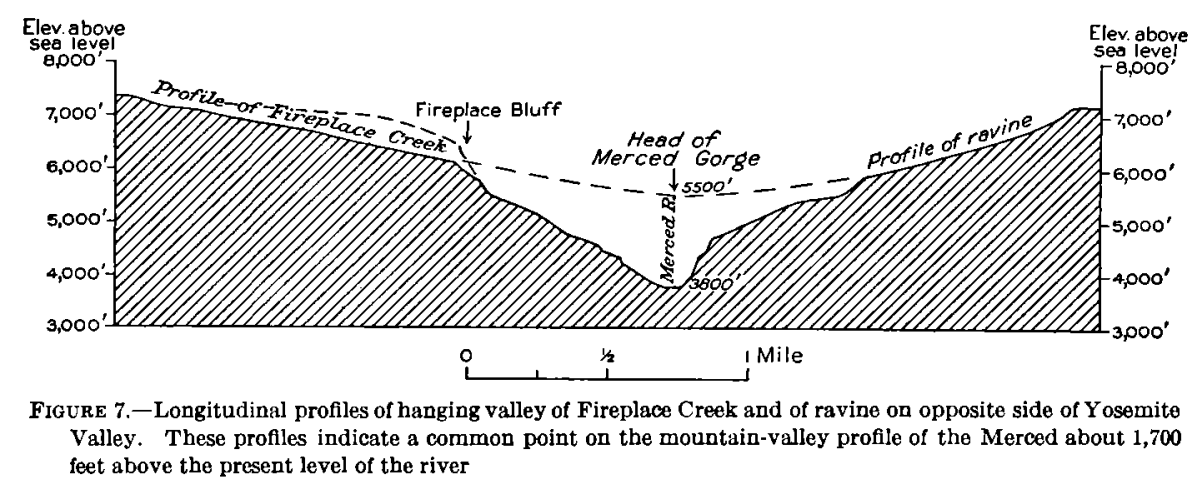

preceded the cutting of the inner gorge -in other words, it represents the profile of the Merced in the mountain-valley stage, which has been tentatively assigned to the end of the Pliocene epoch. It will be referred to hereafter, for the sake of brevity, as the mountain-valley profile.

The correctness of this interpretation being granted, it follows that not only the hanging valleys but the spurs and ridges between them must be remnants of the landscape of the mountain-valley stage-somewhat eroded, of course, during Quaternary time. The Quaternary erosion, however, has been in all probability slight, not more than 100 feet in the bottoms of the valleys. Allowance for this erosion has been made in plotting the profiles, but on the small scale on which they are here reproduced it is scarcely noticeable.

The question now arises, naturally, whether any of the hanging valleys in the Yosemite region belong to the same category. Are any of them remnants of the landscape of the mountain-valley stage? If so, their restored profiles should give points accordant with the old profile of the Merced established by the hanging side valleys of the lower Merced Canyon. Actual
About $3 \frac{112}{2}$ miles farther up is the hanging valley of Grouse Creek. This also presents certain complications, and its profile could scarcely be used in this connection without an intimate knowledge of local conditions. Grouse Creek, it would appear, has been deflected from its original lower course by a heavy embankment of glacial débris-the left lateral moraine of the Yosemite Glacier-and it now follows a new course, having broken through the embankment at a point half a mile farther south. Clearly the profile of the old course, which is still recognizable, is the one to be used, and when this is extended forward, it furnishes an accordant point.

It is scarcely necessary here to enter into the details of each individual valley: suffice it to say that throughout the Yosemite region there are hanging valleys that furnish accordant points for the extension of the mountain-valley profile of the Merced. Among them are the valley of Tamarack Creek, which has remained unglaciated and presents a simple case; the hanging valley of Fireplace Creek, which is likewise unglaciated (fig. 7); several small hanging valleys or ravines on the south side of the Yosemite chasm, opposite Fireplace 
Bluff; and similar hanging ravines on the north side, opposite the Pohono Bridge. The profiles of these little valleys and ravines are short, but the accurate contouring of the topographic map (pl.7) permits them to be extended forward with a fair degree of confidence.

Farther up in the Yosemite chasm are the hanging valleys of the two branches of Indian Creek. (See fig. 8.) These valleys, though repeatedly buried under ice to a depth of fully 600 feet, have suffered but slight excavation, for the ice came into them through the passes to the north and northeast and spread out as a partly inert mass that was held back by the powerful current of the passing Yosemite Glacier, much as backwater is held stagnant in a tributary channel by a swollen river. The profiles of these two hanging valleys should therefore be particularly valuable for an accurate determination of the mountain-valley profile of the Merced. They give, in fact, a common point for the extension of the profile. probably will permit its extension still farther, both toward the foothills of the Sierra Nevada and toward the crest.

It is possible likewise to reconstruct the mountainvalley profile of Tenaya Creek as far up as the head of Tenaya Canyon. The hanging valley of Snow Creek furnishes an accordant and valuable point, and the profile of the upper course of Tenaya Creek, which lies above the Tenaya Cascade, when duly corrected for glacial deepening, appears itself to lie directly in the line of continuation of the mountain-valley profile.

\section{SIGNIFICANCE OF HIGHER HANGING VALLEYS}

The reader may wonder why the hanging valleys just enumerated do not include those of Yosemite Creek and Bridalveil Creek. These two certainly stand preeminent among all the hanging valleys of the Yosemite region, being associated with its most famous waterfalls. The reason is that they do not accord

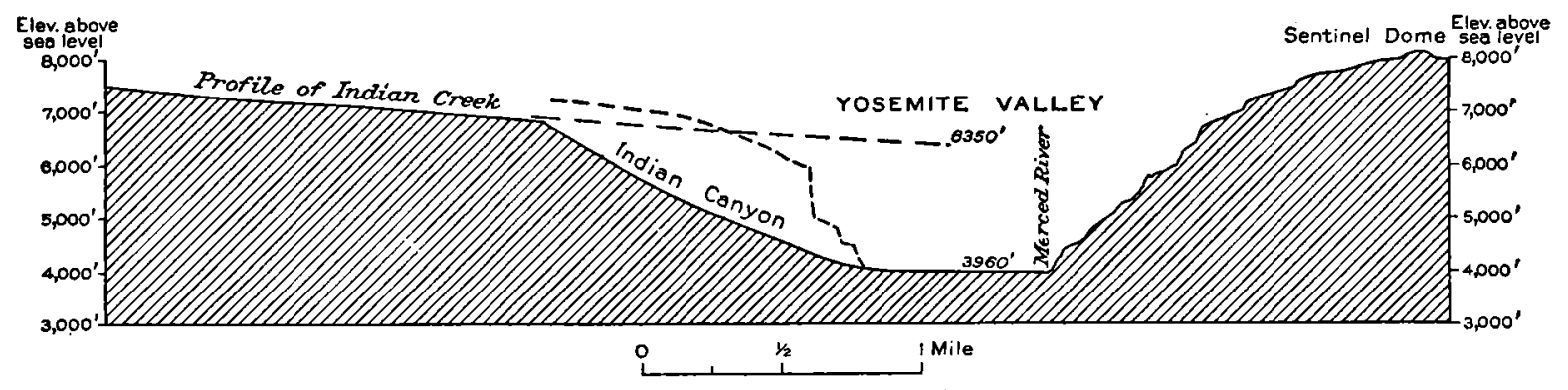

FIGURE 8.-Longitudinal profile of hanging valley of Indian Creek and section across Yosemite Valley to Sentinel Dome. The profle, extended forward, indicates the depth to which the Yosemite had been cut in the mountain-valley stage

At the extreme head of the Yosemite chasm is the hanging valley of Illilouette Creek. This valley has always seemed puzzling to students of the Yosemite region, as it hangs considerably lower than most of the other side valleys. The real difficulty is that the glacial history of this valley has hitherto been misunderstood. It has commonly been supposed that the Illilouette Valley was deepened by a powerful tributary glacier that came down from its own headwater basin, but it is now definitely established that most of the deepening was done by a massive lobe of ice that split from the Merced Glacier below the mouth of the Little Yosemite and that forced its way a short distance up the valley, thereby excavating the lower end with particular vigor. The profile of the Illilouette Valley, when properly corrected for this local glacial deepening, as well as for the considerable cutting done by Illilouette Creek, gives a point on the mountain-valley profile that accords well with the other points.

As will be clear from Plate $27, B$, the mountainvalley profile of the Merced can be extended up into the Little Yosemite by means of several points determined from short side valleys. The total distance over which this ancient profile of the river can be reconstructed with reasonable certainty is thus about 40 miles. Future research, aided by accurate mapping, with the other hanging valleys but belong to a separate category.

If the profile of the hanging valley of Yosemite Creek (fig. 9) is extended forward over the main chasm, duly corrected for the effects of stream erosion and glacial erosion, it is found to indicate for the Merced a former level about 700 feet higher than that of the mountain-valley profile. Similarly the extended profile of the upper part of the hanging valley of Bridalveil Creek (fig. 10) indicates for the river a former level nearly 900 feet above the mountain-valley profile.

These large disparities can not be due merely to inaccurate plotting of the profiles. These profiles have been plotted on a much larger scale than that of the published diagrams and with considerable care, in strict accordance with the contouring of the topographic maps. The probable error to be expected from that source is in the neighborhood of 50 feet for the detailed map of the valley (pl. 7) and in the neighborhood of 100 feet for the map of the park (pl. 2). Neither can the disparities be due to erroneous estimates of the depth of stream erosion and glacial erosion, for which allowance must be made in the restoration of the hanging valleys. Such estimates are necessarily approximate, it is true, but the observational data now at hand concerning each individual valley are so plentiful that there is scarcely any chance 
of errors as great as 900 feet, or even half as great, creeping in. Indeed, careful consideration of all the facts involved makes it entirely clear that the disparities are not errors susceptible of elimination by adjustment or compromise. The high levels indicated by the valleys of Yosemite Creek and Bridalveil Creek can not in any legitimate way be brought down, nor can the low levels indicated by the other set of valleys be raised so as to make all accordant.

It is highly significant, furthermore, that several other hanging valleys, those of Ribbon Creek, Cascade Creek, Meadow Brook, and Sentinel Creek, indicate for the Merced high levels closely accordant with those indicated by the valleys of Yosemite Creek and Bridalveil Creek. When plotted on the longitudinal profile of the Yosemite Valley, the points obtained from these hanging valleys are found to lie on a smooth, unbroken curve $(\mathrm{A}-\mathrm{A}, \mathrm{pl} .27, A)$ analogous to that which was previously interpreted as the Merced's profile of the mountain-valley stage but considerably higher and somewhat flatter. Evidently this curve represents a still older profile-namely, that of the broad-valley increases gradually in depth downstream and has a distinctly steeper gradient. The profile of this gorge, when extended forward, also meets the mountainvalley profile of the Merced, thus showing that Bridalveil Creek, like Yosemite Creek, had made some headway in gulch cutting during the mountain-valley stage.

The profile of Bridalveil Creek suffers a second break at $B$ (fig. 10), the part $B C$ being much steeper than the rest. This lower part is the profile of the V-shaped gulch between the Cathedral Rocks and the Leaning Tower through which the stream rushes to the precipice of the Bridalveil Fall. As the profile clearly shows, this gulch is not part of the upland valley properly so called but lies wholly below the brink. It is a feature produced during the canyon stage of the Yosemite Valley, which will be considered further on.

The establishment of the old profile of the Merced ( $A A$, pl. $27, A$ ) as the profile of the broad-valley stage leads to some interesting inferences. In the first place, it follows that the upland valleys from which its level has been determined-the upland valleys of Yosemite

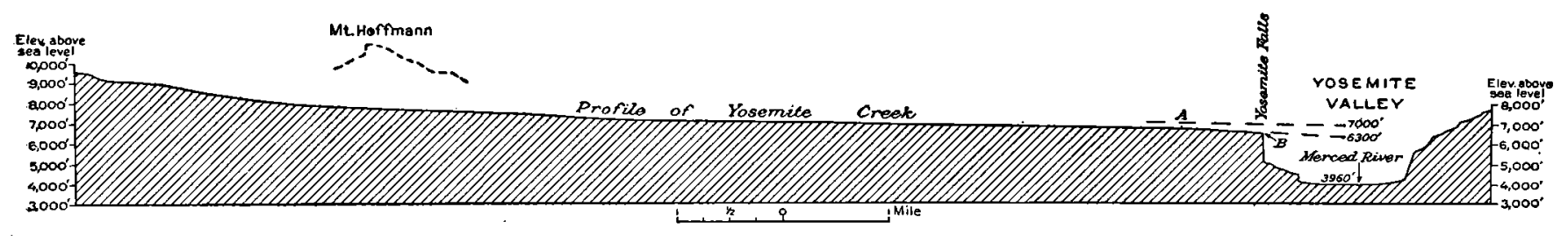

Figure 9.-Longitudinal profile of hanging valley of Yosemite Creek. Extended forward to the axis of the Yosemite Valley it indicates the level at which the Merced flowed in the broad-valley stage, about 700 feet above the level of the mountain-valley stage. The lower part of the hanging valley, from $A$ to $B$, was trenched and steepened by the stream presumably during the mountain-valley stage

stage, which antedated the mountain-valley stage and has been referred to late Miocene time.

The valleys of Yosemite Creek and Bridalveil Creek present certain peculiarities that would seem to strengthen this conclusion. The profile of the valley of Yosemite Creek (fig. 9) describes on the whole a remarkably smooth curve, yet it is broken at a point about 1 mile back from the brink and there becomes appreciably steeper. This lower part of the valley is quite unlike the prevailingly open upper part, being trenched by a narrow, rugged gorge through which the waters make a boisterous descent. Now the profile of this gorge, when extended forward, satisfactorily meets the mountain-valley profile of the Merced. It may be inferred, then, that while the Merced was carving its mountain valley Yosemite Creek was cutting a gulch at the mouth of its hanging valley in precisely the same fashion in which Feliciana Creek is cutting a gulch at the present time. The head of the gulch has reached a point about a mile back of the brink.

The profile of the valley of Bridalveil Creek is similarly broken and seems to indicate a similar history. As far down as the point marked " $A$ " in Figure 10 the valley is broadly open and characterized in places by gently sloping meadows. But from point $A$ to the brink $(B)$ it is trenched by a steep-walled gorge that
Creek, upper Bridalveil Creek, Sentinel Creek, Meadow Brook, Cascade Creek, and Ribbon Creek-are themselves remnants, only slightly modified, of the landscape of that early stage. That being granted, it follows further that the rounded hills and low mountains that form the divides between the valleys are also parts, somewhat modified, of that ancient landscape. In short, it appears that the configuration of the uplands is to-day, save for minor changes, still representative of the country as it was in that remote epoch (late Miocene) when the Yosemite region was a land of moderate altitude above the sea and when the Merced, as yet unaccelerated by any major uplifts of the Sierra block, wandered sluggishly in a broad-floored valley cut only a few hundred feet below the tops of the flanking ridges and hills.

This may seem a daring statement to make, for the time that has elapsed since those early days amounts probably to about $8,000,000$ years, and the erosive processes have been active throughout that period. However, it is to be borne in mind that the upland streams have small volume and for the most part gentle gradients and therefore slight cutting power; that the massive granitic rocks from which both hills and valleys are carved are exceptionally resistant; and that throughout most of the long interval, until the 
latest great uplift, the land was covered with luxuriant, dense vegetation promoted by a humid climate, so that the effectiveness of the erosional processes was minimized by a protective mat. Thus, it will be seen, several circumstances have combined to preserve the Yosemite upland in nearly its original state during those very epochs when the canyon of the Merced was being actively cut.

Probably the most conspicuous changes in the configuration of the upland were wrought by the glaciers of the ice age, which broadened and deepened some of the valleys, scraped and rounded the divides which they overrode, and hewed out the valley heads on some of the higher ridges into amphitheaterlike hollows. But those changes were confined only to certain parts of the upland. Large areas have remained uninvaded by the ice and therefore retain their preglacial configuration but slightly changed.

The vertical measure of the wearing down which the Yosemite upland has suffered, apart from the changes wrought by the ice, is in any event small-presumably less than 200 feet on an average-and accordingly it rock into plane-sided, sharp-edged blocks and slabs. Ordinarily the joints are spaced about a foot or a few feet apart, and a mountain of granite so jointed may be conceived as being composed of a great multitude of blocks and slabs accurately fitted together. The granitic rocks of the Yosemite region, however, are for the most part sparsely jointed, the intervals between fractures measuring tens or hundreds of feet, in some places even thousands of feet. (See pls. 35, $B, 36$, and 17.) The uplands, accordingly, are to be conceived as being made up in part of large blocks and sheets of granite, in part of huge monolith ${ }^{42}$ measuring hundreds: or thousands of feet in horizontal and vertical extent.

Now the rate at which a mass of igneous rock yields to the agents of decomposition and disintegration depends largely on the spacing of its joints, for every joint constitutes a plane of weakness. Through the joints water penetrates to the interior, carrying with it carbon dioxide and acids derived from decomposing vegetal matter, which dissolve the weaker minerals. In the joints also water congeals in freezing weather, exerting its well-known expansive force. Thus a closely

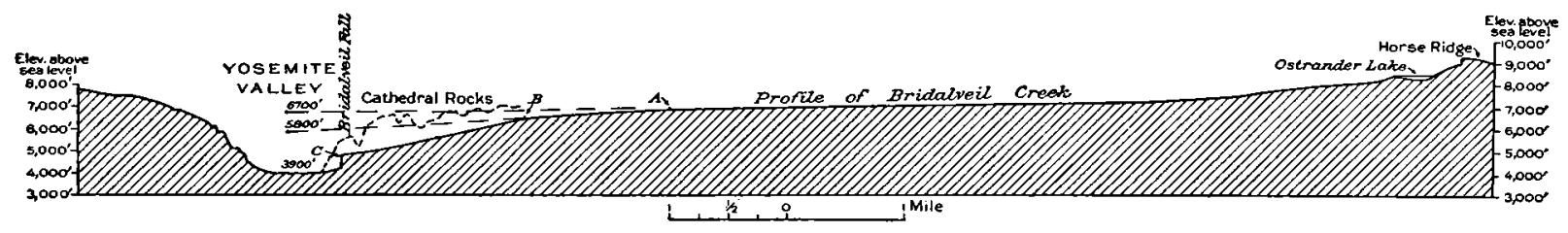

FigdRe 10.-Longitudinal profile of hanging valley of Bridalveil Creek. The upper part, as far down as $A$, belongs to the broad-valley stage; the middle part, from $A$ to $B$, was trenched and steepened during the mountain-valley stage; the lower part, from $B$ to $C$, was cut during the canyou stage

may be properly said that the present billowy topography of the upland is in a general way still representative of that which was evolved before the land acquired its present altitude.

\section{PRESERVATION OF THE YOSEMITE UPLAND ON MASSIVE GRANITE}

Of the various circumstances to which the Yosemite upland owes its preservation, the most influential by far is the exceeding durability of its massive granitic rocks. The massive structure of these rocks is, indeed, peculiar to the Yosemite region and is in large measure the cause of its distinctive sculpture. Only in a few other localities in the Sierra Nevada and in others widely scattered over the earth is there granite of comparable structure. It seems appropriate, therefore, to set forth the characteristics of this unusual material, in order that the reader may fully appreciate the part which it has played in the development of the Yosemite landscape.

All igneous rocks are characteristically traversed at intervals by straight or nearly straight fractures, commonly termed "joints" because they resemble the joints between stones in masonry. (See pl. 41, B.) Such fractures occur as a rule in parallel sets, three or more sets crossing one another in such a way as to divide the jointed mass of rock suffers attack from within as well as from without and tends to be converted into an aggregate of loose blocks. Manifestly, the more closely jointed the rock the more rapidly will it break up; and conversely the more sparsely jointed it is, the longer will it hold out. A huge monolith, being wholly devoid of fractures and vulnerable only at its surface, will endure for a very long time.

The rate at which streams cut their channels in igneous rocks also depends in large measure upon the spacing of the joints. For in hard rocks of this kind streams accomplish little by abrading with the sand and gravel they carry; they erode most effectively by plucking and removing entire joint blocks and joint slabs that have been partly loosened by solution and frost. This is evident from the hackled, angular configuration of their beds. It follows that in the Yosemite region, whose granitic rocks are very hard, channel erosion can proceed with some rapidity only where the rock is divided into small, light blocks or slabs. Wherever the rock is only sparsely fractured or wholly massivewherever, in other words, the individual blocks and slabs are too large and too heavy to be dislodged by the current-erosion is limited to the abrasive processes only and works at an extremely slow rate.

12 The term monolith was applied by the ancient Greeks to a column or monument composed of a single large block. 
How nearly impotenc even the most powerful stream of the Yosemite region is to erode massive granite may be readily seen at various points along the course of the Merced, notably above the Vernal and Nevada Falls. There in all the 10,000 years or more that has elapsed since the glaciers of the ice age melted away the river has worn its bed only a foot or two, in places only a few inches, below the polished surface left by the ice.

Thus the Yosemite upland and its hanging valleys have remained well preserved, in spite of their great age. The upland is limited, of course, to the area of the prevailingly massive granitic rocks. Its western border coincides in general with the western limit of those rocks, which follows an irregular line passing from north-northwest to south-southeast through The Gateway, at the elbow bend of the Merced Gorge. West of this line the granitic rocks are prevailingly fractured, and in the vicinity of El Portal they give place to the thin-bedded and generally shattered sedimentary rocks of the lower Sierra slope. There the country is deeply and intricately dissected, and only scattered remnants of the ancient upland surface remain preserved on narrow skeleton ridges and isolated peaks. Hanging upland valleys dating back to the broad-valley stage are wholly absent, and there are consequently no data for the extension of the broadvalley profile of the Merced. A tentative extension of that profile in a downstream direction (pl. 27, $A$ ) shows that it must have passed but little below the higher summits, such as Pinoche Peak and Trumbull Peak.

It may be asked, perhaps, why Indian Creek and Illilouette Creek were able to cut their valleys down to the level of the mountain-valley stage. The reason is that each of these streams flowed over more or less regularly jointed rock and thus had a decided advantage over those which flowed over prevailingly massive rock. Even in the relatively short interval that has elapsed since the second Sierra uplift (which initiated the canyon stage) these two streams have cut deep gulches at the mouths of their hanging valleys. Indian Creek, in spite of its small volume, has carved a gulch 1 mile in length (known as Indian Canyon), thereby depriving the Yosemite landscape of an additional waterfall. Illilouette Creek, though a much larger stream, has carved a gulch only half a mile in length, having to deal with more sparsely jointed rock. It still makes a waterfall 370 feet in height, its gulch cutting having been arrested by a body of massive granite.

Upstream the broad-valley profile of the Merced is readily extended into the Little Yosemite, for the upland south of that valley is also a large remnant of the broad-valley landscape, preserved on massive granite, and the hanging valley of the brook that runs through the Starr King Meadows furnishes a closely accordant point for the profile. (See pl, 27, A.) Still farther upstream the broad-valley profile of the Merced is more difficult to reconstruct, as the hanging side valleys have been deeply excavated by the glaciers of the ice age. Nevertheless, close study of these hanging valleys and of the high shoulders that extend on both sides of the main canyon trough leaves little doubt that these features, all of which are carved from prevailingly massive granite, are remnants, more or less modified by glaciation, of the ancient landscape of the broad-valley stage. That landscape can thus be traced all the way to the head of the drainage basin of the Merced, and it would appear that even there, in the heart of the High Sierra, the hanging valleys are not products of glacial action alone but are at least in part of preglacial origin, having been left hanging in the first instance through the rapid trenching of the Merced after the first great Sierra uplift.

\section{THE HALF-YOSEMITE AT WAWONA}

Hanging valleys and upland tracts that have remained preserved since remote geologic time as a result of the exceeding durability of massive granite are common throughout the southern half of the Sierra Nevada. Examples might be cited by the score, but one seems particularly deserving of mentionthat which is associated with the valley of the South Fork of the Merced near Wawona. (See pl. 2.)

This valley forms a wide basin in an otherwise narrow canyon and is in this respect analogous to the Yosemite Valley. But it is only what may be called a half-yosemite, for though it is flanked on the north by imposing cliffs, on the south it is flanked merely by low mountains and hills whose forested slopes descend at moderate angles. The cliffs on the north side rise abruptly 3,000 feet to the brink of a billowy upland and are adorned by a beautiful cascade, the Chilnualna Falls, which pours from the mouth of a typical hanging valley. (See fig. 11.) From the mountains and hills on the south side, by contrast, the streamlets descend through deeply cut valleys, without any cascades or falls. Indeed, the great height of the hanging valley of Chilnualna Creek and the upland of which it forms a part is rendered the more impressive because of the absence of an upland of equal height on the other side of the South Fork.

The explanation of this remarkable contrast in land sculpture on the two sides of the valley at Wawona is that on the north side the progress of erosion has been greatly retarded by the presence of massive granite comparable to that of the Yosemite region, whereas on the south side erosion has proceeded at a relatively rapid rate in prevailingly welljointed rocks, granitic and sedimentary. Particularly impressive is the fact that the valley of Chilnualna Creek remains in part untrenched, although it has a southwesterly course and consequently must have been steepened by each tilting of the Sierra block. Its 
general level corresponds to that of the upland valleys of Bridalveil and Yosemite Creeks, and it therefore forms part of the ancient landscape of the broadvalley stage. Only its lower portion appears to have been trenched and steepened during the mountainvalley stage.

It is highly significant, further, that the valley of the South Fork at and below Wawona is wholly a product of stream erosion and not in any measure of glacial erosion, for the boulder deposits that mark the farthest limits reached by the South Fork Glacier lie at and above Wawona. It follows that the hanging valley of Chilnualna Creek lies 2,000 feet above the valley of the South Fork solely because the creek has been unable to trench the massive granite of the upland as rapidly as the master stream has trenched the jointed rocks along its course.

\section{A THIRD SET OF HANGING VALLEYS}

Besides the two sets of hanging valleys from which the profiles of the broad-valley stage and the mountainvalley stage have been determined, there is still another set, situated at a lower level. These are really gulches ite chasm. Yet these hanging gulches hold the key to the Yosemite's most significant secret: they indicate the level to which the Merced had cut the valley immediately prior to the advent of the glaciers.

The depth to which any valley or canyon was cut before being remodeled by glacial action is as a rule impossible to ascertain with any degree of precision. In most localities only the roughest sort of approximation can be made, the glaciers having blurred or destroyed all vestiges of the preglacial topography. The Yosemite is exceptional in this respect: several features of its preglacial topography remain preserved, and these are of such a kind as to afford a clue to the depth to which the chasm had been cut by the Merced before the glaciers began their work. This is truly a fortunate circumstance, for the Yosemite problem centers about the question, How much excavating was done by the river, and how much by the glaciers?

The profile in Figure 12 shows that the gulch of Bridalveil Creek lies wholly below the level to which the Yosemite had been cut in the mountain-valley stage. What is equally significant, the lower part of the flanking spur surmounted by the Cathedral Rocks,

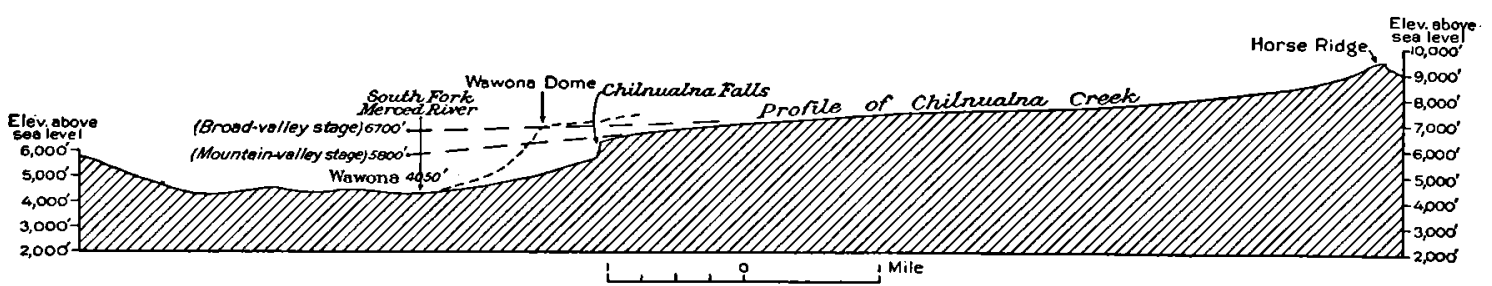

FIGURE 11.-Longitudinal profle of hanging valley of Chilnualna Creek and section across the "half-yosemite" of the South Fork of the Merced at Wawona. The hanging valley belongs to the brosd-valley stage. Only its lower portion appears to have been cut down to the level of the mountain-valley stage

rather than valleys, for their gradients are very steep. The largest is the hanging gulch from whose mouth the Bridalveil Fall leaps. (See pl. 3.) It terminates at a height of only 850 feet above the floor of the Yosemite Valley, or fully 1,600 feet below the mouth of the upland valley of Bridalveil Creek. Another example is the hanging gulch of Royal Arch Creek, which terminates at the shoulder above the Royal Arches, at a height of 1,400 feet above the main valley. To the same set belong also the gulches of Cascade Creek and Tamarack Creek, which unite just above the brink of the Merced Gorge below the valley, at a height of 650 feet above the river; and the gulch of Wildcat Creek, which terminates at the brink of the gorge at a height of 700 feet.

None of these hanging gulches have been given prominence in the literature on the Yosemite Valley, probably because they are only minor features in the landscape and because their streams and falls have but small volume. Even the gulch of Bridalveil Creek has received but scant attention, although it is associated with one of the world's most famous waterfalls and is itself a decidedly anomalous feature, projecting on a boldly sculptured promontory far out into the Yosem- including the lowest of their three summits, also lies below that level. It is clear, then, that all these features have been carved since the mountain-valley stage during that cycle of vigorous erosion which produced the canyon stage. To some extent, of course, they have suffered erosion also during glacial and postglacial time, but their configuration is such as to show beyond a doubt that they are primarily stream-cut features of the canyon stage.

The gulch of Bridalveil Creek is sharply V-shaped and in general exhibits the characteristic forms of stream erosion but hardly any marks of glacial erosion. True, it has been completely submerged by the highest ice floods, for it lies below the level of the highest moraines (see pp. 64-65), but evidently it has not been exposed to the full force of the Yosemite Glacier, being protected by the mighty bulwark of the Cathedral Rocks. Even when that bulwark was overwhelmed by the ice, as must have happened at least twice during the glacial history of the valley, the gulch was filled mostly with stagnant ice that was held imprisoned by the main current of the Yosemite Glacier, as backwater is held imprisoned in a side slough by a powerful river. Nor is there any evidence 
that the gulch has ever been traversed lengthwise by an actively excavating tributary glacier. On the contrary, the moraines on the upland show that the feeble Bridalveil Glacier failed to reach the brink of the chasm, save at the time of maximum glaciation, when the chasm was filled with ice literally to the brim.

Stream erosion effected during and since glacial time accounts probably for only a small part of the total depth of the gulch. The clean-cut form of the lip of the gulch, which is not marred by any streamcarved notch or recess, shows in itself that stream erosion proceeds but very slowly here owing to the resistant nature of the granite. The effects produced by stream erosion since the glacial epoch are in fact negligible, and the cutting accomplished by it during glacial and interglacial time aggregates probably but little over 100 feet. In the profile (fig. 12), therefore, which these cliffs cut off the gulches as well as the flanking spurs shows that they were produced later than those features of the canyon stage and by an agency that worked in a different way and with much greater vigor than the streams. Their sheer profiles, their prevailingly straight or smoothly curved courses, and their alinement essentially parallel to the axis of the main chasm, moreover, show plainly that that agency was a glaciera mighty glacier that forced its way lengthwise through the chasm. (The processes whereby glaciers operate to produce such cliffs are explained on pp. 89-91.) It may be concluded, then, that whereas the gulches are essentially preglacial features, the cliffs in which they terminate are glacial features produced during the ice age.

It is not desired to imply, however, that all the excavating done in the main chasm below the lips of

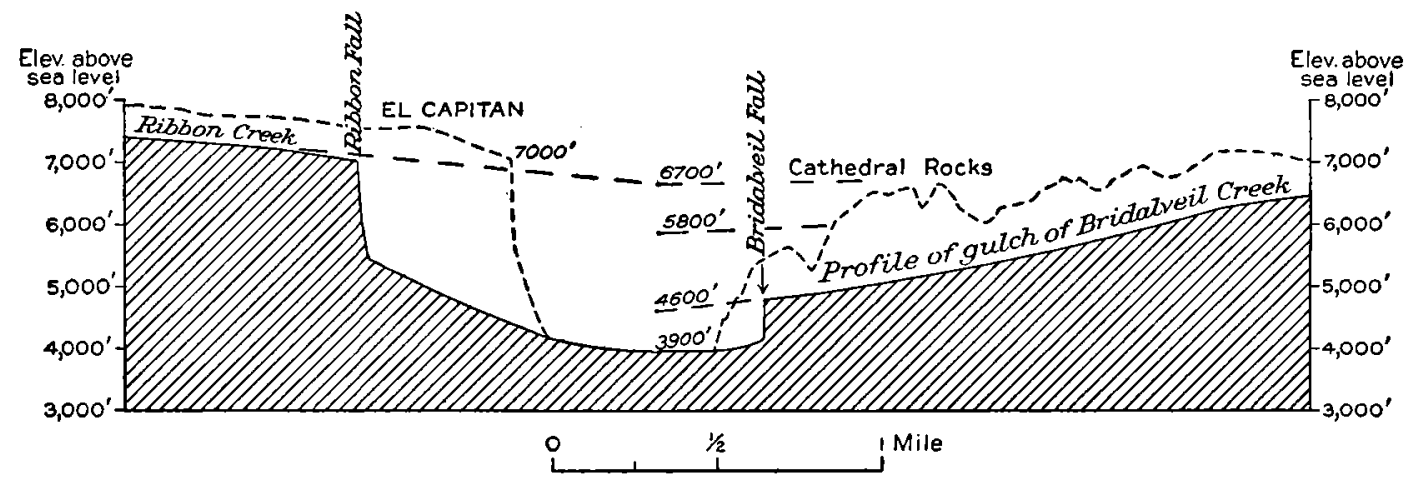

FIGURE 12.-Longitudinal proflles of hanging gulch of Bridalveil Creek and of hanging upland valley of Ribbon Creek. The former indicates the depth to which the Yosemite had been cut in the canyon stage, before it was invaded by any glaciers of the ice age. The latter indicates its depth in the broad-valley stage. The difference in level, 2,100 feet, is the total depth of cutting done by the Merced during the mountain-valley and canyon stages. From this diagram it is manifest that the Yosemite prior to the ice age had a depth of 2,400 feet, measured from the brow of El Capitan

an allowance of that amount has been made for stream erosion since the canyon stage.

It can be demonstrated, similarly, that none of the other hanging gulches mentioned have been deepened appreciably by glacial erosion, in spite of the fact that they have all been submerged by the highest ice flood. The spurs flanking them have been in part planed away by the ice, but the gulches themselves evidently were sufficiently recessed in the sides of the chasm to escape the eroding force of the glacier's current. Probably they were filled by feeble eddies at the margin of the ice stream. Neither is there any indication that any of the gulches have been exposed to the eroding action of tributary glaciers. The cutting done by their respective streamlets during and after the ice age is probably even less than that done by Bridalveil Creek. It may be properly concluded, then, in view of these considerations, that the hanging gulches all are primarily features left over from the canyon stage.

Quite different is the story told by the cliffs at the mouths of the hanging gulches. The abruptness with the hanging gulches was performed by the ice. The glaciers did not work continuously throughout the ice age but were interrupted by long intervals of relatively mild climate, when they melted back to their sources, or nearly so, and the streams resumed their normal activities. Doubtless, therefore, that part of the cross section of the Yosemite Valley which lies below the lips of the hanging gulches represents stream work as well as glacier work accomplished during the ice age. But the glacier work clearly was greatly preponderant, for the cliffs are characteristic glacial features, and the configuration of the bottom of the valley, in so far as it is not modified by postglacial stream work, has the characteristic form of a glacier bed. It is permissible, then, to speak of the lower part of the valley, below the lips of the hanging gulches, as the glacially excavated part.

It follows from all this that the profiles of the hanging gulches, if extended forward by the method applied to the profiles of the hanging valleys above them, should indicate very closely the depth to which the Yosemite Valley had been cut by the beginning of the ice age. 


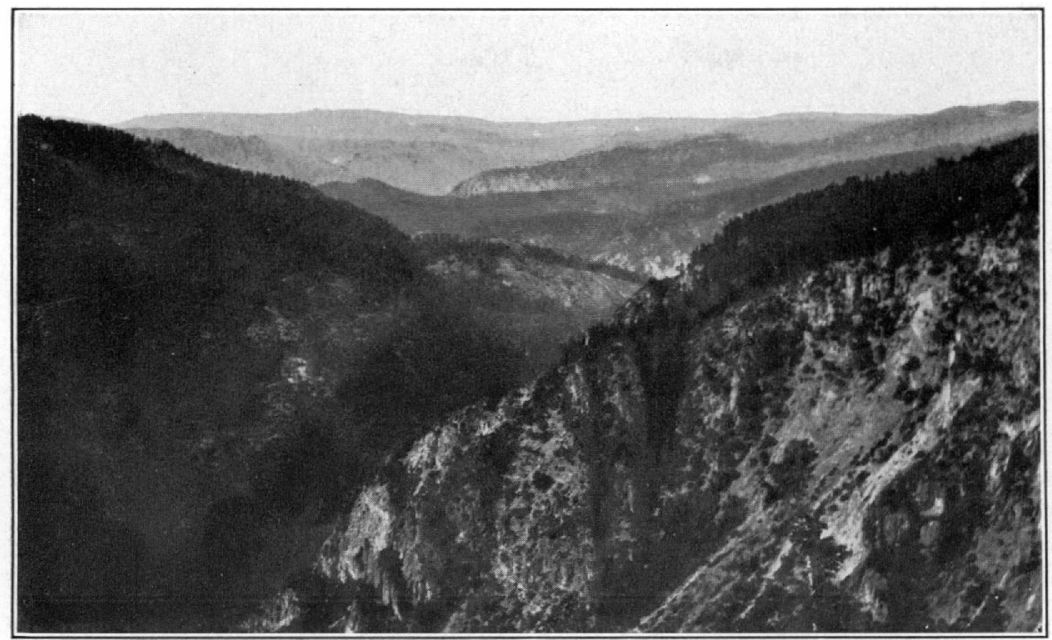

A. VIEW DOWN LOWER MERCED CANYON FHOM EL CAPITAN

The landscape has three dislinel sels of elements, indicative of three stages in the development of the Merced Cunyon. The level-topped ridges at the sky line end in gentle opposing slopes that oulline dimly a very broad, shallow valley of greal antiquity. The steeper slopes below and the broad llats to which they descend outline clearly the sides and floor of at deeper valley cul al in less remole cpoch. Abruptly incised in the llow of this valley is a narrow, stertp-sulled porge of relatively recent origin. The Merced flows at the bollom of this gorte and is still actively an-
gaged in lurther decpening it. Pholograph by $\mathbf{F}$. C... Calkins.

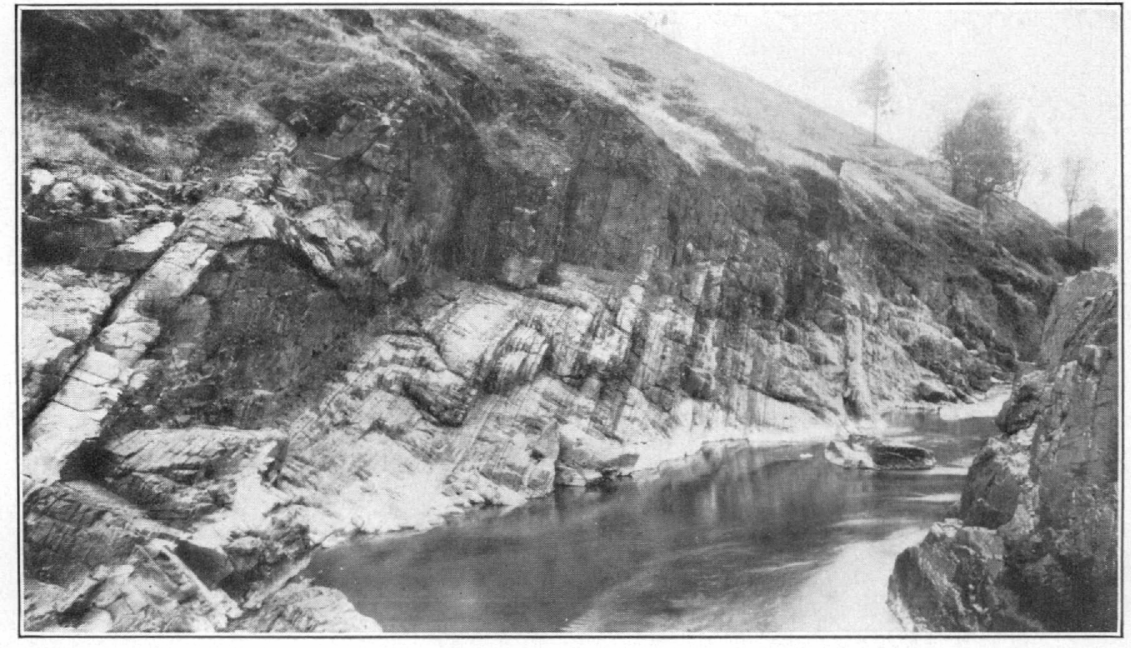

is. UPTURNED BEDS UF SLATE AND SCHIST IN LOWER MEHCED CANYON

These upturned strata are the remnints of the huge wrinkles in the carth $\mathrm{s}$ crust of which the earlier mountains on the site of the present Sirrea Nevada were composed. Plotograph by F. (. Calkins.

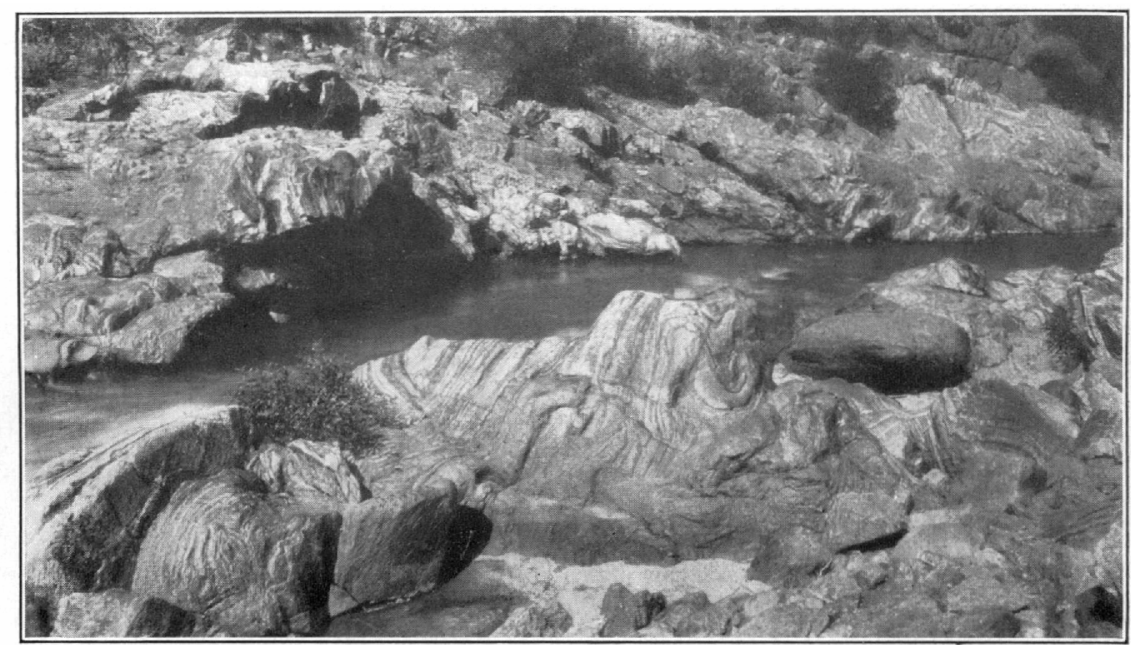

c. CONTORTED LAYEHS OF CHEHT EX POSED IN HED OF MEHCED RIVER

Their crumpled appeurance altests inpressively the intense pressure to which the earthis crust was subjected here at the lime when the earlier mountains were made. pholograph by $\mathrm{F}$. C. Calkins. 


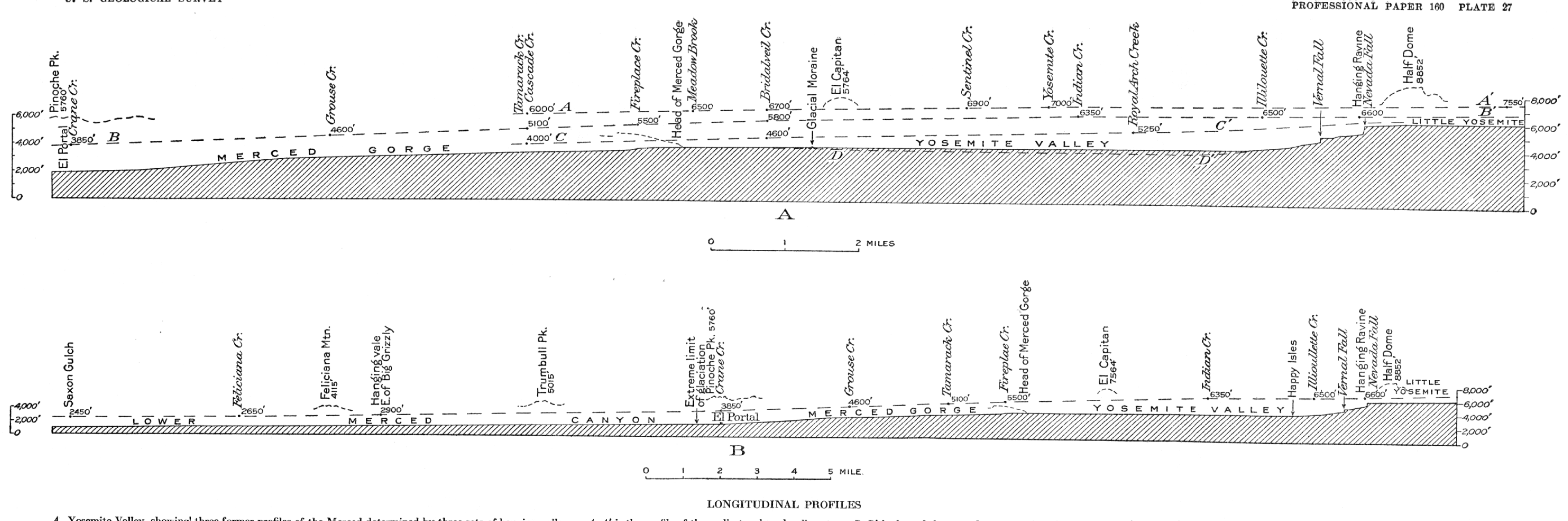

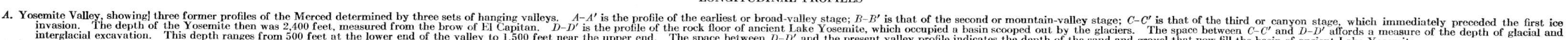

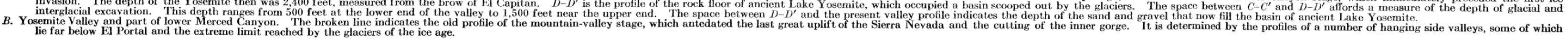




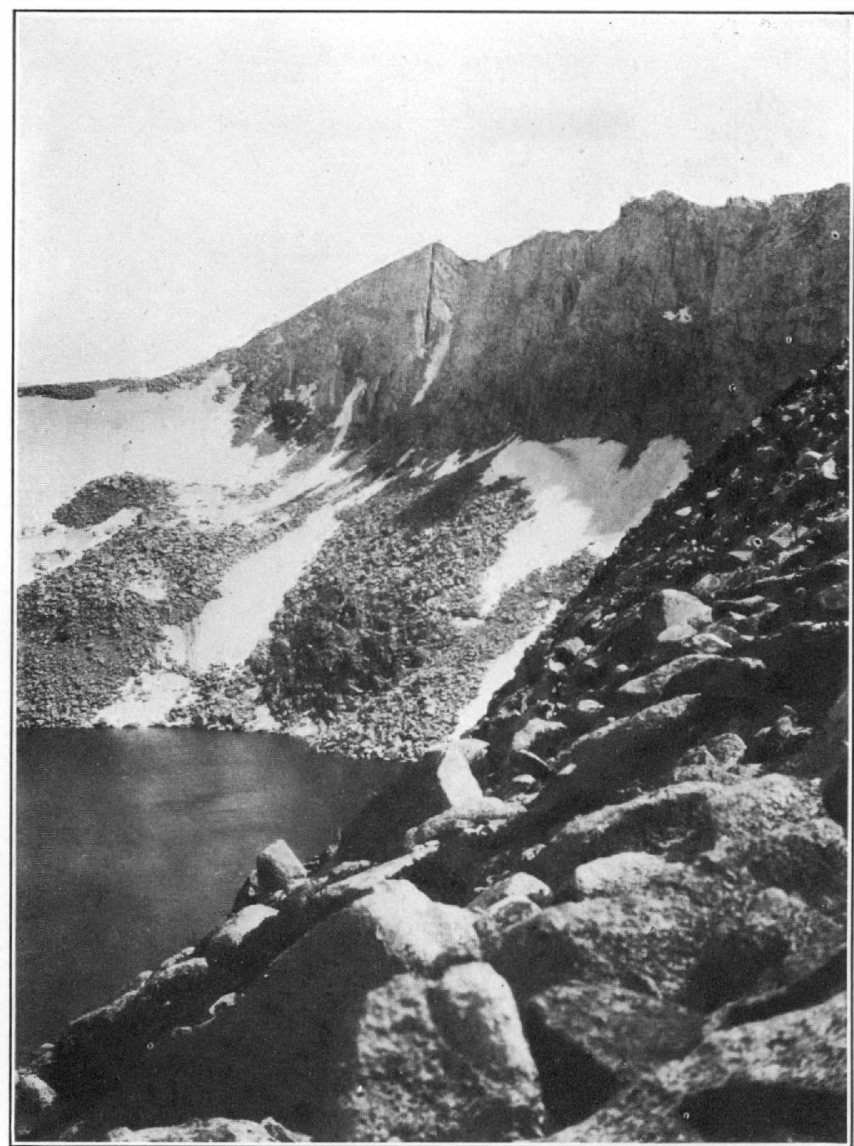

A. EMPTY CIRQUE ON SIIADY NORTIIEAST SIDE OF KUNA CREST

Deep amplithealerlike hollows of this kind nere the soures of the amcient Sierra placiers. Urionally sharp-cul valloy heids, they have been enlarged glaciers Most of them have rock-rimrmed like bisiess in their flours. Photogruph by G. h. Gilhert.

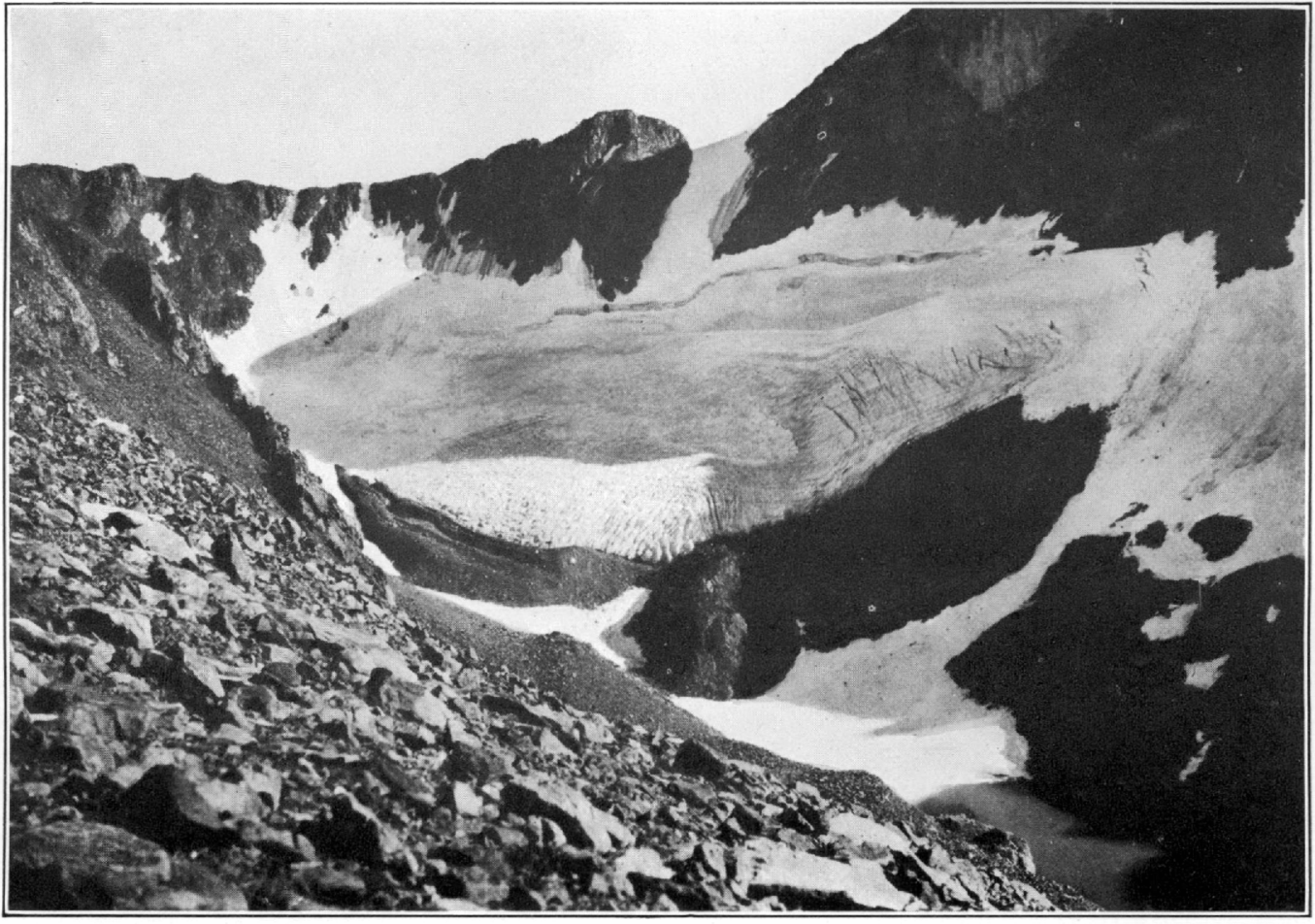

B. DANA GLACIER

The Dana Giacier occupies the shaded side of a cirque cut by a much larger flacier of the ice age. At its front are several moraine ridges composed of rork débris. Pholograph by $G$. K. Gilbert. 

PREgLACIAL PROFILE OF THE YOSEMITE VALLEY

The altitude of the preglacial floor of the Yosemite Valley, indicated by the profile of Bridalveil Creek in Figure 12, appears to be about 4,600 feet-that is, 700 feet higher than the present floor. The levels indicated by the profiles of the other gulches are entirely consistent with it, and when plotted on the longitudinal profile of the Yosemite Valley (pl. 27, $A$ ) are found to lie on a smooth curve analogous to the two older profiles of the Merced but more strongly concave. The very smoothness and regularity of this curve would seem to confirm the belief that it truly represents the profile of the preglacial canyon floor. It can be drawn from the elbow bend of the Merced Gorge to the mouth of the Little Yosemite Valley.

Of peculiar interest is the rapidly increasing steepness of the profile toward the head of the Yosemite Valley. It shows that during the canyon stage the Merced was still cutting its inner gorge headward and had not yet carried it up to the Iittle Yosemite. The abrupt headward termination of the gorge was due in part, doubtless, to the fact that above the junction of Tenaya Creek and Illilouette Creek the river had less volume and consequently less cutting power than below; but of much greater influence, probably, was the fact that at the head of the chasm the relatively well jointed Sentinel granodiorite is replaced by the prevailingly massive Half Dome quartz monzonite, which is exceedingly resistant to stream erosion. The boundary between these two types of rocks crosses the head of the Yosemite Valley, as may be seen on the map in Plate 51.

Up along the course of Tenaya Creek, however, a branch of the inner gorge extended probably for a distance of several miles, for, though Tenaya Creek has small volume, its cutting action was favored by the presence of a zone of fractures in the granite, the same zone which even now enables Tenaya Creek to trench more effectively than the Merced River above the Yosemite Valley.

The profile of the canyon stage, as drawn in Plate 27, $A$, permits fairly definite answers to be given to the crucial questions, To what depth was the Yosemite cut by the Merced prior to the ice age, and how much deeper was it cut by the glaciers? The space between the profile of the broad-valley stage $\left(A-A^{\prime}\right)$ and the profile of the canyon stage $\left(\mathrm{C}-\mathrm{C}^{\prime}\right)$ gives the measure of the stream cutting, and the space between the canyon profile $\left(\mathrm{C}-\mathrm{C}^{\prime}\right)$ and the profile of the glacially carved rock bottom of the valley (D- $\left.\mathrm{D}^{\prime}\right)$ gives the measure of the glacial cutting, including whatever stream cutting was accomplished during interglacial time.

The depth of the preglacial stream cutting ranges from 1,600 feet at the head of the chasm to 2,100 feet at its lower end; the glacial cutting, on the other hand, increases from 500 feet at the lower end to fully 1,500 feet at the head. A better appreciation of the great depth to which the Yosemite had been cut by the beginning of the ice age may be gained from the statement that its depth measured from the brow of El Capitan was then fully 2,400 feet (compared with 3,000 feet at the present time), and its depth below the promontory of Glacier Point was about 2,000 feet (compared with 3,200 feet at the present time).

\section{INTERPRETATION OF OLDER PROFILES}

The two older profiles of the Merced (pl. 27, $A$ ) still require a bit of scrutiny. To the layman they may seem to be mere lines in a diagram, but to the geologist they convey a wealth of information concerning the configuration of the Yosemite region at each of the early stages which they represent. What is more, they afford a basis for estimates of the magnitude of the two great Sierra uplifts that caused the Merced to trench so deeply. Indeed, most of the foregoing story of successive uplifts and periods of valley and canyon cutting and all the figures that have been given for the height of the Sierra Nevada and the depth of the Yosemite Valley at each stage are based largely on these profiles.

In Plate 27, $A$, both profiles appear as they now are, steepened by the tiltings of the Sierra block. The mountain-valley profile has been steepened by one tilting, the broad-valley profile by two tiltings. It is thus clear that originally both had much flatter slopes. By what method can these original slopes be ascertained?

Professor Lindgren, ${ }^{43}$ in his studies on the goldbearing gravel in the ancient stream beds of the northern Sierra Nevada, found that the profiles of these ancient stream beds, when plotted with care, exhibit steep stretches alternating with relatively flat stretches. The slope of each stretch depends upon its trend with respect to the general slope of the range. Naturally those stretches which trend westsouthwestward, directly down the slope of the range, are steepest, having been most strongly affected by the tilting; those stretches which trend at considerable angles to the direction of the tilting are less steep; and those few stretches which trend east-northeast-. ward, in a direction opposite to the tilting, are flattest or even slightly reversed. Most instructive, however, are those stretches that have north-northwesterly or south-southeasterly trends, at right angles to the direction of the tilting, for they have been neither steepened nor flattened by the tilting and still have their original slopes. There are a sufficient number of such stretches to afford a fair conception of the prevailing slopes of the ancient rivers in the northern part of the Sierra Nevada.

43 Lindgren, Waldemar, The Tertiary gravels of the Slerrs Nevada of California: U. S. Geol. Survey Prof. Paper 73, pp. 46-48, pl. 10, 1911. 
The Merced in the Yosemite Valley has but one stretch with northwesterly trend that might possibly afford such indication of its former slope-the stretch from the mouth of Illilouette Creek to the mouth of Indian Creek. This stretch is only $2 \frac{1}{2}$ miles long, scarcely long enough to serve as a basis for definite figures, yet it deserves to be considered in this connection. In the mountain-valley profile in Plate 27, $A$, this stretch has a slope of only 60 feet to the mile, whereas the southwesterly stretch immediately below averages 140 feet to the mile, and the southwesterly stretch immediately above rises to about 175 feet to the mile. From these figures it may be inferred that this part of the Merced's course was steepened by the last tilting from an original slope of about 60 feet to the mile to the present average slope of 150 feet-that is, by about 90 feet.

However rough these data may be, they are in any event consistent and of the kind to be expected. Moreover, they harmonize remarkably well with those which Lindgren obtained for a number of northern rivers and also with those which the present writer has obtained for the San Joaquin. They may, therefore, be tentatively adopted as representative in a general way. A slope of 60 feet, it may be added, is entirely compatible with the volume and character of the Merced and with the conditions of flow that must have prevailed during the mountain-valley stage.

The original slope of the broad-valley stage is less readily determined, for the profile of that stage, as it appears in Plate 27, $A$, has been steepened by two uplifts, and, besides, it is not controlled by a sufficient number of points to afford any definite data for the northwesterly stretch from Illilouette Creek to Indian Creek. However, a rough approximation can be made for it. The last tilting, as has just been shown, steepened the slope of the mountain valley by about 90 feet, and it must therefore have steepened the slope of the broad valley by the same amount. Deducting 90 from 114, the slope indicated in Plate 27, $A$, leaves 24 feet to the mile as the slope prior to the last tilting. The slope prior to the first tilting must have been still less, presumably in the neighborhood of 12 feet to the mile. The remarkable smoothness of the broadvalley profile and its near approach to a straight line up to a point within a short distance of the sources of the river show that the river's course was "well graded"-that is, had reached a stage in which, as a result of long-continued erosion, a flat, smooth slope had been evolved.

To explain in detail how, with the aid of these slopes of the Merced River in the broad-valley and mountainvalley stages, the increase in the height of the range with each uplift may be computed would lead beyond the bounds of this paper. Suffice it to say that the extension of each of the profiles toward the foothills and the similar extension of the old profiles of the San
Joaquin and the northern rivers investigated by Lindgren permit the hinge line of the Sierra block-that is, the line east of which the block was elevated and west of which the block was depressed--to be determined approximately for each stage. From this zero line as a base it is possible to calculate within reasonable limits the altitude of the crest of the range and likewise the altitude of the Yosemite for each stage.

Mount Lyell, which at present stands 13,090 feet above the sea, accordingly, appears to have had an altitude of about 4,000 feet in the broad-valley stage (at the end of the Miocene epoch) and of about 7,000 feet in the mountain-valley stage (at the end of the Pliocene epoch). The first uplift, in other words, raised the crest of the Sierra Nevada at the head of the Merced River about 3,000 feet; and the second uplift raised it about 6,000 feet more. The Yosemite Valley, or rather, that part of the Merced's valley which ultimately became the Yosemite, had an altitude of only about 800 feet in the broad-valley stage and of about 1,800 feet in the mountain-valley stage.

Many other deductions of interest may be based upon the two old profiles of the Merced. To a geologist familiar with the laws that govern the eroding action of streams and with the laws of valley development in general, these profiles, together with their original slopes, as determined approximately, are suggestive of the character and aspect which the valley of the Merced in general, and the Yosemite Valley in particu. lar, must have had at each of those two remote stages.

Thus the flatness and straightness of the broad valley profile indicate for the valley of late Miocene time a very mature stage of development, such as could have been attained only by erosion during a long period of prevailing stability of the land. They show that the river was cutting but feebly and in the lower part of its course was gradually broadening its valley and creating what is termed a "flood plain." The steeper slope and the more pronouncedly concave curvature of the mountain-valley profile, on the other hand, indicate for the valley of late Pliocene time a much less mature stage of development. Evidently the interval of time between the first uplift and the second, though of long duration, was much shorter than that during which the broad-valley profile had been evolved. It was not long enough, in any event, to enable the Merced to produce a flat, even slope more than halfway up to its source. Within the length of the Yosemite alone the slope increased headward from 50 feet to 90 feet to the mile. In this part of its course doubtless the Merced was still a swift and actively cutting mountain stream, and its valley narrowed gradually headward to a simple $\mathrm{V}$ shape.

The inferences drawn from the two old profiles of the Merced accord closely with the indications as to the character of the two older valleys that are afforded by the features of the landscape of to-day and also with 
the story told by the hanging valleys. There is thus available from these three sources a considerable mass of data, consistent among themselves and in large part of a quantitative nature, from which the landscape of the Yosemite at each of these two stages in its evolution can be reconstructed in imagination.

\section{EVOLUTION OF THE YOSEMITE VALLEY IN PREGLACIAL TIME}

LANDSCAPE OF BROAD-VALLEY STAGE

Although the broad-valley stage is the most remote, antedating the mountain-valley stage by probably $6,000,000$ years and the canyon stage by perhaps $7,000,000$ years, it is not difficult to picture the Yosemite at that early time, for its longitudinal profile and the profiles of several of its tributary valleys at that stage are definitely known, and the shapes of the flanking hills and ridges remain to-day but slightly changed. There are thus plenty of data from which a bird's-eye view such as that shown in Figure 13 may be constructed. This bird's-eye view the reader is requested to compare with the views following and also with Plate 15, representing the Yosemite Valley in its present state. All the views are from the same assumed high point and are drawn to scale.

The Yosemite in the broad-valley stage was a broadly open, level-floored valley flanked by rolling hills. Most of these hills stood between 500 and 1,000 feet above the valley. The crown of El Capitan, which then had much the same rounded contour as now, rose in gentle curves to a height of 900 feet. Sentinel Dome stood somewhat more than 1,000 feet high, and Half Dome, as yet a bulky, irregularly shaped mass that fell off on the northwest side in a steep, ravined slope, but not a cliff, reared its summit 1,500 feet above the valley.

The landscape as a whole was characterized by subdued, billowy forms and smooth, curving lines. Cliffs, pinnacles, and other angular rock forms were absent. The Cathedral Rocks were represented only by a massive, hummocky spur that sloped down gradually to the valley floor. The Leaning Tower did not yet lean but was a mere knob on another, somewhat narrower spur. The Cathedral Spires and Sentinel Rock were still to be carved from the sloping south side of the valley, and the high ridge on which Glacier Point is situated was not yet cut off by a precipice but continued northward in the form of a projecting spur. Another still longer spur sloped from the base of Half Dome down to the confluence of Tenaya Creek and the Merced River.

Neither were there any waterfalls or cascades in the landscape. The tributary streams, without exception, entered the main valley at the level of its floor and emptied into the placid master stream with scarcely a ripple. The giant stairway at the mouth of the Little Yosemite had not yet been hewn, the Merced winding lazily in serpentine curves down a gently sloping valley floor. Tenaya Creek occupied a valley commensurate in size with its small volume-a valley that lay somewhat higher than the path of the Merced and was flanked mostly by wooded slopes. The entire region was densely covered by rain-loving vegetation, which included such species as laurel, magnolia, maple, sycamore, and willow. It is probable, nevertheless, that Clouds Rest already had some cliffs of bare granite, and that Mount Starr King had much the same domed form that it has today, for massive granite produces cliffs and domes even in regions of humid climate, as is attested by Stone Mountain, in Georgia, and other mountains in the southern Appalachian region.

The peaks and crest of the High Sierra stood far above the general level of the country, just as they now stand above the Yosemite upland, but they were full-bodied and rounded in contour, instead of angular and hollow-sided, as they now are; they were simply wooded mountains, no more distinguished in appearance than many others of to-day. Their sides sloped down in gentle curves to the broad floors of the Merced and Tuolumne Basins, neither of which had yet been trenched below the shoulders and benches that now flank them.

\section{LANDSCAPE OF MOUNTAIN-VALLEY STAGE}

The mountain-valley stage of the Yosemite Valley is less easy to portray than the broad-valley stage, for the valley had become much deeper and more complexly modeled. As may be seen in Figure 14 the Yosemite had developed into a broadly V-shaped and fairly rugged mountain valley about 1,600 feet in depth. On both sides it was flanked by uplands, a number of its tributary valleys not having been cut down to its level. No sharp rims defined the edges of the uplands, but the change in declivity from upland surface to valley side was fairly abrupt. El Capitan had a distinct brow separating its rounded summit from the new, steep slope below. The brow rose 1,200 feet above the floor of the valley, but the drop was distributed over a horizontal distance of about half a mile, and consequently the slope was not marked by precipitous cliffs. Probably it was, like the valley sides elsewhere, largely wooded, though, owing to the massive structure of the granite, it must have been studded with crags and pinnacles.

The Cathedral Rocks formed an asymmetric spur, much steeper on the east side than on the west and surmounted by two knobs corresponding to the two higher summits of the present group. The highest of these knobs stood about 900 feet above the floor of the valley. The third and lowest summit of the present group was still to be hewn from the rock below the level of the valley floor.

The Cathedral Spires and the other crags in their nejghborhood were only dimly foreshadowed by rocky spurs separated by deep ravines. In the 
place of Sentinel Rock there was an irregularly shaped spur that projected far out into the valley and deflected the river to the north. Eagle Peak, on the other hand, less sharply attenuated than it is to-day, was the culminating summit of a massive asymmetric spur that deflected the river to the south. It stood fully 1,700 feet above the valley.

Half Dome was probably a long ridge, whose northwest side, furrowed by ravines and mostly wooded,
The most distinctive feature of the Yosemite landscape of that early epoch was the array of foaming cascades that descended from the mouths of the hanging upland valleys. Of leaping waterfalls such as adorn the sides of the Yosemite to-day there probably were none, but the descent of the streams was abrupt enough to cause their waters to break into cascades. Yosemite Creek tumbled from a hanging valley 600 feet high. As is shown by its profile, it had carved

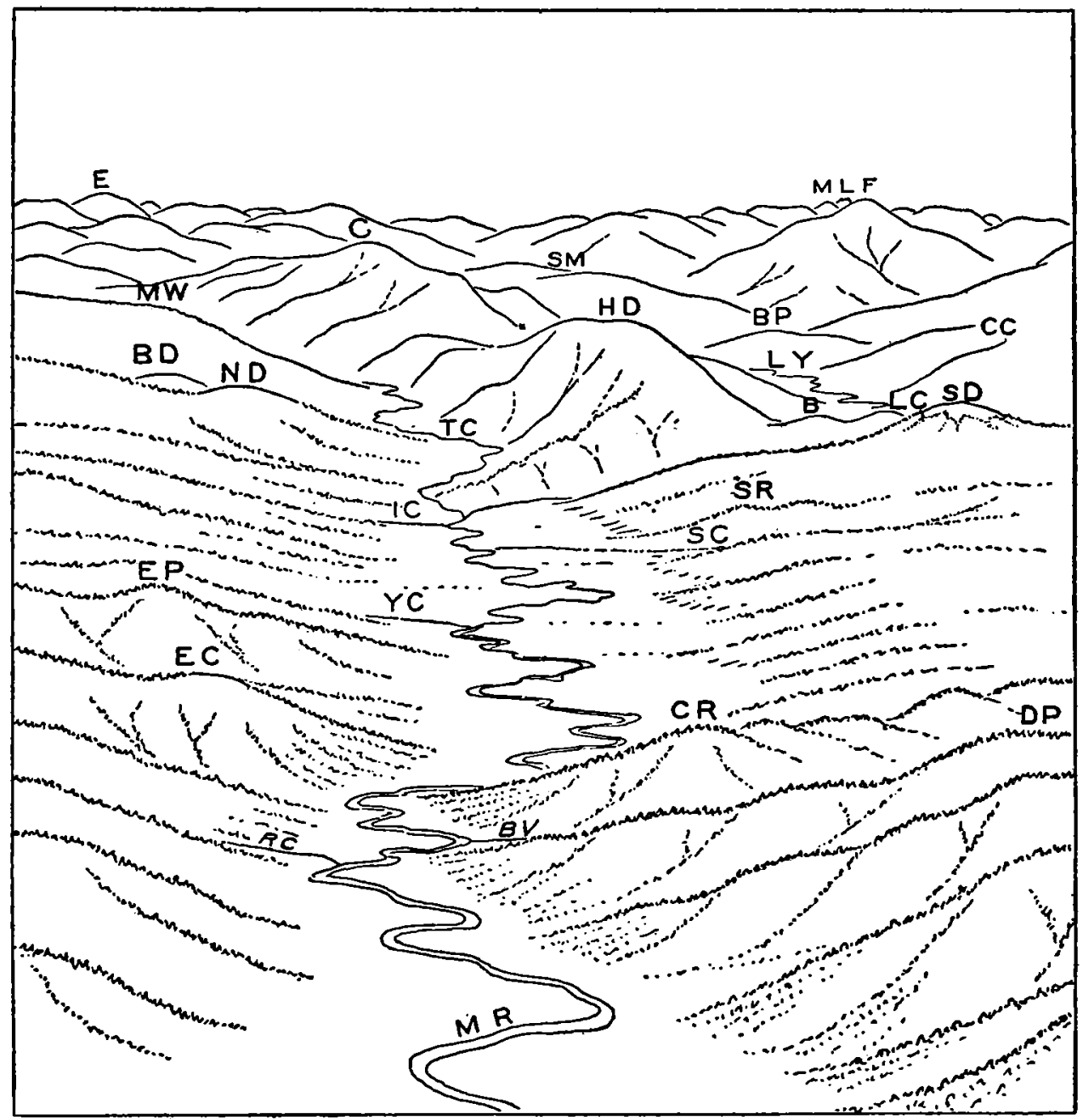

Figdre 13.-Bird's-ye view of the Yosemite Valley as it probably was in the broad-valley stage, prior to the flrst great uptilting of the Sierra Nevada. The Merced River meandered sluggishly over a broad, level valley floor flanked by rolling hills between 500 and 1,000 feet in height. The crown of El Capitan stood about 900 feet high. There were no cliffs or waterfalls. The tributary streams all sloped gently down to the level of the Merced. The entire region was covered with dense rain-loving vegetation. The drawing is based on the broad-valley profile of the Merced and on the profiles of the upper set of hanging valleys. For key see Figure 14

carried as yet no suggestion of a sheer cliff with overhanging cornice. Its southeast side, on the other hand, in all likelihood was already in part smoothly curved and bare. The crest of the ridge rose at least 2,200 feet above the Little Yosemite and about the same height above the valley of Tenaya Creek. That stream joined the Merced, as before, opposite Glacier Point, but owing to the increased depth of their valleys the tapering spur between them had assumed much greater relative height. The granite from which the Washington Column and the cliff of the Royal Arches were later carved still lay beneath the level of the valley. a gulch $1 \frac{3 / 4}{4}$ miles in length, the head of which is: now 1 mile back from the rim. Ribbon Creek had the highest hanging valley of all and cascaded down 1,400 feet in a horizontal distance of somewhat less. than a mile. Meadow Brook made a mile-long cascade 1,200 feet high through a gulch that headed just. back of the present upland rim. Bridalveil Creek descended about 900 feet through a gulch $2 \frac{1}{2}$ miles. long, and Sentinel Creek made a much steeper cascade of the same height through a gulch less than 1 mile long that headed not as far back as the present. upland rim. 
Only a few tributary streams had cut their valleys down to the level of the Merced and joined that river without cascades or falls. Among these were Indian Creek, Illilouette Creek, and Tenaya Creek. The basin of Indian Creek to-day still has the general character which it acquired during the mountainvalley stage, having been changed only slightly by glaciation. The Illilouette Basin has been modified more significantly by the glaciers, but for the most of that valley is, however, reliably indicated by the hanging valley of Snow Creek and by the upper Tenaya Basin. That basin, indeed, may be regarded as a large remnant of the mountain-valley landscape, severely though not profoundly remodeled by the ice.

The Little Yosemite in the mountain-valley stage had been cut to a depth of about 1,200 feet. Liberty Cap, still a mere knob on a low spur that projected, uninterrupted by any gaps, southward from the base

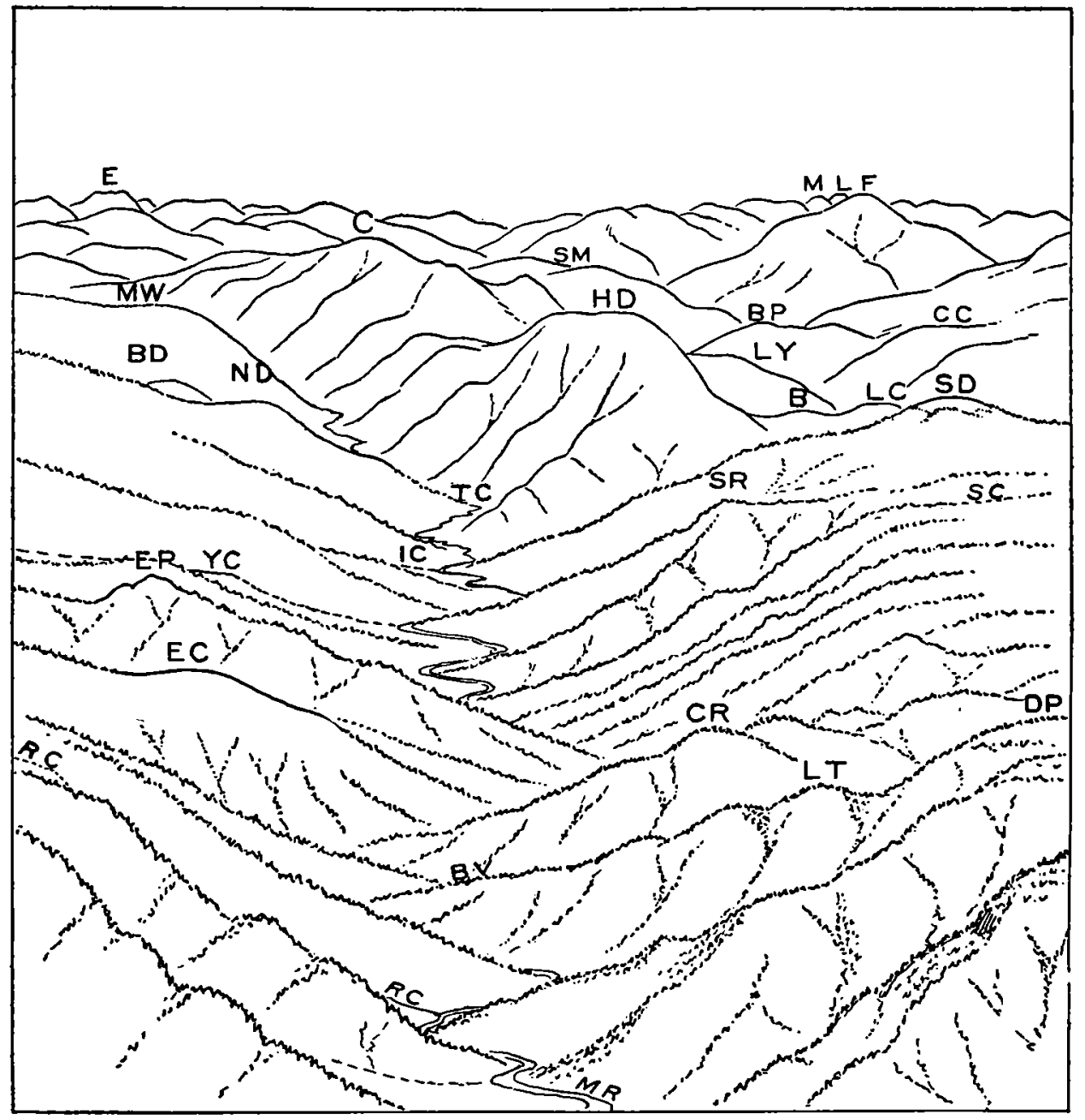

FIGURE 14.-Bird's-ye view of the Yosemite Valley as it probably was in the mountain-valley stage, after it had been deepened about 700 feet by the Merced River in consequence of the first great uptilting of the Sierra Nevada. The valley was flanked by uplands, and Ribbon Creek, Yosemite Creek, Sentinel Creek, Bridalveil Creek, and Meadow Brook cascaded steeply from the mouths of hanging valleys. Tenaya Creek, Illilouette Creek, and Indian Creek, however, had cut their valley's down to the level of the Merced. The region was covered with mixed forests containing sequoias. The drawing is based on the mountain-valley proflle of the Merced and on the profiles of the middle set of hanging valleys

RC, Ribbon Creek.

EC, El Capitan.

EP, Eagle Peak.

YC, Yosemite Creek.

IC, Indian Creek.

R, Royal Arches.

W, Washington Column.

TC, Tenaya Creek.

ND, North Dome.

BD, Basket Dome.
MW, Mount Watkins.

E, Echo Peak.

C, Clouds Rest.

SM, Sunrise Mountain

HD, Half Dome.

M, Mount Maclure.

L, Mount Lyell.

F, Mount Florence

BP, Bunnell Point.

CC, Cascade Cliffs.

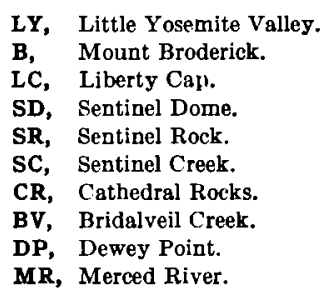

part only locally, and as a consequence it also retains in a broad way the configuration of the mountainvalley stage. Tenaya Canyon, on the other hand, offers in its present appearance no suggestion whatever of the mountain-valley which it replaces. The depth of Half Dome, stood only 600 feet above its floor. Above the Little Yosemite the mountain valley cut by the Merced extended in the form of a narrow central trench all the way to the head of the Merced Basin. It was the antecedent of the present broad and deep 
glacial trough in which lie Merced Lake and Washburn Lake, but it decreased rapidly in depth toward its head, and as a consequence the side valleys hung at no great height above its floor.

\section{LANDSCAPE OF CANYON STAGE}

The great depth indicated by the profile $C-C^{\prime}$ in Plate 27, $A$, leaves no doubt that the preglacial
The preglacial Yosemite Canyon was not simply $V$-shaped in cross section, for the Merced had cut, in consequence of its acceleration by the last great Sierra uplift, a narrow inner gorge. This inner gorge, according to the testimony of the hanging valleys of the second or middle set, was 1,500 feet deep at El Portal and 1,200 feet deep opposite Fireplace Bluff and thence extended with diminishing depth up through the whole

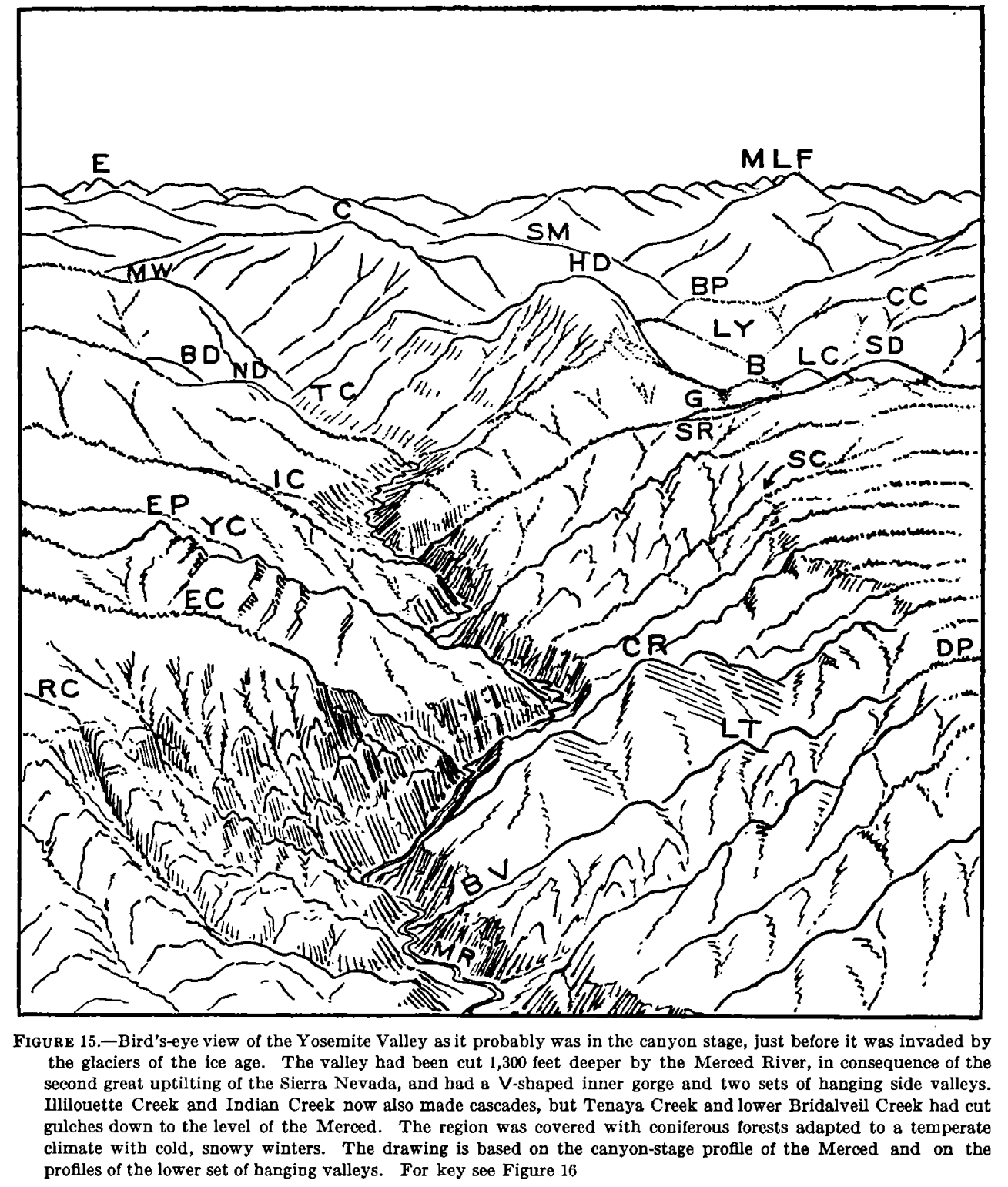

Yosemite had the proportions of a canyon rather than a valley. Its depth was 2,400 feet, measured from the brow of El Capitan, and thence decreased gradually to 2,000 feet opposite Glacier Point. However, there is to be added the height of the hills on the upland, between which the original broad valley of Miocene time lay. The depth of the canyon thus measured averaged close to 3,000 feet. As the width from rim to rim was less than the present width, the ratio of depth to width was almost the same as it is to-day. length of the chasm. Opposite Glacier Point it forked; the southern and shorter prong came rather abruptly to a head just above the mouth of Illilouette Valley, and the northern and longer prong extended up the course of Tenaya Creek for 5 miles.

The narrowness of the preglacial canyon was accentuated by numerous craggy spurs that projected from both sides. These were the same spurs which existed in the mountain-valley stage, but they were more rugged and more angular of outline, owing to the increased depth of the chasm and the consequent 
development of sharp-cut ravines and gulches in its sides. The massive spur of the Cathedral Rocks now attained its greatest length $-1 \frac{1}{2}$ miles. It had acquired its third and lowest summit and, as its east side was gashed by deep ravines, all of its three summits began to stand out, severed from one another by gaps. The slender spur from which the Leaning Tower was to be carved also attained its greatest length, and between it and the front of El Capitan, from the brow down, was carved probably in short, massive buttresses; the south side of the valley immediately opposite was dissected into a number of long, sharp-crested, forking spurs. The great spur that projected from Eagle Peak was doubtless asymmetric. It fell off abruptly and irregularly toward the east and sloped down smoothly and at a fairly constant angle toward the west. On the other

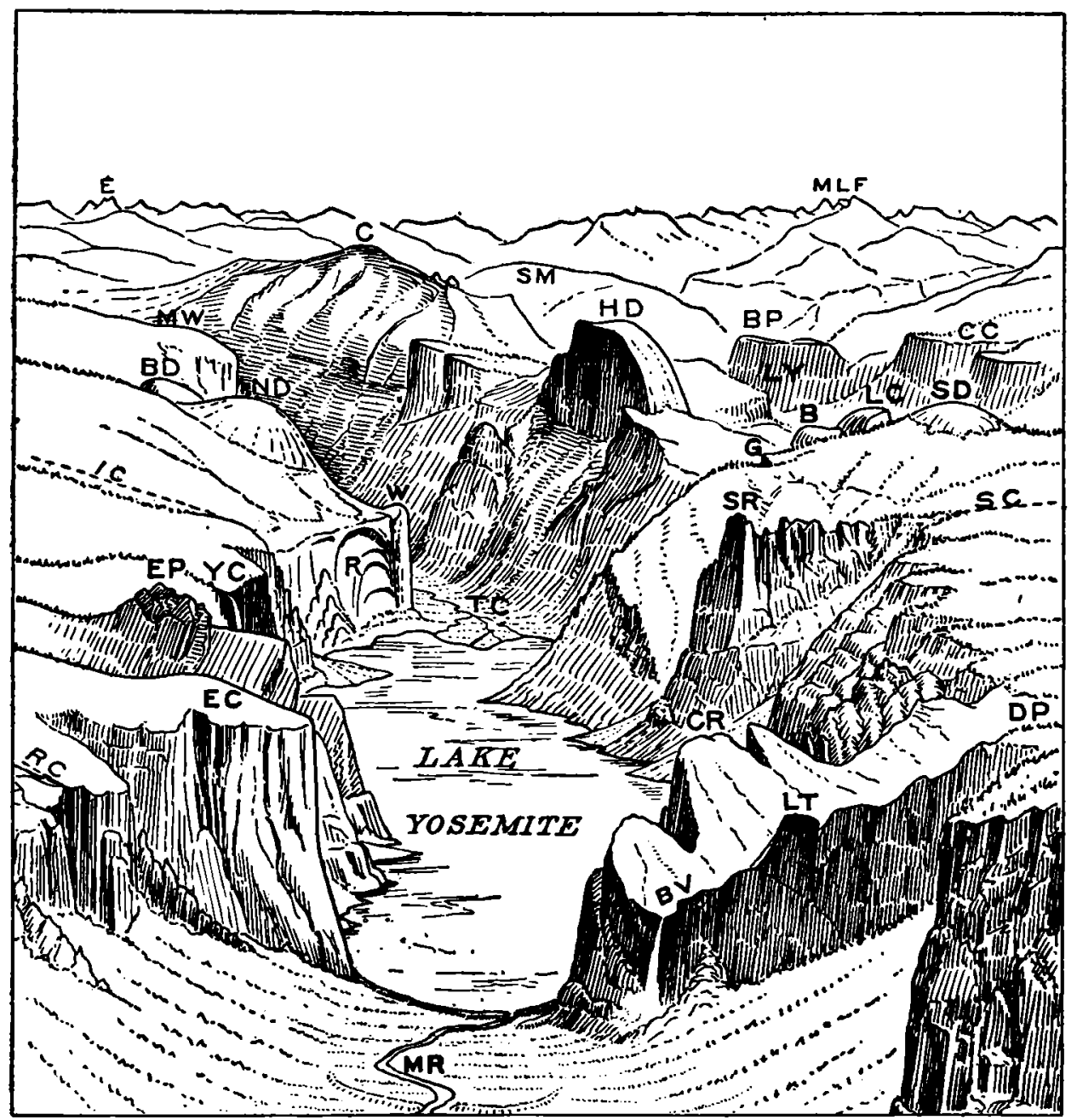

FTGORE 16.-Bird's-eye view of the Yosemite Valley as it probably was immediately after the ice age. The valley had been broadened and deepened to essentially its present proportions. The deepening accomplished by the ice ranged from 600 feet at the lower end to 1,500 feet at the upper end. A third set of hanging valleys had been added, and the Bridalveil Fall was produced. A lake 512 miles long occupied a basin gouged into the rock floor of the valley and dammed in addition by a glacial moraine. The vegetation consisted in the main of types now prevailing. The drawing is based primarily on a systematic survey of the moraines and the other glacial features of the valley

\begin{tabular}{l|ll} 
RC, Ribbon Creek. & E, & Echo Peak. \\
EC, El Capitan. & C, & Clouds Rest. \\
EP, Eagle Peak. & SM, & Sunrise Mountain. \\
YC, Yosemite Creek. & HD, Half Dome. \\
IC, Indian Creek. & M, & Mount Maclure. \\
R, Royal Arches. & L, & Mount Lyell \\
W, Washington Column. & F, & Mount Florence \\
TC, Tenaya Creek. & BP, & Bunnell Point. \\
ND, North Dome. & CC, & Cascade Cliffs. \\
BD, Basket Dome. & LY, & Little Yosemite Valley. \\
MW, Mount Watkins. & B, & Mount Broderick.
\end{tabular}

\begin{tabular}{|ll} 
LC, & Liberty Cap. \\
SD, & Sentinel Dome. \\
G, & Glacier Point. \\
SR, & Sentinel Rock. \\
SC, & Sentinel Creek. \\
CR, & Cathedral Rocks. \\
BV, & Bridalveil Creek. \\
LT, Leaning Tower. \\
DP, & Dewey Point. \\
MR, & Merced River.
\end{tabular}
Cathedral Rocks Bridalveil Creek was actively cutting its steep, $V$-shaped gulch all the way down to the river.

The style of modeling of the other spurs in the Yosemite Canyon may be likewise inferred in a general way, as the structure of the rock, which controlled the modeling, is indicated in the present rock forms. The hand, the spur which now ends in the sheer face of Sentinel Rock bore on its declining crest probably a series of pinnacles and crags. The spur under Glacier Point, again, was in all probability rounded and massive, though in some places castellated like the present cliffs east of Union Point. 
The long spur that projected from the base of Half Dome westward into the head of the canyon is difficult to picture definitely, as nothing whatever remains of it to-day. Yet the mere fact that the glaciers were able so completely to destroy it throws light on the structure of the rock of which it was composed. That rock must have been thoroughly fractured, or jointed, and it may be inferred, therefore, that the spur sloped down rather evenly, undiversified by pinnacles, knobs, or buttresses.

Half Dome itself doubtless already possessed some features that foreshadowed its present unique configuration. The back probably was already in large part smoothly rounded and bare; perhaps the crown was bare also, but the great cliff face on the northwest side was yet to be hewn out, and in its place there was a craggy, splintered slope. Half Dome then stood about 3,800 feet high above the point of confluence of Tenaya Creek and the Merced and already was the highest and most remarkable eminence in the immediate vicinity of the chasm.

The Little Yosemite in this stage was not much deeper than in the preceding, for the Merced had carved its inner gorge but a short distance up beyond the mouth of Illilouette Valley, and from this point upstream it had accomplished but little cutting, owing largely to the exceedingly resistant nature of the rock. Doubtless the river at that time descended from the Little Yosemite, not by successive leaps, as it does to-day, but by a long chain of cascades. To judge by the canyon profile in Plate 27, $A$, the descent amounted to 1,000 feet in a distance of about 3 miles.

The valley of Tenaya Creek, on the other hand, was rapidly assuming the depth and aspect of a canyon, for though Tenaya Creek was inferior to the Merced in volume and cutting power, its cutting was greatly facilitated by a zone of closely fractured rock. Thus, it will be seen, even at this early epoch, prior to the coming of the glaciers, Tenay a Creek approached the Yosemite rhrough a deeper valley than that of the Merced.

Tenaya Creek, however, was the only tributary stream that was able to cut to such great depth. All the other tributary streams had hanging valleys from whose mouths they cascaded steeply into the main canyon. Even Illilouette Creek and Indian Creek, which in the mountain-valley stage had cut their valleys down to the level of the master stream, now tumbled precipitously down from the brink of the inner gorge. Illilouette Creek, emptying near the head of the gorge, had a cascade only 600 feet in height, but Indian Creek had a chain of cascades 1,000 feet in height.

Yosemite Creek, Ribbon Creek, and the other streams of the upper set of hanging valleys had much higher cascades than in the preceding stage, owing to the added depth of the inner gorge. Some of them probably made two cascades in succession, an upper from the upland to the bottom of the old mountain valley, and a lower from the brink of the inner gorge to the river. Their total heights were as follows:

Yosemite Cascade . . . . . . . . . . . . . . 1, 900

Ribbon Cascade ................... 2, 400

Meadow Brook Cascade............. 2, 300

Bridalveil Cascade. . . . . . . . . . . . . . 1, 800

Sentinel Cascade $\ldots \ldots \ldots \ldots$ 2, 400

Spectacular as these lofty cascades doubtless were they did not add so much to the beauty of the landscape as the present leaping falls of the Yosemite Valley, for each of them descended through a narrow, sharply incised gulch flanked by craggy spurs. The gulch through which Bridalveil Creek now cascades down to the brink of its great fall is the only one of these preglacial gulches that remains well preserved. It is probably representative in a general way of the entire category, as it has suffered but slight change by glaciation, though there is reason to believe that it is more regularly $V$-shaped and more smooth-sided than most of the other gulches, its configuration being determined largely by inclined master joints in the granite, whereas the other gulches were cut in diversely structured rocks.

\section{GLACIAL HISTORY OF THE YOSEMITE VALLEY}

\section{GLACIATION OF THE SIERRA NEVADA}

\section{NATURE OF ICE MANTLE}

During the great ice age, which began presumably early in the Quaternary period (see table of geologic time divisions, p. 50), the climate of the Sierra Nevada turned wintry, and the higher parts of the range became heavily mantled with snow and ice, much like the higher ranges in Canada and Alaska at the present time. As a consequence the streams in the High Sierra and in most of the Yosemite region were superseded as valley-cutting agents by glaciers, and thus these regions entered upon a new epoch in the history of their development.

The ice mantle of the Sierra Nevada was not, as some of the pioneer observers supposed, part of the vast continental ice sheet which overspread most of Canada and the northern United States east of the Rocky Mountains. It was a distinct and wholly separate mass that originated locally, on the range itself. Indeed, the Sierra Nevada in glacial time was, like most of the higher mountain ranges of the Far West, a separate center of snow accumulation. That it receives heavy snowfalls to-day, owing to its great height and its position across the path of the moistureladen winds that blow in from the Pacific Ocean, has already been explained (p. 10). In glacial time, under essentially analogous conditions, the range was the recipient probably of still greater quantities of snow. In any event the heat of summer then did not suffice to melt away all the snow that fell in winter, and as a 
consequence an annual residue was left, so that in the course of time great fields of compacted snow and, ultimately, glaciers were formed. A true ice cap, such as completely buries the mountains of Greenland, however, there was not. At all times, even during the culminating stages of the glacial epoch, the highest peaks and crests of the Sierra Nevada stood out partly bare. That fact is attested by the best of evidence, as will be shown further on.

Comparative study of the glaciated areas in the western mountain ranges of the United States discloses the fact that the Sierra Nevada had a more extensive ice mantle than any other range in the same latitude. Its ice mantle was larger, even, than that of the Cascade Range, which adjoins the Sierra Nevada on the north. This fact seems incredible at first, for one would naturally suppose that the ice of glacial time was most extensive in the northern latitudes and dwindled gradually southward. However, two other factors besides latitude determine the extent which snow fields and glaciers may attain on mountainsnamely, altitude and precipitation-and their influence was preponderant throughout most of the Sierra-Cascade chain. A brief survey of that chain will readily show how greatly its glacial covering varied locally in extent as a result of the combined influences of latitude, altitude, and precipitation and will help to make clear why the Yosemite Valley lay in the midst of the largest separate area of glaciation west of the Rocky Mountains.

\section{DISTRIBUTION OF ICE ON SIERRA-CASCADE CHAIN}

The Sierra-Cascade chain, 1,000 miles in length, extends over 14 degrees of latitude, from the 49th parallel down to the $35 \mathrm{th}$, and traverses regions of the utmost geographic and climatic diversity. Beginning near the Canadian boundary, in a region of extremely wet, snowy climate, it terminates at the edge of the Mohave Desert, which is one of the driest and most torrid areas on the continent.

Naturally its glacial covering was very extensive at the north end, in the vicinity of Mount Baker, Mount Rainier, and Glacier Peak, where the great height and breadth of the Cascade Range, the enormous quantities of snow supplied by the westerly winds, and the prolonged winters together produced conditions exceptionally favorable for glaciation. This part of the chain lay fairly smothered under snow and ice and sent forth glaciers 80 to 100 miles in length.

South of Mount Rainier, however, the ice mantle contracted rapidly in breadth, mainly as a result of declining altitude. Throughout southern Washington and northern Oregon, where the crest line, not counting the isolated volcanic peaks, rises scarcely above 5,000 feet, the glaciers attained lengths of only a dozen to a score of miles. Still farther south, throughout that 200-mile stretch of which Crater Lake,
Mount Shasta, and Lassen Peak are the dominant landmarks, there was no ice mantle properly so called but only detached glaciers and snow fields that lay in sheltered canyons high up under the main peaks. This dearth of ice, this state of semiaridity, was due not to a further decline in altitude, for the range here again rises to 6,000 and in places even to 8,000 feet, but to deficient snowfall caused by the presence between the Cascade Range and the Pacific Ocean of a large complex of mountains-the Siskiyou, Salmon, Trinity, and Contra Costa Ranges-which intercepted a considerable share of the moisture from the westerly winds.

Southward from the canyon of Feather River, however, in the northern part of the Sierra Nevada, glaciation developed on an increasingly large scale, owing both to greater altitude and greater snowfall, the intercepting power of the Coast Ranges here diminishing with decline in height. In the vicinty of Lake Tahoe, where the Sierra Nevada attains altitudes of more than 9,000 feet, the ice fields and ice streams were large enough to coalesce and produce trunk glaciers from 15 to 20 miles in length. And in the stretch from Lake Tahoe to Mount Lyell, in which the crest rises progressively to altitudes of $11,000,12,000$, and 13,000 feet, the snows were so abundant as to mantle the range continuously over a breadth of 20 to 30 miles and to create trunk glaciers 40 to 60 miles in length. In short, there was reached in this central part of the Sierra Nevada, where the Yosemite is situated, another climax of glaciation-a climax second only to that which was attained near the Canadian boundary, 800 miles to the north.

Over a stretch of fully 100 miles-from Mount Lyell to Mount Whitney-the glacial mantle extended almost undiminished in breadth. It covered all those parts of the High Sierra which are drained by the San Joaquin, Kings, Kaweah, and Kern Rivers and which are crowned by the culminating peaks of the range. A short distance south of Mount Whitney, however, the glacial mantle came abruptly to an end. Beyond the Kern Glacier there were only small detached ice bodies, the southernmost of which lay on Olancha Peak, in latitude $36^{\circ} 15^{\prime}$, at an altitude of about 10,000 feet. South of this point no glaciers could exist, owing to the rapidly declining height of the range, the lack of sufficient snow precipitation, and the great losses of snow by evaporation in the heated and parched air that was wafted up from the torrid southern part of the Great Valley of California and from the Mohave Desert.

\section{ORIGIN AND GROWTH OF ANCIENT SIERRA GLACIERS}

How, it may be asked, did the glacial mantle of the Sierra Nevada originate, and how did it grow to such vast extent? These are matters that deserve a word of elucidation in passing, the more so as the term "glacial 
mantle," which has been used repeatedly here, is somewhat misleading. That term might seem to imply a thick layer of snow and ice spread rather evenly over the ups and downs of the landscape, but in reality the bulk of the snow and ice in a region of rugged mountains in process of being glaciated is concentrated in the valleys, where it may attain depths of hundreds or even thousands of feet, whereas on the steep-sided peaks and crests there may be but a thin veneer of snow, or in places none whatever. Such, doubtless, was the state of things also in the Sierra Nevada during the ice age, and its glacial mantle, therefore, is to be conceived as a composite mass that was made up of a multitude of independently formed ice bodies lying mostly in the valleys and basins between the peaks.

The snow in a region of high mountains tends from the start to accumulate unevenly - in the first place, because on southerly slopes the snow wastes away rapidly, whereas on northerly slopes, especially in places shaded by peaks or cliffs, it is conserved for long periods, owing to the fact, primarily, that at high altitudes the radiant heat of the sun is almost the sole melting agent, the thin and dry air remaining cold, even in midsummer; in the second place, because the gales of winter sweep the snow, while still in a powdery state, from the slopes exposed to their blasts and drop it on the lee sides of peaks and crests, and, as the gales come prevailingly from the same quarter, they tend to heap the snow ever in the same sheltered spots, the "wind shadows," as they have been termed; and in the third place, because on very steep slopes snow can not accumulate indefinitely but is removed by avalanches.

Now in the Sierra Nevada, as in many other mountain ranges, these circumstances governing the distribution of the snow, especially the first two mentioned, though entirely independent from one another, in large measure enhance one another's effect. As the prevailing winds are westerly or southwesterly, the wind shadows lie mostly on the easterly or northeasterly sides of the mountains and thus coincide in large measure with the sun shadows. Avalanches are likely to be most frequent on northerly and northeasterly slopes because these are the most heavily laden with snow. The tendency for both wind and avalanches is thus in general to concentrate the snow in the very spots where it will be exposed to the least amount of solar heat, and where the chances for its conservation are the best.

The results may be readily observed in the High Sierra at the present time, although the snow there no longer accumulates from year to year, the gains made in winter being offset by the losses sustained in the ensuing summer. The two sides of a northwestwardtrending crest, such as the Clark Range, the Cathedral Range, or the main divide, stand in striking contrast to each other: the sunny and wind-swept southwest side as a rule is wholly bared of snow by the middle of July, whereas the shady and sheltered northeast side remains checkered with drifts and fields of snow until the end of the summer. (See pl. 13, B.) The deeply inset valley heads that open to the north, the northeast, or the northwest naturally hold the largest accumulations; a few still contain small glaciers. It was in these favorably situated valley heads that the first glaciers of the ice age originated; and even to-day the conditions in them closely approach an equilibrium between accumulation and wastage. The losses by melting in summer only slightly outbalance the gains by deposition in winter, and in occasional years the gains slightly exceed the losses. No one conversant with these facts through repeated visits to the High Sierra can doubt that it would require but a trifling change in the present climate to bring on again a period of continued glacier growth.

One contributory reason for this state of things, however, remains to be pointed out: the valley heads mentioned, owing to prolonged and vigorous glaciation, now have amphitheater-like forms, semicircular or horseshoe-shaped in plan, and encircled by precipitous cliffs. (See pl. 28.) They have been transformed into what the Swiss mountaineers term "cirques," and no sculptural forms are better designed than these for the effective entrapment of snow, by drifting and by avalanches, nor for its conservation in well-shaded compact bodies. Throughout the High Sierra these glacier cradles abound. There are literally thousands of them, and they constitute a characteristic and highly picturesque element of the landscape. It will readily be seen, therefore, that the configuration of the High Sierra is now far more propitious for the development of glaciers than it was at the beginning of the ice age.

With this insight into the conditions that govern the accumulation of snow on high mountains, one may readily picture in imagination how the glaciers in theSierra Nevada originated and how they expanded by degrees into a continuous glacial mantle. At first there were only drifts and fields of compacted snow that survived from year to year in valley heads with northerly or northeasterly exposures; by degrees these perpetual bodies of snow ice, or "névé," attained depths of a hundred feet or more, until under the influence of the force of gravity they acquired an imperceptibly slow, flowlike motion and, being constantly replenished at their heads, lengthened forward in tonguelike ice streams or glaciers. Each of these small ice streams followed a preglacial stream-worn valley, and where such valleys united the glaciers became confluent, forming broader and deeper ice streams. These in turn coalesced farther down into powerful ice rivers, or trunk glaciers, that advanced down the main Sierra canyons. As the glacial climate increased in severity, moreover, glaciers were formed 
also in the valley heads on the less favored southwestern flanks of the mountain crests. Thus at length every valley in the High Sierra came to hold an ice stream, and there resulted a vast system of glaciers whose ramifications corresponded closely to those of the system of preglacial valleys and canyons.

During the periods of maximum glaciation the snows were so abundant that the trunk glaciers, though thousands of feet in thickness, could not carry the snow-ice away from the gathering grounds in the High Sierra as fast as it accumulated. The branch glaciers in consequence overflowed, submerged the low divides between them, and coalesced to form unbroken expanses scores of miles in extent. The glacier currents at this stage no longer followed everywhere the axes of the preglacial valleys but were diverted through gaps and over low ridges and even advanced broadly over the billowy uplands, such as those of the Yosemite region, regardless of the trend of the lesser features. Only the major peaks and crests stood out above the ice flood, like dark rocky islands above a dazzling sea.

\section{EXTENT REACHED BY ANCIENT SIERRA GLACIERS}

The extent of the glacial covering of the Sierra Nevada has long been a subject of conjecture and dispute. Some writers have maintained that the glaciers enveloped the entire range down to its very base and even spread far beyond, over the lowlands of California. Others have insisted that the glaciers were restricted to the higher parts of the range. This wide divergence of opinion was due to the fact that the evidences of glaciation, though conspicuous and unmistakable in the High Sierra, are obscure in the heavily forested middle zone of the western flank and had not been systematically traced to their outer limits.

To-day the situation is quite different, for, as a result of a systematic survey of glacial deposits, the margin of the glacial mantle is definitely mapped, and the dimensions of the individual glaciers are known over a considerable part of the Sierra Nevada. Even where the ice margin remains unmapped, its position can now be determined tentatively within narrow limits. There is thus no further doubt that the glacial mantle was confined wholly to the upper parts of the Sierra, and that it reached at no point down to, or even near to, the western base of the range. In the south-central portion of the range, where the glacial mantle was broadest, its western margin descended to altitudes of somewhat under 5,000 feet. The trunk glaciers, of course, descended to still lower levels, yet even they fell far short of reaching the foot of the range. The Tuolumne Glacier, which was the longest ice stream north of the Yosemite region, attained a maximum length of 60 miles and projected about a dozen miles beyond the margin of the ice mantle that lay on the adjoining uplands. It terminated, however, fully 30 miles from the foot of the range and at an altitude of about 2,000 feet. The Yosemite Glacier at the time of maximum glaciation was 37 miles long and projected 7 miles beyond the margin of the ice mantle. Its terminus lay in the Merced Canyon just below the site of El Portal, about 50 miles from the foot of the range and about 2,000 feet above it. The San Joaquin Glacier was nearly as long as the Tuolumne Glacier, but it advanced only a few miles beyond the margin of the ice mantle on the flanking uplands. The glacier halted 45 miles from the mouth of its canyon, at an altitude of about 3,000 feet. The Kings Glacier, despite the great altitude of the crest region which it drained, attained a length of only 44 miles (measured along its middle branch) and came to an end about 37 miles miles from the base of the range at an altitude of 2,500 feet.

The low levels reached by these trunk glaciers seem truly remarkable when it is considered that their lower portions lay wholly in the zone of wastage, where even in the shaded spots the heat of summer was abundantly able to remove the snows of winter. The Yosemite Glacier, for instance, reached more than a mile below the level (somewhat above 8,000 feet) in which glaciers were formed in the Yosemite region. The Tuolumne Glacier reached 6,000 feet below this level; the San Joaquin Glacier, about 5,300 feet; the Kings Glacier, about 6,000 feet. (The level of glacier generation rose gradually southward.)

The ability of these glaciers to reach such low levels in spite of the warmth that prevailed in the zone of wastage affords impressive testimony of the immense surplus of snow ice that descended from the higher parts of the range. However, it is accounted for also in part by the protection from the sun's rays that was afforded to the glaciers by the high walls of the canyons; by the relatively small surface areas proportionate to their bulk which the glaciers, 3,000 feet to over 4,000 feet in thickness, presented to the melting agencies; and the relatively rapid movement of the ice, which in the thicker glaciers must have averaged several feet a day.

There can be little doubt, further, that the trunk glaciers penetrated also far below the upper limits of vegetation and even well into the zone of forests, like so many of the glaciers now existing in the Alps of Switzerland and in Canada. A comparison with the present glaciers on Mount Rainier, which are readily accessible to the public, is particularly instructive in this connection. These glaciers originate at altitudes considerably above 7,000 feet, yet the larger ones descend to altitudes as low as 3,900 and even 3,400 feet-that is, 2,000 to 2,500 feet below the timber line. ${ }^{44}$

"That the Sierra Nevada in glacial time bore forests on its lower slopes seems scarcely open to doubt. There is reason to believe, moreover, that its forests then contained sequoias or "big trees." None of the present sequoias, of course, witnessed the reign of ice in the Sierra, for the oldest of them probably do not exceed 4,000 years in age, whereas the glacial epoch came to an end between 15,000 and 20,000 years ago; but the present trees are doubtless descendants of those which lived in the glacial epoch, and their ancestry goes back much farther still, to the Tertiary period, as is evident from the occurrence of fragments of fossil sequoia wood in the sediments of lava-entombed stream beds of that period. 
On its eastern flank also the Sierra Nevada bore a great array of glaciers, there being a glacier in almost every canyon; but these glaciers were in general much shorter than those on the western flank, owing to the abruptness of the escarpment, the shortness of the canyons, and the small extent of glacier-generating territory at their heads. Most of these glaciers, nevertheless, reached down to the eastern foot of the range, and not a few projected well out into the adjoining lowlands. This was true especially in the northcentral and south-central parts of the range, where the adjoining lowlands have altitudes of 5,000 to nearly 7,000 feet. Doubtless the abundant waters that issued from the glaciers were instrumental in transforming these now arid wastes into fertile, verdant land.

The basin of Mono Lake was invaded by no less than six ice tongues, each of which extended several miles out from the range-indeed, to the shores of Mono Lake itself, which at that time was considerably larger than it now is. In the regions south of Mono Lake the glaciers projected as a rule but little beyond the mouths of their canyons, and along the border of Owens Valley the glaciers were confined mostly to the upper parts of the canyons; still farther south there were only scattered snow fields, and the array of ice bodies came to an end.

\section{EVIDENCES OF GLACIAL ACTION IN THE YOSEMITE REGION}

In no part of the Sierra Nevada have the evidences of glacial action been studied in greater detail than in the Yosemite region. John Muir was the first to engage in this work. During the years of his residence in the Yosemite Valley he devoted a large part of his leisure time to tracing the pathways followed by the ancient glaciers, not only in the immediate vicinity of the valley but also in the High Sierra above. Thirty years later Henry W. Turner, of the United States Geological Survey, undertook to locate the larger glacial deposits on a small-scale map, but he did not finish the task. It was not until 1913 that a systematic and detailed glacial survey - the survey on which the present account is based-was instituted and that the data obtained were assembled on a large-scale map. In subsequent years this survey was extended to the High Sierra as well as to the country below the Yosemite region, until at length the entire area that once lay under the dominion of the Yosemite Glacier, with its tributaries and neighbors, was covered. As a result the length, breadth, and depth attained by each of these glaciers at the time of their greatest extension are now definitely known. What is more, some insight has been gained into the history of their advances and recessions in response to climatic changes, so that it is now reasonably certain that the Yosemite Valley was invaded by a glacier three times. There is even some warrant for the presumption that the valley was invaded more than three times, the glacial history of the Sierra Nevada, like that of the northern parts of the continent, having consisted of several wintry subepochs, or "glacial stages," alternating with mild subepochs, or "interglacial stages."

The reader not familiar with the methods of glacial research will wonder, probably, upon what manner of data these conclusions rest. It seems appropriate, therefore, to explain at the outset the nature and significance of the evidences searched for and the procedure followed in the glacial survey.

\section{KINDS OF EVIDENCE STUDIED}

The evidences of glacial action in a mountain region are in general of three kinds-grooved and polished rock surfaces, characteristic topographic forms, and deposits of ice-borne rock débris. Of these three kinds of evidence the first would naturally suggest. itself, because of its highly distinctive nature, as the easiest to recognize and therefore the most valuable for the identification of ancient glacier paths.

Glaciers, indeed, literally grind, tool, and polish their beds with the rock débris that is frozen in their bottom layers. The large angular blocks produce grooves a fraction of an inch in depth; the smaller fragments produce fine parallel "striae"; and the sand and mud scour and polish the rock until it fairly gleams. The resulting striated and glassy rock surfaces are familiar to all who have visited intensely glaciated mountain areas. In the upper Yosemite region and the adjoining parts of the High Sierra such surfaces are particularly plentiful and extensive; there one may walk on "glacier polish" for considerable distances.

However, these vivid evidences of glacial action are not as a rule long lived. The reason is obvious; the rock, being constantly exposed to the weather and the wearing action of running water, inevitably decomposes and disintegrates in the course of time; the polish flakes off, the surface becomes increasingly rough and irregular, and the evidence of glaciation disappears. Some types of rock, naturally, weather more rapidly and lose their polish sooner than others, and this is true also in the Sierra Nevada. To assume, therefore, that the ancient glaciers on that range extended no farther than the polished and striated rock surfaces seem to indicate would be clearly unjustifiable. Actually the glaciers extended much farther; they spread over a vast contiguous territory from which all vestiges of glacial abrasion have now vanished.

Neither can the testimony of the topographic forms be safely relied upon. Among the more conspicuous forms that are generally held to be characteristic products of glaciation are U-shaped, troughlike canyons having spurless, parallel walls and stairwise descending floors that commonly hold shallow lake basins on their treads; also, hanging side valleys from whose mouths the waters cascade abruptly down into the main 
canyons. Such forms the reader already knows to be abundantly represented in the Yosemite region, and it might therefore seem to him that it would be a simple matter to determine the limits reached by the ice by observing how far these telltale forms extend down the flank of the range. However, it is to be borne in mind that the development of characteristic glacial forms is conditioned in part by the nature of the rock. Glaciers do not work with equal facility in all kinds of rock. As will be shown more fully further on, they work to best advantage in soft rocks and closely jointed rocks. In massive or sparsely jointed granite they accomplish relatively small results and seldom produce characteristic glacial forms. Thus it is that in the Sierra Nevada, where granitic rocks of massive habit prevail over large areas, many canyons and valleys retain in large measure their preglacial $V$ shapes in spite of repeated vigorous glaciation. A conspicuous example is the Grand Canyon of the Tuolumne River, which lacks for the most part the characteristic $U$ form of glaciation, although it was the pathway of the greatest and most powerful ice stream in the Sierra Nevada. Again, some valleys and canyons, though considerably remodeled by the ice, lack steps and lake basins in their floors, as, for instance, the valley of the Dana Fork of the Tuolumne River.

As shown on pages $34-35$, side valleys can be left hanging as a result of other than glacial processes, notably by the rapid trenching of a master stream whose course has been steepened, in consequence of tilting, more than the courses of its tributaries. The Sierra Nevada abounds in hanging valleys of just such an origin, the Merced and the other southwestwardflowing master streams having intrenched themselves rapidly in consequence of the tilting of the range, whereas many of the small tributaries trending at right angles to their courses have not been able to trench at the same rate. In the Sierra Nevada, therefore, hanging valleys can not be accepted as prima facie evidence of glacial action.

The most reliable record of glacial activity, on the whole, is that embodied in the deposits of rock waste left behind by the glaciers, particularly those ridgeshaped deposits termed "moraines." These unobtrusive features, wherever well preserved, accurately define the limits reached by the ancient glaciers. It was, therefore, with the moraines that the survey was mainly concerned. What now are the characteristics and the significance of a moraine?

Every glacier carries large quantities of rock waste, ranging from huge boulders down to the finest mud. Of this material part has fallen upon its surface from the frost-riven canyon walls; part has been torn from the floor and sides of the canyon by the glacier itself. The margins and bottom layers of a glacier naturally are most heavily loaded, and in consequence, as the ice melts in summer, some of the rock waste is released and dropped at the sides and the front. If the glacier remains essentially unchanged in size for a considerable period, the rock waste accumulates around it in the form of a more or less sharp-crested ridge or moraine. Commonly the ridges along the flanks of a long-drawn glacier are called the lateral moraines, and the ridge at its front the terminal or, more properly, the frontal moraine, but in their most perfect development these ridges really form together a continuous loop.

The height to which moraines may be piled depends naturally upon the size and eroding power of the glacier, the abundance of rock waste, and the length of the period of accumulation. In the Sierra Nevada few moraines are over 60 feet in height and most are only 10 to 30 feet, for the glaciers were but lighlty loaded; the granitic rocks over which they passed being for the most part too massive to be readily disrupted by the glacial processes. By contrast, in the Rocky Mountains and the Cascade Range, where the rocks are closely fractured and readily disrupted, many of the moraines, even those built by small glaciers, attain heights of a hundred or several hundred feet.

When a glacier melts back, as a result of amelioration of climate, the moraine loop formed during its previous stationary period is left standing as a sort of mold that bears witness to the former proportions of the ice mass. (See fig. 17.) Although composed of unconsolidated materials, the moraine loop may persist in a fair state of preservation for thousands of years-for a long time after the glacier has ceased to exist. It may be recognizable even when the glacier polish has all flaked off from the rocks. Thus it is in the Sierra Nevada - the farthest limits reached by the glaciers of the ice age there are still marked by moraines, or at least by remnants of moraines, although the glacier polish has disappeared over large areas. In addition, many phases in the slow decline of the glaciers remain similarly outlined, for whenever, in obedience to climatic variations, the glaciers made a prolonged halt in their retreat, or a minor readvance, they each left a subsidiary, recessional moraine loop. As a consequence each valley contains as a rule a series of moraine loops lying one within another and growing progressively shorter toward the crest of the range. The frontal parts of these loops curve across the valley floors in the form of low embankments, commonly breached by the streams, and the lateral parts extend for miles along the valley sides, wherever these are not too steep, in the form of boulder-strawn ridges or terraces paralleling each other at different levels.

In the glacial survey of the Yosemite region all identifiable moraines and remnants of moraines, even isolated glacial boulders, were duly located and mapped, and thus there is now at hand a detailed record of the successive advances and recessions of the ancient glaciers. This record, for the Yosemite Valley and the areas immediately contiguous to it, is embodied in 
the map of glacial and postglacial deposits forming Plate 29. Let us now, with the aid of this map, analyze the morainal system of the Yosemite Glacier and see what story it tells.

\section{MORAINES IN THE YOSEMITE VALLEY}

In the lower half of the Yosemite Valley six frontal moraines may be counted within the distance of 1 mile. The lowermost of the series is immediately above the Bridalveil Meadow. Being widely breached by the Merced River, it consists really of two short segments, one on the south side of the valley, the other on the north side. The southern segment is readily identified as a massive wooded ridge about 40 feet high, that extends in a northwesterly direction

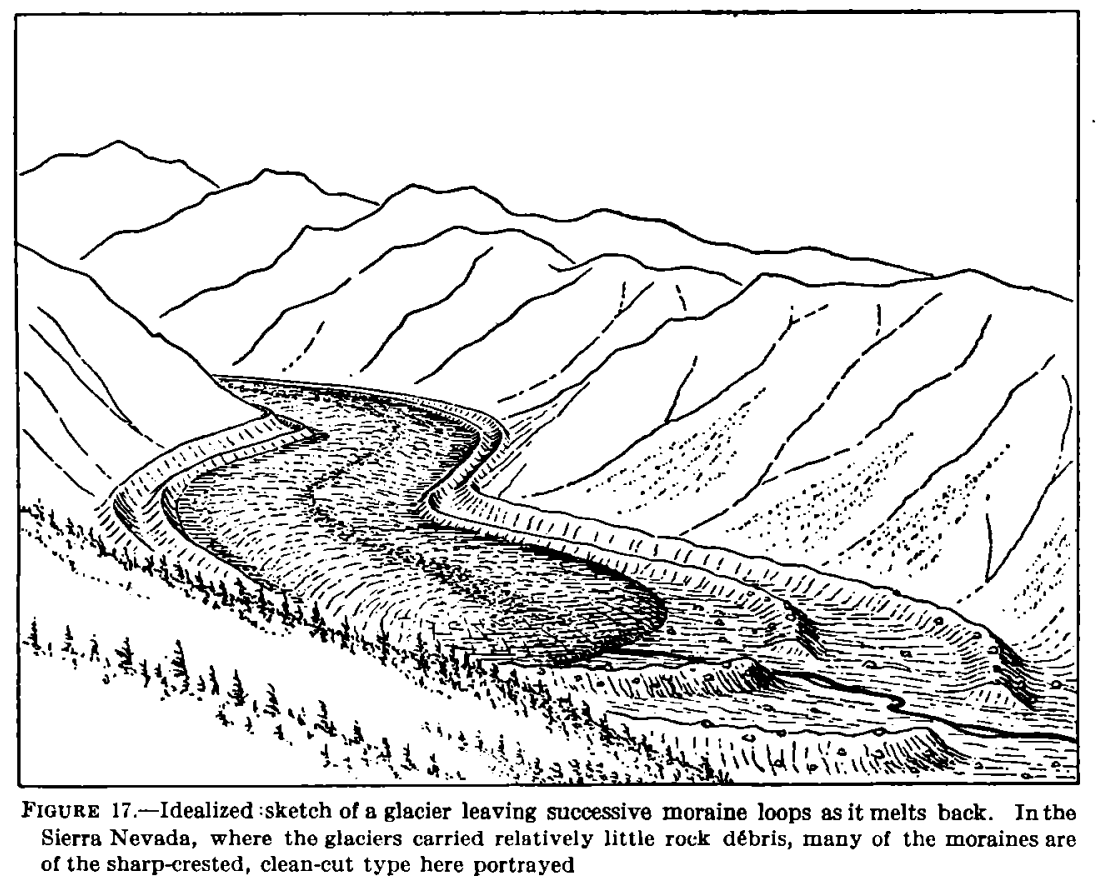

moraine curved across the entire width of the valley floor, from cliff base to cliff base.

The materials of which this moraine is built may be readily inspected in the road cuts. Most conspicuous are the large, smoothly rounded boulders, but mixed with these are cobbles, pebbles, angular fragments of rock of different sizes, and an abundance of sand and mud. Many of the rounded boulders and cobbles, moreover, when washed clean and held to the sunlight, appear highly polished and in places scratched or scored, like the glaciated canyon floors of the High Sierra. This fact in itself proves that they have been brought down by a glacier-that they are glacier-worn as well as stream-worn-for, though their roundness of form doubtless is due largely to stream wear, their polish could have been imparted only by long-continued abrasion with "rock flour," that almost impalpable substance produced by the grinding action of glaciers, which is many times finer than the sand or mud in a stream bed.

To the trained eye of a geologist, moreover, it is readily apparent that among the boulders and cobbles, as well as among the angular fragments, there are some representing rock types foreign to the Yosemite region, though prevalent in the High Sierra. Among these are several types of quartzite, schist, and limestone, but the most readily identified is a buff or pinkish granite containing nearly rectangular crystals of white feldspar 1 to $2 \frac{1}{2}$ inches in length and resembling pieces of domino sugar. Whoever has traveled observantly through the High Sierra will at once recognize this rock as the type of granite which is most abundant in the Merced and Tuolumne Basins and of which notably Cathedral Peak and ad-

and breaks off abruptly at the bank of the river. The highway is cut through its southeast end, thus affording a glimpse of its internal composition. The northern segment consists of a narrower and sharper crested ridge that extends southwestward to the edge of the northern motor road, where it also breaks off abruptly.

To a casual observer the relations which these two ridges bear to one another are not likely to be manifest, owing to the obscuring forest growth; but a glance at their positions as platted on the map will at once convince him that the two ridges are indeed the severed remnants of a formerly continuous moraine loop. Just how much farther on each side this moraine loop originally extended can only be surmised, as its outer ends are now buried under masses of rock waste that have fallen from the cliffs in postglacial time; but it seems probable in any event that the joining parts of the Cathedral Range are made. Its appearance is equally striking in the glacier-polished canyon floors, where the crystals lie as in a natural mosaic (pl. 52, $B$ ), and in the rough, weathered crags and blocks on the peaks, where the crystals project. fantastically from the less resistant matrix. It is known, appropriately, as the Cathedral Peak granite. (See pl. 37, B.)

The presence of these materials of distant origin, both in rounded, polished boulders and in rough, irregular fragments, mixed with rocks of local derivation. and with sand and mud, is characteristic of the make-up of a glacial moraine and, taken together with the forms. and position of the ridges, leaves no doubt whatever as to their glacial origin.

The second and third moraines of the series are even more widely breached than the first; indeed, they are very largely demolished. Their remnants, moreover, 
are covered by thickets and therefore are not readily recognizable by their forms, yet they may be identified by their constituent materials, which project through the pine-needle litter here and there and are exposed in the sections at the banks of the river.

Of the fourth moraine, by contrast, the principal remnant stands out boldly in a place where it could scarcely be overlooked. It projects from the northwest base of the Cathedral Rocks in the form of a stony scantily timbered ridge about 30 feet high.

Of greatest interest are the fifth and sixth moraines, which together form a nearly straight dam across the valley just below the El Capitan Meadow. Only a small gap interrupts the continuity of this dam-the gap cut by the river and now spanned by the El Capitan Bridge. North of the bridge the road is laid upon the sixth moraine, as upon a causeway raised a few feet above the level of the meadow, and it is flanked on the west by the crest of the fifth moraine, which attains a maximum height of 15 feet. Northward both moraines gradually disappear from view under the sloping mass of rock waste derived from the north wall of the valley. Their southern extremities are similarly buried under the coarse débris that has fallen from the sheer cliffs of the Cathedral Rocks.

The height of these moraines above the meadow is probably but a fraction of their total height above their base on the rock floor of the valley. Only their crests are now exposed, the major part of their bodies being buried, on the upstream side under stratified sand and gravel, on the downstream side under streamwashed glacial debris, in the manner shown in Figure 18. The glacial débris was doubtless deposited at the time when the Yosemite Glacier lay with its front directly against the fifth moraine. The waters flowing from the ice mass at different points then spread part of their load of débris in front of the moraine in the form of an "outwash apron." The sand and gravel on the upstream side, on the other hand, must have been laid down in a lake basin that was created by the moraine dam when the Yosemite Glacier finally melted away. The postglacial lake whose former presence these sediments attest-ancient Lake Yosemite it may be called-probably reached at first to the very head of the valley and had a length of $5 \frac{1}{2}$ miles, but it was filled in time by the gradual forward growth of the delta of the Merced River and thus was ultimately replaced by the present level valley floor.

That the two moraines should have been buried by the sediments so nearly up to their crests is explained by the inability of the river to breach the dam to any great depth. Inspection of the gap shows that the cutting action of the river was impeded by the presence of many large boulders. As a consequence the lake was maintained at a high level to the very last.

Though the full height of the moraines above the rock floor of the valley remains conjectural, it may reasonably be estimated at not more than 60 or 70 feet, for no other moraines in the Yosemite region are known to attain greater height. It may seem surprising, that a moraine dam of such moderate height should have sufficed to impound the water for a distance of $5 \frac{1 / 2}{12}$ miles, but, as shown on page 94 , there are good reasons for believing that the dam rests on a swell or sill in the rock floor of the valley and that a glacially excavated basin formerly extended up the valley from the sill.

As early as 1863 Clarence King recognized the existence of a terminal moraine in the lower part of the Yosemite Valley. He also interpreted the present level valley floor as having been created by the filling of a temporary lake impounded by the moraine. However, the passage in Whitney's report ${ }^{45}$ relating to King's observations is so loosely worded that there is no certainty as to which of the several moraines actually existing is meant. The description given seems best to fit the lowermost moraine, the one near the Bridalveil Meadow, but that moraine is fully three-quarters of a mile below the one that impounded Lake Yosemite.

King also noted that in the part of the valley above the terminal moraine observed by him debris is con-

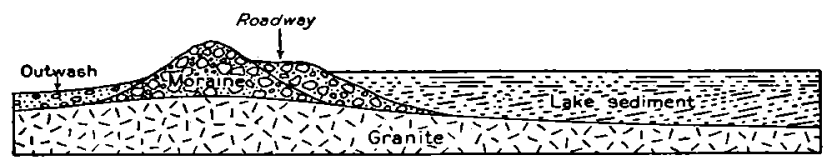

Figure 18.-Section across moraine dam at El Capitan Bridge, showing the depth to which it is believed to be buried under lake sediment on the upstream side and under outwash material on the downstream side

spicuously scant and in places almost wholly absent at the bases of the cliffs, whereas in the part of the valley below the moraine the walls are cloaked with débris to a great height. He therefore concluded, not unnaturally, that this moraine marks the farthest limit reached by the ancient Yosemite Glacier, and that below it the valley has remained unglaciated. As a matter of fact, the moraine next to the Bridalveil Meadow marks the farthest limit reached by the glacier during the last stage of glaciation only-the last chapter of glacial history, so to speak. In the earlier glacial stages the ice extended many miles beyondas far as the site of El Portal, as is demonstrated on page 67. The six frontal moraines between the Bridalveil Meadow and the El Capitan Meadow, therefore, are to be interpreted as recording the oscillations of the Yosemite Glacier's front during and immediately after the climax of the last glacial stage.

Above the El Capitan Bridge no further moraines are to be found in the Yosemite Valley for a stretch of about 5 miles-that is, to a point within a short distance of the head wall. There, however, is the largest and most conspicuous moraine of all. It is a

45 Whitney, J. D., Geological survey of California, Geology, vol. 1, pp. 422-423, 1865 
hummocky ridge 50 to 60 feet high and half a mile long that extends from the head wall directly down the middle of the valley and declines gradually to the level of the valley floor at the Clark Bridge. The road that leads from the Happy Isles to Mirror Lake passes through a saddle in this ridge. From the cut have been taken many rounded and polished boulders of Cathedral Peak granite and other rock types from the High Sierra.

This ridge is commonly supposed to be a "medial moraine" that marks the line of junction between the Merced and Tenaya Glaciers, the two main branches of the Yosemite Glacier. The supposition would seem reasonable enough, for wherever two glaciers are confluent the débris carried on and in their coalescing margins is brought together in a narrow débris zone in the ice that extends down the middle of the trunk glacier and forms at its surface a hummocky dirt band known as a medial moraine. Doubtless the Merced and Tenaya Glaciers by their confluence gave rise to such a medial moraine on the Yosemite Glacier. The ridge at the head of the valley accordingly, is supposed to have been formed when the débris in this medial moraine and in the dirt zone in the ice underneath dropped to the ground as the glacier melted away.

The correctness of this interpretation, nevertheless, seems open to question, for although medial moraines are common features on glaciers, they are not known to give rise, upon the departure of the ice, to prominent ridges that extend longitudinally down the valleys. The fact is that a medial moraine consists only of débris in transit, and the quantity of material present in it at any given time would be far too small to produce a high, bulky moraine ridge if it were let down to the ground. Now the moraine at the head of the Yosemite Valley compares favorably in height and bulk with the largest frontal moraines left by the Yosemite Glacier. It must therefore be, like them, a product of long-continued deposition and can not have been formed by the dropping to the ground of the débris in a medial moraine. It is in all probability a frontal moraine, either of the Tenaya or of the Merced Glacier. Its position in the axis of the valley gives no clue as to which of these glaciers might have built it; neither do the boulders which it contains, for both glaciers carried about the same kinds of rock on their coalescing margins. However, the faint curvature of the ridge, concave toward the north, suggests that it is the remnant of a moraine loop of the Tenaya Glacier, and this suggestion finds support in the fact that there is a small remnant of a moraine also near the base of the Royal Arches, at a place where the opposite end of such a moraine loop might be looked for. It is not impossible, finally, that the ridge in question is compound, consisting of a frontal moraine of the Tenaya Glacier and a frontal moraine of the
Merced Glacier that were pushed together by the opposing ice streams, but as to that there is no tangible evidence.

The complete absence of moraines in the 5-mile stretch between the El Capitan Bridge and the Clark Bridge can scarcely be explained by the great thickness of the sediments that fill the basin of ancient Lake Yosemite (the prominent ridge at the head of the valley doubtless lies in the shallow upper part of the basin). These sediments, it is true, may reach a thickness of more than 200 feet, as would appear from the cross sections of the valley in Figures 24 and 25 , and might therefore readily cover up any moraine loops left by the Yosemite Glacier; but even if they did, it seems likely that the ends of the loops would remain visible at the sides of the valley. As no such ends of moraine loops exist, it may be concluded that the Yosemite Glacier did not deposit any frontal moraines above the El Capitan Bridge but melted back steadily or as a stagnant mass throughout the 5 -mile stretch to the valley head. Observations on the moraine systems in a number of other valleys in the Sierra Nevada bear out the correctness of this conclusion: they show that each of the other glaciers, after depositing about half a dozen closely spaced frontal moraines, melted back for a considerable distance without leaving any distinct moraine loops.

\section{MORAINES IN THE LITTLE YOSEMITE VALLEY}

In the Little Yosemite Valley moraines are much more plentiful than in the main Yosemite. They form an orderly system rich in lateral and in frontal moraines and including several almost complete loops. The arrangement of its component members is strikingly brought out on the map of glacial and postglacial deposits (pl. 29), and its details record some interesting phases in the progressive decline of the Merced Glacier. For instance, it is evident from the positions of the moraines at the lower end of the Little Yosemite that at one stage the waning glacier, no longer able to overtop Mount Broderick (it did not overtop Liberty Cap), split into three lobes that cascaded down to the gorge of the Merced below, each through a separate gap. At a later stage, when the three lobes had become too short to cascade from the mouth of the Little Yosemite, the northernmost lay stagnant in the pocket between Mount Broderick and Half Dome. Doubtless it impounded there a small lake, which grew in size as the ice lobe melted back, until at last the rocky spur that projects eastward from Mount Broderick was entirely uncovered, when the water drained out. The present reed-grown pond known as Lost Lake, which is dammed at its east end by a small moraine left by the retreating glacier, is all that remains of that peculiar body of water.

Perhaps the most significant feature of the series of moraine loops left by the middle and southern lobes 


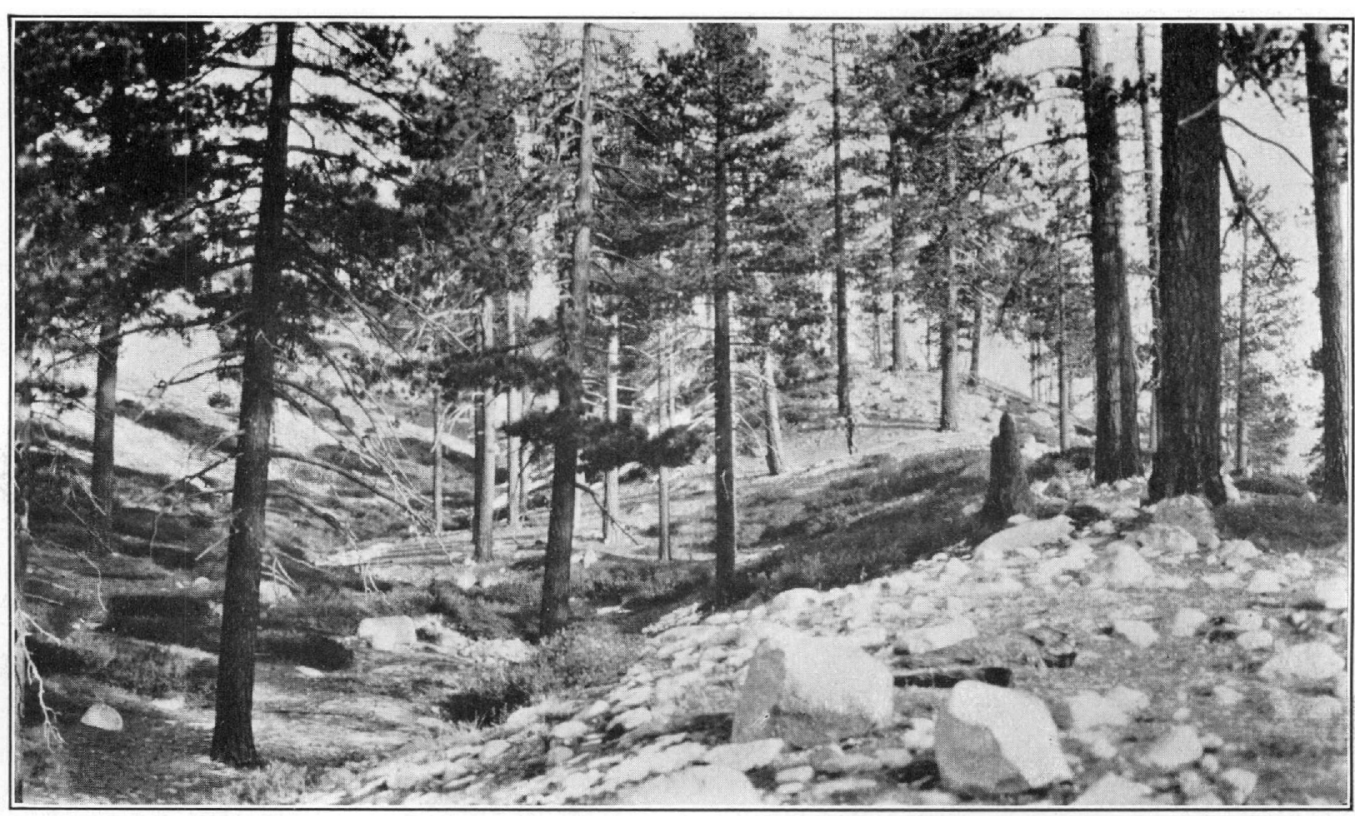

A. CREST OF MORAINAL EMIBANKMENT ON THE SIDE OF MORAINE DOME

This morainal embankment. marks the highest level atlained by the Merced (ilacier during the last or Wisconsin slage of lacialiou.

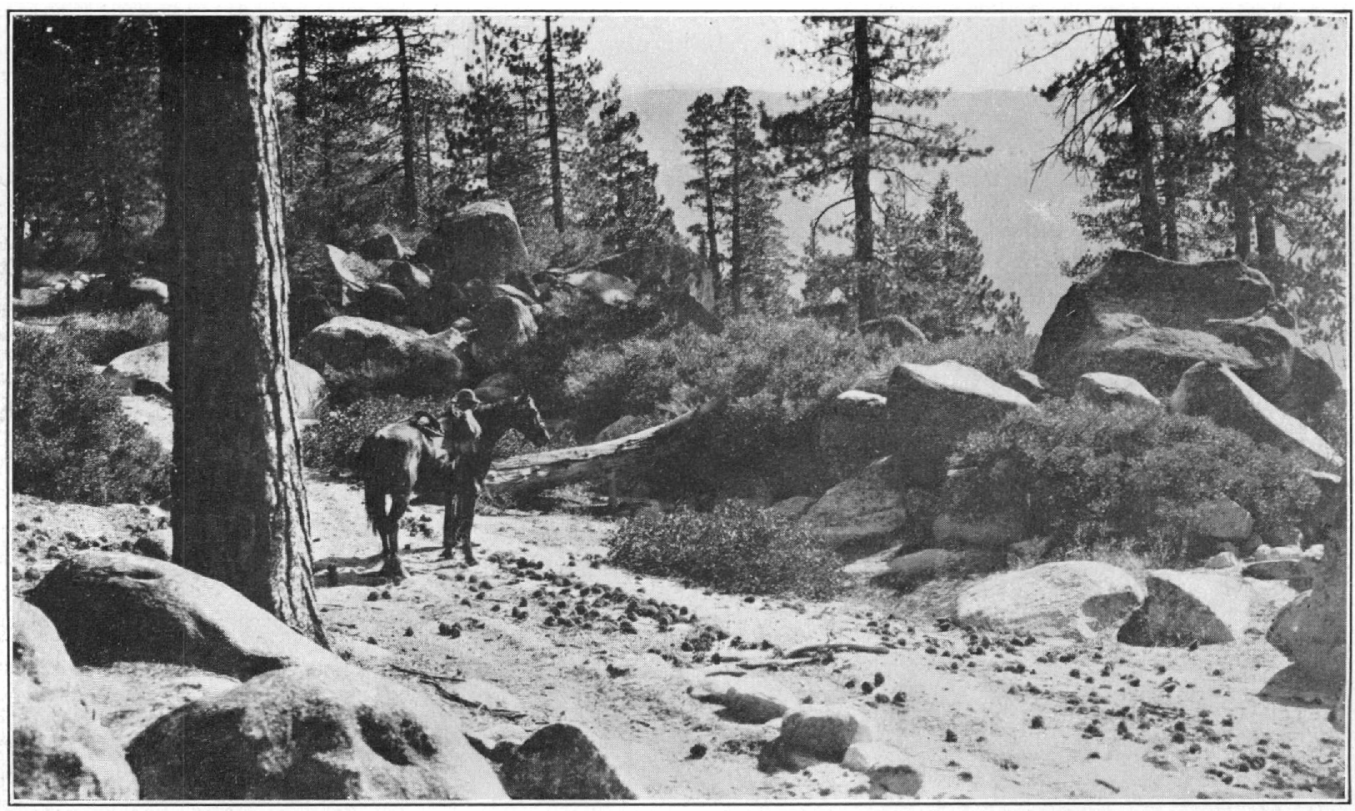

B. ONE OF THE LATERAL MORAINES ON NORTII SIDE OF IITTLE YOSEMITE VALLEY

This moraime is composed larrely of angular blocks torn by the glacier from the clitfs farther up in the. Litıle Yosemite and in the upper Merced Cinyon. The Sunrise and soxla Springs Trail follows the sindy hollow between this moraine and the 


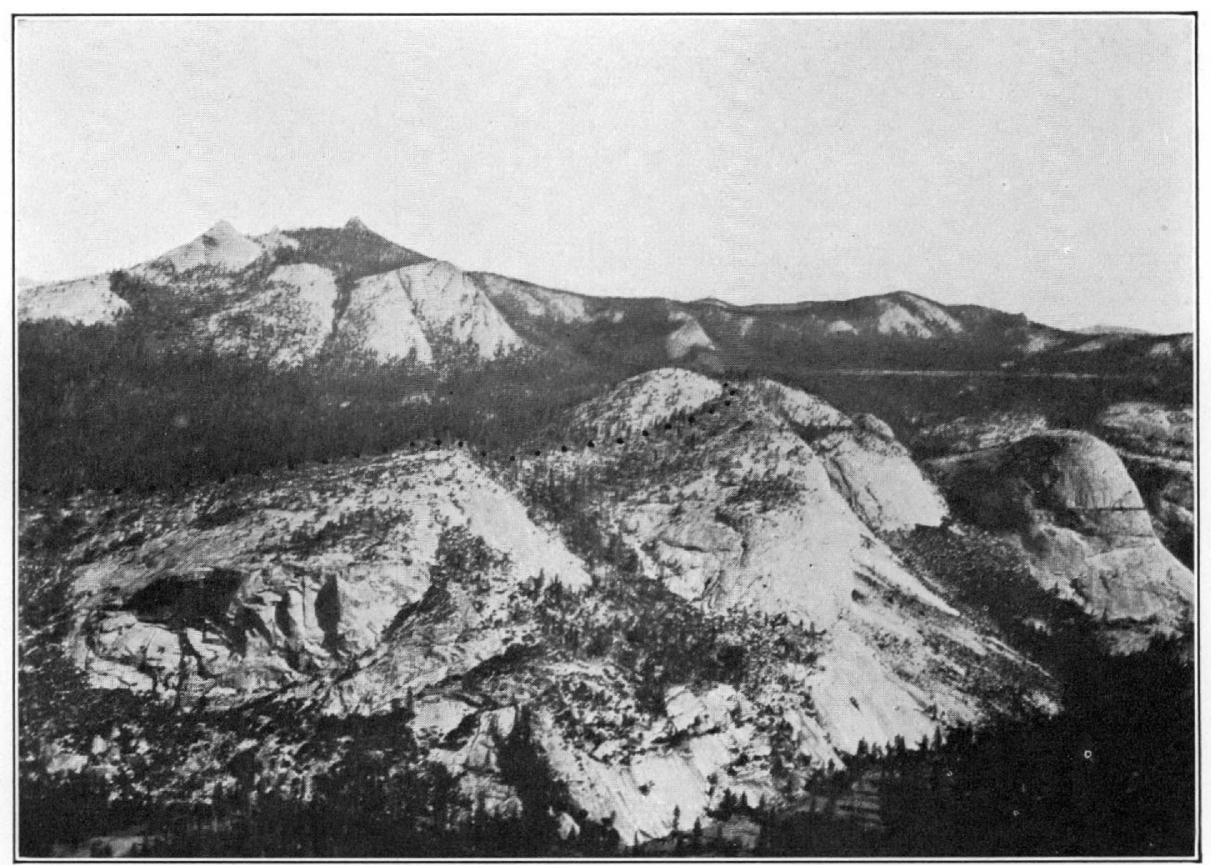

A. VIEW ACROSS LITTLE YOSEMITE VALLEY FROM A POINT NEAR HELEN LAKE

In the center is Moriune Dome, with the morainal erubankment (indicated by a row of dots) elinging to its sides. Across the waoded slopes, beyond, the course of (hie moraine is marked by a white line produced by the blocks of grauite on its crest. At the left is Clouds Rest. 'To the right of Maraine Dome is Sugar Loaf.

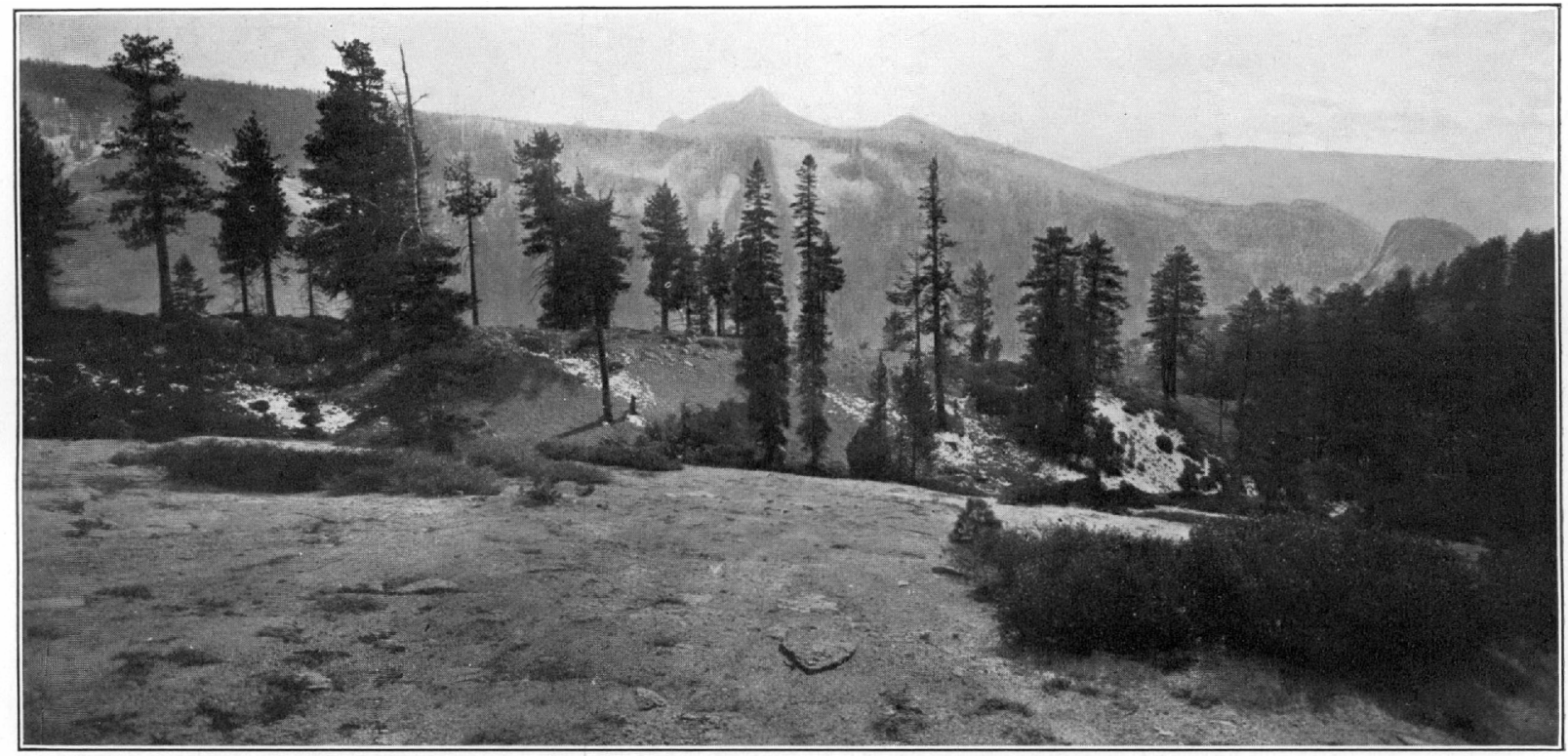

B. THE GHEAT MORAINAL EMBANKMENT, FROM TOP OF MORAINE DOME

In the foreground is the disintegrating upper slope of Moraine Dome, which was nol touched by the ice of the last glacial stage. Iu the background is the Starr hing group on the Yosemile upland. 


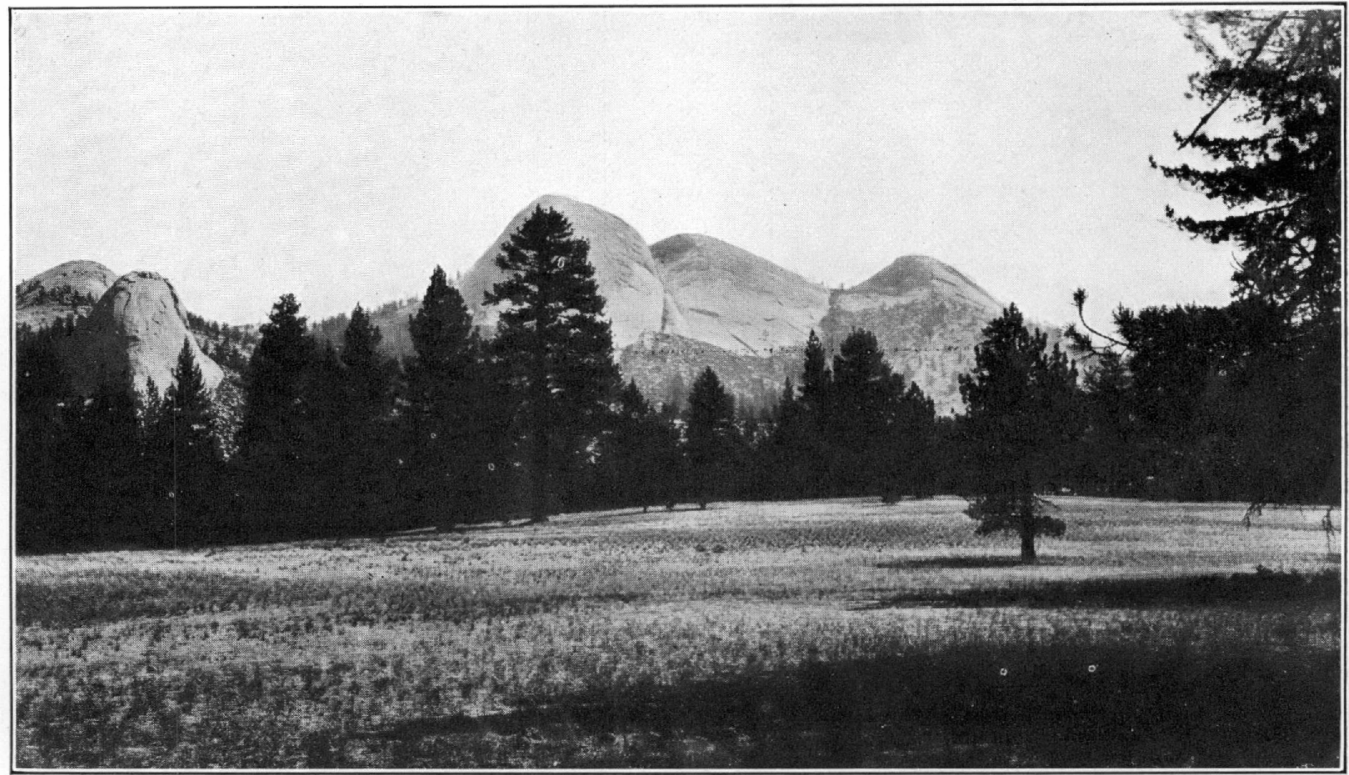

1. SANDY FLd'T IN ILIIJOUEINIE VALLEY AND STARR KING GHOUP

This barren flat is produced by a bed of sand and pravel deposited in at temporary lake that lay between the Illilouette Glacier and a lobe of the Merced Ciluer whic!' blocked the valley.

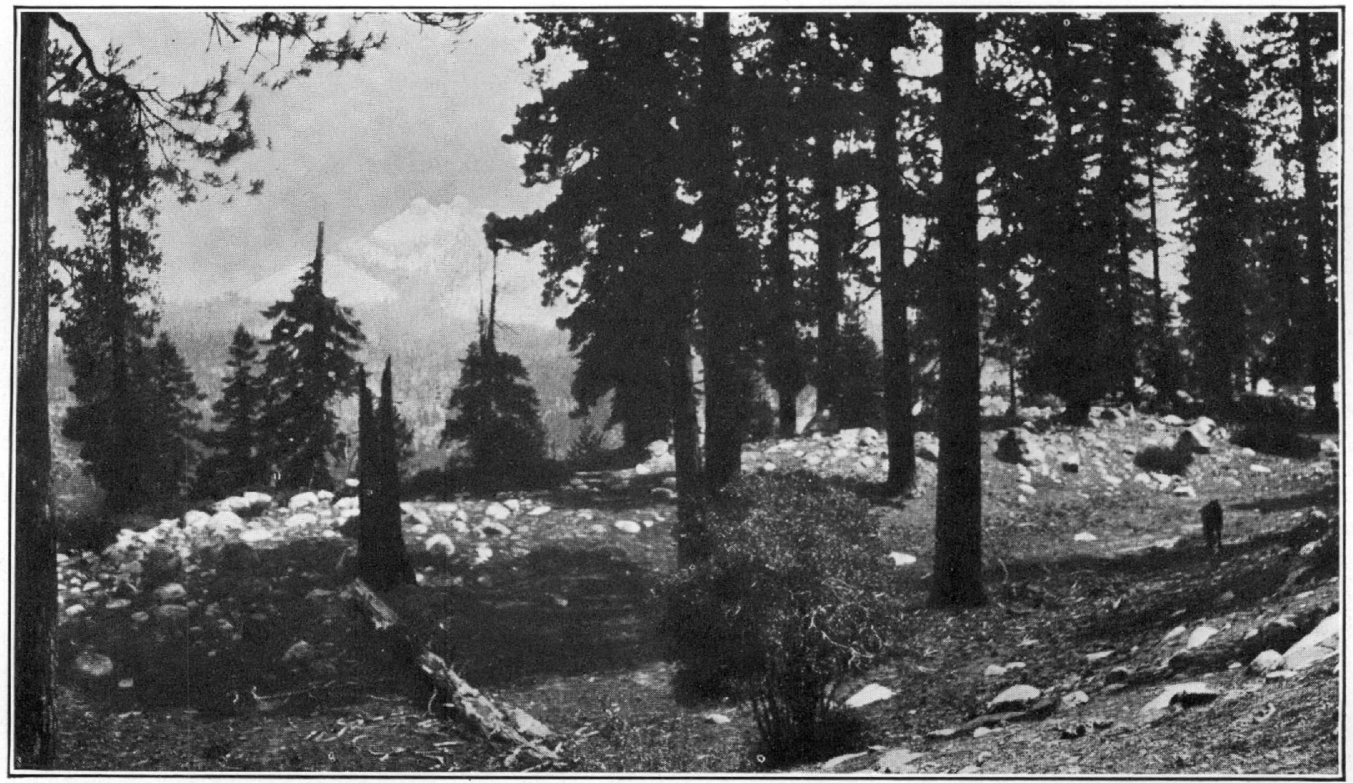

B. LATERAL MORAINES OF MERCED GLACIER ON SOUTH SIDE OF LITTLE YOSEMITE VALLEY

The view is taken from the highcst moraine of the series and shows the second highest. The figure of the horse at the right serves to indicale the size of the moraines. In the background is Clouds Rest. 


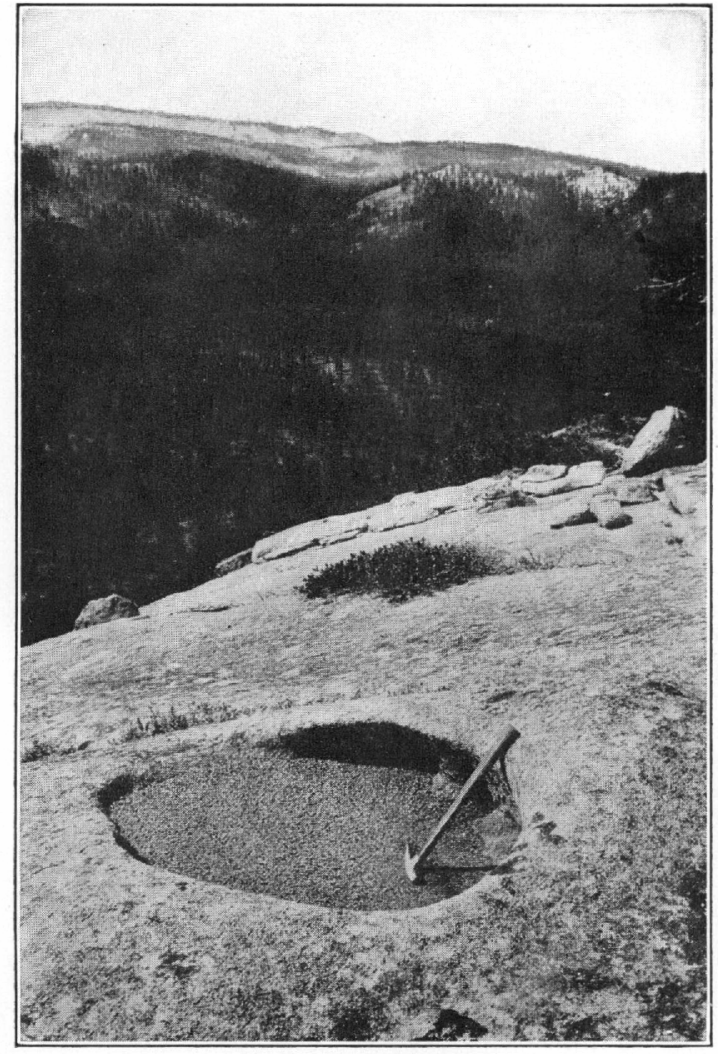

A. WEATHEH PIT AT GLACIER POINT

Cavities of this type are commonly mistaken for jwtholes such as are worn in stream beds by swiftly roliting cobbles. Those at Glacier l'oint have been pointed to as evidence of the passage of a placier over the promontory. The earlier ice did pass over Glacier Foint, but these cavilies were produced long af lerward by strongly localizen weathering of the rowk, Siem

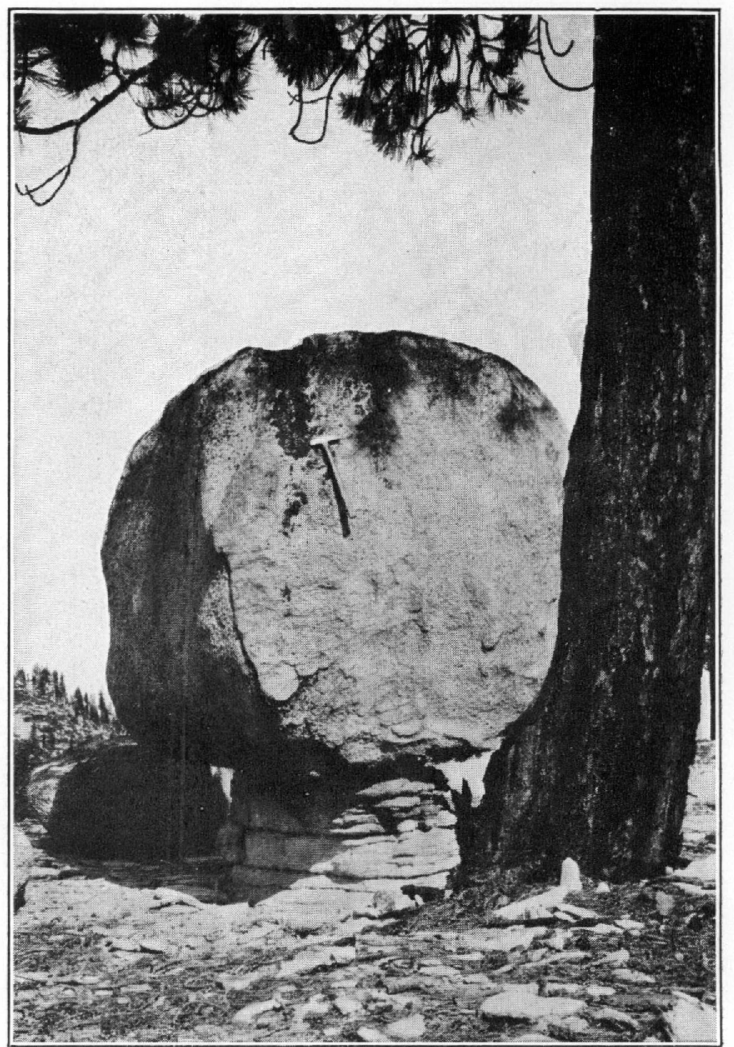

B. TYPICAL "PERCHED" BOULDER OF AN EARLIEH GLACIATION

The boulder is on the divide south of the Starr King Meadows, ahout :3 miles [rom its probable place of oritpin on the Clark Ranire. It measures about 5 feet to the side and is perched on a pedestal 20 inches high. The pedestal is composed of local rock and has remained preserved as a result of the prolection from the weather afforded by the boulder. Photograph by F. C. Cilkins.

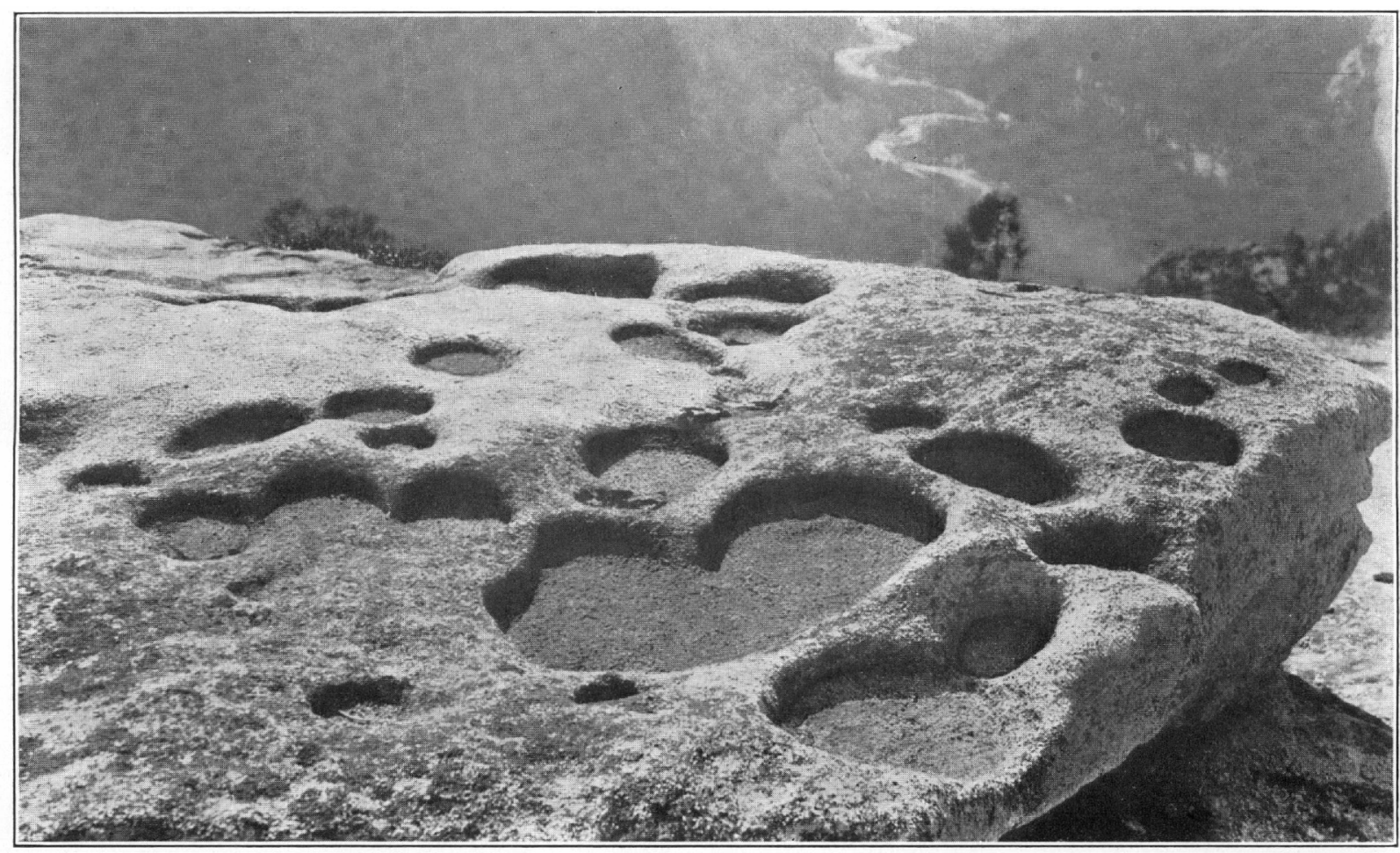

C. WEATIIER PITS IN SLAB ON NORTH DOMF

These weather pits have been formed entirely since the earlier ice passed over and smoolhed the crown of the domp. The ice of the last glacial stage did not reach this level. Several of the weather pits here shown huve expanded until thoy conleses. (others are inout lo coileses, the rock partitions between them being already partly broken down. 


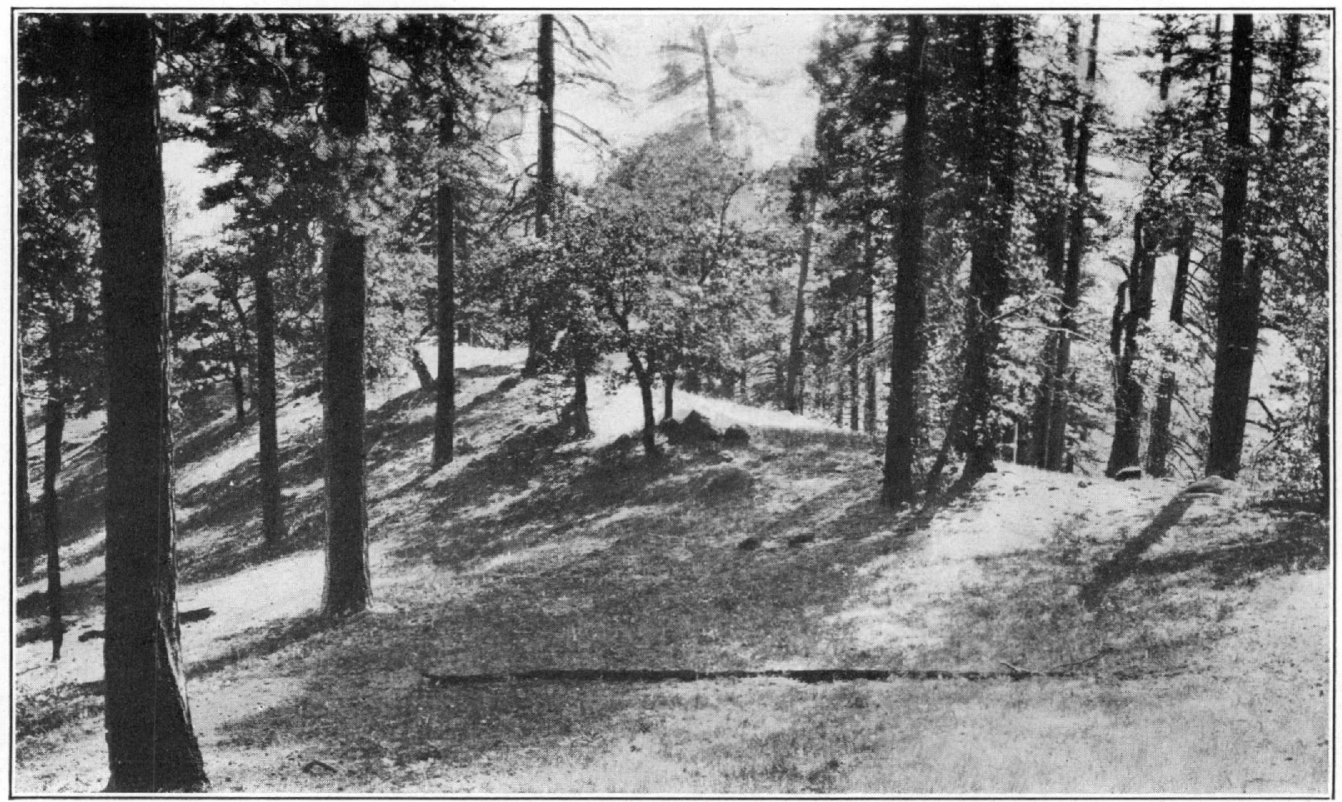

A. OLD MORAINE NGAR WAWOMA IOOAD

One of the hest preserved moraines of the older serics. Most of the older moraines have long since lost their ridge forms and the Wawona Road, south of Turldelink Dome.

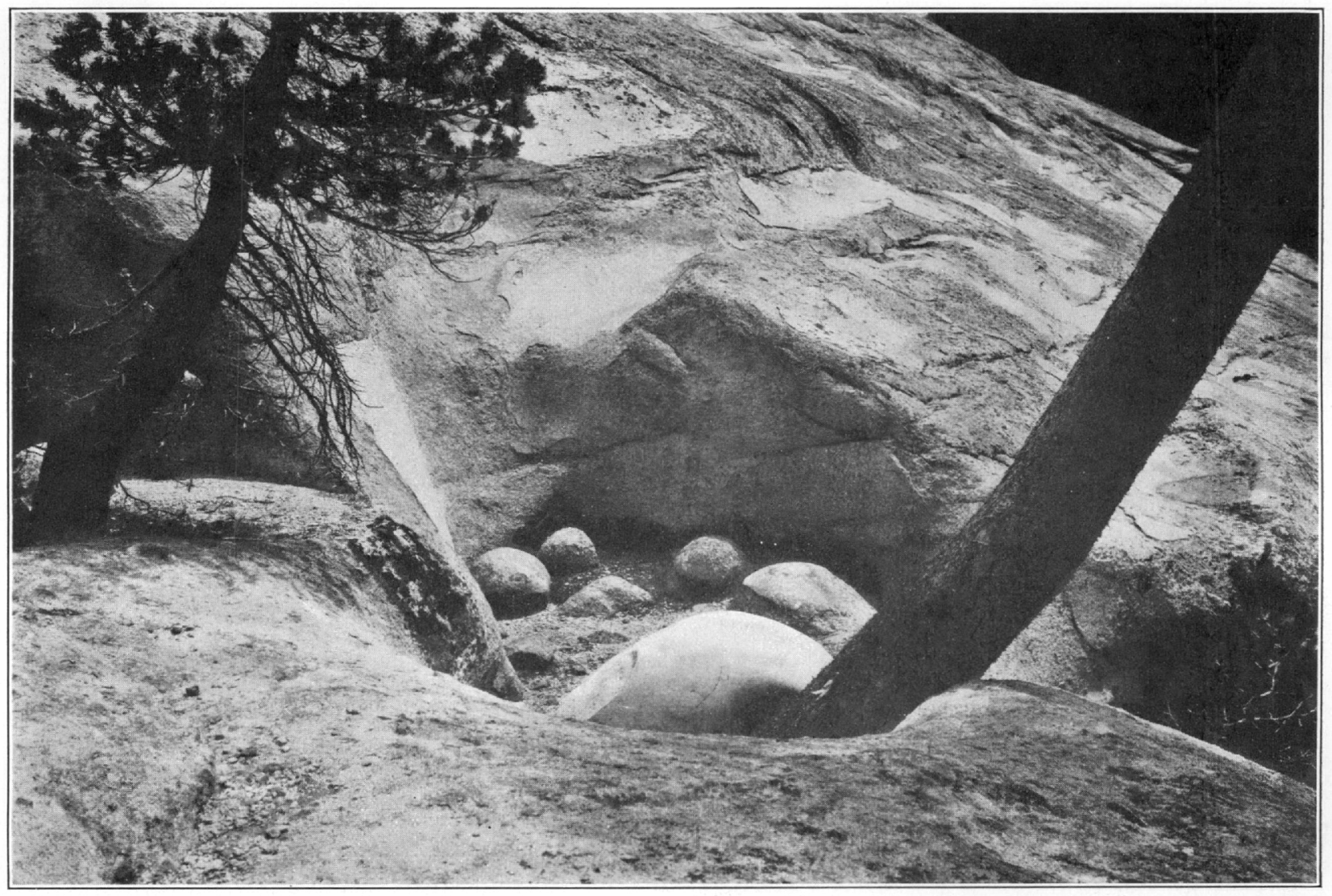

B.,TYPICAL POTHOLE OF SUbGLACIAL ORIGIN, AT LOWLH END OF TUULUMNE MEADOWS

Above the pothole are remnants of a torrent channel extending across a slecp rock slope where, manifestly, no stream could have flowed in the open. The

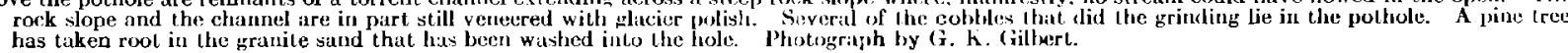




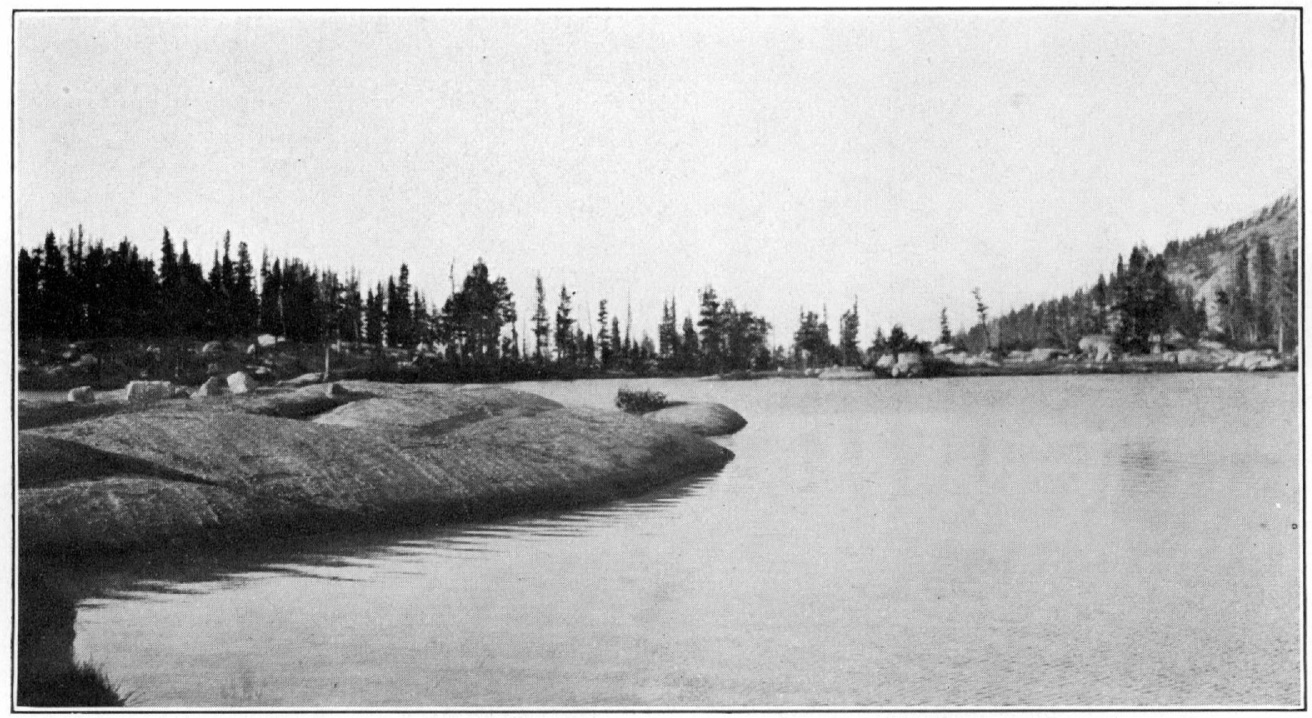

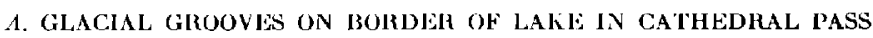
The glacier polish has disappeared for the most part, its a result of iutense frost aclion, but the grooves, being deep, remain

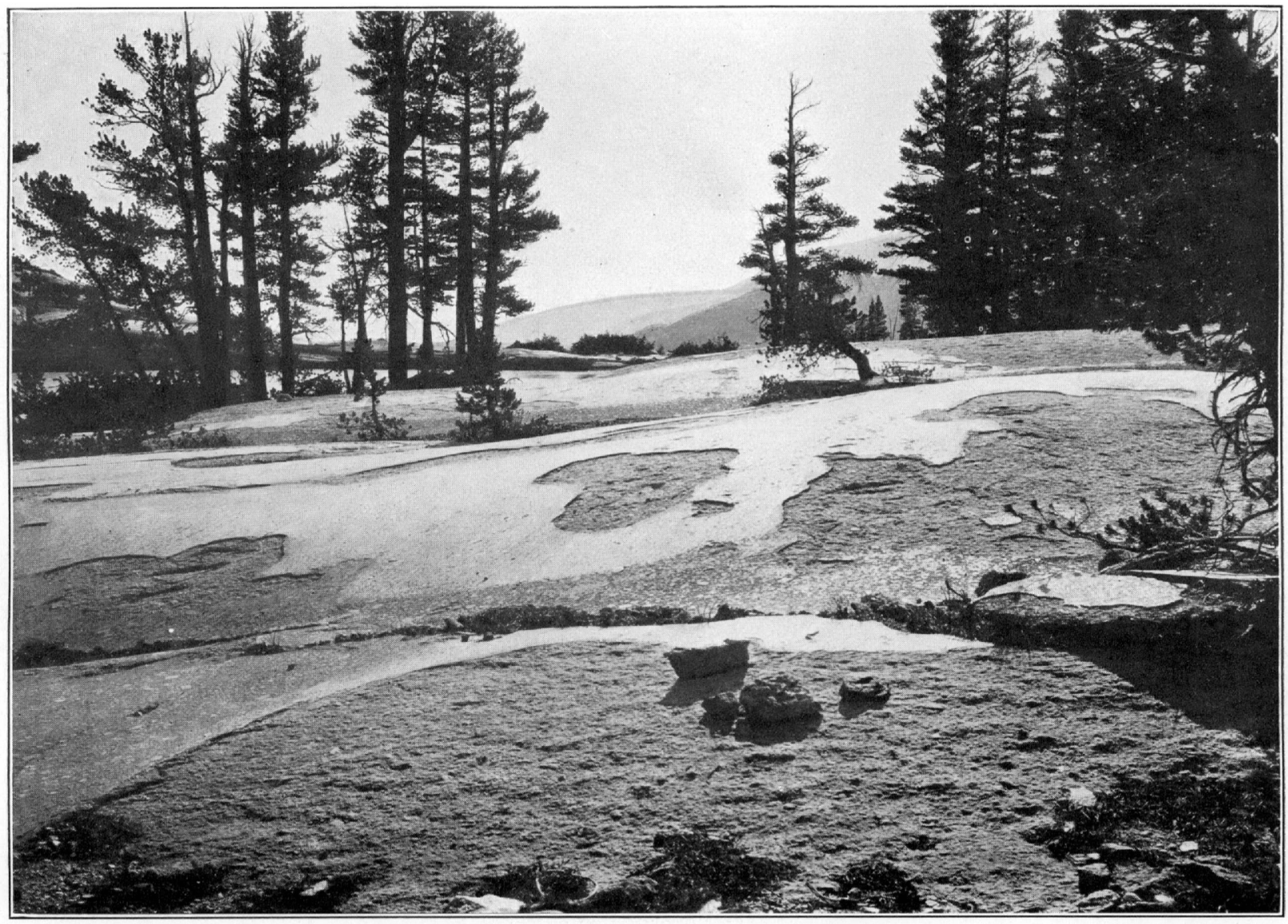

B. GLACIER POLISH ON FLOOR OF MASSIVE GRANITE The surface of the rock is scaling off in places as a result of weathering, but much of the polish is still in place and is likely lo endure for a long time.
Pholograph by $\mathrm{G}$. $\mathrm{K}$. (Gilbert. 


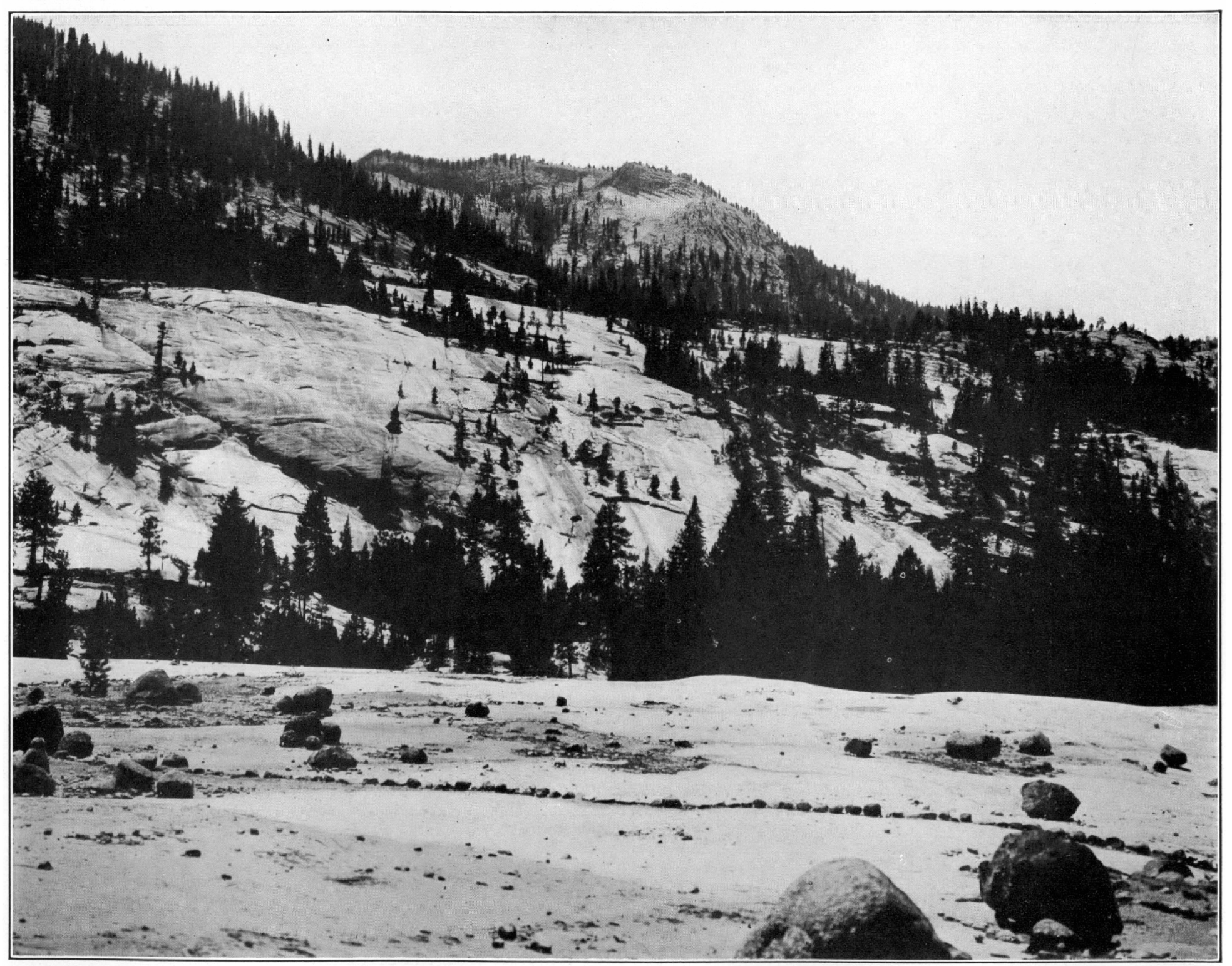

GiACIATED FLOOR AND SIDE OF UPPEA MERCED CANYON

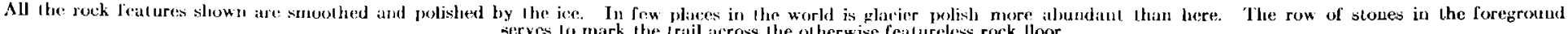




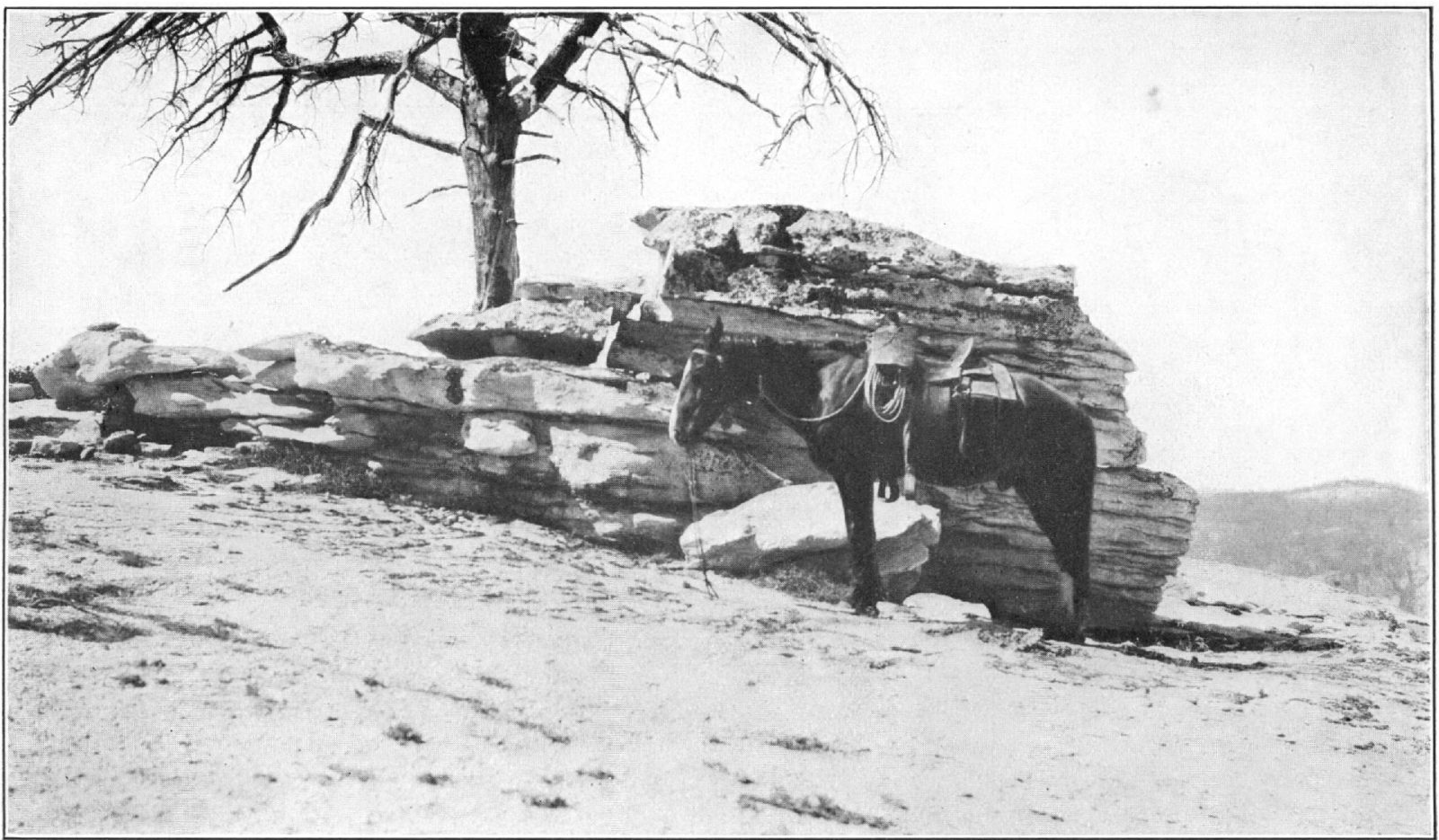

A. WALL OF APLITE ON MORAINE DOME

The 7-foot wall is formed by a vertical dike of aplite and has remained standing because the aplite disintegrates much more slowly than the surrounding granite. The height of the wall affords a minimum measure of the depth to which the granite has been stripped awity since the earlier ice passed over and smoothed the crown of the dome. Photograph by G. K.'Gilbert.

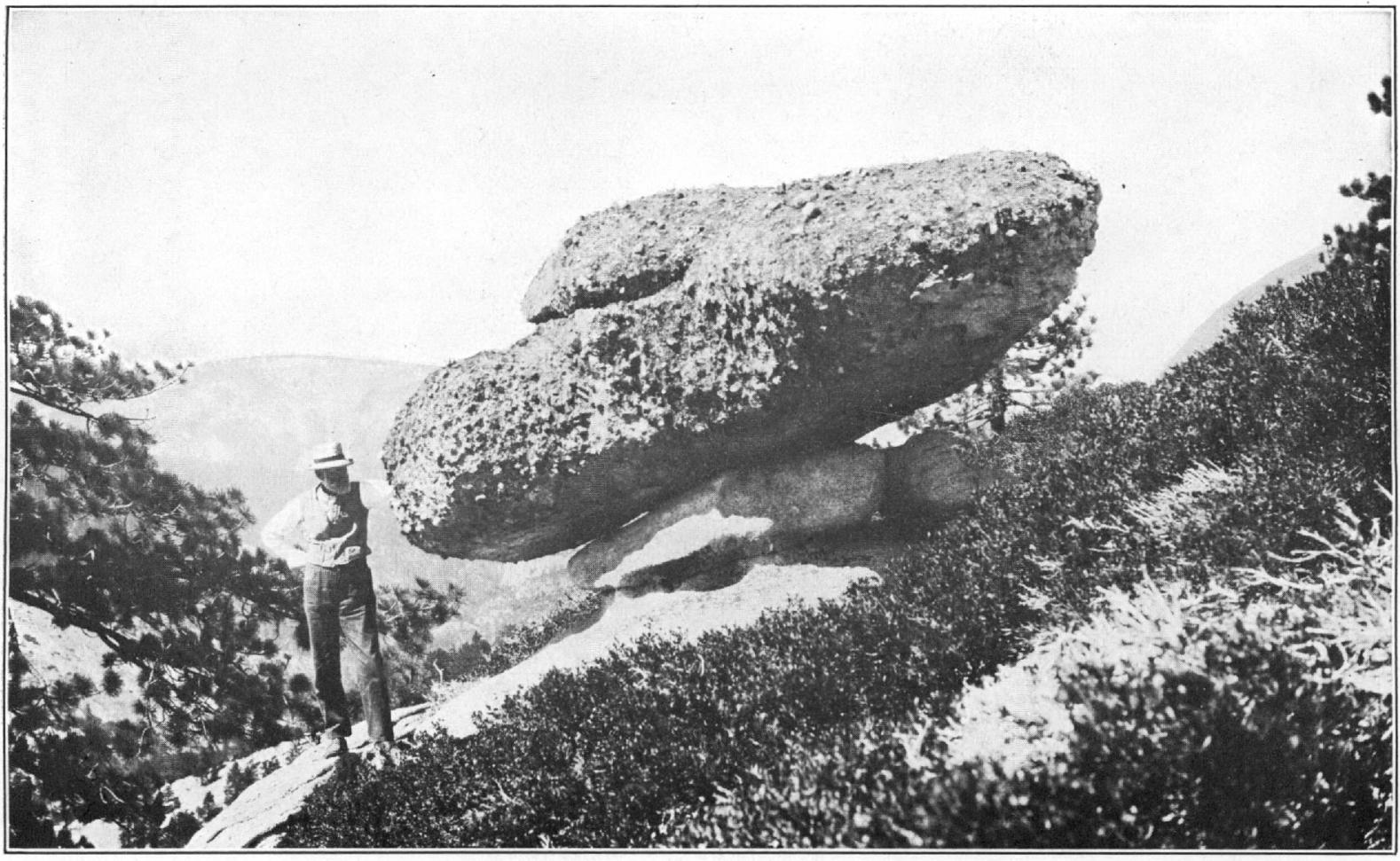

b. LARGE ERRATIC BOULDER ON MORAINE DOME

The boulder is composed of Cathedral Peak granite, readily recognized by the big feldspar crystals that project from its surface. It measures 12 by 6 by 5 feet and is perched on a pedestal 3 feet high. The pedestal consists of a remnant of a shell detached by exfolialion from the body 
is their approximately regular spacing. Perhaps the spacing would appear even more regular on the map were all the moraines laid down by the glacier actually represented, but some of the moraines are now reduced, as a result of rain wash and other agencies, to only a few scattered boulders and therefore were not mapped. In any event, the spacing is so prevailingly regular as to justify the inference that the recurring fluctuations of the declining Merced Glacier were essentially periodic. The same inference may be drawn also from the spacing of the frontal moraines that curve across the entire width of the valley floor about a mile above Liberty Cap, though their intervals are considerably larger than those between the moraines at the lower end of the valley.

The moraines that span the entire width of the valley, above Liberty Cap, naturally are more voluminous than those which outline the individual lobes, yet they are for the most part inconspicuous in the landscape. The reason is that they are buried almost up to their crests in sand and gravel-materials that were deposited by the Merced in a shallow basin that was excavated by the glacier in the rock floor of the Little Yosemite and was analogous to the much larger and deeper glacial basin in the main valley, which was occupied by the waters of ancient Lake Yosemite.

Particularly full and enlightening is the record of fluctuations of the Merced Glacier that is embodied in the lateral moraines. These moraines are best developed and most advantageously spread out for individual study on the north side of the valley, in the broad embayment southeast of Half Dome, where cliffs are lacking and slopes of moderate declivity prevail. No less than 30 distinct moraine ridges are situated there, one above another in a great, essentially parallel series. As seen on the map their arrangement in parallel curves and tangents and their coalescence by twos and threes at the east end strongly resemble the layout of the tracks in a large railroad yard.

The regular spacing of these moraines on the sloping valley side, again, is perhaps their most significant feature; it indicates much more fully and more convincingly than the spacing of the incomplete system of frontal moraines on the valley floor that the climatic pulsations by which the Merced Glacier was affected during its decline occurred with essentially rhythmic periodicity.

The Sunrise Trail zigzags up across the entire series of lateral moraines, thus affording many opportunities for their close inspection. Impressive even to the casual observer is the prevalence of large blocks in these moraines. Some of the ridges are made up almost wholly of large fragments and contain but little fine material. (See pl. 30, B.) Blocks 5 or 6 feet in length are common; not a few measure 10 or 15

$$
82564^{\circ}-30-5
$$

feet to the side. Most of the blocks are imperfectly rounded, or at least subangular, their edges and corners having been blunted and worn smooth in the course of their long journey on and in the ice; but there are some sharply angular, clean-cut blocks that appear to have suffered almost no wear since the day when they were torn from the cliffs. The proportionate number of these sharp-edged blocks increases noticeably up the valley, toward the sources of the glacier.

The excellent state of preservation of many of the blocks is also worthy of comment. Though weathered boulders are plentiful in all these moraines, nevertheless the traveler on the Sunrise Trail is constantly impressed by the great number of fresh-looking, essentially unweathered blocks that are in view on every hand. These blocks ring when struck with a hammer and give every proof of being composed of sound, hard granite. This fact gains significance when it is considered that these blocks have lain exposed to the weather for certainly not less than 10,000 years-those in the highest moraines of the series more probably

IGURE 19.-Sketch showing in section lateral moraines such as are situated in tiers one above nother on the north side of Little Yosemite Valley. The loose rock grains washed down om them accumulate to form sandy terraces between the crests

for about 40,000 years, that being the length of time which some geologists now estimate, on the strength of several lines of evidence, to have elasped since the glaciers began to recede from their culminating stage.

One reason why so many of the moraines are composed largely of coarse material is that most of the finer particles have been washed from them by rain water. Granite sand inherently has poor binding qualities and in consequence is easily dislodged, grain by grain, by running water, even by the merest rain-water rills. The extent to which some moraines have been thus despoiled of their sandy constituents is particularly evident in those places where the grains washed down the slope have been arrested by the moraine next below and have accumulated so as to form a smooth sandy terrace. (See fig. 19.) Terraces of this kind afford good going, and the trail builder wisely has taken advantage of them for considerable stretches.

On the rocky slopes of the promontory southeast of Sunrise Creek the higher moraines of the series gradually approach one another until at length they unite by twos or threes to form massive embankments from 10 to 50 feet in height. The topmost and largest of these embankments leads up over the very summit of the promontory, thence down nearly 100 feet to a 
saddle and again up in a grand spiral curve around the south side of Moraine Dome. It is, indeed, for this remarkable morainal embankment that the dome is named. The strip of forest which the moraine supports sets it off from the barren rock slopes above and below, thereby enhancing its prominence in the landscape. (See pls. $30, A$, and $31, B$.)

At a point about 150 feet below the summit of the dome the moraine is cut off by a precipice too steep to retain glacial débris; but a few hundred yards farther on, near the end of the ridge that extends northeastward from the dome, the moraine reappears, wrapped tightly around a knob that evidently stemmed the ice flood and caused it to divide. Pursued still farther, the moraine is found to plunge steeply down the north side of the ridge, dipping into the vale of Sunrise Creek, and to rise again on the other side to the base of the Clouds Rest massif. It describes, as is evident from the map, an arc outlining the front of a lobe that split off from the Merced Glacier. This lobe pushed through the saddle northeast of Moraine Dome but,

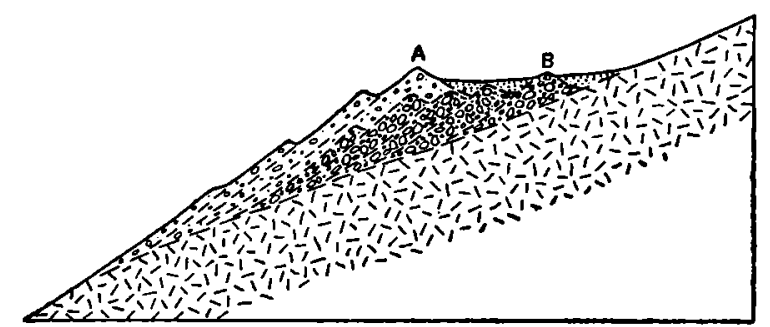

Figure 20.-Section across lateral moraines on south side of Little Yo semite Valley, showing why the great morainal embankment (A) is separated from the valley side by a broad sandy flat. It was built by the glacier upon a series of older moraines. The highest of these (B) still projects slightly above the granite sand that has been washed down from the slope above

curiously, advanced only a short distance, although favored by the steep downward slope. Behind the main moraine are several lesser ones disposed in concentric curves and marking successive phases in the recession of the lobe.

From the saddle just mentioned the moraines extend northeastward for a distance of $2 \frac{1}{2}$ miles, as far as the steep rocky spur at the south end of Sunrise Mountain, forming another great series of parallel crests and terraces. It is here that the moraines attain their greatest volume and are best developed, many of them resembling artificial embankments, evenly graded and laid out in smooth curves. The topmost moraine is the largest and the most impresssive. It bears on its crest a row of granite blocks which, shimmering white through the dark foliage of the trees, produces the effect in a distant view of a chalk line drawn across the mountain side to mark the highest level reached by the ice flood. (See pl. 31, A.)

On the south side of the Little Yosemite the lateral moraines are not so well displayed as on the north side, mainly because of the prevalence of smooth rock faces on which the glacial débris can find no resting place. The only moraines of the series that are strongly developed are the upper ones, which rest on a shoulder above the precipitous ice-carved cliffs. (See pl. 32, B.) This shoulder marks the lower margin of the relatively gentle upper slopes, which are remnants, but slightly modified, of the preglacial valley side. From the point where the trail leading from the Nevada Fall to Glacier Point reaches the shoulder the upper moraines extend eastward for a distance of 1 mile, the highest forming a mighty rock-crowned bulwark. They end at the ice-smoothed ledges on the salient north of Helen Lake, this being a place of glacial scouring and not of deposition; but farther east, in the deep recess between the salient mentioned and the Cascade Cliffs, the moraines reappear in force. They fill this recess so completely that their frontal slope is almost flush with the two flanking promontories. (See pl. 29.)

It is a significant fact that the topmost moraine, instead of curving into the recess and hugging the wall, extends across the opening in the form of an almost straight embankment, and that behind it there is a flat formed of granite sand that has been washed down from the slope above. What is more, in two places the low crest of a moraine projects slightly above this sandy flat, close to the slope. It is thus evident that before the Merced Glacier attained its highest stage and laid down the straight morainal embankment it had attained a slightly lower stage during which it invaded the recess to its full depth and deposited a moraine against the slope. The question naturally arises: Why did not the glacier invade the recess also during its culminating stage and deposit the second moraine directly upon or against the first? There can be only one explanation-that the glacier, after invading the recess and depositing the first moraine against the slope, subsided with repeated fluctuations and deposited a series of moraines at successively lower levels, in the manner indicated in Figure 20, and that, having thus nearly filled the recess with débris, it rose to a second climax a little higher than the first. Being unable now to expand as broadly as before, it built its new moraine in the form of an embankment upon the old accumulation.

It is to be concluded, then, that there were really two ice floods separated by an interval during which the glacier melted down to a relatively low level or perhaps withdrew from the valley altogether. The interval, however, was not a long one, for the moraine of the first ice flood looks but little older than the embankment produced by the second, and the continuity of the embankment shows that the mass of débris left in the recess by the first ice flood had suffered but little from erosion when the second ice flood supervened. Similar evidence pointing to the occurrence of two ice floods separated by a brief interval is to be found farther west on the south side of the 
Little Yosemite Valley and at several places on the north side. There is, further, an abundance of confirmatory evidence in the moraine series in other valleys of the Sierra Nevada.

It is entirely probable, in view of all these facts, that the six frontal moraines which the main glacier left in the Yosemite Valley are to be divided into two series also. The four lower moraines, which are widely breached by the river, may record the first ice flood; the two better-preserved moraines which together form the dam at the El Capitan Bridge may record the second ice flood.

\section{MORAINES IN THE TENAYA BASIN}

Tenaya Canyon, in contrast to the Little Yosemite, contains scarcely any moraines. Muir ${ }^{40}$ sought to explain this fact by supposing that the Tenaya Glacier toward the end of the ice age "became torpid, withering simultaneously from end to end"; but a systematic survey of the Tenaya Basin above the head of the canyon and to the west of it reveals a fine series of regularly spaced lateral moraines analogous to those left by the Merced Glacier in the Little Yosemite. The Forsyth Trail leads down into the basin over the left laterals, and the Tenaya Lake Trail crosses the right laterals in the rugged country near Hidden Lake. From this neighborhood the right laterals swing northward to Snow Flat, around which they curve in concentric loops, outlining an ice lobe, and thence they extend northeastward to the gentle rock slopes under the bench of May Lake, where they spread out broadly.

To one who views these series of moraines comprehensively on a topographic map it is manifest that the Tenaya Glacier fluctuated repeatedly during its decline, in precisely the same way as the Merced, Glacier. Doubtless the two ice streams were affected by the same periodic oscillations of the climate. Moreover, it is to be inferred from the general trend of the moraines in the Tenaya Basin and from the levels at which they lie that they would be prolonged for considerable distances along the sides of Tenaya Canyon if there were suitable slopes to which they might cling. The absence of lateral moraines in Tenaya Canyon, therefore, is seen to be due primarily to the excessive steepness and smoothness of its walls.

It may seem inconsistent with this explanation, perhaps, that the bottom of the canyon is not littered with large quantities of morainal material that slid from the walls, but the fact is that the Tenaya Glacier was very lightly loaded with débris. The moraines which it left in the Tenaya Basin are notably of very meager volume, individually, compared with those of the Merced Glacier. The reason is obvious: the Tenaya Basin is carved in hard and prevailingly

40 Muir, John, Studies in the Sierra-Ancient glaciers and their pathways: Sierra Club Bull., vol. 10, p. 187, 1917. massive granite that was, necessarily, very difficult for the glacier to erode.

The scarcity of distinct frontal moraines in Tenay a Canyon is explained by the exceeding ruggedness of its bottom, by the paucity of glacial débris, and also, doubtless, by the fact that the Tenaya Glacier, not having any great tributaries in its upper course, bore no strong medial moraines such as would have provided material for the building of frontal moraines.

A small amount of glacier-worn débris, a mere remnant of a frontal moraine, occurs near the lower end of Mirror Lake, opposite the first bay. Mirror Lake itself, however, does not owe its existence to a morainal dam. It is impounded by large masses of coarse, angular rock débris that evidently fell in avalanches from the cliffs back of the Washington Column and from the wall opposite at a time long after the glacial epoch. Clarence King ${ }^{47}$ believed these obstructing masses to be a moraine loop of the Tenaya Glacier, but the material of which they are composed, upon close examination, proves to be derived wholly from the adjacent canyon walls.

Were space available it would be in order, next, to describe the remarkably complete and well-preserved systems of moraines in the Illilouette Basin; likewise the moraines left by the glaciers that occupied the hanging valleys of Yosemite Creek, Bridalveil Creek, and the lesser upland streams. It seems preferable, however, in order not to weary the reader, to describe instead the glaciers themselves which are so clearly outlined by these moraines. Before doing so, however, it is important to invite attention to certain facts: that tell, unmistakably, of earlier and more extensive ice invasions in the Yosemite region than the one that. is recorded in the distinct moraines just described.

\section{EVIDENCES OF AN EARIIER ICE INVASION}

\section{ON THE SIDES OF THE LITTLE YOSEMITE VALLEY}

To one who has not extended his observations beyond the great series of lateral moraines that cling to the sides of the Little Yosemite it would seem entirely justifiable to conclude that the conspicuous embankments at the top of that series mark the highest level ever attained by the Merced Glacier. Indeed, no further moraines of a like nature are to be seen on the slopes above, nor do these slopes exhibit any of the sculptural effects characteristic of glacial action. On the contrary, they are in places corrugated by spurs and ravines or show other inequalities that are obviously products of normal erosion-that is, chiefly of the erosive action of running water in streamlets and rills.

Nevertheless, careful scrutiny of the slopes above the highest morainal embankments reveals the presence of scattered boulders of Cathedral Peak granite-

"Whitney, J. D., Geological survey of California, Geology, vol. 1, p.422, 1865. 
the granite with the large feldspar crystals which is so readily identified among the materials that have been brought down from the High Sierra by the glaciers (p. 56). There are also scattered boulders of quartzite, schist, and other types of rock that are foreign to the Yosemite region and clearly derived from the crest of the range. Most of these boulders are, like those in the moraines described, imperfectly rounded, but unlike them they are invariably rust stained and weathered to a depth ranging from an eighth to half an inch. Many of them are so "rotten," to use the popular expression, that they are traversed by a network of cracks and fall apart at a moderate blow. Thus it becomes increasingly apparent, as the search is continued, that the ice of the glacial epoch did once, at a relatively remote date, attain a level much higher than that indicated by the prominent moraines.

An excellent locality for such a search is the slope on the north side of the Little Yosemite which is traversed by the trails that lead to Half Dome and Clouds Rest. This slope is remarkably smooth and easy to traverse, compared with the rough, stony belt of moraines below. It is surfaced for the most part with a thick layer of granite sand and forest soil, materials whose formation must have required considerable time. In some places the slope is cut by ravines such as occur in unglaciated regions. It also bears here and there crags and pinnacles of granite that evidently form part of the body of the mountain and owe their fantastic shapes to longcontinued disintegration under atmospheric influences.

In the deeper trail cuts and in holes left by uprooted trees, moreover, boulders and cobbles of typical glacial forms protrude from under the surficial blanket of sand and soil. When freshly exhumed these boulders and cobbles are enveloped almost invariably in a yellowish, rusty coating that masks their constituent minerals and makes all look alike, although they may belong to widely different rock types. Thus, as the traveler proceeds up the slope, he comes to realize that, though smooth, it is in reality veneered for the most part with old glacial materials and that the conspicuous boulders of Cathedral Peak granite which attract the eye are but a few of the larger fragments that are not entirely covered over with soil. What is more, he perceives that in many places the old glacial materials form indistinct swells a foot or two in height that extend across the slope. When traced out and plotted on a map these swells are found to lie roughly parallel to one another like the crests of the series of lateral moraines below. They are indeed old, dim moraines that have long since lost their crests and have been reduced by slow disintegration to a mere fraction of their original height. As may be seen on the map (pl. 29), they are on the average broader individually and spaced farther apart than the younger, sharp-crested moraines and would seem to record the fluctuations of a larger and more heavily loaded glacier.
The highest of these old moraines lies to the southeast of the upper of the Quarter Domes, at an altitude of about 8,250 feet, more than 1,000 feet above the level of the highest of the younger moraines. It terminates at the brink of Tenaya Canyon in such a way as to show that at one time the Merced Glacier there united with the Tenaya Glacier at a common level, the two forming one vast, continuous sea of ice above which only the summits of Clouds Rest and Half Dome rose like bold rocky isles and beneath which the saddle separating these two eminences lay submerged to a depth of fully 700 feet.

On the south side of the Little Yosemite similar vestiges of old moraines occur at corresponding levels. On the plateau-like upland to the northeast of Mount Starr King the conditions evidently were particularly favorable for their preservation, for there several of the old moraines still retain for considerable distances their characteristic ridge forms, though the sharp crests which doubtless they originally possessed are now reduced to rounded backs cloaked with granite sand derived from disintegrated boulders. They may be readily traced south of Helen Lake and in the vicinity of the Starr King Meadows, where they describe great arcs, showing how the glacier deployed broadly over the more level parts of the upland and again contracted when it met the obstructing masses of Mount Starr King and its companion domes.

It is on this upland to the south of the Little Yosemite, perhaps, that the student may best learn to recognize these older moraines by their constituent materials as well as by their indistinct forms. His eye, having become sensitive to these characters, will then discern dim vestiges of old morainal deposits in many parts of the Yosemite region where otherwise it would detect nothing indicative of the former presence of glaciers. Thus a little searching will reveal the remnants of a series of old lateral moraines that swing in sympathetic curves across the recess in the south side of the Little Yosemite, north of the Starr King group. Another, still dimmer series of moraines slope from the north shoulder of that group southwestward into the Illilouette Valley, outlining, as may be seen on Plate 29, the successive positions occupied by the retreating margin of a massive ice lobe of the Merced Glacier which penetrated the Illilouette Valley for about 2 miles.

No one who has traced these ancient moraines (one of them is a massive, fairly well preserved embankment that extends unbroken for a distance of more than a mile) can have the slightest doubt as to the reality of this ice lobe which pushed up the valley, nor is he likely to entertain the belief which so many writers on the Yosemite region appear to have shared, that the Illilouette Valley formerly contributed a large volume of ice to the Yosemite Glacier. The younger moraines show clearly that during the last glacial stage 
the Illilouette Valley contained no ice for a distance of 5 miles up from its mouth, and the older moraines show that during the earlier stages, when the ice reached its greatest extent and depth, the Illilouette Glacier was effectually imprisoned by a lobe from the' trunk glacier itself.

The older moraines indicate, further, that at the time of maximum glaciation the Illilouette Glacier and the opposing lobe met and united, forming a broad sea of ice that eventually rose high enough to find an outlet westward into the Bridalveil Basin. Later, when the Illilouette Glacier and the lobe melted apart, there was formed between them a temporary lake- ancient Lake Illilouette it may be called. The gravel and sand deposited in this body of water remain to attest its former presence. (See pl. 32,A.) They cover a stretch of nearly 3 miles, in part bare, in part covered with manzanita bushes, whose brilliant green, contrasting with the somber tones of the surrounding pines, creates the illusion, at a distance, of a verdant meadow. Muir ${ }^{48}$ long ago recognized these deposits of sand and gravel as indicative of a temporary glacial lake, but he makes no mention of an ice lobe, nor is there anything in his writings to show that he apprehended the real nature of the dam by which the waters were impounded.

\section{IN THE VICINITY OF GLACIER POINT}

Of more than academic interest are the glacial deposits that occur near Glacier Point, for they definitely answer the question so often asked by visitors, whether that high promontory was ever overtopped by the ice. The extreme point of the promontory is wholly bare, but in the immediate neighborhood of the Glacier Point Hotel, on the slopes below, in the hollow to the west, and, most significantly, on the wooded slope above, glacial material is abundant. This material is spread out in a sheet that scarcely suggests distinct moraine ridges, yet its glacial origin is definitely proved by the presence in it of rocks derived from the Little Yosemite and the High Sierra. As so much depends upon the testimony of these rocks it seems worth while here to describe some of them.

Most plentiful are rounded boulders and cobbles and angular fragments, all deeply weathered, of Half Dome quartz monzonite, ${ }^{49}$ the light-colored granite of which not only Half Dome but all of the Little Yosemite and its surrounding heights are composed. Clearly this rock would make up a large proportion of the load gathered by any glacier passing through the Little Yosemite, and naturally it would be abundant in the moraines left by such a glacier at Glacier Point. Some of the quartz monzonite in the deposits about Glacier

46 Muir, John, Studies in the Sierra-Ancient glaciers and their pathways: Sierra Club Bull., vol. 10, p. 193, 1917.

49 The characteristios of this rock and those mentioned in the following paragraphs are described more fully in the appendix, p. 126.
Point might possibly be derived from localities nearer than the Little Yosemite-for instance, from the giant stairway, or from the walls of the Illilouette Gorgebut if so, it obviously could not have been carried from those places up to Glacier Point, which is fully 2,000 feet higher, save through the agency of a glacier.

There are also a few boulders of a coarse-grained, highly siliceous granite, light buff in general tone when fresh but vivid rose when weathered. They are of peculiar interest because there is only one place in the High Sierra above the Yosemite from which they can be derived-Mount Clark, the sharp-profiled peak which stands on the east side of the Illilouette Basin, 8 miles from Glacier Point. Being devoid of hornblende and biotite, the dark minerals that speckle all the granitic rocks of the Yosemite region, the Mount Clark granite is readily identified in the miscellaneous assortment of rocks that make up the moraines.

Finally, there are fragments of yellowish quartzite and gray schist whose places of origin have been located by Calkins on the long northern. spur of Mount Clark. It is evident that these two highly distinctive materials and the Mount Clark granite were carried to Glacier Point on the southern margin of the ice stream.

On the slope above Glacier Point the morainal deposits, traced by these and other diagnostic materials, are found to extend up to an altitude of 7,700 feet, thereby affording indubitable proof that the ice once rose 500 feet above the promontory. Higher still, however, on the bare rock slope at the immediate base of Sentinel Dome, scattered boulders indicate that, perhaps at a very early stage in the glacial history of the region, the ice attained an altitude of over 7,900 feet, or fully 700 feet above Glacier Point. Of the significance of these scattered boulders more will be said on another page.

\section{FEATURES AT GLACIER POINT OFTEN MISTAKEN FOR EVIDENCES OF GLACIATION}

The rocky platform at Glacier Point, from whose edge the sightseer beholds the grand panorama of the Yosemite Valley and the High Sierra, presents some features that are commonly, though erroneously, regarded as evidence of the passage of a glacier over the promontory. Whether it was for these features that Glacier Point was named is uncertain-the origin of the name is obscure-but in any event it seems appropriate here briefly to digress in order to explain their true nature.

The features mentioned are basin-shaped cavities in the rock, measuring as a rule from 12 to 18 inches in diameter, and from a few inches to 6 inches in depth. A typical example is shown in Plate 33, $A$. They bear some resemblance to "potholes" such as are worn in the rocky beds of streams by cobbles whirled round and round by a swift current, and this is true especially of the deeper basins. 
Now it happens that in the minds of many persons such potholes are associated with glaciers, being held to be characteristic products of "glacier mills" (called "moulins" by the Swiss)-that is, torrents of water descending through crevasses in the ice and impinging with great force on the rock bed below-and as a consequence the cavities at Glacier Point are generally linked with the former presence of a glacier. As a matter of fact, potholes are formed by whirling cobbles in the beds of open streams as well as in the beds of subglacial streams, and they do not, therefore, afford prima facie evidence of glaciation. Potholes of both kinds abound in the Sierra Nevada. A fine series of potholes that are unquestionably of subglacial origin is to be seen at the lower end of the Tuolumne Meadows, extending across the ice-smoothed slope of a low dome of granite where, manifestly, no stream could have flowed in the open. (See pl. 34, B.) On the other hand, potholes that clearly have been formed without the intervention of a glacier are plentiful in the lower Merced Canyon and in other canyons and gulches that have never been penetrated by glaciers.

The cavities at Glacier Point, however, upon close scrutiny, are found to be not stream-worn potholes but products of strongly localized weathering, a process that affects the granitic rocks of the Sierra Nevada in many places where they are directly exposed to the atmosphere. They belong to a class of features that will here be referred to as "weather pits." The development of cavities of this type is promoted as a rule by the presence in the rock of local aggregates of readily soluble minerals. A small initial hollow having been formed by the decomposition of such an aggregate of minerals, it becomes a receptacle for water from rains or melting snow and is enlarged gradually by both chemical and mechanical processes. Acids produced by decomposing pine needles, lichens, or other vegetal matter attack the weaker minerals, and in freezing weather the ice, expanding with force as it crystallizes, pries off flakes and grains of rock from the walls. Thus weather pits may expand from an initial diameter of about an inch to diameters of 2 or 3 feet, and those situated close together may eventually coalesce as their rims intersect. (See pl. 33, C.) Their growth in depth, on the other hand, seldom keeps pace with their lateral expansion, for the less soluble particles of rock detached from the rims collect at the bottom and, although the finer particles are blown out by the wind in dry weather, usually enough of the coarser ones remain to form a protective pad that tends to retard downward excavation.

Some weather pits are difficult to distinguish from stream-worn potholes, but as a rule such pits possess characteristics that set them clearly apart, for the processes whereby they are enlarged, being dependent largely upon the presence of standing water, operate intensively only up to the level of the water surface and thus tend to undercut the sides, leaving the rims overhanging. This undercutting action is of course intensified in those weather pits in which the depth of water is definitely controlled by an outlet, giving rise to sharply overhanging rims. Plate $33, A$, shows a characteristic example, and other examples are to be seen in Plate 33, $C$. The weather pit in Plate 33, $A$. moreover, has alcovelike recesses under the rim, which show that enlargement is proceeding more rapidly at some points than at others. The resultant scalloped form contrasts strikingly with the smoothly cylindrical forms characteristic of true potholes, produced by the grinding, boring action of whirling cobbles.

It is a significant fact that weather pits do not occur on freshly glaciated rock surfaces. Not a single one is to be found within the area that was covered by the later glaciers. Evidently they develop at an extremely slow rate, and not enough time even for their initiation has elapsed since the glacial epoch. On the other hand, weather pits do occur on rock surfaces that were overridden by the earlier glaciers, as well as on such surfaces as have remained wholly unglaciated, these two kinds being indistinguishable, so far as effects of weathering are concerned. Particularly fine examples of weather pits that have developed since the passage of the earlier ice are to be seen on the summit of North Dome (pl. 33, C); examples of weather pits that have developed in unglaciated localities are to be seen on the summits of Sentinel Dome and Illilouette Ridge.

The presence of weather pits on Glacier Point thus clearly affords no proof of the glaciation of that promontory but attests its long exposure to the weather since it was glaciated.

\section{ON THE SOUTH SIDE OF THE YOSEMITE VALLEY}

Along the south rim of the Yosemite Valley, west of Sentinel Dome, one looks in vain for older moraines. Evidently the earlier Yosemite Glacier in this part of its course declined rapidly westward, so that it lay entirely beneath the brink of the upland. The precise level of its surface at the time of maximum glaciation is not indicated on the cliffs, for these are too precipitous to retain glacial débris and have long since lost whatever glacial polish, striae, or sculptural effects were imparted to them by the ice. Fortunately, however, the Cathedral Rocks bear on their summits and slopes small deposits of glacial botilders that give some idea of the depth attained by the earlier Yosemite Glacier.

To Frank C. Calkins belongs the credit of discovering these boulders on the Cathedral Rocks and of identifying them beyond all possible doubt as ice-borne boulders. Among those on the main summit of the Cathedral Rocks he found several boulders composed of the porphyritic phase of the Half Dome quartz monzonite which occurs near Tenay a Lake and Merced 
Lake; also a fragment of limestone derived from the metamorphic belt of the High Sierra. On the slope immediately south of the main summit he found a boulder of the familiar Cathedral Peak granite.

So imposing are the Cathedral Rocks, especially when viewed from the floor of the Yosemite Valley (pl. 18), that it is difficult to imagine them as once having been completely overtopped by the ice, yet the testimony of the boulders leaves no doubt that they were. Even the highest of these boulders, at an altitude of 6,638 feet, do not mark the higest level reached by the ice flood, for on the brush-covered summits south of the Cathedral Rocks other remnants of moraines occur at altitudes ranging from 6,800 to 6,900 feet. These remnants show that the earlier Yosemite Glacier passed over the main summit of the Cathedral Rocks with a depth of not less than 300 feet.

Turner, ${ }^{60}$ who first noticed these higher remnants of moraines, thought that they might have been deposited by the tributary glacier which issued from the hanging valley of Bridalveil Creek. However, from their very position on the east, up-valley side of Bridalveil Creek, it would seem more likely that these moraines were deposited by the main valley glacier, and this inference is borne out by an examination of their constituent materials.

A survey of the Bridalveil Basin discloses that the tributary glacier which it sent forth was of small volume and carried but little débris. Older moraines are scarce in the basin and, on the whole, are difficult to trace. However, they indicate unmistakably that the Bridalveil Glacier, which had its sources in the cirque now occupied by Ostrander Lake and on the adjoining slopes of Horse Ridge, was reinforced in its lower course by a considerable flow of ice from the Illilouette Basin. This flow came through the saddle southwest of Mono Meadow.

ON THE NORTH SIDE OF THE YOSEMITE VALLEY

As compared with the south side of the valley, the north side is rich in glacial deposits and affords an abundance of data that throw light on the earlier glacial history of the Yosemite region. The slope between North Dome and Basket Dome, for instance, is veneered with old glacial débris up to an altitude of about 7,600 feet. Higher still, on the southeast side of Indian Ridge, is a fairly distinct lateral moraine that marks the junction of the Snow Creek Glacier with the Tenaya Glacier, a short distance above the confluence of the Tenaya with the ice stream in the Yosemite Valley. This lateral moraine, which is comparable in size and state of preservation to the morainal embankments that are situated near the Starr King Meadows, can be traced up to an altitude of about 8,150 feet. However,

so Turner, H. W., The Pleistocene geology of the south-central Sierra Nevada, with especial reference to the origin of Yosemite Valley: California Acad. Sci. Proc., 3d ser., vol. 1, p. 304, 1900. even this is not, apparently, the highest level reached by the earlier ice, for in the vicinity of Indian Rock, at altitudes as high as 8,400 feet, there are scattered boulders, among which are several composed of porphyritic granite from Mount Hoffmann.

Large quantities of glacial débris, including several remnants of lateral and frontal moraines, occur in the valley of Snow Creek; but instead of describing these deposits it seems far more important to invite attention to the few isolated boulders and cobbles that lie on the bald, rounded summit of Mount Watkins. These clearly attest that this Capitan-like eminence, which stands 3,300 feet above the floor of Tenay a Canyon, was once completely overswept by the ice. The observer marvels that snow and ice could have accumulated in this part of the Yosemite region to so great a depth, yet the testimony of the boulders and cobbles is not to be doubted. Among them is a 3 -foot boulder representing the porphyritic phase of the Half Dome quartz monzonite which occurs near Tenaya Lake; and some of the subangular fragments and rounded cobbles consist of yellowish, reddish, and banded quartzites from the High Sierra.

North of Mount Watkins, at several places on the upland, are other glacial boulders and patches of morainal material which show that all of this upland, as far north as Mount Hoffmann, was once enveloped by a continuous mantle of ice. West of Indian Ridge this glacial mantle extended over a considerable part of the upland north of the Yosemite Valley, as is shown by the occurrence of fragments of granite from Mount Hoffmann in the basins of Indian Creek and Yosemite Creek and by the presence of southward-trending moraines on the divide that separates those two basins. Even the summit immediately west of the head of the Yosemite Falls is crowned by glacial boulders.

Farther west, however, are eminences which, beyond a doubt, were never overridden by the ice. Such are Boundary Hill and the long crest that extends northward from that hill to the head of Yosemite Creek. They were high enough to stem the westward flow of the ice-high enough, even, to bear small glaciers of their own, as is attested by the cirques that scallop their sides.

Another eminence that stood above the highest ice flood is Eagle Peak, the sharp, craggy summit which surmounts the massif of the Three Brothers, on the north side of the Yosemite Valley. The highest moraine lies but a short distance north of the peak and at an altitude of somewhat over 7,500 feet, or only about 250 feet below its top. Northward and northeastward from Eagle Peak, on both sides of the Eagle Peak Meadows, extend dim old moraines that outline the front of an ice lobe which pushed southward up into this basin.

Of peculiar interest is the story told by the moraines in the little valley of Ribbon Creek. Muir ${ }^{51}$

s1 Badè, W. F., The life and letters of John Muir, vol. 1, pp. 304-305, 1924. 
did not fail to observe these moraines, but he was puzzled at the utter absence of glacier polish, of which there is so much in the neighboring valley of Yosemite Creek, and he therefore concluded that the little Ribbon Glacier, because of its southerly exposure and its small volume, "was one of the first to die"-a very reasonable conclusion considering the fact that in 1871, when Muir wrote this, the ice age was still conceived of as a single uninterrupted reign of ice, instead of a succession of protracted cold glacial stages separated by equally protracted mild interglacial stages, as it is now known to be. The fact is that the valley of Ribbon Creek contains only older moraines. It was filled with ice only during the earlier parts of the glacial epoch, of which no polish now remains preserved in the Sierra Nevada, save in a few exceptionally favored localities. Of this ice only a small proportion came from local cirques; most of it was supplied by overflow from the valley of Yosemite Creek, through the gap north of Boundary Hill. During the last glacial stage, which is so vividly recorded in other parts of the Yosemite region by sharp-crested moraines and polished rock pavements, the valley of Ribbon Creek remained wholly free of ice.

\section{IN THE LOWER YOSEMITE REGION}

Most important of all in this study are the older moraines in the lower part of the Yosemite region, for they indicate the farthest limits reached by the ice. Though covered almost throughout with forest and brush and though in places washed away, they are nevertheless not difficult to trace, and together they outline distinctly the margins of the earlier Yosemite Glacier within a short distance of its terminus. Indeed, they outline the course of the glacier so distinctly that it seems surprising that there should ever have been any controversy as to the maximum extent of the Yosemite Glacier.

The highest lateral moraine on the south side of the valley begins in the first hollow west of Old Inspiration Point and thence extends westward along the slope. It is crossed by the Pohono Trail at an altitude of 6,300 feet, or 2,400 feet above the floor of the valley. Below it are other relatively dim moraines, across which the Pohono Trail zigzags down to the Wawona Road. One of them bears a large angular block of Cathedral Peak granite.

The highest moraine, though gashed at intervals by ravines, and in places reduced to an inconspicuous terrace, is readily traced westward for a distance of nearly 2 miles. It reaches the Wawona Road near the point where that road turns southward at an altitude of 5,650 feet. On the precipitous rock slopes below the road, however, the moraine loses its identity, and the second highest moraine, situated on the back of a sloping spur, gains prominence. (See pl. 34, A.) Indeed, so well preserved is this ancient moraine for a stretch of a quarter of a mile that it constitutes one of the notable landmarks of glacial origin in the lower Yosemite region. About 500 feet below it, on Turtleback Dome, several lesser moraine ridges record successive phases in the recession of the glacier. In the hanging valley of Grouse Creek the highest moraine reappears as a strong and continuous embankment that effectually blocks the creek and deflects it southward for a distance of half a mile. Grouse Creek now finds its way to the canyon through a sharp notch which it has cut in the embankment south of a rocky knoll. Thence it cascades down over the sloping cliffs through a rough, unfinished rock channel. Evidently the stream has not followed its new path long enough to wear a smooth channel in the resistant granite.

Undiminished in strength the morainal embankment extends south-southwestward, over the next divide, to the mouth of the hanging valley of Avalanche Creek, outlining the sinuosities in the glacier's margin uninterruptedly for a distance of 2 miles and indicating the slope of its surface from a level of about 5,000 feet down to about 4,500 feet. Parallel to the embankment, between it and the edge of the Merced Gorge, lie several lesser moraines. All end at the gorge of Avalanche Creek. Beyond this gorge, on the prominent granite spur that marks the lower end of the Merced Gorge, none of them reappear, for want of a place on which to rest, but on the ravined sides of the lower Merced Canyon, west of the granite spur, a few disconnected patches of morainal material still remain in place. Naturally they are best preserved on the spurs between the ravines, the spurs having suffered least from erosion. Opposite El Portal, on the spur followed by the funicular logging railroad, such patches occur at altitudes ranging from 3,300 to 3,500 feet. A few cobbles and subangular fragments of granitic rocks (the local rocks are slate and quartzite) have been found west of the track at an altitude of only about 2,800 feet, but it is possible that these have rolled down from above.

On the north side of the Yosemite Valley the configuration of the cliffs and slopes does not permit the preservation of continuous embankments of great length, and only fragments of the right lateral moraines of the earlier Yosemite Glacier occur at intervals. The most distinct and perhaps most impressive fragment is situated at an altitude of 5,800 feet, on a knoll east of the valley of Cascade Creek, near the head of the main grade of the Big Oak Flat Road. Though this is doubtless one of the highest lateral moraines left by the glacier, it can not be the topmost, for it trends at right angles to the valley of Cascade Creek and evidently was deposited at a time when the tributary Cascade Glacier had already receded some distance up that valley. That the Cascade Glacier was confluent with the Yosemite Glacier during the culminating phases of the earlier glaciation is amply attested by the numer- 
ous lateral moraines which it has left behind. It attained a breadth of three-quarters of a mile and a depth of 500 feet just above the point of confluence.

On the slopes west of Cascade Creek the lateral moraines of the earlier Yosemite Glacier are relatively well preserved. The highest extend almost unbroken for a distance of $2 \frac{1}{2}$ miles. No tributary glacier ever issued from the valley of Tamarack Creek to interrupt them. On the mountainous spur west of Wildeat Creek the moraines attain their fullest development, forming a parallel series analogous to the series of newer morajnes that exists on the north side of the Little Yosemite, though, of course, much less distinct.

As the moraines curve around the brow of the spur most of them die out, but a few can be traced along its steep west side, where they decline rapidly to the Big Meadow Flat. Evidently this flat was invaded by a broad lobe of the earlier Yosemite Glacier, the hills on the west side of the Merced Gorge being too low to stem the ice flood. A series of concentric moraines, some of which are more massive than any other moraines in the Yosemite region, record the fluctuations of the front of this lobe on the north and west borders of the flat. Sandy terraces on the inner slope of the innermost of the concentric moraines show that during certain episodes in the recession of the ice front the waters of Crane Creek were imprisoned and formed a temporary lake along the north side of the ice lobe.

At the lower end of the Big Meadow Flat the moraines turn to the west and outline the margins of a narrow ice stream that flowed out from the flat. This ice stream cascaded abruptly into the deep gulch of Crane Creek and, following that gulch to its mouth, finally joined the Yosemite Glacier just above El Portal. The left lateral moraine of this Crane Creek Glacier is dimly visible on the crest of the spur east of the mouth of the gulch. Obscure remnants of the right lateral moraine lie near McCauley's ranch.

The farthest point reached by the earlier Yosemite Glacier is not marked by any terminal moraine, but that point can be determined, approximately at least, from the longitudinal profile of the glacier, as shown in Figure 22. The curve of the glacier's profile is definitely determined by the lateral moraines as far west as El Portal, beyond which the curve can be built out"extrapolated"-with some confidence, in accordance with the known laws governing the forms of glaciers. In any event, the absence of morainal material in the canyon west of El Portal does not imply that the glacier ended abruptly at that point. On the contrary, the very height at which the last patches of morainal material lie above the floor of the canyon-between 1,200 and 1,300 feet-shows rather definitely that the ice tongue extended some distance, perhaps fully a mile, farther west; for glaciers of the type to which the earlier Yosemite Glacier belonged ordinarily thin down to a depth of only a few hundred feet at their lower ends.
In this connection account must be taken, of course, of the fact that the lower Merced Canyon has been deepened somewhat by the river since the departure of the earlier ice. The depth of cutting is, however, only about 50 feet, as would appear from the position on both sides of the canyon of masses of boulders and coarse gravel that evidently are remnants of a "valley train" composed of outwash from the glacier. This outwash material is conspicuous in many cuts along the new automobile highway and also in some places along the railroad. It shows that the valley train extended down the canyon for about 30 miles and had a maximum depth, next to the ice front, of more than 100 feet. The base of this material, so far as can be ascertained, is about 50 feet above the present river bed; hence it may be concluded that the lower Merced Canyon had already been cut within 50 feet of its present depth by the time the glacier made its farthest advance. That it has been deepened no more than 50 feet since that time is explained in part by the fact that the river had to cut first through the accumulated outwash material, in part by the fact that owing to its low gradient on the metamorphic rocks below $\mathrm{El}$ Portal ( 70 feet to the mile, as compared with 350 feet to the mile in the granite gorge above El Portal) the river had but moderate cutting and transporting power and for a long time after the melting of the glacier it was too heavily loaded to cut.

As will be clear from the foregoing statements, the absence of a terminal moraine may possibly be accounted for by the erosive action of the Merced. A river that could remove an entire valley train of outwash material 30 miles in length might well have been able to remove also a terminal moraine or even several such moraines. On the other hand, it is possible that the glacier failed to pile up the débris in the form of a distinct moraine. Its front may have oscillated back and forth in such a way as to cause the débris to be spread out in an irregular sheet. That the second explanation is more probable than the first would seem to be indicated by the fact that no terminal moraines of the earlier glacial stage exist in any of the main canyons on the western flank of the Sierra Nevada that have been examined, not even in the canyons of the Tuolumne, San Joaquin, and Kings Rivers, which contained the mightiest trunk glaciers. Naturally all these trunk glaciers would have fluctuated in essentially the same way, being affected by the same climatic changes. Had they all deposited terminal moraines, it is more than likely that recognizable remnants of such moraines would still exist to-day in at least some of the canyons.

The absence of a massive terminal moraine in the lower Merced Canyon was one of the circumstances that led Prof. I. C. Russell and others among the earlier observers to doubt that the Yosemite Valley had been profoundly excavated by the ice. What has become, 
they asked, of the large quantities of boulders and fine débris which the glacier is supposed to have removed from the valley? However, these doubters overlooked the remnants of the long train of glacial outwash material in the lower Merced Canyon, which, when first laid down, must have had enormous volume. Even so, it contained but. the coarser parts of the material excavated by the glacier. The finer parts had been swept away by the Merced River. Again, this train of outwash material represented the product of only one stage of glaciation. Farther down in the Merced Canyon are terraces composed of coarse gravel and boulders that are in all probability remnants of more extensive valley trains produced during earlier stages of glaciation. These terraces have not yet been studied in detail.

DIFFERENCE IN AGE BETWEEN OLDER AND YOUNGER MORAINES

That the older and younger moraines differ considerably in age will be sufficiently clear from the foregoing paragraphs; still it is a pertinent question, how great the difference between them really is. Is it a matter of a few thousand years, or of hundreds of thousands of years? The significance of the question lies in the fact that if the difference is only a few thousand years, then in all probability the two series of moraines record merely two major advances made by the Yosemite Glacier in the course of a presumably continuous period of glacial conditions; whereas, if it is some hundreds of thousands of years, then the two series of moraines probably record two wholly distinct advances in separate stages of the ice age.

On the plains of the north-central United States, where the glacial record lies broadly spread out, there is evidence of four and possibly five extensions of the continental ice sheet that took place at widely different times, each in a separate glacial stage. Not only do the successive drift sheets differ considerably in the degree of dissection due to stream erosion and in the degree to which their constituent materials are oxidized and decomposed, but intercalated between them in some places are layers of ancient soil containing roots and stumps of trees and other plant remains that tell unmistakably of long intervals of nonglacial conditions, or "interglacial stages." In some places, even, the character of the vegetal remains indicates for the interglacial stages a climate warmer than that of the present time, and accordingly it is to be inferred that the ice sheet each time melted away entirely, or nearly so.

The spans of time represented by these alternating glacial and interglacial stages are best gaged with reference to the length of the postglacial intervalthat is, the interval that has elapsed since the last glacial stage and that has witnessed the rise of man from the stone age to his present high plane of culture. Whereas postglacial time, according to the best numeri- cal data now at hand, comprises about 20,000 years (the ice melted away gradually, hence there was no sharply defined ending of glacial conditions), each of the glacial stages lasted probably from 50,000 to 100,000 years, and the interglacial stages were of equal or somewhat greater duration. Such, at least, are the estimates given by some of the foremost students. of glacial geology.

The glacial record on the western mountain ranges, being less broadly spread out and more subject to destruction by stream action than that on the plains, has proved on the whole much more difficult to decipher. Nor has its study as yet progressed very far. On most of the ranges examined, however, evidence has been found of two distinct glacial stages. In some mountain districts three or even four glacial stages have been recognized. Whether the western mountains have suffered glaciation a less number of times than the plains, or whether the difference is only apparent, owing to the partial obliteration of the morainal record, can not yet be positively stated, but in any event it is certain that on the mountains as on the plains glaciation has been recurrent and discontinuous (except on some of the highest summits), and it is a fair presumption, in the present state of knowledge, that the successive glacial stages on the mountains corresponded to and were synchronous with those on the plains.

There is thus a priori excellent reason to suppose that the Sierra Nevada, which forms an integral part of the great Cordilleran mountain system, has been glaciated two or more times. It is conceivable, nevertheless, that the range forms an exception to the rule because of the lateness of its elevation-that it has suffered glaciation only once, in the later part. of the Pleistocene epoch, because in the earlier part it was not lofty enough to bear glaciers. It is not surprising, therefore, that there should have been division of opinion on this question, some geologists taking one view, some the other. Which way, now, does the evidence in the Yosemite region point? Does it indicate a difference in age between the younger and older moraines amounting to only a few thousand years, or to hundreds of thousands of years? The moraines themselves afford no evidence of a kind that would afford a satisfactory basis for time estimates. Fortunately, however, the rock surfaces that were planed down and smoothed by the earlier and later glaciers respectively do afford some evidence of that kind, as set forth below.

TESTIMONY OF YOUNGER GLACIATED ROCK SURFACES

The floors and walls of the canyons that were the pathways of the later glaciers appear remarkably fresh. and almost unweathered. Over surprisingly large areas they retain their polish and striae and are so smooth and glassy that walking or climbing over them 
with hobnailed shoes is hazardous, and travel with horses or mules is impracticable. (See pl. 35, B.) In many places, it is true, the polish has flaked off and the surface of the rock is rough, but the deeper scorings and flutings are still visible. (See pl. 35,A.) Elsewhere plates of rock a quarter of an inch to perhaps a full inch in thickness have burst off or are in process of being loosened, but even there the smooth-flowing contours produced by glacial abrasion remain.

No one who visits the upper Yosemite region or the adjoining parts of the High Sierra can fail to be profoundly impressed by these facts. Few mountain regions, indeed, exhibit glacially worn and polished rock surfaces on a larger scale; few give the traveler a more vivid sense of the recency of the ice age. Scarcely credible does it seem to one viewing the vast expenses of gleaming granite that fully 20,000 years may have passed since the ice age came to an end; that even in the higher parts of the range, where the glaciers lingered long after they had receded from the canyons below, the rock has been exposed to the weather several thousand years.

Two circumstances explain the unusual abundance of glacier polish in the region above the Yosemite Valleythe prevalence of highly siliceous, slow-weathering types of granite, and the generally massive, sparsely jointed structure of those rocks. The superior durability of siliceous granite is strikingly demonstrated in many places where such granite is contiguous to a weaker rock, as, for instance, diorite. The granite as a rule still gleams with glacier polish, whereas the diorite has a roughened and perceptibly lower surface. Veins of hard, fine-grained aplite stand out in relief, like little narrow causeways with level, polished tops, raised half an inch or more above the rough surface of the coarse granite, or granodiorite, which they transect. Doubtless the polish itself in such places helps to accentuate the difference, for it acts in some measure as a protective coating: it promotes the quick run-off of water from the surface, thereby lessening the proportion absorbed by the rock, and it retards the growth of lichens and mosses, thereby lessening the supply of carbonic acid and vegetable acids which result from the decay of those plants and which attack the weaker minerals.

The massive structure of the granite favors both the production and the preservation of glacier polish. Where the joint fractures are spaced far apart-tens or even hundreds of feet-the glaciers can not pluck or quarry individual blocks but work wholly by abrading, and the conditions are most propitious for the development of continuous expanses of even, polished rock; and there also few avenues are available through which water may penetrate to some depth below the surface, and thus the destructive action of such percolating water by hydration, solution, or freezing is reduced to a minimum.
That the glacier polish is by no means equally distributed throughout the Yosemite region and the adjoining High Sierra readily follows from the foregoing considerations. The distribution is controlled by three independent factors - the mineral composition of the rock, the joint structure, and the length of exposure since the retreat of the ice. Thus it happens that in the Yosemite Valley itself glacier polish is on the whole rather scarce, for the chasm was evacuated by the ice soon after the climax of the last glacial stage, possibly as long as 30,000 years ago; and, besides, its walls are made up in many places of jointed rock that was quarried rather than abraded by the glacier. As might be expected, the polish that remains occurs mostly on bodies of extremely durable and massive rock. Some of it, unfortunately, is inconspicuous or hidden from view and consequently is readily overlooked. A few small patches, remarkably well preserved, are on a buttress at the eastern base of El Capitan; other patches occur at the foot of the Three Brothers, at the base of the cliffs under Union Point, on the platform above the Lower Yosemite Fall, on the sides of the Washington Column, and on the walls near Mirror Lake. Glacial grooves remain visible, though the polish has disappeared, on the buttress west of the Royal Arches, on the cliffs east of Indian Canyon, and on the wall below Union Point.

More abundant is the glacier polish on the platform above the Nevada Fall, both owing to the more recent glaciation of that platform and owing to the durability and massive structure of the Half Dome quartz monzonite, of which it is made. Indeed, the tourist as a rule catches the first glimpse of glacier polish when he arrives at the top of the Nevada Fall. The isolated patches he beholds there, however, measure but a few square yards each and are insignificant compared with the larger tracts to be seen on the floor and sides of the Little Yosemite and on the rounded backs of Liberty Cap and Mount Broderick. These tracts, in turn, seem small in comparison with the vast expanses of glacier polish that occur on the broad floor of massive granite of the upper Merced Canyon, above the Little Yosemite. The trail that leads to Merced Lake takes the traveler over this floor and affords him an excellent opportunity to view this unique area of burnished pavements and slopes. (See pl. 36.)

Almost equally remarkable for its wealth of glacier polish, but far less accessible, is Tenaya Canyon. Indeed, the prevalence of glacier polish on its steeply sloping sides adds greatly to the difficulties which this extremely rugged canyon presents to those who would traverse it. Thus far only a handful of experienced and daring climbers have had the hardihood to pass through the entire length of the chasm. ${ }^{52}$

B2 Le Conte, J. N., Scrambles about Yosemite: Sierra Club Bull, rol. 9, pp. 126-135, 1914. 
In the upper Tenaya Basin, on the shores and in the immediate vicinity of Tenaya Lake, as well as in the shallow trough above the head of Tenaya Canyon, glacier polish is also very plentiful. Much of it may be viewed by the traveler without effort, either along the automobile road and the trails or in the adjoining areas of gentle rock swells that are easily traversed on foot. It was this abundance of glacier polish in the upper Tenaya Basin that led the Indians to refer to the outflowing stream, now called Tenaya Creek, as Py-we-ack ("river of glistening rocks").

\section{TESTIMONY OF OLDER GLACIATED ROCK SURFACES}

If the glaciated rock surfaces in the area surrounded by the younger moraines seem astonishingly fresh and well preserved, quite the reverse is true of the surfaces in the area surrounded by the older moraines. These impress the observer by their manifold signs of age and prolonged exposure to the weather. They have lost not only their polish but even the smooth-flowing contours that were imparted to them by the glaciers. So roughened are they by the irregular disintegration of the rock and the eroding action of rain water that they do not differ perceptibly from ordinary unglaciated rock surfaces. Indeed, were it not for the fact that they are surrounded by ancient moraines, one would not suspect them of ever having been glacially planed and polished.

In only one locality in the Yosemite region is any of the polish that was produced by the earlier ice still in existence-namely, on the slopes above and below the Wawona Road in the vicinity of Artist Point. Its preservation there is accounted for in part by the exceptionally durable nature of the El Capitan granite, of which the slopes are composed, but mainly by the fact that the rock has long been protected by a veneer of glacial débris. The gradual removal of this now thoroughly weathered débris by rain water has recently brought the glaciated surface to light in several spots. The polish is very imperfectly preserved, in spite of the protection by the débris. As a rule, only bits of it remain on the feldspar and quartz in the granite, the hornblende and biotite being decomposed-etched out, so to speak. Indeed, the surface is so closely pitted that the remaining polish is not readily recognized as such, save under favorable light. In a few places, however, it is sufficiently continuous to permit the direction of the striae to be discerned.

Many of the older rock surfaces are diversified by irregular crags, tables, humps, and pillars that afford some indication of the depth to which these surfaces have been eroded and stripped since glaciation. In general, the depth indicated is not a matter of inches, as in the area of the younger moraines, but of feet. Some of the residual features, being composed of especially obdurate rock, stand 6,8 , or even 10 feet high and are of bizarre or monumental aspect. The crags on Glacier Point, which flank the path that leads to the famous precipice, are good average examples. Others, more fantastically shaped, occur on Yosemite Point, North Dome, Mount Watkins, the Quarter Domes, and the domes of the Starr King group.

Most of the residual crags, unfortunately, are too irregularly shaped to afford an accurate measure of the stripping done since the earlier glaciation, but a few have clean-cut forms produced under rather special circumstances and therefore have more promise than the rest. Such are the rock pedestals that support "perched" glacial boulders here and there. (See pls. $33, B$, and $38, A$.) These pedestals are composed of the local rock, attached to the body of the mountain, and clearly owe their preservation to the protection which the perched boulders have afforded them. They have remained standing while the surrounding unprotected rock has disintegrated and been stripped away. So eloquent is the mute testimony of these rock pedestals that, not unnaturally, they are commonly regarded as good yardsticks whereby the depth of the stripping may be measured. One author has asserted, even, that rock pedestals afford "of course an exact measure" of the stripping, and he would let it be inferred that their tops are actually remnants of the ancient ice-worn surface. But such, nevertheless, is not true as a generality. It might conceivably be true of an isolated pedestal, but in the entire Yosemite region no such example has been found. Were it generally true that pedestals afford exact measures of the stripping done since their boulders were deposited, then all perched boulders associated with a given moraine, provided they rest on rock of the same kind, should now have pedestals of about the same height, and, other things being equal, boulders associated with very old moraines, situated at high levels, should have taller pedestals than boulders associated with moraines of later date, situated at lower levels. But the facts of observation are quite otherwise.

For instance, of two boulders on Moraine Dome, deposited doubtless at nearly the same time, one has a pedestal 1 foot high, the other a pedestal 3 feet high. Another perched boulder, situated on the upper of the Quarter Domes at a level fully 500 feet above the crown of Moraine Dome, though associated with a moraine that was deposited a long time prior to the two boulders on Moraine Dome just mentioned, instead of having a correspondingly taller pedestal, actually has one only 2 feet high. Again, the perched boulder on the divide east of Mount Starr King (pl. $33, B$ ) has a pedestal only 20 inches high, though it is probably much older than any of the others mentioned, for it is 250 feet above the highest of the older moraines in the Starr King Meadows and presumably attests a third and very early ice invasion. (See p. 73.) 
The development of rock pedestals, as a little reflection will show, must be influenced by a variety of factors, and there is therefore need of caution in interpreting differences in the stature of pedestals. In the first place, the rate of growth of a pedestal depends upon the character of the rock of which it is made. One kind of rock is stripped away more rapidly than another, and even the same kind of rock is likely to be stripped away more rapidly in one place than in another, for it is bound to vary somewhat in composition, texture, or structure, and, besides, the rate of stripping is affected by local factors, such as the angle of slope, the direction of exposure, whether northerly or southerly, and the amount of débris that litters the surface. In each of the examples adduced the country rock was the same-Half Dome quartz monzonite-yet because of these different factors the rate of stripping probably was not the same.

Again it would be rash to assume that the development of a pedestal begins immediately upon the deposition of the boulder. If the boulder falls on a spot where the surface configuration is especially favorable, a pedestal may begin to form without delay; but if the boulder falls on unfavorable ground, no pedestal may be formed until perhaps thousands of years later, when the configuration of the rock surface has been changed considerably by erosion. Two boulders situated near each other and deposited at the same time may thus come to have pedestals differing appreciably in age and in height.

It must not be overlooked, further, that rock pedestals are subject to decay, in spite of the protection afforded them by the capping boulders. That protection is, after all, only partial, as the pedestals are more or less exposed to the weather on all sides except the top. Moreover, because they are largely shielded from the sun's rays, they retain whatever moisture they may absorb from rain or snow much longer than the sun-heated rock surfaces roundabout. Consequently, the rock in a pedestal is more subject to chemical decomposition than the neighboring rock and in the course of time will be converted into a weak, incoherent mass that will finally break down under the weight of the superincumbent boulder. Some of the granite pedestals in the Yosemite region are so softened by chemical decomposition that they can be scratched with a knife, or even with the finger nail. At least two of them have recently shed their boulders-one on the summit of Moraine Dome, the other on the low nameless dome on the south rim of the Little Yosemite, northeast of Helen Lake. (See pl. 29.) In each place the boulder still leans against its pedestal; hence the fact of its dethronement is evident.

The life of a pedestal also depends in considerable measure on its diameter, for the greater the diameter the more time will be required for the rock to be softened from the periphery inward to the center. A thick pedestal, in other words, has much better chances for longevity than a slender pedestal. As the diameter of a pedestal is determined in the first instance by the size of the capping boulder, it follows that in general large boulders will remain perched longer than small boulders and will develop taller pedestals. It is significant that the dethroned boulder on Moraine Dome is smaller than any of the boulders that still remain perched and that its pedestal is smaller in diameter and also lower than any of the other pedestals cited. The boulder measures only 3 feet in length, 2 feet in breadth, and 1 foot in thickness, and the pedestal measures only 2 feet in length, 1 foot in breadth, and 1 foot in height. The other dethroned boulder is really larger than some of the boulders that are still perched and has a higher pedestal (it is a slab 7 feet long, 5 feet broad, and 18 inches thick, and its pedestal is $2 \frac{1}{2}$ feet high); but the conditions here are probably not typical, for the pedestal is not softened by chemical decomposition and does not appear to have been crushed by the weight of the slab. Perhaps the slab was unbalanced by an unevenly distributed load of snow, or by the caving away of one side of the pedestal, which happened to be weakened by a fracture.

It will be clear that, in general, pedestals can not be relied upon to afford accurate measures of the stripping effected since the earlier glaciation. Probably none of those cited indicate the total depth of stripping, not even the 5-foot pedestal figured in Plate 38, $A$. Certainly the low pedestals of the boulders situated among the highest and oldest moraines-notably the 2-foot pedestal of the boulder on the upper Quarter Dome and the 20-inch pedestal of the boulder on the divide east of Mount Starr King-represent no more than a fraction of the total stripping at their respective localities. Perhaps the boulders did not begin to develop pedestals until a long time after they came to rest; perhaps each of them is now developing a second pedestal, having been dethroned from the first.

Fortunately there are in the Yosemite region some residual rock features of another type that afford much more accurate measures of the stripping than the pedestals. Of these features, the most instructive stands on the very summit of Moraine Dome, in close proximity to the small dethroned boulder and within a stone's throw of the larger, still perched boulder shown in Plate 37, $B$, thus permitting direct comparison with their pedestals. This feature (pl. $37, A$ ) may be likened to a stone wall partly fallen in ruins, 7 feet high at the highest point, 15 feet long, and 4 feet thick. It consists of the upper part of a dike of aplite-a sheet of fine-grained granite that invaded a vertical fissure in the coarser Half Dome quartz monzonite of which Moraine Dome is made, as shown diagrammatically in Figure 21, and it owes its prominence to the fact that the aplite, which is exceedingly resistant to weathering, has remained preserved while the surrounding. 
Half Dome quartz monzonite has disintegrated and been stripped away. Only the thickest part of the dike thus stands out in the form of a wall, the thinner parts having tumbled down. The horizontal slabs of which the wall appears to be built are remnants of concentric shells of rock that extended formerly over the entire crown of the dome, as indicated in the diagram, and that have burst loose one after another, by the process of exfoliation, which characteristically affects all large masses of undivided granite in the Sierra Nevada and results in the production of the familiar dome forms.

Now it is not conceivable that the aplite wall was in existence at the time of the earlier glaciation, for the ice then passed over Moraine Dome with a thickness of 500 feet and with sufficient power to raze all such frail projections. Indeed, when the ice withdrew, the dome doubtless emerged divested of all incoherent, disintegrating outer parts, a shining globular mass of hard, sound rock, and the aplite dike was planed off
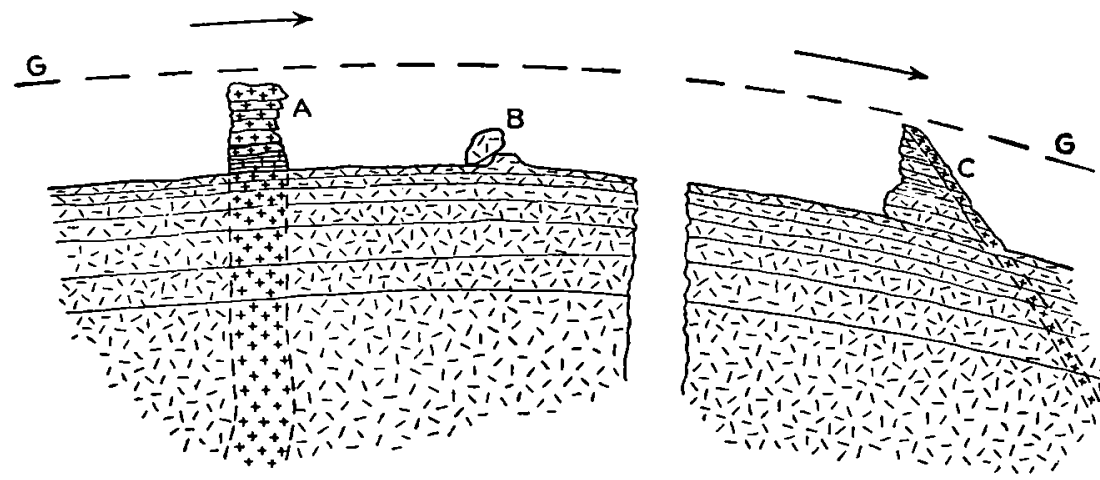

Figure 21.-Section across parts of Moraine Dome showing the features on and near its summit that afford a measure of the stripping effected since the earlier glaciation. A is the 7-foot wall consisting of the exposed upper part of a vertical dike of aplite; $B$ is the dethroned boulder leaning against its pedestal; $C$ is the 8-foot wall produced by an inclined dike of aplite. The features are shown in their true proportions but closer together than they actually are. The broken line $G G$ indicates approximately the original ice-smoothed surface of the dome, and the arrows show the direction in which the glacier moved

even with the surrounding granite, just as the aplite dikes in Mount Broderick to-day appear planed off as a result of the last ice flood. There can be no doubt, then, that the aplite wall has come to stand out entirely since the time of the earlier glaciation.

Though the wall obviously affords a much more accurate measure of the stripping than either pedestal it nevertheless affords no exact measure, for its top is not a remnant of the original glaciated surface. At least this is to be inferred from the fact that several slabs dislodged from the top of the wall lie at its foot. Just how much the wall has been reduced in height is difficult to estimate, but as it has lost very little in thickness and does not taper upward as a result of progressive disintegration at the sides, it probably has lost but little in height also-perhaps less than a foot.

In any event the height of the wall is to be taken only as a minimum measure of the stripping on Moraine Dome, for that part of the summit on which the wall stands is nearly level and consequently is stripped more slowly by the rain water than the steeper parts roundabout. It is covered in part with loose granite sand, which acts of course as a protective blanket. On the more steeply sloping parts of the dome, where the rain water runs off with some velocity, residual sand is absent and stripping proceeds evidently at a relatively rapid rate. It is not surprising, therefore, to find that two other wall-like features on the sloping south side of the crown, both consisting of masses of granite preserved under steeply inclined dikes of aplite, have greater height than the vertical aplite wall on the summit. One stands 8 feet high, the other 12 feet.

It may be concluded, then, that 7 feet is a conservative measure of the reduction in height which bare eminences such as Moraine Dome have suffered since the climax of the earlier ice flood. In some localities, doubtless, the reduction has been greater; in others less. The fantastically shaped crags on the rock platform of Glacier Point, on the summits of North Dome, the Quarter Domes, Mount Watkins, and those other heights that were overridden by the earlier ice but not by the later are to be interpreted in the light of this knowledge.

When this profound stripping of the older glaciated surfaces is contrasted with the merely incipient weathering of the younger glaciated surfaces, the difference in their age looms up impressively. Nowhere is the comparison more readily made than on Moraine Dome itself. Below the great morainal embankment that marks the highest level reached by the last ice flood the granite is still essentially unweathered and retains its polish over large areas. In some places the polish is beginning to scale off, but only to a depth of less than an inch. Above the morainal embankment, on the contrary, the granite is deeply weathered and is breaking upinto slabs, slivers, and individual grains, the glacial erratics all have pedestals, and the aplite dikes stand out from 7 to 12 feet in height. Though the rate of stripping is difficult to estimate, owing to complicating factors that need not be discussed here, there seems little reason to doubt that the interval of time indicated by the thickness of rock removed is of a much higher order of magnitude than the postglacial interval-at least ten and more probably twenty times as long. If, therefore, the age of the younger rock surface is placed, conservatively, at 10,000 years, then the age of the older rock surface may readily be 100,000 or even 200,000 years. There is thus ample warrant for the conclusion that the earlier and later ice floods in the Yosemite region took place in separate stages of the glacial epoch.

The successive stages of glaciation generally recognized by American glacialists are, in order from the oldest to the youngest, the Nebraskan, Kansan, Illinoian, Iowan, and Wisconsin, named from the States in which their effects are most clearly shown. 
In view of the comparative freshness of the moraines and polished rock surfaces resulting from the last glaciation in the Sierra Nevada there is little doubt that it corresponds to the latest stage of the continental glaciation, and it will therefore be referred to here as the Wisconsin stage. The earlier glaciation in the Sierra Nevada is more difficult to correlate, as the glacial record on the range has not yet been connected across the intervening mountains and deserts with the glacial record on the plains. To judge by the erosion suffered by the older moraines, the depth to which their boulders are weathered, and the depth to which the domes have been stripped of disintegrated rock-allowance being made for the slower rates of weathering and disintegration in the semiarid climate of the Sierra Nevada than in the more humid climate of the central parts of the continent-the earlier glaciation of the range would seem to correspond to either the Illinoian or the Kansan stage, but more probably to the Illinoian. For the present it will be referred to as the El Portal stage, as the Yosemite Glacier during that stage terminated in the vicinity of El Portal.

\section{INDICATIONS OF A STILL EARLIER ICE INVASION}

In several localities in the Yosemite region glacierborne boulders occur singly, in groups or in rows, without any accompanying fine débris. Most of them lie in places where it seems likely from the character of the topography and from the courses pursued by the ancient glaciers that heavy, continuous moraines once existed. The majority of the boulders are composed of extremely durable types of rock, such as quartzite and highly siliceous granite, which weather and disintegrate more slowly than most of the rocks in the moraines of the Yosemite region. It seems entirely probable, therefore, that these boulders are the last remnants of moraines of a very early glaciation antedating the El Portal stage.

Were these boulders all situated on slopes of bare massive granite this inference as to their great age might seem open to question, for on such slopes, where the washing action of rain is particularly effective, a moraine may be reduced by the removal of the finer débris to a mere row of boulders in a relatively short time. Many moraines of the Wisconsin stage, even, are thus reduced, as may be seen on the undulating platforms of bare, smooth granite that flank the upper gorge of the Merced, above the Little Yosemite. The erratic boulders here referred to, however, lie for the most part on flat or very gently sloping ground, where the washing action of rain water is but moderately effective. The conclusion seems therefore justified that the boulders are remnants of very ancient moraines.

A number of the boulders in question lie on the broad divide east of Mount Starr King, between 200 and 400 feet above the highest moraines of the El Portal stage, which curve around the Starr King meadows. All are derived from Mount Clark or its inmediate vicinity. Many of them consist of the light-colored siliceous granite of which Mount Clark itself is composed; others consist of the yellowish quartzite whose parent mass is on the northern spur of Mount Clark-the same quartzite that is represented also in the moraines back of Glacier Point. One boulder, perched on a pedestal 20 inches high (pl. 33, B) consists of a relatively dark but also siliceous granite from an adjoining part of the Clark Range. The general direction of the ice movement is thus plainly indicated by the boulders, and it is evident from their derivation and from their arrangement in an east-west belt that the Merced and Illilouette Glaciers at one time met and coalesced on the divide, leaving there a more or less continuous body of moraine. The fact that only a few sparse boulders now remain, especially on the flatter portions of the divide, where the ground is favorable for the preservation of moraines, would seem to show that a long period has elapsed since the glaciers met on the divide, a much longer period than has elapsed since the moraines about the Starr King Meadows, which are still fairly continuous and in places massive, were laid down. It seems entirely in order, therefore, to refer the erratic boulders on the divide to a stage of glaciation earlier than the El Portal.

The highest level reached by the ice of this early stage can scarcely be determined with exactness, but two erratic boulders of Mount Clark granite, lodged in the saddle between Mount Starr King and the lesser dome to the northwest, attest in any event that the ice rose high enough to spill through the gaps in the Starr King group.

Other erratics belonging in all probability to the same early glaciation lie near the east base of Sentinel Dome, at altitudes between 7,800 and 7,900 feet. (See p. 63.) Some of them, conspicuous by their large size (pl. $38, B$ ), are close to the trail that leads to the dome. They are strung out at intervals of 100 feet or more in an irregular line that curves from the dome southeastward to the north end of the Illilouette Ridge. Their exact positions are indicated on the map of glacial and postglacial deposits forming Plate 29.

All these boulders lie on gently sloping ground that is clearly more favorable for the preservation of a moraine than the steep slope immediately below, yet they are isolated, unconnected by finer glacial débris, whereas the steep slope below is still heavily cloaked with such material of the El Portal stage. It can hardly be doubted, therefore, that the boulders are the last vestiges of a once continuous moraine that was deposited by the ice during a stage much earlier than the El Portal. This early stage, which may 
correspond to either the Kansan or the Nebraskan stage of the continental glaciation, will here be referred to as the Glacier Point stage.

It happens that these boulders are composed not of distinctive rock materials derived from the High Sierra, but of a granodiorite somewhat similar in appearance to the granodiorite in the slope on which they rest, and consequently their status as ice-borne erratics might seem open to question. Close inspection, however, reveals a decided difference between the two rock types, although unquestionably both are varieties of one and the same intrusive, the Sentinel granodiorite. (See appendix.) The rock in the slope is distinguished by roughly parallel black streaks composed of minute crystals of hornblende and indicative of the flow structure of the intrusive mass; the rock of the boulders is wholly devoid of streaks, is somewhat coarser grained, and contains ragged flakes of biotite (black mica), many of which measure fully an inch in diameter.

The origin of the boulders seemed puzzling until it was discovered by Calkins that granodiorite of precisely the same variety as that in the boulders occurs in the ledges at Glacier Point and south of it along the edge of the precipice below the automobile road. These ledges are three-quarters of a mile east of the base of Sentinel Dome and from 500 to 700 feet below its level, and it would thus appear that the boulders had been carried by the ice up the slope to their present positions. This explanation may seem daring, but it is entirely in accord with the facts known about the direction and character of the ice movement. The Merced Glacier impinged with a strong westerly current against the Glacier Point promontory and, as it rose to higher and higher levels, must have carried the rock débris up with it.

The rounded forms of some of the boulders would perhaps seem to belie this explanation, for blocks torn from a ledge by a glacier are naturally angular, and in the short distance here involved angular blocks could not have been worn down to rounded boulders by abrasion. The indications are, however, that the boulders in question have become rounded in place by exfoliation, for fragments of curving scales lie about their bases, and a few such scales still cling to their surfaces. The almost complete elimination of the original angularities, as shown in Plate $38, B$, would seem to imply that exfoliation has been active for a long period of time. The very roundness of the boulders, therefore, affords independent proof of their great antiquity and strengthens the supposition that they date back to an earlier stage of glaciation than the El Portal.

Boulders that presumably are indicative of this very early glaciation occur also near the summit of Indian Rock, about $1 \frac{1}{2}$ miles north of Basket Dome and considerably above the upper limit of the more or less continuous veneer of glacial débris of the El Portal stage that covers the lower slopes. Most readily identified as true glacial erratics are those boulders which are composed of distinctive porphyritic granite from Mount Hoffmann.

At the lower border of the Yosemite region also there are dim indications of a glaciation that antedated the El Portal stage. These indications are found in the obscure form and advanced state of decay of the outermost of the concentric moraines that encircle the Big Meadow flat. Not only has the outermost moraine suffered more from erosion than the others, but the boulders in it are decomposed to the consistency of sand or loam, so that they are readily cut with a pick or shovel. Many boulders thus sliced through are to be seen in the road cuts west of Big Meadow, each outlined in cross section by a rusty ring. Similar sliced boulders occur in the road cuts near McCauley's ranch, about a mile southwest of Big Meadow. They show that the outflow of ice from the flat toward El Portal took place largely, if not wholly, during the earliest of the three glacial stages.

There remains to be considered the indirect but nevertheless highly significant evidence afforded by the capacious $U$ form of the Yosemite Valley itself (except for the filling of sand and gravel in the basin of ancient Lake Yosemite). That $U$ form is a typical product of glacial erosion and must have required for its elaboration from the essentially sharp-cut $V$ form of the preglacial canyon a tremendous amount of excavation. The completeness of the transformation is patent from Figures 24-27, in which the preglacial cross profiles of the valley are superimposed on the postglacial profiles.

Now, it is evident from the mere fact that the Yosemite Glacier of the Wisconsin stage ended within the valley and, further, from the fact that the valley (disregarding the talus) is about as wide below the group of frontal moraines as it is above, that the glacier of the Wisconsin stage did not perform any significant share of the excavating. This glacier found the valley presumably almost as deep and as broad as. it is to-day and did little more than reoccupy it. Only in the upper part of the valley, where it attained a thickness of nearly 1,500 feet, did the glacier effect any appieciable changes. Probably it plucked off shells from the Royal Arches, rounded off a bit more the promontory under Glacier Point and added somewhat to the depth of the basin of ancient Lake Yosemite. But it is not to be supposed that this small and relatively shallow ice stream gouged out wholly, or even largely, a rock basin whose depth exceeded 200 feet, as would appear to be indicated by cross sections of the valley. (See figs. 24 and 25.) The excavation of that basin clearly must have been accomplished by a much larger and more powerful glacier. It follows, then, that the Yosemite's capacious $U$ form was produced very largely by the earlier ice. 


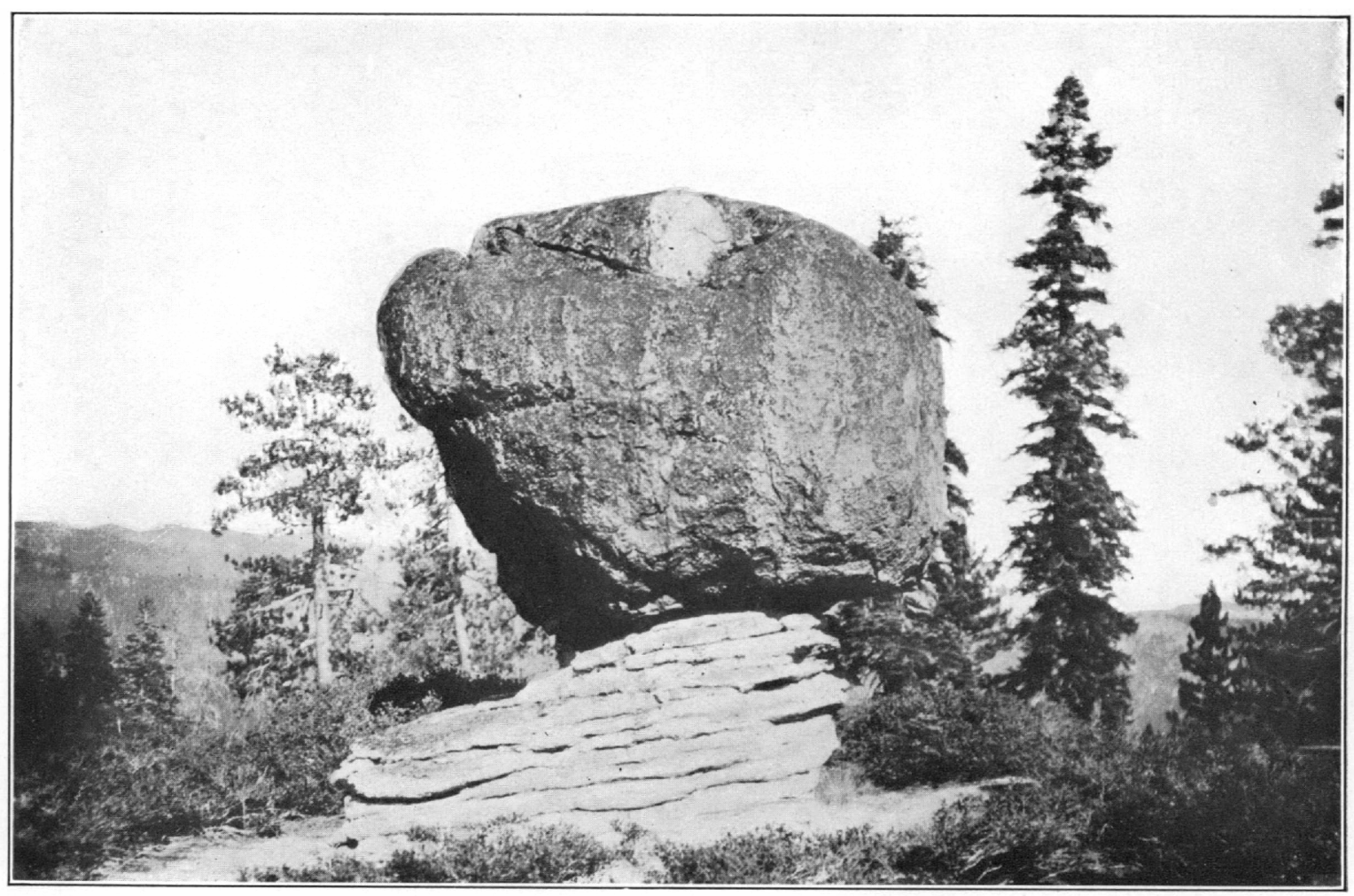

A. GLACIAL BOULDER PERCHED ON 5-FOOT PEDESTAL

This perched boulder has the highms pedestal in the Yosemite region. It is siluated on the mountain west of the upper Yosemite Fall. The pedestal is composed of slabs of the locial rock-remnants of concentric shells that formerly enveloped a large pirt of the summit. Photo-
uraph by $F$. C. Calkins.

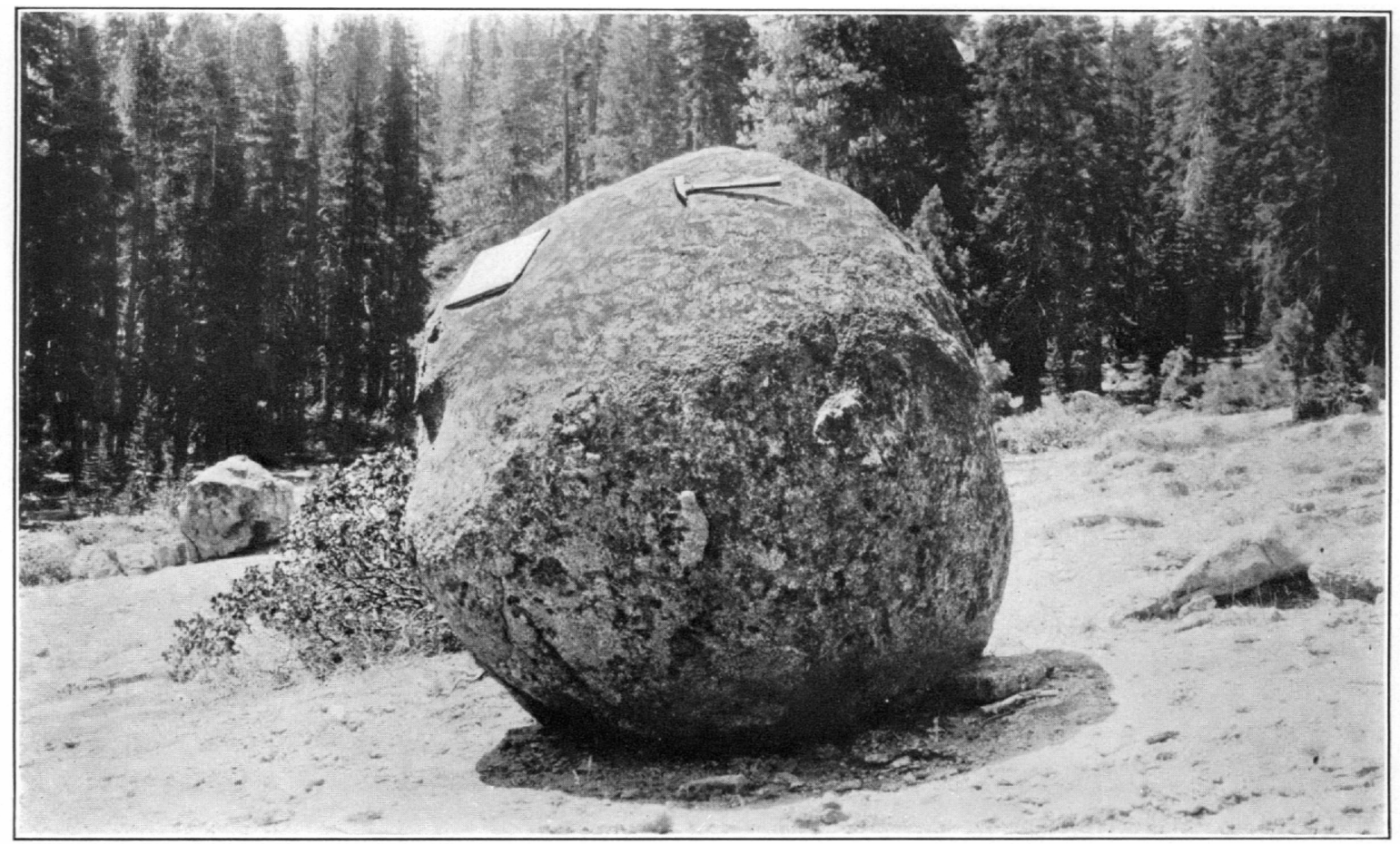

B. ERRATIC BOULDER AT BASE OF SENTINEL DOME

A row of such boulders marks the highest level reached by the ice in the vicinily of Gacier Point. They are the sole remnants of a very incient. moraine, the rest of which has long since disappeared, and they ire believed to record a stage of nlacialion that antedaled the El Portal by F. C. Culkius. 



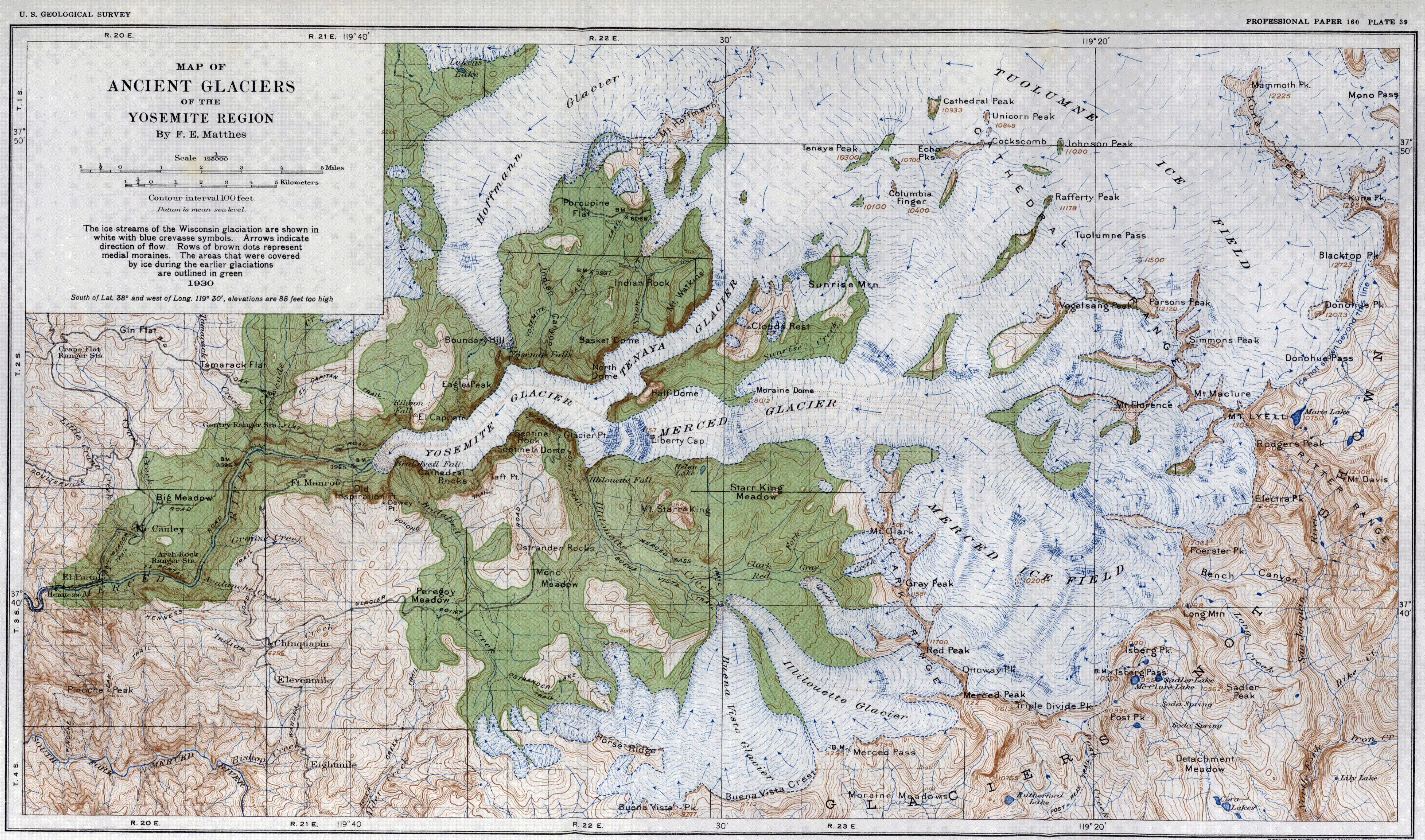



So thoroughgoing, however, was the transformation, so enormous were the quantities of rock removed, that this work can scarcely be attributed to a single glaciation. Even when the great thickness indicated for the earlier ice is taken into consideration (it measured about 3,000 feet at the head of the valley and thence declined to 2,400 feet at the lower end), and when allowance is made for the special rock structures in the valley that facilitated the excavating action of the ice, it seems much more probable that the work was performed by two ice invasions, if not more than two. On this score also, then, there appears to be good warrant for supposing that at least two ice invasions took place prior to the Wisconsin.

The probability that the Sierra Nevada has been glaciated three times was first suggested by Prof. I. C. Russell, who in 1882 and 1883 studied the moraines built in Mono Valley by the glaciers that descended from the east flank of the range. The glacier that issued from Bloody Canyon, he believed, had made "three advances and three corresponding recessions," indicating "climatic oscillations of considerable duration." ${ }^{53}$ Willard D. Johnson, ${ }^{54}$ who in 1905 and 1906 investigated the glacial deposits in the Bridgeport Valley and along the West Walker River, went further and recognized, tentatively, a record of three stages of glaciation differing markedly in age. Still more significant, as affording corroboration of the conclusions here set forth in regard to the occurrence of at least three glaciations in the Yosemite region, is the finding in 1927 and 1928 by Prof. Eliot Blackwelder ${ }^{55}$ of evidence of three stages of glaciation at several points along the eastern base of the Sierra Nevada. More recently he has found what apparently proves to be evidence of a fourth stage..$^{56}$

\section{ANCIENT GLACIERS OF THE YOSEMITE REGION}

\section{EXPLANATION OF MAP OF ANCIENT GLACIERS}

Although the ancient glaciers no longer exist in the Yosemite region it is possible to describe them in considerable detail, for the data furnished by the moraines, the erratic boulders, and the other evidences of glaciation are very full and mutually consistent. Not only are the position, shape, and dimensions of each individual ice stream definitely indicated, but also the slope and to some extent the configuration of its surface, and hence one can form a fairly clear conception of the character of these ice bodies and of their appearance in the landscape.

\footnotetext{
33 Russell, I. C., Quaternary history of Mono Valley, California: U. S. Geol. Survey Eighth Ann. Rept., p. 340, 1889.

4 Unpublished notes in the possession of the U. S. Geol. Survey.

ss Blackwelder, Eliot, Evidence of a third glacial epoch in the Sierra Nevada [abstract]: Geol. Soc. America Bull., vol. 39, p. 268, 1928

${ }^{56}$ Blackwelder, Eliot, Glacial history of the east side of the Sierra Nevada [abstract]: Geol. Soc. America Bull., vol. 40, p. 127, 1929. Professor Blackwelder has also made an attempt to identify these four stages of glaciation in the Yosemite region, but bis findings could not be veriffed in time for incorporation in this report
}

The map of the ancient glaciers (pl. 39) is the product of a systematic and comprehensive survey of the moraines and other glacial features. On it the glaciers of the Wisconsin stage, for which the data are fullest, are represented with the symbols commonly used on maps for existing glaciers. Those of the El Portal and Glacier Point stages, which are known in less detail, are shown merely in outline. As they were of very nearly the same extent no attempt has been made to differentiate between their outlines on the small scale of the map. Only the glaciers of the Yosemite region and those in the Tuolumne Basin which need to be considered in this study are shown. The glaciers in the basins drained by the San Joqquin River and the South Fork of the Merced River are purposely omitted in order to make more clear the limits of the area that contributed ice to the Yosemite region.

The fullness of detail with which the glaciers of the Wisconsin stage are portayed deserves, perhaps, a word of explanation. The crevasse symbols are used not merely in a conventional manner but in part specifically to indicate crevasses that are definitely located and oriented-some spaced close together, some far apart, some crossing one another in an intricate network. The symbols for medial moraines likewise are employed in a specific rather than in a purely conventional way. They show such moraines to begin in definite places, to wind in curves down the backs of the glaciers, and to terminate in definite places. To what extent, the reader may ask, are these specific details based on ascertained facts and to what extent are they merely imagined?

The crevasses of glaciers are distributed and oriented in accordance with well-known laws. Transverse crevasses, extending approximately at right angles to a glacier's axis, are of rather general occurrence, being due to the tearing apart of the brittle upper layers of the ice as they ride on the more pliant, ductile lower layers. Naturally such crevasses are particularly numerous wherever a glacier descends over a step in its bed, its surface there being convexly curved and its upper layers stretched in longitudinal direction. They are least numerous at the base of each step, where the glacier's surface is concavely curved and the upper layers are under compression. It follows, then, that some of these crevasses are definitely associated with irregularities in the glacier's bed, forming and re-forming constantly at the same critical spots, to heal up again in the quieter stretches below. They may be likened to the standing waves in the rapids of a swift river. Now the canyons of the Sierra Nevada still exhibit, almost unchanged, the steps and other obstructions on which the ice streams of the last glacial stage broke; hence the precise spots at which transverse crevasses were formed in those ice streams are known, and even the directions in which the crevasses extended are definitely indicated. 
Another set of crevasses is associated with the margins of a glacier. They owe their existence to the fact that the middle part of a glacier moves forward faster than the marginal parts, which are retarded by friction. Such marginal crevasses, produced by torsional stresses in the ice, extend as a rule from the sides inward, describing arcs bowed upstream.

The nature and mode of occurrence of medial moraines have already been explained on page 58 . Such moraines begin invariably at the points of confluence of ice streams and extend downstream as narrow, sinuous bands, parallel to the glacier's current. It is entirely in order, therefore, to show on the map one such medial moraine beginning at the point of confluence of each pair of joining glaciers. Those trunk glaciers which had several tributaries in their upper courses naturally bore a corresponding number of medial moraines. Normally medial moraines extend all the way down to the terminus of a glacier, merging there in the mantle of débris released by the melting of the ice; but where a glacier cascades tumultuously over abrupt steps in its path the medial moraines disappear, as a rule, the débris being entrapped by the crevasses.

The positions of the medial moraines can be determined on the earlier glaciers with just as great precision as on the later; but the same is not true for the crevasses, for the steps in the canyon floors over which the earlier glaciers cascaded are now either destroyed or greatly modified. It has been deemed best, therefore, to omit from the map any representation of the surface features of the earlier glaciers.

\section{GLACIERS OF THE WISCONSIN STAGE}

The glaciers of the Wisconsin stage will be described first, as they are most definitely known and were for the most part simple ice tongues confined to individual valleys. Having obtained a definite image of them, the reader will then be able to visualize also the more extensive glaciers and ice fields of the earlier stages, which coalesced over divides and in part moved in disregard of them.

Yosemite Glacier.-During the Wisconsin stage of glaciation the Yosemite Valley was occupied by an ice stream of only moderate dimensions. This ice stream, which may be named the Yosemite Glacier, did not extend the full length of the valley but terminated within a mile of the lower end, just above the Bridalveil Meadow, as is attested by the moraines which it left there. Nor did it receive a single tributary ice stream from any of the hanging valleys on either side of the chasm. It was formed wholly by the confluence of the Merced Glacier and Tenaya Glacier, the two great ice streams that issued from the Little Yosemite Valley and Tenaya Canyon.

At the head of the valley, where these two ice streams joined each other, the Yosemite Glacier had a thickness of about 1,500 feet, but down the valley its thickness diminished by degrees, so that in the portal opposite the
Cathedral Rocks it was only 400 to 500 feet. Through. out the greater part of its course the surface of the glacier sloped rather gently and evenly, the average rate being 100 feet to the mile, but at the upper end as well as at the terminus it sloped much more steeply.

A better conception of the depth to which the glacier filled the Yosemite Valley may be gained by reference to a few well-known landmarks. The ice surface reached almost up to the shoulder above the Royal Arches; it was about level with the rock platform above the lower Yosemite Fall and lay just below Columbia Rock. On the south side of the valley Glacier Point towered fully 2,000 feet above the glacier; Union Point rose about 1,000 feet above it, and even the Cathedral Spires stood entirely clear, the ice reaching barely up to the base of the lower spire. The Bridalveil Fall, then as now, leaped from its 600 -foot precipice, but its lower portion probably disappeared in an abyss which the waters had melted in the side of the glacier.

The Yosemite Glacier must have presented the appearance of a fairly clean ice stream-much cleaner than most of its contemporaries in the Cascade Range or the Rocky Mountains, much cleaner also than the present glaciers on Mount Rainier, for the granitic rocks of the Yosemite region and the adjoining High Sierra, being not only hard but tough and prevailingly massive, yielded a much smaller proportion of débris to the passing ice streams than the relatively well-jointed and less coherent rocks in the other regions mentioned. Nevertheless the Yosemite Glacier was not a dazzling white "mer de glace" throughout. Its margins were littered with large blocks and smaller fragments of granite, and along its middle extended a medial moraine which resulted from the junction of the Merced and Tenaya Glaciers.

Doubtless this medial moraine was one of the glacier's striking features. Beginning at the head of the valley as a narrow dirt band, it broadened gradually, at the same time assuming the form of a low, hummocky ridge on the back of the glacier. Medial moraines commonly stand out as low ridges on rapidly melting glaciers, owing to the fact that the débris, where thick enough, absorbs a large share of the sun's heat and thus retards the melting of the ice beneath it. Such medial ridges are therefore composed not wholly of débris, but of dirty ice mantled with débris. Excellent examples of prominent medial ridges are to be seen on several of the glaciers on Mount Rainier. The Nisqually and Kautz Glaciers, notably, have medial ridges from 10 to 25 feet in height.

On the margins of the Yosemite Glacier the debris probably had a similar though less pronounced protective effect, thus keeping the surface slightly raised. The glacier is to be pictured, accordingly, as having had two broad lanes of clean ice parted by a dirtcovered medial ridge and flanked by inconspicuous dirt-covered ridges at the margins. The clean lanes became narrower toward the glacier's terminus and 
ultimately vanished, as the entire surface became mantled with débris.

The ice front itself doubtless varied in character as it oscillated back and forth. During periods of advance it was abrupt and wall-like; during periods of recession it sloped at a moderate angle, and when stationary for any length of time it probably was not clearly distinguishable from the moraine in process of being piled up before it. As the glacier finally melted back toward the head of the valley, its front, being immersed in the water of Lake Yosemite, was kept sheer by the breaking off of ice masses that floated about as small icebergs.

Merced Glacier.-The glacier which occupied the upper Merced Canyon and the Little Yosemite, and which may be called the Merced Glacier, had its sources in an ice field about 70 square miles in extent, that occupied all of the upper Merced Basin. The north half of this Merced Ice Field consisted of a series of parallel ice rivers parted by the long, attenuated spurs of the Cathedral Range. The south half, on the other hand, presented an almost unbroken expanse of crevassed ice that sloped down in sweeping curves from the Clark Range, yet it too was made up of many parallel ice streams which, though coalescing with one another, possessed each a distinct current and followed each a separate channel. Through the middle of the ice field, completely filling the upper Merced Canyon, flowed the great ice current that, farther down, became the Merced Glacier.

Besides being fed by the snows that accumulated in the cirques on the Cathedral and Clark Ranges, the Merced Ice Field also received large contributions by overflow from the great Tuolumne Ice Field, which lay to the north. This fact, which is plainly attested by the directions of the glacial striae in several gaps in the Cathedral Range, was recognized as far back as 1863 by the exploring parties of the Geological Survey of California under Whitney. Accordingly, the broad ice stream that filled the twin valleys of Emeric Creek and Fletcher Creek consisted largely of ice that had been forced over Tuolumne Pass; and the glaciers in the basin of Echo Creek received reinforcements through the gap north of Rafferty Peak and through the saddle west of Unicorn Peak. A strong current of ice also came through Cathedral Pass and swelled the glacier in the valley of the Cathedral Fork. At the climax of the Wisconsin stage these tributary ice streams attained thicknesses of 500 to 1,000 feet, as is shown by the height of the glacier polish and the positions of the lateral moraines; but the Merced Ice Field itself was almost twice as thick at the center. At Washburn Lake the ice had a thickness of fully 1,800 feet, and thence it increased to 2,200 feet opposite the south spur of Sunrise Mountain, where the Merced Glacier issued from the ice field. This glacier, about 2 miles wide, not only filled the entire gorge of the
Merced but overflowed the broad rock benches on both sides to a height of 1,400 feet.

At the head of the Little Yosemite, which was capacious enough to hold the entire volume of ice, the Merced Glacier contracted to a width of only 1 mile. It filled the valley, however, literally to the brim, and even pushed a short lobe through the saddle northeast of Moraine Dome, as is shown by the moraine loops. (See pl. 29.) In the broad lower half of the Little Yosemite the Merced Glacier deployed gradually to a width of $1 \frac{1}{2}$ miles, at the same time diminishing in thickness from 1,700 feet opposite Moraine Dome to 900 feet opposite Liberty Cap. Consequently it failed to overtop Liberty Cap, leaving its summit standing out like a small round island. The Merced Glacier, however, overrode Mount Broderick by 300 feet, breaking on its dome-shaped top in radially diverging crevasses. Half Dome stood wholly above the ice, not even its base on the south side being touched.

From the mouth of the Little Yosemite the ice stream tumbled in magnificent chaos down the giant stairway, whose great steps are now marked by the Nevada and Vernal Falls, and it also plunged over the sheer front of Mount Broderick and through the gaps on each side. Broken into fantastic blades and pinnacles (séracs) the cascading portion of the glacier must have presented the appearance of a tumultuous cataract frozen into immobility. By contrast the even, compact ice mass that lay below in the Yosemite Valley must have seemed like a deep, tranquil pool.

The head of the ice cascade is still indicated by the highest lateral moraine on the south side of the Little Yosemite. Just west of the fork of the Mono Meadow Trail and the Glacier Point Trail this moraine begins to descend steeply along the edge of the precipice. A short distance farther west, where the ice surface broke, it disappears.

Tenaya Glacier.-The Tenaya Glacier had its sources far beyond the limits of the drainage basin of Tenaya Creek and drew a large part of its substance from the Tuolumne Ice Field, one of the largest in the entire High Sierra. The gently sloping surface of this vast mass of ice extended dazzling white, scarcely sullied by medial moraines, from Mount Lyell and the adjoining peaks of the Cathedral Range northward to Kuna Crest and Koip Crest, to Mount Dana and Ragged Peak, and westward to Tuolumne Peak and Mount Hoffmann. It had an area of 140 square miles and attained over the Tuolumne Meadows a thickness of about 2,200 feet. Northward and westward it connected with the numerous lesser glaciers of the upper Tuolumne Basin, the aggregate area being close_to 500 square miles.

The main outflow from this vast ice field went by the Tuolumne Glacier, one of the longest and mightiest trunk glaciers in the Sierra Nevada. It followed the Grand Canyon of the Tuolumne River, filling that 
chasm, which is 4,500 feet deep, to overflowing, as is impressively attested by the lateral moraines at Harden Lake and those on the uplands bordering the Hetch Hetchy Valley. So superabundant, however, were the snows that accumulated in the ice field that they could not all be drained off by the Tuolumne Glacier, and as a consequence overflow took place in several directions through notches and gaps in the confining mountain ranges. Small ice streams escaped, as already stated, southwestward through the gaps in the Cathedral Range and reinforced the feeders of the Merced Ice Field. A broad ice stream poured southeastward over Donohue Pass and joined the glaciers in the Rush Creek Basin; and relatively large ice streams flowed eastward through Parker Pass and Mono Pass and northward through Tioga Pass, descending through the precipitous canyons of the eastern Sierra front and spreading out in the basin of Mono Lake.

The largest diversion of ice, however, took place over the hilly divide east of Tuolumne Peak. There an ice sheet $4 \frac{1}{2}$ miles broad split off and passed over into the Tenay a Basin. The highest knobs on the divide were but small obstacles in the path of this ice sheet; they were submerged during the culminating phases to depths of more than 1,400 feet. Fairview Dome, the highest of the granite knobs, standing 1,200 feet above the Tuolumne Meadows, was overtopped fully 800 feet.

Not all of the diverted ice, however, went to feed the Tenaya Glacier. Although much of it gravitated directly into the head of Tenaya Canyon, a considerable proportion deployed southwestward along the base of Mount Hoffmann, and this ice lost most of its substance by melting as it spread out. At Snow Flat its thickness was reduced to 400 feet, and a mile farther southwest it was too thin to override any more knobs and ridges and was deflected to the south by the long ridge that extends southward to Mount Watkins.

The descent of the main ice current at the head of Tenaya Canyon was marked, of course, by crevassetorn ice cascades, but these cascades probably did not compare in spectacular grandeur with those of the Merced Glacier, for when glacial conditions approached their climax the head of Tenaya Canyon was almost filled with ice so that the entering glaciers had but a few hundred feet to fall. After the ice flood began to wane the entering glaciers made higher plunges but had less volume.

In Tenaya Canyon itself the ice formed a narrow, compact glacier of great thickness that probably wasted but slowly, as it lay mostly in the shade of the lofty ridge of Clouds Rest and had a small exposed surface proportionately to its bulk. The narrowness of the Tenaya Glacier is strikingly revealed on the glacier map (pl. 39) and stands in marked contrast to the breadth of the Merced Glacier. In only a few places was the Tenaya Glacier as much as a mile wide; through most of its length it was only three-quarters of a mile wide, and in one place, opposite the blunted nose of Mount Watkins, it contracted to half a mile.

However, the Tenaya Glacier and the Merced Glacier are not to be compared on the basis of their width alone. It is necessary also to take cognizance of their thickness. As is evident from the cross section in Figure 23 the Tenaya Glacier was by far the thicker of the two. Opposite Half Dome it was 1,800 feet thick, whereas the Merced Glacier was only 1,000 feet. Their cross sections consequently differed but little in area; as measured on the diagram they stood to each other in the ratio of about 7 to 8 . When it is considered, further, that opposite Half Dome the Tenaya Glacier had a more rapid fall and therefore greater velocity of flow than the Merced Glacier, it will be seen that the daily discharge of the two ice streams was closely balanced.

The cross section in Figure 23 reveals also the marked disparity in level between the two glaciers. Opposite Half Dome the surface of the Merced Glacier was at an altitude of 7,100 feet; the surface of the Tenaya Glacier, on the other hand, was at only 5,900 feet. The Merced Glacier descended to the Yosemite Valley by a tumultuous ice cascade, but the Tenaya Glacier sloped down rather evenly and joined the Yosemite Glacier without break.

The highest level reached by the ice of the Wisconsin stage is not so readily determined in Tenaya Canyon as in the Little Yosemite, for moraines are almost wholly absent from the steep, smooth walls of Tenay a Canyon. Fortunately, however, there are sculptural features that serve to indicate roughly the level attained by the ice in the canyon. As may be seen in Plate $40, B$, several short spurs project from the sloping rock façade of Clouds Rest. These are all distinctly truncated, their lower parts having been pared away by the glacier. Their slopes above the points of truncation are rough as a result of longcontinued weathering and give footing to bushes and trees, but the walls below are sheer and smooth and practically bare. The upper limit of glacial action may thus be inferred approximately from the change in the sculpture of the cliffs. A line drawn through the most definite points connects well with the moraines in the upper Tenaya Basin on the one hand and with the level determined for the ice in the Yosemite Valley on the other hand. The absence of a lateral moraine across the mouth of the hanging valley of Snow Creek corroborates the essential correctness of the line as drawn. Evidently the Tenaya Glacier did not reach quite up to the level of that hanging valley. By inference, it must have lain fully 800 feet below the base of the sheer front of Half Dome. 
Snow Creek Glacier. ${ }^{67}$-The southerly slopes of Mount Hoffmann, which were exposed to the heat of the sun and also to the sweep of the southwesterly gales, naturally accumulated but little snow. Nevertheless, when glacial conditions reached a climax, these slopes bore ice fields of moderate thickness, which, uniting at the base of the mountain with the broad lobe of Tuolumne ice that advanced from the direction of Snow Flat, formed a small glacier in the valley of Snow Creek. This, the Snow Creek Glacier, was but 1 mile long and ended fully 2 miles north of the brink of Tenaya Canyon.

Hoffmann Glacier. - On the steep north side of Mount Hoffmann the conditions were particularly favorable for the development of glaciers. There, in the lee and shade of four lofty westward-trending crests, the snows accumulated to great thickness and formed several cirque glaciers that united into one massive ice stream more than 1,000 feet thick-the Hoffmann Glacier. Reinforced by tributaries from Tuolumne Peak and from the group of mountains north of Mount Hoffmann this ice stream turned westward and then southward, down the valley of Yosemite Creek. It filled that valley completely, some of the ice spilling through gaps in the western divide.

At the point where the Tioga Road crosses the valley of Yosemite Creek the Hoffmann Glacier attained its greatest width-about $3 \frac{1}{2}$ miles-and a thickness of 1,300 feet; but so great were the losses which it suffered by melting on its broad surface that from this point southward the glacier dwindled rapidly in width and thickness, coming to an end just before reaching the brink of the Yosemite Valley. (See pl. 29.) Clearly it is useless to look for glacier polish on the platforms and slopes of bare rock above the Yosemite Falls or on Yosemite Point; they were never touched by the ice of the last glacial stage. Nor are the fantastic rock tables that lie near Yosemite Point ice-borne erratics; they are remnants of a sheet of rock from 6 to 8 feet in thickness that has disintegrated in place and has been stripped away almost entirely since the time of the earlier glaciers.

The long ridge that hems in the upland valley of Yosemite Creek on the west was high enough to generate small glaciers of its own. Five such ice bodies carved cirques into its eastern slope, but none of them were long enough to connect with the Hoffmann Glacier. On the west side of the ridge the snows evidently were more plentiful and gave rise to glaciers several

\footnotetext{
si This ice stream has been referred to by Muir as the Hoffmann Glacier, and the ice stream here called Hoffmann Glacier as the Yosemite Creek Glacier. Though it is desirable, wherever possible, to adhere to the names proposed by the pioneer observers, in this instance departure from ther seems advisable in order to avoid the confusion that would almost surely arise from the use of two names so closely similar as "Yosemite Creek Glacier" and "Yosemite Glacier" (the logical name for the trunk glacier that occupied the Yosemite Valley). The ice stream in the valley of Yosemite Creek, accordingly, will here be called Hoffmann Glacier, as it headed mainly on the north side of Mount Hofmann and was the only large ice stream that came from that peak. The small ice tongue in the valley of Snow Creek, which consisted largely of Tuolumne ice, will here be called Snow Creek Glacier.
}

miles in length. These extended down into the basin of Cascade Creek, but none of them reached the Yosemite Valley. The longest ended about 2 miles above the bridge on the Big Oak Flat Road.

Glaciers of the Illilouette Basin.-Contrary to the belief of previous students of the Yosemite region, the Illilouette Basin furnished no tributary to the Yosemite Glacier but contained only ice tongues of moderate size that were confined to its upper half. The longest did not reach within 5 miles of the mouth of the valley. This paucity of ice in the Illilouette Basin is explained by the fact that but little snow accumulated on the sun-heated and wind-swept southwest flank of the Clark Range, and that Buena Vista Crest and Horse Ridge, which encircle the head of the basin, were too low to generate glaciers of any considerable magnitude.

The largest ice stream-the Illilouette Glacier, properly so called-issued from the capacious amphitheaters northwest and southwest of Merced Peak. Reinforced by lesser ice streams from the vicinity of Merced Pass, it attained a length of about 7 miles. A remarkable series of lateral moraines, one of the finest in the Yosemite region, attests the numerous oscillations in volume and extent that marked the final waning of the Illilouette Glacier. They were laid down mostly along the right-hand margin of the glacier, which was abundantly supplied with débris from the masses of fractured granite in the vicinity of Merced, Ottoway, and Red Peaks.

From the cirques west of Red Peak issued another ice stream worthy of note. It extended down the valley of Red Creek and, being also heavily laden with débris, built up marvelously high and regular morajnal embankments. It attained a maximum length of about 2 miles, but it failed to connect with the Illilouette Glacier. Immediately west of the Illilouette was another glacier of nearly the same length and even slightly greater breadth, which may be named the Buena Vista Glacier, as it was made up of a number of confluent ice streams that originated in the lee of the long line of cliffs on Buena Vista Crest. Still farther west lay some smaller glaciers that came from Horse Ridge.

Glaciers of the Bridalveil Basin.-The upland valleys of Bridalveil Creek and its tributaries were largely devoid of ice during the last stage of glaciation. Only at the extreme heads of these valleys existed a few small ice tongues. All of the region now traversed by the automobile road that leads to Glacier Point was free from ice, and the beautiful natural meadows that are skirted by that road probably were already in existence.

Of the small ice tongues at the head of the basin the easternmost and largest is of peculiar interest, as it scooped out the basin of Ostrander Lake and built with the slabs and blocks of granite which it quarried from the north flank of Horse Ridge and from the lake basin 
the surprisingly large and rough moraines over which one travels with difficulty to reach the lake. In few

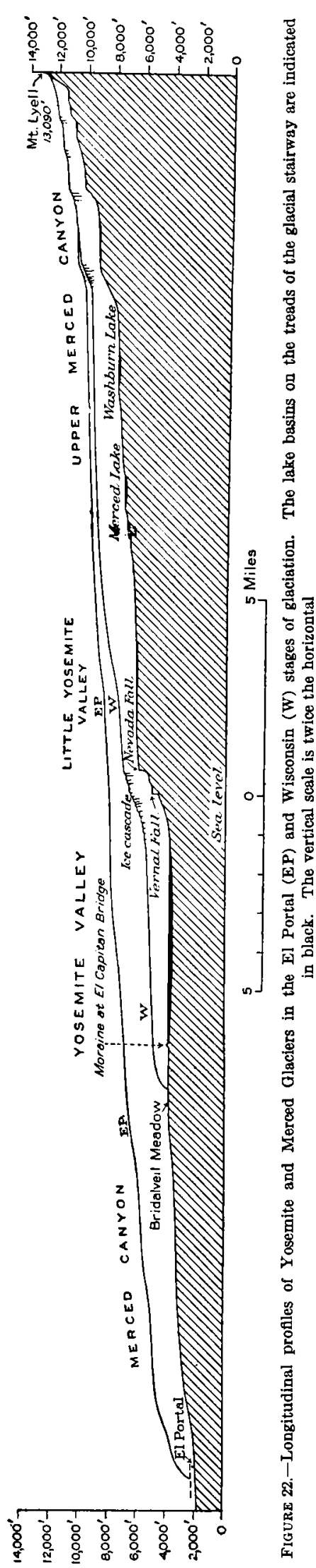
other places in the Yosemite region are the effects of glacial quarrying and transportation more vividly exemplified on a small, compact scale than at Ostrander Lake.

Lowest level of glacier generation.--In the vicinity of Ostrander Lake, furthermore, the student of glacial phenomena will find valuable indications of the lowest level at which glaciers were formed in this part of the Sierra Nevada during glacial time. Short glaciers, manifestly, give more precise information as to that level than long glaciers, as they protrude but little below the region of snow accumulation. Indeed, the shorter a glacier is the more closely does it indicate the level of glacier generation. Now it happens that on the northeast slopes of the low mountains north of Ostrander Lake there clung two tiny glaciers that scarcely projected beyond the bottoms of their cirques. These glaciers, it may be concluded, indicate accurately the lowest level at which, in favorably situated spots, snow could accumulate to sufficient thickness to form a true glacier. That level was slightly above an altitude of 8,000 feet.

Observations of a like nature made in other parts of the Sierra Nevada have yielded closely accordant data, and as a result the level of glacier generation can now be traced for a considerable distance over the range. Toward the north, naturally, it descended gradually; toward the south, on the other hand, it rose to higher and higher altitudes.

The definite determination of the lowest level at which glaciers were formed in the Yosemite region helps to settle some much mooted questions. Thus it is now clear that no glaciers could have been formed locally on the walls of the Yosemite chasm, as was thought by some of the earlier observers. Muir, notably, supposed a small glacier to have lain at the foot of the great eastward-facing cliffs west of the upper Yosemite Fall; but the altitudes there were 1,500 to 2,000 feet too low for the generation of a glacier even under the most favorable conditions. Again, it is commonly supposed that the northwest side of Half Dome owes its sheerness to the sapping action of a small glacier that lay in the shade and the lee of the great rock monument; but it is now evident that such can not be true, as the altitudes at the base of the cliff are 800 to 1,600 feet too low. Neither was it possible for a small glacier to be formed in the shady recesses of the south wall of the Yosemite Valley above Artist Point, for the altitudes there are nearly 2,000 feet too low.

\section{GLACIERS OF EARLIER STAGES}

Great extent and thickness.-The aspect of the Yosemite region in those earlier stages of the Ice Age when the glaciers attained their greatest spread is most readily pictured to the mind by imagining all the glaciers of the last or Wisconsin stage, just described, considerably enlarged. The Yosemite Glacier and its principal branches had, of course, the same general arrangement as in the Wisconsin stage, for they followed the same canyons and valleys, but all were much longer and broader.and thicker, and in many places they spilled over the flanking divides. Moreover, the ridges and knobs on the Yosemite upland generated glaciers of considerable magnitude, and as a consequence large areas of upland which in the Wisconsin stage remained bare were in the earlier stages mantled by extensive ice fields.

The greater length and greater volume of the main glaciers in those earlier stages might be ascribed to a proportionately greater piling up of snow on the crest of the range, yet that is not the true explanation. Strange though it may seem, the ice fields in the Merced and Tuolumne Basins had but slightly greater thickness than they had in the Wisconsin stage, and the cirques on the Clark Range, the Cathedral Range, and the main divide were filled to scarcely any greater depth.

This remarkable fact is brought out clearly in Figure 22, in which the longitudinal profiles of the Yosemite and Merced Glaciers in the earlier stages are superimposed upon the profiles of those glaciers in the Wisconsin stage. The profiles are based on a systematic survey of moraines and other features that indicate the highest level reached by the ice in each stage. In the lower part of the Yosemite Valley, it is to be noted, the earlier ice was 2,700 feet thick at the place 
where the later ice came to an end. In the upper part of the valley the two ice surfaces were about 2,000 feet apart in altitude, and thence upward the difference between them diminished rapidly. Opposite Liberty Cap it was only 1,000 feet, and at the head of the Little Yosemite it was only 500 feet. At Washburn Lake the earlier ice stood only 370 feet higher than the later, and farther up toward the Sierra crest the difference became so small that in the cirque at the immediate base of Mount Lyell it dwindled to a negligible quantity. It likewise dwindled in the other cirques at the head of the Merced Basin. In the Tuolumne Basin and, indeed, throughout the High Sierra, the earlier and later ice levels similarly coincided in the summit cirques.

From these facts it would appear, then, that the summit cirques of the Sierra Nevada received annually little if any more snow in the earlier stages of glaciation than they received in the Wisconsin stage. Why, then, it may be asked, did the glaciers of the earlier stages grow to so much greater length and bulk than did the glaciers of the Wisconsin stage? Primarily, it is believed, because the earlier stages were each much longer than the Wisconsin-in each of them the snow was permitted to accumulate for a longer period of time. It is probable that the earlier stages were marked also by somewhat greater severity of climate, so that the zone of snow accumulation in each of them was extended to a lower level, but as to this the evidence is not clear. In any event the great expanse of snow and ice must itself have become a secondary factor that served to intensify the wintry conditions and to increase the precipitation of snow by its chilling effect on the moisture-laden winds that swept up over the west flank of the range.

Upper limit of glaciation in the High Sierra.Because in the High Sierra the ice reached so nearly the same level in the earlier and in the later stages, the upper limit of glaciation, which for convenjence may be called the ice line, is there much more definitely marked in the landscape than lower down on the flanks of the range. And because the work of the glaciers in the High Sierra was largely erosional and only incidentally depositional, the ice line there is defined chiefly by sculptural features and only locally by moraines.

The ice line is particularly prominent in that part of the High Sierra of which Cathedral Peak is the outstanding feature. The mountains in that area have massive, rounded forms ( $\mathrm{pl} .40, A$ ), the projecting angularities having been smoothed away by the ice currents that swept over and around them in passing from the Tuolumne Basin over into the Tenaya and Merced Basins. Of this fact glacier polish, striae, and grooves afford abundant evidence. But surmounting these rounded, ice-smoothed mountains here and there are craggy pinnacles and splintered crests. These delicate superstructures doubtless have always stood above the ice, exposed to the atmosphere, like the "nunataks" that project above the ice cap in Greenland. Had they been overwhelmed by the ice for ever so brief an interval, surely they would have lost their angular forms and been largely demolished. Noteworthy examples of these frail superstructures are the spires of Cathedral Peak (pl. 12, A) and the horn of Unjcorn Peak, but even more impressive, because giving more definite indication of the ice line at their base, are the clustered pinnacles of the Echo Peaks and the attenuated crest of the Cockscomb (pl. 40,A). Very clearly marked also is the ice line at the bases of those lesser and more readily accessible cockscombs southwest of Cathedral Pass, of which the best known bears the slender shaft named Columbia Finger.

In the vicinity of Mount Lyell and on the main divide the ice line is distinct in only a few places, as the mountains there are so high that they were not extensively overswept by the ice. They were, in fact, the main centers of dispersal from which the ice streams radiated in different directions. On these lofty mountains, nevertheless, there are abundant indications of an upper limit above which the ice never rose. The more extensive summit tracts of these mountains are clearly unglaciated. Their gently sloping or undulating surfaces are littered with angular blocks, large and small, which have been loosened by intense frost. action but which have never been moved by gravitating glaciers. Nor are there any other evidences of glaciation such as polish, striae, or moraines. Doubtless these summit tracts have at no time borne anything more than temporary drifts and fields of snow, the violent gales that sweep over them having kept them partly bare.

It follows that these summit tracts are remnants of the preglacial landscape that have remained but little changed in configuration. Most of them have the appearance of elevated, uneven table-lands ending in sharp edges above the cliffs of the glacial cirques and canyons that bite deeply into the mountain sides. Some of them are so regularly scalloped by the inset arcs of cirques as to suggest, as Willard D. Johnson has aptly put it, "the irregular remnants of a sheet of dough, on the biscuit board, after the biscuit tin has done its work." 58 Unglaciated summit tracts of this kind exist notably on Parsons Peak and on the mountains east of Vogelsang Lake. Smaller tracts remain on Blacktop Peak, and Kuna Peak, and on some of the higher knobs of Kuna Crest. (See pl. 41, A.) The largest and most impressive remnants of preglacial topography are on Mount Dana and Mount Gibbs.

Merced Glacier.-It follows from what has been stated about the nearly exact coincidence of the ice

se Johnson, W. D., The profle of maturity in alpine glacial erosion: Jour. Geology vol. 12, p. 571, 1904; The grade profile in alpine glacial erosion: Sierrs Club Bull., vol. 5, p. 273,1905 
levels in the High Sierra that the Merced ice field must have presented substantially the same appearance in the earlier stages of glaciation as it did in the Wisconsin stage. This is true especially of its upper portion, but at its lower end the earlier ice was appreciably thicker than the later. It overrode the south spur of Sunrise Mountain, which in the last ice stage stood out as a prominent landmark, scraped off the pinnacles, and rounded that spur to its present smooth contours. Only a slender strip of land on the back of Sunrise Mountain remained bare of ice. Clouds Rest, too, was isolated, the ice of the Merced Glacier coalescing with the ice of the Tenaya Glacier across the saddles to the east and west of the crest. A small ice field of local origin lay even in the upland vale southeast of the Pinnacles on Clouds Rest.

Half Dome was deeply immersed in the ice, but its crown was not overwhelmed. The roundness of its crown has been ascribed to the abrading action of overriding ice masses, Half Dome being pointed to by many as a "roche moutonnee" ${ }_{59}$ of gigantic proportions; but the fact is that Half Dome, like the other domes of the Yosemite region, owes its roundness to long-continued exfoliation -the casting off of successive concentric shells of rock-as explained more fully on page 115 .

The exact height to which the ice rose on the sides of Half Dome is not indicated by any discernible line, for the marks of glaciation have been long since destroyed by weathering; but the ice level can be ascertained within narrow limits from the highest moraines on the mountains to the north, south, east, and west of Half Dome. These moraines afford sufficient data for the construction of a contour map of the ice surface, and a map so drawn shows that the ice did not reach within 500 feet of the level of the dome's summit. At the upstream side of the dome the ice banked up to an altitude of about 8,350 feet, the subsidiary dome from which the ascent of Half Dome is usually made being left just barely emergent. At the southwest or downstream end of the dome the ice surface declined to an altitude of about 8,200 feet.

South of the Little Yosemite the Merced Glacier deployed broadly over the Starr King Meadows and, when it reached its culminating stage, overtopped the divide east of Mount Starr King, thus coalescing with the ice in the Illilouette Basin. Up the Illilouette Valley, moreover, the glacier thrust a massive lobe that eventually met and united with the Illilouette Ice Field, and thus the Starr King group was completely surrounded by ice, the two highest summits only remaining uncovered, like two smooth, egg-shaped nunataks.

Illilouette Ice Field.-The conditions that prevailed in the Illilouette Basin during this stage of maximum glaciation differed vastly from those of the Wisconsin

${ }^{39}$ For definition of roche moutonnée see p. 96. stage. The glaciers generated on the Clark Range and on the crests at the head of the basin coalesced with the lobe of the Merced Glacier that blocked the mouth of the Illilouette Valley to produce an ice field of great magnitude and thickness. The obstructing lobe caused the level of this ice field to rise until at last the ice overflowed through the saddle southwest of Mono Meadow, passing westward with a thickness of about 200 feet and joining the ice field that lay in the Bridalveil Basin.

After the climax of glacial conditions had passed the Illilouette Ice Field again subsided below the level of the saddle and ceased to have any outflow. Nor did it need any, for the local glaciers, on the one hand, and the lobe of the Merced Glacier, on the other, melted back in opposite directions, leaving a space in which the waters collected to form a temporary, fluctuating lake -ancient Lake Illilouette. As the water accumulated, it found an outlet presumably over the surface of the ice that lay close-packed in the gorge of the Merced below.

During a later phase, when the obstructing lobe had melted away, the Merced Glacier itself remained high enough to pond the water at the mouth of the Illilouette Valley. In the shallow lake thus created a bed of stream-borne gravel and sand was laid down. This deposit has since been trenched by Illilouette Creek, but much of it remains in the form of low terraces. (See pl. 29.) The terrace on the east side of the stream still extends directly out to the brink of the Illilouette Gorge. Further examinations may show that this gravel bed was formed as late as the Wisconsin stage of glaciation.

Bridalveil Ice Field.-The basin of Bridalveil Creek contained a broad expanse of snow and ice. But the thickness of that ice field was only moderate, perhaps 500 feet at the most, and the outflow to the Yosemite Glacier was small. The obscureness of the morainal deposits in the basin renders it difficult to ascertain the exact relations which the Bridalveil Ice Field bore to the trunk glacier. It is entirely probable that the ice field was short lived, its existence being limited to that period when the Illilouette Ice Field overflowed through the saddle near Mono Meadow; for it seems unlikely that the low crests encircling the head of the basin were able of themselves to generate glaciers of sufficient volume to cover the entire area.

Tenaya Glacier.-The diversion of ice from the Tuolumne Basin to the Tenaya Basin took place on a much larger scale in the earlier stages of glaciation than in the last. On the divide between the two basins the ice attained a thickness of fully 1,700 feet. It rose high enough to overtop the crest that connects Tuolumne Peak with Mount Hoffmann, thus isolating both summits. It overrode Polly Dome to a depth of 600 feet and stood 2,300 feet thick in the basin of Tenaya Lake. Tenaya Canyon itself was so completely filled that there was no cascade over the cliffs at its head. 
The entire upland north of Tenaya Canyon was overmantled, largely by Tuolumne ice but in some measure also by ice from the southerly slopes of Mount Hoffmann. That mountain itself stood above the ice, clad in resplendent white. Only the narrow rock partitions and craggy chimneys that diversify its broad back remained silhouetted in black against the brilliant snow. The valley of Snow Creek was filled to a depth of 1,500 feet, the ice closing over both Mount Watkins and Indian Ridge, so that there was no distinct Snow Creek Glacier to be seen. The extreme summit of Indian Rock, however, probably remained emergent like a small island. Basket Dome lay under 700 feet of ice; North Dome under 600 feet.

South of Mount Hoffmann, in what is now known as Porcupine Flat, the westward-expanding Tuolumne ice met southeastward-flowing currents from the Hoffmann Glacier. The composite ice mass moved southward and invaded the basin of Indian Creek, but there its flow was checked by the powerful Yosemite Glacier, and it remained almost stagnant, like backwater in a side slough of a great river in flood. erosive action of the ice current in the defile. The ice thus diverted met and united with the overflow from the Tuolumne Glacier, which overspread the upland south of the Grand Canyon of the Tuolumne for many miles.

When the Hoffmann Glacier reached its culminating stage it joined the Yosemite Glacier without appreciable break of surface. It coalesced also with the partly stagnant ice mass in the basin of Indian Creek, and thus was formed a vast expanse of ice that stretched continuously from the south rim of the Yosemite Valley northward to Mount Hoffmann and northeastward to the main crest of the range. The Hoffmann Glacier at this stage also was thick enough and powerful enough to push a lobe of ice upgrade into the Eagle Peak Meadows and over the divides to the south, thus connecting with the Yosemite Glacier and surrounding the craggy summit of Eagle Peak.

As the glacier subsided it left on the unnamed summit west of the upper Yosemite Fall the moraine that includes the boulder perched on the 5-foot pedestal already referred to. (See pl. 38, A.) Subsiding still further, it became detached from the ice in the

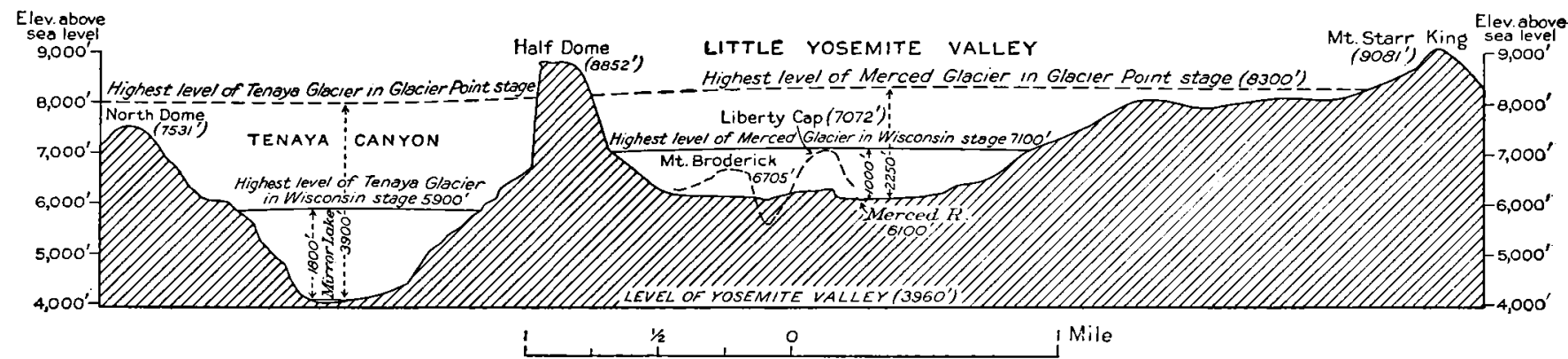

Figdre 23.-Section across Tenaya Canyon and the Little Yosemite, showing the highest levels reached by the Tenaya and Merced Glaciers during the earlier and later ice stages

The highest level attained by the Tenaya Glacier itself is shown in the cross profile in Figure 23, which is based on all the information available from the altitudes of moraines. The surface of the Tenaya Glacier was slightly lower than that of the Merced Glacier, and hence it may be inferred that in the broad saddle between Clouds Rest and Half Dome the ice currents moved in northwesterly directions from the Little Yosemite toward Tenaya Canyon.

Hoffmann Glacier.-The Hoffmann Glacier attained in the earlier ice stages the proportions of a true "mer de glace." It had a length of 13 miles and a breadth ranging from 2 to nearly 4 miles. Its surface area comprised about 45 square miles. So completely did the glacier fill the valley of Yosemite Creek that the ice overtopped the hills as well as the gaps in the northwesterly divide over a stretch of several miles and poured in considerable volume into the valleys tributary to the Middle Fork of the Tuolumne River. One of the largest diversions of ice took place through the pass now occupied by Lukens Lake, a body of water which owes its existence to the concentrated
Indian Creek Basin and deposited successive lateral moraines on the long, straight divide that terminates. in Yosemite Point.

The crown of El Capitan and the ridge north of it known as Boundary Hill, were high enough to stand above the highest ice flood. They constitute the first unglaciated area of any considerable extent on the north side of the Yosemite Valley and west of Clouds Rest. They were, however, completely surrounded by the ice, for at the culminating stage the Hoffmann Glacier sent a lobe of ice through the saddle north of Boundary Ridge, and this lobe, reinforced by small glaciers of local origin, formed the Ribbon Creek Glacier.

Cascade Glacier.-The most westerly ice stream tributary to the Yosemite Glacier on the north side was the Cascade Glacier. It was nourished wholly by cirques on the divide west of Yosemite Creek and existed independently of the Hoffmann Glacier, yet it. was by no means insignificant. It had a length of 5 miles and, in its lower course, a thickness of 1,500 feet. It was thus comparable in magnitude to some. 
of the finest glaciers now to be seen on Mount Rainier. The fact that an ice body of this size could be generated by only half a dozen small cirques in the side of a ridge not over 9,000 feet high speaks eloquently of the abundance of snow and the severity of climate that prevailed in the Yosemite region during the earlier stages of the glacial epoch.

Yosemite Glacier.-During the phases of maximum glaciation the Yosemite Glacier filled the Yosemite Valley literally to the brim and wound its way, like a broad, majestic river, down through the Merced Canyon below, as far as a point somewhat beyond the site of El Portal. At the head of the Yosemite Valley its surface probably was continuous with that of the vast ice sea that overspread the Little Yosemite, Tenaya Canyon, and the Illilouette Basin. So great was the congestion of ice caused by the bottle neck between North Dome and Glacier Point that the abrupt increase in depth at the head of the Yosemite Valley did not give rise to any significant break in the surface of the ice. Before and after the climax of each of the earlier glacial stages, however, when the ice had less thickness, yet sufficient to overtop the broad platform at the west base of Half Dome, there was a marked break in its surface at the head wall of the valley, for there the ice plunged down in the form of a grand cataract. This slow-moving Niagara of ice, which must have dwarfed the cascades by which the Merced Glacier descended from the giant stairway, persisted probably for considerable periods of time and, as explained more fully on page 97 , was a powerful factor in the excavation of the Yosemite chasm.

From the vicinity of Glacier Point westward the surface of the Yosemite Glacier probably declined rather evenly. The ice nowhere spilled over the upland on the south side of the valley, even during the culminating phases of glaciation, but it did not fall far short of reaching the brink, for it passed completely over the Cathedral Rocks and even over the high brushy summit south of them, as is plainly attested by the boulders which it left on those heights. Having overwhelmed the Cathedral Rocks, the ice filled the V-shaped gulch of Bridalveil Creek and passed westward over the summit of the Leaning Tower. This entire group of features, to-day so conspicuous in the landscape, was submerged beneath the dazzling sea of ice.

Except for the Bridalveil Glacier, which was but a shallow ice stream, the Yosemite Glacier received no tributaries from the south, and its southern margin was therefore sharply defined throughout, by cliffs as far as Old Inspiration Point and by lateral moraines beyond. The northern margin of the Yosemite Glacier was, by contrast, ill defined, at least as far west as El Capitan, owing to the fact that the ice which mantled the northern upland sloped down gradually to the level of its surface. Eagle Peak was the first sharp nunatak to split the ice sea, but a short dis- tance farther west rose the bare rounded crowns of $\mathrm{El}$ Capitan and Boundary Ridge. West of the small Ribbon Glacier the Yosemite Glacier was flanked by another area of unglaciated upland, of which Fireplace Bluff and the hanging vale of Fireplace Creek were the principal features. At the junction of the Cascade Glacier the northern margin of the trunk glacier was indefinite for a stretch of three-quarters of a mile, but beyond this stretch there were no more tributary glaciers and the margin of the trunk glacier continued well defined down to the end.

Below the elbow bend of the Merced Gorge, where the northern upland breaks down to a mere row of hills, the Yosemite Glacier ceased to be confined to the gorge. Sweeping over the low hills, as a river in flood might sweep over a broken levee, a large share of its ice invaded the Big Meadow flat. There the ice spread out in the form of a broad lobe that thinned rapidly toward its northern and western margins. The main ice stream, depleted by this diversion of its substance, declined rapidly in thickness. The great breadth of surface exposed to the sun, moreover, increased its losses by melting, and so, although a small volume of ice from the Big Meadow flat rejoined it through the gulch of Crane Creek, the Yosemite Glacier came to an end a short distance below El Portal.

From the junction of the Merced and Tenaya Glaciers to its terminus the ice stream measured 16 miles in length. It had a breadth averaging 2 miles, save in its lower course, where it expanded to almost double that breadth. In the Yosemite Valley the glacier attained the greatest thickness-from 2,500 feet over the Bridalveil Meadow to more than 3,000 feet opposite Glacier Point. Measured from its ultimate sources on Mount Lyell the Yosemite Glacier attained a maximum length of 37 miles. It was for the Sierra Nevada but a moderately large ice stream, however. Its neighbors on the north and the south, the Tuolumne Glacier and the San Joaquin Glacier, each attained a length of about 60 miles. The Yosemite Glacier, nevertheless, reached a lower level on the flank of the range than most of the other great trunk glaciers. It terminated at an altitude of about 2,000 feet.

\section{TRANSFORMATION OF THE YOSEMITE VALLEY BY THE ICE}

\section{KERNEL OF THE YOSEMITE PROBLEM}

What, it may now be asked, was the effect of these repeated ice invasions upon the configuration of the Yosemite Valley? To what extent has the valley been remodeled by the glaciers, and in what measure is its present form due to their action? These are the questions that contain the kernel of the Yosemite problem.

The opinions that have been advanced by previous students of the problem have been briefly reviewed in the introductory section of this paper. Their wide divergence was due principally to three circumstances- 
to the lack of definite data as to the extent and magnitude of the ancient Yosemite Glacier; to the vagueness of ideas that prevailed as to the nature and the duration of the ice age; and to the absence of reliable information as to the eroding power of glaciers-as to whether or not glaciers are capable of excavating deep canyons in hard rock. In other words, it was not known whether the Yosemite Glacier extended but a few miles beyond the valley or all the way down to the foothills of the Sierra Nevada; whether it was in existence a few thousand years or a million years; whether it possessed the power to cut deeply into the solid granite or could do little more than sweep out loose débris.

To-day the situation is quite different, for the maximum extent and maximum thickness of the Yosemite Glacier have been ascertained within narrow limits, and it is clear that the valley was invaded by the ice several times for prolonged periods, the history of its alternating stages of glaciation and deglaciation corresponding in general to that of the major advances and retreats of the great ice sheets over North America and Europe. What is more, glacial research has advanced to a point where it is possible to form rough estimates of the duration of the successive stages of glaciation and deglaciation and of the ice age as a whole. Though the precise number of centuries involved is not known, there is little doubt as to the order of magnitude of the time intervals involved as compared with that of the postglacial interval, whose length in years is no longer a matter of guess.

As regards the capacity of glaciers to excavate deep canyons in hard rocks, little doubt now remains on that score. Though there are still skeptics, it is safe to say that most geologists are convinced that glaciers are indeed powerful eroding agents. It is clear also that much depends upon the character of the rocks involved: in some kinds of rock glaciers erode much more effectively than in others. Probably few glaciated valleys that have come under investigation recently have shed more light on this question than the Yosemite itself, for not only does this valley afford striking illustrations of the degree to which the efficiency of the glacial processes is influenced by the character and the structure of the rocks, but its preglacial depth and form have been determined with a fair degree of accuracy, and hence it is possible to calculate with corresponding accuracy the amount of rock material that was actually excavated from the valley during glacial time.

\section{DEEPENING EFFECTED BY THE YOSEMITE GLACIER}

The downward excavating effected by the Yosemite Glacier is clearly indicated by the longitudinal profiles in Plate 27, A. All the space between the profile $C-C^{\prime}$ of the preglacial canyon stage and the profile $D-D^{\prime}$ of the glaciated rock floor of the valley (the bottom of ancient Lake Yosemite) represents excavating done since the beginning of the ice age. True, this is not a measure of glacial cutting alone: it represents glacial cutting and stream cutting combined, for the glaciers were active only at intervals during the ice age, and during the prolonged interglacial stages the Merced River performed its characteristic work. However, it is plain from the very character of the profile $D-D^{\prime}$ and from its extension by the giant stairway to the Little Yosemite and the upper Merced Canyon (pl. 27, $A$ ) that glacial cutting was vastly preponderant, for a stairlike canyon profile of this type, characterized by alternating treads and risers-the treads approximately level or bearing shallow lake basins, and the risers cut in the form of precipitous cliffs-is a characteristic product of glacial erosion, not of stream erosion. The particular manner in which glaciers produce steps in canyon floors is elucidated on pages 95-96. The tendency of streams is to produce fairly smooth, unbroken valley profiles-to eliminate steps as well as basins. The Merced has done nothing since the ice age to accentuate the stairlike profile of its pathway; on the contrary, it has done what it could do to demolish the steps and fill the basins.

Plate 27, $A$, shows strikingly the inequalities in the depth of glacial excavation. Evidently the ice accomplished much more work in some places than in others. At the lower end of the valley the glacial deepening measures only about 500 feet, but up the valley it increases gradually, reaching a maximum of about 1,500 feet near the head of the valley. Thence it diminishes rapidly to 850 feet at the top of the Vernal Fall and to a minimum of about 250 feet near the top of the Nevada Fall, to increase again gradually to 700 feet in the Little Yosemite. One can not but marvel at these marked inequalities in the deepening effected by the ice-indeed, it is hard to say which seems more astonishing, the maximum or the minimum. However, the true significance of these inequalities becomes apparent only when they are considered together with the variations in the lateral cutting.

\section{WIDENING EFFECTED BY THE YOSEMITE GLACIER}

The lateral cutting effected by the Yosemite Glacier is strikingly revealed in the cross profiles in Figures 24 to 30 . Nothing, indeed, serves better to give a true conception of the thoroughgoing transformation which the Yosemite Valley has suffered by glaciation than this series of diagrams. Each shows exactly to scale- that is, without vertical exaggeration-the cross profile of a certain part of the valley as it is to-day, plotted from the contours of the topographic map (pl. 7), and the corresponding cross profile of preglacial time. The reconstruction of the preglacial cross profile has not been simply a matter of imagination, for the depth of the preglacial Yosemite Canyon has been determined (see profile $C-C^{\prime}$, pl. $27, A)$, and the character of its sides was governed by a number of elements such as the heights and 
gradients of hanging valleys and hanging gulches and the forms of truncated spurs and projecting rock monuments. General guidance, further, is afforded by the well-known laws of canyon cutting by streams and of the progressive conversion of sheer canyon walls into slopes of moderate declivity by the processes of weathering and erosion. In some places intimate knowledge of the local structure of the granite has enough to spread over the whole width of the valley and that it performed a significant share of the lateral cutting. If it had had such volume and power it would have produced many broad-bottomed yosemites in the relatively unresistant sedimentary rocks below El Portal long before it evolved a single valley of that type in the resistant granitic rocks of the Yosemite region.

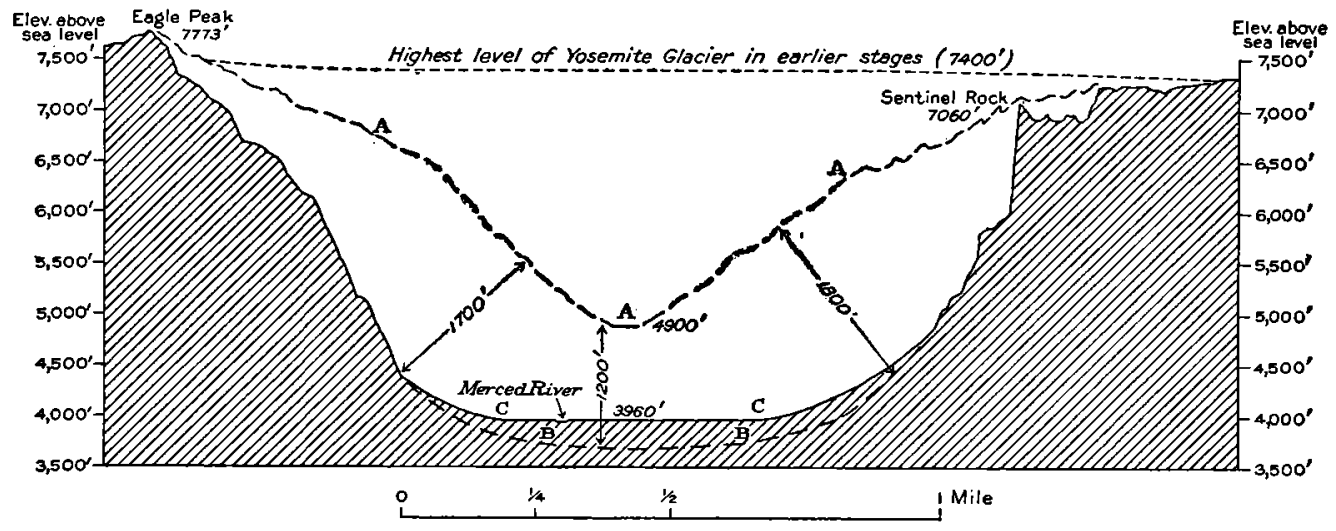

Figure 24.- Cross profle from Eagle Peak to Sentinel Rock. Depth of glacial excavation, 1,200 feet. Quantity of rock removed by the ice estimated at $1,400,000$ cubic yards. A-A, Preglacial profle; B-B, approximate bottom curve of the glacial $U$ trough; $\mathbf{C}-\mathrm{C}$, present profile

permitted the introduction of sculptural details such as benches, facets, pinnacles, and knobs.

From all these cross profiles it is manifest that lateral cutting has been a more important element in the transformation of the Yosemite chasm than downward cutting. At every point the widening accomplished exceeds the deepening. It is, in fact, mainly through lateral cutting that the narrow $V$ can-
Comparison of the different cross profiles with one another reveals also the fact that the widening accomplished was no more uniform than the deepening and that in general the glacial processes worked very unequally. They accomplished large results in each of the two chambers of the Yosemite Valley, but considerably less in the portal between those chambers and astonishingly little in the Merced Gorge below the

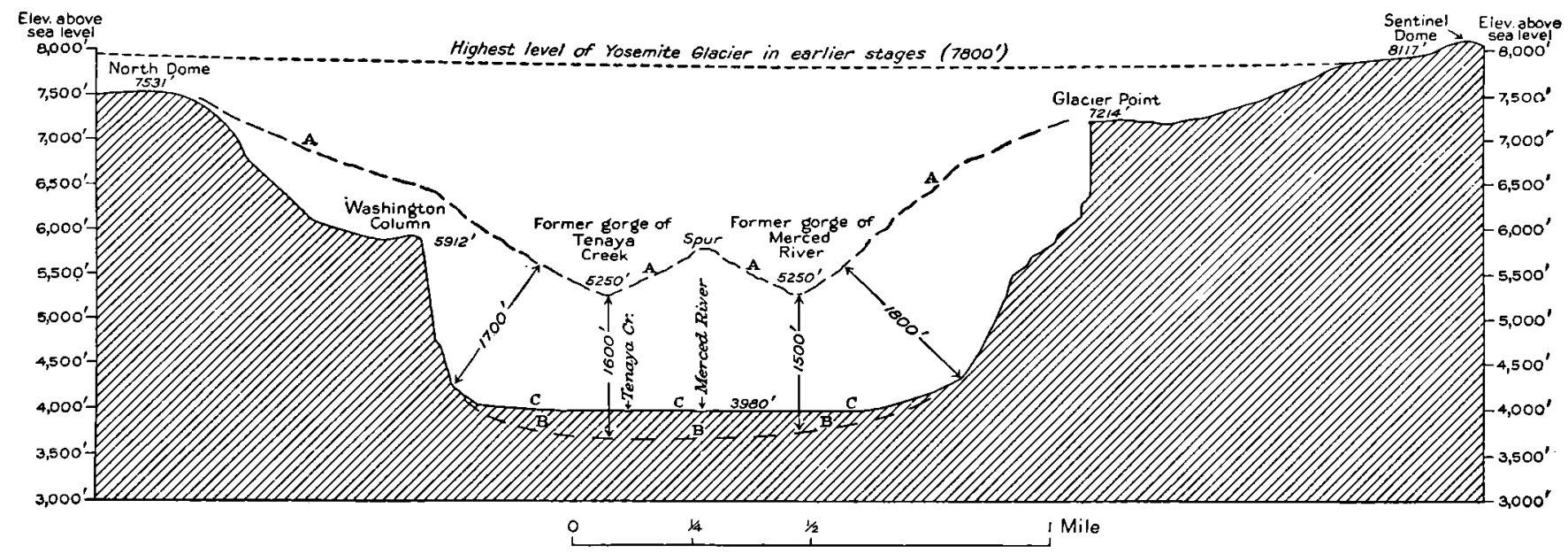

Figure 25.-Cross profile from North Dome to Glacier Point, showing maximum depth of glacial excavation, 1,500 to 1,600 feet. Quantity of rock removed by the ice estimated at 1,700,000 cubic yards. A-A, Preglacial profile; B-B, approximate bottom curve of the glacial U trough; C-C, present profile

yon of preglacial time has been transformed into the broad $U$ trough of to-day. It is evident, further, from the very breadth of the $U$ profile that the glacial processes far outstripped the fluvial processes, for whatever trenching the river did in interglacial epochs must have tended to produce an inner gorge, yet of such a gorge there is no vestige whatever. Surely it is not to be supposed that the river at any time possessed volume valley and in the gorge below the mouth of the Little Yosemite.

A fair measure of the lateral cutting effected in the main Yosemite chamber is indicated in the cross profile from Eagle Peak to Sentinel Rock shown in Figure 24. Measured at right angles to the sides of the preglacial canyon it amounts to fully 1,800 feet, whereas the deepening amounts to approximately 1,200 feet. 
The space between the preglacial and postglacial profiles as shown in the diagram measures about $1,400,000$ square yards; hence the ice excavated from a section of the valley 1 yard long in the direction of its axis about $1,400,000$ cubic yards of rock. This measurement, it is true, is made at a point where a jagged spur projected from the face of Sentinel Rock, yet the amount stated may be considered fairly representative of most of the main Yosemite chamber, for there from Glacier Point, and a smaller spur projected from North Dome in the direction of the Washington Column. The quantity of rock excavated by the ice from a section of the valley 1 yard long in the direction of its axis, computed from this diagram, approximates $1,700,00^{\prime}$ ) cubic yards.

Representative of the lower Yosemite chamber is the cross profile shown in Figure 26. Here too, unquestionably, entire spurs were removed by the

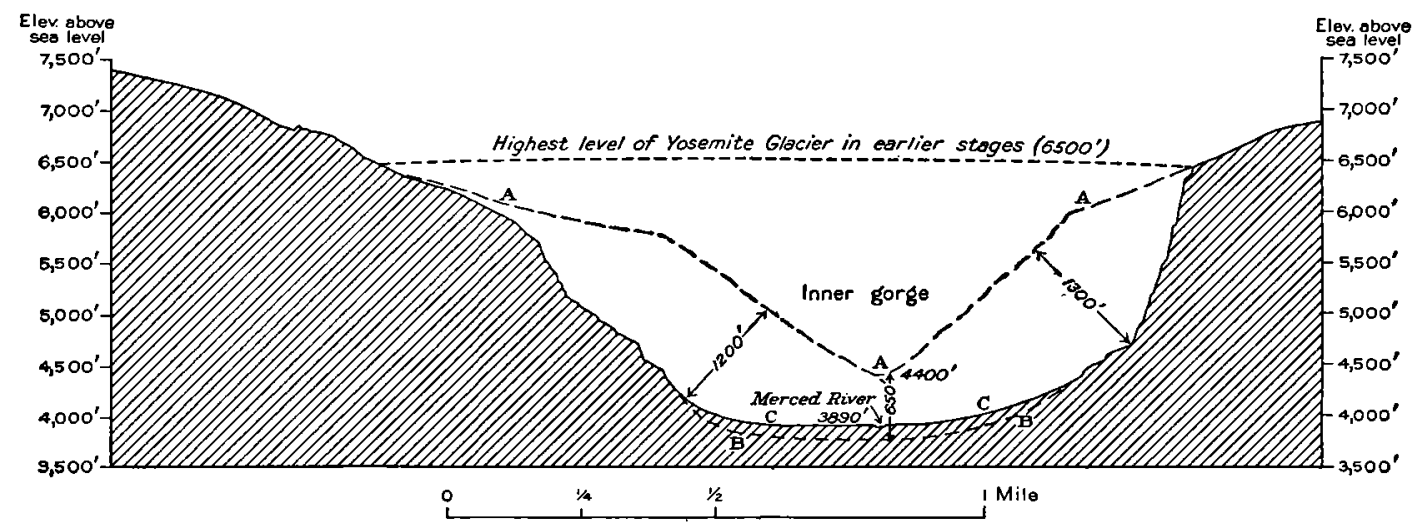

Figure 26.-Cross profle below Bridalveil Meadow. Depth of glacial excavation, 650 feet. Quantity of rock removed by the ice estimated at 800,000 cubic yards. A-A, Preglacial profile; B-B approximate bottom curve of the glacial U trough; C-C, present profile

were several other spurs, all of which were planed away by the glacier. The amount is of course merely an approximation, but it will serve for comparison with similar amounts indicated by other cross profiles.

The maximum of glacial excavation is shown in the cross profile from North Dome to Glacier Point and Sentinel Dome (fig. 25). The ice there accomplished truly prodigious results: at no other place did it effect a more complete transformation. The condi- ice. The lateral cutting, measured as before at right angles to the preglacial canyon sides, amounts to nearly 1,400 feet, and the total quantity of rock excavated over the distance of 1 yard is about 800,000 cubic yards. The cross profile of the portal between El Capitan and the Cathedral Rocks (fig. 27), on the other hand, shows only 700,000 cubic yards of excavation. But the most marked contrast is offered by the profile in Figure 28, which is taken across the Merced

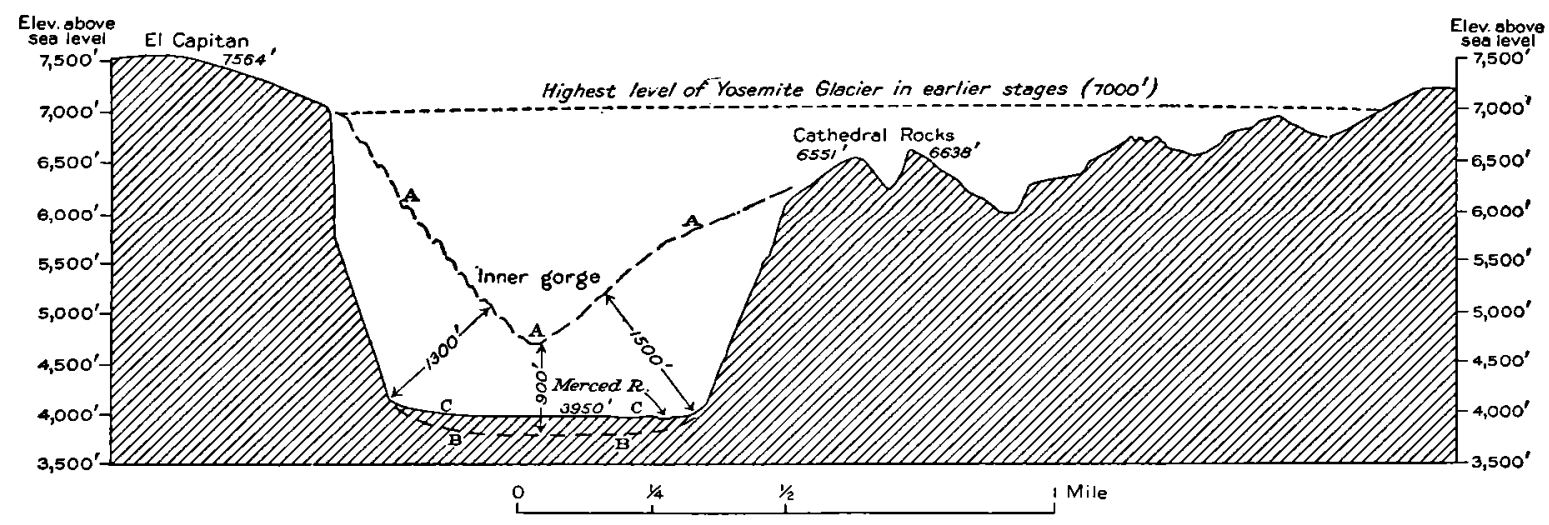

Figure 27,-Cross profile from El Capitan to the Cathedral Rocks. Depth of glacial excavation, 900 feet. Quantity of rock removed by the ice estimated at 700,000 cubic yards. A-A, Preglacial profile; B-B, approximate bottom curve of the glacial U trough; C-C, present profile

tions were, however, peculiar to the head of the valley, for the two preglacial gorges of Tenaya Creek and the Merced River there came together, and the two main branches of the Yosemite Glacier were confluent. The hump in the middle of the profile represents in section the tapering spur that sloped formerly from the west base of Half Dome to the junction of the gorges. A more massive spur doubtless projected northward
Gorge, just below the Yosemite Valley. The work done there by the ice can scarcely be called a transformation. There was only moderate enlargement of the valley section and no real change in general form, the inner gorge, though widened somewhat, remaining strongly in evidence. The quantity of rock excavated per yard here is less than 500,000 cubic yards-that is, little more than one-half the quantity indicated 
for the lower chamber and little more than one-third the quantity indicated for the upper chamber.

Another cross profile of special interest is that in Figure 29, drawn across the mouth of the Little Yosemite and over Mount Broderick and Liberty Cap. It shows an abrupt diminution in the glacial excavation, the quantity removed from a section 1 yard long being only about 300,000 cubic yards. Of course this quantity is not comparable on even terms winding across a large billowy mass of bare granite that obstructs the canyon for a distance of 2 miles.

\section{MUIR'S EXPLANATION}

How are these extreme and in places abrupt variations in the depth and breadth of glacial excavation to be explained? Why have the glaciers been able to accomplish so much in some parts of the Yosemite region and so little in others?

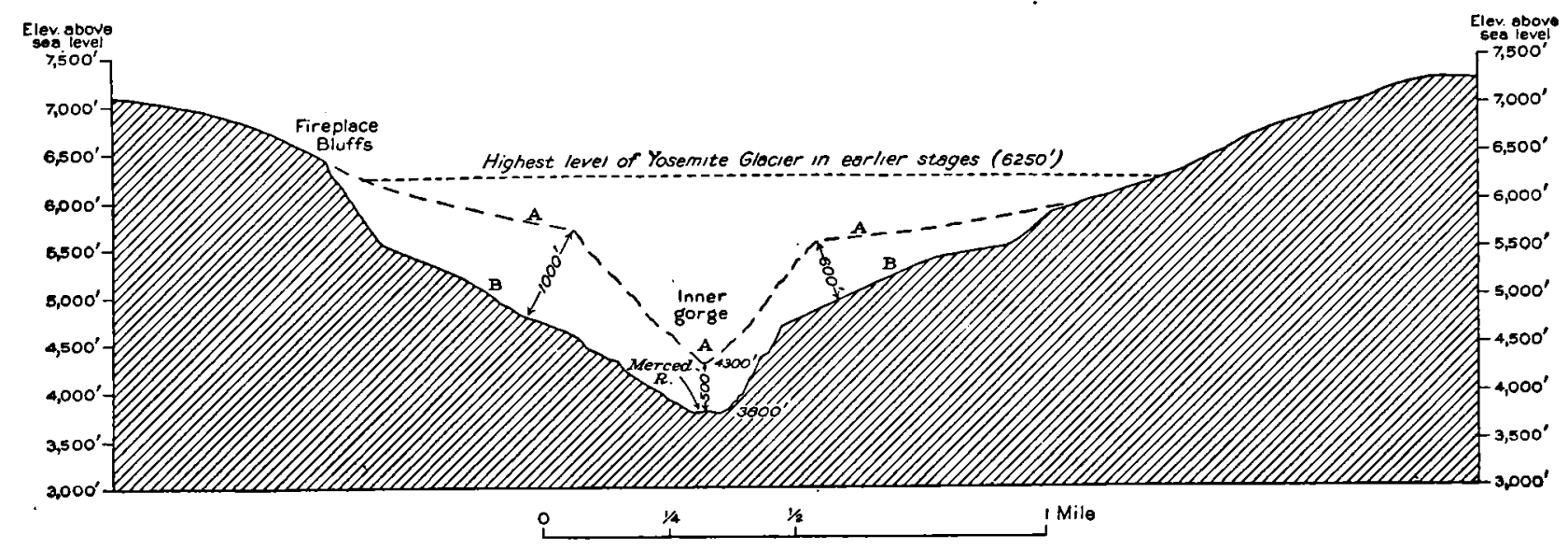

FIGURE 28.-Cross profle 'at head of Merced Gorge, showing minimum depth of glacial excavation, 500 feet. Quantity of rock removed by the ice estimated at 500,000 cubic yards. A-A, Preglacial profile; B-B, present profle

with the quantities shown in the cross profiles previously considered, for it represents work done only by the Merced Glacier, not by the entire Yosemite Glacier. But even for the Merced Glacier the quantity stated is very small. The profile in Figure 30, which is taken across the middle of the Little Yosemite, shows an amount of material excavated more than half as large again.

At the head of the Little Yosemite, finally, glacial excavation dwindles to a minimum. There, opposite
It was pointed out by Muir ${ }^{60}$ that the Yosemite Valley begins just below the junction of three converging canyons from each of which formerly issued a mighty glacier. In reality there were only two glaciers, the Merced and the Tenaya, for no ice stream ever issued from Illilouette Valley, as already explained (pp. 62-63); but this does not invalidate Muir's argument. Similarly, he showed that the Hetch Hetchy Valley and the Kings River Canyon, two of the most typical yosemites in the Sierra Nevada, each begins below the

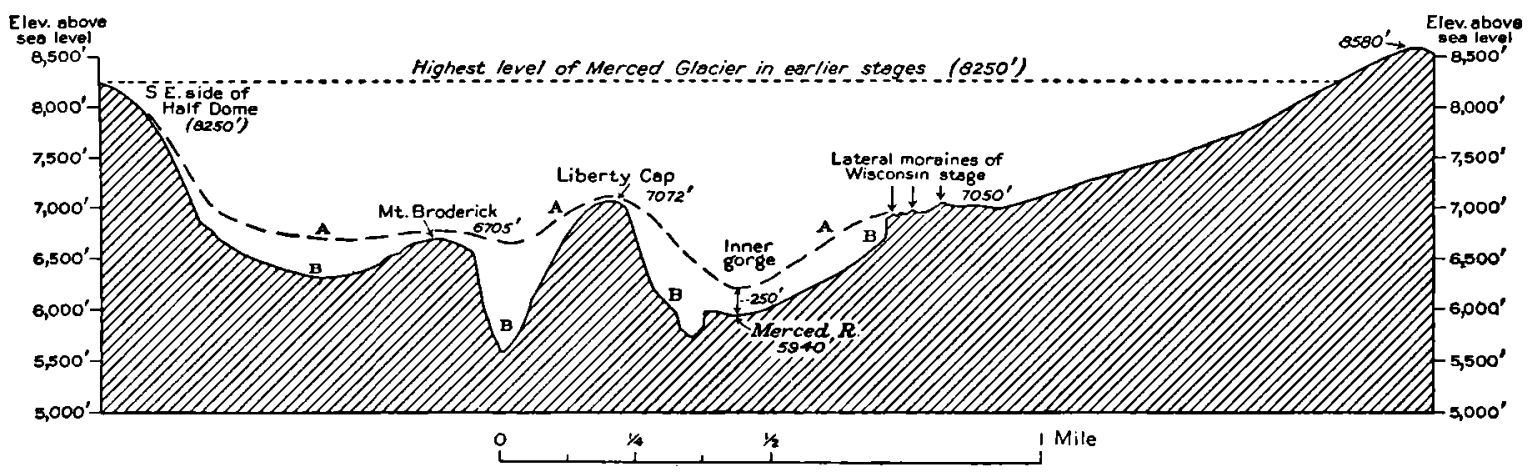

Figure 29.- Present cross profile (B-B) at mouth of Little Yosemite Valley compared with the preglacial cross profile (A-A). The changes produced here by glacial action were relatively slight and involved the removal of less than 300,000 cubic yards of rock

Bunnell Point, the walls contract and the upper gorge of the Merced begins-a gorge so narrow that, were it not for the smoothness of its walls and the presence of polish, striae, and grooves, it might readily seem a product of stream erosion purely. (See fig. 37.) To obtain a true conception of that gorge in its relations to the upper Merced Canyon as a whole, one should view it from a lofty summit such as Half Dome or Clouds Rest. It is then seen to be a mere inner trench junction of two or more great glaciated canyons. The confluence of two or more great ice streams, which results in an abrupt increase in excavating power, Muir was therefore inclined to regard as the primary cause of the formation of a capacious Yosemite-like valley. No doubt this explanation is correct as far as it goes, for the consolidation of two or more ice

Muir, John, Studies in the Sierra-Mountain sculpture; origin of Yosemite valleys: Sierra Club Bull., vol. 10, p. 68, 1916. 
streams into one does result as a rule in greater compactness of form and therefore in increased economy of movement and increased excavating capacity per unit mass. However, some yosemites in the Sierra Nevada quite as typical as any of those mentioned are not associated with the junction of large glaciated canyons; and there are plenty of examples of two or more powerful ice streams uniting without giving rise to a typical yosemite.

The Little Yosemite, notably, has no converging canyons at its head. It has been developed at a place where the Merced Glacier received no significant increments but where, on the contrary, that ice stream dissipated part of its volume by overspreading the flanking uplands. The Grand Canyon of the Tuolumne, on the other hand, affords several good examples of glacier junctions that have not resulted in the production of any yosemites. From the canyon of Return Creek (pl. 2) there issued a tributary glacier 3,000 feet thick, yet its confluence with the Tuolumne Glacier, which was 4,000 feet thick, produced no yosemite. Nor was a yosemite produced below the mouth of Cataract Canyon, which was another large glacier channel. Even the junction of the Piute Creek Glacier, which was 3,500 feet thick, with the Tuolumne Glacier gave rise to only a minor enlargement of the canyon-the incipient yosemite known as Pate Valley.

A comparative study of the principal yosemites of the Sierra Nevada, further, shows that they are by no means proportionate in size to the glaciers that occupied them. Some of the greatest yosemites were the pathways of only moderately large glaciers, and some of the lesser yosemites were the pathways of very large glaciers. Thus the Yosemite itself, the most capacious of all the valleys of its type, was the pathway of a glacier only 37 miles long and slightly over 3,000 feet thick at the time of maximum glaciation; whereas the Hetch Hetchy Valley, though only half as long and half as wide as the Yosemite and about 1,000 feet shallower, was traversed by a glacier 60 miles long and 4,000 feet thick. Moreover, lateral moraines left by that glacier (the Tuolumne Glacier) show clearly that not only was the Hetch Hetchy completely overwhelmed by the ice of the earlier stages, which was 1,000 feet thicker there than in the Yosemite, but during the last glacial stage it was again filled to overflowing by an ice stream comparable in magnitude and eroding power to the earlier Yosemite Glacier, whereas during the same stage the Yosemite itself contained only a shallow and feeble ice tongue that did not reach quite to its lower end.

The Kings River Canyon, though a few miles longer than the Yosemite Valley, is only half as wide and two-thirds as deep. So narrow is its floor that "canyon" seems at least as appropriate a term for it as "valley"; yet the ice streams that occupied it in the earlier and later stages of glaciation respectively had but little less volume and power than the glaciers that occupied the Yosemite Valley in each of those stages.

These facts afford no little food for thought. They show that typical yosemites have been produced not only below the points of confluence of large branch glaciers but also at points where there was no such confluence, and, further, that the dimensions of a yosemite bear no definite relations to the size and power of the glacier that occupied it. Evidently another factor is involved-a factor that in large measure controlled the glacial processes and determined how much excavational work they might accomplish at any place. That factor is the structure of the rock.

In order that the influence of rock structure on the excavating efficiency of glaciers may be understood

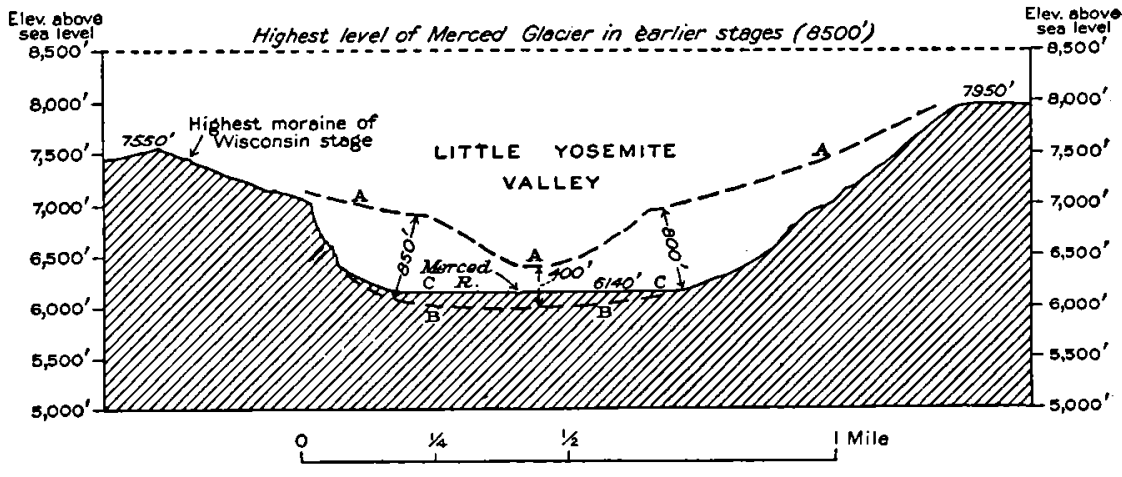

ss profile at the middle of the Little Yosemite Valley compared with the preglacial profle (A-A). At least 450,000 cubic yards of rock was removed from this section by the ice. B-B, Approximate bottom curve of the glacial U trough; C-C, profle of the present valley floor on the ke basin

it is desirable first to gain a clear idea of the manner in which glaciers do their work.

\section{HOW DO GLACIERS EXCAVATE?}

It is commonly supposed that glaciers erode their beds mainly by grinding and scouring. It is true that with the rock fragments which they hold in their bottom layers glaciers perform considerable abrasive work - witness the polished, striated, and even deeply grooved floors and walls of glaciated canyons. Nevertheless, the efficacy of this abrasive action is not inherently great. Only in soft, friable rocks does it accomplish really large results. In hard, tough rocks, such as granite, it achieves but little-not enough, in any event, to account for the profound remodeling of entire valleys and canyons. On such rocks, as a rule, the presence of glacier polish is indicative of moderate changes slowly produced.

The process whereby glaciers excavate to best effect in hard rocks is by plucking, or "quarrying" entire blocks and slabs. Because of their very weightsome 30 tons to the square foot for every thousand. 
feet of thickness-and the fact that they are shod with coarse rock waste frozen in their basal layers, glaciers have a strong frictional hold on their beds; and so, as they move forward, though at a rate of only an inch or two a day, they dislodge and drag forth entire blocks and slabs. The peculiar property that ice has of freezing tightly to objects with which it is in contact is probably a potent factor in the process, as has been suggested by Profs. T.C. and R.T. Chamberlin, ${ }^{61}$ of the University of Chicago.

The blocks and slabs thus dislodged are, however, rarely broken off from sound, unfractured rock. The glaciers take advantage, rather, of the fractures already existing in the rock-the joints by which it is divided into natural blocks and slabs. (See pl. 41,B.) This is true especially of hard, tough rocks such as granite, for even a glacier 3,000 feet thick does not exert pressure

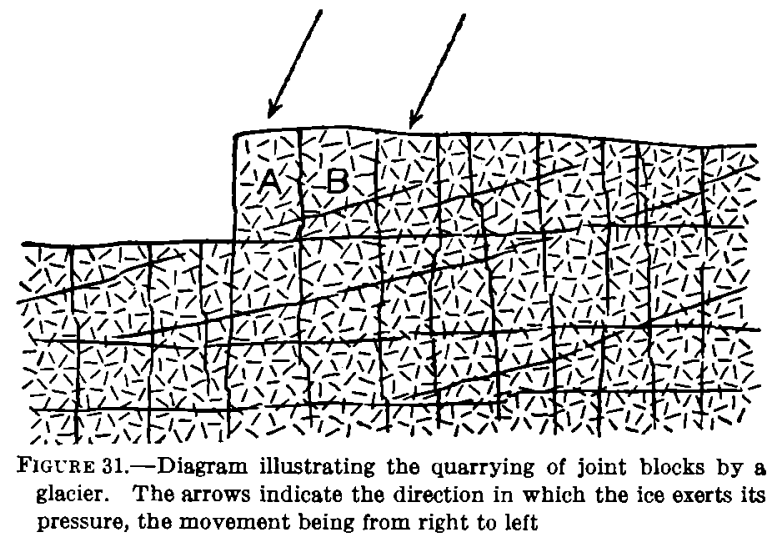

enough to disrupt a floor of sound, massive rock of that type. It is clear, then, that the joint structure plays a very important part in glacial quarrying. Without it, in fact, the process is scarcely operative in hard rocks.

Several agencies, furthermore, tend. to facilitate the quarrying process, by loosening up the blocks and slabs. Acid carried by water that percolates through the joint fractures dissolves the weaker minerals and lessens cohesion; and water freezing in the fractures pushes the blocks and slabs apart with its momentary but strong expansive force. (See pl. 42, B.) It has even been contended, by those who would attribute only slight erosive power to glaciers, that the quarrying is limited practically to the removal of blocks and slabs previously loosened in preglacial or interglacial time, but there is ample evidence to the contrary. In many glacier channels the quarrying can be seen to have progressed far below the zone of weathering, its depth varying primarily with the thickness and power of the glacier concerned.

The manner in which the glacial quarrying process operates is illustrated by Figure 31. Any joint block in the bed of a glacier, such as that marked $A$, which is for any reason unsupported or weakly supported on its

\footnotetext{
61 Chamberlin, T. C. and R. T., Certain phases of glacial erosion: Jour. Ceology, vol. 19, pp. 209-211, 1911 .
}

downstream side, is particularly susceptible of being dislodged, for the force of the glacier is exerted upon it at a small angle forward from the vertical, as indicated by the arrow. The block $A$ and its side companions having been removed, the block B and those flanking it will next be unsupported and ready for removal, and so the process will continue farther and farther up the valley. Its rate of progress will depend upon the power of the glacier, the size and weight of the blocks, and the looseness of the joints.

Muir ${ }^{82}$ in one of his earlier papers described long trains of glacially quarried blocks which he had observed in the vicinity of Tenaya Lake and which he had succeeded in tracing back to their points of origin on the mountain side. The mountain was not smoothed or rounded but cut in square-edged steps bounded by joint planes. Stepped and hackled rock surfaces are, indeed, the rule in glaciated mountains.

Impressive evidence of the quarrying action of glaciers is to be found also in the presence of angular, sharp-edged blocks in the moraines. Such blocks abound especially along the upper courses of lateral moraines, where they were dropped before they had been carried far enough to lose their angularity by wear. A particularly striking example is that shown in Plate $42, A$. The small moraine represented consists almost exclusively of clean-cut, angular blocks, mostly from 4 to 12 feet in length, that were torn from the jointed cliffs of a glacial cirque near by.

\section{SELECTIVE QUARRYING}

Because glacial quarrying in hard rocks is so largely. dependent upon the presence of joints, its action naturally is strongly influenced by the spacing of the joints. Where these fractures are close together, so that the rock is divided into small, light blocks or slabs, quarrying will proceed with relative ease and rapidity; there even a small, feeble glacier will be able to accomplish much. Where the joints are far apart-50 feet or more - the blocks between them are too large and too heavy even for a mighty trunk glacier to dislodge. Rock so sparsely jointed is virtually massive, so far as the glacial processes are concerned, and can be reduced only by slow abrasion.

Between these two extremes, of course, there are many intergradations, depending upon the distribution and the arrangement of the fractures. In these intermediate rocks in which the jointing is moderately coarse the excavating force of the glacier is as a rule the decisive factor. In dealing with rocks so jointed a small shallow glacier exerting relatively little pressure on its bed may be almost impotent, whereas a glacier of great depth, exerting correspondingly great pressure, may accomplish signally large results. It is, in fact,

a2 Muir, John, Studies in the Sierra-Glacial denudation: Sierra Club Bull., vol. 10, pp. 304-318, 1918 (reprinted from Overland Monthly, August, 1874). 


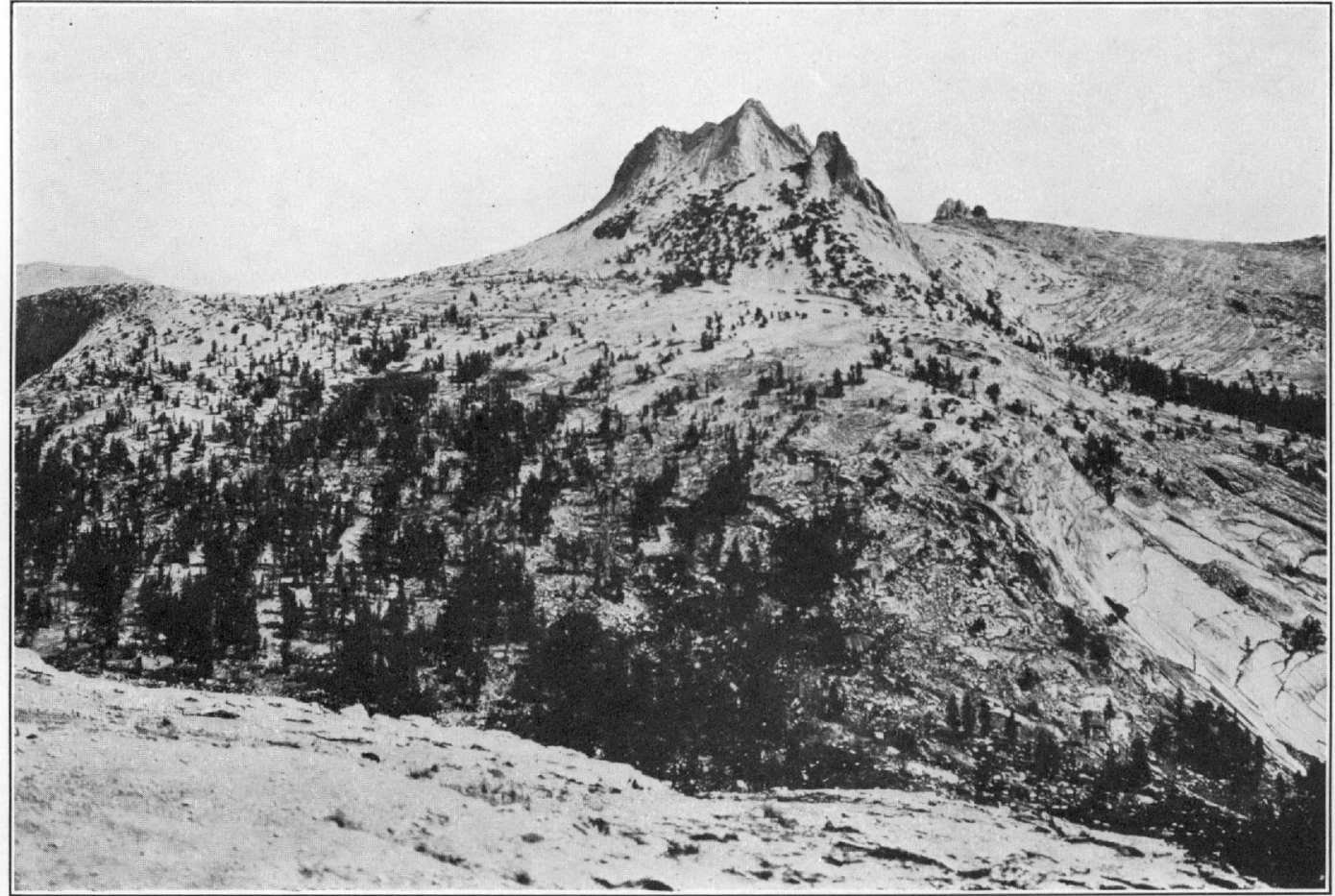

1. ECHO PEAKS AND 'III' COCKSCOMB

These eraggy pintades are the only fealures in the landscape shown that have not heen overwhelmed by the flacial ice. The

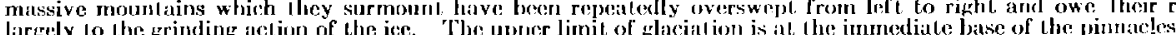

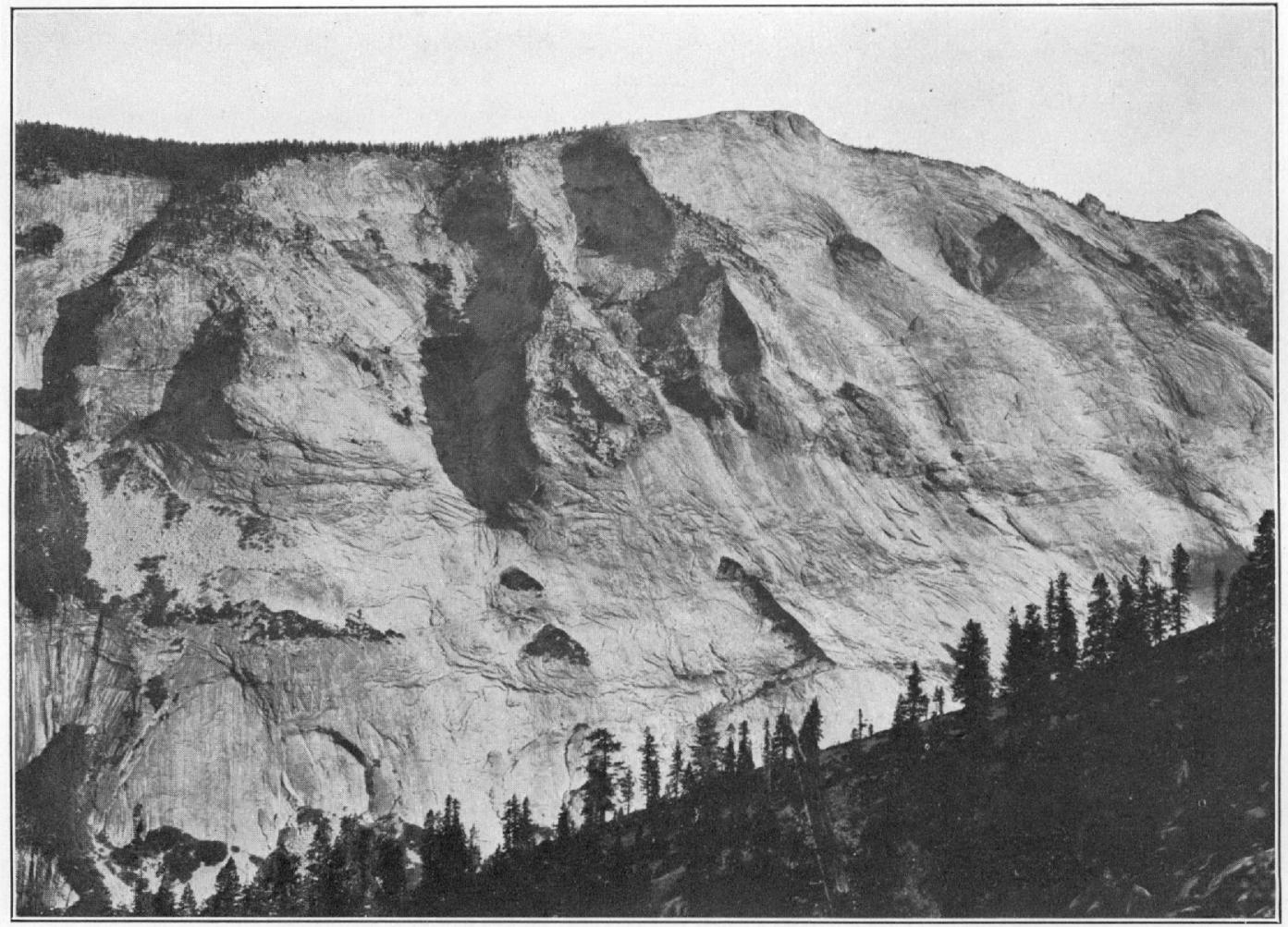

B. THE GREAT FACADE OF CLOUDS HWST, FIOM MOUNT WATKINS

No moraines cling to the steen, smooth rock face, lut the highest level reached hy the 'Tenaya (ilacier can be delermined approximately from the seupplure of the spurs. 'J he highest level of the ite of the last folacialion is indicaled ly tle urper limit of smoothed rock on the spur to the left of the cenler. The hiphest level of the earlier ice is indicated by the shoulder on the

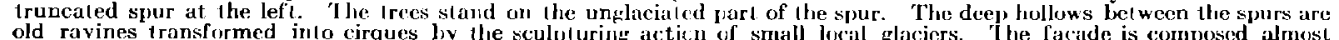
throughout of massive granice, exfeliuting ut the surfice, and has a height of 4,00 f cet. 


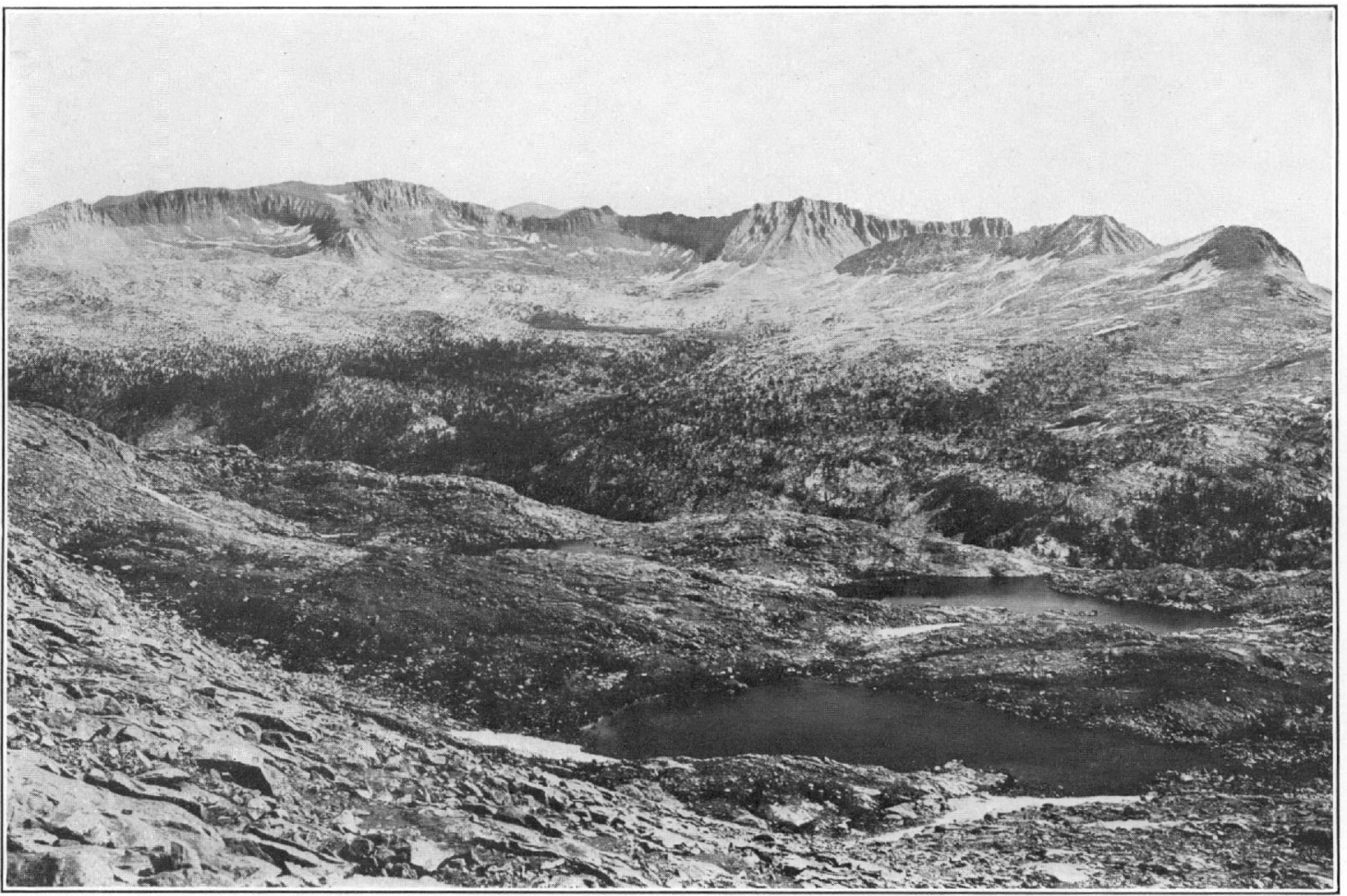

A. Chest OF SIlikR NEVADA AND IIEAD OF TUOLUMNE BASIN

Though decply scalloped by flacial circues, this pirt of the crest still bears remnants of its preqlacial lopography, therehy showing

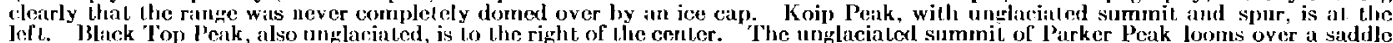

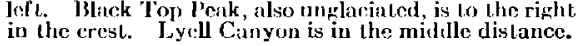

-

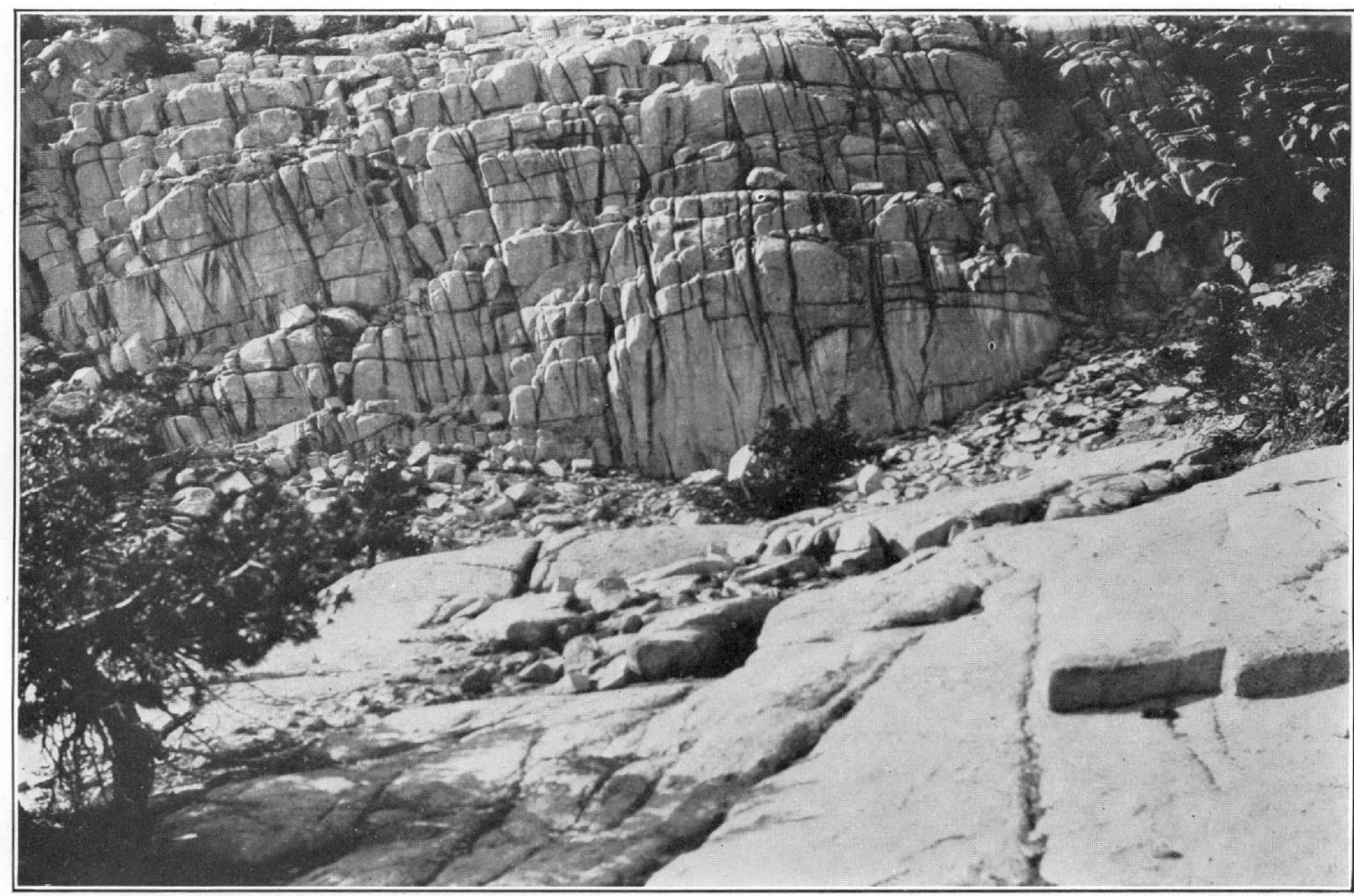

b. WELL-JOINTWD GRANITE IN THE HIGH SIERHA

The roek is divided into lairly regular blocks by several intersecling sets of joints. Natural masonry of this kind is readily destroyed by glaciers. Pholograph by G. K. Gilbert. 


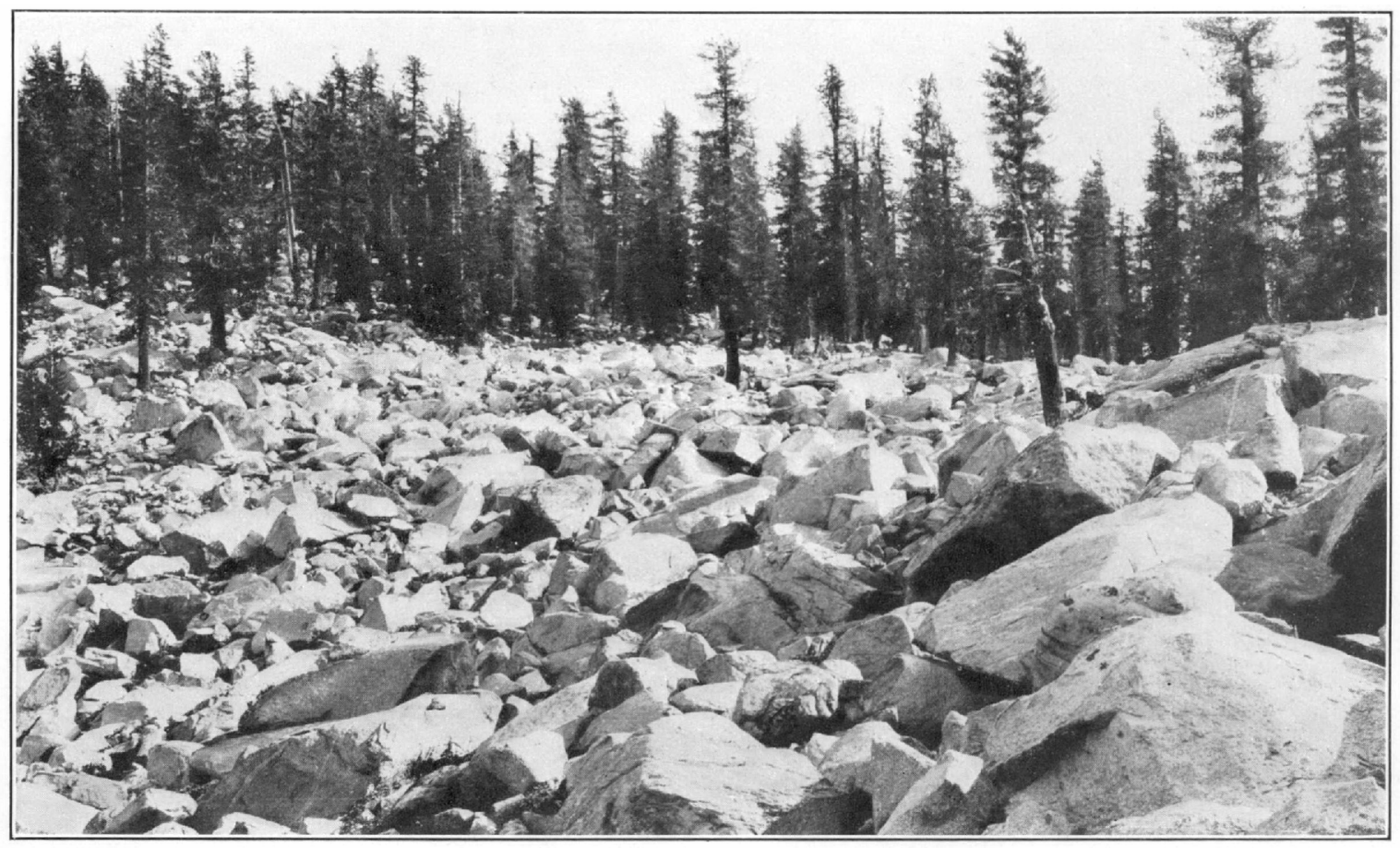

A. MQRAINE COMPOSED OF ANGULAR BLOCKS

This moraine lies on the edge of a glacial cirque on the west shoulder of Mount Hoffmann. The blocks have suffered hardly any wear in the short distance they have traveled and still have the sharply angular forms with which they were quarried from the cirque.

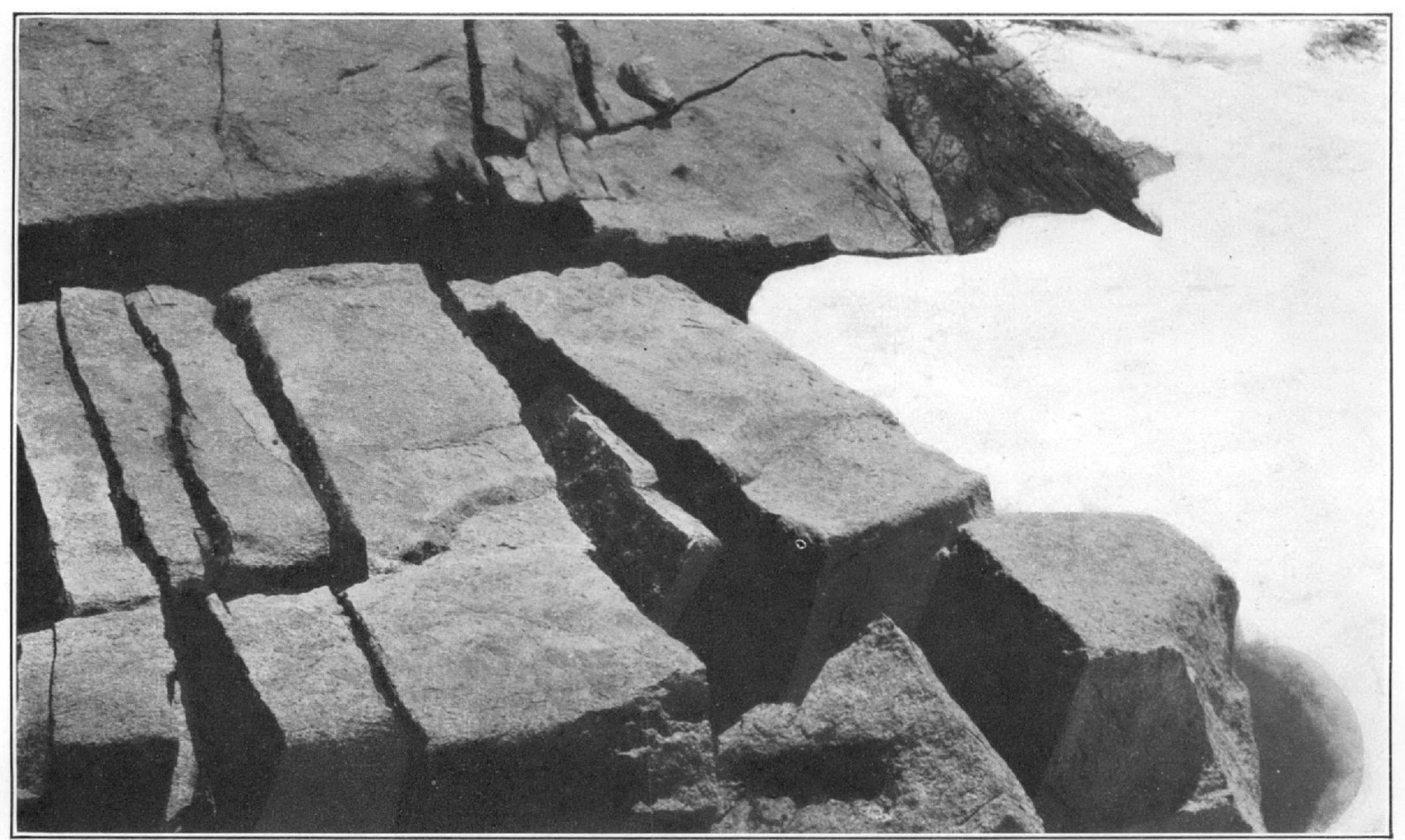

B. JOINT BLOCKS LOOSENED BY FROST

The large block was quarried by the glacier from the head wall of the cirque above Ostrander Lake. Frost has since split it into minor blocks. Many of the blocks quarried by glaciers are first loosened by frost. 


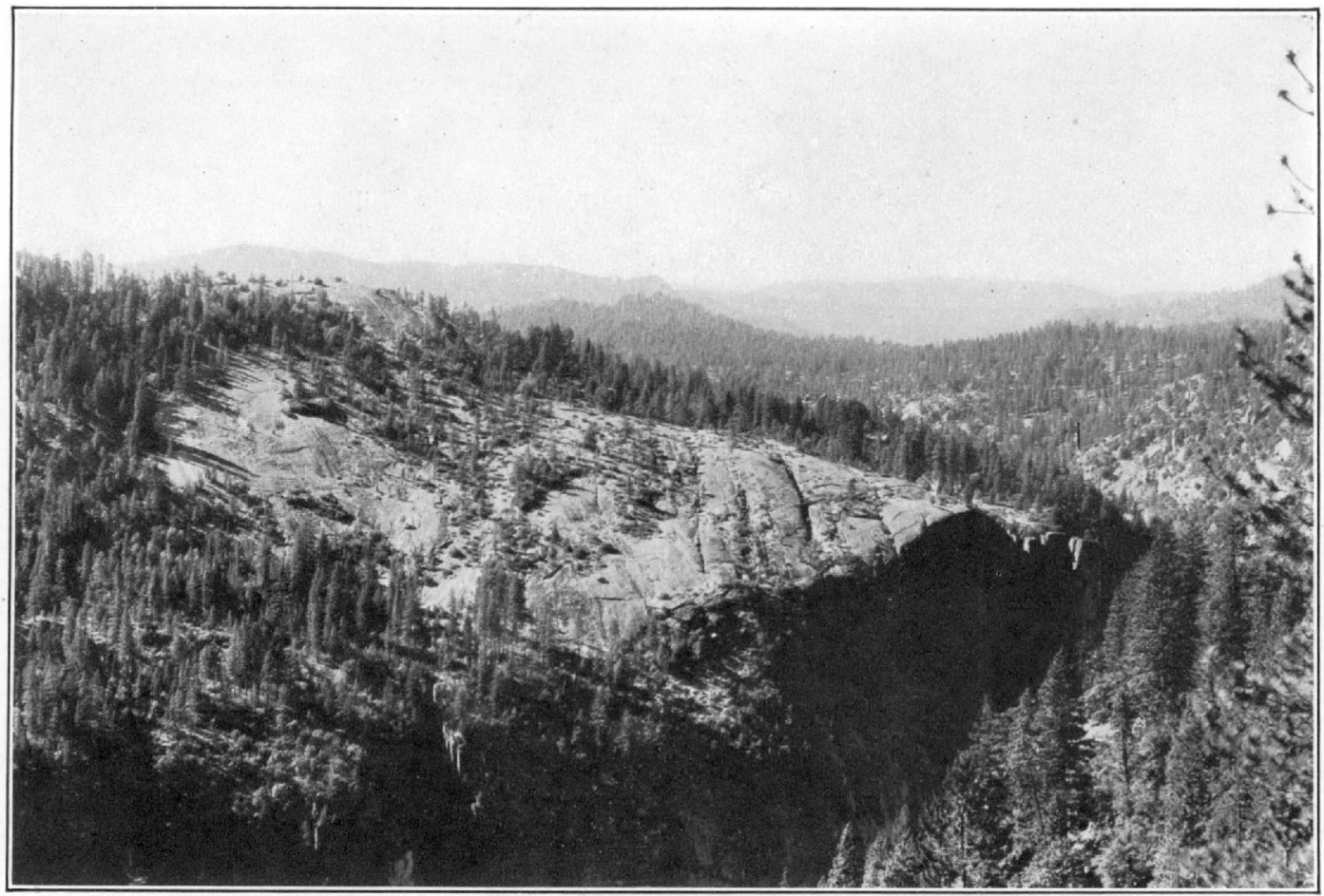

A. TURTLEBACK DOME AND MERCED GORGE BELOW YOSEMITE VALLEY

Turlleback Dome is composed of sparsely and imperfectly joimled granile. The uverrinling Yusemile (ilacier consecpuently found

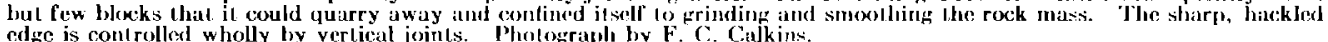

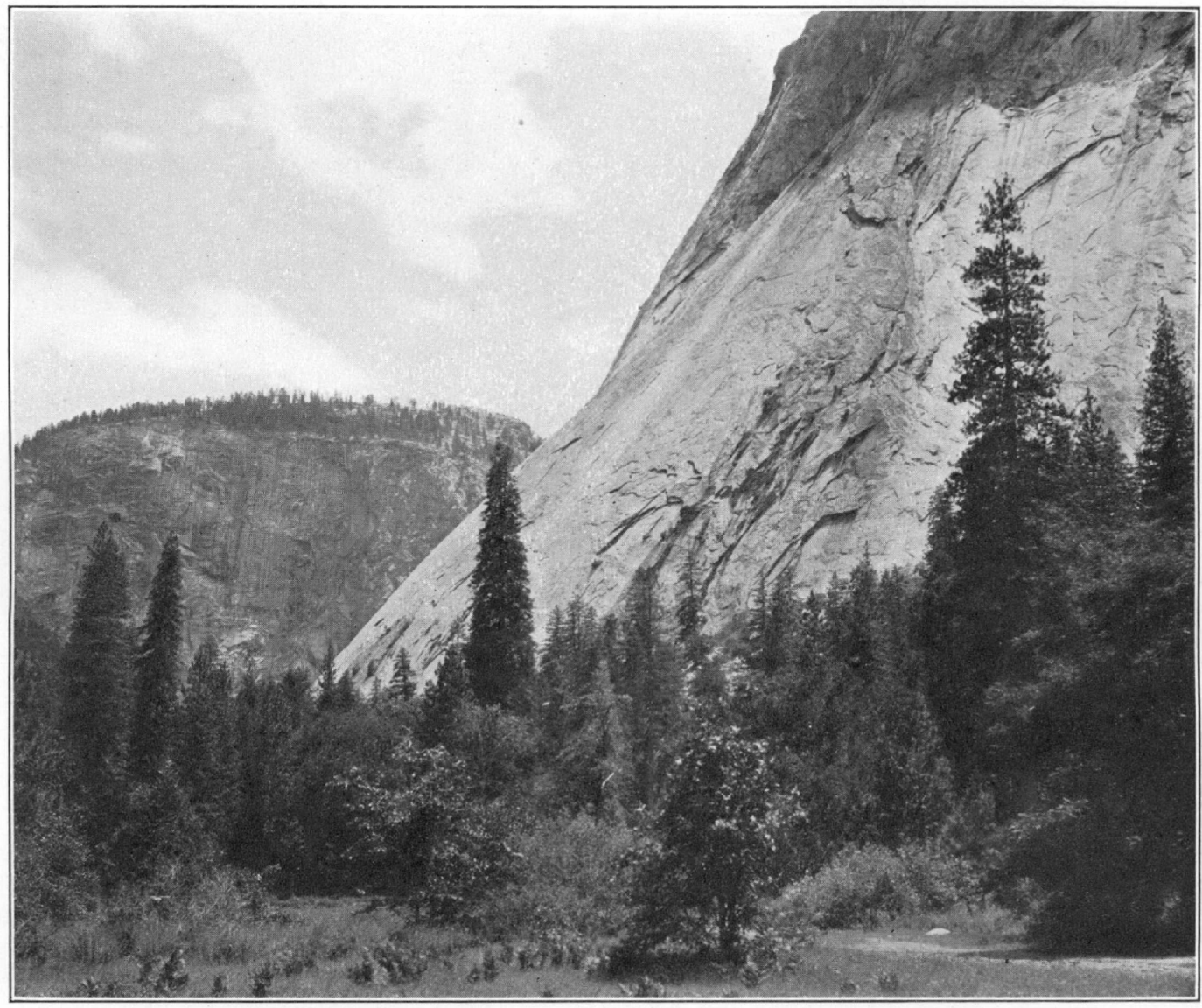

B. GLACIATIED ROCh MASS UNDPR GIACIER POINT

This rock mass, which was rounded off and smoothed hy the Yosemile Glacier and the confluent Mercel Glicier. consists of a singlr: huge monolith. undivided by fractures for a height of 1,600 feel. Like the domes, it is exfoliating-that is, casiling oll shells from its surface. 
precisely in those areas where the joint blocks are fairly large - from 5 to 25 feet to the side - that a powerful glacier may attain its greatest excavating efficiency, for every block it removes has great cubical content. And this explains why in regions of coarsely jointed rocks there is usually a vast difference between the amount of excavational work done by the great trunk glaciers and that done by the small tributary glaciers.

This brief analysis shows that the quarrying action of glaciers is inherently selective,especially in regions where the rocks are hard and tough. There its effectiveness is dependent in large measure upon the character of the rock structure--more specifically upon the spacing of the joints.

Bearing this in mind let us now briefly examine the jointing of the rocks of the Yosemite region and see in what manner it has affected the action of the glaciers.

THE KEY TO THE SECRET OF THE YOSEMITE'S ORIGIN

No one who gives the rock walls of the Yosemite, the Little Yosemite, and Tenaya Canyon more than a superficial glance can fail to note the marked variations that occur in their joint structure. Not only does the arrangement of the joints differ from place to place, but the spacing varies widely; in certain zones the joints are only a few inches apart, and the rock is shattered into small slabs or mere slivers; elsewhere and more commonly the intervals between joints range from a foot to a score of feet, so that the rock is divided into great angular blocks or thick sheets; and in still other places joints are altogether lacking for distances of hundreds and even thousands of feet, and the rock is wholly undivided. What is more, these variations are sometimes remarkably abrupt, so that structural extremes are brought into immediate juxtaposition. In few other regions where granitic rocks occur is there so great structural diversity or are sharp contrasts in structure so prevalent as in the Yosemite region.

Now the course of the Merced in its larger aspects is by no means related to or controlled by these structural vagaries in the granitic rocks. It must not be supposed that the river follows a belt of jointed rock and that the divides on both sides are composed of massive rock. Though it may be guided here and there for a short distance by a set of joints or by a master fracture, the Merced runs on the whole in disregard of the rock structure. The reason is that when the Merced first established its southwesterly course down the slope of the Sierra Nevada there still was a veneer of folded sedimentary rocks over the granite. It was not until later in its history that the river wore its channel down through the sedimentary rocks and in to the granite underneath. Then, being well intrenched and unable to deviate widely from its original course, it perforce had to cut the jointed and the massive rocks alike. The Merced is, indeed, what geomorphologists term a "superimposed" stream; and so are most of the other rivers on the western slope of the range. Therein lies the key to the secret of the origin of the Yosemite Valley and of all the other yosemites in the Sierra Nevada. Each of these capacious U-shaped valleys has been developed in an area of prevailingly fractured rocks in which the agents of erosion worked with comparative facility and in which the glaciers, when they came upon the scene, quarried with extraordinarily great effect. The narrow portals and gorges above and below the yosemites, on the other hand, are cut in bodies of prevailingly massive rock which the glaciers could not quarry and could reduce only by slow grinding.

These facts became evident to the author in 1905, while he was engaged in the topographic surveys for the map of the Yosemite Valley shown on Plate 7. The very task of delineating the cliffs in detail drew his attention to the relationship that exists between their sculpture and their inner structure. ${ }^{63}$ But the reason for the prevailingly close jointing in the area of the Yosemite Valley was not wholly clear until his colleague Frank C. Calkins in 1913 showed that the chasm is situated in an exceptional locality where many small bodies of relatively basic rocks-granodiorite, diorite, and gabbro-have been intruded into the otherwise vast, unbroken bodies of siliceous granite and monzonite that make up the central parts of the great Sierra batholith (see pl.51), also that these basic rocks are in general more closely jointed than the siliceous rocks.

Of course it is not possible now to determine exactly the original extent within the valley area of each of these masses of well-jointed basic rocks, as they are in large part removed by erosion. The rock floor of the valley, moreover, is hidden from view by a thick deposit of sand and gravel. However, numerous remnants of the basic rocks are visible in the walls and on the adjoining uplands, and from a detailed survey of these remnants it is possible to form some estimate of the original extent of the intrusive bodies and to appraise the effect they must have had on the quarrying action of the glaciers. Indeed, enough is known of the distribution and extent of the different bodies of jointed and of massive rock, respectively, to account satisfactorily for the development of all the major features of the Yosemite region-for the division of the Yosemite Valley into two broad chambers; for its peculiar spoon-shaped lower end and its equally peculiar square upper end; for the stepwise ascent of the giant stairway; for the breadth of the Little Yosemite and the depth of Tenaya Canyon.

CONFIGURATION OF THE YOSEMITE VALLEY EXPLAINED

The central part of the main Yosemite chamber has been excavated from a body of coarsely jointed grano-

63 Matthes, F. F., Sketch of Yosemite National Park and an account of the origin of Yosemite and Hetch Hetchy Valleys, pp. 30-38, Dept. Interior, 1912. 
diorite - the Sentinel granodiorite. (See appendix.) This rock extends directly across the valley in a belt about 2 miles wide. The Three Brothers and Taft Point mark its western margin; the Royal Arches and Glacier Point its eastern margin. (See pl. 51.) It is divided mainly by vertical and horizontal joints and hence has in many places a distinctly columnar or prismatic structure. This is evident especially in the columnar crags and pinnacles on the wall east of Union Point. In other places, especially in Sentinel Rock (pl. 19, $A$ ), it has a smoothly sheeted structure, the partings being nearly vertical. Almost throughout, therefore, this rock material is divided into blocks and sheets of large size - of a size, in fact, which the Yosemite Glacier during its higher stages could quarry with great efficiency.

From the vicinity of Taft Point west as far as the Cathedral Rocks diorite and gabbro predominate. These of all the rocks of the Yosemite region are the most thoroughly fractured; hence they must have been readily quarried by the glacier, even at times when it had only moderate volume. It is not surprising, therefore, to find that in the area of these rocks the south wall is embayed. Just how far into the valley these well-jointed rocks extended originally can only be surmised, but there is reason to believe that they occupied considerable space, for the valley here attains its greatest width, in spite of the fact that its north wall is composed of prevailingly massive granite.

The narrow portal between El Capitan and the Cathedral Rocks is, as might be expected, framed by promontories of exceptionally massive rock that could not be quarried by the glacier. The great prow of $\mathrm{El}$ Capitan consists wholly of this highly siliceous, massive granite-El Capitan granite it has been appropriately named. The Cathedral Rocks consist only in part of granite of this type and are traversed by numerous sheets and dikes of other igneous rocks, but they are nevertheless for the most part unfractured, the different rock materials in them being intimately welded together. But for this fact the whole promontory surmounted by the Cathedral Rocks and bearing the hanging gulch of Bridalveil Creek would probably have been quarried away by the glacier flush with the south wall of the valley.

The lower Yosemite chamber doubtless owes its great width to the ease with which the glacier quarried in the large bodies of well-jointed gabbro and diorite which extend throughout most of its length. Considerable masses of these dark-hued basic rocks still cling to the north side, west of the Ribbon Fall. Their unstable masonry, crisscrossed by numerous joints, has not remained standing in the form of a sheer wall but has broken down completely, producing the immense talus known as the Rock Slides, over which the Big Oak Flat Road is built.
On the south side glacial quarrying has been less effective, the bulk of the rock being El Capitan granite. As a consequence sheer walls and massive buttresses remain, but there are several recesses which show that the quarrying has been facilitated and guided locally by zones of intense jointing and shattering. The recess dominated by the Leaning. Tower is of this kind. It is entirely probable, further, that the abrupt increase in the width of the valley below the portal and the persistent southward trend of the wall extending from the Bridalveil Fall to the Leaning Tower are due in large part to the influence. exerted by the same zone of shattering on the glacial quarrying.

Significantly the lower Yosemite chamber contracts. abruptly west of the body of fractured gabbro and diorite, and the great barrier which incloses the spoonshaped lower end of the valley consists of massive El Capitan granite. The benches that flank the Merced Gorge as far west as the Gateway are composed of the same obdurate material, a fact which accounts for the narrowness of the gorge. Close examination shows, however, that this granite is not wholly massive but. traversed at long intervals by vertical and horizontal master joints. It is therefore really divided into blocks, but these were much larger than the glacier could dislodge. The ice merely rode over them, grinding their surfaces, as is strikingly revealed by the: smoothly curving shieldlike hump of Turtleback Dome, shown in Plate 43, $A$.

The lower end of the Yosemite Valley (pl. 16, $A$ ), though scenically unattractive, is of peculiar scientific. interest. Few other localities in the Yosemite region afford more striking evidence of the dependence of glacial quarrying upon the presence of favorable structures in the rock and of the comparative inefficiency of glacial abrasion in massive rock. Though the abrupt. contraction of the valley at its lower end might at first sight seem to indicate the place where the glacier usually terminated and beyond which it only rarely advanced, it marks in fact but the western limit of the quarriable rocks in the Yosemite Valley and the beginning of the unquarriable rocks along the Merced Gorge.

The lower end of the valley is of interest, further, because there a considerable share of the glacier's mass had to move upward in order to get out. The central portion of the glacier, of course, passed through the Merced Gorge without moving upward, but the flanking masses (fig. 22) rode up the rock slope at the end of the valley and surmounted the uneven benches that flank the gorge on both sides. Indeed, the deeper the glacier excavated the Yosemite Valley, the higher these ice masses had to climb in order to make their exit. Toward the end of the earlier stages of glaciation they had to climb 1,000 feet. 
This almost incredible ascent of the ice is attested beyond possible doubt by the striae and associated glacial markings on the rock slope, especially in the vicinity of Artist Point. It is by a fortuitous circumstance, really, that these markings which date back to the El Portal stage of glaciation remain preserved. They have been protected from the weather by a thin mantle of glacial débris and are now being brought to light again by the gradual washing away of the débris. They are, however, by no means plain and might readily be overlooked, for the rock surface, though smooth on the whole, is closely pitted owing to the etching out of the biotite crystals in the granite. Only on the feldspar and the quartz do bits of polish and striae remain, and it is only under a favorable light that they can be clearly recognized.

Of greatest value as indicators of the direction of ice movement are the so-called "chatter marks," of which a few can be distinguished here and there. These are fine curving tension cracks in the rock produced by heavy boulders that were dragged by the glacier, and they are invariably bowed upstream. Unfortunately, the finest series of these chatter marks are now destroyed, for the ledge on which they were situated was blasted out when the Wawona Road, near Artist Point, was widened for automobile traffic.

The upward movement of the ice thus indicated was induced by the contraction of the spoon-shaped lower end of the valley. It must have required a strong propelling force, but such a force was generated by the piling up of the ice at the head of the valley, where there was a great ice cataract, as will be explained more fully presently. From the head of the valley, in fact, the surface of the Yosemite Glacier sloped forward uninterruptedly, as is attested by the gradual descent westward of the lateral moraines. Evidently the ice mass did not buckle over the obstructing rock barrier at the lower end of the valley. (See fig. 22.)

The square-cut head of the Yosemite Valley is more puzzling than the spoon-shaped lower end. That it was quarried out in large part from jointed rock is not directly demonstrable but can only be inferred from circumstantial evidence. The Half Dome quartz monzonite, in which it is carved, is notably massive over large areas and gives rise to numerous domes. The inclosing walls are prevailingly massive. The Royal Arches (pl. 21, B), on the north side, have a sheeted structure, but the sheeting is of an unusually massive type. The wall at the head of the chasm, which seems to be crossed by a bewildering maze of fractures, upon closer study is found to consist largely of massive rock that is merely exfoliating-casting off scales from its exposed surface. The rounded conoidal mass which forms the basal part of the wall under Glacier Point (pl. $43, B$ ) is a gigantic monolith comparable for unbroken continuity with the prow of El Capitan.
It seems probable, nevertheless, that the rock excavated from the head of the valley was divided by many fractures and on the whole readily quarriable, for the Half Dome quartz monzonite, though locally massive, is extremely varied in structure, being in some places rhythmically jointed and elsewhere closely sheeted or even intensely shattered. This is readily observed in the Little Yosemite, in Tenaya Canyon-indeed, throughout the upper Yosemite region where the monzonite is the country rock. Several pronounced zones of shearing that must have penetrated deeply into the head of the valley are visible in its walls. One of these zones gives rise to the sharp recess that separates the Washington Column from the Royal Arches (pl. 21, B), and another is to be seen in the recess to the northwest of Grizzly Peak (pl. 16, $B$ ). A relatively broad belt of fractures that extends northeastward into Tenaya Canyon and facilitated the excavation of that canyon was prolonged in all likelihood some distance into the Yosemite Valley and must have facilitated its excavation also. But the strongest indication of the influence of fractures on the shaping of the valley head is found in the straightness and the orientation of the head wall. Only the presence of a north-south belt of fractures at the extreme head of the valley could have caused the quarrying glacier to produce so straight a wall trending in a direction unrelated to that of the ice movement. Had the rock been prevailingly massive, some parts of it would still remain projecting in the form of irregular salients. There is, further, indirect evidence of control by a north-south belt of fractures in the fact that at the south the wall terminates abruptly at the westward-trending zone of shearing which delimits the massive body of Grizzly Peak. This rock mass projects beyond the great façade, forming an obstruction which to the very last deflected the Merced Glacier and compelled it to twist itself through a narrow, tortuous gorge. All these facts and others of a similar nature would seem to warrant the conclusion that the: head of the Yosemite Valley was excavated from prevailingly fractured rocks and that it owes its peculiar square-cut form to the controlling influence exerted by local fracture systems on the glacial quarrying.

Three other facts of prime importance remain to be explained-the great depth to which the head of the valley has been excavated below the level of the preglacial gorge, a depth not less than 1,500 feet, it, would appear from the longitudinal profiles in Plate $27, A$; the steady decrease in the depth of glacial cutting from the head of the valley down to the lower end, where it measures only about 500 feet; and the scooping out of the basin of ancient Lake Yosemite in the rock floor of the valley. These matters, however, are all bound up with the question, How are the stairlike steps with basined treads characteristic of pro- 
foundly glaciated canyons produced? It seems best, therefore, to defer their explanation until that question has been answered.

\section{ORIGIN OF GLACIAL STAIRWAYS}

The giant stairway from whose main steps the Vernal and Nevada Falls descend, impressive though it may be, taken by itself, is after all only the beginning of a much longer stairway that extends throughout the upper Merced Canyon, from the Yosemite Valley to the base of Mount Lyell-a stairway 21 miles in length and making a total ascent of 7,600 feet. This fact is clear from the longitudinal profile shown in Figure 22. Some of the steps in that greater stairway are ill formed, none are as clean-cut as those at the Vernal and Nevada Falls, and nearly every one of them has a shallow basin hollowed out in its tread, yet the stairlike character of the canyon profile as a whole is unmistakable. Moreover, the floors of the main Yosemite and Little Yosemite are seen to constitute
Johnson ${ }^{64}$ believed that the glacial remodeling of a canyon is performed in large part by oft-recurring frosts, which split the rock and render its fragments available for removal, and that the glacier itself acts mainly as a transporting agent. Such frost action he believed to be sharply localized on the cross cliffs in the rock bed, because the glacier there breaks in its descent, and the crevasses permit the air, and with it the oscillations in temperature back and forth across the freezing point, to penetrate to the rock, whereas those parts of the rock bed which are covered by the unbroken body of the glacier are protected against such temperature changes. Each cross cliff would therefore be subjected to intense frost sapping, as he termed it, and in the course of time would be cut back by that process, receding gradually up the valley in the manner illustrated in Figure 32. Furthermore, hesupposed that the frost attacks the floor at the foot of thecliff as well as the cliff itself, and that its tendency therefore is to produce a nearly level or even slightly backward-sloping

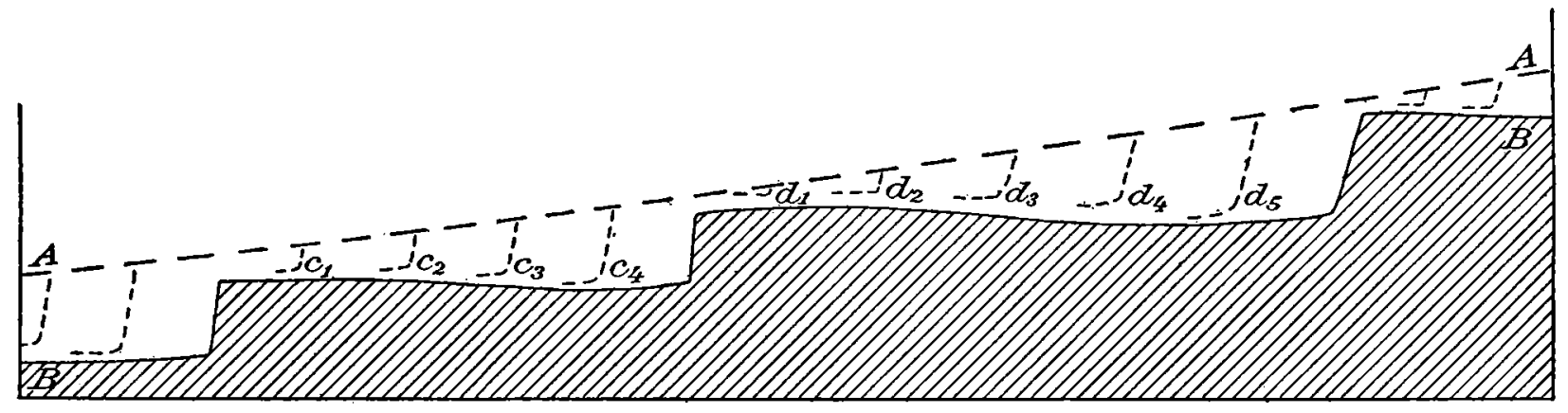

Figure 32--Longitudinal section of a canyon illustrating the process whereby, according to $\mathrm{W}$. D. Johnson, a glacial stairway would be produced by the recession of successive cross cliffs. $A A$ represents the profle of the preglacial canyon floor; $B B$ that of the glacial stairway. A cross cliff such as $c_{1}$ would be cut back by intense frost action at the foot of crevasses in the glacier, thus receding in the course of time to the successive positions marked $c_{2}, c_{3}$, etc., and leaving a flat or slightly basined tread. Meanwhile another cross cliff, $d_{1}$, situated at a higher level, would recede headward to the successive positions marked $d_{2}, d_{3}$, etc. The steps of a glacial stairway, according to this conception, would be essentially migrant features that would shift their positions rather rapidly while the glacial processes were active, regardless of the structure of the rock. Compare with Figure 34

treads in that greater stairway. They do not differ materially from the other treads save in their greater length and in the fact that the basins in them are completely filled with stream-borne sediment, whereas on the upper treads the basins are filled only in part. The rock floor of the Yosemite Valley really comprises two treads differing but slightly in altitude-a short one in the lower chamber and a long one in the upper chamber. The rock sill on which the moraine dam at the El Capitan Bridge rests forms the edge of the upper tread.

Such stairwise ascent by successive steps has long been recognized as a characteristic feature of strongly glaciated canyons, but the precise nature of the process whereby such canyon steps are produced is still a moot question. Several different hypotheses have been offered in explanation, but only two need be here outlined-those of Willard D. Johnson and E. C. Andrews, both of whom, it is of interest to note, were led to their conclusions largely through observations made in the Sierra Nevada. stretch in the place of the original steeply graded canyon floor. With continuance of the process each of these nearly level or ponded stretches would be extended headward as the cross cliff above it receded and at the same time would be cut off at its lower end by the recession of the cross cliff below, and thus the canyon floor would eventually acquire a stairlike character. It is only fair to Johnson to add that he himself later abandoned this hypothesis, realizing that crevasses do not as a rule reach down to the bed of a glacier. A short time before his death he announced to the present writer that he was "about to make a violent attack on the Johnson frost-sapping hypothesis," but unfortunately he did not carry out his plan.

Andrews, ${ }^{65}$ on the other hand, supposed the cross cliffs to recede primarily as a result of the quarrying

of Jobnson, W. D., The proflle of maturity in alpine glacial erosion: Jour. Geology, vol. 12, pp. 569-578, 1904; The grade profile in alpine glacial erosion: Sierra Club Bull., vol, 5, pp. 271-278, 1905

65 Andrews, E. C., An excursion to the Yosemite (California), or studies in the formation of alpine cirques, "steps," and valley "treads": Roy. Soc. New South Wales Jour, and Proc., vol, 44, pp. 262-315, 1910. 
action of the glacier, which, he argued, must be particularly effective at the edge of each step, as the blocks there are unsupported on the downstream side. The tendency to excavate a basin in each tread he explained as being due chiefly to the great vigor with which the ice cascading from the step above abrades the rock bed at its foot.

According to both of these hypotheses, it is to be noted, the cross cliffs, or steps, would recede headward with some rapidity while glaciation was in progress. They would be essentially unstable, migrant features. The long basined rock floor of the Yosemite Valley would have resulted from the headward recession of a single cross cliff over a distance of 7 or 8 miles. Originating, presumably, as a low inconspicuous break in the floor near the lower end of the valley (a short distance below the constriction between El Capitan and the Cathedral Cliffs, Andrews thought), this cross cliff would have gained progressively in height as it receded almost horizontally into the steeply rising bottom of the preglacial canyon. According to Andrews's conception the cross cliff "must have been at least 2,000 feet in height" when it reached a point opposite the hanging valley of Yosemite Creek and, under the powerful erosive action of the great ice cascade that poured over it, it was cut back so rapidly that "the glacial energy had no time in which to excavate deep basins * * * but merely formed a huge tread with relatively shallow basins upon it." On passing Glacier Point the great cliff split into two parts, one part receding into Tenaya Canyon, the other along the course of the Merced, where it resolved itself into the flight of the giant stairway just before the ice age came to an end. ${ }^{66}$

It does not seem probable, however, that the glacial remodeling of the Yosemite Valley took place in just that way. The steps of the giant stairway can scarcely be migrant features that have reached their present positions by headward recession through distances of several miles and that would, by implication, promptly resume their rapid headward march if glaciation were renewed. They are composed not of fractured rock that would be readily quarried by a glacier or broken up by frost action but of massive rock that is scarcely susceptible either of being quarried or of being split by frost. The cliff over which the Vernal Fall leaps (pl. 24) consists of a monolith unmarred by a single fracture throughout its height of 300 feet or its breadth of 600 feet. The cliff of the Nevada Fall (pl. 25), which is twice as high and

\footnotetext{
60 Andrews, E. C., op. cit., pp. 312-313
}

twice as broad, consists of massive rock for a height of about 400 feet from its base, and its upper portion is divided by only a few nearly horizontal fractures spaced from 50 to more than 100 feet apart.

It is significant, further, that all the other steps in the upper Merced Canyon have risers and sills composed of very sparingly jointed or wholly massive rock. Indeed, observations carried over a considerable part of the Sierra Nevada show that the same holds true for all canyon steps carved from its granitic rocks. Even in the areas of sedimentary and volcanic rocks the canyon steps have as a rule sills of more than ordinarily resistant materials. Particularly instructive in this regard is the flight of steps in Bloody Canyon, on the east flank of the Sierra Nevada, which is composed of a variety of rocks, sedimentary, volcanic, and granitic. In nearly every step the slightly raised edge or sill, from whatever material it may be hewn, is associated with a constriction in the canyon section due to the resistance offered to glaciation by the same obdurate rock in the sides of the can-
URE 33.-Longitudinal section of a typical roche moutonnée fashioned by a glacier from an obdurate mass them smoothed and gently curved, and it subjected the downstream face to quarrying mainly, leaving it hackled side, there would have resulted an asymmetric dome, smoothed on all sides but steeper on th massive granite is the small nameless dome that stands in the Little Yosemite about half a mile northeast yon. Such a constriction is to be seen at the Vernal $\mathrm{Fall}$; and another is to be seen at the top of the giant stairway, where the mouth of the Little Yosenite is partly blocked by the obdurate masses of Liberty Cap and Mount Broderick. The treads, on the other hand, are almost invariably broad. They are the broadest parts of the canyons and, with their embayed sides and concave floors, constitute roughly spoon-shaped basins situated at successive levels one above another.

It must be clear to anyone who considers these facts that rock structure, or, more broadly, rock resistance, plays an important part in the development of canyon steps by glaciation; that, indeed, it determines in large measure at what points in a given canyon the individual sills and treads shall develop. That being so, it follows that no hypothesis that aims to explain the production of glacial stairways can be considered satisfactory that fails to take into account this influence of rock resistance. Accordingly, a new 
explanation suggests itself-an explanation that is in harmony with the principle of selective quarrying already laid down.

Briefly stated, this new explanation is as follows: In a canyon or valley cut in granitic rocks of widely varying structure such as prevail in the Sierra Nevada, a glacier is bound to excavate with locally varying efficiency; where the rock is massive or only sparsely divided by fractures, the glacier, being unable to disrupt the rock, can reduce it only by abrasion-a slow and relatively feeble process; on the other hand, where the rock is plentifully divided by natural partings, the glacier will quarry out entire blocks and excavate at a fairly rapid rate. ${ }^{67}$ From the first, therefore, it will tend to work irregularly, producing hollows in the areas of jointed rock and leaving obstructing humps in the areas of massive, unquarriable rock. The humps, however, will tend to assume strongly asymmetric forms, gently sloping and smooth on the upstream side, abrupt and more or less hackly on the downstream side, for, as will be seen in the diagram in waves a few feet high to canyon steps a thousand feet high, and there the inherent kinship of all these features is readily manifest to one who takes the trouble to compare them with one another.

A typical example that is intermediate between a mere roche moutonnée and an entire canyon step and is readily accessible for inspection is the abrupt rise in the canyon floor halfway between the Vernal Fall and the Nevada Fall, which was the site of the historic hostelry known as La Casa Nevada. It has been referred to as the second step of the giant stairway, but it extends really only part of the way across the canyon. The trail leads steeply up to the top of the sill through a notch in the downstream face, which is determined by strong vertical master fractures, and then it leads down again along the gentle back slope of sparsely fractured granite.

The manner in which the basined treads of a glacial stairway are evolved will be most readily understood if the treads are viewed in reference to the slope of the preglacial canyon floor. If the diagram in Figure 34

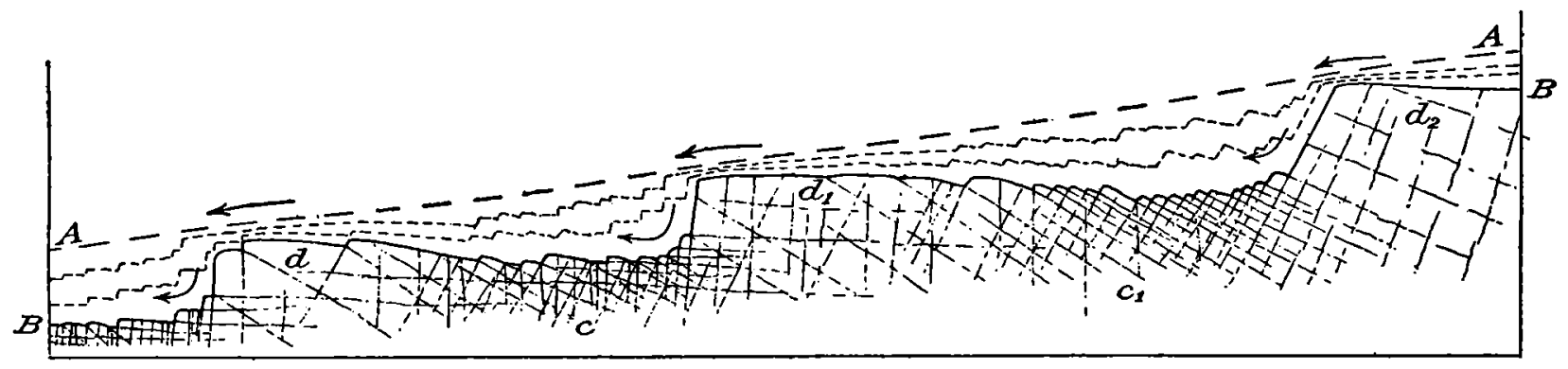

FIGURE 34.-Longitudinal section of a canyon illustrating the mode of development of a glacial stairway by selective quarrying. $A \boldsymbol{A}$ represents the profle of the preglacial canyon floor; $B B$ that of the glacial stairway. Bodies of closely jointed rock, such as $c$ and $c_{1}$, are readily quarried out by the glacier, but bodies of sparsely jointed, unquarriable rock, such as $d$ and $d_{1}$, being reducible only by abrasion, remain standing as obstructions with flattened and smoothed tops and steep, more or less hackled fronts. The broken lines indicate successive stages in the development of the steps and treads. The arrows indicate the direction of ice movement

Figure 33, the force of the ice is directed at an angle against the upstream side and so subjects it to intense abrasion; and the force is directed at a small angle away from the downstream side and so exerts there a pull favorable for quarrying.

The smaller knobs of this asymmetric type have come to be known by the quaint name "roches moutonnées," which was given to them by the Swiss mountaineers because, when viewed from up the valley, their rounded forms suggest the backs of grazing sheep. That they owe their peculiar modeling to abrasion on the upstream side and quarrying on the downstream side is quite generally recognized, but that the larger obstructions which occupy the entire breadth of the canyon floor and form the sills and edges of the steps are shaped in essentially the same way appears not to be generally understood. In the upper Yosemite region and the adjoining parts of the High Sierra, however, moutonnée forms of all sizes abound, ranging from mere hillocks and rock

\footnotetext{
67 This simple statement, the writer realizes, does not cover all the multifarious conditions that really affect glacial action in diversely structured rocks and needs qualification in several particulars, but it is not desired, nor is it necessary, here to go into a detailed analysis.
}

is so tilted as to make the preglacial canyon floor appear horizontal, the treads will assume the aspect of basins that are strongly asymmetric, being deepest at their upper ends. They are so shaped manifestly because the ice erodes with greatest vigor at their upper ends; it is thicker there than at their lower ends, descends into them with plunging motion, and at the foot of its cascade is compelled to make an abrupt turn, as is indicated by the arrow-circumstances all of which cause the ice to exert particularly great pressure on its bed. Downstream, of course, the pressure diminishes progressively, reaching a minimum at the edge of the step.

Treads are shaped both by quarrying and by abra sion, but it is a fair presumption that the quarrying process is dominant wherever the rock is jointed and the glacier has sufficient power to dislodge the blocks. In Figure 34 several stages in the evolution of a tread are shown in order to bring out the fact that, as the quarrying proceeds, always in the headward direction, numerous minor cross cliffs controlled by joints are likely to be developed. But these are only temporary hackles in the canyon floor that migrate 
headward and are eliminated in the course of time. The main canyon steps, on the other hand, are seen to be fairly stable features that are cut back only very slowly, their sills and risers being composed of the more massive and therefore more obdurate rock. Likewise they are worn down very slowly-mainly by abrasion-and the sill of each step therefore controls the general level of the tread back of it. No other hypothesis advanced hitherto has explained what determines the level at which a tread shall be developed.

It is evident, further, that the process is a selfintensifying one, which constantly tends further to accentuate the stairlike profile of the canyon. For the greater the depth of excavation at the foot of a given step becomes the more powerful will be the glacial action there. The limits to which the process can go in any locality are determined, of course, by the force of the glacier, the length of time it is active, and the resistance of the rocks. Finally, there is no inherent tendency in the process to produce level or nearly level treads; it works regardless of gradients. It may produce treads that are approximately level, or that platform at the west base of Half Dome-the platform above the head wall of the valley-that generated most of the power. (See fig. 35.)

During each of the earlier ice floods the Merced Glacier and the Tenaya Glacier swelled to such great volume that they coalesced into one vast ice field above which only the crown of Half Dome was visible. At those times the ice covered the platform overlooking the head of the valley to a depth of fully 1,000 feet and thence plunged in the form of a mighty cataract, a glacial Niagara. During the last ice flood, which had relatively moderate volume, the two glaciers did not coalesce over the platform but made separate entry into the Yosemite Valley, each through its own portal. The Merced Glacier then descended wholly by way of the giant stairway and the gorge below. Figure 35 affords an impressive comparison of the mighty ice cataract that plunged over the head wall and the relatively modest ice cascades that tumbled from the steps of the giant stairway.

From the longitudinal profile in Figure 35, it is clear further, that even at the beginning of its career the

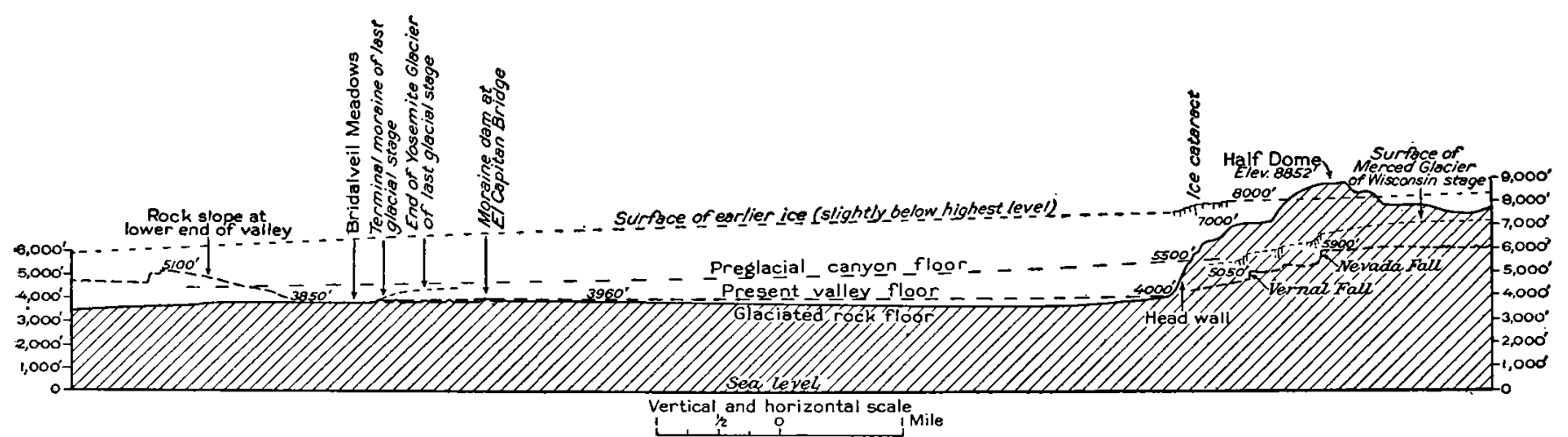

FIGURE 35.-Longitudinal section of Yosemite Valley showing the depth of glacial excavation, which increases headward to a maximum of about 1,500 feet; also the head wall and the platform above, whence the earlier ice plunged in the form of a great cataract. For comparison there is shown the relatively small cascade by which the Merced Glacier of the last ice stage descended from the giant stairway. Vertical scale same as horizontal scale

have a gentle slope, either forward or backward, or that have one or several basins scooped out in them, all depending upon the structure of the rocks involved and the degree to which that structure controls the glacial action.

\section{APPLICATION TO THE YOSEMITE VALLEY}

When this conception of the way in which glaciers produce stairlike steps in canyons is applied to the Yosemite Valley, it will be readily seen that the basined rock floor of that valley is a typical canyon tread excavated in a long stretch of prevailingly well-jointed rocks dominated at its head by a large body of massive granite from which the ice plunged down abruptly; also that the great depth of glacial excavation at the head of the valley-about 1,500 feet-is due primarily to that plunging movement. But it was not the descent from the giant stairway that endowed the ice with its great excavating power; the energy which the ice derived from that descent it expended largely in excavating the narrow gorge immediately below the stairway. It was the much greater plunge from the great ice cataract made a descent of not less than 1,500 feet, the platform from which it plunged having an altitude of about 7,000 feet and the preglacial gorge of the Merced River below an altitude of about 5,500 feet. Of course, the descent at first was not nearly so abrupt as it grew to be later, after the valley head had been enlarged by glacial quarrying and the head wall had acquired a steep profile; still the descent was abrupt enough to cause the ice to break and to develop considerable power. (See fig. 15.) As the valley head was excavated to greater and greater depth-the platform above, meanwhile, being worn down but little-the height of the cataract was increased to 2,000 feet and finally to more than 2,500 feet.

The great depth of glacial excavation at the head of the Yosemite Valley is thus amply accounted for; at no other place was there an ice cataract so high and so powerful. Nevertheless, the work is not all to be credited to the ice cataract. A considerable share must have been performed by glacial action of a less spectacular type. During the long periods of moderate 
ice supply that preceded and followed the maxima there was not ice enough to produce a cataract, and the Merced and Tenaya Glaciers, entering the valley by separate portals, eroded each its own pathway as far down as their junction. Later, after the spur at the head of the valley had been cut away, these glaciers debouched directly into a great ice pool that occupied the valley head, their currents meeting to form one central current of great eroding power. The depth of ice at the point of junction was always considerable. It amounted to about 1,500 feet even during the last glacial stage, when the Yosemite Glacier reached no farther than the Bridalveil Meadow. The transformation of the valley head is therefore to be regarded as having been brought about by glacial action of different kinds, that of the plunging ice cataract being the most powerful though not the most lasting.

It remains to account for the remarkably clean-cut forms of the steps of the giant stairway. These steps have remained standing because they are composed of massive, unquarriable rock. Yet all three have conspicuously sheer, smooth fronts, or risers, and welldefined, straight edges clearly indicative of quarrying controlled by joint fractures. Close examination of the steps reveals, indeed, that the risers of all three are controlled by vertical master joints. The step at the Vernal Fall affords the simplest case; its riser coincides with a single joint plane, belonging to the northwestward-trending system which prevails in many parts of the Yosemite region. This fact explains not only the verticality and straightness of the riser but also its orientation diagonally across the canyon, in disregard of the direction of ice movement. The riser of the second step-the one above the Diamond Cascade-owes its orientation, also at an angle to the axis of the canyon, to a master joint of the northeastward-trending system. As is obvious from the contouring on Plate 7, this step is directly alined with the narrow gash between Liberty Cap and Mount Broderick, which has been cut along a zone of northeasterly joints. The step from which the Nevada Fall leaps is not so obviously controlled by a master fracture as those just described, for the lower portion of its riser slants at a considerable angle to the vertical and is composed of massive, exfoliating granite. But the upper portion has a verticality and straightness that could not possibly have been produced by the adventitious breaking of massive rock under the stresses imposed by a cascading glacier. Besides, it trends northeastward, roughly parallel to the riser of the second step, and thus it also appears to have been controlled by a master joint of the northeasterly system.

The explanation of the clean-cut character of these three steps is, then, that although the steps themselves are composed of massive rock, there was formerly in front of each of them a body of vertically jointed or sheeted rock that was readily quarried by the glacier. In other words, at each step the glacier quarried directly up to the massive rock. To the cliff of the Vernal Fall, notably, there still clings a large fragment of a vertical rock sheet that tells the story clearly.

\section{DEVELOPMENT OF THE LITTLE YOSEMITE VALLEY}

The position of the Little Yosemite at a level 2,000 feet above the main Yosemite, which gives it the appearance of a hanging valley, although it is in fact the path of the master stream, seems no longer anomalous in the light of the foregoing explanation of the development of glacial stairways. Its nearly level floor is one of the treads in the long glacial stairway that extends throughout the upper Merced Canyon. The general level of that floor was determined mainly by the sill of massive granite at the mouth of the valley - that is, by the top of the body of granite from which the precipice at the Nevada Fall is hewn. So exceedingly resistant to glaciation was that body of massive rock that it has been worn down only about 250 feet below its preglacial level. (See pl. 27, A.)

However, not only the mouth of the Little Yosemite but a large share of its floor appears to be composed of massive granite which the glacier found difficult to excavate. In the few places where the floor is not concealed by sand and gravel, as in the vicinity of the Sunrise Trail and opposite Sugar Loof, it is seen to be made of massive granite; and throughout most of the valley the cover of sediment is so thin that the crests of the small frontal moraines left by the Merced Glacier (see pl. 29) project above it.

The great breadth of the Little Yosemite, on the other hand, was produced, unquestionably, by effective lateral quarrying in masses of well-jointed rock. The lower half of the valley, which is almost as broad as the Yosemite itself, probably was broad even in preglacial time, for its sides have only moderate declivity; but this statement does not invalidate the preceding one-it rather implies that the glacial as well as the preglacial processes of erosion were favored in lateral cutting by the prevailingly fractured condition of the rock.

The two bosses that obstruct the mouth of the Little Yosemite-Mount Broderick and Liberty Cap-have survived the onslaughts of the glacier by virtue of the exceedingly resistant nature of their massive rocks. Rounded and smoothed on the up-valley side (pl. 44, $A$ ), sheer and angular on the down-valley side (pl. 44, $B)$, they are typical roches moutonnees, but they are so enormous compared with most knobs of that kind that it would seem more appropriate to liken them to elephants than to sheep. Liberty Cap stands nearly 1,000 feet above the floor of the Little Yosemite; Mount Broderick about 600 feet. 


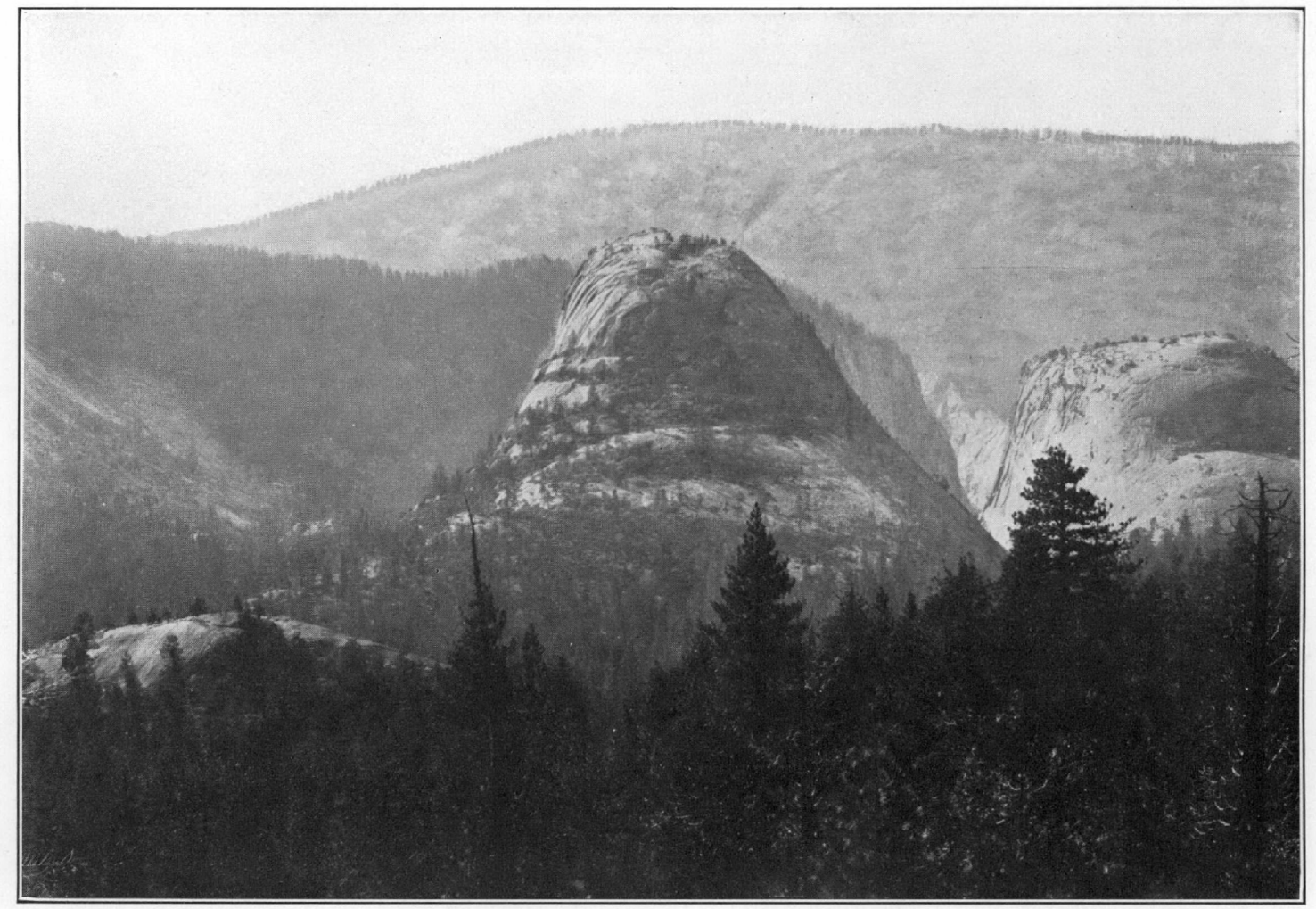

A. REAR VIEW OF LIBERTY CAP AND MOUNT BRODERICK

Their curving hacks and crowns were ground and polished by the overriding Merced Glacier. Both rock masses are roches moutonnées of gigantic size.

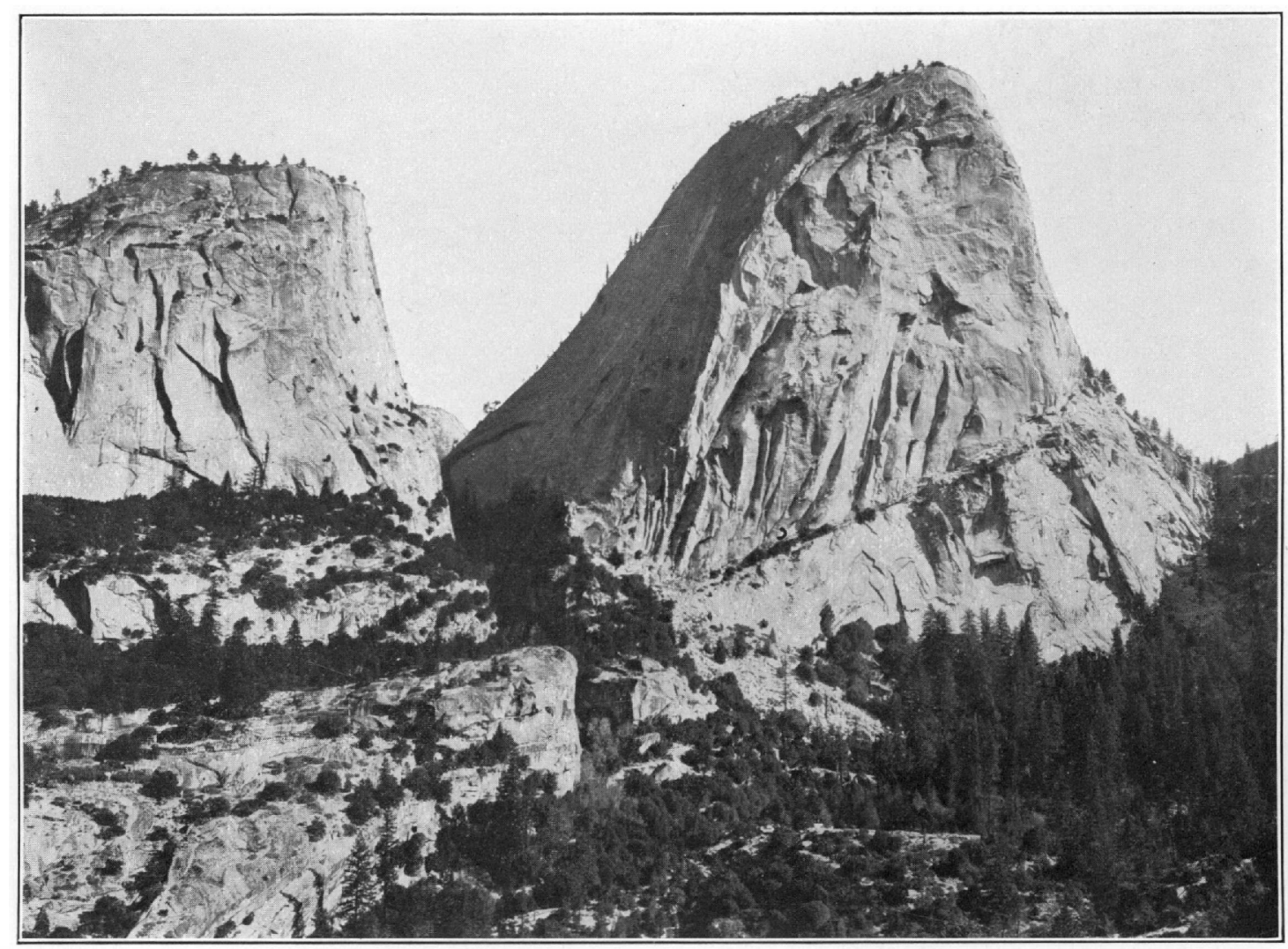

B. FRONT VIEW OF LIBERTY CAP AND MOUNT BRODERICK

Their sheer, hackly fronts were subjected to the quarrying action of the Merced Glacier. The V-shaped cleft between them was gouged out along a narrow zone of shattered rock. 


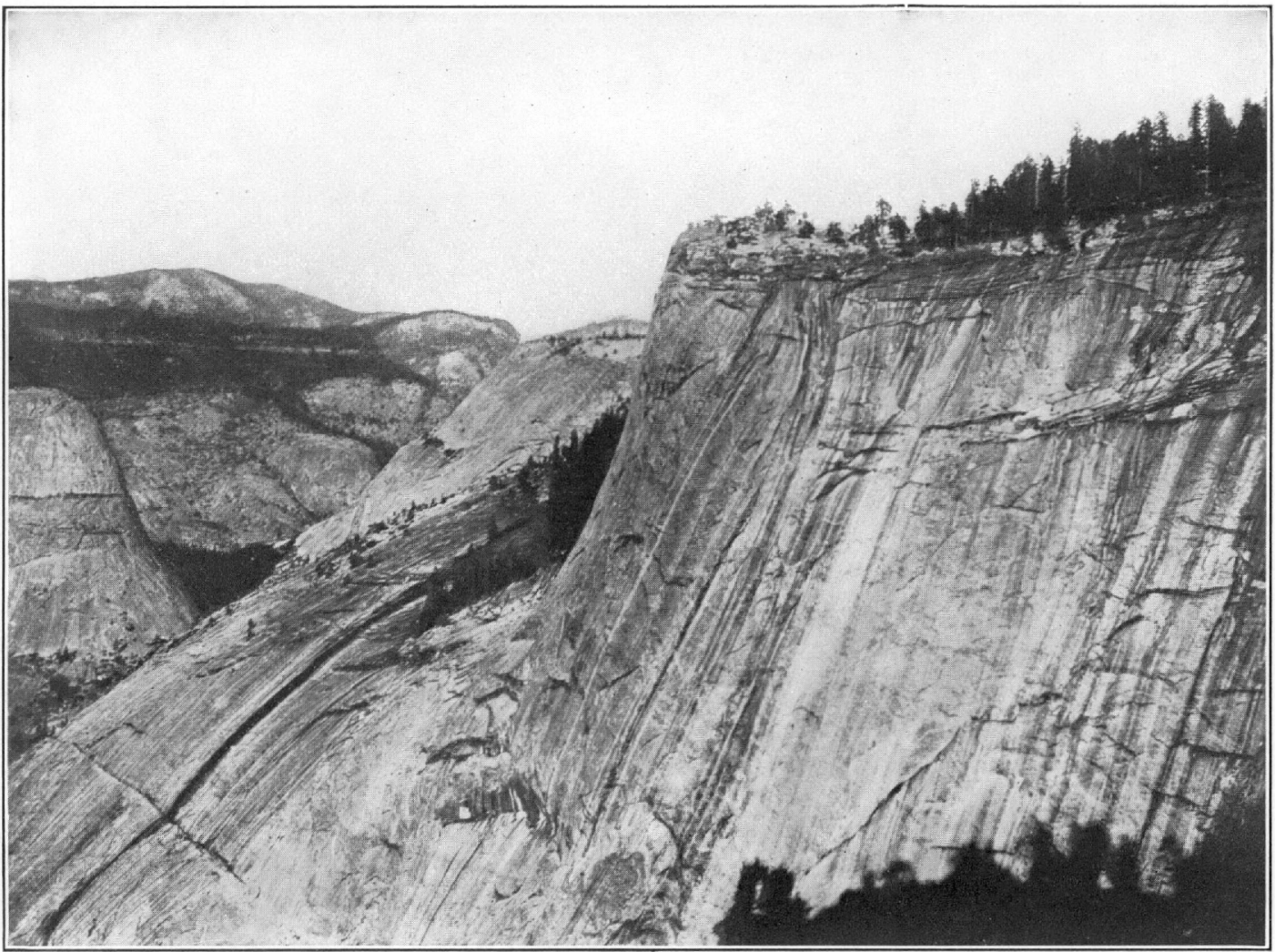

A. CASCADE CLIFFS, IN LITTLE YOSEMITE VALLEY

In fow other places in the Yosemile revion is the granite more continuously massive than in the Cascade Cliffs. Only one horizontal master joint divides the rock (in the lower left-hand corner of the view). 'The scales on the clifts are merely surficial feat ures due to exfoliation. The dark streaks indicale the paths followed by the ribbon cascades, which descend from the
spring, when the snow is molling, and from which the clifts take their nimuc. In the hackground is Sugar Loaf.

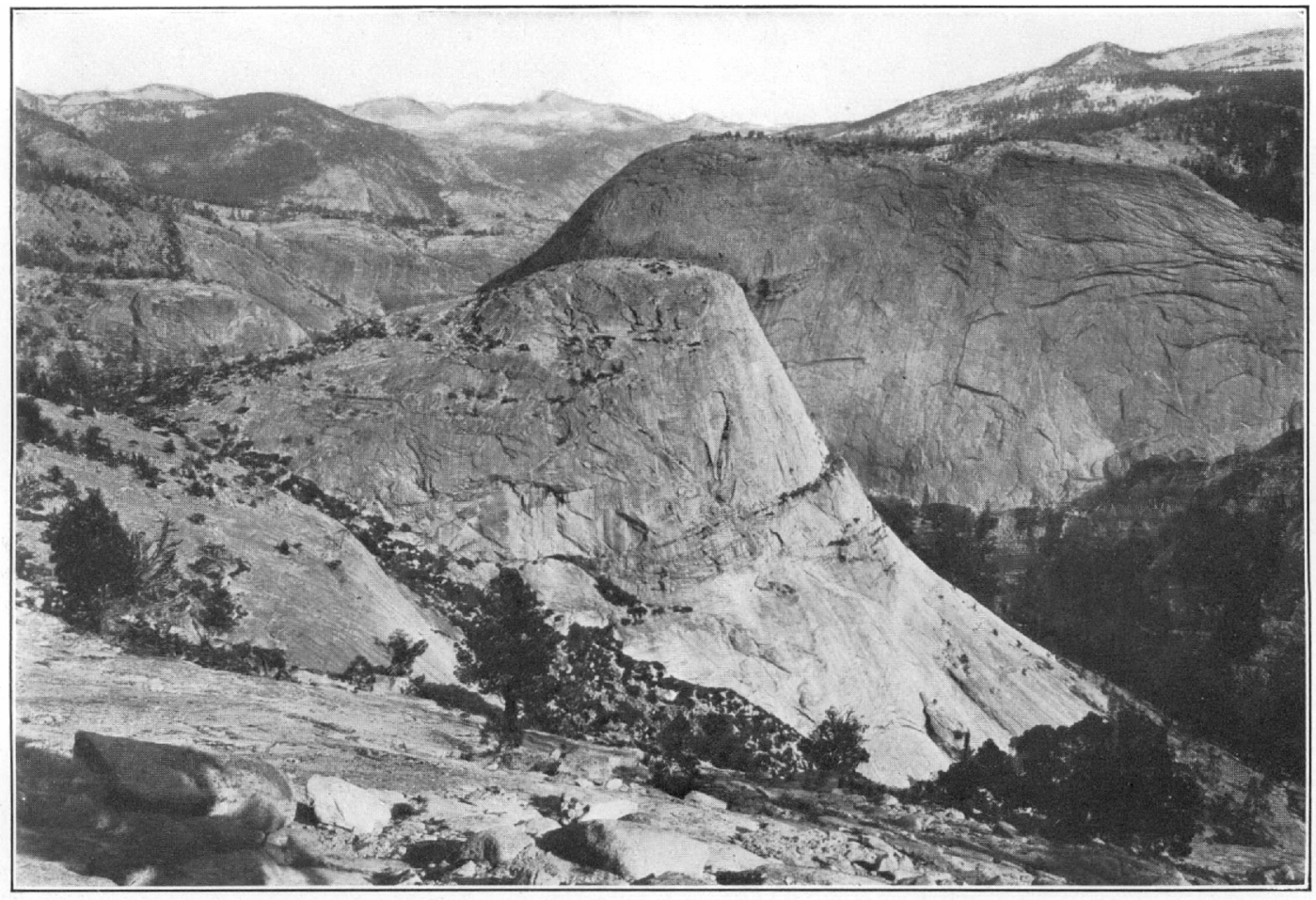

b. SUGAR LOAF AND BUNNELL POINT, FROM MORAINE DOME

Viewed from this angle Sugar Loaf is seen to be a dume-crowned spur of the north wall of the Little Yosemite Valley. It has been repeatedly overridden hy the Merced Glacier but has escaped destruction because it is composed largely of massive rock. Beyond is the exfoliating cliff of the promontory known as Bunnell Point, and to the left of it, in the distance, are the icesmoothed rock beuches that flunk the upper gorge of the Merced. 
That Mount Broderick consists essentially of one great monolith is evident at a glance, but the massive nature of Liberty Cap is not perhaps so readily apparent. Its rounded back is cut by several horizontal master joints, and its sheer front is hackled by a series of nearly vertical fractures that begin at a prominent shear plane near the base (pl. $44, B$ ); still, a study of the boss in its entirety leaves little doubt that none of the joints and fractures mentioned penetrate far into its interior. They are indicative, rather, of structural features that traversed the rock which formerly enveloped Liberty Cap and which has been quarried away by the glacier.

The control exerted on the glacial quarrying by fractures in the surrounding granite is clearly revealed also in the sheer fronts and equally sheer sides of the two bosses. As a glance at Plate 7 will show, their fronts are controlled in the main by northwestwardtrending fractures and their sides by northeastwardtrending fractures.

It is manifest, further, that the narrow cleft which separates Mount Broderick from Liberty Cap has been gouged out along a zone of northeastward-trending fractures. Its sharp $V$ shape might seem suggestive of stream erosion rather than of glacial action, yet there can be little doubt that this cleft is a product mainly of selective quarrying. Prior to the ice age, probably, Mount Broderick and Liberty Cap formed part of a continuous ridge, or spur, that projected southeastward from the base of Half Dome. Instead of a cleft there was then only a shallow saddle from which ravines descended in opposite directions. The Merced Glacier, when it overtopped the ridge, naturally singled out the unresistant, slivered rock in the narrow zone and quickly deepened the saddle to an acute notch. Though downward its excavating action was facilitated by the fractures, sideward it was restrained by the massive, unquarriable bosses, and so perforce the glacier gave rise to a strikingly unglacial-looking cleft. Its scorings remain displayed on the smooth walls of the cleft, most vividly on the side of Mount Broderick.

Running water doubtless has played some part in the cutting of the cleft but only a minor part. Whenever the Little Yosemite was filled with ice as far down as its mouth, some water must have escaped through the unfinished notch, supplementing the glacier's action in a feeble way. And when finally it was cut down to the floor of the valley, the cleft probably became the temporary channel of a larger stream derived from the melting glacier. To-day it is traversed by only an insignificant streamlet-that which issues from the spring-fed pool known as Lost Lake.

At the south base of Liberty Cap is another, smaller cleft, or gorge-namely, that through which the zigzag trail leading to the Little Yosemite is laid. This gorge also dates back to glacial time, but as it belongs to a subordinate class of sculptural features which are appropriately treated together, its explanation will be deferred to another place (p. 113).

The upper half of the Little Yosemite is narrower and steeper sided than the lower half, because in it lateral quarrying by the glacier was impeded by flanking bodies of massive rock. The walls of this part of the valley are exceptionally massive; few cliffs elsewhere in the Yosemite region exhibit a more complete absence of fractures. In the Cascade Cliffs, for instance (pl. $45, A$ ), the rock is divided by only one approximately horizontal master joint at a height of about 600 feet from the base, and under Bunnell Point (pl. 45, $B$ ) the wall is unmarred by a single fracture throughout its height of 2,000 feet. Innumerable scales cling to the faces of all these cliffs, it is true, but they are purely surficial features due to exfoliation, and the partings behind them penetrate the rock to only slight depth. Indeed, the very presence of these scales affords proof of the wholly massive nature of the rock bodies to which they adhere, for only massive rock exfoliates in this manner.

The almost complete absence of fractures in the walls of the upper Little Yosemite accounts also for the equally complete absence of vegetation on them. They afford no roothold for either trees or bushes and in consequence are strikingly bare. Moreover, as they are also devoid of prominent sculptural details or angular features, they present a singularly blank, expressionless aspect. The prevalence of smooth, gently curving surfaces is due in part to the grinding action of the glacier, in part to exfoliation of the rock.

The two promontories on the south wall known as the Cascade Cliffs (pl. 11, B) obviously are stubs of spurs that were neatly cut off by the glacier. They consist largely of massive rock (the western cliff exhibits imperfectly developed diagonal joints), but the parts that have been removed from them probably consisted of jointed rock. Indeed, the straight, sheer faces of the promontories clearly betray the influence of vertical joints of the northeastward-trending system, and there is thus reason to suppose that the points of the spurs were traversed by other joints of that system which facilitated and guided the glacial quarrying.

The north wall of the Little Yosemite has been planed off less severely than the south wall. From it projects, near the head of the valley, that remarkable dome-crowned spur of bare granite known as Sugar Loaf. (See pls. 31, $A$, and $45, B$.) Although repeatedly overridden by the glacier, this spur, which is massive throughout save for a single horizontal master joint, still stands 1,300 feet high and partly blocks the valley.

Less remarkable scenically but even more instructive is the broad spur that projects southward from Moraine Dome, opposite the Cascade Cliffs. This spur, too, has been repeatedly overriden by the 
Merced Glacier, as is strikingly attested by the lateral moraines that curve across its back. (See pl. 29.) The topmost of the series, the great embankment that marks the highest level attained by the Merced Glacier during the last glaciation, is fully a quarter of a mile back from the end of the spur, and accordingly it is clear that the spur, even in its present blunted form, projected at least a quarter of a mile into the body of the glacier.

To obtain a true appreciation of the stout resistance which this spur has offered to reduction by the glacial processes one must view it also in its relations to the margins of the very broad Merced Glacier of the earlier ice stage. This may be best done in a cross section such as that in Figure 36, which shows that this earlier glacier spread over the upland to the north of the spur for a distance of fully $1 \frac{1 / 2}{2}$ miles. Southward the glacier spread over the upland back of the Cascade Cliffs to a distance of three-quarters of a mile, and thus it had a $T$-shaped cross section resembling deeply buried, even - by the later as well as by the earlier Tuolumne Glacier. Its cross section, therefore, affords no measure whatever of the maximum volume attained by that glacier. The Yosemite Valley, on the other hand, is conspicuous as one of the few $U$ troughs that had sufficient capacity to accommoda te the entire volume of its glacier, even at times of maximum ice accumulation-because in its generally fractured rocks glacial quarrying proceeded with greater facility than in the rocks of the other valleys.

Rock resistance to glaciation reached a climax at the head of the Little Yosemite. The narrow upper gorge of the Merced (fig. 37), which begins there, is carved into a vast body of massive Half Dome quartz monzonite that obstructed the path of the Merced Glacier in precisely the same way in which the body of massive El Capitan granite into which the lower Merced Gorge is cut obstructed the path of the Yosemite Glacier. Over this unquarriable body of monzonite the Merced Glacier was compelled to lift a considerable part of its

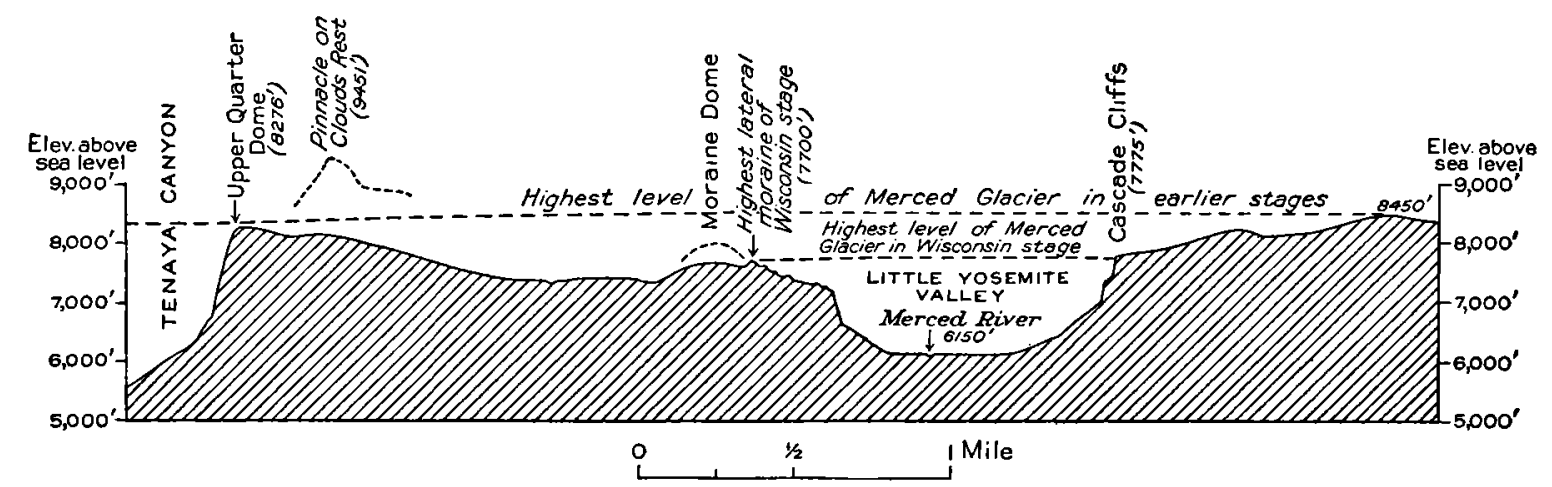

FIGURE 36. - Section across the Little Yosemite Valley and the adjoining uplands, showing the great breadth of the earlier Merced Glacier cornpared to that of the valley. Though shaped like a typical $U$ trough, the Little Yosemite affords no measure of the maximum volume attained by the Merced Glacier in either the earlier or the later glacial stages

somewhat the figure of a mushroom with massive stem and broad, flat cap.

The great disparity in breadth between the Little Yosemite Valley and the earlier Merced Glacier thus revealed is most enlightening to the student of glacial phenomena. For it shows that even so capacious and so perfect a $\mathrm{U}$ trough as the Little Yosemite does not afford an accurate gage of the maximum volume attained by the glacier whose pathway it was. The Little Yosemite appears to have been elaborated mainly by the prolonged and doubtless oft-repeated action of glaciers of moderate volume, and whenever during times of particularly great snow accumulation the ice exceeded such volume, it found the trough too small and deployed over the adjoining uplands, as a river at high stages deploys over its flood plain. The exceeding stubbornness of the massive granitic rocks evidently prevented these relatively rare and shortlived ice floods from enlarging the cross section of the valley to suit their volume. The same has happened in other yosemites in the Sierra Nevada. The Hetch Hetchy, notably, was completely overwhelmed- mass, just as the Yosemite Glacier had to lift part of its mass over the unquarriable body of granite at the lower end of the Yosemite Valley. The two gorges, it will be seen, are analogous features; both are essentially stream-worn gorges but slightly enlarged by glaciation. They differ mainly in that the upper gorge, having been glaciated in the last ice stage as well as in the earlier, still has smoothed and in part polished walls, whereas the lower gorge, having remained untouched by the later ice, has lost all evidence of glacial abrasion from its walls.

The question may here be raised, Why is not the head of the Little Yosemite, like that of the main Yosemite, marked by a great cross cliff over which the ice plunged abruptly in glacial time? Is it not to be inferred from the explanation given on page 97 of the mode of development of the head of the main valley that such a cross cliff is a necessary feature for the development of any spacious Yosemite-like valley chamber with approximately level floor? The answer is that during glacial time there were indeed great ice cascades at the head of the Little Yosemite. They 
plunged from the broad, uneven benches of massive rock that flank the narrow gorge above and that come abruptly to an end at the head of the valley; but the cliffs bordering those benches do not extend at right angles to the axis of the valley but flare out irregularly, doubtless in obedience to the local structure.

\section{DEVELOPMENT OF TENAYA CANYON}

Tenaya Canyon owes its great depth unquestionably to the fact that throughout its length both stream and glacier have eroded with comparative facility owing to the presence of a narrow belt of fracturing in the Half Dome quartz monzonite. In preglacial time Tenaya Creek, accelerated by the successive uplifts of the Sierra Nevada, deepened the canyon almost as rapidly as the Merced River deepened the Yosemite Valley. The valley of Snow Creek in consequence remained hanging a thousand feet above the canyon bottom. Later the Tenaya Glacier effectively quarried the fractured rocks, adding greatly to the depth of the canyon, though but little to its width. To-day whereas the Little Yosemite would be excavated very slightly.

Entirely different from the low, irregular steps just mentioned is the abrupt 600 -foot step that marks the head of Tenaya Canyon and the beginning of the upper Tenaya basin. As is evident from its smooth, unbroken front, down which the Tenaya Cascade glides and evidently has been gliding for thousands of years, without carving a notch, this great step is composed of the most massive, durable kind of rock. Like the steps of the giant stairway it was only moderately reduced in height by glacial abrasion, whereas the fractured rock masses in front of it were quarried away in wholesale fashion. It differs from the steps of the giant stairway mainly in that its edge is rounded instead of square, its top convexly curved, and its front concavely curved, in profile as well as in plan. Nor is there any clear evidence in its smooth-flowing outlines of direct control by master fractures.

Tenaya Canyon has been cited as a fine example of a glacial $U$ trough, but this characterization is

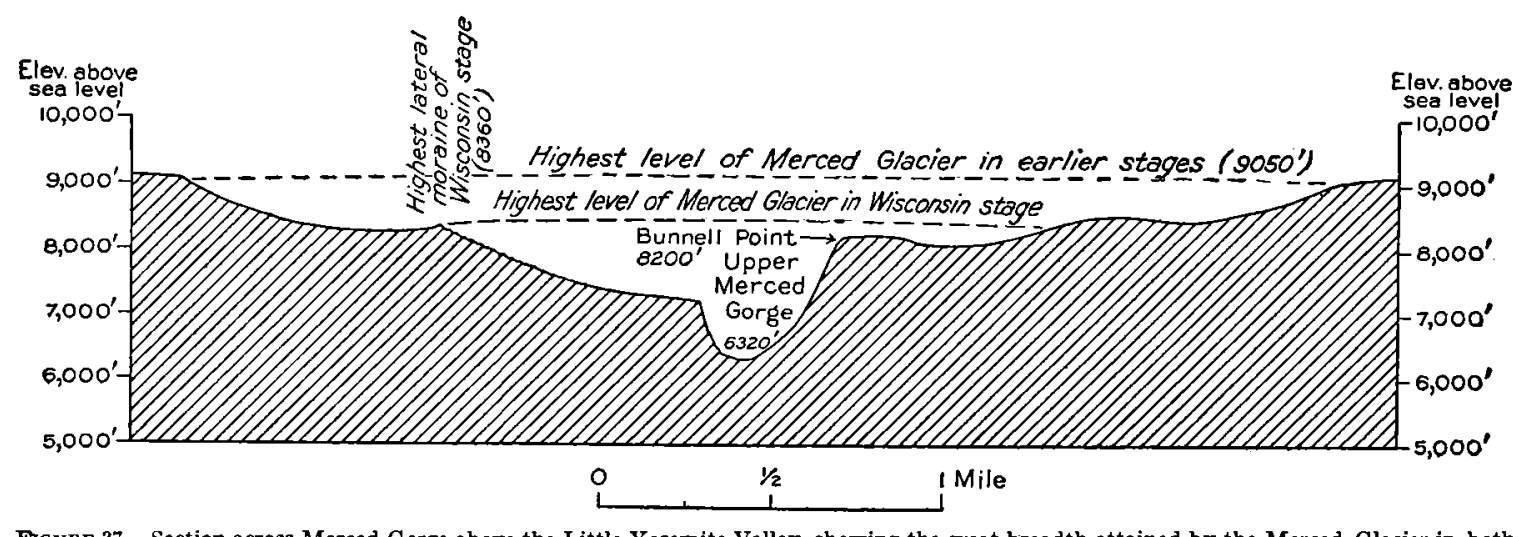

Frgure 37.-Section across Merced Gorge above the Little Yosemite Valley, showing the great breadth attained by the Merced Glacier in both the earlier and the later ice stages, compared with that of the gorge

Tenaya Creek is again rapidly intrenching itself. Since the ice age that little stream has cut into the canyon step at the base of Mount Watkins a gorge 100 to 300 feet in depth, in striking contrast to the almost negligible depth to which the relatively powerful Merced River has cut the massive rock of the giant stairway.

The irregularity of the trenched steps in Tenaya Canyon also is due to the prevailingly fractured state of the rock, which has permitted the glacier to quarry more or less effectively throughout the length of the canyon. Nor are these ill-formed, trenched steps at all comparable in point of permanence to the cleancut, monolithic steps of the giant stairway. Were glacial conditions to return some day, doubtless they would be cut back appreciably and also reduced in height by vigorous quarrying; whereas the steps of the giant stairway, being unquarriable, would be but slowly worn by abrasion. Indeed, in case of renewed glaciation, probably all of Tenaya Canyon would again be excavated to an appreciably greater depth, justly applied only to its broad-floored lower portion in which Mirror Lake is situated. (See pl. 8, A.) There, evidently, the Tenaya Glacier was able to quarry both broadly and deeply, owing to the presence of considerable masses of jointed rock. There also it gouged out in the rock floor a shallow basin analogous to the glacial basins in the main Yosemite and the Little Yosemite - at least such a basin appears to be indicated by the long stretch of level, sandy floor above Mirror Lake. Of that basin Mirror Lake might seem at first to occupy the unfilled remnantindeed, it has been long regarded as a lake of glacial origin, but, as is explained in greater detail on page 105 , it is now known to have been formed after the ice age by a dam composed of rock débris that fell in avalanches from the walls of the canyon.

Throughout its middle course Tenaya Canyon is narrower than near its mouth and its cross section resembles that of a sharp-keeled boat, as may be seen from the summits of the Quarter Domes. (See pl. $46, A$.) This peculiar shape is due in part to the 
incision of the narrow inner gorge in the bottom of the canyon, in part to the angle at which great bodies of massive rock slope out from the bases of the walls toward the middle. It is the smoothness, the continuity, and the prevailing steepness of these flanking rock slopes, no less than the ruggedness of the central gorge, that render Tenaya Canyon so extremely toilsome and hazardous to traverse. They call for ingenuity and daring on the part of those who would attempt to fight their way through the entire length of the chasm. ${ }^{68}$

Toward its head, again, Tenaya Canyon widens out somewhat and assumes an approximate $U$ shape. There its floor ascends by two low yet well-defined steps, each with a rounded edge of massive granite and a filled lake basin on its tread. This part of the canyon is directly overlooked by the great cliffs that inclose its head. It was the bowl into which the converging ice cascades plunged from above. That it was not gouged out to greater breadth in spite of the tremendous eroding power developed by the plunging ice is explained, manifestly, by the exceptionally resistant nature of its massive walls.

Tenaya Canyon as a whole presents the most stupendous exhibit of massive granite in the entire Yosemite region, perhaps in the entire Sierra Nevada. (See pls. $46, B$, and $40, B$.) Not even the Grand Canyon of the Tuolumne nor the Kings River Canyon is hemmed in by walls so uniformly and continuously massive. It is no wonder, therefore, that Tenaya Canyon has remained on the whole narrow in proportion to its depth. It affords in that respect a direct antithesis to the Little Yosemite: in the lower part of that valley the ice was permitted to quarry broadly but not to great depth; in Tenaya Canyon the ice was permitted to quarry deeply but not to great breadth.

SUMMARY OF CHANGES PRODUCED BY THE GLACIERS

The changes that were brought about in the configuration of the Yosemite region by the repeated ice invasions of the glacial epoch may be summed up as follows:

In the Yosemite Valley itself, where the rocks were prevailingly well jointed, glacial quarrying was particularly effective and accomplished conspicuously large results. Both downward and sideward the Yosemite Glacier quarried, trimming off projecting spurs, cutting back the craggy slopes of the preglacial river canyon to sheer, smooth cliffs, and transforming the brawling cascades descending from the hanging side valleys into leaping falls of astounding height. Throughout the length of the valley the inner gorge of the Merced was wiped out of existence and in its stead there was produced a broadly concave, basin-

os Lo Conte, J. N., Scrambles about Yosemite: Sierra Club Bull., vol. 9, pp. 126-135, 1914. shaped rock floor. Even the features of the mountain valley of the Pliocene epoch were largely destroyed, and thus from a tortuous $V$ canyon the Yosemite was enlarged to a spacious, moderately sinuous $U$ trough with approximately parallel, spurless sides and with a long lake basin in its bottom. Only between $\mathrm{El}$ Capitan and the Cathedral Rocks, composed of massive rock which the glacier was unable to quarry away, did it leave a marked constriction. In the areas of sparsely jointed granite immediately above and immediately below the Yosemite Valley the ice was able to effect but moderate changes in the form of the canyon. There in consequence the inner gorge of the Merced remains preserved and still presents the characteristics of a trench worn by the river in the bottom of an old mountain valley.

In the Yosemite Valley the depth of glacial excavation decreases from a maximum of about 1,500 feet at the head to a minimum of about 500 feet at the lower end. The reason for this decrease in glacial deepening down the valley is found in the fact that during all phases of glaciation the ice was thicker and therefore had greater excavating power at the head of the valley than at the lower end, and during the maximum phases it plunged into the head of the valley in the form of a mighty cataract.

Above the Yosemite Valley the Merced Glacier sculptured the steps of the giant stairway from local bodies of extremely massive rock. By quarrying headward directly up to the vertical master joints delimiting those bodies and by grinding them down from above, it gave them their marvelously cleancut, steplike forms.

In the lower half of the Little Yosemite lateral quarrying was favored but downward quarrying was impeded by the structure of the rocks, and as a consequence that part of the valley was given great breadth but relatively little depth. Liberty Cap and Mount Broderick, being composed almost wholly of massive, unquarriable rock, were left standing at its mouth as two roches moutonnées of gigantic size. The upper half of the Little Yosemite has remained narrower than the lower half because it is hemmed in by extensive bodies of massive rock. The head of the Little Yosemite was, like the head of the main Yosemite, the site of a powerful ice cataract and to that circumstance largely owes its great depth and peculiar configuration. In the Little Yosemite as in the main Yosemite the depth of glacial excavation decreases steadily down the valley and for the same reasons.

In Tenaya Canyon downward quarrying was favored by the presence of a longitudinal belt of fractures, but lateral quarrying was restricted by flanking masses of undivided rock. As a consequence that canyon was cut down almost to the level of the Yosemite Valley and was given even greater depth than that valley, but 
it was left comparatively narrow and in part shaped like a sharp-keeled boat rather than like a $U$ trough. Only an imperfect stairway was developed in its floor, but at its head a gigantic step was fashioned from a body of massive granite under the cascading action of the Tenaya Glacier.

The Yosemite, the Little Yosemite, and Tenaya Canyon, then, owe their present configuration very largely to glacial action. All three had been cut in preglacial time to considerable depth by the streams flowing through them and had acquired the aspect of rugged $V$ canyons, but so thoroughgoing was the remodeling action of the glaciers that now only a few vestiges of their preglacial forms remain. Each chasm had a glacial cataract at its head, yet each differs from the other two in general shape and proportions because in each the structure of the rocks was different and influenced the glacial processes in a different way.

\section{POSTGLACLAL history OF THE YOSEMITE VALLEY}

It remains to consider the changes that have been wrought in the aspect of the Yosemite Valley during postglacial time - that is, during the interval that has elapsed since the ice age. The magnitude of those changes is commonly underestimated-indeed, the belief seems to prevail that the Yosemite region presents to-day much the same appearance as it did immediately after the evacuation of the ice. Close observation, however, reveals the fact that some radical and many minor changes have taken place and that the Yosemite of to-day differs in some respects markedly from the Yosemite at the end of the glacial epoch.

The postglacial interval is variously estimated by geologists at 15,000 to 30,000 years. It has therefore been brief, in the geologic sense, yet it has lasted long enough to permit the processes of disintegration, erosion, and deposition to accomplish significant results in some places. It has permitted the valley walls to be dismantled in part and to be cloaked with rock waste at their bases, and it has permitted the lake basins excavated by the glaciers to be filled with stream-borne sediments. During the postglacial interval, therefore, the Yosemite region has lost much of its ice-given grandeur and grimness of aspect and has gained in habitableness and charm.

The most radical changes produced in its landscape were due to the filling and complete obliteration of the glacial lakes. It will be appropriate, therefore, to describe these changes first.

\section{FILLING OF THE GLACIAL IAKES}

\section{FILLING OF LAKE YOSEMITE}

To the camper who pitches his tent in one of the Yosemite's shady groves it may not occur, perhaps, that the spot he has selected for his temporary abode once lay in the midst of a mountain lake of exceptional beauty-a sheet of water in which the cliffs of $\mathrm{El}$ Capitan and Half Dome as well as the sprays of the Yosemite Falls were reflected. Yet there can be no doubt that the present embowered, parklike floor of the valley replaces such a body of water.

Ancient Lake Yosemite occupied the entire length and breadth of the main Yosemite chamber. (See fig. 16.) It was $5 \frac{1}{2}$ miles long, extending from the moraine dam at the El Capitan Bridge to the great wall at the head of the valley, and its waters lapped the bases of the freshly glaciated walls on each side. As already explained (p. 94), the lake owed its existence not to the moraine dam alone; it occupied an elongated basin scooped out in the rock floor of the valley by the ancient Yosemite Glacier, and its depth was merely increased somewhat by the moraine dam, which was situated on a broad rock sill at the lower end of the basin.

The depth of the lake basin is not known, as no borings have ever been made, but cross profiles of the valley (figs. 24 and 25), plotted accurately from the contouring of the topographic map, give a fair basis for estimates. If the bottom curves in these cross profiles are drawn in accordance with the characteristics of the exposed rock floors of other Yosemite-like canyons in the High Sierra, they indicate a depth ranging from 100 to not less than 300 feet. The basin was deepest probably in the upper part of the valley, opposite Yosemite Village.

The filling of the lake no doubt began before the ice completely left the valley, but the main work was done by the Merced River and Tenaya Creek. When the Yosemite Glacier had departed each of these streams, by depositing the glacial débris which it carried at the point where it entered the lake, began to build a delta. These deltas grew forward rapidly and in time coalesced into one large delta when the streams joined each other. This large delta then grew forward down the valley until, probably in the course of thousands of years, its front reached the moraine dam, and the basin was completely filled.

The appearance of Lake Yosemite during its gradual extinction and the aspect of the delta at its head may be readily imagined by anyone who has visited Merced Lake (pl. 12, B) or Washburn Lake. Each of these lakes is now being encroached upon in precisely the same manner as Lake Yosemite was, by a slowly forward growing delta composed of stream-borne sand and gravel. Each lake, in fact, is already reduced to twothirds its original length and has at its head a delta plain half a mile long. These delta plains have gently sloping surfaces, cut only by the channel of the river and by a few old, abandoned channels. Each delta is fronted by a sandy beach that is beaten by the waves in a sweeping concave curve on each side of the slightly projecting river mouth.

It is probable, further, that like the deltas at Merced Lake and Washburn Lake, the delta at the head of Lake 
Yosemite was largely covered with vegetation. Its more stable portions bore forest trees, and its shore was fringed with willows. That the climatic conditions permitted vegetation thus to establish itself upon the delta shortly after the retreat of the glaciers can scarcely be doubted, for there are indications in various parts of the Sierra Nevada that even during glacial time extensive forests of pine and sequoia flourished on its lower slope and well up on the ridges between the canyons.

As the delta plain was extended forward it was also built up gradually, for the streams, which were heavily loaded with débris, had to maintain a sufficient slope to transport it. The coarser material naturally they dropped soon after emerging into the valley, and as a consequence their gradients were steepest at the valley head. They had a fall there of about 20 feet to the mile, whereas throughout the greater part of the lake basin they had a fall of only 3 feet to the mile.

The present valley floor, as a matter of fact, does not represent the original delta plain that was formed in the manner just described but is a relatively new plain that lies at a level 14 to 16 feet lower. Probably as the result of a rather sudden breaching of the moraine dam the Merced River cut down its bed and trenched the plain until at length it established a new grade similar to the first. Then, winding sluggishly from side to side, it widened out a new plain at the expense of the old one. In only a few places are remnants of the old plain left in the form of terraces. A particularly prominent terrace of this sort overlooks Tenaya Creek near the head of the valley. The level plain in front of Camp Curry is another terrace. More extensive remnants of the old plain occur north of the Cathedral Spires and the Cathedral Rocks.

The present valley floor has the characteristic features of what is properly termed a flood plain; low natural levees along the river banks slope gently away from the stream and are breached in places by overflow channels, and in the plain beyond are numerous crescent-shaped sloughs outlining old oxbow bends abandoned by the river when it shifted its course. All these features show that the river has almost ceased to cut and at times of high water builds up the valley somewhat by depositing sediment. Every year, as a rule in the month of May, floodings occur as a result of the rapid melting of snow in the High Sierra. Fortunately the water spreads only over the lower ground and attains a depth of only a few feet. No material damage is done, as all permanent structures in the valley are built on relatively high ground.

\section{FILLING OF LAKE IN THE LITTLE YOSEMITE VALLEY}

But scant reference has been made thus far to the lake that once occupied the Little Yosemite Valley. It must have extended over the entire length and breadth of the floor, measuring about $2 \frac{1}{2}$ miles in length and somewhat less than half a mile in average width. Like the body of water in the Yosemite Valley, it lay in a rock basin scooped out by the glaciers, but it was impounded only by a rock barrier and had no moraine dam in addition. The rock barrier at the lower end, now cleft by a narrow gorge through which the river passes in brawling rapids, is situated about half a mile above the Nevada Fall. The lake shallowed gradually toward its outlet and probably attained no great depth at any point. The deposit of river gravel that now fills the basin is not thick enough to cover the crests of the numerous small moraines which the Merced Glacier left as it retreated. As may be seen on Plate 29, some of these moraines cross the basin fully a mile above the outlet. They stood probably only about 30 feet in height, hence the depth of the lake in that vicinity must have been only about 25 feet. 'The maximum depth occurred probably half a mile farther up and may have exceeded 50 feet.

A basin so shallow naturally was not long in filling. The lake in the Little Yosemite, therefore, was obliterated perhaps even before Lake Yosemite was filled, although the Little Yosemite was evacuated by the ice much later than the main valley. The general process of filling, by the forward growth of a delta, no doubt was the same in each lake.

\section{SIGNIFICANCE OF LOST LAKE}

Lost Lake has probably always been a separate body of water, not communicating with the larger lake in the Little Yosemite. It lies on a rock bench raised somewhat above the river gravel in the Little Yosemite and is walled in on the south side by a ledge of granite and on the southeast side by a moraine. It owes its existence to the collection of seepage water and the run-off from the surrounding mountain sides.

Lost Lake is now being filled gradually with a deposit of peat resulting from the accumulation of vegetal material. It is little more than a watery swamp and will soon reach that stage where it can no longer be referred to as a lake.

\section{SURVIVAL OF EMERALD POOL}

It may seem anomalous that Emerald Pool, the smallest of all the glacial lakes in the Yosemite region, should still be unfilled and in precisely the same condition as at the end of the glacial epoch. The explanation is found in the very smallness of the basin, in the smoothness of its sides and bottom, which are composed of massive granite throughout, and in the great momentum with which the water of the Merced River rushes into the pool as a result of its descent in the Silver Apron. (See p. 19.) At times of flood all the water in the pool is set in motion, and the powerful current sweeps through it unchecked, carrying all sand and gravel with it. 


\section{FILLING OF LAKES IN TENAYA CANYON}

Although the steps in the floor of Tenaya Canyon are not especially clean-cut, their configuration nevertheless indicates or at least suggests the former existence of a glacially scooped lake basin on each tread. There were apparently four such lake basins in the stretch extending from the mouth of the canyon to the great step from which the Tenaya Cascade descends. The upper three were little more than ponds that must have been quickly filled, but the lowermost, near the mouth of the canyon, measured over a mile in length and probably was not filled until a long time after the glacier had withdrawn from the canyon.

Mirror Lake (pl. 47, A) might readily be supposed to be a remnant of this ancient lake-in fact, it is generally assumed to be of glacial origin, like most lakes in the High Sierra-but a scrutinizing study of it reveals that it is of relatively recent making and has had no connection whatever with the ice age. It is impounded wholly by masses of rock débris that fell in avalanches from both walls of the canyon, principally from a place on the west wall, just back of the Washington Column. West of the outlet of the lake, it is true, there is a small quantity of morainal débris, readily distinguishable from the angular avalanche material by the water-rounded and glacier-polished cobbles and pebbles which it contains; but there is no dam composed of such glacial material across the canyon.

The creation of Mirror Lake by obstructing rock avalanches was of course favored by the fact that the lower part of Tenaya Canyon already had a nearly level floor due to the previous filling of a glacial lake basin. Had the floor not been so nearly level, the low, irregular avalanche dam would not have backed up the water for any great distance.

The postglacial history of lower Tenaya Canyon may be summed up as follows: (1) A glacially gouged lake basin about a mile in length was filled by the forward growth of a delta built by Tenaya Creek; (2) great rock avalanches fell from the walls near the canyon mouth and impounded the water anew, forming Mirror Lake; (3) Tenaya Creek built a new delta, which, growing forward, is now reducing the size of Mirror Lake.

The relative recency of its creation therefore explains why little Mirror Lake is still in existence, whereas the large lake basin in the Yosemite Valley is completely filled. Mirror Lake itself, however, appears to be not far removed from extinction. The rate at which the delta at its head is encroaching upon it from year to year is sufficiently rapid to be discernible to the eye without the aid of precise measurements. Indeed, unless steps are taken to check the further growth of the delta, Mirror Lake will soon be reduced to a small, unimpressive pond, and the Yosemite region will lose one of its most valued scenic treasures.
PRODUCTION OF ROCK WASTE IN THE YOSEMITE VALLEY

UNEQUAI DISTRIBUTION OF ROCK WASTE

Because of the sheerness of its walls the Yosemite Valley has been the scene of many rock falls. The glaciers, having transformed it from a V-shaped canyon to a U-shaped trough, left the Yosemite at the end of the ice age with oversteepened sides-that is, with cliffs more precipitous than the ordinary processes of weathering and erosion would have produced. As a consequence, when these processes again prevailed upon the departure of the glaciers, the cliffs naturally tended to revert to less bold and more stable forms.

On the whole this dismantling has as yet made little progress, and most of the cliffs still retain their glacial profiles. The extent of the damage they have suffered is most readily estimated from the size of the piles of rock waste that lie at their bases. These piles, or taluses, are for the most part small-surprisingly small, even, compared with the long slopes of rock waste that partly cloak the sides of the glaciated valleys in the Rocky Mountains, the Cascade Range, and the Alps. So insignificant do they seem under the imposing rock façades of the Yosemite Valley that many observers have commented on the apparent absence of débris in the valley. Whitney ${ }^{69}$ endeavored to explain the paucity of débris by supposing that the bulk of the rock fragments shed from the cliff's had "gone down to fill the abyss" that was formed, according to his hypothesis, when the bottom of the valley dropped out. In reality, however, there is hardly a spot at the base of the cliffs where rock waste is entirely wanting. Only in a few places are there piles less than 50 feet high. At the toe of El Capitan (pls. 3 and 17), which has the appearance of rising directly from the valley floor, there is fully 100 feet of débris. Under most of the great cliffs the débris attains heights of 250 to 500 feet: in a few recesses it reaches 2,000 feet.

What has been said thus far, however, applies strictly to the upper Yosemite chamber. The lower chamber is, by contrast, fairly lined with rock waste. The taluses slope out so far from each side as to leave but a narrow strip of valley bottom free. The great Rock Slides (pl. 3) across which the Big Oak Flat Road is graded are 2 miles broad and reach almost to the brink of the upland. This marked difference in the amount of rock waste in the upper and lower chambers of the Yosemite Valley is explained in the first place by the fact that in the upper chamber rock waste has accumulated only since the last glaciationthat is, for a period of about 20,000 to 40,000 years. In the lower chamber, where the last Yosemite glacier did not penetrate, it has been accumulating ever since the earlier or El Portal glaciation-that is, for a period

60 Whitney, J. D., The Yosemite guide book, p. 86, 1870. 
of about 200,000 to 300,000 years. But in addition there is the fact that the walls of the upper chamber are composed of prevailingly massive or sparsely jointed rocks, whereas the walls of the lower chamber are composed in large part of well-jointed rocks. Its north wall, which consists mostly of closely fractured gabbro, has suffered the most complete demolition. Only a few crags of it remain standing above the vast rock talus.

The spacing of the joint fractures in the rocks, which was so potent a factor in determining the rate of glacial excavation, has also effectually controlled the rate of the postglacial dismantling: Where the joints are most numerous and most closely spaced, naturally the dismantling processes have worked to best advantage; where the joints are few and far apart the dismantling has been correspondingly slow. Throughout the Yosemite region there is consequently a close relationship between the size of the débris piles and the joint structure of the walls above them. The upper Yosemite chamber, especially, offers the most striking variations. At the extreme point of the Cathedral Rocks, where the granite is particularly massive, there is scarcely 50 feet of débris, but in the recesses adjoining the Cathedral Spires, where shattered diorite and gabbro prevail, the débris reaches a height of 2,000 feet. East of Taft Point, where the cliffs are more sparingly fractured, the débris again dwindles to a mere 100 feet. The sheeted granodiorite in and about Sentinel Rock has given rise to taluses 600 to 1,500 feet in height, but the relatively massive granite which alternates with the granodiorite in the cliffs under Union Point has produced a talus only 50 feet high. On the north side of the valley, likewise, the débris piles vary from 100 feet at the base of the Three Brothers to 1,100 feet in the embayment to the east, where they afford a convenient slope for the zigzag trail to the Yosemite Falls. Under Columbia Rock, on the other hand, there is less than 50 feet of débris. In general each embayment or recess that marks a place of weakness in the walls of the valley contains a great cone of débris; each promontory that marks a point of strength has a minimum of débris at its base.

\section{MODES OF PRODUCTION}

The belief prevails among visitors to the Yosemite Valley that most of the rock débris has been thrown down from its walls by earthquakes. One reason is that some of the boulders are of astonishingly large size and lie far out in the valley. Another is that the walls are so massive that nothing less than an earthquake would seem to suffice to break them down. Muir, who was privileged to witness the rare spectacle of the downfall of a pinnacle-the Eagle Rock, which was on the south wall of the valley, not far from Moran point-at the time of the Owens Valley earthquake in 1872, was so deeply impressed by the sight of the great avalanche of bounding rock fragments that resulted from the crash that he was inclined to attribute most of the rock taluses to earthquake avalanches. As most of these taluses bear mature forests and appear to have received no noteworthy increments for long periods, he concluded that "more than nine-tenths" of all the rock waste in the Sierra Nevada had been shaken down by a single mighty quake, a short time after the end of the. ice age. ${ }^{70}$

It is indeed probable that a considerable part of the rock waste in the Yosemite Valley is of earthquake. origin, for tremors must have occurred from time to time during the postglacial interval as a result of minor movements on the fault fractures at the east base of the. range. It is fairly certain, furthermore, that at least one. strong shock was felt in the Yosemite Valley, for only 30 miles away, near the west shore of Mono Lake, the moraines at the mouth of Lundy Canyon are cut across. by a fault scarp 50 feet high that was produced probably by a single, sudden earth movement. But whether as much as nine-tenths of all the rock waste in the Yosemite Valley is to be accredited to this one strong quake, or even to all the postglacial quakes together, seems doubtful, nevertheless, for rock waste is being. shed from the cliffs in quantities by no means negligible at the present time, as the result of the normal weathering and disintegration of the rock walls and of the recurrent action of such destructive agencies as. snow avalanches and torrential rains, and this intermittent shedding of débris doubtless has gone on ever since the glaciers vanished. To credit earthquakes. with five-tenths of the total amount of rock waste in the valley, therefore, would probably be liberal.

Significant light was shed on this question some years ago, when an excavation for road metal was begun at the toe of the great rock talus under the Big Oak Flat Road. In the head wall of this excavation were visible no less than four distinct layers of rock débris each several feet in thickness and separated from the next by a thin layer of dark earthy matter of vegetal origin, doubtless ancient soil. Roots and stumps of forest trees were embedded in these soils. It was thus made clear that this talus had been formed not by a single huge rock avalanche, but by successive avalanches that were separated by long intervals. during each of which a forest was able to establish itself upon the slope.

Whether each of these avalanches was thrown down by an earthquake, it is impossible to say. Some may have fallen without the intervention of a quake. For it often happens that a cliff that has stood for a long time essentially unchanged in outer appearance becomes so weakened internally by the solvent action of acid-bearing water that percolates through the joint cracks that its component parts at

io Muir, John, Studies in the Sierra-Postglacial denudation: Sierra Club Bull., vol. 10, p. 416, 1919 (reprinted from Overland Monthly, November, 1874). 
U. S. GEOLOGI'AL SURVTY

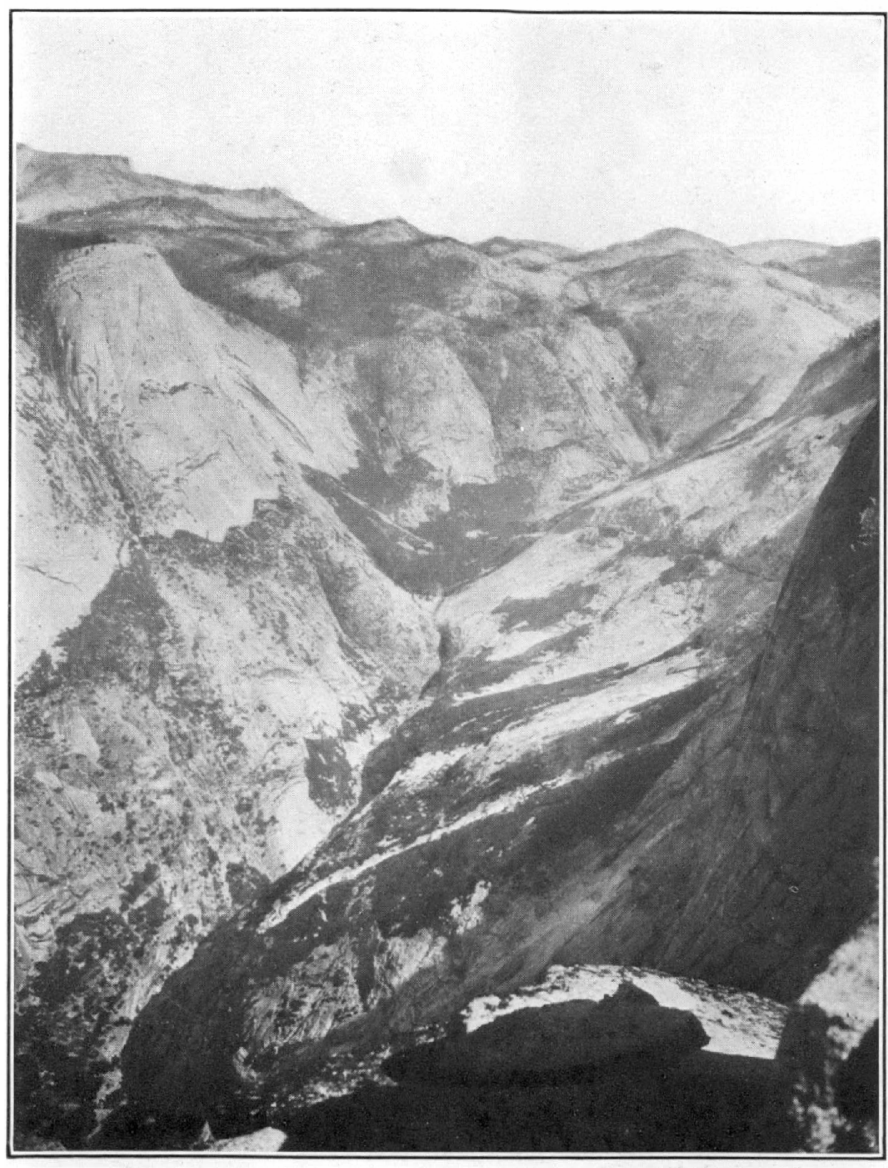

A. UPPEH PAHT OF TENAYA CANYON, FROM UPPER QUARTER DOME Though severely glacialed this part of Tenaya Canyon is shaped not like a $U$ trought
but like a sharp-keeled boat. In the center is one of the steps of massive granite. hut like a sharp-keeled boat. In the center is one of the steps of massive granile. Al the Irft is a buttress of Mount Walkins. In the distarice is part of the great
head wall. The Tenaya Cascade is masked by the rocks slopes of Clouds Hest, on
the right.
PROFESGIONAT, PAPER 160 TLATE 46

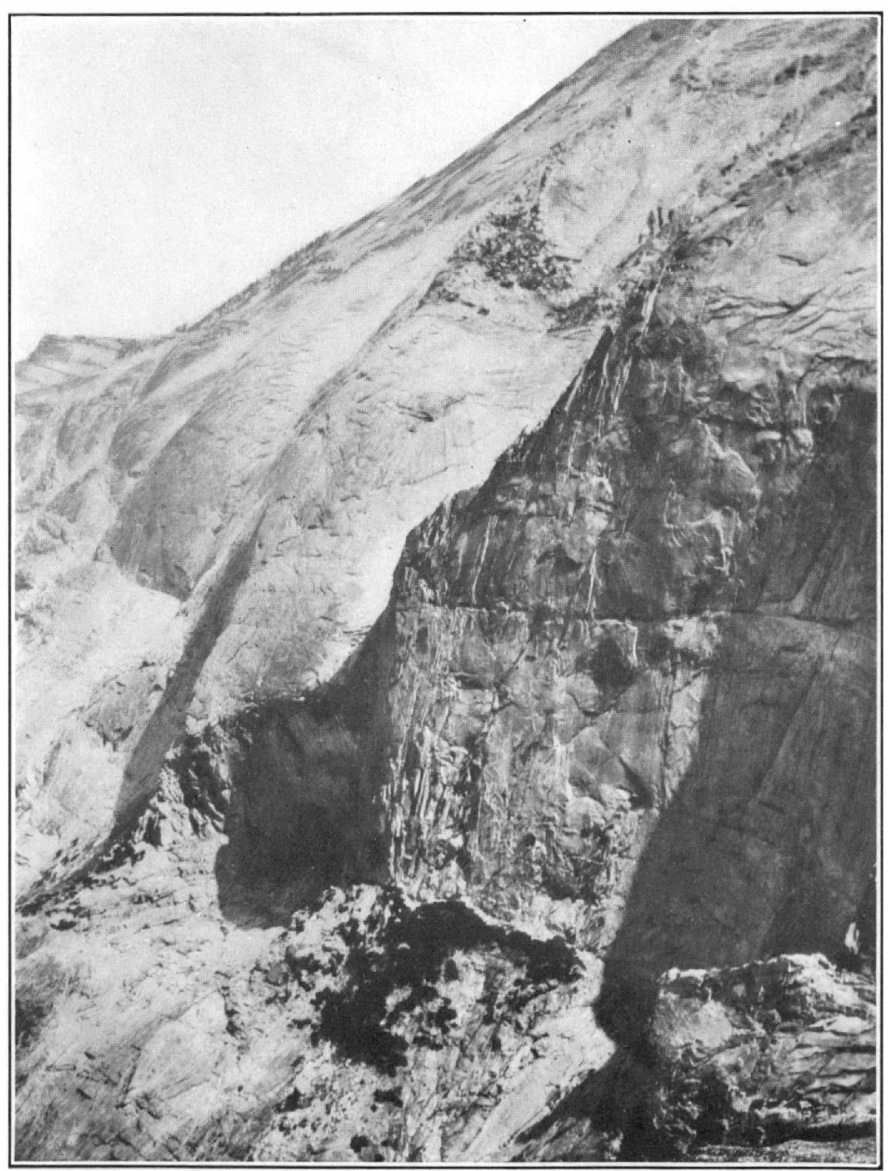

B. ROCK FACADE OF CLOUDS HEST, FHOM UPPEH QUARTER DOME 'The granitc is traversed by only a few approximately horizontal master joints und io olherwise wholly massive. Exfoliation is taking place cverywhere parallel to siow inward-dipping joints 


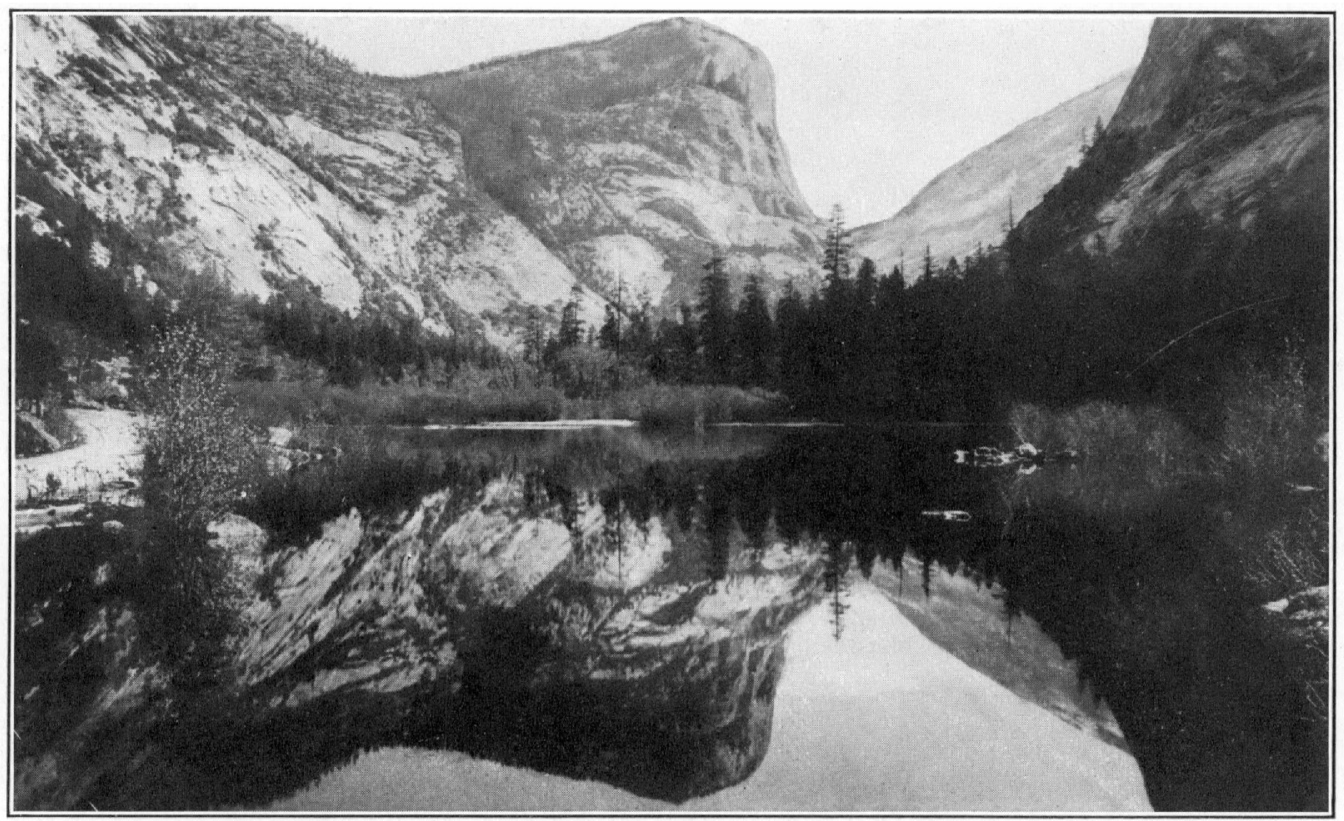

A. MIRIROR LAKE

The basin of Mirror Lake is not of gliceial origin but was formed some lime al tar the jece are by great roek ayalanelhes thrown down

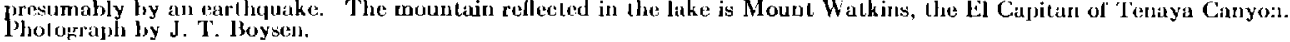

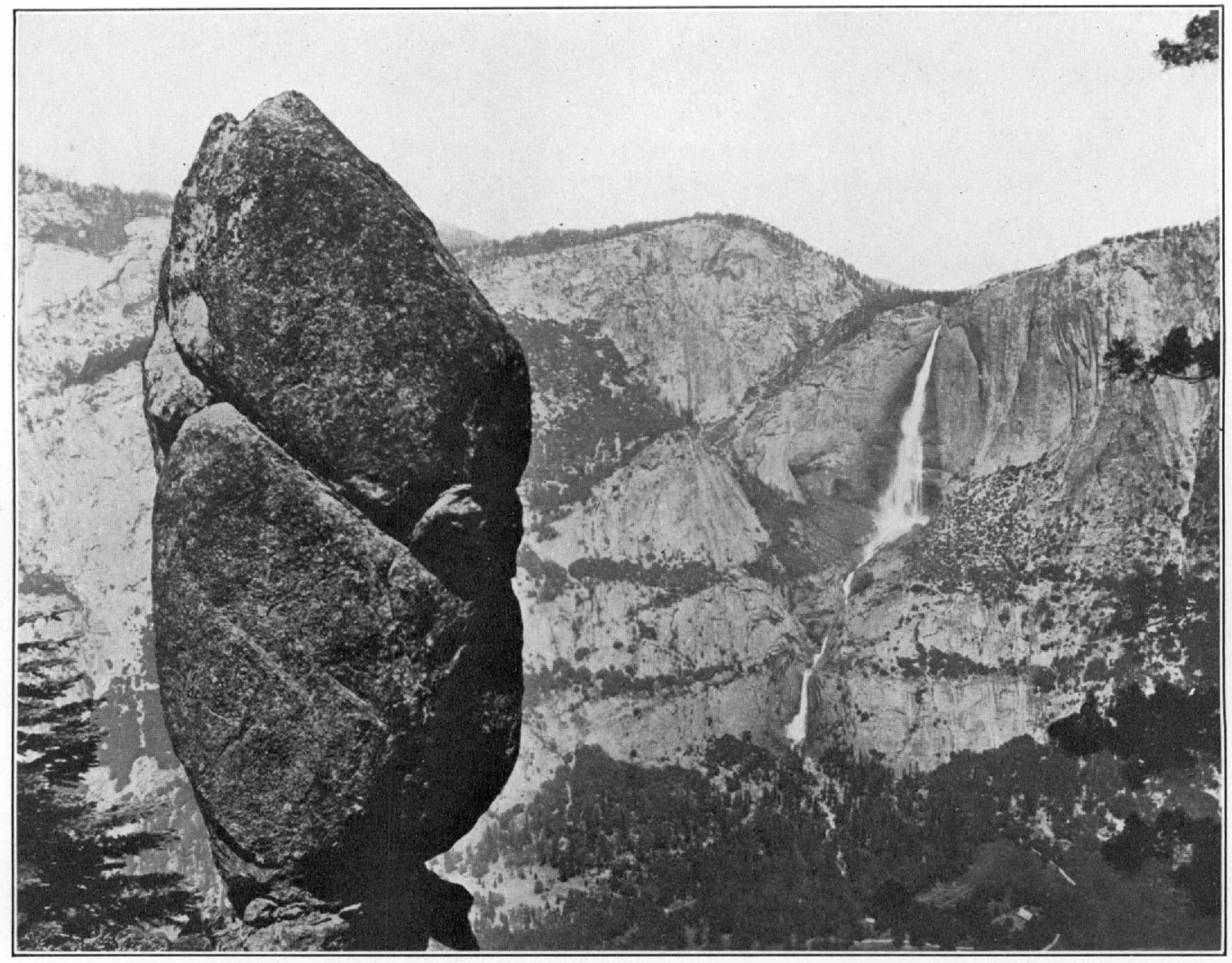

I3. AgAssiz COLUMN

The prismatic form of the Agassiz Column is delermined wholly by intersecting joint planes, vertical and oblicue. The column is the last remmant of a rock mass that was divided hy many such fractures. 'The clifts aboul the Yosemite Falls, in the

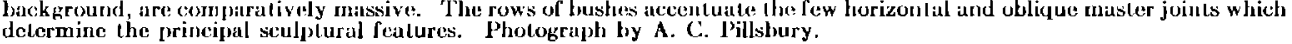


last lose coherence and crash down under the pull of gravity alone. An occurrence of this kind was observed near the base of the Three Brothers in 1923. A large sheet or spall of rock that had been in process of being loosened for centuries, perhaps, suddenly detached itself from the cliff face without being impelled by any noticeable earth tremor and, as it fell, crushed and obliterated with its débris a forest of pine trees that had grown up on the talus below. It is probable that spontaneous rock falls of this sort account for a large share of the vast talus over which the Big Oak Flat Road is laid and likewise of other taluses in the valley.

There is little need for alarm on the part of the visitor lest any spontaneous rock avalanches should occur while he is in the Yosemite Valley, for such avalanches are in the nature of things very infrequent in a valley whose walls are so prevailingly massive. Only in those few spots where the rock is shattered into small fragments and where ground water is fairly abundant, are rock falls likely to occur annually or at shorter intervals, for there frost and thaw, heat and cold, working in alternation, are effective agents. In those places, which are for the most part in recesses, the talus has a relatively fresh appearance and is either bare or only scantily covered by bushes.

Most of the minor rock falls in the Yosemite region take place in the winter or in the spring, either in conjunction with snow avalanches or in thawing weather. On the steep northwest slope of Clouds Rest snow avalanches are the principal agency and have worn smooth, funnel-shaped tracks. During the long dry summers rock falls are rare but not wholly absent. Tenaya Canyon has a particularly evil reputation on their account. The few mountaineers who have had the hardihood to traverse this canyon appear to have been as much impressed by the peril of being struck by falling rocks as by the unusual obstacles that are to be overcome in climbing.

One agency whose effectiveness in causing the mechanical disruption of the granitic rocks in the Yosemite region deserves to be considered here is the radiant heat of the sun. Several circumstances operate to intensify its action on those rocks. Because of the utter absence of vegetation and even of soil the rock over large areas is directly exposed to the rays of the sun. The dryness and purity of the air, coupled with its thinness at the higher altitudes, cause the rays to suffer relatively little loss of heat through absorption or reflection by particles of water vapor and dust. And the cloudless skies that prevail during the summer permit them to strike the rock unhindered day after day, often for weeks or months at a stretch. As a consequence the rock is subjected every year to prolonged periods of intense daily insolation alternating with rapid cooling through irradiation at night.
Now allgranitic rocks are aggregates of several different minerals-mainly feldspar, quartz, mica, and hoinblende - the crystals of which are tightly interlocked. When these crystals expand upon being heated they tend to wedge and pry one another apart. A few heatings have no effect, but thousands upon thousands of heatings are bound to loosen the crystals by degrees until at last they are detached in flakes or individually. In roaming through the Sierra Nevada one sometimes finds rock fragments that, although apparently solid, can not be picked up entire: when lifted they break up into loose grains that run through the fingers like coarse sand. "Rotten" rock fragments of this kind occur only in places where the heat of the sun is felt daily.

The summits of those domes that were not overridden by the glaciers of the ice age, such as Sentinel Dome and Half Dome, and the summits of those domes that were overiidden by the earlier glaciers only, such as North Dome, Basket Dome, the Quarter Domes, and Moraine Dome, afford particularly good places to observe the disruptive effect of solar heat on granite. The granite there is characteristically flaky parallel to the surface, the tendency evidently being for the outer, more intensely heated layers to burst loose by expansion from the less intensely heated layers underneath. (The production of curving shells, 1 foot or several feet in thickness, by exfoliation involves other agencies besides solar heat and is not to be confounded with the flaking here discussed.) The flakes break up into individual rock grains, and ultimately these are washed away by the rain water. The great accumulations of granite sand that occur in the vicinity of domes and other bare masses of granite are produced largely in this way. Frost presumably plays a part in this mechanical disruption, but if so, only a very subordinate part, for typical frost cracks are absent in the domes and the other rock masses referred to.

It is a highly significant fact that the loose grains derived from disintegrating granite in the Yosemite region show scarcely any effects of chemical decomposition. The crystals of feldspar are but slightly cloudy at the edges, and the flakes of biotite and rods of hornblende show as a rule no alteration whatever. This is a very different state of things from that which prevails in the eastern part of the United States and in other regions of fairly high humidity, for there the granitic rocks are reduced by chemical decomposition into clayey soils. However, this crumbling of the granite into undecomposed grains takes place only on the domes, cliffs, and other conspicuously bare rock masses in the Yosemite region that are subjected to intense insolation. In the densely forested areas on the uplands, where the heat of the sun is partly excluded by the foliage of the trees and where the granite is covered by a layer of moisture-conserving, acid- 
producing humus the chemical processes reduce the granite in much the same way as in a humid region.

In closing this discussion of the different processes whereby rock waste is produced in the Yosemite region it will be appropriate to point out a few of the outstanding evidences of earthquake action. Most spectacular among these are the gigantic blocks commonly referred to as earthquake boulders. A few isolated blocks that are as large as cabins and seldom fail to attract the attention of the passer-by lie near the Le Conte Memorial Lodge. Other blocks of various sizes are interspersed among the houses in the old Yosemite Village, which was built at the toe of a chaotic pile of rock débris. Still others encumber the channel of the Merced River in the gorge below the valley, causing the stream to dash itself into foam in its wild descent; these are not boulders rolled down by the current but blocks that have fallen from the walls of the gorge. Most remarkable of all is the famous Arch Rock, between and under whose enormous overarching fragments the automobile road passes about 3 miles above El Portal.

Though earthquake shocks undeniably afford the most plausible explanation for the dislodgment of these huge blocks, nevertheless it must be admitted that there is no clear, uncontrovertible proof at hand. Any or all of these blocks could have been dislodged without the aid of an earthquake, simply as the result of the normal weathering and disintegration of the cliffs. For in many places in the Yosemite's walls, owing to irregularities in the joint structure, very large blocks are flanked or underlain by thin slabs or mere slivers of rock. As these small fragments are loosened and dislodged, ultimately the large blocks are left in unstable positions. Even if no earth tremors should intervene the time would eventually come when the blocks would tumble down for lack of adequate support. Nor is the great distance at which each of the blocks in question lies from the parent wall necessarily any indication of earthquake action. Any block falling from a great height is likely to bound far out, and the larger and heavier the block the greater its momentum and the farther out it will bound.

The probability that the blocks described are of earthquake origin is gieatly increased by the fact that there are in the Yosemite region several masses of rock débris of enormous extent and wholly distinct from the ordinary sloping taluses by reason of their irregular, hummocky, sprawling forms, which can scarcely be accounted for save by the agency of earthquakes. One of these chaotic, far-flung masses obstructs the mouth of Tenaya Canyon and impounds Mirror Lake. It was derived from the wall back of the Washington Column and met lesser avalanches that fell, presumably at the same time, from the cliffs west of Half Dome. The water that issues from Mirror Lake in part percolates through the mass of débris, as is manifest at times of low water, when the stream bed is dry for a considerable distance.

Another far-flung mass of rock débris of the same character lies at the head of the Yosemite Valley, just south of Tenaya Canyon. It is spread out over a space of many acres and projects a quarter of a mile from the base of the head wall, necessitating a curve in the road south of Tenaya Creek. But the most remarkable body of earthquake débris is that which lies in front of El Capitan-not the talus of blocks that slopes steeply from the cliff to the valley floor, but the much vaster hummocky mass, partly obscured by a growth of trees and brush (it can not be detected in pl. 3), that sprawls nearly half a mile out into the valley, as far as the automobile road, which makes a detour around its edge. There can be no doubt that it is the product in the main of one colossal avalanche that came down from the whole height of the cliff face-probably the most spectacular rock avalanche that has fallen in the Yosemite Valley since the glacial epoch.

El Capitan is so often referred to as the very embodiment of the proverbial "rock of ages" that to many readers this may seem surprising news. Indeed, the sweeping concave lines of its great façade are usually regarded as characteristic products of glacial erosion that have suffered scarcely any change from postglacial weathering. Some observers, even, have believed that they could detect on its face the gleam of glacier polish. Yet the quantity of débris that fell in this stupendous earthquake avalanche is so greatit covers nearly a quarter of a square mile of ground to an estimated depth of fully 100 feet-that its removal doubtless altered appreciably the contour and appearance of El Capitan.

All the great masses of débris just described must have fallen a long time ago, for they all support old and large trees. Perhaps they were all precipitated by that severe earthquake which originated near Mono Lake. Apparently only moderate quakes have occurred since then. The quake of 1872 probably was one of the strongest that has taken place during historic time. No tremors of any consequence have made themselves felt in the Yosemite Valley since. Indeed, the Sierra Nevada is to-day a region of marked stability, and this fact is strikingly attested by the presence on the walls of the Yosemite of precariously balanced pinnacles and rocks such as the Agassiz Column (pl. 47, $B$ ), which stands near the trail just below Union Point.

\section{TORRENT FANS AND TORRENT CHANNELS}

The débris piles everywhere are subject to the washing action of rain-water rills. As a result they are fringed by gently sloping aprons of granite sand that spread some distance out upon the floor of the valley. In those places, however, where the water is concen- 
trated into torrents of considerable volume not merely sand grains are washed down but blocks of all sizes up to 10 and even 15 feet in diameter, and these coarse materials are spread out in what are properly termed fans. This is true especially at the mouths of deep-cut recesses from which the storm waters issue in shortlived torrents of well-nigh incredible swiftness and power. The larger of these torrent fans of coarse débris are indicated by a special symbol on the map of glacial and postglacial deposits. (See pl. 29.)

Most typically developed is the torrent fan at the mouth of the recess between the Three Brothers and the massif of El Capitan. Narrowest at its upper end, where the water issues from a rock channel, it deploys symmetrically downward in true fan shape, its surface furrowed by numerous diverging channels. Its upper part, which is composed of the coarsest material, is steepest and has a gradient of 5 feet in 10; its lower margin, which is composed of the finest material, is flattest and merges into the floor of the valley. The size of the fan and the quantity of material which it contains might seem out of proportion to the small extent of the recess and the circumscribed area that is tributary to it. The recess is only $1 \frac{1}{4}$ miles long and receives no drainage from any hanging upland valley but heads abruptly against the rim, not far back of Eagle Peak. Its entire drainage area is considerably less than 1 square mile. However, the upper funnelshaped part of the recess is inclosed almost wholly by steep slopes of bare, smooth granite from which the storm waters run off with amazing speed; and the principal drainage lines converge to one point and are so nearly of equal length and equal steepness that the waters reach the point of confluence almost simultaneously. The conditions, therefore, all operate to intensify torrential action. Finally, the recess contains, in addition to the rock waste derived from its own walls, a large body of morainal débris that was left in it by the ancient glaciers. This unconsolidated material gives way readily before the rushing waters and makes up a considerable part of the fan.

The most extraordinary features of the fan are the walls of blocks that flank the diverging channels on it. These are not natural levees of débris that was dropped at times of overflow-they are really walls, built of blocks superimposed one upon another. Most of them are only 3 to 5 feet in height, but some are twice as high. A few contain blocks 10 to 15 feet in diameter upon which rest smaller fragments that somehow have been thrown up there by the tumultuous waters.

The precise manner in which these channel walls are built by the torrents is not known from direct observation, but that the blocks are really tossed up and not merely dropped by overflowing water, is to be inferred from certain facts that were observed in 1919 , a short time after unusually violent torrential floods had taken place in the recesses near the Cathedral Spires as the result of a severe cloud-burst. The trees standing near to the channel walls were found barked and bruised by leaping blocks to a height of 5 to 8 feet, and many new blocks had been added to the walls, yet there was no evidence of overflow on the ground behind the walls. At the foot of each fan, where the water lost its momentum and spread out unconfined, was a field of blocks aggregating thousands of tons in weight. All of this material had been brought down in less than half an hour, probably during one great rush of water at the climax of the flood.

\section{EVOLUTION OF CLIFF SCULPTURE}

The detail sculpture of the walls of the Yosemite is by no means all of postglacial origin. Much of it was produced during the last stage of glaciation, when the valley was filled with ice only to one-third of its depth and when its cliffs were exposed to particularly intense frost action and to frequent wear by snow avalanches. Much of the sculpturing dates also from the relatively long interglacial stage that preceded, and the deeper recesses doubtless were initiated long before the ice age, while the Yosemite was passing through the mountain-valley and canyon stages of its earlier development. Nevertheless all its sculptured features may appropriately be treated together here, the purpose being rather to explain how they have been formed than to trace their origins.

\section{RELATION OF FORM TO STRUCTURE}

That the verticality of the walls of the Yosemite is due in large measure to the tendency of its granitic rocks to split along vertical partings, or joints, was first noted by Prof. Joseph Le Conte. ${ }^{71}$ The influence of the joints in determining sheer cliff profiles and angular rock forms was recognized also by Becker ${ }^{72}$ and Turner, ${ }^{73}$ who studied the jointing of the granite in the Yosemite region and the adjoining parts of the Sierra Nevada somewhat more closely. But until the topographic map of the valley (pl. 7) was made, there was available no detailed cartographic representation of the Yosemite cliffs on which the different joint systems and their effect upon the sculpture might be traced in detail. It is proposed here with the aid of this map and the available photographs to make a rapid survey of the cliffs, noting the more conspicuous instances of sculptural forms controlled by joint structure.

Sentinel Rock (pl. 19, A) affords an outstanding example. Its sheer, smooth cliff face is determined largely by a single nearly vertical joint plane. The

n Le Conte, Joseph, Ramblings through the High Sierra: Sierra Club Bull., vol. 3, p. $35,1900$.

7 Becker, $G$. F., The structure of a portion of the Sierra Nevada of California: Geol. Soc. America Bull., vol. 2, pp. 67-69, 1891.

73 Turner, H. W., The Pleistocene geology of the south-central Sierra Nevada, with especial reference to the origin of Yosemite Valley: California Acad. Sci. Proc., vol. 1, pp. 309-312, 1900. 
granodiorite of which it is formed has a sheeted structure, the nearly vertical joints, which trend in a northeasterly direction (see pl. 7), being developed to the exclusion of almost all joints in other directions. The influence of these northeasterly joints is evident also in the splintered crest of the spur of which Sentinel Rock forms part, in the sculpture of the rock mass at its base, in the steps over which Sentinel Creek cascades, and in the iruncated spurs for some distance along the south side of the valley.

In the neighborhood of Taft Point (pl. 8, $B$ ) oblique joints dipping $40^{\circ}-50^{\circ} \mathrm{W}$. begin to influence the cliff sculpture, and all the spurs are consequently more or less conspicuously asymmetric. The sloping west side of each spur coincides with one or more oblique joint planes, the precipitous east side is defined by a northwestward-trending vertical master joint, and the point is truncated by a sheer facet of the northeasterly joint system. All the minor sculptural features that diversify the spurs are similarly bounded by fractures of the three sets mentioned and are of asymmetric, rhombic pattern. Even stream erosion is here guided by structural planes. The streamlet that descends through the asymmetric gorge east of Profile Cliff cuts not vertically but obliquely downward, sliding sidewise, so to speak, along the plane of an inclined master joint. The overhang of Profile Cliff and of the entire west wall of the gorge is due to the undercutting action of the streamlet.

The astounding Fissures that gash the overhanging wall and edge of the gorge near Profile Cliff have developed along vertical joints of the northeasterly system. Probably the rock immediately adjacent to these partings was peculiarly susceptible to weathering, having been minutely sheared and slivered by faulting movements that took place under great pressure shortly after the granite had solidified. As a consequence the joints, which were at first mere cracks too narrow for a knife blade to enter, have become enlarged to gaping abysses too wide for a man to stride across. Their enlargement is the more surprising in view of the fact that no streams have ever made their way through them, the surface of the upland here sloping to the west, away from the edge of the gorge.

Oblique master joints, dipping to the west, account also for the asymmetric forms of the Cathedral Rocks. (See pl. 3.) Eastward-dipping joints, on the other hand, determine the angle of the rock slope on the west side of Bridalveil Creek. The V-shaped gulch of that stream owes its wonderful symmetry largely to the fact that the oblique joints controlling the inclination of each of its two sides dip toward one another at approximately the same angle. The finest example of asymmetric sculpture called forth by oblique master joints is presented by the massif of the Three Brothers. (See pl. 19, B.) Its three successive roofs slant with architectural regularity, all at a uniform angle, because they are determined by joint planes having the same westerly dip. The gables, on the other hand, are carved along vertical joint planes trending in a northeasterly direction. (See pl. 7.)

In the embayment east of the Cathedral Rocks (pl. 8, $B$ ), where diorite and gabbro are the prevailing rocks, the jointing is intense and chaotic, and the sculpture in consequence is intricate and irregular. The wall of the valley here is so thoroughly dissected by deep, ramifying gulches that it is reduced to a bewildering mass of craggy, slivered spurs. Some of the outstanding pinnacles consist of Bridalveil granite, sheets of which cut through the other rocks. Of this resistant and relatively massive granite are made also the twin shafts of the Cathedral Spires (pl. 18), which alone have survived the wholesale dismantling that has taken place roundabout them.

In the lower Yosemite chamber vertical joints predominate. Exclusive control by eastward and northward trending vertical joints is seen in the sheer square-cut cliffs that frame the recess of the Ribbon Fall. Easterly and northerly joints, combined with northeasterly and northwesterly joints, have influenced the shaping of the cliffs on the south side. So strong has been their directive control that in several places, notably below Crocker Point, the cliffs have been quarried back by the glaciers and have since been chiseled in detail irrespective of the positions of the drainage lines on the slopes above. In the Merced Gorge northwesterly and northeasterly joints of approximately equal strength have given rise to the clean-cut, prismatic forms along the edge of Turtleback Dome. (See pls. $43, A$, and 7.)

In the upper Yosemite chamber the most impressive example of a rock face determined by a single master joint is found in the great cliff at Glacier Point, shown in Plate 20, $B$. Though not without minor irregularities, it coincides throughout most of its height and length with one vertical joint plane trending almost due east. (See pl. 7.) The projecting slabs at its top (pls. 9, $B$, and $20, B$ ) are explained by the local development of horizontal fractures that interfere with the continuity of the vertical master joint. They were left overhanging when the last vertical rock sheet fell from the cliff face.

Below the main cliff at Glacier Point is a second, even higher cliff (about 1,200 feet) also defined by an eastward-trending master joint; and a short distance to the west is the singularly straight, narrow cleft through which the Ledge Trail leads steeply to Glacier Point - a cleft caused by weathering and erosion along a nearly vertical master fracture, probably a fault, that traverses the rock in a southeasterly direction.

In striking contrast to the colossal rock forms just mentioned are the finely chiseled, castellated, and columnar features in the vicinity of Moran Point and Union Point, which have been called forth by numer- 
ous intersecting joints, vertical, oblique, and horizontal. The best-known representative of this type of sculpture is the Agassiz Column (pl. 47, B) which stands, precariously balanced on a crumbling base, near the Glacier Point Short Trail, just below and east of Union Point. Every facet of this rock is determined by a joint plane.

Further scrutiny deserves to be given to the view in Plate $47, B$, for the clear relations between sculpture and structure in the cliffs about the Yosemite Falls that are revealed in its background. The alinement of the bushes in rows gives prominence to the few fractures that traverse the otherwise massive, bare rock and shows plainly that the two terraces to the right and the left of the Lower Yosemite Fall are defined by horizontal master joints, whereas the incline west of the Upper Yosemite Fall coincides with a zone of oblique master joints. These features are of peculiar human interest because, were it not for them, the building of a trail to the top of the Yosemite Falls (see pl. 7) would have been an extremely difficult feat to accomplish. As it is, the trail builder has taken advantage of the upper rock terrace to carry the trail from Columbia Rock to the embayment of the upper fall, and the upper flight of zigzags he has constructed on the incline produced by the oblique joints. (See also pl. 9, B.)

The 1,500-foot precipice over which the Upper Yosemite Fall (pl. 22) leaps is determined, like the cliff at Glacier Point, by an eastward-trending master joint. It is not strictly vertical but inclined at an angle of about $80^{\circ}$. Only the west half, which is composed of Sentinel granodiorite, approximates a plane, smooth wall, the east half, which is composed of El Capitan granite, being diversified by overlapping rock sheets. A narrow ledge defined by a horizontal master joint-Muir's famous Fern Ledge-extends westward across the face to and slightly beyond the path of the fall, about 450 feet above the base. This ledge is the most advanced part of the cliff, yet it is cleared by the main body of the fall, owing to the parabolic descent of the water. Below the ledge the cliff overhangs or leans out at angles ranging from $10^{\circ}$ to $30^{\circ}$, and at its base there is a deep cavern developed along another horizontal master joint.

A fuller description and interpretation of the features of this remarkable cliff can not be given here; it must suffice to point out that the fall has failed to carve a recess because the cliff as a whole has receded by the scaling off of immense rock sheets. The stubs of a considerable number of these are to be seen in the projecting buttress under Yosemite Point. The most remarkable remnant of such a sheet, however, is the gigantic tapering rock monument known as the Lost Arrow (pl. 22), which clings to the cliff east of the fall. It has a total height of about 1,500 feet, and its upper third stands detached, like a pin- nacle, the parting behind it having been enlarged to an open cleft, doubtless as a result largely of the destructive action of the spray from the fall which freezes in it in the winter.

It goes almost without saying that every one of the major waterfalls of the leaping type in the Yosemite region is, like the Upper Yosemite Fall, associated with a cliff determined by a vertical or nearly vertical master joint. The Lower Yosemite Fall (pl. 23, C) leaps over a northwestward-trending cliff; the Bridalveil (pl. 23, $A$ ) and Illilouette Falls, each over a northeastward-trending cliff; the Vernal Fall (pl. 10), again, over a northwestward-trending cliff. The precipice over which the Nevada Fall (pls. 10 and 25) descends is not so clearly determined by a master joint as the others just named, but its straight front and northeasterly trend unquestionably betray the influence of a northeasterly joint plane. At nearly every fall, moreover, the cliff cuts at an angle diagonally across the path of the stream and without reference to the direction in which the ancient glaciers moved: the directive control exercised by the rock structure is supreme, and its effect is unobscured by either stream or glacial erosion. On the other hand, the Cascades (pl. 23, B), the only major falls that are not of the leaping type, descend over irregularly fractured rock that does not stand in a smooth, clean-cut wall.

\section{INFLUENCE OF ZONES OF FRACTURING}

Among the most puzzling features of the walls of the Yosemite are the deeply cut recesses and gulches that occur at places where no streams or only insignificant streamlets come down from the upland. A striking example is the capacious recess west of El Capitan (see pl. 7), whose dimensions are out of all proportion to the little upland vale that drains into it. Not only is it many times as large as the recess cut by the Ribbon Fall, but it is larger than the embayment at the Upper Yosemite Fall. Nor can it be attributed to the eroding action of a powerful torrent that came from a melting glacier on the upland during the ice age, for the crown of El Capitan and the hills to the north and northwest of it have never borne any glacial ice.

Whitney, ${ }^{74}$ denying the possibility of its having been formed by the ordinary processes of erosion, sought to account for the recess and the other reentrant angles in the valley walls as by-products of the catastrophic downfaulting of the bottom of the Yosemite which he had postulated. Examination of the recess however, leaves no doubt that it has been developed in a zone of intensely fractured rock by the destructive action of ground water, frost, torrential rains, and snowslides. Several master joints converge toward the head of the recess, and between them the rock is cut by a multitude of cross joints, so that even its

\footnotetext{
7 Whitney, J. D., The Yosemite guide book, p. 83, 1870.
} 
more resistant portions stand up only in the form of a slivered, comblike crest. Naturally rock so thoroughly broken would yield much more readily to the dismantling agents than the exceptionally durable masses of undivided rock immediately adjacent. The lesson is made the more telling by the fact that the recess is carved in granite of the same kind as that of which the towering mass of El Capitan is composed. The contrast in sculpture is called forth by the contrast in structure.

Other sharply incised recesses that are similarly etched out, so to speak, along narrow zones of intense fracturing separate the three summits of the Cathedral Rocks (pls. 3 and 7 ) from one another. None of these recesses receives any drainage at its head. They cut across the backbone of the ridge and head against a slope that drains in the opposite direction. Selective quarrying by the Yosemite Glacier, which overwhelmed the Cathedral Rocks during the earlier glacial stages, may account in part for the cutting of these recesses, but it seems more probable, to judge from the large piles of débris at their mouths, that they have been sculptured mainly by the processes enumerated above during the long interval that has elapsed since the departure of the earlier ice.

The largest and deepest recess of this type is the gulch of Eagle Creek, west of the Three Brothers. It is larger than Indian Canyon, yet, unlike that canyon, it receives no drainage from any upland valley. Like the recess west of El Capitan, however, it has been developed along a zone of shattering, in which the sculpturing agents-in particular storm waters and snowslides, which converge in its funnel-like formhave worked with especial ease.

To this class of recesses belong also the mysterious notches, gulches, and alcoves cut in the lips of the hanging valleys near to but not at the waterfallsfeatures whose significance has long been a subject of speculation. Such are the broadly open notch west of the Upper Yosemite Fall (pl. 22), the alcove with overhanging roof at the head of the recess into which the Lower Yosemite Fall plunges, and the alcove at the head of the Illilouette Gorge, which is carved in the mountain side irrespective of the position of the Illilouette Fall. (See pl. 7.) Similar features occur on the steps of the giant stairway over which the Merced River descends. The cliff at the Vernal Fall is cut obliquely past the fall and heads southeast of it in an alcove with overhanging roof; and north of the Nevada Fall, at the base of Liberty Cap (pls. 25 and 10 ), is a gorge several hundred feet deep that is carved about 800 feet back into the lip of the Little Yosemite Valley.

The late Professor Branner ${ }^{75}$ offered the explanation that each of these notches, gorges, and alcoves

\footnotetext{
75 Branner, J. C., A topographic feature of the hanging valleys of the Yosemite: Jour. Geology, vol. 11, pp. 547-553, 1903.
}

marks the place where during the later part of the ice age a torrent flowing along the margin of the glacier in the valley above had poured over the brink. And he regarded these features as prima facie evidence of the superior cutting power of streams over glaciers. It is now realized, however, that the matter is not so simple as Professor Branner supposed, that the location and character of each notch, gorge, or alcove are determined by a zone of fracturing in the rock, and that several of these features have been produced without the agency of any glacial torrent. Each case differs somewhat from the others and must be considered by itself.

That the broadly open notch west of the Upper Yosemite Fall (pl. 22) was once the path of a stream flowing along the western margin of the Hoffmann Glacier can hardly be doubted, for what appears to be an old stream channel leading to the notch is traceable along the west side of the hanging valley for a quarter of a mile, and 1,600 feet below the brink, at the foot of the incline on which the zigzag trail is built, there appears from beneath the débris a deeply cut stream channel, now dry, that joins the gorge of Yosemite Creek a short distance above the lower fall. However, as already explained (p. 111), the incline and notch at the top are developed in a zone of strong oblique jointing. (See pls. $47, B$, and $9, B$.) This zone must have been peculiarly susceptible to glacial erosion as well as to stream erosion, and, as the general modeling of the notch and the incline is suggestive of glacial quarrying rather than of stream cutting, it seems a proper inference that these features were carved largely by the ice of the Hoffmann Glacier, which was confluent with the Yosemite Glacier during the earlier stages of the ice age. Erosion by a torrent followed when the Hoffmann Glacier had shrunk to a narrow ice tongue, but it lasted probably for a short period only and accomplished relatively small results.

Another recess, more sharply cut than that below the notch west of the Yosemite Fall, exists east of the fall, between Yosemite Point and the Castle Cliffs. (See pl. 9, B.) According to Branner's idea, this recess might be supposed to have been cut by a torrent that flowed along the eastern margin of the Hoffmann Glacier, but there is no trace of a channel that leads to its head. On the other hand, the rock in the recess is divided by numerous vertical joints and shows evidence of having been and of still being plucked away along this zone of weakness, presumably by torrential rains and snowslides chiefly.

The recess into which the Lower Yosemite Fall leaps (pls. 23, C, and 7) appears to have been eroded past this fall, yet there is no warrant for assuming that its sharp, undercut head marks a former site of the fall, for on the sloping ledges above the alcove there is no vestige of a stream channel. Here again an examination made at a time when the fall was dry dis- 
closed the fact that the recess has grown and is still growing headward along a narrow zone in which the rock is finely sheared and slivered by vertical fractures. Evidently the recess was initiated by Yosemite Creek and has been extended in the direction of the zone of shearing, irrespective of the position of the fall, by the wasting away of the slivered rock. In this process the flying spray from the fall doubtless has played and still plays a prominent part; by permeating the slivered material and by freezing in the interstices it materially hastens disintegration. The production of an alcove is explained by the fact that the vertical zone of shearing stops at a horizontal master joint above which the rock is massive.

The headward growth of the Illilouette Gorge (pl. 7) for a distance of 500 feet past the Illilouette Fall has a similar explanation. There is no evidence that any stream ever flowed along the margin of an ice tongue in the hanging valley above and poured down at the head of the gorge. Nor can the former existence of such a glacial stream properly be assumed, for, as has already been shown, the Illilouette Glacier at no time extended in the form of an ice tongue down to the lip of the valley. The facts are that the Illilouette Gorge has been excavated along a southwestwardtrending zone of fracturing, partly by the ice of the Merced Glacier, partly by the ordinary processes of weathering and stream erosion, and that it has continued to grow headward, past the fall, by the caving away of the rock in the zone of fracturing. Here, as in the recess at the lower Yosemite Fall, the spray from the falling water has been a potent factor in hastening disintegration.

The alcove southeast of the Vernal Fall (pls. 10 and 7) has been produced in a closely analogous manner. No glacial torrent was ever concerned with its making, but it has been "stoped out," to use a miner's term, at a place where the rock is traversed by many fractures. The overhanging roof of the alcove, on the other hand, is composed of relatively massive rock.

The gorge north of the Nevada Fall (pls. 25 and 7), through which the tourist trail to the Little Yosemite Valley is laid, is more nearly the kind of feature that Branner had in mind than any of those just considered. It was cut, in all probability, by a torrent that flowed along the northern margin of the Merced Glacier at a time when that glacier still occupied the Little Yosemite but had already melted back from the lower steps of the giant stairway. However, the fact must not be disregarded that the gorge coincides with a zone of fracturing-the only zone of that kind which traverses the otherwise massive granite at the mouth of the Little Yosemite. Were it not for the presence of this favoring structure, it may well be doubted whether the glacial torrent in the short period of its existence would have succeeded in trenching so deeply. No corresponding gorge exists on the south side of the Nevada
Fall, though doubtless there was a glacial torrent also along the southern margin of the Merced Glacier. But the granite on the. south side of the valley is extremely massive, and this fact suffices to explain the absence of a gorge.

It is to be borne in mind, further, that the zone of fracturing north of the Nevada Fall must have facilitated glacial erosion as well as stream erosion. The selective manner in which glaciers excavate in rocks of variable structure has already been explained (pp. 90-91). The most impressive product of such selective action by a glacier is the deep gorge between Liberty Cap and Mount Broderick, which was excavated along a northeastward-trending zone of vertical fractures. It is entirely probable, therefore, that the gorge north of the Nevada Fall was excavated in large part by the Merced Glacier and then was deepened somewhat further by the temporary glacial torrent.

In conclusion attention is invited to the gorges and gulches that are carved at the mouth of the hanging. valley of Snow Creek. (See pl. 7.) The deep central gorge, through which Snow Creek descends at the present time, doubtless has been the path of the stream for a long time- ever since the EI Portal stage of glaciation. The gorge has two heads, however, and it is a significant fact that the east head, which is dry, is just as deeply and sharply incised as the west head, through which Snow Creek now flows. There is, moreover, in the floor of the hanging valley a faint. remnant of an old channel that leads to the east head of the gorge. It is to be inferred, therefore, either that. Snow Creek formerly entered the gorge by the east. head, or else that a torrent flowing along the east. margin of the Snow Creek Glacier (in the El Portal stage) followed that path.

Half a mile west of the gorge of Snow Creek is a relatively shallow gulch through which the Mirror Lake and Soda Springs Trail ascends. This gulch in all likelihood was carved by a glacial torrent that flowed along the west side of the valley, but it may also be a temporary channel of Snow Creek itself. Indoed, it seems probable, in view of the great breadth of the valley, that during those phases of glaciation. when the Snow Creek Glacier extended to or nearly to the brink of Tenaya Canyon, the waters coming from the ice coursed to the lip of the valley by diverse and varying paths, not only because they were crowded aside by the ice body, but also because they were obstructed by masses of morainal débris. The gulches were cut, however, only in those places where the otherwise massive granite is traversed by numerous joints.

At the extreme east side of the hanging valley, near Mount Watkins, is still another sharply incised gulch. This gulch may possibly have been the path of a glacial torrent at one time or another, but it seems more probable, in view of the absence of any channel 
leading to its head, that it has been carved, like many other features of its type, solely by the processes of disintegration and erosion previously mentioned along a narrow zone of intense fracturing.

\section{FORMS CARVED IN MASSIVE ROCK}

In striking contrast to the angular, faceted types of sculpture that are called forth in jointed rocks are the smoothly rounded forms produced in unjointed, massive rocks. The domes of the Yosemite region are the outstanding representatives of this class. Each of them consists of a wholly undivided body of granite, a gigantic monolith. The same is true also of the whaleback spurs, cylindrical ridges, and conoidal buttresses, which are closely allied to the domes. Indeed, the Yosemite region is peculiarly rich in such distinctive forms carved from massive granite; it contains a greater and more varied assemblage of them than any other area of similar extent in the Sierra Nevada or, perhaps, anywhere on the earth.

There have been various misconceptions, among scientists as well as laymen, regarding the origin of these smoothly rounded forms. Whitney ${ }^{76}$ conceived the domes "to have been formed by the process of upheaval itself," for he could "discover nothing about them which looks like the result of ordinary denudation." Galen Clark, ${ }^{77}$ the old pioneer of the Sierra, who became the first guardian of the Yosemite State Park, evidently influenced by Whitney's conception, supposed the domes to have been forced up by the pressure of gas from underneath at a time when the granite was still in a semiplastic condition, and he imagined the Yosemite to have been created by the bursting open of several domes in a row. But Clark's and Whitney's views need scarcely more than passing mention here, for they do not take into account the now well-established fact that granite is inherently a material of deep-seated origin that has crystallized under a confining roof or crust of older rocks and that has not flowed out upon the surface of the earth (p. 25). The domes in any event can not be original surface forms but must have resulted from the action of erosive processes of some sort, after the granite had become uncovered.

A belief that has long been widely prevalent is that the domes are essentially gigantic "roches moutonnées," worn round by mighty overriding glaciers. The late Prof. Joseph Le Conte ${ }^{78}$ was among those who gave voice to this belief. He supposed that "the whole surface of the region with its greater and smaller domes had been molded beneath a universal ice sheet or confluent glacier which moved onward with a steady current careless of domes." Le Conte had no means of

\footnotetext{
76 Whitney, J. D., Geology of California, vol. 1, p. 421, 1865.

7 Clark, Galen, in Salter, N. L., Yosemite Valley, pp. 23-24, 1910.

ro Le Conte, Joseph, Ancient glaciers of the Sierras: Am. Jour. Sci., 3d ser., vol 5, pp. $328,338,1873$.
}

testing the soundness of this idea, but there is now abundant proof that the Sierra Nevada was never overwhelmed by a "universal ice sheet" but bore only glaciers of local origin, and the depth to which these glaciers covered the Yosemite region is known within a narrow margin of error from the survey of the moraines. (See pp. 73, 82). Several of the domes, it can be stated positively, were never overtopped by the ice of the glacial epoch: Sentinel Dome stood wholly above the highest level of glaciation; all of the bare, domelike part of Mount Starr King has remained untouched by the ice; and the crown of Half Dome rose like a rocky isle fully 500 feet above the surface of the Merced and Tenaya Glaciers, which coalesced about it. Yet these domes are among the most conspicuous and most typical domes of the Yosemite region. That glacial abrasion is not a necessary factor in the development of domes is demonstrated, further, by the fact that the celebrated Stone Mountain, near Atlanta, Ga., which is a granite dome of precisely the same type as those of the Yosemite region, stands 300 miles south of the southernmost limit reached by the continental ice sheet in the eastern part of the United States.

It is now generally recognized by geologists that the domes owe their rounded forms to the exfoliation of massive granite - that is, the casting off. of successive curving shells or scales from their exposed surfaces. Every dome bears a number of such curving shells, arranged concentrically about one another like the layers of an onion, and the outer ones, it is evident, break up in the course of time and drop off. On Sentinel Dome (pl. 21, $A$ ) which is readily accessible, this concentric shell structure may be studied at close hand. The shells are seen to vary from about half a foot to several feet in thickness. The outer shells are as a rule the thinnest. On Half Dome some of the shells are 6 to 10 feet thick, and in the Royal Arches shells measuring 10 to more than 100 feet in thickness are displayed, but these massive shells are truly exceptional. The aggregate thickness of all the shells on a dome varies widely but seldom exceeds 100 feet.

The cause of exfoliation is at the time of this writing still somewhat of a mystery. That the shells burst loose from the core of a dome because of expansive stresses in the granite is clear from the facts of observation (see pl. $48, A$ ) as well as from the principles of mechanics, but how the expansive stresses originate is a matter of doubt. External heating of the rock by the rays of the sun is unquestionably a factor, for the quarrymen on Stone Mountain, who produce shells artificially - by blasting and pneumatic pressure-find that their process is effective only in the summer, when the rock is warmed by the sun. But neither solar nor seasonal warming nor the two combined, are found, upon mathematical analysis, to be capable of producing stresses powerful enough to disrupt granite to depths of as much as 100 feet. Neither can the 


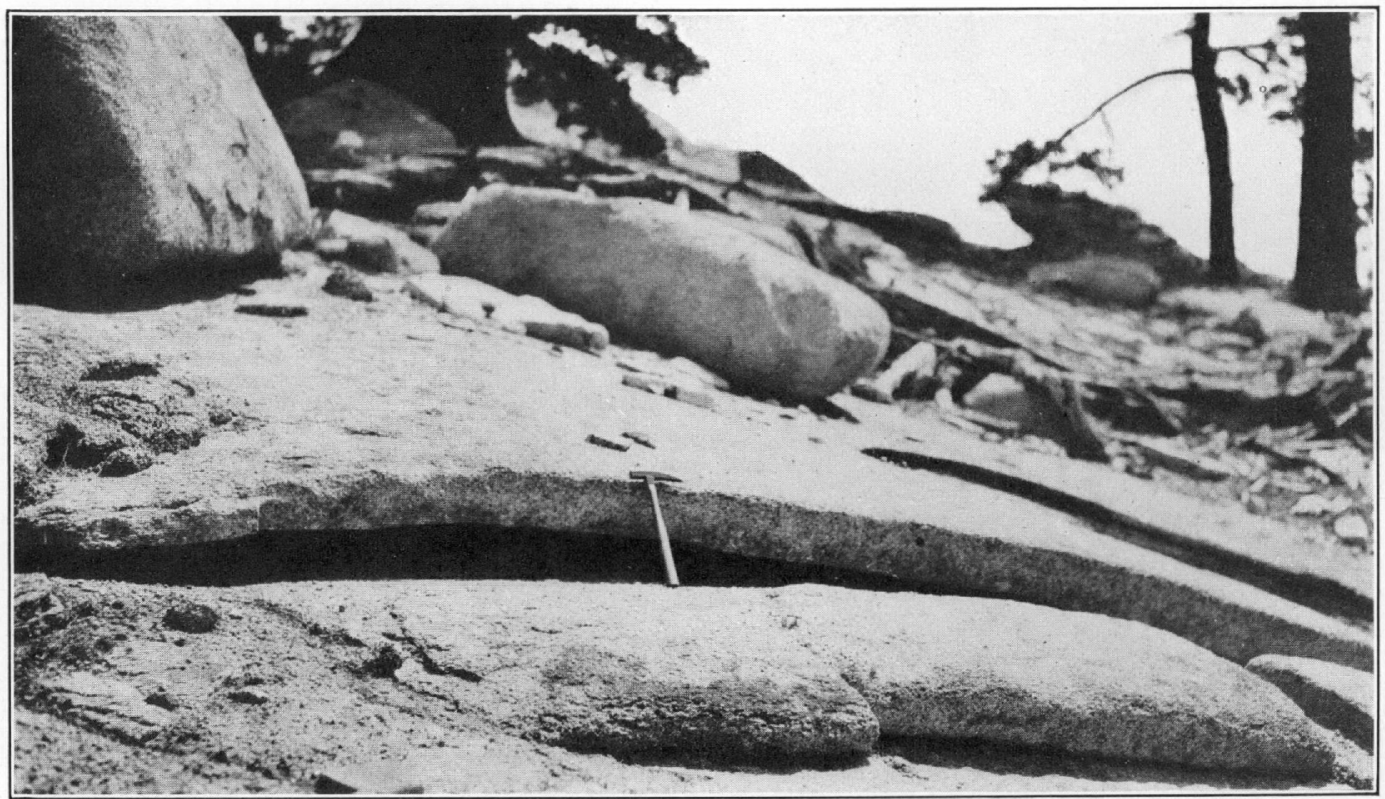

A. ARCIIED EXFOLIATION SHELI.

That exfoliation is due to expansion of the granite is demonstrated by the uparcling of this shell on the shoulder of Clouds Rest. which was prevented from expanding laterally.

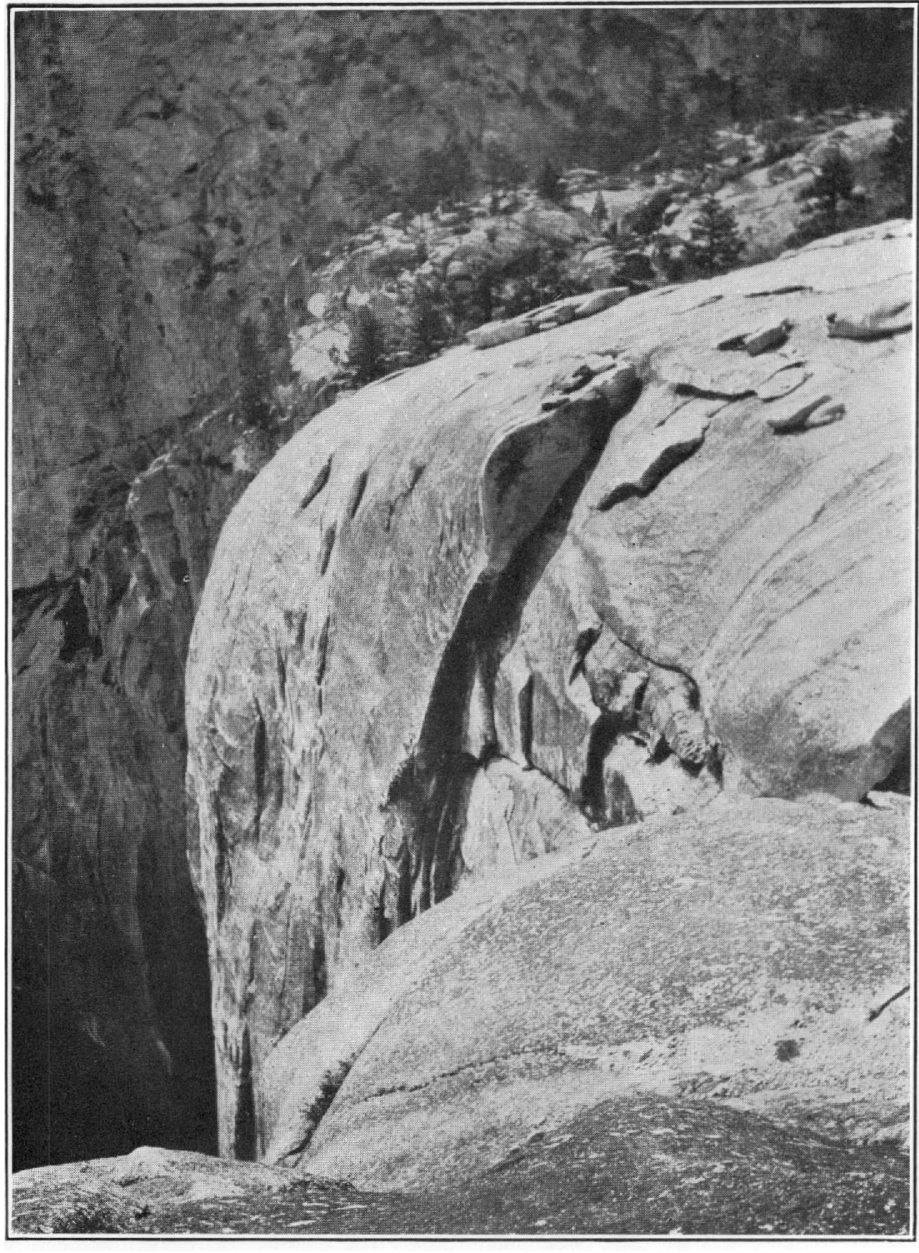

B. BHINK OF I'RECIIICE OF UPPEI YOSEMITE FALL

The edge was oriminally square cut, but it has become rounded by the casting off of successive shells. A part of an old, sharply curved shell still remains in place.

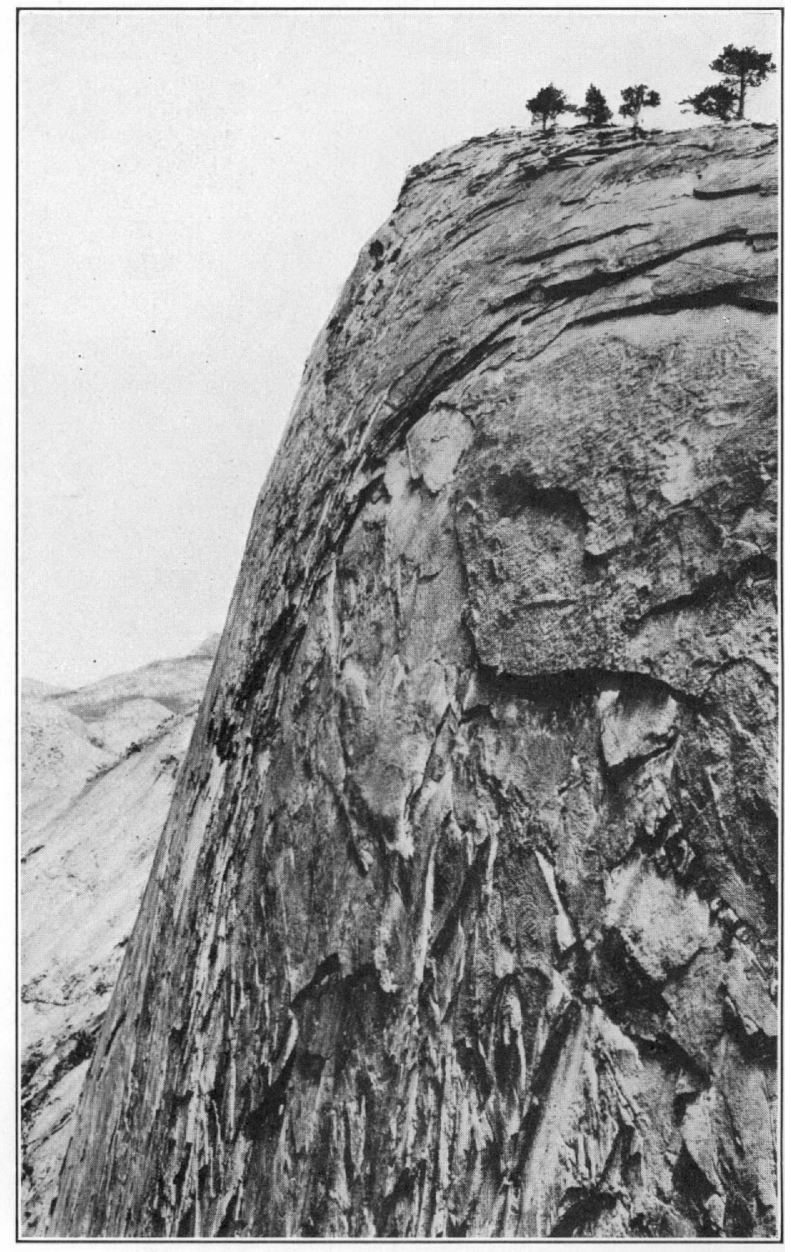

C. EXFOLIATING GRANITE ON LOWER QUARTER DOME

This rock mass had originally ancular solues and a sharp point, hut these are now largely transformed into smooth curves by exfolialion. 


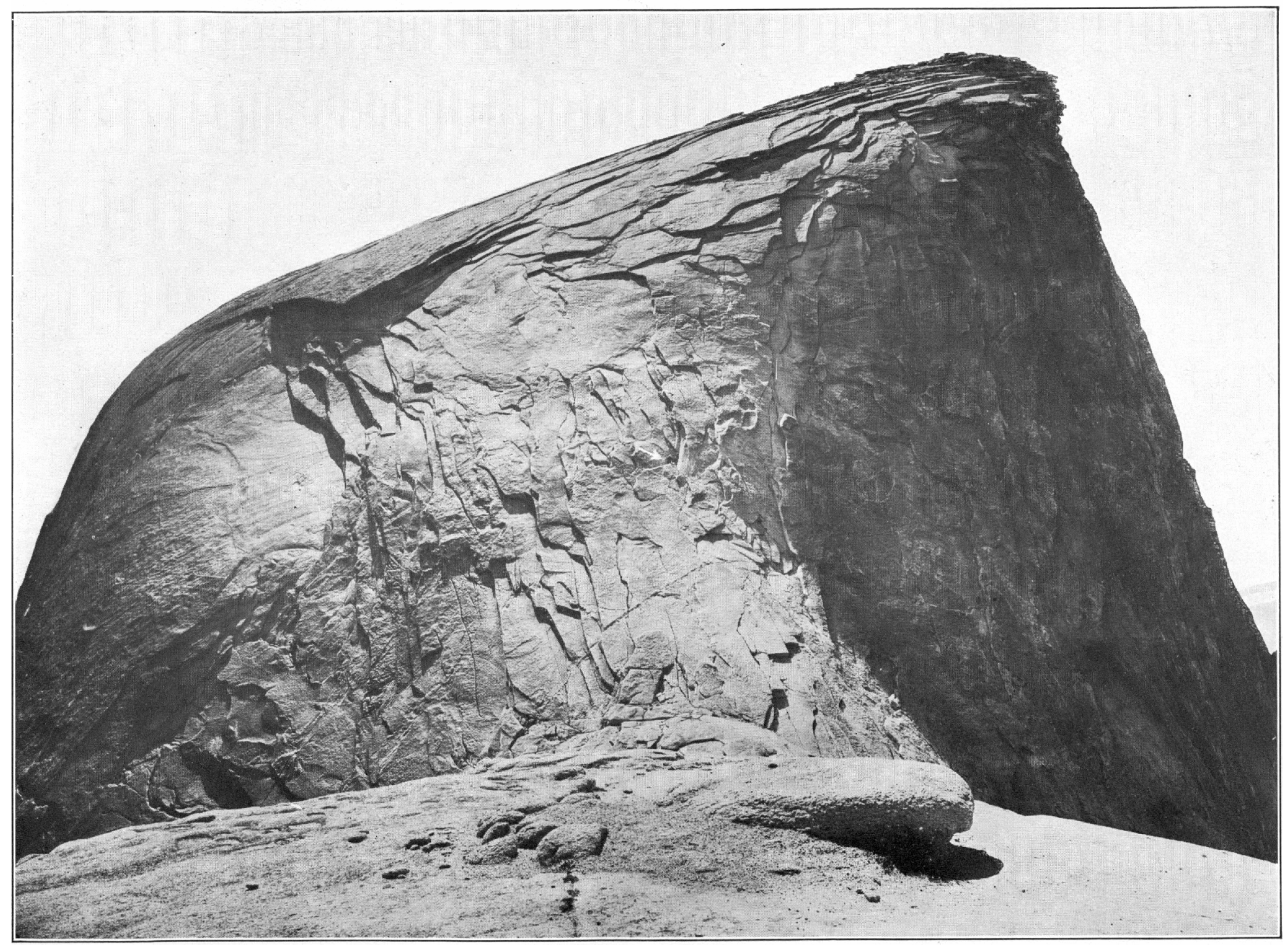

\section{NORTHEAST' SIDE OF HALF DOME} This view, taken from the subsidiary dome at the northeast end of the rock mass, reveals exfoliation on a gigantic scale. The white arrow poinls to a man, half way up the slope. In 


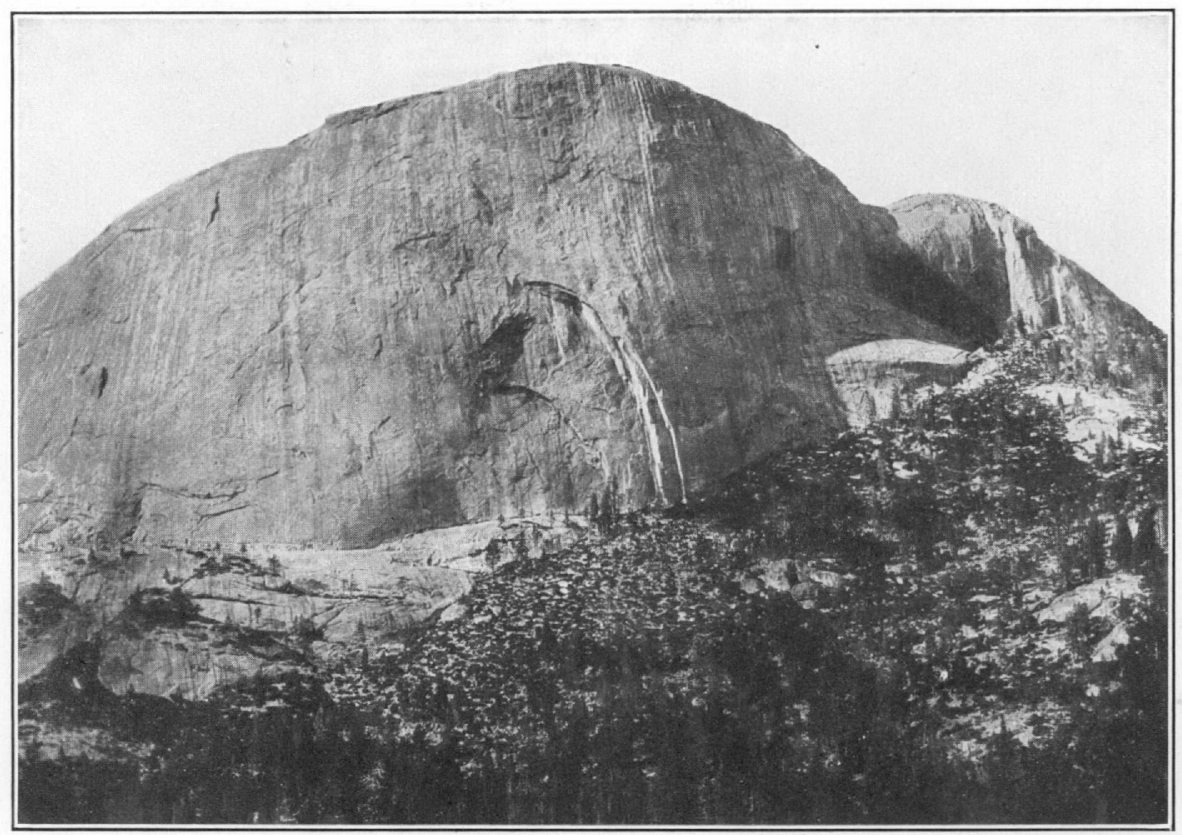

1. BACK OF HALF DOME

'The curving hack of Finlf Dome is enveloped largcly hy a single, enormous shell. Its surface is not only striped with lichens, as are most clifts in the Yosemite region, hut it is in places fluted, the rock grains washed down from the summit having worn furrows in it several feet in depth. At the base are several imperfect arches produced by the droping off of parts of shells.

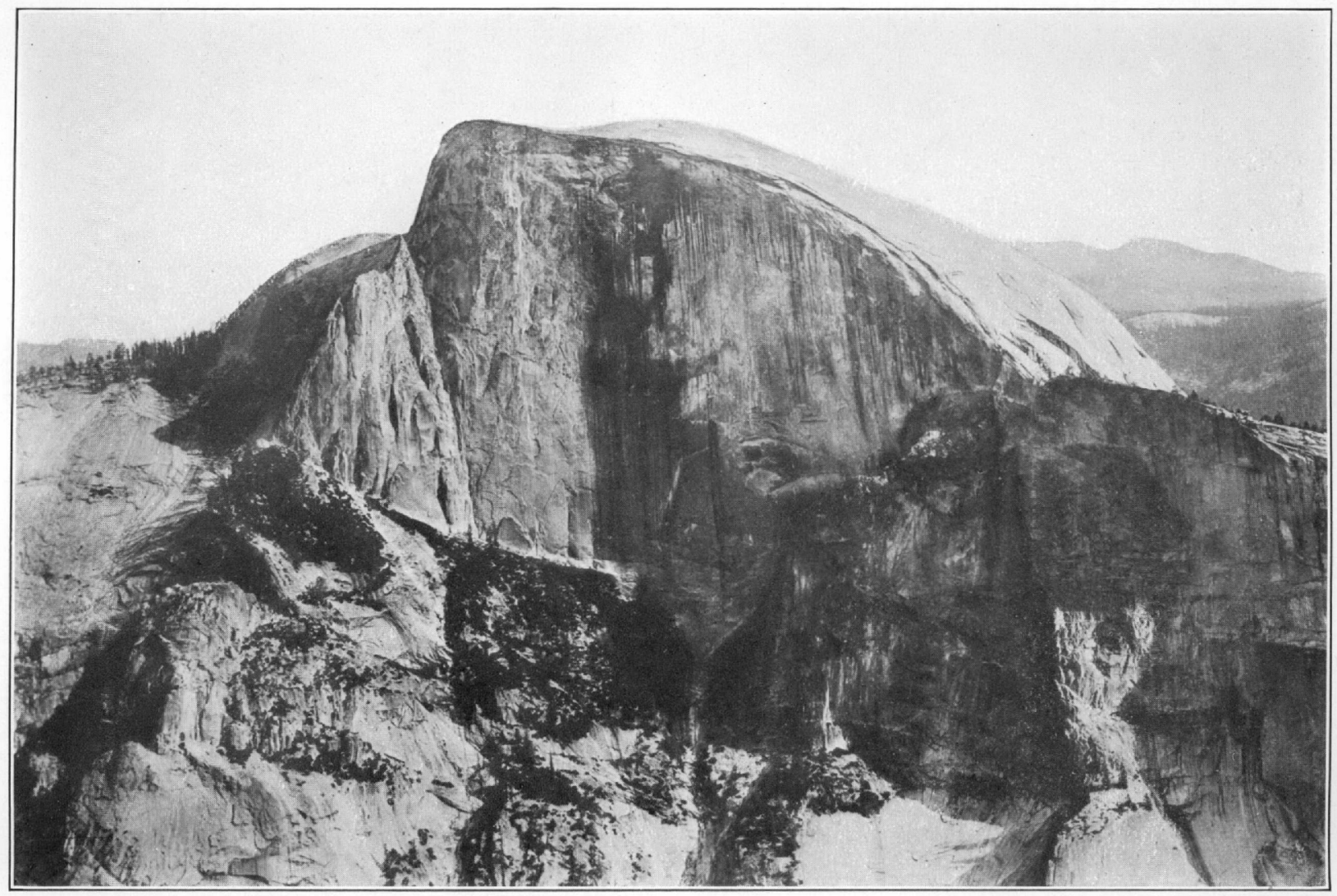

b. FRONT OH HALF DUML

The eliff came into existence first hy the removal of thin rock sheets from a zone of nearly vertical joints, still visible in the shoulder at the northeist (left) end. The preat monolith then began to exfoliate at its newly exposed surface, in plane shelis curving under the old shells at the top. The old shells now form au overhanging corvice. 

swelling of the granite as a result of hydration-that is, the chemical union of water with the constituent minerals-be a competent cause. It can be at most only a feeble subsidiary cause, for microscopic examinations of rock taken from some of the outermost and oldest shells of exfoliating bodies of granite reveal only signs of very moderate hydration. Not to go into an exhaustive discussion of all the processes that may possibly be concerned in the production of exfoliation shells, it may be stated that for the present the most probable cause is held to be simply the relief from pressure experienced by the granite as the superincumbent masses of rock are removed by erosion. As the load diminishes naturally expansive stresses are liberated within the granite. In jointed rock such stresses are relieved by slight readjustments along the numerous fracture planes, but in massive rock the stresses accumulate until at last they cause rupture along partings approximately parallel to the exposed surface.

Whatever may be the ultimate cause of exfoliation, the manner in which the process operates to produce smoothly rounded forms is sufficiently clear from the numerous examples at hand. Its tendency is first to eliminate projecting corners and angles and to replace them by fairly sharp curves, as shown in Figure 38. With the dropping off of the succeeding shells these sharp curves are replaced by more and more gentle curves, and thus in the course of time a smoothly and continuously rounded surface is evolved. A striking illustration of the successive steps in the process is afforded at the brink of the great precipice of the Upper Yosemite Fall, near the top of the Lost Arrow. (See pl. 48, B.) Doubtless there was originally a square edge, produced by the dropping away of the huge sheet of rock of which the Lost Arrow is the principal remnant; but in the course of the 200,000 years or more that has elapsed since the El Portal glaciation (the later ice did not touch the cliff) the square edge has been transformed by progressive exfoliation to a gently curving one. At one place, however, there still remains part of what was presumably the second shell to be formed, characterized by a sharply curving outer surface. The next shell under it is much more gently curved, and the next more gently still.

Similar but on a larger scale are the exfoliation features displayed at the edges of the Quarter Domes. (See pl. 48, C.) As is clear from Plate 7, each of these two domes owes its peculiar configuration to the controlling influence on the side facing Tenay a Canyon of a northeasterly and a northwesterly master joint that intersect each other at approximately right angles. Each dome doubtless had, at the end of the El Portal glaciation, a fairly sharp point and angular edges, but through exfoliation these points and angles have been blunted and rounded off. On the lower Quarter Dome (pl. $48, C$ ) a sufficient number of the older shells remain in place to give some indication of the original point and edges.

In both of the examples above noted the exfoliation features were produced since the El Portal glaciation. The length of time involved in their development is therefore known approximately, and thus some idea may be had of the rate at which exfoliation shells are formed. In each instance 2,000 centuries was required for the moderate rounding off by exfoliation of an originally angular edge. The postglacial interval, which comprised only about 200 centuries, was too short, in many places, for the production of a single shell. The crown and back of Mount Broderick (pl. 44, A), which were stripped of all their shells by the overriding Merced Glacier of the Wisconsin stage, still show no signs of renewed exfoliation over the greater part of their surfaces. The severely glaciated sides of the Little Yosemite likewise are devoid of shells over large areas. Only here and there a new, thin shell has recently been detached from them.

From these facts it is evident that the domes of the Yosemite region have been a long time in the making;

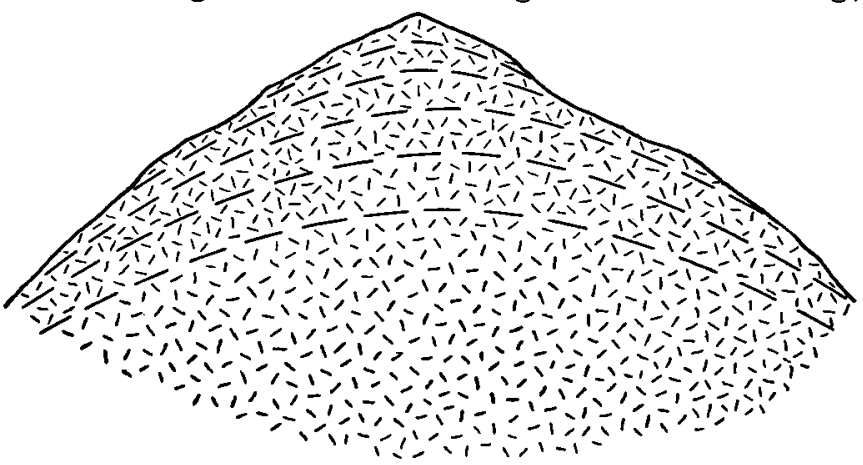

FIgURE 38.-Diagram showing how, by progressive exfoliation, the angularities of a rock mass are replaced by smooth curves

they are among the oldest features of its landscape. Their sweeping curves attest their great antiquity. Domes such as Sentinel Dome and Mount Starr King, which stand above the general level of the Yosemite upland, doubtless were in process of exfoliation as far back as the Miocene epoch, at least $8,000,000$ years ago, when the upland was still an undulating lowland and when the Merced River flowed in a broadly open, shallow valley. It follows that these domes, as they now appear, are the much reduced, rounded-off remnants of originally much larger rock masses.

It is probable that all the domes of the Yosemite region were at first more or less angular and irregularly shaped, for they were originally surrounded by jointed rock. Some suggestion of their original forms still remains in their present outlines. None of the domes are wholly symmetrical. Every one of them is elongated in some one direction and more or less pronouncedly one-sided. (See pl. 7.) They really grade over into whaleback ridges such as Mount Watkins, Boundary Hill, and the summit of El Capitan. Straight sides 
are a common feature of them, and there is little doubt that the trend of these sides is inherited from master fractures that bounded the original rock masses. North Dome, for instance, appears to be derived from a rock mass bounded by north-south master joints, and the cylindrical ridge immediately north of it evidently was delimited originally by northeasterly master joints. Mount Watkins, Half Dome, Mount Broderick, Liberty Cap, and the whaleback spurs of the Starr King group also betray in their outlines the controlling influence of northeasterly joints.

In the features of Half Dome the student of dome development will read the most interesting story. The curving back of the dome (pls. 49 and 50, $A$ ) is evidently a product of long-continued exfoliation. Shells have been formed on it and have dropped from it in succession for millions of years. That the process must have been extremely slow may be judged from the fact that the huge shell which at present envelops almost the entire back of the dome has been in place so long that furrows several feet in depth have been worn in it by the rock grains washed from the crown. The central parts of the shell have so many of these furrows that they present a ribbed or fluted appearance. (See pl. $50, A$.)

On the broad crown of Half Dome, where gravity and snowslides are not effective removing agents, the shells remain in place still longer. They remain, in fact, until, mainly as a result of daily heating by the sun, in less measure because of recurrent frost action, they disintegrate into mere slivers and grains of rock. As a consequence the dome bears on its summit a great accumulation of old shells, the aggregate thickness being estimated at 90 to 100 feet.

The straight, sheer front of Half Dome is by comparison a rather new feature, yet it too has suffered from exfoliation. Its general trend and its angle of declivity (about $82^{\circ}$ ) were determined by a zone of nearly vertical joints extending in a northeasterly direction. This sheeted structure terminated in the shoulder at the northeast end of the cliff face, as may be seen in Plate 50, $B$, and it has given rise to a sharply incised notch at the southwest end. (See pl. 7.) Doubtless the thin sheets were readily plucked away by the Tenaya Glacier, which during the earlier stages of glaciation reached within 500 feet of the top of the dome. (See fig. 23.) Then, the body of the monolith being exposed, it began to exfoliate in plane sheets parallel to the zone of joints but curving in under the old shells at the top. Perhaps the Tenay a Glacier plucked away some of these newly formed sheets also, but it seems more probable that the exfoliation took place largely during the interval following the El Portal glaciation. The ice of the Wisconsin stage did not reach the base of the cliff. (See fig. 23.) In any event the sheets sealed off in relatively rapid succession, owing to their verticality and the intense frost action that prevails on the shaded northwest side of the dome, and as a consequence the old shells on the summit were left overhanging, and there was formed the cornice which projects from the top of the cliff.

This modern interpretation of the evolution of Half Dome, it will be seen, finds no room for any assumed demolition of one-half of the dome. No such assumption appears justified by the facts known about the structure of the rock on the northwest side of Half Dome, nor would it accord with the present conception of the erosional origin of the Yosemite Valley and Tenaya Canyon. Had there been another half of the dome consisting of a gigantic monolith, it would be still in existence to-day, for neither the Tenaya Glacier nor the agents of normal erosion that shaped the preglacial valley of Tenaya Creek could have demolished it.

A rare type of sculpture produced characteristically in exfoliating granite and associated with the domes consists of successive arches recessed one within another. The back of Half Dome (pl. 50, $A$ ) presents an imperfect example that is nevertheless instructive because it shows clearly how such arches originate through the caving off of the lower portions of shells. The remaining portion of each shell naturally tends to assume the shape of an arch, because the arch is, as architects well know, the form of structure best adapted to bearing a heavy distributed load. The finest example is afforded by the Royal Arches. (See pl. 21, B.) They are fashioned on a colossal scale, the main arch rising to a height of 1,000 feet (measured to its underside) and having a span of 1,800 feet. Many of the shells range from 10 to 80 feet in thickness, and several of them unite near the top of the main arch to form one shell nearly 200 feet thick. The Yosemite Glacier was the principal sculptor; during the last stage of glaciation it plucked away the lower portions of the shells, which had previously been loosened by exfoliation from a partial, low-set dome that bulged out into the valley. The great strength of the massive shells has permitted the forming of exceptionally high and broad arches, and the homogeneity of the granite has given rise to unusually perfect, smooth curvature. A short distance west of the Royal Arches is another set of arches, sculptured likewise by the Yosemite Glacier but from much thinner shells. (See pl. 16, B.) Because of their proximity to the Royal Arches they receive little attention, yet they are a good average example of the type as it occurs in different parts of the Sierra Nevada.

In conclusion it is to be pointed out that the shells produced by exfoliation are not invariably convexly curved. As has been shown, on the cliff face of Half Dome they are plane, and the same is true in other places, notably on the south side of the Little Yosemite. There are, however, also examples of concave exfoliation, the shells produced having hollow outer surfaces. 
Wherever a powerful glacier, after plucking away all the exfoliation shells, gouges into a structureless mass of granite in the bottom or side of its channel, it tends to grind out a smoothly concave surface. When later exfoliation begins anew, it produces concave shells. Imperfect examples of concave shells are to be seen in the salient of El Capitan (pls. 3 and 17), which is itself an imperfect dome, not wholly massive throughout, that has been vigorously gouged into by the Yosemite Glacier. Much finer examples of concave exfoliation are afforded by Mount Watkins, whose southeast side was gouged into by the Tenaya Glacier, and by the shallow glacial cirques that scallop the great cliff front of Clouds Rest. (See pl. 40, B.) Concave exfoliation on a large scale is exhibited in the canyon of the Merced River above the Vernal Fall. The sides and floor of that canyon exfoliate in more or less concave shells parallel to its U-shaped cross profile. Emerald Pool occupies the central basin gouged by the Merced Glacier in massive granite. Many similar examples of glacial $U$ canyons and cirques whose walls and floors exfoliate in concave curves exist in the High Sierra above the Yosemite region. It is not to be supposed that these canyons and cirques were excavated in rock that was traversed originally by concentric $U$ partings; on the contrary, the partings have been developed since the canyons and cirques were gouged out.

A host of other remarkable rock forms due to exfoliation might here be mentioned, not only in the Yosemite Valley but in the Little Yosemite, in Tenaya Canyon, on the Yosemite upland, and in the adjoining parts of the High Sierra. Indeed, it may be conservatively estimated that nearly half of the landscape features of these regions owe their modeling to exfoliation. But the foregoing brief explanations must suffice; they will at least furnish the key to the interpretation of all those features.

\section{SUMMARY AND CONCLUSIONS}

The geologic history of the Yosemite Valley, so far as present knowledge permits, may be epitomized as follows:

Probably early in the Tertiary period the area now occupied by the Sierra Nevada first acquired an appreciable slant to the southwest, and the Merced River came into existence as a southwestward-flowing master stream. For long periods thereafter the region, though affected by sundry gentle upwarpings, remained of moderate altitude, and the valley of the Merced was shallow and sloped gently to the sea, which then occupied most of the Great Valley of California. During that stage in the Miocene epoch of which definite indications still remain visible in the features of the Yosemite upland the river, by sluggishly winding from side to side, gave its valley a broad, level floor. That part of the valley which was destined to become the Yosemite was flanked by rolling hills averaging less than 1,000 feet in height. The crown of El Capitan was one of those hills. It rose from the valley in gentle slopes to a height of about 900 feet. Half Dome and Clouds Rest, however, stood well above the general level of the hills, being less slowly reduced by erosion because of the exceedingly massive nature of their rocks, and the region about the headwaters of the Merced was diversified by parallel mountain ranges 1,000 to 3,000 feet in height-remnants of an earlier mountain system. The climate was mild and rainy, and the land was covered by luxuriant vegetation.

In the later part of the Miocene epoch there set in a series of uplifts that raised the eastern border of the Sierra region several thousand feet and steepened its western slope. Fault fractures were formed along certain parts of the eastern border, and the country beyond subsided in part or remained relatively low, and thus the Sierra came to stand out as a tilted mountain block. The flow of the Merced River having been greatly accelerated by the tilting, that stream intrenched itself rapidly in the floor of its old broad valley and carved a narrow inner gorge. During the ensuing interval of stability, which lasted through all of the Pliocene epoch, this gorge developed gradually into a rugged mountain valley more than 1,000 feet in depth.

The tributary streams were not accelerated by the tilting as much as the Merced. A number of these streams, having courses inherited from the earlier mountain system and trending at right angles to the master stream and therefore at right angles to the direction of the tilting, were not steepened at all and flowed no faster than before. Their valleys, consequently, remained hanging untrenched above the gorge of the master stream. Later, when the master stream had cut its gorge down to a low gradient and was trenching with less vigor, most of the tributary streams caught up with it - all but a few in the Yosemite region whose valleys were underlain by exceptionally resistant, massive granite and which succeeded only in notching the mouths of their hanging valleys with short, steep gulches. Accordingly, by the end of the Tertiary period the Yosemite had become a mountain valley about 1,500 feet deep flanked by billowy uplands from whose hanging valleys the waters cascaded down through steep gulches. Yosemite Creek made a cascade fully 600 feet in height.

The beginning of the Quaternary period was marked by a second series of uplifts, which were greater even than the first series. The eastern edge of the Sierra block was raised about 6,000 feet more and gained its present great altitude. At the same time Owens Valley and the other lowlands to the east were depressed, or remained low, and thus the great eastward-facing escarpment of the range was formed. The course of the Merced having again been steepened, that stream was accelerated to torrential speed. Its cutting power 
was enhanced, moreover, by spring freshets caused by the melting of snow that now fell in abundance on the crest of the range in winter, and so the river intrenched itself with greater energy than before. It produced a new inner gorge 1,500 feet in depth-the gorge in which it still flows from the lower end of the Yosemite Valley to the foothills.

As happened after the first uplift, so after the second, most of the tributary streams, especially those flowing at right angles to the direction of the tilting, were unable to trench as rapidly as the master stream. Even those which had previously succeeded in cutting their valleys down to the level of the Merced, among which were Illilouette Creek and the two forks of Indian Creek, were now unable to keep step with its vigorous cutting. And so the Yosemite acquired a second, lower set of hanging valleys and a second set of cascades.

Several streams, however, among which was Bridalveil Creek, being specially favored by local jointing in the rock, were able to carve short gulches that reached all the way down to the floor of the chasm. These gulches still afford some indication of the depth to which the Yosemite had been cut prior to the ice age. They show that it had a depth of 2,400 feet measured from the brow of El Capitan, and 2,000 feet below the rim at Glacier Point. It was a profound and rather narrow, roughly $V$-shaped canyon, with a three-story profile telling of three successive stages of cutting. Its sides were deeply gashed by ravines, and through these the waters cascaded boisterously from the hanging valleys. Yosemite Creek now made a cascade 1,900 feet in height.

During the glacial epoch of the Quaternary period the Yosemite chasm was invaded at least three times by a trunk glacier, formed at its head by the junction of two lesser glaciers that came from the High Sierraone through the upper Merced Canyon, the other through Tenaya Canyon. The earlier of these ice invasions reached to the vicinity of El Portal and filled the Yosemite to the brinks; but the last ice invasion was of relatively small extent, reaching only to the Bridalveil Meadow and filling the Yosemite to about one-third of its depth.

By these successive glaciations, but mainly by the great and prolonged earlier ones, the Yosemite was transformed from a strongly winding $\mathrm{V}$-shaped river canyon to a slightly sinuous U-shaped glacier trough. It was so greatly widened and deepened that the inner gorge was wholly wiped out, and even the mountain valley of the Pliocene epoch was largely destroyed. The craggy canyon sides were cut back to sheer cliffs, and the broken cascades were replaced by high leaping falls. What is more, the gulch of Bridalveil Creek was cut off by a 600 -foot precipice, and so the Bridalveil Fall was created.
Throughout the length of the valley, save at the portal between El Capitan and the Cathedral Rocks, which are largely massive, the glacier quarried the coarsely jointed granitic rocks with exceptional efficiency. At the head of the valley it produced the largest results, for there, during the periods of maximum glaciation, the ice plunged into the valley from the top of the head wall in a glacial Niagara of tremendous power. Thus the depth of glacial excavation was increased up the valley from 500 feet at the lower end to 1,500 feet at the head, and the bottom of the valley, which before the advent of the glaciers had a steep slope, was scooped out in the form of a basin. When the glacier finally melted away this rock basin, deepened in addition by a moraine dam, held a lake $5 \frac{1}{2}$ miles long-ancient Lake Yosemite.

Below the valley the prevailingly massive structure of the granite prevented glacial quarrying on any large scale, and as a consequence the valley there contracts abruptly and the inner gorge remains preserved.

In the Merced Canyon between the main valley and the Little Yosemite, the Merced Glacier, with the power derived from its 2,000-foot descent, hewed out the steps of the giant stairway, and in the Little Yosemite itself it scooped out a shallow rock basin analogous to that of Lake Yosemite. In Tenaya Canyon the ice produced a flight of imperfect steps with basined treads culminating in the 600 -foot step from which the Tenaya Cascade now descends. In Tenaya Canyon, however, the structure of the granite facilitated quarrying vertically downward but impeded widening, whereas in the Little Yosemite the structure facilitated lateral quarrying but impeded deepening. As a consequence Tenaya Canyon is deep but narrow, and the Little Yosemite is wide but shallow and remains suspended high above the main valley.

Since the ice age the basin of Lake Yosemite and the lesser basins in the Little Yosemite and Tenaya Canyon have been filled by forward-growing deltas of gravel and sand deposited by the streams. The cliffs have been dismantled in places, and the débris that has fallen from them has accumulated in piles at their feet. Huge avalanches of rock, some thrown down probably by earthquakes, have dammed Tenaya Canyon at its mouth, thereby impounding Mirror Lake; others have fallen from the face of El Capitan, and still others bave produced the Rock Slides, in the lower part of the valley, thereby creating slopes over which man has been able to build roads leading out to the uplands.

To the unusual and varied structure of its granitic rocks the Yosemite owes its highly distinctive cliff sculpture. The sparsely jointed granites have given rise to high, smooth walls; the more closely jointed rocks have been sculptured into angular, faceted forms, 
in which the controlling influence of master joints trending in different directions is evident. Narrow zones of intensely shattered rock, particularly vulnerable to the weathering processes, have been etched out here and there, giving rise to variously shaped recesses, clefts, and gulches, sharply incised into the walls. And the large bodies of wholly undivided, massive granite, by the progressive casting off of concentric shells from their surfaces, have been reduced to smoothly rounded domes.

The waterfalls of the Yosemite region, being intimately associated with the cliffs, also reflect the influences of the rock structure. The high leaping falls are associated with cliff faces determined by vertical or steeply inclined master joints; the broken cascades are associated with the hackled surfaces of rock masses traversed by numerous fractures; and the gliding cascades and spreading "aprons" are associated with large bodies of massive granite whose smooth surfaces are due in part to exfoliation, in part to glacial grinding. The story of the evolution of the Yosemite Valley, then, is a story of several chapters-of successive periods of valley and canyon cutting by the Merced River, induced by successive uplifts of the Sierra Nevada; of vigorous glaciation, several times repeated, during the ice age, the quarrying action of the ice being controlled and guided locally by the varying structure of the granitic rocks and giving rise to exceptionally bold, clean-cut sculptural effects; and finally of a period of dismantling, resulting in greater detail and intricacy of sculpture, the production of slopes of rock waste, and the formation of level valley floors. 


\section{APPENDIX}

THE GRANITIC ROCKS OF THE YOSEMITE REGION

By Frank C. Calkins

\section{INTRODUCTION}

At first glance the walls and domes of the Yosemite region appear to be formed of one and the same kind of rock, for they present no striking variations in color suggestive of different rock types. Gray tints prevail throughout, and it is difficult even for a discerning observer to tell at a distance in what measure the differences in shade are expressive of differences in rock composition and in what measure they are due merely to the varied distribution of the lichens that grow on the surface of the rocks. In reality, however, there are present in the Yosemite region about a dozen distinct types of rock, all granitic and ranging in color from nearly white through gray to nearly black; but so universal is the mottled effect produced by the lichens that the contrasts in rock color are greatly subdued, or even completely obscured, especially on the little-sunned northward-facing cliffs, on which the lichens form an almost continuous veneer.

In spite of the obscuring lichens, nevertheless, the walls of the Yosemite Valley afford an exceptionally instructive field for the student of igneous intrusion: In few places elsewhere can he behold in cross section a more remarkable complex of intrusive bodies. To the layman also the rock walls, when duly interpreted, present a display of unusual interest; they show him the astonishing details of a portion of the earth's crust that once lay miles below the surface, beneath the roots of a former mountain system, and that was disturbed by repeated upwellings of molten rock.

In the following pages it is proposed briefly to outline the nature and significance of this highly complex assemblage of rocks and to describe, without going too far into petrographic technicalities, the specific characters of the individual rock types, so as to afford a guide for their identification in the field. Technical terms can not be avoided altogether in such descriptions; still it is hoped that the reader will not be deterred thereby from perusing this chapter and thus gaining an acquaintance with the materials of which the walls and domes of the Yosemite Valley are built.

\section{GENERAL CHARACTER OF THE ROCKS}

The granitic rocks of the Yosemite region form part of the great central mass of igneous rocks (the batholith) of the Sierra Nevada, whose general character has been explained on page 25 . They consist of materials that have surged up in a molten state from the interior of the earth and that have crystallized under a confining roof of other rocks - the slate, quartzite, marble, and volcanic rocks of whose buckled and folded beds the ancestral Sierra ridges of Cretaceous time were made. (See table of geologic time divisions, p. 23.) That the granitic rocks are now exposed to view over large areas is due to the fact that in the course of periods aggregating about $100,000,000$ years the roof rocks were removed by the slow wearing action of streams and other eroding agents. The ancestral Sierras, once presumably thousands of feet in height, have vanished, only their roots remaining in the bodies of metamorphic rock that cover the lower slope and the crest of the present range.

In the Yosemite region a few small remnants of the ancient roof rocks remained preserved here and there, but these have been sufficiently described on page 26 and therefore will not be mentioned here.

The batholith of the Sierra Nevada is compositethat is, it is made up of a number of distinct bodies of igneous rock, each of which differs somewhat from its neighbors in mineral composition and represents a separate upflow of molten material. Of these component bodies many are of great extent, their areas at the surface being measured in hundreds of square miles. The uplands flanking the Yosemite Valley are made up almost wholly of such large intrusive bodies. The valley itself, on the contrary, crosses an area where many small intrusive bodies and narrow projections from the larger ones intersect each other in an intricate manner. Indeed, the rocks of the middle and lower parts of the Yosemite Valley are varied in composition and complex in their relationships to a degree exemplified in few areas of similar extent that have been described or mapped in detail. This complexity of the valley area, as compared with the relative simplicity of the surrounding areas, is clearly shown on the geologic map (pl. 51), even though the limitations imposed by the scale require the omission of many of the lesser intrusive bodies.

The species of rock represented in the Yosemite region range from nearly black hornblende gabbro through successively lighter-colored diorite, granodiorite, quartz monzonite, and biotite granite to nearly white alaskite. No variety differs markedly from the most closely similar rock that can be shown to be of distinctly different age, and all, considered collectively, exhibit a strong family resemblance, which suggests that they may have welled up from a common reser- 
voir of molten rock within the earth in rather quick succession-that is, within a period that was brief in the geologic sense.

The great bulk of the granitic rocks in the Yosemite region belong to two series of intrusions, the members of each series exhibiting an especially close relationship to one another. These may be termed the biotite granite series of the Yosemite Valley and the Tuolumne intrusive series. The former includes the El Capitan and Taft granites and several minor intrusive masses confined mostly to the lower and middle parts of the valley; the latter includes the Sentinel granodiorite, Half Dome quartz monzonite, Cathedral Peak granite, and Johnson granite porphyry - formations which extend in large bodies from the upper half of the Yosemite Valley northward to the Tuolumne River and northeastward into the High Sierra. (See pl. 51.) In addition there are several kinds of rock, not assignable to either of these series, that occupy small areas in the lower Yosemite Valley and along the Merced Gorgenotably hornblende gabbro, the granodiorite of the Gateway, the granite southwest of the Gateway, and the granodiorite atEl Portal; and at the upper boundary of the Yosemite region, in the Clark Range, are the Mount Clark granite and the porphyritic rocks of Gray Peak and Red Peak.

As shown by the geologic map (pl. 51), the rocks forming the bodies of greatest extent are the El Capitan granite, the Sentinel granodiorite, the Half Dome quartz monzonite, and the Cathedral Peak granite. The other rocks are relatively of small extent.

\section{DESCRIPTION OF THE ROCKS}

\section{EL CAPITAN GRANITE}

The walls of the lower half of the Yosemite Valley are composed in large part of a light-colored biotite granite of moderately coarse and in part obscurely porphyritic texture. ${ }^{79}$ This rock is here named $\mathrm{El}$ Capitan granite, ${ }^{80}$ because it forms the greater part of El Capitan. It is the oldest and the most extensively developed of the biotite granites in the region.

Because of its prevailingly sparse jointing and its great resistance to weathering the El Capitan granite constitutes many of the outstanding cliffs and rock monuments of the valley. Besides El Capitan it forms the cliffs about the recess of the Ribbon Fall and most of the massif of the Three Brothers, including Eagle Peak. It also forms the bulk of the great promontory of the Cathedral Rocks and is the cause of the narrow-

\footnotetext{
70 In porphyritic rocks some of the minerals are present characteristically in large and fairly well formed crystals, or phenocrysts, embedded in the groundmass, or matrix, of smaller grains.

${ }^{80} \mathrm{H}$. W. Turner was the first to use the name El Capitan granite (The Pleistocene geology of the south-central Sierra Nevada, with especial reference to the origin of the Yosemite Valley: California Acad. Sci. Proc., 3d ser., vol. 1, pp. 304, 308, 1900), but, as would appear from his unpublished manuscript map of the Yosemite quadrangle, he applied the name indiscriminately to two distinct types of rock, which together make up most of the mass of El Capitan. It seems desirable to reserve the name El Capitan granite tor the more extensive of these two rocks and to name the other Taft granite.
}

ing of the valley between that promontory and El Capitan. It forms a large part of the walls west of Dewey Point, as well as the sloping barrier that closes the valley at its lower end. The walls of the Merced Gorge, as far down as the Gateway, are composed almost wholly of this rock, and so are the adjoining uplands for considerable distances to the north and south.

In the upper half of the valley the El Capitan granite occurs in smaller masses-in the cliffs west and east of the Yosemite Falls, in the cliffs under Union Point, on Sentinel Dome, and on Illilouette Ridge. Sentinel Dome is the only one of the many dome-shaped features of the Yosemite region that is made of this granite.

The El Capitan granite is cut by all the adjoining intrusive rocks excepting the granodiorite of the Gateway and some of the gabbro and diorite that occur near the lower end of the valley. It is therefore clearly among the oldest of the intrusive rocks of the Yosemite region.

In composition and appearance the El Capitan granite varies somewhat from place to place. Most typical and most abundant, probably, is the vaguely porphyritic variety which is readily seen in place at the foot of El Capitan. Its phenocrysts consist of unstriated alkali feldspar, which is faintly flesh-tinted and partly transparent. Most of them are about half an inch long. Their outlines are not sharply defined, so that the porphyritic texture is not conspicuous on freshly broken surfaces; but the phenocrysts are readily distinguished on weathered surfaces, from which they project slightly in relief. The groundmass in which the phenocrysts are embedded is a moderately coarse granular aggregate of whitish feldspar and brownish-gray quartz, interspersed with a little biotite in small and irregular flakes.

In the areas north of the Yosemite Valley and west of Ribbon Creek the El Capitan granite is more distinctly porphyritic than elsewhere, and fairly clean phenocrysts are somewhat common in the sand formed by the disintegration of this facies of the granite. Near the eastern margin of the main mass, on the other hand, the texture of the El Capitan granite passes gradually but rather rapidly from porphyritic to nonporphyritic. The nonporphyritic facies is to be seen on Illilouette Ridge, in the upland valley of Yosemite Creek, and on the ridge east of that stream. In this facies the grains of potash feldspar, distinguished by their pinkish hue, are but little larger than the grains of plagioclase and are irregular in form. The nonporphyritic El Capitan granite has some resemblance to the Taft granite, but it is coarser and more pinkish.

Within a zone a few feet wide next to the surface of contact with the older rocks, such as the granodiorite of the Gateway, the El Capitan granite is commonly nonporphyritic and richer in biotite than elsewhere; it even contains sporadic grains of hornblende. 
Microscopic study of representative specimens of El Capitan granite shows that plagioclase is somewhat more abundant than quartz and that alkali feldspar is somewhat less abundant than quartz. The potash feldspar is chiefly orthoclase, intergrown with a little albite. The biotite is of the common brown sort. The accessory minerals, present in minute quantities, are titanite, magnetite, apatite, zircon, and allanite.

\section{TAFT GRANITE}

The Taft granite, named for Taft Point, which it composes, somewhat resembles the El Capitan granite, with which it is intimately associated, but it is not porphyritic. Its texture is even, medium coarse, and typically granitic. It consists chiefly of white feldspar and smoky-gray quartz in grains that are mostly about 5 millimeters in diameter, and it contains a little biotite in evenly disseminated small flakes. The plagioclase and alkali feldspar do not differ markedly in habit or color, though some of the alkali feldspar is faintly tinged with flesh color and may be seen to form larger grains than the snow-white plagioclase. On weathering the rock assumes the same yellowish and reddish tints as the El Capitan granite. The composition and texture of the Taft granite are remarkably uniform, though the texture is noticeably finer near the contacts with older rocks than elsewhere.

Microscopic examination shows that the alkali feldspar, which is perthitic orthoclase or microcline, is distinctly more abundant than the plagioclase. Titanite and other accessory minerals are constantly present in minute quantities.

The Taft granite is so similar to the El Capitan granite in general appearance that on superficial examination it might be regarded as a mere facies of that rock. The two rocks do not intergrade, however, and were not intruded at the same time. Their relations are readily observed in the outcrop a little south of Taft Point, and it is here quite evident that the Taft granite is the younger, for it incloses fragments of the El Capitan granite. But though unquestionably younger than the El Capitan granite, the Taft granite is probably not much younger. So far as could be observed, it is cut by all the rocks that cut the El Capitan granite, and it seems to have been the next to be intruded.

The Taft granite occurs in considerable abundance on both sides of the middle part of the Yosemite Valley. On the north side a large mass, which forms part of El Capitan, extends westward to the hanging valley of Fireplace Creek. It is bounded on the north, east, and west by the main body of El Capitan granite. South of the valley the Taft granite is rather irregularly distributed. It occurs in many places in the basins of Bridalveil Creek and near-by streams. Boulders of it occur in the moraines at Ostrander Lake. Its southern limit has not been definitely traced.

\section{BRIDALVEIL GRANITE}

The name Bridalveil granite was given by Turner ${ }^{81}$ to a rock which occurs in the valley of Bridalveil Creek and forms the brink of the Bridalveil Fall. Fragments of the rock are abundant in the talus at the foot of the fall and may there be most conveniently studied, though care must be taken to avoid confusion with the Leaning Tower quartz monzonite, with which it is associated and which it superficially resembles.

The Bridalveil granite is a fine-grained pepper-andsalt mixture of feldspar, quartz, and a little biotite, whose general tint is a very pale bluish gray. The plagioclase, alkali feldspar, and quartz are present, as a rule, in nearly equal proportions. The alkali feldspar is usually orthoclase but sometimes microcline. The accessory minerals are the common ones, including titanite and, rarely, allanite. A little muscovite (white mica) occurs here and there.

The main bodies of Bridalveil granite occur on the south side of the Yosemite Valley, from the vicinity of Taft Point as far west as Crocker Point and at various places in the Bridalveil Basin. On the north side only narrow tongues of the rock invade the coarser granites at the base of El Capitan and the diorite and gabbro exposed on the Big Oak Flat Road.

The Bridalveil granite appears to be the youngest of the granitoid rocks of the Yosemite region, for it cuts all the rocks with which it is in contact, except some aplite and pegmatite which are closely related to it. Because of this fact its intrusive bodies are not interrupted or obscured by later intrusions, and they are therefore readily traced in the walls of the valley. The greater number of them are sheets, inclined to the horizon at angles less than $45^{\circ}$ and ranging from a few inches to 100 feet or more in thickness. One of the most massive of these sheets forms the brink of the Bridalveil Fall. From the talus west of the Leaning Tower it ascends gradually toward the east and is readily traced to the cleft between the north and middle summits of the Cathedral Rocks, where it appears to split into a number of branches.

Another sheet caps the north summit of the Cathedral Rocks and cuts through the upper part of the middle summit. Still other sheets are visible on the faces of these rocks and on the sloping sides of the gulch of Bridalveil Creek. In the embayment east of the $\mathrm{Ca}$ thedral Rocks the intrusions of Bridalveil granite are particularly large and irregularly shaped. Because of their superior resistance to weathering they form the summits of several of the pinnacles and crags situated in that embayment. Bodies of considerable size, finally, are exposed on the upland, south of the rim. Their form and extent can not be completely traced, owing

B1 Turner, II. W., The Pleistocene geology of the south-central Sierra Nevada, with especial reference to the origin of Yosemite Valley: California Acad. Sci. Proc., 3d ser., vol. 1, pp. 304, 308, 1900. 


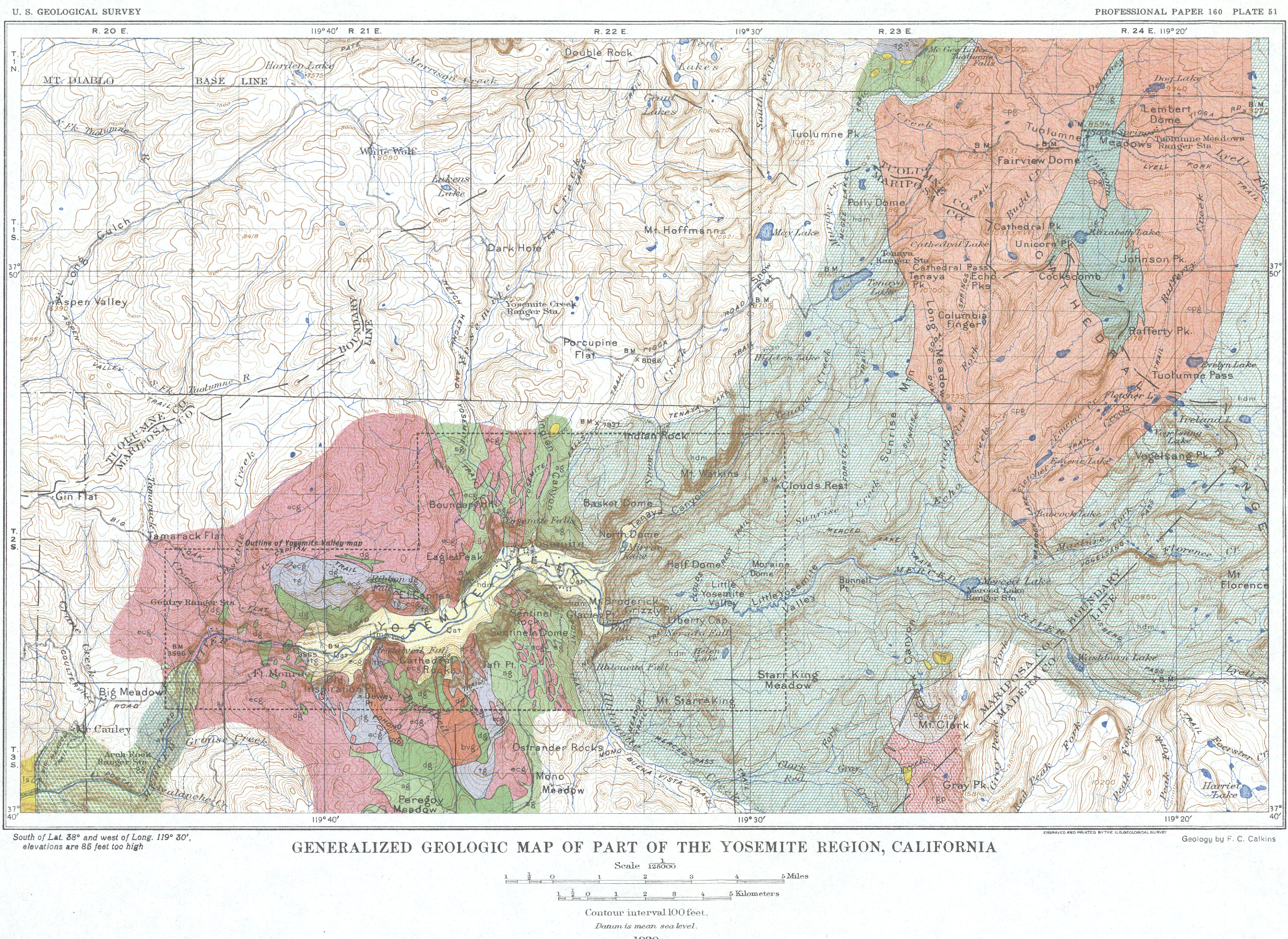

EXPLANATION

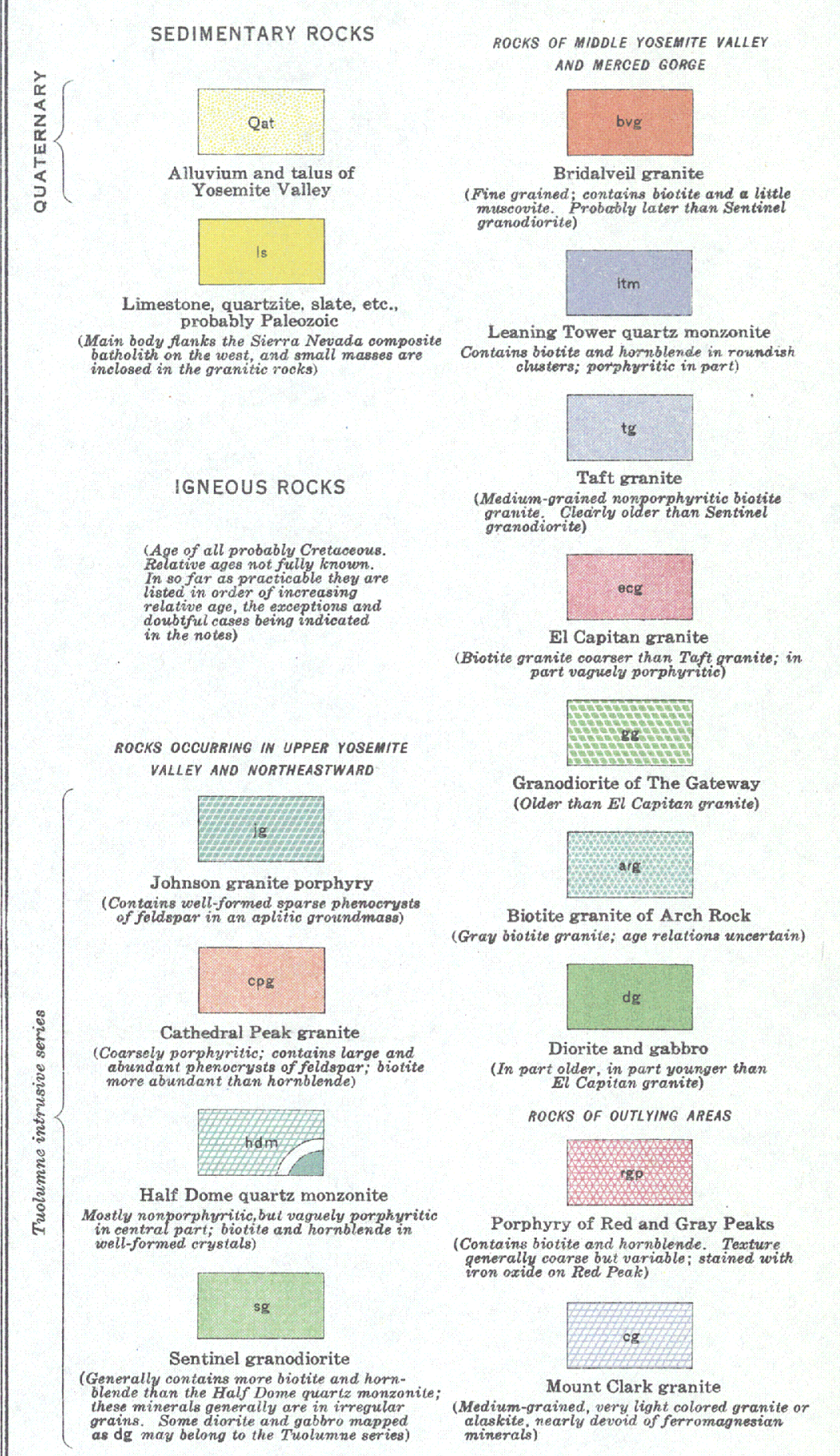





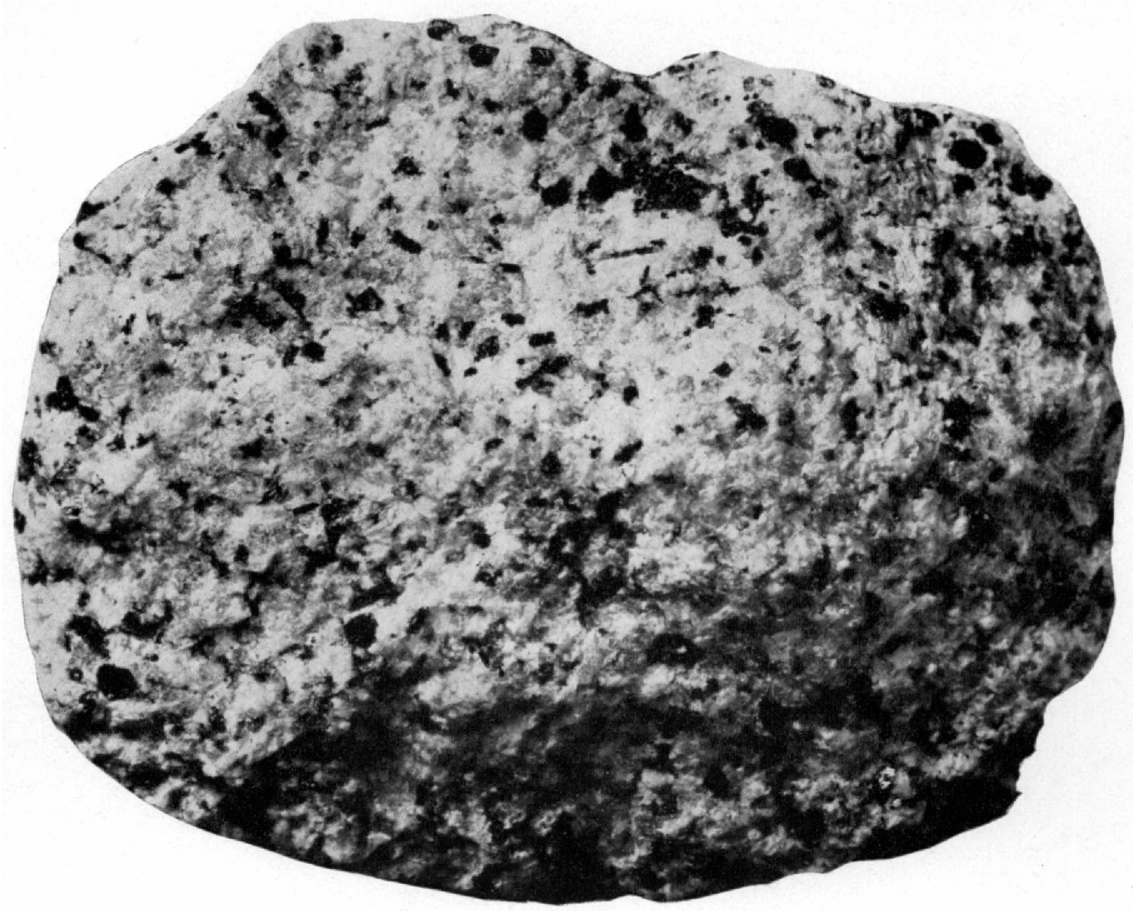

A. HALF DOME QUARTZ MONZONITE:

A number of the hexagonal tatheds of tholite and elongaled prisms of hornblende charateristic of this rock are visible in this sperimen

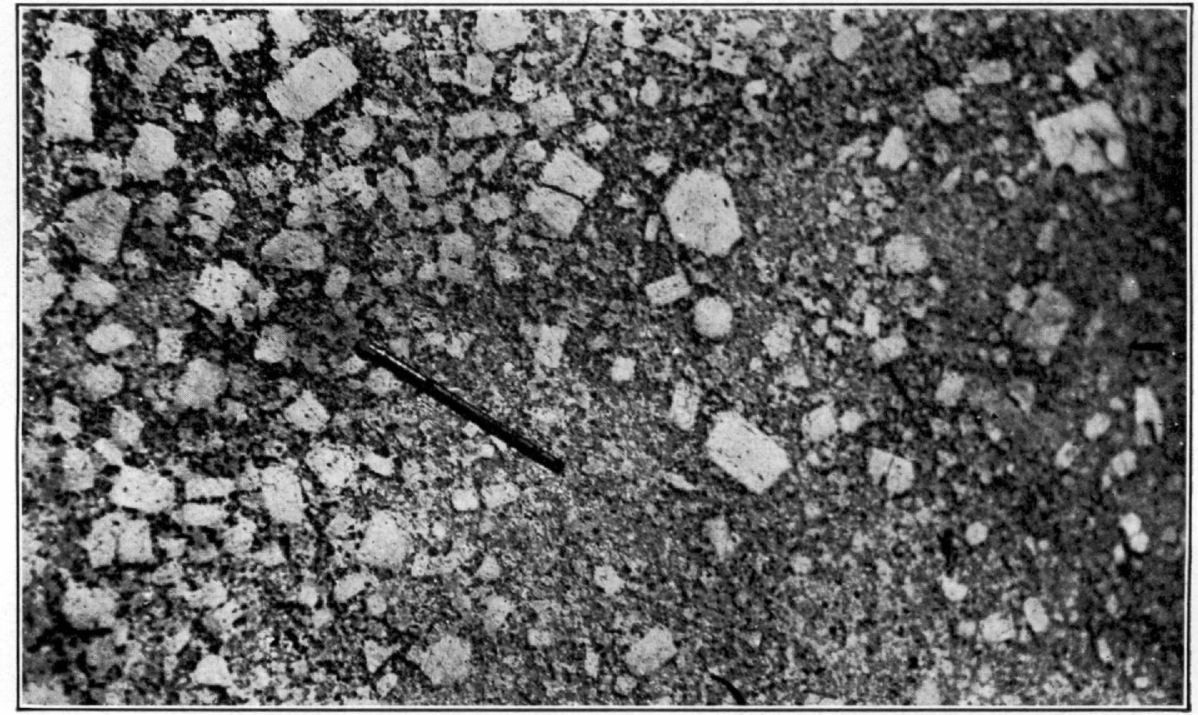

B. Cathedral peak granite, polished by the ancient glaciers

On this ice-smoothed surface of Cathedral Peak granite the phenocrysts of feldspar appear in cross section and resemble pieces of domino sugar. The largest are about 2 inches in length. Pholograph by $F$, C. Calkins. 

to masking soil, but it is entirely probable that they, like the sheets visible in the cliffs of the valley, are in general lenticular or wedge-shaped bodies of no great thickness.

\section{LEANING TOWER QUARTZ MONZONITE}

The character of the Leaning Tower quartz monzonite-so named because it forms a considerable part of the slopes of the Leaning Tower-is readily observed at the foot of the Bridalveil Fall. On weathered surfaces, especially those frequently wetted by the spray from the fall, the rock is deeply decayed and rusty; but on fresh fractures it has the dull-gray tone characteristic of granodiorite. Its texture is moderately fine, and at first glance it appears fairly even grained.

The orthoclase and plagioclase in this rock are difficult to distinguish from each other, and only by microscopic examination is it ascertained that the two are present in nearly equal quantity. Quartz is rather abundant. Biotite and hornblende are both present in moderate amount. In part they are evenly disseminated in particles about 1 millimeter or less in diameter; in part, however, they are assembled in roundish clusters about 5 millimeters in diameter, which give the rock a characteristic spotted appearance.

Viewed under the microscope the rock appears to be in reality porphyritic, although the phenocrysts, which are of plagioclase, are sparse and not much larger than the grains in the groundmass. Orthoclase is about as abundant as quartz and but little less so than plagioclase.

The typical Leaning Tower quartz monzonite appears to form but one small intrusive body restricted to the mouth of the gulch of Bridalveil Creek, though a more definitely porphyritic facies of the same rock occurs near the Big Oak Flat Road, near Taft Point, and at points directly opposite on the north side of the valley. The larger phenocrysts in this facies consist of orthoclase.

\section{POHONO GRANODIORITE}

In the upland valley of Bridalveil Creek and in the massif of the Cathedral Rocks there occurs a granodiorite whose aggregate quantity is considerable but which it is impracticable to represent on the geologic map (pl. 51) because of the extreme irregularity and small size of its ramifying intrusions. Its upwelling must have followed a remarkably thorough shattering of the older rocks. The El Capitan granite, the gabbro, and the diorite are penetrated by a veritable web of this granodiorite, and much of the body of diorite that is shown on the map as lying in the upland valley of Bridalveil Creek is in reality a sort of agglomerate of fragments of diorite in a matrix of granodiorite.

The name Pohono granodiorite is applied because the rock occurs near the Pohono Trail, which is laid along the south rim of the Yosemite Valley.

$82564^{\circ}-30-9$
This granodiorite is composed largely of a grayishwhite mixture of quartz and feldspar in which elongated grains of hornblende and biotite, about 1 millimeter in a verage diameter, lie embedded. Some of the crystals of orthoclase are poikilitic--that is, they inclose small grains of other minerals. Some of the biotite is ragged and also full of small inclusions. The plagioclase, viewed under the microscope, appears variably zoned and mottled.

\section{HORNBLENDE GABBRO AND HORNBLENDIC DIORITE}

Contrasting with all the rocks above described and, indeed, with all the other granitic rocks of the Yosemite region by their darker color are the hornblende gabbro and associated diorite, which occur notably in the lower part of the Yosemite Valley and form the great Rock Slides over which the Big Oak Flat Road is laid. The granites, monzonites, and granodiorites present, on fresh surfaces, various tones of light gray or medium gray; the gabbro is very dark gray or nearly black. It is, however, an extremely variable rock, not only in color but in texture and composition, as may be readily observed in the Rock Slides.

Comparison of almost any two adjacent boulders in this great talus is likely to show some appreciable difference in color and texture. Some of the rock resembles basaltic lava, being greenish black and so fine grained that its constituent minerals can hardly be distinguished. In the coarser-grained boulders, which as a rule are not so dark in color, the principal minerals are readily seen to be feldspar and hornblende, which are generally accompanied by small amounts of quartz and biotite. Between rocks equally coarse in texture the most conspicuous difference is in the abundance and the form of the hornblende crystals. With all their thousand variations they approach one or the other of two types, of which one may be distinguished as the gabbroic, the other as the dioritic.

The most striking development of the gabbroic type occurs near the mouth of the upland valley of Bridalveil Creek. There the hornblende forms irregular but somewhat roundish grains most of which measure one-fourth of an inch to an inch in diameter and some of which attain a diameter of 2 inches. The luster of the cleavage faces is as a rule broken by numerous included grains of feldspar. Small interstices between these large individuals of hornblende are filled with a granular mixture of plagioclase, hornblende, and quartz. Hornblende makes up about half the volume of the rock. Biotite is present in very small amounts.

Besides the essential minerals mentioned, the microscope reveals the common accessories and in some sections a little orthoclase. Most specimens contain some augite, or amphibole that is clearly derived from augite. In the dioritic type hornblende is less abundant than feldspar and is distinctly 
prismatic in form. Biotite is invariably present in this type, its amount being sometimes considerable, though always subordinate to that of hornblende. As in the gabbro, orthoclase may be present but is always scarce.

The age of some of the gabbro and diorite intrusions relative to the other rocks is still obscure. Evidently the intrusions are not all of the same age, for some are cut by the El Capitan granite, which is the oldest granite in the valley proper, and others cut rocks that are themselves younger than the El Capitan granite.

The gabbro and diorite in the lower part of the valley are unmistakably pregranitic. The evidence of this relationship may be well observed on the Wawona Road north of Inspiration Point, near the south bank of the Merced River between Pulpit Rock and the Pohono Bridge, and near the base of the cliff under Old Inspiration Point. At these and other localities the diorite is penetrated by tongues of granite. An intimate commingling of granitic and dioritic material appears to have occurred at the contact, for the granite is there enriched in biotite, and the small fragments of diorite included in the granite have a porphyritic texture that must be secondary. The granite on Turtleback Dome and Fireplace Bluff contains swarms of dioritic inclusions, and though these lie at some distance from the nearest large visible mass of diorite, they are in all probability fragments of a large body of the older diorite rather than segregations of mineral from the granite magma.

On the great façade of El Capitan, on the other hand, may be seen intrusions of diorite that are clearly of later origin than the El Capitan and Taft granites. (See pl. 17.) The most conspicuous of these intrusions presents a remarkable resemblance to the map of North America-a wall map about 2,000 feet in height, showing the continent all the way down to the Isthmus of Panama and a part of South America. Another large intrusion farther east has a very irregular shape that defies description.

As no consistent differences of composition between the older and younger gabbros and diorites appear to exist, it is evident that the age of any particular intrusion must be established from local evidence. This evidence is in many places singularly inconclusive, even where the contact of diorite and granite is fairly well exposed, and consequently the age of much of the diorite is still in doubt.

\section{GRANITIC ROCKS OF LOWER YOSEMITE REGION}

The lower part of the Merced Gorge, from the Gateway, at Elephant Rock, down to its mouth, near El Portal, is cut through three rock bodies of moderate extent that form part of the complex of intrusions characteristic of the Yosemite region. (See pl. 51.) Just below the Gateway is a small body of granodiorite; then follows a body of biotite granite extending $1 \frac{1}{2}$ miles along the river; then another body of the granodiorite first mentioned, extending for about 3 miles to the lower end of the gorge.

The granodiorite is of peculiar interest, as it is even older than the El Capitan granite and therefore one of the very oldest intrusive rocks in the Yosemite region. Its relation to the El Capitan granite may be observed along the lower part of the Coulterville Road, where fragments of the granodiorite are inclosed in the granite. It is conspicuously finer grained and darker in tone than the El Capitan granite. Considerably more than half of it consists of feldspar and quartz in a confused grayish-white mixture, but the appearance of the rock is characterized chiefly by the form and distribution of the biotite and hornblende. The biotite, which is the more abundant of the two, forms irregular or rudely hexagonal tablets, mostly less than 2 millimeters in diameter. The hornblende occurs in slender rodlike crystals about 2 millimeters long.

The biotite granite is readily identifiable in Arch Rock, the huge fallen boulder between whose overhanging fragments the highway is laid. It is a medium-grained nonporphyritic rock, somewhat like the Taft granite, but it contains a larger proportion of biotite, and its quartz is less brownish and consequently less easily distinguished from the feldspar. The potash feldspar, moreover, unlike that of the Taft granite, is poikilitic, a characteristic which on a sunny day when the light flashes from the bright cleavage planes of the orthoclase, is readily observed in the fresh fragments that have fallen in the neighborhood of Arch Rock. The individual crystals of this mineral, which are nearly an inch in diameter, inclose small grains of quartz, plagioclase, and biotite. The biotite flakes measure 3 millimeters or less in diameter and are of rather irregular form. The rock, though somewhat lighter in color, is not strikingly different in appearance from the granodiorite by which it is flanked on both sides, but it contains no hornblende.

In the immediate vicinity of El Portal, where the batholith of the Sierra Nevada abuts upon the western belt of slates and other metamorphic rocks, there is, as is to be expected, a zone containing a considerable variety of intrusive rocks. There are several types of hornblende gabbro, diorite, granodiorite, and biotite granite.

Particularly noteworthy is the gabbro, which consists almost wholly of hornblende and calcic feldspar, mainly bytownite, and is remarkably varied in texture. In some places its hornblende crystals are slender prisms which lie rudely parallel to one another and determine a ready cleavage of the rock; in other places the hornblende forms roundish grains about half an inch in diameter, which inclose smaller grains of feldspar; elsewhere the gabbro is extremely coarse grained, containing ragged prisms of hornblende as much as a foot in length. 


\section{SENTINEL GRANODIORITE}

From the Three Brothers nearly as far east as the Royal Arches and from the Fissures eastward to Glacier Point the walls of the Yosemite Valley consist mainly of granodiorite, a light-gray granitoid rock, in which soda-lime feldspar predominates decidedly over potash feldspar, quartz is abundant, and hornblende and biotite are present in moderate and nearly equal quantities. The rock forms part of a large irregular intrusive body, but the portion of it here considered is a belt about 2 miles broad that crosses the valley from north to south. This granodiorite is named the Sentinel granodiorite, because it is the sole material of Sentinel Rock. It is the oldest member, so far as known, of the Tuolumne intrusive series.

At the west side of the belt crossing the valley the Sentinel granodiorite is in contact with the Taft and El Capitan biotite granites, which are older. The contact is a rather smooth, steep surface, but a few narrow tongues of granodiorite extend into the granite, which had become solidified and fissured before the granodiorite was injected. Along the east side, on the contrary, the granodiorite is undercut by the Half Dome quartz monzonite, which is slightly more recent and sends flat sheets into the granodiorite. The granodiorite does not extend continuously between these main eastern and western contacts, for along its medial portion, near the longitude of Sentinel Dome and the Yosemite Falls, it incloses a great swarm of fragments of El Capitan granite, some of them hundreds of feet across, others ranging downward in size to mere crumbs.

The Sentinel granodiorite is less uniform in composition than most of the other intrusive bodies. In the western part of the zone crossed by the Yosemite Valley this rock is relatively light-colored and homogeneous; the eastern part is much more streaky and uneven in composition and texture and on the whole is considerably darker than the western part. The eastern portion, again, may be roughly divided into two or three bands that differ mainly in texture.

The western type, as it may be called, is exposed on both walls of the Yosemite Valley from the foot of Eagle Peak and of Taft Point at the west to an indefinite zone, passing through old Yosemite Village, at the east, where it grades into the darker type. The rock of the western type forms the greater portion of this intrusive body. It is fairly uniform, and its general tint is rather light gray, but it is a little darker and more bluish than the El Capitan granite. Its most abundant constituent is white or gray soda-lime feldspar. Potash feldspar is present in rather small amount; it is not conspicuously different from the dominant sodalime feldspar, though it may be distinguished by its greater transparency. Quartz, which is a moderately abundant constituent, is sugar-white and is also incon- spicuous. Against the whitish background formed by these light minerals black hornblende and biotite stand out prominently. In large part the two are clustered together and not readily distinguished, but some separate crystals of hornblende show roughly prismatic forms and intersecting cleavages, and on the larger individuals of biotite one may see the wellknown micaceous cleavage. Neither mineral ever shows, in this rock, conspicuously perfect crystal form. Rock of this type may be observed most easily in the great aprons of talus ascended by the trail to the Yosemite Falls and the short trail to Glacier Point.

Near its contact on the west with the older biotite granites the granodiorite is a little streaky and darker than in the main body, but this variation here extends only a few feet or a few yards from the contact. In the zone where the inclusions of granite are abundant this streaky character becomes very marked. The granodiorite is darker on the whole than in the western facies, but this fact is due in large measure to the presence of abundant roundish or lens-shaped, nearly black masses, a few feet or a few inches in diameter, in which the black minerals, hornblende and biotite, are strongly concentrated. These dark inclusions tend to be alined, like the streakiness of the inclosing rock, which roughly follows the boundaries of the granitic inclusions in sinuous curves.

In the fairly broad clear space between the zone of inclusions and the contact with the Half Dome quartz monzonite, the granodiorite has not the light color that it has farther west. It is not so streaky as in the vicinity of the older granite but is uniformly rather dark. On the north side of the valley it has a character that may readily be observed in the great talus cone at the mouth of Indian Creek. This type of granodiorite has a faint schistosity along nearly north-south vertical planes, and it carries many of the small dark inclusions already described. The dark minerals have the same character as in the western facies of the granodiorite, though they are here more abundant. The rock, in short, has about the same average character as that around and between the granitic inclusions but is more uniform.

On the south side of the valley, in the vicinity of Glacier Point, the granodiorite has a highly distinctive character, which is given chiefly by the character of the biotite. This mineral forms unusually large crystals, some of them as much as an inch in diameter, which inclose many small grains of feldspar and other mineralsthat is, they are poikilitic. The discrimination between these two varieties in the dark eastern zone has been helpful in working out the glacial geology near Glacier Point and Sentinel Dome, for boulders of granodiorite resting on the rock platform just east of Sentinel Dome consist of rock like that of Glacier Point, rather than like the nearest outcrops of granodiorite, and therefore must have been transported southwestward. 


\section{HALF DOME QUARTZ MONZONITE}

The head of the Yosemite Valley, all of Tenaya Canyon and the Little Yosemite, and all the domes and other eminences surrounding them are carved from a single continuous body of granitic rock that extends far into the High Sierra. This rock was named by Turner ${ }^{82}$ the Half Dome quartz monzonite, as Half Dome is the most remarkable eminence composed of it.

The monzonite is a medium-grained light-gray rock that bears considerable resemblance to the western type of the Sentinel granodiorite, being composed of plagioclase, quartz, orthoclase, biotite, and hornblende. In the monzonite, however, the dark minerals are somewhat less abundant than in the granodiorite, and they are distinguished by exceptionally regular crystal forms. (See pl. 52, A.) The biotite commonly occurs in hexagonal tablets or in little prisms from one-eighth to one-fourth inch in height. The hornblende occurs in prisms one-eighth of an inch to nearly an inch in length and generally clean-cut save at the ends.

As the rock crumbles the biotite tablets and hornblende prisms usually fall out entire and form conspicuous, gleaming objects in the sand. Such is true especially on the summit of Half Dome, in and about the Little Yosemite Valley, and in the Illilouette Basin. Probably no granitic rock in the Yosemite region affords better opportunity to become acquainted with the ferromagnesian minerals-biotite and hornblende-than the Half Dome quartz monzonite.

To the geologist, however, the most significant and reliable distinction between the monzonite and the granodiorite consists in the fact that the potash feldspar is considerably more abundant in the monzonite, this being, indeed, the reason for classing the rock as a monzonite. This feldspar is recognized rather readily in the monzonite, being more transparent than the plagioclase and generally pinkish. Instead of forming only ragged interstitial particles, as it does in the granodiorite, it tends here and there to assume its own crystal form.

Microscopic analysis shows that plagioclase is the preponderant mineral. Quartz is somewhat less abundant and is about equaled in quantity by the potash feldspar, which is chiefly microcline. Biotite is a trifle more abundant than hornblende. Titanite is a conspicuous accessory mineral and in many places occurs in well-shaped crystals.

In the eastern part of the area shown the Half Dome quartz monzonite is obscurely porphyritic, owing to the development of large crystals of potash feldspar. The transition from the nonporphyritic to the porphyritic facies is readily observed on the northwest shore of Tenaya Lake, where the surface of the rock is swept clean by the ancient glaciers and is in part still polished.

82 Turner, H. W., unpublished manuscript.
In passing along the road toward the head of the lake the attentive observer is likely to become aware of a gradual development of grayish dappling in the rock due to phenocrysts. These phenocrysts have, however, rather indefinite outlines and are rarely more than an inch in diameter. They are prominent on some weathered surfaces, from which they project as little knobs.

The Half Dome quartz monzonite is younger than the Sentinel granodiorite, as is clear from the tongues which it sends far into that rock. The nearly plane surface of contact between these rocks, which is traceable on the walls of the upper part of the Yosemite Valley, dips in general westward at an angle of about $30^{\circ}$, and as a consequence the monzonite for considerable distances forms the lower parts of the cliffs, and the granodiorite forms the upper parts. This relation is strikingly expressed in the sculptural detail of the cliffs under Glacier Point, on the south side of the valley. The granodiorite, above, is jointed and rugged; the monzonite, below, is unjointed and smooth.

The Half Dome quartz monzonite is also younger than the Mount Clark granite and the porphyritic rocks of Gray Peak and Red Peak. On the other hand, it is older than the Cathedral Peak granite, whose mass it completely surrounds. It is significant. that the porphyritic facies of the monzonite invariably lies next to the Cathedral Peak granite, which is. itself conspicuously porphyritic. The zone of porphyritic texture in the monzonite is on the average about. half a mile broad.

Of all the granitic rocks of the Yosemite region the Half Dome quartz monzonite is the most prevailingly massive. It is wholly devoid of joint fractures over considerable areas and characteristically forms huge. exfoliating monoliths. Not only Half Dome but. North Dome, Basket Dome, Mount Watkins, Mount. Starr King, and many other more or less dome-shaped prominences are composed of it. In some places, however, it is traversed by many closely spaced joints and possesses a sheeted structure that has greatly facilitated the erosion of canyons and gulches.

\section{CATHEDRAL PEAK GRANITE}

With the Cathedral Peak granite the reader has already been made acquainted in the account of the glacial history of the Yosemite Valley (p. 56), for, as. is explained in that account, it is largely upon the presence of ice-transported boulders of this highly distinctive granite that the glacialist depends for the certain identification of the older and more obscure moraines. It indeed is fortunate, from the glacialist's. point of view, that in a mountain region where so many closely similar granitic rocks occur there should be one of unusual and quite unmistakable aspect in the very area from which the main glaciers radiated. 
The distinguishing feature of the Cathedral Peak granite is that it contains unusually large phenocrysts of feldspar. Whereas in most porphyries the phenocrysts are only a fraction of an inch in length, in the Cathedral Peak granite they measure not uncommonly 2 to 4 inches in length and from 1 inch to 2 inches in breadth. Where the rock is smoothed and polished by the glaciers these large, oblong crystals present an appearance suggestive of lumps of domino sugar, their whitish color contrasting with the somewhat darker tone of the groundmass. (See pl. 52, B.) On weathered rock surfaces also they are conspicuous, for, owing to their greater resistance to decomposition than the groundmass, they project from it in high relief. (See pl. 37, B.) As the rock finally disintegrates into granular sand, the phenocrysts are freed entirely from the groundmass, and as a consequence on many mountain sides in the High Sierra such loose crystals are found lying about in large numbers.

Many of the phenocrysts are twinned in accordance with the Carlsbad law, as is readily apparent from the flash of their surfaces in the sunlight. Others show no evidence of twin structure. Their color in many localities is slightly pinkish. Inclosed in them as a rule are numerous small grains of the other minerals present in the groundmass, including biotite and hornblende. These grains are most prevalent in their outer portions, and as a consequence the phenocrysts when entirely weathered out from the groundmass have as a rule rough surfaces, yet even so they are much more clean-cut than the phenocrysts of the porphyritic variety of the Half Dome quartz monzonite.

The groundmass of the Cathedral Peak granite consists mainly of small grains of quartz and feldspar and contains a fine sprinkling of biotite and hornblende. The crystals of these dark minerals are much smaller and less regular in form than they are in the Half Dome quartz monzonite. The feldspar is as a rule pure white, and the general tone of the rock is lighter than that of any of the rocks described on the preceding pages. The microscope shows that plagioclase is somewhat more abundant in the groundmass than potash feldspar, but the latter is slightly more abundant on the whole, if the phenocrysts are taken into account. The accessory minerals-magnetite, apatite, titanite, and zircon-are present in small quantities.

The Cathedral Peak granite is fairly uniform in character, but in some places, especially near its contacts with the older Half Dome quartz monzonite, the phenocrysts of feldspar are crowded in swarms and the crystals of biotite and hornblende are distributed in groups or streaks.

The intrusive body as a whole appears to be rather compact, but its limits are not yet completely known. The mass is in general elongated from north to south.
The southern tip is about a mile northeast of Merced Lake, and the greatest breadth-about 8 miles-is attained in the vicinity of the Tuolumne Meadows. To judge from the course of the outer boundary, as traced on the walls of deep canyons, the intrusive body broadens downward and is shaped somewhat like a broadly elliptical dome, diversified by no great offshoots or irregularities.

Wherever its periphery has been examined the Cathedral Peak granite is found to be in contact with the porphyritic facies of the Half Dome quartz monzonite. It has many characteristics in common with that rock, yet the boundary between them is everywhere sharp, and there is ample evidence that the Cathedral Peak granite is the younger of the two.

\section{JOHNSON GRANITE PORPHYRY}

The Johnson granite porphyry forms a relatively small body situated entirely in the High Sierra, at a considerable distance from the Yosemite Valley, yet its description here seems appropriate, for it is the youngest of the Tuolumne intrusive series, the other members of which have just been described. It occupies an area about 7 miles in length from north to south and 2 miles broad from east to west, centering about the Tuolumne Meadows. The name is derived from Johnson Peak, south of the meadows, which is entirely composed of this rock.

The intrusion is completely surrounded by the much larger mass of Cathedral Peak granite, into which it has broken; and, as the latter is almost completely surrounded by the older Half Dome quartz monzonite, whose outer margin, again, is in contact in most places with the still older Sentinel granodiorite, it will be seen that the Johnson granite porphyry is centrally placed with respect to the older members of the Tuolumne intrusive series. It is also the most highly siliceous member, intrusion having taken place in the order of increasing silicity throughout the series.

The Johnson granite porphyry has various aspects. Its major portion resembles an aplite, as it has a fine sugary texture, but it is distinguished by widely scattered phenocrysts of microcline. These are remarkably clean-cut in form and very large compared with the fine grain of the groundmass, many of them exceeding 2 inches in length. Scattered phenocrysts of quartz and of soda-lime feldspar about a quarter of an inch in diameter also occur in the groundmass. The rock contains quartz, oligoclase, and microcline in nearly equal proportions and also a small amount of biotite.

A part of the mass has the characteristics of a more typical granite porphyry, for it contains, in addition to the large phenocrysts of microcline, many small phenocrysts of quartz, plagioclase, and biotite.

The boundaries of the intrusive body are irregular and difficult to trace, a number of flat-lying sheets 
penetrating far into the surrounding Cathedral Peak granite. However, the mass as a whole appears to fall off steeply on the east side and to slope outward at a moderate angle on the west side.

The Johnson granite porphyry is, like aplite, much more resistant to weathering than the adjoining granite and consequently retains much of its icepolished surface in localities where the granite has already lost most of its polish. Glaciated surfaces of the porphyry may be seen near the Tuolumne Soda Springs, but the finest exhibit of glacier polish is to be found in the high saddle between Johnson Peak and Rafferty Peak.

\section{MOUNT CLARK GRANITE}

The granite of which Mount Clark, the sharp peak at the north end of the Clark Range, is composed is readily distinguished from all the other granitic rocks of the Yosemite region by the fact that it is essentially devoid of ferromagnesian minerals, such as biotite and hornblende, and therefore is not speckled. It is a very siliceous, light-colored granite, or alaskite, composed almost wholly of feldspar and quartz. It is moderately coarse grained and even textured and in these respects resembles the Taft granite. The feldspar is snow-white where fresh but yellowish where it is weathered, and in not a few places it assumes a beautiful rose tint. The quartz is generally brownish gray, sufficiently dark in tone to contrast with the feldspar.

The microscope shows that quartz, alkali feldspar, and plagioclase are about equally abundant. The alkali feldspar is in part orthoclase, in part microcline, with which more or less albite is intergrown; the plagioclase is partly albite and partly oligoclase. Accessory minerals are magnetite, zircon, titanite, apatite, and allanite. Minute grains of hornblende occur here and there.

The Mount Clark granite is clearly older than the Half Dome quartz monzonite, being penetrated by sheets of that rock, but its relations to the granitic rocks of which Gray Peak and Red Peak are composed are not yet certain.

Like the Half Dome quartz monzonite, the Mount Clark granite is in the main sparsely jointed and tends to exfoliate in curved shells. That Mount Clark is not dome-shaped but sharply triangular in form is due to the fact that it has been glaciated on three sides. The exfoliating habit of the rock is most prominently displayed on the sides and at the head of Clark Canyon.

Because of its high silica content the Mount Clark granite is exceedingly slow to decompose, and this accounts for the fact that erratic boulders of it, dropped on the divide east of Mount Starr King by very early glaciers, still remain in a fair state of preservation, although nearly all the other ice-borne materials there have long since disintegrated into sand and have been washed away.

\section{PORPHYRITIC ROCKS OF CLARK RANGE}

The Clark Range as seen from Glacier Point has a. ruddy appearance, as compared with the rest of the Sierra landscape, which is almost uniformly pale-hued. Gray Peak and Red Peak in particular stand out by reason of their distinctive coloring, as their names well indicate. One might suppose that these peaks are composed of other than granitic rocks-of metamorphic rocks of sedimentary or volcanic origin, such as those which occur on the lower Sierra slope. In fact, however, the two peaks consist of granitic rocks, very similar in character, that form what may be regarded as an intrusive body produced in installments. A number of distinct surfaces of contact may be observed on the walls of the peaks, between intrusive rocks which differ somewhat from one another yet have so strong a family resemblance that they can scarcely be mapped separately.

These rocks may be described collectively as porphyritic intrusive rocks having phenocrysts of potash feldspar and a groundmass of feldspars, quartz, biotite, and, in most places, hornblende. Despite their differences in texture and composition, these rocks look much alike, especially on weathered surfaces, where the texture is brought out by atmospheric etching: the phenocrysts are rather closely crowded together, and many of them show nearly square cross sections; and the dark minerals are clustered into somewhat mosslike forms. These textural characters have served to identify many erratic boulders in the lower part of the Illilouette Basin.

The coarsest material, which occurs in the cirque north of Gray Peak, is a porphyritic granite whose phenocrysts are about an inch in length. The summit. and southern flank of Gray Peak and the bulk of Red Peak consist of a finer-grained rock which might more correctly be called a granite porphyry. Its phenocrysts hardly exceed half an inch in length, and the groundmass is moderately fine grained. It somewhat resembles the porphyritic granite which forms the summit of Mount Hoffmann.

The ruddy color of the rock in Red Peak appears to be due to iron oxide derived from one of the constituent. minerals. A certain facies of the porphyry seen on the west spur of Red Peak contains abundant magnetite, and a relatively small quantity of such rock, distributed in the form of dikes, might stain a great bulk of the light-gray porphyry. The oxidation of the iron minerals and the dissemination of the resulting red pigment. must have been facilitated by the thoroughly fissured state of the rock.

\section{APLITE AND PEGMATITE}

Dikes of aplite and pegmatite are plentiful throughout the Yosemite region. They range from a fraction of an inch to scores of feet in thickness and cut all the major bodies of intrusive rock. Some extend in 
nearly straight sheets, following apparently old joint fractures; others are crooked and branch irregularly, like fantastic trees. They are as a rule easily distinguished from the other rock bodies by their lighter, creamy color and may be traced by the eye for long distances on the bare walls and domes of the Yosemite region.

Each major intrusion of granitic rock seems to have been followed by the injection of highly siliceous material-aplite or pegmatite-into open fissures. The siliceous material was derived, apparently, by differentiation from the parent magma and possesses a slight family resemblance to that magma, yet on the whole the injections following different major intrusions are so nearly alike in composition that separate description of them is here unnecessary.

The aplites and pegmatites of the Yosemite region consist almost wholly of alkalic feldspars and quartz, with biotite in very small amounts. In some dikes garnet occurs instead of biotite. The fine sugary texture characteristic of aplite passes gradually into coarse pegmatitic textures. Well-defined graphic intergrowth of quartz and feldspar is not common, but striking examples of it occur in a few places, as, for instance, in blocks of pegmatite mingled with Sentinel granodiorite in the talus west of the Royal Arches. Somewhat similar intergrowths of garnet with feldspar occur near the castellated spur east of the Cathedral Spires.

The most remarkable outcrop of pegmatite in the neighborhood of the Yosemite Valley occurs a few hundred feet west of the junction of the Pohono Trail and the Chinquapin Road. The mass appears at first glance to be composed wholly of clean milkwhite quartz, but closer examination reveals a few huge crystals of flesh-colored feldspar, some of which measure as much as 2 feet in length. The aggregate is clearly a true pegmatite, exceptional in its very coarse texture and its great preponderance of quartz. A similar but smaller outcrop is situated about half a mile southeast of the one described, and there are others in the Illilouette Basin and on the Cathedral Range. These very coarse pegmatites form no dikes of great extent but relatively thick, irregularly shaped bodies.

Dikes of aplite and pegmatite are especially abundant in the Half Dome quartz monzonite, as may readily be observed in the Little Yosemite, in Tenaya Canyon, and on the surrounding heights. Their superior hardness causes these dikes to stand out in relief from weathered surfaces. On the curving back of Half Dome, for instance, especially in a grazing light-that is a light striking the surface at a very slight angle - they appear like the branching veins on the back of a man's hand. On the summits of Indian Rock and Mount Watkins interlacing dikes of aplite remain in fantastically shaped masses as a result of the more rapid disintegration of the granite between them. In the gabbro and diorite of the Rock Slides, in the lower part of the Yosemite Valley, dikes of pegmatite are almost as abundant as in the Half Dome quartz monzonite. Many of them fill old joint fractures and extend in nearly horizontal sheets. They are the more conspicuous because of the contrast between their whiteness and the somber tones of the basic rocks. 


\section{BIBLI OGRAPHY}

Andrews, E. C., Corrasion by gravity streams, with applications of the ice-flood hypothesis: Roy. Soc. New South Wales Jour. and Proc., vol. 43, pp. 204-330, 1909.

- An excursion to the Yosemite (California), or studies in the formation of alpine cirques, "steps," and valley "treads": Idem, vol. 44, pp. 262-315, 1910.

BaDì, W. F., Life and letters of John Muir, 2 vols., Boston and New York, 1923-24.

Brake, W. P., Sur l'action des anciens glaciers dans la Sierra Nevada de Californie et sur l'origine de la Vallée de Yosemite: Compt. Rend., vol. 65, pp. 179-181, 1867.

- Glacial erosion and the origin of the Yosemite Valley: Am. Inst. Min. Eng. Trans., vol. 29, pp. 823-835, 1900.

Becker, G. F., The structure of a portion of the Sierra Nevada of California: Geol. Soc. America Bull., vol. 2, pp. 49-74, 1891.

Branner, J. C., A topographic feature of the hanging valleys of the Yosemite: Jour. Geology, vol. 11, pp. 547-553, 1903.

Bonnell, L. H., Discovery of the Yosemite, and the Indian war of 1851, 4th ed., Los Angeles, 1911.

Clark, Galen, The Yosemite Valley, 1910.

Diller, J. S., The Tertiary revolution in the topography of the Paeific coast: U. S. Geol. Survey Fourteenth Ann. Rept., pt. 2, pp. 404-411, 1894.

Fajrbanks, H. W., The great Sierra Nevada fault scarp: Pop. Sci. Monthly, vol. 52, pp. 609-621, 1898.

Farouhar, F. P., Exploration of the Sierra Nevada: California Hist. Soc. Quart., vol. 4, 1925.

Gannetr, Henry, The origin of the Yosemite Valley: Nat. Geog. Mag., vol. 12, pp. 86-87, 1901.

Gilbert, G. K., Peneplain on western slope of Sierra: Science, vol. 1, pp. 194-195, 1883.

_ Variations of Sierra glaciers: Sierra Club Bull., vol. 5, pp. 20-25, 1904.

Domes and dome structure in the High Sierra: Sierra Club Bull., vol. 5, pp. 211-220, 1905.

- Systematic asymmetry of crest lines in the High Sierra of California: Idem, vol. 5, pp. 279-286, 1905; Jour. Geology, vol. 12, pp. 579-588, 1904.

Fall, A. F., Handbook of Yosemite National Park [contains chapter on geology, by A. C. Lawson], New York, 1921.

Hutchings, J. M., In the heart of the Sierra, Oakland, Calif., 1886.

Johnson, D. W., The origin of the Yosemite Valley: Appalachia, vol. 12 , pp. 138-146, 1910.

- Hanging valleys of the Yosemite: Am. Geog. Soc. Bull., vol. 43, pp. 1-25, 1911.

Johnson, W. D., The profile of maturity of alpine glacial erosion: Jour. Geology, vol. 12, pp. 569-578, 1904.

- The grade profile in alpine glacial erosion: Sierra Club Bull., vol. 5, pp. 271-278, 1905.

King, Clarence, Mountaineering in the Sierra Nevada, 4th ed., Boston, 1874.

Lawson, A. C., Geomorphogeny of the upper Kern Basin: California Univ. Dept. Geology Bull., vol. 3, pp. 291-376, 1904.

- The recent fault scarps at Genoa, Nev.: Seismol. Soc. America Bull., vol. 2, pp. 193-200, 1912.
Lawson, A. C., Geology of Yosemite National Park, in Handbook of Yosemite National Park, compiled and edited by A. F. Hall, New York, 1921.

Le Conte, Joseph, A journal of ramblings through the High Sierra of California by the University excursion party, San Francisco, 1875 .

On some of the ancient glaciers of the Sierras: California Acad. Sci. Proc., vol. 4, pp. 259-262, 1872; Am. Jour. Sci., 3d ser., vol. 5, pp. 325-342, 1873.

- A post-Tertiary elevation of the Sierra Nevada shown by the river beds: Am. Jour. Sci., 3d ser., vol. 32, pp. 167-181, 1886.

- The origin of transverse mountain valleys and some glacial phenomena in those of the Sierra Nevada: Univ. Chronicle, vol. 1, pp. 479-497, Berkeley, Calif., 1898.

- Ramblings through the High Sierra: Sierra Club Bull., vol. 3, pp. 1-107, 1900 (reprinted from A journal of ramblings, 1875).

Le Conte, J. N., The High Sierra of California: Alpina Americana, No. 1, pp. 1-16, 1907.

IIndgren, Waldemar, The Tertiary gravels of the Sierra Nevada: U. S. Geol. Survey Prof. Paper 73, 1911.

Matrhes, F. E., Little studies in the Yosemite Valley-I, The extinct Eagle Peak Falls: Sierra Club Bull., vol. 7, pp. 222-224, 1910; II, The striped rock floor of the Little Yosemite Valley: Idem, vol. 8, pp. 3-9, 1911; III, The winds of the Yosemite Valley: Idem, vol. 8, pp. 89-95, 1912; IV, El Capitan moraine and ancient Lake Yosemite: Idem, vol. 9, pp. 7-15, 1913.

- Sketch of Yosemite National Park and an account of the origin of Yosemite and Hetch Hetchy Valleys, U. S. Dept. Interior, 1912.

- Studying the Yosemite problem: Sierra Club Bull., vol. 9, pp. 136-147, 1914.

- Moraine Dome and the moraines of the Iittle Yosemite Valley: Washington Acad. Sci. Jour., vol. 4, pp. 295-296, 1914.

- Cockscomb Crest: Sierra Club Bull., vol. 11, pp. 21-28, 1920.

- The story of Yosemite Valley: Making of American Scenery, No. 1, National Park Service, 1922.

- The story of Yosemite Valley (printed on back of map of Yosemite Valley), U. S. Geol. Survey, 1923.

- Kings River Canyon and Yosemite Valley: Sierra Club Bull., vol. 12, pp. 224-236, 1926.

- Multiple glaciation in the Sierra Nevada: Science, new ser., vol. 70, pp. 75-76, 1929.

Moir, John, Winter phenomena of the Yosemite Valley: Boston Soc. Nat. Hist. Proc., vol. 15, pp. 148-151, 1873.

- On the effects of the earthquake of 26th March, 1872, in the Yosemite Valley: Idem, vol. 15, pp. 185-186, 1873

- Discovery of glaciers in Sierra Nevada: Am. Jour. Sci., 3d ser., vol. 5, pp. 69-71, 1873.

- Studies in the formation of mountains in the Sierra Nevada, Calif.: Am. Assoc. Adv. Sci. Proc., vol. 23, pt. 2, pp. 49-64, 1874.

The mountains of California, New York, 1894.

- Our national parks, 1901; enlarged ed., Boston and

New York, 1909.

- My first summer in the Sierra, New York, 1911. The Yosemite, New York, 1912. 
M nally in Overland Monthly, 1874-75, republished by Sierra Club)-I, Mountain sculpture: Sierra Club Bull., vol. 9, pp. 225-239, 1915; II, Mountain sculpture - origin of Yosemite valleys: Idem, vol. 10, pp. 62-77, 1916; III, Ancient glaciers and their pathways: Idem, vol. 10, pp. 184-201, 1917; IV, Glacial denudation: Idem, vol. 10, pp. 304-318, 1918; V, Postglacial denudation: Idem, vol. 10, pp. 414-428, 1919; VI, Formation of soils: Idem, vol. 11, pp. 69-85, 1920; VII, Mountain building: Idem, vol. 11, pp. 181-193, 1921.

Russell, I. C., Quaternary history of Mono Valley, Calif.: U. S. Geol. Survey Eighth Ann. Rept., pt. 1, pp. 261$394,1889$.

Turner, H. W., The Pleistocene geology of the south-central Sierra Nevada, with especial reference to the origin of the Yosemite Valley: California Acad. Sci. Proc., 3d ser., Geology, vol. 1, pp. 261-321, 1900.
Torner, H. W., The rocks of the Sierra Nevada: U. S. Geol. Survey Fourteenth Ann. Rept., pt. 2, pp. 435-495, 1894.

- Geologic notes on the Sierra Nevada: Am. Geologist, vol. 13, pp. 228-249, 297-316, 1894.

The age and succession of the igneous rocks of the Sierra Nevada: Jour. Geology, vol. 3, pp. 385-414, 1895.

- Further contributions to the geology of the Sierra Nevada: U. S. Geol. Survey Seventeenth Ann. Rept., pt. 1, pp. 521-762, 1896.

Whitney, J. D., Geology of the Sierra Nevada: Geol. Survey of California, Geology, vol. 1, 1865.

The Yosemite book, New York, 1868.

The Yosemite guidebook, Cambridge, 1870.

The auriferous gravels of the Sierra Nevada of California: Harvard Coll. Mus. Comp. Zoology Mem., vol. 6, 1880.

$Y_{\triangle R D}, R$. S., The book of the national parks, 1919. 



\section{INDEX}

A

Abstract of report

Access to the Yosemite Valley

Acknowledgments for aid.

Agassiz Column, significance of

structure and sculpture of view of

Ancestral mountain systems. . .

Ancient stream beds in Sierrs Nevada, profiles of

Andrews, E. C., belief of, concerning origin of Yosemite Valley......... 6, 94-95 hy pothesis of, to explain development of glacial stairways . ............ 94 photograph by . ....... $37 B$

Aplite dikes, general features of walls tormed by, on Moraine Dome.......... 37

Arches in exfoliation shells.

Arch Rock, significanco of

Artist Point, glacier polish near

interpretation of glacial markings near

A valanche Creek, moraines near

$\mathbf{B}$

Basaseachic Falls, compared with upper Yosemite Fall

Basket Dome, depth of earlier ice over. general character of

17 nature of

Bella Coola Valley, waterfall in

Bibliography............................. 130-131

Big Meadow Flat, moraines in

significance of .

Big Oak Flat Road, rock slides under ............................. 16, 92, 105-106, 123

Blacktop Peak, unglaciated summit of

Blackwelder, Eliot, recognition by, of four stages of glaciation in Bierra Nevada.

Blake, William P., belief of, concerning origin of Yosemite Valley...

Block range, definition of.

Boulders, erratic, significance of

Bowen Falls, character and height of

pls. 3, $6 B, 16 B, 47 A$ interpretation by, of notches and alco ves near waterfalls................ 112

Bridalveil Basin, glaciers of W isconsin stage in

Bridalveil Cascade, preglacial

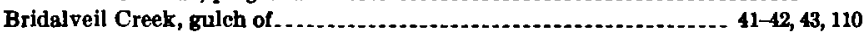
hanging valley of $\ldots$

Bridalveil Fall, character and height of compared with Staubbach......... 21 views of $\ldots$.

Bridalveil granite, general features of

Bridalveil Ice Field in earlier stages ......................................... 65,82

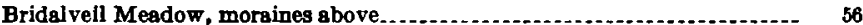

Broad-valley stage in cutting of Merced Canyon, definition of ............... 32

Broad-valley stage in evolution of Yosemite Valley, determination of landscape of

Bunnell Point, character of $\ldots \ldots \ldots \ldots \ldots . . . . . . .17,89$ view of, from Moraine Dome . 45

C

Calaveras formation, character of............ 20

California, relief map of

Calkins, Frank C., acknowledgments to ......

discovery of glacial boulders on Cathedral Rocks by

recognition of numerous small intrusions in Yosemite area by

The granitic rocks of the Yosemite region ............................ 120-129

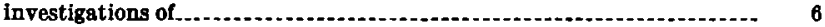

photographs by .- pls. $8 B, 8 A, 11 B, 19,20 A, 21 A, 26,33 A B, 3843 A, 49,52 B$

Canadian life zone, altitude and vegetation.

Canyon stage in cutting of Merced Canyon, definition of .........................

Cenyon stage in evolution of Yosemite Valley, determination of .............. 41-43 landscape of . . . .

Cascade Cliffs, form and structure of $\ldots \ldots \ldots \ldots$ view of.
Cascade Creek, hanging gulch of Page

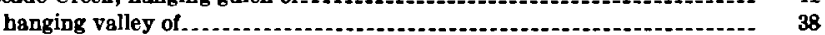
Cascade Glacier in earlier stages, features of $\ldots . \ldots \ldots \ldots$

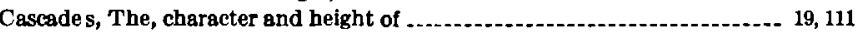
view of

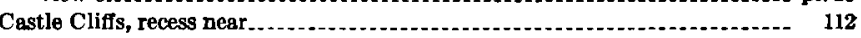
Cathedral Pass, view of glacial grooves on border of lake in Cathedral Peak, ice line at base of spires of ................................ 81 view of - 12

Cathedral Peak granite, general features of . . . perched boulder of..................... 37 view of glaciated floor of . . .

Cathedral Range, amphitheaters and gaps in significance of northwestward trend of

Cathedral Rocks and Cathedral Spires, view of............................... pl. 18

Cathedral Rocks, features of 17

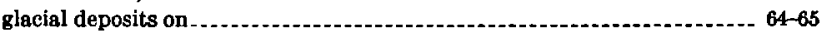
structure and sculpture of

Cathedral Spires, character and height of structure and sculpture of............................................ 110

Chamberlin, T. C. and R. T., views of, concerning processes of glaciation.-- 90

Chaney, Ralph W., acknowledgments to................................. 7 and Stock, Chester, paleontologic determinations by ............... 28

Channels, torrent, in Yosemite Valley................................... 108-109

Character of the Yosemite Valley

Chert, origin of................................................................... 26

view of contorted layers of . _.... pl. 26

Chilnualna Creek, hanging valley of ......... $40-41$

Cirque, empty, on Kuna Crest.

Cirques, development of, in Sierra Nevads.

Clark, Galen, belief of, concerning origin of domes.

Clark Range, features of porphyritic rocks of . . . . . significance of northwestward trend of view of, from Half Dome. . . . . 11

view of, from Half Dome
Clifi at Glacier Point, features of

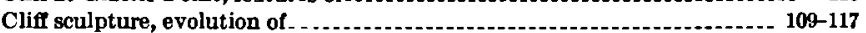
influence of zones of fracturing on

Cliffs of the Yosemite Valley, details of...................................... 16-18 relation of form of, to structure.

Clouds Rest, general character of _. 17-18 view of arched erfoliation shell on shoulder of

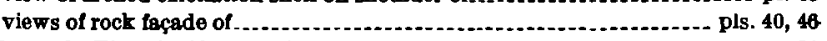

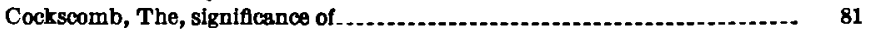
view of

Conflgu ration of Yosemite region, general ................................... 11

Configuration of Yosemite Valley, explanation of

Crane Creek, hanging valley of .............. 36

Crane Creek Glacier, moraines of............................................ 67

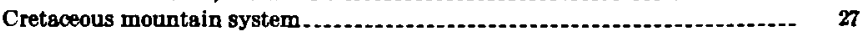

Crevasses in glaciers, causes of

D

Dana Glacier, character and location of ...................................... 15 view of

Difference in age between older and younger moraines.................... 68

Dikes, aplite, features of ......................... 71-72, 128-129

Diorite, tractured, influence on glacial quarrying of $\ldots \ldots \ldots$

hornblendic, general festures of $123-124$

Diversion of ice from Tuolumne Basin into Tenaya Basin................. 78, 82

Domes, development of, by erfoliation............ 114-116

E

Eagle Peak, character of nunatak of, during earlier stages of glaciation......... 84 Eagle Peak Meadows, lobe of Hoffmann Glacier in

Eagle Rock, downfall of. .

Earthquake avalanches in Yosemite Valley . . . .

Earthquake débris at base of Fl Capitan . ..................... 108

Earthquake in Owens Valley ................... 30

Eartbquakes in Yosemite Valley, evidence of ............. 106

Echo Peaks, ice line on......... 81

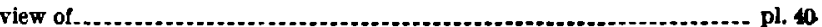


El Capitan, damage by earthquakes to............................................ 108

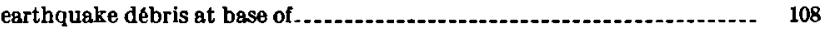
height of ........ 16 recess west of

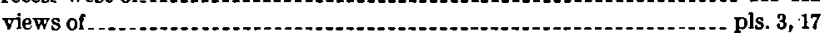

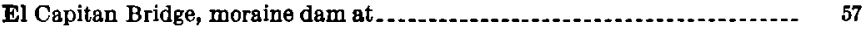

El Capitan granite, general features of ................................ 121-122

El Capitan Meadow, moraines below

El Portal, remnants of moraines near......................................... 67

El Portal stage of glaciation, correlation of evidences of

Emerald Pool, significance of basin of survival of . . . . . .

Erratic boulder at base of Sentinel Dome, view of . . . . . . .

Erratic boulders, significance of - . . .

Evolution of Yosemite Valley, landscape of broad-valley stage of . . landscape of canyon stage of . . landscape of mountain-valley stage of preglacial .......................................... 45-50

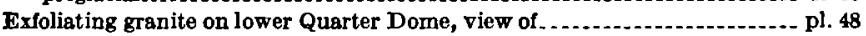

Exfoliating granite on northeast side of Half Dome, view of

Exfoliation, artiflcial, on Stone Mountain.................................. 114 at brink of precipice of upper Yosemite Fall, view of concave . . . . diagram showing progressive . . .

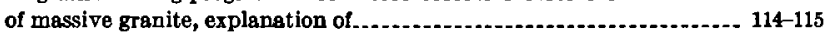
rate of

Exfoliation shell, on shoulder of Clouds Rest, view of

Exfoliation shells, arches in.

116

$\mathbf{F}$

Fans, torrent, in Yosemite Valley

$108-109$

Faulting movements at east base of Sierra Nevada

Faults along eastern margin of Sierra block

Fault scarp at mouth of Lundy Cenyon................................... 30

Feliciana Creek, hanging valley of.................... 35

Fern Ledge, character of ............. 19, 111

Fireplace Creek, hanging valley of

Fissures, The, near Profle Cliff, explanation of .......................... 110

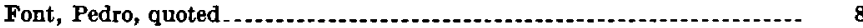

Form of Yosemite Valley

Forms carved in massive rock

Fossil remains found near Table Mountain $\ldots . . \ldots \ldots \ldots$

Fossil river beds in Sierra Nevada............................................ 28, 43

Fracturing, influence of zones of, on cliff sculpture

Frontal moraines in the Yosemite Vslley.................................. 56-57

G

Gabbro, hornblende, general features of.

Gabbro, talus of

Gannett, Henry, belief of, concerning origin of Yosemite Valley ........

belief of, concerning signiflcance of hanging valleys.

Gavarnie, falls of, character and height of

Geologic history, early, of the Yosemite Valley $21-50$

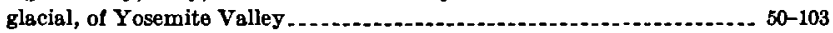

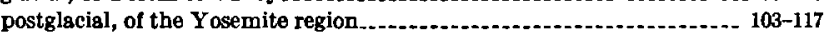
of Yosemite region, summary of

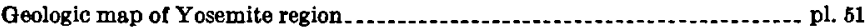

Geologic time divisions, table of

Gersopps Falls, character and height of.......................... 21

Giant stairway, explanation of

general character of

view of, from Glacier Point........... 10

Qilbert, G.K., photographs by

Glacial action in Yosemite region, evidences of ............................ 54-61

Glacial and postglacial deposits, map of.............................pl. 29 (in pocket)

Glacial boulder perched on 5-foot pedestal, view of -

Glacial boulders on pedestals, significance of

Glacial cirques, nature and development of

Glacial excavation in Yosemite Valley, depth of

Glacial grooves, occurrence of, in Yosemite Valley.

view of, at lake in Cathedral Pass

Glacial lakes, flling of .

Glacial mantle of Sierra Nevada, nature and development of

Glacial quarrying, effectiveness of . . . . . .

Glacial stages, duration of

Glacial stairways, diagrams showing modes of production of origin of . . .

Glaciated rock surfaces, evidence of an earlier ice invasion from

Glacier generation, lowest level of

Glacier Point, cliff at

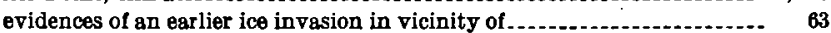
features on, that are often mistaken for evidences of glaciation............ 63-64

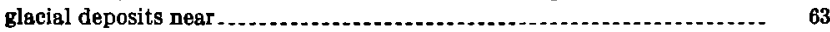
overhanging rock at silbouet te profile of cliff at
Glacier Point, stage of glaciation view of glaciated rock mass under. . ....................................... pl. 43

view of weather pit at . . 33 weather pits at, explanation of

Glacier polish of early stage of glaciation $\ldots$

Glacier polish of Wisconsin stage, distribution of . . .

Glacier polish, short life of $\quad 54$ view of, on floor of massive granite

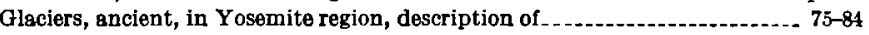
ancient, map of . . . . 39

changes produced by, summary of................................... 102-103 earlier, great extent and thickness of excavation by, modes of .....

selective quarrying by .............. $90-91$

Glaciers of earlier stages, features of.........- 80-84

Glaciers of the Wisconsin stage, features of .

Grand Canyon of Tuolumne River, character of

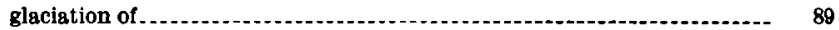

Granite, disruption of, by solar heat...... 107 massive, preservation of Yosemite upland on ............................ $39-40$ nature of . . Granitic rocks of the Yosemite region, general character of Grouse Creek, hanging valley of H

Half Dome, explanation of features of general character of ....................... 17 views of -

Half Dome quartz monzonite, general features of . . view of specimen of

Half-yosemite at Wawona

Hanging side valleys of lower Merced Canyon.

Hanging valleys, explanation of

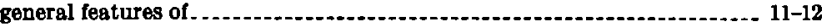

higher, signiflcance of

interpretation of, by A. C. Lawson...................... 33-34

interpretation of, by $D$. W. Johnson

previous hypotheses of origin of......... 33-34

third set of - .

Hetch Hetchy Valley, character of

glaciation of........................... 89

view of

High Sierra, bird's-eye view of general character of geographic features ot.......................... 13-15

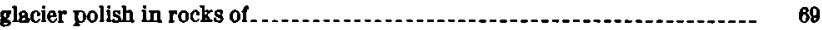

unglaciated summits in........... 81

upper limit of glaciation in.

view of, from El Capitan

view of well-jointed granite in

Hiilawe Falls, character and height of . ............. 20

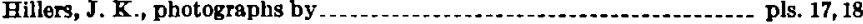

Hoffmann Glacier in earlier stages, description of

Hoffmann Qlacier of Wisconsin stage, description of

Ice cataract, at head of Yosemite Valley

Ic $\theta$ invasion, evidences of an earlier in lower Yosemite region. . .

indications of a still earlier.

Ice line in High Sierra, marking upper limit of glaciation 81

Ice mantle, nature of . . .

IC $\infty$, work of, in development of the Little Yosemite Valley work of, in development of the Yosemite Valley ..................... 97-98

milouette Basin, glaciers of Wisconsin stage in ................ 79

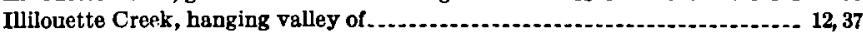

Illilouette Fall, character and height of . ................................... 19

Illilouette Glacier, deposits of

Illilouette Gorge, significance of.$\ldots \ldots \ldots \ldots \ldots$

mlilouette Ice Field, during earlier stages of glaciation. .................... 82

Illilouette Valley, features of . . . . . . view of ancient lake beds in . . . . . .

Indian Creek, hanging valleys of . . . .

Indian Rock, emergence of, above surface of glaciers....................... 83

$\mathrm{J}$

Johnson, Douglas W., belief of, concerning origin of Yosemite Valley ....-.-. 6 interpretation of hanging valleys by .................................... 33-34

Johnson, W. D., hypothesis by, of development of glacial stairways........ recognition by, of three stages of glaciation in Sierra Nevada.......... 75

Johnson granite porphyry

Joint blocks loosened by frost_._.

Jointed granite, view of

Joints, effect of, on rate of erosion..... 39

influence of, on cliff sculpture............... 109-111

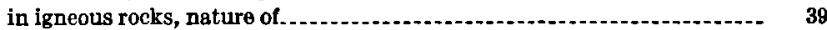

oblique, influence of, on cliff sculpture..... 110

promotion of glacial quarrying by . . . . . . . . 
$\mathbf{K}$

Kaieteur Fall, character and height of.

Kalambo Falls, character and height of

King, Clarence, belief of, concerning existence of moraine at Mirror Lake.... belief of, concerning origin of Yosemite Valley report by, of existence of terminal moraine in Yosemite Valley

Kings Glacier, length of

Kings River Canyon, general features of glaciation of. view of. view of cirque on northeast side of $\mathbf{L}$

Lake Illilouette, former existence of view of site of

Lake Tahoe, nature of basin of.

Lake Yosemite, filling of .

Lakes, glacial, filling of

Lateral moraine on north side of Little Yosemite Valley, view of .............. pl. 30

Lateral moraines indicative of two ice floods during Wisconsin stage........ 60-61

Lateral moraines on north side of Little Yosemite Valley, general view of...- pl. 11

Lateral moraines on south side of Little Yosemite Valley, section across..... 60 view of.

Lawson, Andrew C., belief of, concerning origin of Yosemite Valley .......

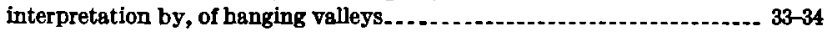
studies of, in Kern River region.

Leaning Tower, character of

Leaning Tower quartz monzonite, gener

Le Conte, J. N., photograph by

Le Conte, Jaseph, belief of, concerning glacial origin of domes. belief of, concerning origin of Yosemite Valley..................... observations by, of jointed structure of granite $\ldots \ldots$

Lewis, W. B., acknowledgments to

Liberty Cap and Mount Broderick, explanation of cleft between . . . ........... 99

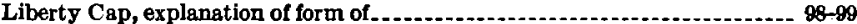
moraines near views of .

Lindgren, Waldemar, studies by, of profiles of ancient stream beds.......... 43

Lippincott, J. B., photograph by . . ......... 4 B

Little Yosemite Valley and Tenaya Canyon, section across................... 83

Little Yosemite Valley, cross profiles of evidences of an earlier ice invasion on sides of ........................ 61-63

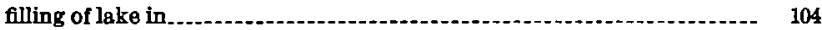
lateral moraine on north side of

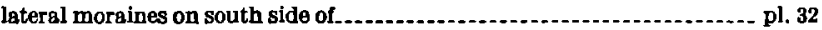
moraines in - 58-61 section actoss, showing relative size of Merced Olacier.............. 100 view of Cascade Cliffs in. . . . . . . . . . . . . . . views of lateral moraines in.......................................... pls. $30,31,32$ views of pls. 4, 11, 31 waterfalls in work of ice in development of

Location of the Yosemite Valley.....- 7-8

Lost Arrow, signiflcance of.

Lost Lake, significance of

Lower Yosemite Fall, character and height of .

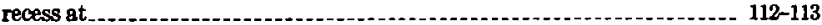
view of

Lowest level of glacier generation in Sierra Nevada.

Lyell Glacier, location and dimensions of . .

view of . . ................... 14

\section{$\mathbf{M}$}

Map of ancient glaciers of Yosemite region, explanation of ................... 75-76

Maripose formation, character of 26

Mariposa grove, giant sequoias in $\ldots \ldots$

Massive granite, in Little Yosemite Valley ........ in Tenaya Canyon preservation of Yosemite upland on ................ $39-40$

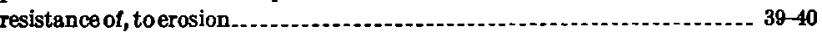
Massiverock, forms carved in

Meadow Brook, hanging valley of

Medial moraine, supposed, at head of Yosemite Valley ...................... 68

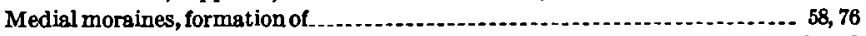

Mendenhall, W. C., photograph by .............................. 5 C

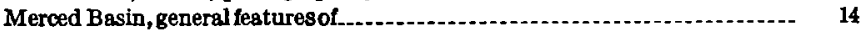

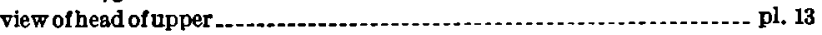

Merced Canyon, character ofupper cutting of evidences of threestages of cutting of

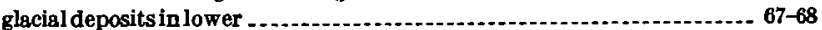
hanging side valleys oflower............. 34-35 hanging valleys of, correlation of, with hanging valleys of the Yosemite region...
Merced Canyon, longitudinal profle of part of lower ..................... $\begin{array}{r}\text { Page } \\ \text { pl. } 27\end{array}$ outwashed material in lower. stages of cutting of

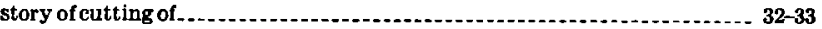
unglaciated lower partof

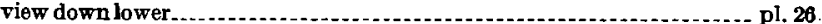
view of glaciated floor and sideof upper.... view of upturned bedsof slate and schistin lower $\ldots$ view of contorted layersof chertin........... pl, 26

Merced Glacier, earlierstagesof in $W$ isconsin stage moraines of

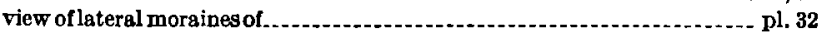

Merced Gorge, explanation of narrownessof.... $\quad 92$

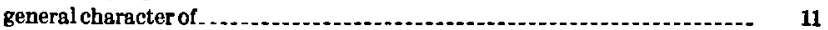
slight changes effected byglaciation in _ upper, glaciation of - 100 sectlon across, showing relativesize of Merced Qlacier................. 101 views of . . . . . . . Merced Lake, flling of, by forward-growing delta........................... 103 view of

Merced River, explanation of arrangement of tributaries of origin of . ........ 30

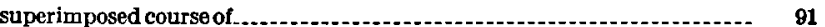
view of contorted layers of chert exposed in bed of .................... 26

Metamorphic rocks of Sierra Nevada, nature of . . . views of structure of

Mirror Lake, origin of

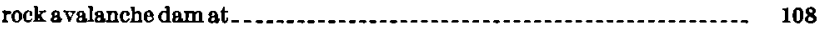
view of .

Modeling of the Yosemite Valley, peculiar features of...................... 16

Moraine composed of angular blocks on Mount Hoffmann, view of . .......... pl 42

Moraine dam at El Capitan Bridge..................... 57

Morsine Dome, features of morainal embankment on

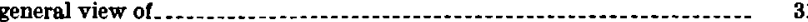

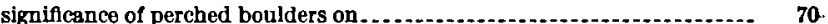

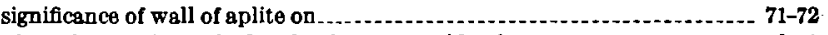
view of crest of morainal embankment on side of ............. 30 view of great morainal embankment from top of ..................... pl. 31 view of large erratic boulder on....................... 37 view of wall of aplite on . . . 37

Moraine of earlier glaciation near Wawona Road, view of..................... pl 34

Moraine, supposed medial, at head of Yosemite Valley ............. terminal, absence of, in lower Merced Canyon........................... 67-68

Moraines, difference in age between older and younger. formation of in the Little Yosemite Valley ........................ 68-61 in the Tenaya Basin

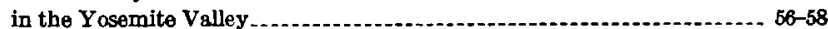
lateral, in the Little Yosemite Valley, views of................... pls. 30, 31, 32

Mountain-building events in Sierra region, sequence of..................... 23

Mountains of Cretaceous period................ 27

Mountain-valley stage in cutting of Merced Canyon, definition of ............

Mountain-valley stage in evolution of Yosemite Valley, determination of _._. 37-39

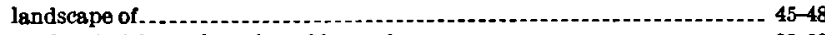

Mount Broderick, explanation of form of . views of

Mount Clark, views of .

Mount Clark granite, general features of........ 128

Mount Hoffmann, view of moraine composed of angular blocks on ..... . pl 42

Mount Lyell, view of

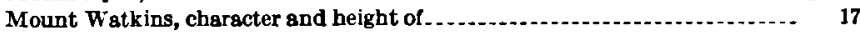
explanation of form of . . . . glacial deposits on

Muir, John, belief of, concerning origin of Yosemite Valley . .............. 4,5 estimate by, of débris shaken down by earthquake................... 106 explanation by, of absence of moraines in Tenaya Canyon explanation by, of formation of yosemite-like valleys..................... 88-89 interpretation by, of moraines in valley of Ribbon Creek ............ 66 observation by, of glacially quarried blocks............................ recognition by, of lake beds in Tenaya Canyon....................... 63

Multnomah Falls, character and height of.

Nevada Fall, character and height of cliff at

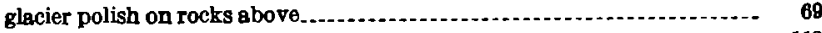
gorge near - 113 views of. . .................. pls 10,25

North Dome, weather pits in slab on views of 
0

Oblique joints, infuence of, on cliff sculpture

Origin of glacial stairways

Origin of the Yosemite Valley, hypotheses of

key to secret of

Outwash material, in lower Merced Canyon

$P$

Peiestals of perched boulders, development of views of

Pegmatite, dikes of

Perched glacial boulders, significance of views of -

Pillsbury, A. C., photographs by

Pohono

Portal between El Capitan and Cathedral Rocks, explanation of .............. $\quad 92$

Pothole of subglacial origin, view of ................ pl. 34

Potholes, different modes of origin of -

Preglacial development of Yosemite Valley _.................................. 45-50

Preglacial depth of Yosemite Valley ......................................... 43

Preglacial history of Yosemite Valley _.................................... 21-50

Preglacial profile of Yosemite Valley ___.

Profle Cliff, explanation of sculpture of

Profle of Yosemite Valley, preglacisl.

Profles of ancient stream beds in Sierra Nevada

old, interpretation of.

$$
\text { Q }
$$

Quarter Domes, explanation of forms of

Quarter Dome, view of exfoliating granite on lower.

$\mathbf{R}$

Ribbon Creek, hanging valley of moraines in valley o

Ribbon Fall, character and height of

Roche moutonne $\theta$, longitudinal section of

Roches moutonnees, formation of

Rock avalanches in Yosemite Valley, causes of

Rock monuments of the Yosemite Valley

Rock Slides, the, character of rock in the, signiffcance of

Rocks, metamorphic, of Sierra Nevada

ock waste in Yosemite Valley, production of............................ 105-117 unequal distribution of .

Roof of metamorphic rocks, over batholith

Roof pendants, in batholith of Sierra Nevada

Royal Arch Cascade, general features of.

Royal Arch Croek, hanging gulch of.

Royal Arches, explanation of general features of . ....... 17 view of.

Russell, I. C., belief of, concerning origin of Yosemite Valley recognition by, of three glacisl advances in Sierra Nevada . ........ $\mathrm{s}$

San Joaquin Canyon, hanging side valleys of...

San Joaquin Glacier, length of

Saxon Gulch, hanging valley of

interpretation of

Selective quarrying, by glaciers, explanation of

Sentinel Creek, hanging valley of ................... 12, 38

Sentinel Dome, concentric shell structure of

view of......................... 21

view of erratic boulder at base of -

Sentinel Fall, character and height of

Sentinel granodiorite, general features of

Sentinel Rock, cliff face of, controlled by joint plane........................ 109-110 general features of.

view of

location of groves of.

Gierra block, cross section of

diagram of part of

taults at eastern margin of

general character and outlines of

internal structure of

tilting of .......................................................... 29, 44

Sierra-Cascade chain, distribution of ice on .......................................... 51

Sierra Nevada and Yosemite Valley, antiquity of............................ 21-24

Sierra Nevada, batholith of .......

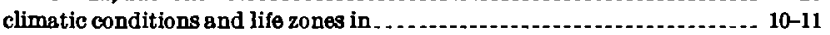

fossil river beds in $\ldots \ldots \ldots$

geographic description of .................................. 8-9

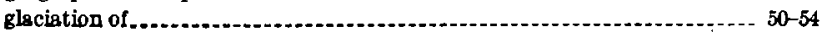

Sierra Nevada, height of uplifts of .
history of uplifts of

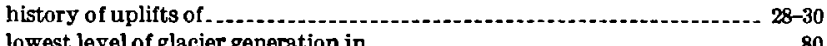

80

metamorphic roeks of _.......

profles of ancient stream beds in ....................................... 43

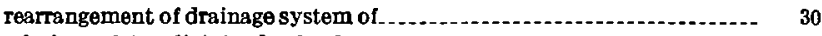

relations of, to adjoining lowlands................ 9-10

remnants of ancient rock roof of batholith of ..........................- 25-27

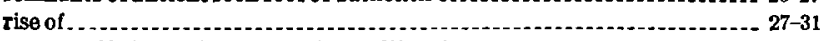

sources of information concerning uplifts of .............................. 27-28

upper limit of glaciation in - 81

vegetation in

view of crest of

view of east front of ........................................................ 5

Sierra Nevada glaciers, extent reached by ancient $\ldots \ldots \ldots \ldots \ldots \ldots \ldots \ldots \ldots . . . \ldots$. $53-54$

origin and growth of ancient $\ldots . . . . . . . . . . . . . . . . . . . . . .51-53$

Sierra region, mountain-building events in, sequence of .......... 23

Silver Apron Fall, general features of . ............................... 19-20

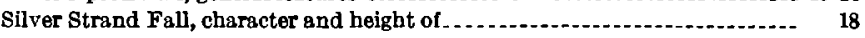

Snoqualmie Fall, character and height of

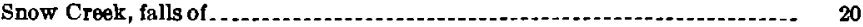

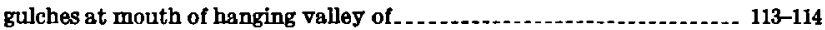

hanging valley of......................................................... 12, 37

Snow Creek Glacier of Wisconsin stage, general features of....................... 79

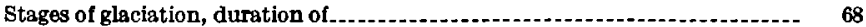

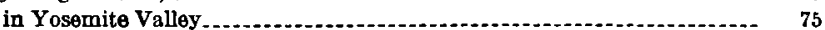

Staircase Falls, general features of .................................... 19

Starr King group, view of ..................................................... 32

Start King Meadows, old moraines near .................................... $\quad 62$

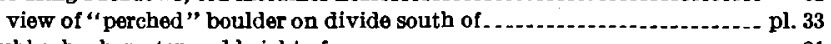

Staubbach, character and height of....................................... 21

Steps, stairlike, in canyon floors ................................ 12-13

stairlike, in canyon floors, explanation of .......................... 94-96

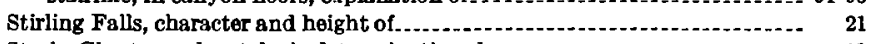

Stock, Chester, paleontologic determinations by

Stone Mountain, artificial exfolistion on $\quad 114$ location of, south of limit of glaciation........................... 114

Sugar Loaf, explanation of features of view of, from Cascade Cliffs ............................................. pl. 45

view of, from Moraine Dome_.._._...................................... pl. 45

Sunrise Trail, moraines on

Surface forms carved in massive rock, explanation of

Sutherland Falls, character and height of

Table Mountain, fossil remains found near . . general character of -

Taft granite, general features of -

Taft Point, asymmetric spur of explanation of asymmetric sculpture $\ldots \ldots \ldots \ldots \ldots$

Takakkaw Falls, character and height of

Tamarack Creek, hanging gulch of

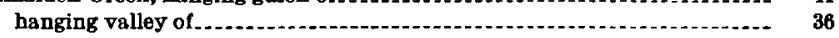

Tehipite Valley, general features of

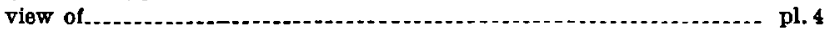

Tenays Basin, general features of........... 14-15

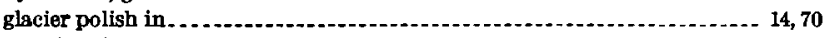
moraines in

Tenaya Canyon and Little Yosemite Valley, section across................... 83

Tenaya Canyon, development of....................................... 101-102 fllling of la kes in glacler polish in

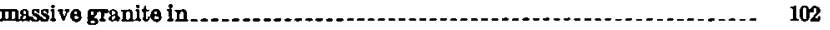
stairlike steps in view of, from Glacier Point........................................... pl. 8

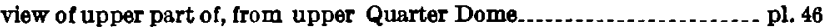

Tenaya Cascade, character and height of ..................................... 20

Tenaya Glacier in earlier stages, features of

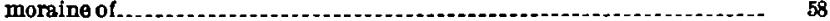

Tenaya Glacier of Wisconsin stage, features of ................................ 77-78

Tequendams Fall, character and height of ..........................- 20

Terminal moraine, absence of, in lower Merced Canyon..................... 67-68

Three Brothers, asymmetric forms of explanation of sculpture of view of

Tilting of Bierrs block ......................................... 24-25, 29, 44

Timber line, altitude of .................................................... 10 view of characteristic storm-bent tree at

Topographio map of Yosemite Valley_......................pl. 7 (in pocket)

Torrent fans and torrent channels......................................... 108-109

Tueeulala Fall, character and height of................................ 20

Tuolumne Basin, diversion of ice from, into the Tenaya Basin-............ 78,82

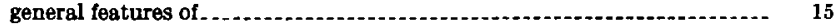

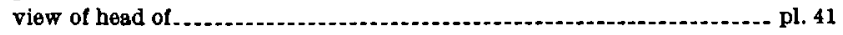


Tuolumne Glacier, character of length of

Tuolumne Ice Field, extent and character of................................... 77

Tuolumne Meadows, view of view of pothole at lower end of ....................................... 34

Tuolumne River, Grand Canyon of

Turner, Henry W., belief of, concerning origin of Yosemite Valley. interpretation by, of moraines south of Cathedral Rocks.

Turtleback Dome, explanation of sculpture of moraines on

view of..

Twin Falls in Yoho Valley, character and height of

\section{$\mathbf{U}$}

Unglaciated areas on upland north of Yosemite Valley.

Unglaciated summits in High Sierra.

Uplifts of Bierra Nevada, effect of, on drainage system

height of

Upper limit of glaciation in the High Sierra.

Upper Yosemite Fall, character and height of

cliff at.

$\mathbf{V}$

Valur Fos, character and height of

Vernal Fall, alcove near.

character and height of cliff at.

view of.

Vettis Fos, charactor and height of

Vöring Fos, character and height of

\section{$\mathbf{W}$}

Washburn Lake, filling of, by forward-growing delta $\ldots \ldots \ldots \ldots$ Washington Column, form and character of.

Waterfalls of the Yosemite Valley, comparison of, with those in other parts of the world. general features of

Wawong, half-yosemite at $40-41$

Wawona Road, old moraine near........... 34

Weatber pit at Glacier Point, view of

Weather pits at Glacier Point, explanation of

Weather pits on North Dome, view of......................................... 33

Weckerly, C. A., drawing by_............... 15

Whitney, Josiah D., belief of, concerning origin of domes................. 11 f́ belief of, concerning origin of Yosemite Valley explanation by, of paucity of débris................................ 105

Wildeat Creek, hanging gulch of

Wisconsin stage of glaciation, evidence of two ice floods in.................. 60

evidences of, in Yosemite region.

glacier polish of ................. $68-70$

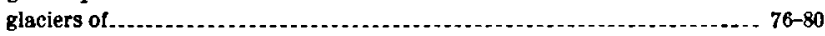

Wooloomumbi Fall, chargeter and height of
$\mathbf{Y}$

Page

Yellowstone Fall, character and height of lower

20

Yosemite Creek, hanging valley of ........ 11, 37 hanging valley of, view of

Yosemite Fall, notch west of upper

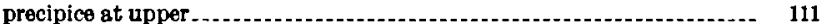

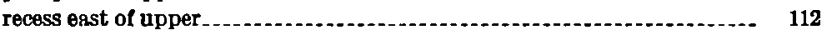
recess near lower view of brink of precipice of upper ............... 48

Yosemite Falls, character and height of view of, from Glacier Point........ 9 view of, from Merced River........... 22

Yosemite Glacier, deepening effected by ................ 85 in earlier stages, features of

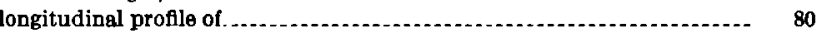
of Wisconsin stage, features of . .......... 76-77

widening effected by ................. 85-88

Yosemite National Park, extent of

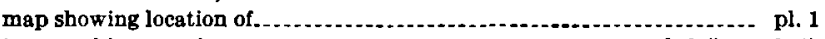
topographic map of

Yosemite problem, kernel of

Yosemite region, deflnition of

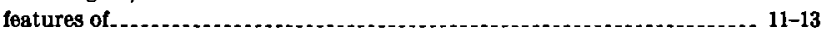
evidences of glacial action in

Yosemite upland, definition of .......... 11 preservation of, on massive granite....... $39-40$

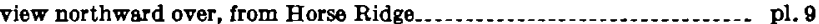

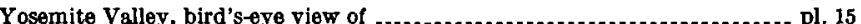
conflguration of, explained... $91-94$

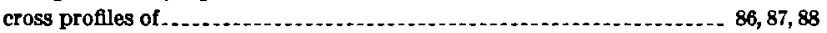
details of features of evidence of earthquakes in.................................... 106-107, 108 head of, explained former ice cataract at head of ................................... 83-84, 97 longitudinal profiles of longitudinal section of, showing depth of glacial excavation lower end of, ascent of ice at lower end of, explained. north side of, evidences of an earlier ice invasion on $-65-66$ peculiar modeling of ............ 15-16 postglacial history of preglacial development of

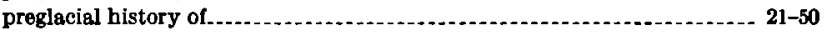
rock avalanches in south side of, evidences of an earlier ice invasion on................... 64 topographic map of transformation of, by glaciation. $84-98$ view across, from Ribbon Fall view of, from Glacier Point

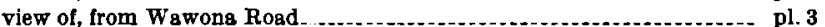
view of head of, from Columbia Rock........ 16 view of lower end of .................................................... pl. 16

$\mathbf{Z}$

Zones of tracturing, influence on cliff sculpture of 



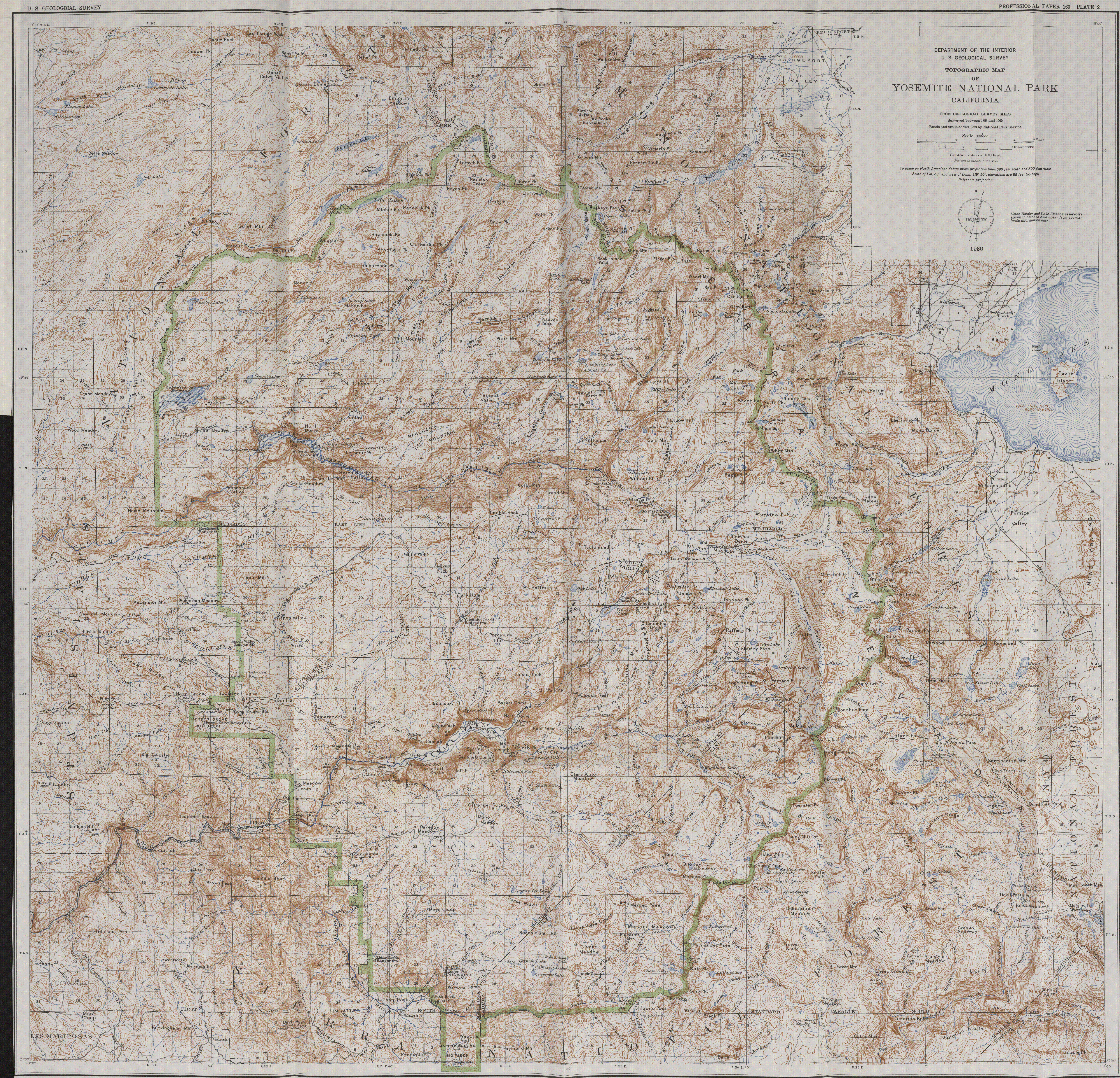



MAP OF

YOSEMITE VALLEY

YOSEMITE NATIONAL PARK, CALIFORNIA

MARIPOSA COUNTY

Gut

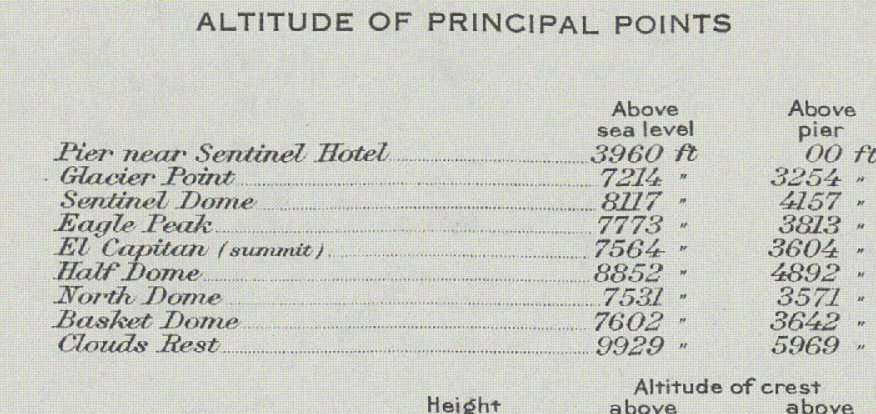

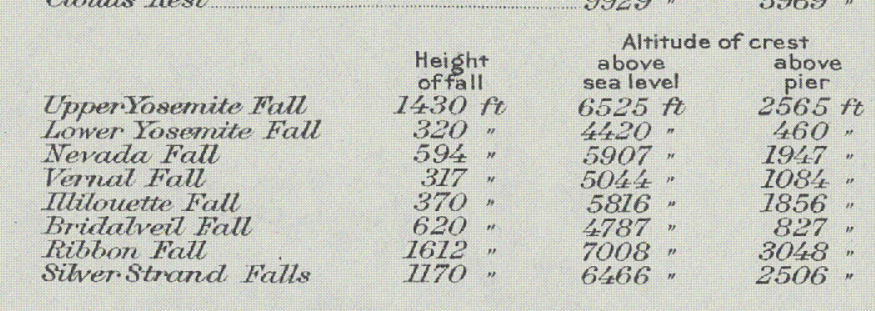

$\frac{1-10}{3}$
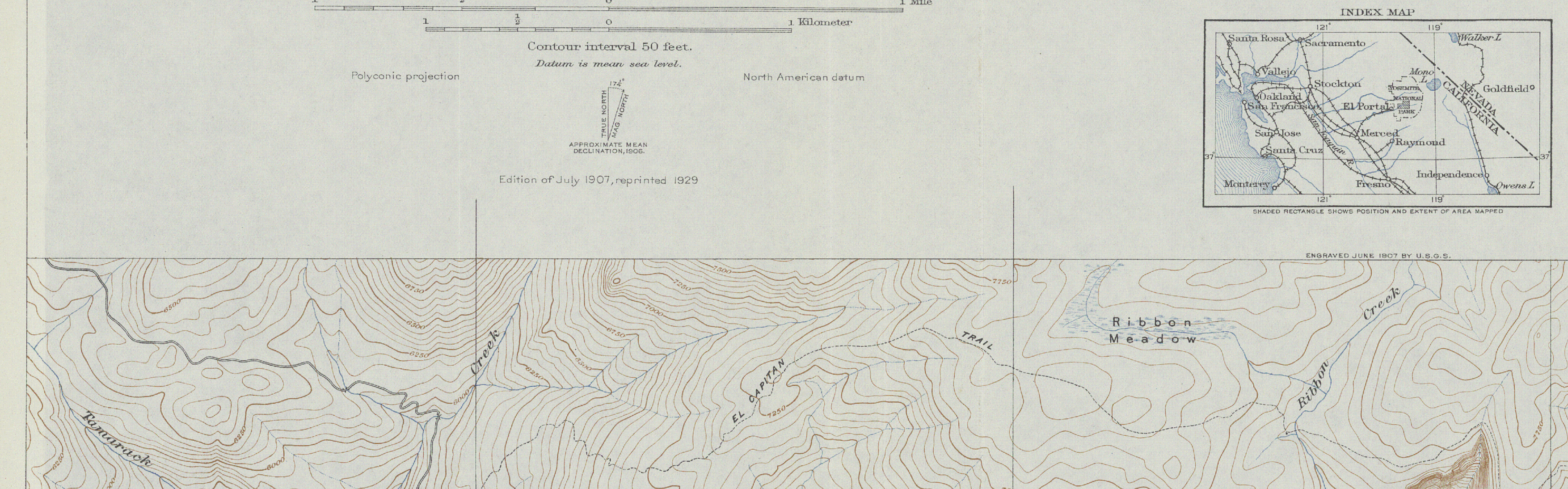

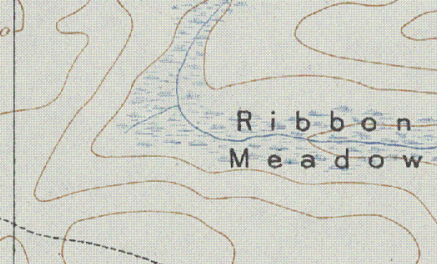

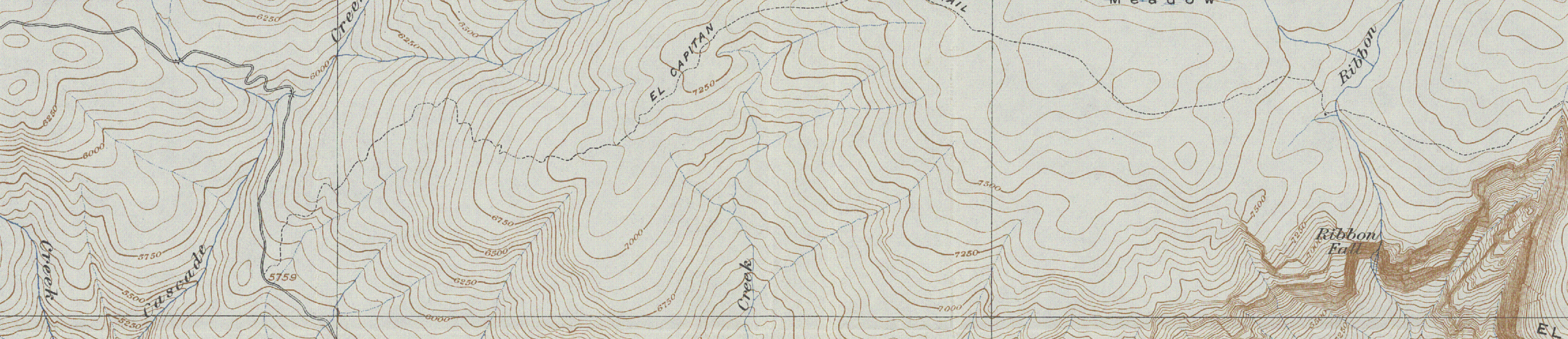

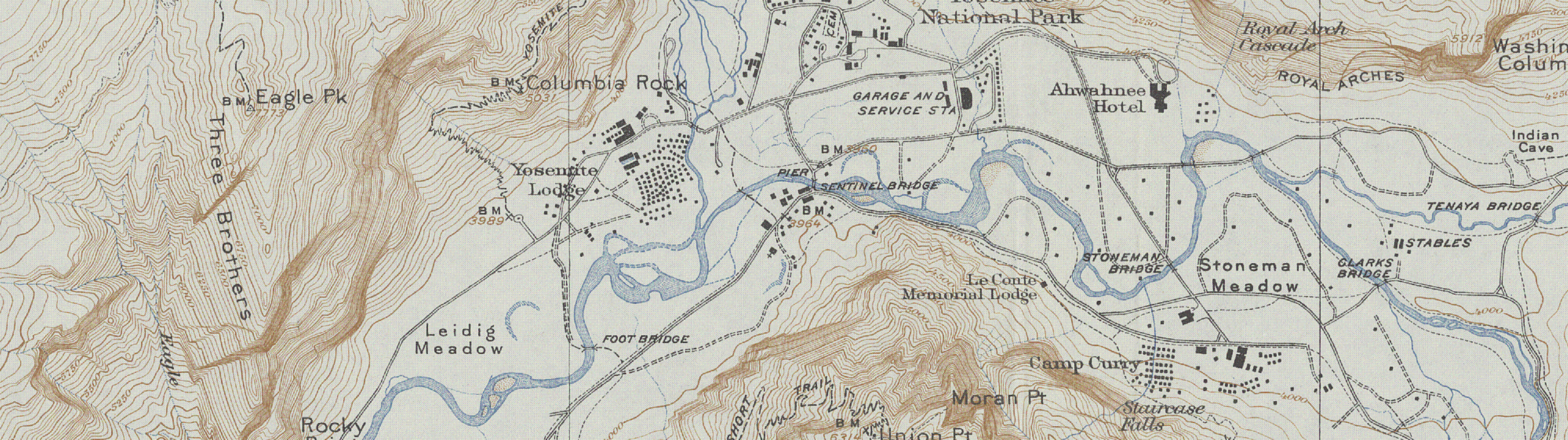

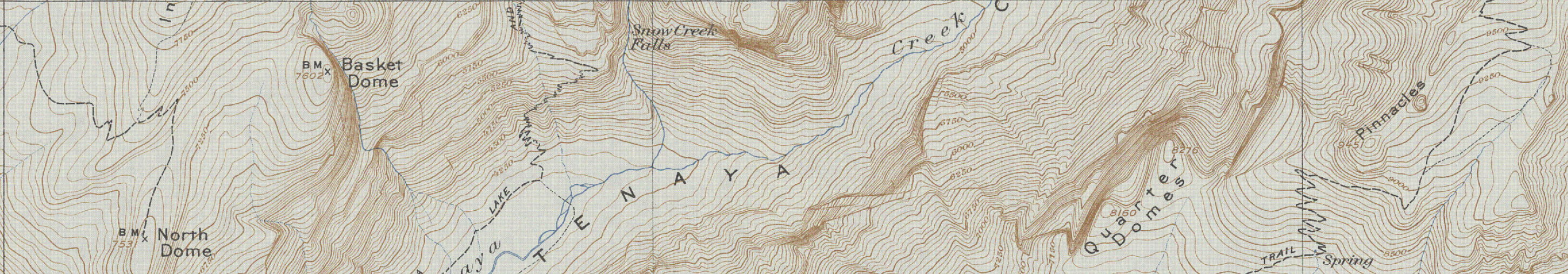

(c)
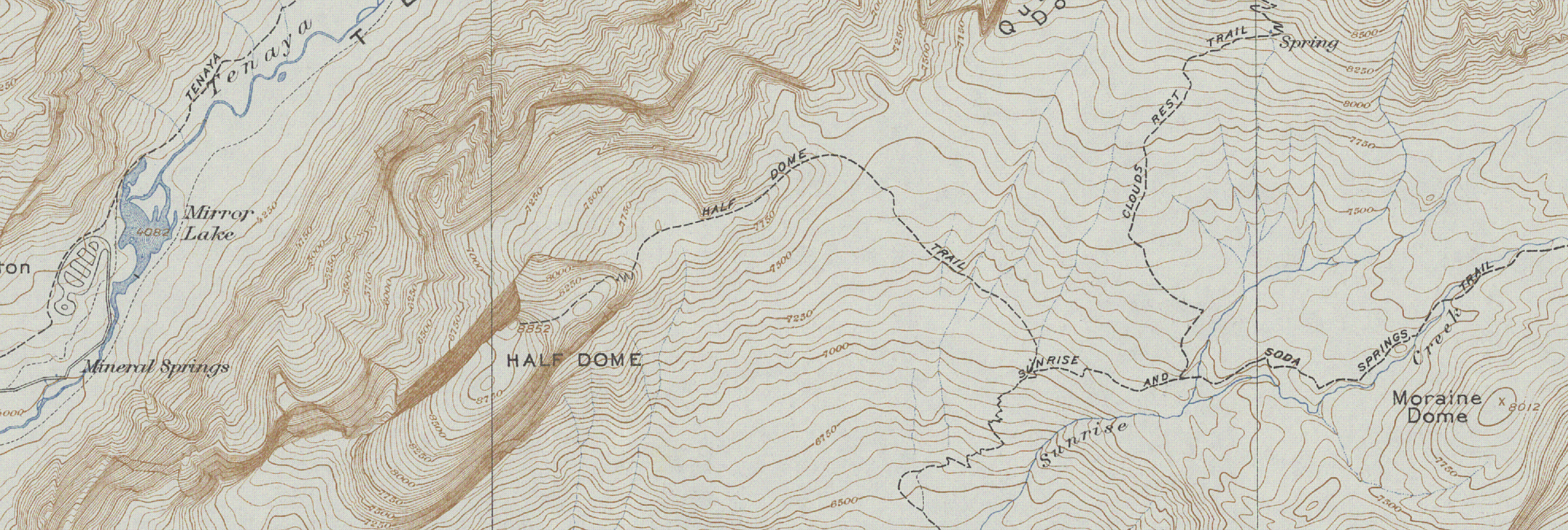
- im
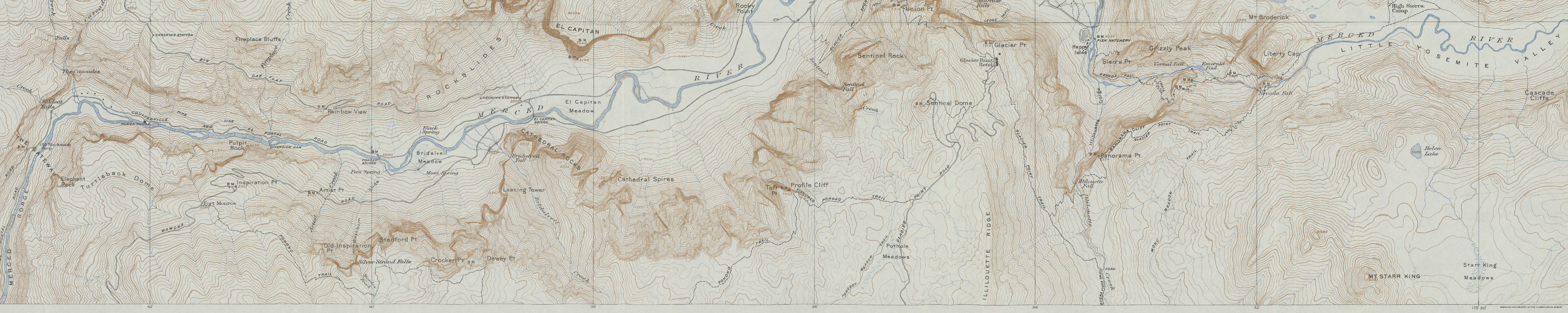


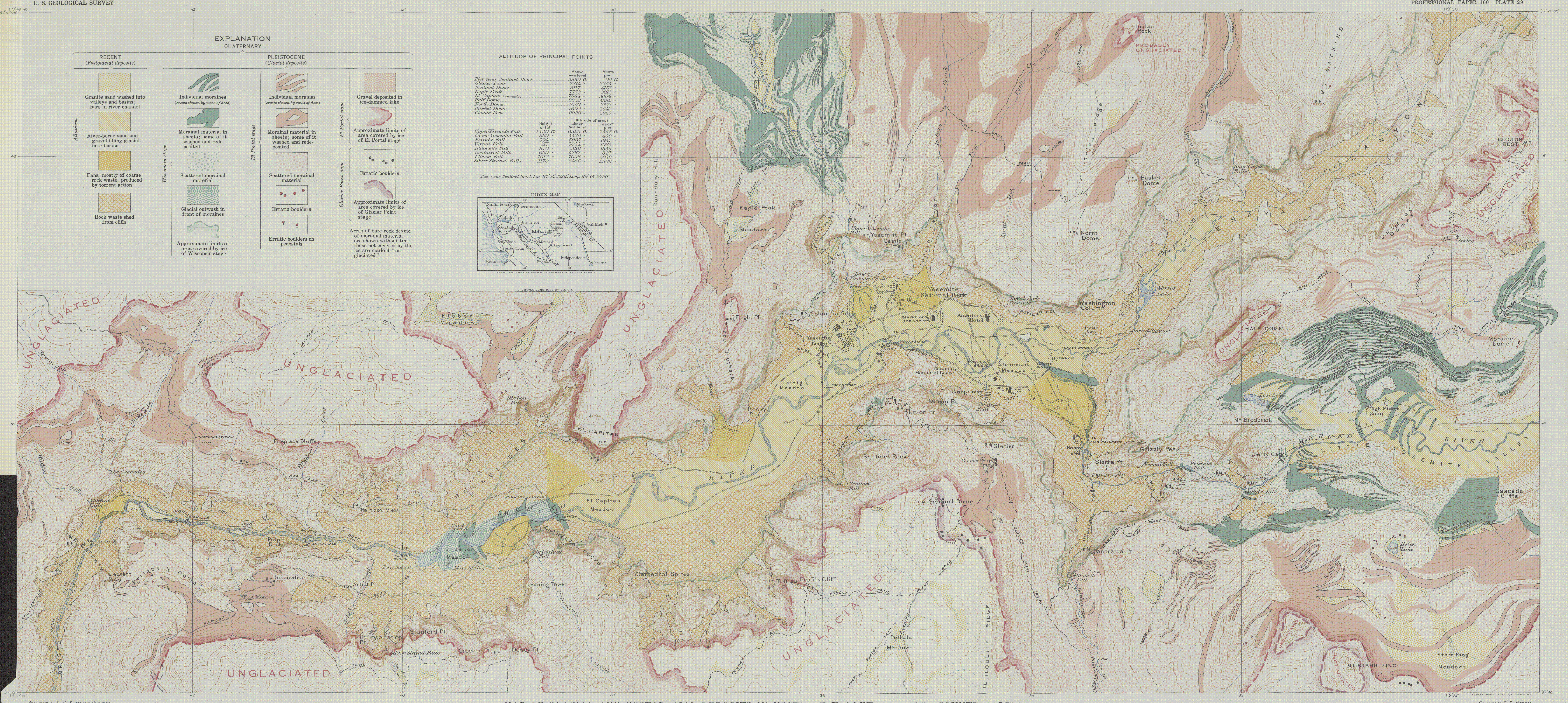

MAP OF GLACIAL AND POSTGLACIAL DEPOSITS IN YOSEMTTE VALLEY, MARIP

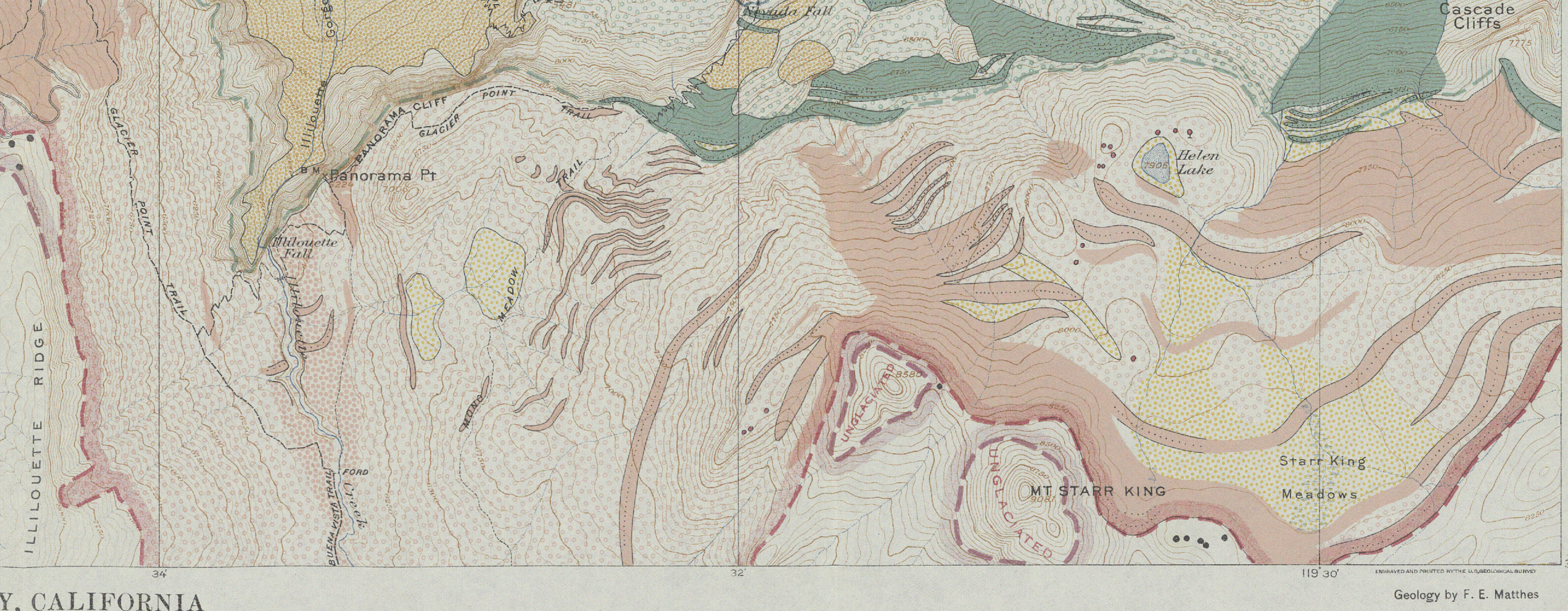


